WILHELM VOSSKAMP, GÜNTER BLAMBERGER

UND MARTIN ROUSSEL (HRSG.)

\title{
MÖGLICHKEITSDENKEN
}

\section{Utopie und Dystopie in der}

\section{Gegenwart}

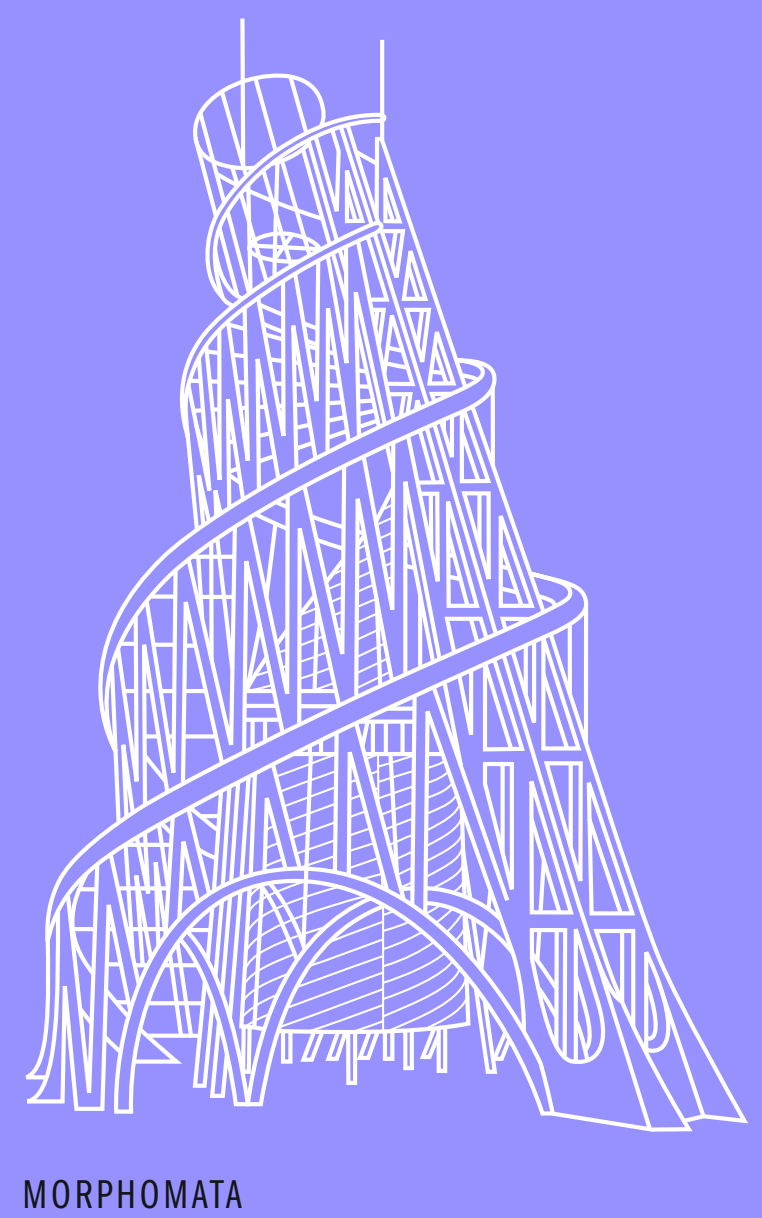


Utopien denken Möglichkeiten von Zukunft. Mit Beginn der historischen Moderne, in der die Erwartung an die Zukunft die Erfahrung der Vergangenheit übersteigt, entstehen in der je aktuellen Gegenwart Entwürfe, die Utopien genannt werden können. Die Temporalisierung der Erfahrung macht Projektionen in die Zukunft möglich (Reinhart Koselleck). Diese sind nie eindeutig. Sie liefern mehrdeutige Wunsch- und Schreckbilder auch in eigentümlichen Verschränkungen. Die Einsicht in diese Dialektik nimmt mit dem Grad der Selbstreferentialität von Zukunftsentwürfen zu; Utopie und Dystopie bedingen sich wechselseitig. Gegenwärtig leben wir mit außerordentlich unsicheren Zukunftsperspektiven. Haben Utopien nur in Dystopien überlebt? Nach dem Ende des Utopismus-Verdachts am Beginn der 9oer Jahre geht es heute um eine Bestandsaufnahme von Zukunftspotentialen, um Diskussionen von Denkformen des Hypothetisch-Möglichen. Bietet die Tradition des utopischen Denkens Anknüpfungspunkte für aktuelle, positiv oder negativ konnotierte Zukunftsbeschreibungen? Wunsch- oder Warnbilder sind noch immer jenem utopischen Impuls verpflichtet, der den Blick aus der Gegenwart in die Zukunft richten will. Die Frage nach der Zukunft utopischen Denkens stellt somit in den Möglichkeiten temporalen, visionären und konjunktivischen Denkens zugleich die Frage nach dem Ort des Gesellschaftlichen und der Gesellschaft heute - und damit die Frage nach der Verbindlichkeit von Tradition, und das heißt auch: nach Traditionen des Utopischen. 


\section{MÖGLICHKEITSDENKEN}

HERAUSGEGEBEN VON GÜNTER BLAMBERGER UND DIETRICH BOSCHUNG

BAND 9

Utopie und Dystopie in der

\section{Gegenwart}




\section{INHALT}

GÜNTER BLAMBERGER Über die Aktualität

des Zukunftsdenkens. Vorwort

WILHELM VOSSKAMP Möglichkeitsdenken.

Utopie und Dystopie in der Gegenwart. Einleitung

\section{UTOPIE UND DYSTOPIE ALS PROBLEM DER FORSCHUNG UND IHRER GRENZEN HEUTE}

GABRIEL MOTZKIN Utopie, Dystopie und Evolution

FRIEDRICH BALKE Michel Foucault und die Möglichkeiten eines Denkens in der "Leere des verschwundenen Menschen«

unter dem Förderkennzeichen 01UK0905. Die Verantwortung für den Inhalt der Veröffentlichung liegt bei den Autoren.

Bibliografische Informationen der Deutschen Nationalbibliothek: Die Deutsche Nationalbibliothek verzeichnet diese Publikation in der Deutschen Nationalbibliografie; detaillierte Daten sind im Internet über www.dnb.d-nb.de abrufbar.

Alle Rechte, auch die des auszugweisen Nachdrucks, der fotomechanischen Wiedergabe und der Übersetzung vorbehalten. Dies betrifft auch die Vervielfältigung und Übertragung einzelner Textabschnitte, Zeichnungen oder Bilder durch alle Verfahren wie Speicherung und Übertragung auf Papier, Transparente, Filme, Bänder, Platten und andere Medien, soweit es nicht $\ 53$ und 54 UrhG ausdrücklich gestatten.

(C) 2013 Wilhelm Fink Verlag, München

Wilhelm Fink GmbH \& Co. Verlags-KG, Jühenplatz 1, D-33098 Paderborn

Internet: www.fink.de

Lektorat: Martin Roussel und Christine Thewes

Gestaltung und Satz: Kathrin Roussel, Sichtvermerk

Printed in Germany

Herstellung: Ferdinand Schöningh GmbH \& Co. KG, Paderborn

MATHIAS LÖWE Utopie versus Anthropologie.

Konstellationen eines Konflikts um 1800 und heute

\section{GRUNDLEGUNGEN DES UTOPISCHEN MÖGLICHKEITSDENKENS}

ARBOGAST SCHMITT Der Staat als Möglichkeitsraum individueller Selbstentfaltung bei Platon

KLAUS L. BERGHAHN Möglichkeit als Kategorie der Philosophie, Politik und Dichtung in Ernst Blochs Das Prinzip Hoffnung

VIVIAN LISKA Sprache und Gesetz im Messianismus Walter Benjamins und Giorgio Agambens

MARTIN ROUSSEL Möglichkeitsdenken. Utopie, Dystopie und Lektüre in Robert Musils Der Mann ohne Eigenschaften 


\section{LITERARISCHE UND VISUELLE FORMEN}

HANS ULRICH SEEBER Präventives statt konstruktives Handeln. $\mathrm{Zu}$ den Funktionen der Dystopie in der anglo-amerikanischen Literatur

JUDITH LEISS Gattungsgeschichte als Spirale. Die Heterotopie als Möglichkeit utopischen Schreibens in der Gegenwart

RYOZO MAEDA Techno, Apokalypse, »Ikai«. Utopien und

Dystopien in der visuellen Massenkultur Japans

ROBERTO SIMANOWSKI Utopien und Dystopien im Internet und die antiutopische Botschaft des Mediums

\section{AKTUELLE GEGENWART}

JÜRGEN FOHRMANN Die Versprechen einer Institution.

Die Universität als Projektionsraum

KARL HEINZ BOHRER Utopie `Europar.

Eine Ursache ihres Zerfalls

Verzeichnis der Autoren

\section{GÜNTER BLAMBERGER}

\section{ÜBER DIE AKTUALITÄT \\ DES ZUKUNFTSDENKENS}

\section{Vorwort}

Vielleicht gibt es keinen schöneren Rückzugsort für Literaturliebhaber als den idyllischen Park in François Truffauts Verfilmung von Ray Bradburys Roman Fahrenheit 451, in den der Feuerwehrhauptmann Montag sich flüchtet, weil er genug hat von dem ihm befohlenen Verbrennen aller Bücher. Oskar Werner spielt diesen Feuerwehrhauptmann, auf unvergessliche Weise. Im Park trifft Montag auf eine Gemeinschaft von Dissidenten, auf Bibliophile, die ihr Lieblingsbuch wieder und wieder memorieren und so an die nächste Generation weitergeben, an ihre jungen Begleiter, die während der gemeinsamen Spaziergänge aufmerksam zuhören und nach dem Tode ihrer Lehrer das Buch verkörpern und rezitieren werden. So changiert in diesem tröstlichen Schluss Truffauts Film von der Dystopie zur Utopie: Nicht im Schreckbild des totalen Biblioklasmus endet er, sondern im Wunschbild von Büchermenschen, die im Vergangenen den Funken der Hoffnung für eine humane Zukunft werden anzufachen wissen.

Dergestalt ist auch ein historisches Kolleg wie das Internationale Kolleg Morphomata der Universität zu Köln, das im Juni 2012 eine hier in diesem Band dokumentierte Tagung über »Möglichkeitsdenken« ausrichtete, Gegenwarts- und Zukunftskolleg zugleich. Der Name >Morphomata<, griechisch für Gestaltbildungen, ist Programm. Die Fellows und Mitarbeiter dieses Kollegs verpflichten sich auf die einfache Annahme, dass die Geschichte kulturellen Wissens und Fortschritts nicht in einer Systematik abstrakter Begriffe oder Vernunftideen allein aufgeht und analysieren stattdessen Artefakte unterschiedlicher materialer oder medialer Gestalt und historischer bzw. kultureller Herkunft im Hinblick auf die mit ihnen verflochtenen ästhetischen Ideen, die eine Kultur nachhaltig 
geprägt haben und vermutlich weiter prägen werden. Sie richten ihr Augenmerk also auf die Ausformung der Einbildungskraft in Werken der Literatur, der Malerei, der Musik, der mythischen Rituale, auf das Zusammenspiel von gestaltbildendem Bewußtsein und gestaltgebendem Material, auf das in jedem großen Kunstwerk erst dank seiner je besonderen Gestalt erfahrbare Wissen über Grundfragen des menschlichen Daseins, und dazu gehört auch die Frage, wie man sich menschliches Leben über die engen Grenzen des eigenen Lebens hinaus vorzustellen hat - eine Frage, die historische wie futurische Denker und ihre Leser gleichermaßen antreibt.

Aber klingt das alles nicht zu schön, um wahr zu sein, handelt es sich nicht um eine altbekannte Legitimation des historischen Geschäfts, deren Wirkmacht bei genauerem Hinsehen selbst passé ist? Ist die Kopplung von historischem und futurischen Denken nicht längst so verblasst wie Truffauts Film bzw. nur Consolatio und Camouflage dessen, dass es heute keine genuin futurischen, geschweige denn utopischen Denker jenseits der Gen-, Computer- und neurobiologischen Laboratorien mehr gibt? Verschafft man als Geisteswissenschaftler mit einer "Cur der Geister «, wie Nietzsche es in $\ 188$ von Der Wanderer und sein Schatten genannt hat, den Heutigen Luft, indem man den Lebenden den Spiegel der Toten vorhält und sie aus der Eindimensionalität des je eigenen Daseins befreit? Oder verschleiert man nur das Faktum, dass gegenwärtig ohnehin die Wiedergänger und Epigonen dominieren, dass unsere Gegenwartskultur keinen Eigenausdruck mehr findet und völlig visionsfrei ist? Wie konnte es sonst der schmalen, in ihren Gedanken wahrlich nicht aufregenden Streitschrift des 1917 geborenen ehemaligen Résistance-Kämpfers Stéphane Hessel mit dem Titel Indignez-vous gelingen, im Jahr 2011 zum Bestseller in Deutschland zu werden? Gut, Aufstand war allenthalben seit 2011: Vom Stuttgarter Wutbürger bis zum arabischen Frühling, von der Occupy-Bewegung in den Bankvierteln bis zu den Demonstrationszügen in Athen oder Madrid! Aber welche Gemeinsamkeiten haben diese Aufstände, welche Visionen treiben sie an? Sind es nicht nur Aufstände gegen das Bestehende, ohne utopische Gegenbilder? Leben wir nicht in einer Zwischenzeit ohne Utopien seit der realgeschichtlichen Verabschiedung der grands récits 1989? Einer namen- und etikettenlosen Zeit? Signifikant sind die englischen Buchtitel zur letzten Jahrhundertwende, die zumeist mit dem Adverb beyond beginnen. Dieses beyond heißt eigentlich >darüber hinaus`, bezeichnet aber de facto weder einen neuen Horizont noch ein Zurücklassen der Vergangenheit, sondern das Verharren in Zwischenorten, Zwischenzeiten, in Wartesälen, in denen nichts mehr wirklich erwartet wird. Bei Intellektuellen wie Politikern im Westen scheint heute Stillstand im Fortschritt zu herrschen, jeglicher Richtungssinn verloren gegangen zu sein, selbst das permanente Krisengerede ist nicht wörtlich zu nehmen, denn Krise meinte ja einmal Entscheidung, Entscheidung wenigstens vom Schlechten zum Nächstbesseren und Handeln danach.

So ist es kein Wunder, dass das futurische Denken wieder zum Thema wird. Zeitgleich mit der in diesem Band dokumentierten Tagung über "Möglichkeitsdenken« fand im Juni 2012 in Berlin eine Tagung der Kulturstiftung des Bundes statt, unter dem Titel »Kulturen des Bruchs«, bei der man sich mit »Gründen und Energien unserer Memoria-Leidenschaft auseinandersetzen und nach Alternativen suchen « wollte, in einer »fundamentalen Aussprache über Nutzen und Nachteil des Vergessens für unser Leben «. Nietzsche, auf den hier angespielt wird, ist dagegen bekanntlich davon überzeugt, dass der Mensch das Vergessen im Gegensatz zum Tier weder beherrscht noch eigentlich lernen kann und »immerfort am Vergangenen zu hängen« pflegt, es folglich darum geht, über den Nutzen und Nachtheil der Historie für das Leben weiter nachzudenken. In dieser Konsequenz haben wir auf unserer Tagung die neuzeitliche Gattungstradition der Utopie selbst in den Blick genommen und gefragt, ob ihre Wunsch- und Schreckbilder noch Anknüpfungspunkte für futurisches Denken heute bilden.

Die Konzeption der Morphomta-Tagung über »Möglichkeitsdenken « verdankt sich vor allem Wilhelm Voßkamp, der im Jahr 1982 drei umfassende Bände zur Utopieforschung herausgegeben hat, als Ertrag einer von ihm geleiteten interdisziplinären Forschergruppe zur `Funktionsgeschichte literarischer Utopien in der frühen Neuzeit` am berühmten Zentrum für interdisziplinäre Forschung in Bielefeld. Vorausgegangen war dieser Utopieforschung ein Kolloquium über »Utopie und Melancholie« 1975. Das bezeichnet den zeitgenössischen Kontext der Bielefelder Bestandsaufnahme, die Spannung einerseits zwischen den utopischen Entwürfen der 6oer und der Melancholie der 7oer und frühen 8oer Jahre, ablesbar etwa in Peter Schneiders Lenz, und der jüngeren No-future-Generation der Friedens- und Ökologiebewegungen andererseits. Die Melancholie der 7oer und 8oer Jahre resultierte daraus, dass die Utopien der 6oer Jahre von der klassenlosen Gesellschaft bis zur 〉Großen Weigerung politisch nicht einzulösen waren. So entstand eine Melancholie der Handlungshemmung, aber kein Zweifel am utopischen oder futurischen Denken selbst. Melancholie als Habitus des >westlichen Intellektuellen galt damals als Kehrseite der Utopie. Gänzlich anders 
verhält es sich mit der Tristesse royale, so der Titel des u. a. von Christian Kracht 1999 herausgegebenen Selbstverständigungstextes der Generation der Jahrtausendwende. Melancholie erscheint hier als elitäre Einsicht in die Omnipotenz des Absurden und zugleich als Todsünde der Acedia, als Trägheit des Herzens und des Kopfes, weil man dem kritisierten Bestehenden weder praktisch noch theoretisch etwas entgegenzusetzen hat. Kein futurisches Denken, keine Utopien und schon gar keine millenarischen Phantasien.

»Die Angst vor der Zukunft fordert Zukunftsdenken heraus." So Wilhelm Voßkamp in seinem Vorwort zu den Bänden der Utopieforschung von 1982 - ein Satz, der durch die Ereignisse des 11. September 2001 eine unerwartet neue Qualität bekommen hat. Im Fokus steht nicht mehr die Konstellation von Melancholie und Utopie; über die Beziehung von historischen Traumata und Utopien bzw. Dystopien ist wieder nachzudenken. Der 11. September 2001 markiert eine traumatische Zäsur, einen Bruch des historischen Kontinuums, der Zeit- wie der je individuellen Lebensgeschichten, und damit verbunden die Einsicht in die Unmöglichkeit eines unmittelbaren Verstehens, aus der paradoxerweise utopisches Denken und Handeln resultieren kann. Utopisches Handeln, das aus einem Trauma folgt, steht unter dem Diktat des $>$ Nie wieder darf das geschehen! Der Utopiewille ist der Wille der Opfer, die sich vor der schrecklichen Zerstörung ihres Lebensplans in Zukunft schützen wollen. Reduktion von Komplexität, Kontrolle, Transparenz, das waren und sind die vorherrschenden Reaktionsformen nicht nur der Amerikaner nach den Terroranschlägen. Um Freund und Feind zu unterscheiden, werden seitdem an allen Grenzen Koffer und Körper durchleuchtet, in der Erfahrung, dass Freundschaft nur vorgetäuscht sein kann und Seelen sich nicht berechnen lassen. In der unheimlichen Erfahrung, dass ein für seine Kommilitonen völlig unauffälliger Hamburger Student wie Mohammed Atta, als Stadtplaner diplomiert, nur ein sleeper war. Aus Angst vor so verstecktem und verborgenem Terror wurden damals die Überwachungsmaßnahmen totalisiert und globalisiert. Schon ein Jahr nach dem 11. September 2001 registrierte George Bush stolz, dass 90 Nationen 2400 Terroristen verhaftet hätten und 130 Staaten dem Überwachungsbündnis beigetreten seien. Gegen traumatische Erfahrungen reagierte man mit Notwehrmaßnahmen, konkret: mit einer Kultur des Misstrauens. Das Fatale nach dem 11. September 2001 war die Universalisierung der Verdachtskultur und die allmählige Verfertigung von Techniken der Abgleichung von Äußerem und Innerem in der Utopie des sichtbaren, gläsernen, jederzeit kontrollierbaren Menschen.
Über Zeitgemäßes und Unzeitgemäßes der historischen Utopien nachzudenken, ist heute nicht einfacher, sondern vielleicht sogar schwieriger als vor dreißig Jahren 1982. Ich danke allen Beiträgern dieses Bandes für diesen Mut. Ich danke Wilhelm Voßkamp und dem wissenschaftlichen Geschäftsführer von Morphomata, Martin Roussel, für die Planung der Tagung und ihre Dokumentation. 


\title{
WILHELM VOSSKAMP
}

\section{MÖGLICHKEITSDENKEN.}

\section{UTOPIE UND DYSTOPIE IN DER GEGENWART}

\section{Einleitung}

\author{
Erkenntnis, die den Inhalt will, \\ will die Utopie. Diese, das Bewusstsein \\ der Möglichkeit, haftet am Konkreten \\ als dem Unentstellten. ${ }^{1}$
}

\section{MÖGLICHKEITSDENKEN}

Möglichkeitsdenken ist die Voraussetzung für jede Form philosophischer, anthropologischer, gesellschaftlicher und künstlerischer Utopie oder Dystopie. Bereits in der aristotelischen Kategorienlehre, in der der Modus des Möglichen durch Widerspruchsfreiheit und Potentialität definiert ist, geht es im Gegensatz zum Wirklichen und Notwendigen um »das Noch-nicht-Seiende. Es steht am Anfang jedes Werdens, Entstehens, jeder Bewegung, Veränderung und ist in den Materialursachen begründet «. Vermögen (dynamis) wird der Wirklichkeit (energeia) gegenübergestellt.

Nicht anders bei Leibniz: »Möglich ist eine Realität, die nicht existiert, aber zur Existenz gelangen kann, [...]. $\aleph^{3}$ Leibniz beschreibt den $»$ Drang des Möglichen zur Existenz [...] weil ein Grund für ein Zurückhalten von gewissem Möglichen in allem nicht gefunden werden kann [...]«.

1 Theodor W. Adorno: Negative Dialektik. Frankfurt a. M. 1966, S. 64. 2 Horst Seidl: Möglichkeit [Art.]. In: Joachim Ritter und Karlfried Gründer (Hrsg.): Historisches Wörterbuch der Philosophie. Bd. VI. Darmstadt 1984, Sp. 72-92, hier Sp. 77 .

3 Ebd., Sp. 86.

4 Zit. nach Wilhelm Schmidt-Biggemann: Theodizee und Tatsachen. Das 
An diese für die $>$ Metaphysik der deutschen Aufklärung grundlegenden Gedanken anknüpfend, ${ }^{5}$ suchen Karl Mannheim, ${ }^{6}$ Robert Musil ${ }^{7}$ und Ernst Bloch ${ }^{8}$ den Begriff des Utopischen und der Utopie in den ersten Jahrzehnten des 20. Jahrhunderts zu entwickeln. Karl Mannheim bezeichnet ein "Bewußtsein, das sich mit dem es umgebenden ,Sein nicht in Deckung befindet, [als] utopisch ${ }^{9}$ und "unterscheidet das utopische vom ideologischen Bewußtsein«. Darüber hinaus grenzt er das Utopische »auf jene Art wirklichkeitstranszendente Orientierung [ein], die zugleich eine bestehende Ordnung auch sprengt [...]. $\ll^{10}$ betont:

üngst noch hat Martin Seel in seinen »Drei Regeln für Utopisten«

Utopien sind in Raum und Zeit unerreichbare Zustände, deren Erreichbarkeit dennoch gedacht werden kann und gedacht werden soll. Sie soll gedacht werden, um innerhalb des Wirklichen den Sinn für das Mögliche zu schärfen [...]. Alle Utopien lassen ferne Möglichkeiten absehbar werden, um hier und jetzt ergreifbare Möglichkeiten sichtbar werden zu lassen $[\ldots]^{11}$

philosophische Profil der deutschen Aufklärung. Frankfurt a. M. 1988, S. 24 5 Vgl. ebd. außerdem: Ingetrud Pape: Von den »möglichen Welten« zur »Welt des Möglichen«. Leibniz im modernen Verständnis. In: Studia Leibnitiana Sublementa. Bd. I. Wiesbaden 1968, S. 266-287 (Akten des internationalen Leibnizkongresses Hannover 14-19.11.1966).

6 Vgl. Karl Mannheim: Ideologie und Utopie (1929). Zit. Ausg. Frankfurt a. M. 1978.

7 Vgl. Robert Musil: Der Mann ohne Eigenschaften (1930 ff.), zit. Ausg. Reinbek bei Hamburg 1987.

8 Vgl. Ernst Bloch: Geist der Utopie (1908), zit. Ausg. der 2. Fassung von 1923. Frankfurt a. M. 1964; ders.: Das Prinzip Hoffnung (1938 ff.), zit. Ausg. Frankfurt a. M. 1959. Vgl. außerdem Nikolai Hartmann: Möglichkeit und Wirklichkeit. Meisenheim 1938.

9 Zit. Ausg. Karl Mannheim: Ideologie und Utopie. 6. unveränderte Auflage Frankfurt a. M. 1978, S. 169.

$10 \mathrm{Ebd}$. Zu den »anthropologischen Grundgesetzen« (»Das Gesetz des utopischen Standorts. Nichtigkeit und Transzendenz«) zählt Helmuth Plessner die Vielfalt von Möglichkeiten als dem für den Menschen eigentümlichen Charakteristikum. Vgl.: Die Stufen des Organischen und der Mensch.

Einleitung in die philosophische Anthropologie. Berlin, New York ${ }^{3} 1975$, S. 346.

11 Martin Seel: Drei Regeln für Utopisten. In: Merkur-Sonderheft 5 (2001): Zukunft denken. Nach den Utopien, S. 747-755, hier S. 747 und S. 753.
Die Entwicklung eines >Möglichkeitssinns` entspricht dem >Wirklichkeitssinn`, der die jeweilige Realität als potentiell veränderbar ansieht. Der Möglichkeitssinn ist deshalb keine bloß romaneske Erfindung, er liegt vielmehr in der Wirklichkeit selbst begründet.

Die konstitutive Verbindung von Möglichkeitsdenken und Utopien lässt sich als Kennzeichen der Moderne bezeichnen. Mit ihrem Beginn, in der die Erwartung an die Zukunft die Erfahrung der Vergangenheit übersteigt, entstehen in der je aktuellen Gegenwart - der »nächsten Gesellschaft ${ }^{12}$ - Entwürfe, die unter Anknüpfung an das klassische traditionsbildende Werk von Thomas Morus >Utopien ' genannt werden. Die Kontinuität von Vergangenheit und Zukunft wird unterbrochen. Die Temporalisierung der Erfahrung macht Projektionen in die Zukunft möglich und nötig, da sich der »überkommene Erfahrungsraum immer weniger mit den auftauchenden und hochschnellenden Zukunftserwartungen zur Deckung bringen « lässt. ${ }^{13}$

Zukunft bleibt indes stets auf Gegenwart fixiert; die damit verbundene "Entscheidungsabhängigkeit künftiger Zustände» ist dadurch bedingt. ${ }^{14}$ Utopien sind deshalb, wie oft und zu Recht betont worden ist, stets hervorragende Indikatoren für das Verständnis jener Gegenwart, die sie hervorbringt. Indes:

In welchen Formen präsentiert sich die Zukunft in der Gegenwart? [...] Heute haben wir mit extrem verunsicherten Zukunftsperspektiven zu leben, und die Verunsicherung hat ihren Grund nicht im Heilsplan Gottes, sondern im System der Gesellschaft, das sich selbst $\mathrm{zu}$ verantworten hat $[\ldots]^{15}$

Deshalb kann über Zukunft nur im Hier und Jetzt einer Gesellschaft (vor-)entchieden werden. ${ }^{16}$ Das hat jenen Experimentalcharakter von

12 Vgl. Dirk Baecker: Studien zur nächsten Gesellschaft. Frankfurt a. M. 2007. Der Gegenwart, so Baecker, fehle eine »übergreifende Ordnung und [...] jeder Gesamtsinn « (ebd. S. 9).

13 Reinhart Koselleck: Geschichte, Historie [Art.]. In: Otto Brunner, Werner Conze und Reinhart Koselleck (Hrsg.): Geschichtliche Grundbegriffe. Historisches Lexikon zur politisch-sozialen Sprache in Deutschland. 8 Bände in 9. Bd. II. Stuttgart 1975, S. 593-717, hier S. 703.

14 Niklas Luhmann: Die Beschreibung der Zukunft. In: ders.: Beobachtungen der Moderne. Opladen 1992, S. 129-147, hier S. 136.

15 Ebd., S. 130.

16 Vgl. ebd. 
Utopien zur Folge, der sich nicht auf spezifische Diskursstrategien festlegen lässt. Entscheidend ist ein Kommunikationsmodus des Alternativdenkens im Weltverhältnis. ${ }^{17}$

\section{UTOPIEN UND DYSTOPIEN}

Zukunftsprojektionen sind nie eindeutig. Sie liefern mehrdeutige Wunschund Schreckbilder (Utopien und Dystopien) auch in eigentümlichen Verschränkungen, wie Norbert Elias am Prototyp der Gattung, der Utopia von Thomas Morus gezeigt hat. ${ }^{18}$ Die Einsicht in diese Dialektik nimmt mit dem Grad der Selbstreferenzialität von Zukunftsentwürfen zu - sie ist aber historisch nicht neu. »Endzeitstimmung und Zukunftserwartung sind in der jüdisch-christlichen Tradition [...] in merkwürdiger und vielleicht historisch einzigartiger Weise miteinander verbunden $\ll_{.}^{19} \mathrm{Die}$

17 Vgl. dazu Inge Münz-Koenen: Kommunikationsform Utopie. In: Ludwig Pfeiffer und Michael Walter (Hrsg.): Kommunikationsformen als Lebensformen. München 1990, S. 261-289. Zur utopischen Methode vgl. Raymond Ruyer: L’Utopie est les Utopies. Paris 1950, und Ludwig Stockinger: Ficta Respublica. Gattungsgeschichtliche Untersuchungen zur utopischen Erzählung in der deutschen Literatur des frühen 18. Jahrhunderts. Tübingen 1981. Zur Begriffs- und Gattungsgeschichte zusammenfassend: Wilhelm Voßkamp: Utopie [Art.]. In: Dieter Lamping (Hrsg.): Handbuch der literarischen Gattungen. Stuttgart 2009, S. 740-750.

18 Norbert Elias: Thomas Morus' Staatskritik. In: Wilhelm Voßkamp (Hrsg.): Utopieforschung. Interdisziplinäre Studien zur neuzeitlichen Utopie. Bd. 2. Stuttgart 1982, S. 101-150. Vgl. auch Thomas Schölderle: Utopia und Utopie. Thomas Morus: Die Geschichte der Utopie und die Kontroverse um ihren Begriff. Baden-Baden 2011.

19 Kurt-Victor Selge: Endzeitangst und Kirchenreform im Mittelalter: Joachim von Fiore. In: Gebhard Fürst (Hrsg.): Kassandra die Ahnungsvolle. Propheten des Endes - Propheten neuer Zeiten. Stuttgart 2002, S. 28-48, hier S. 29. Zur Konzeption und Geschichte der Apokalypse in der Moderne vgl. Klaus Vondung: Die Apokalypse in Deutschland. München 1988; Wolfgang Braungart: Apokalypse und Utopie. In: Gerhard R. Kaiser (Hrsg.): Poesie der Apokalypse. Würzburg 1991, S. 63-102; Jürgen Brokoff: Die Apokalypse in der Weimarer Republik. München 2001; Reto Sorg und Stefan Würffel (Hrsg.): Utopie und Apokalypse in der Moderne. München 2010 und Wilhelm Voßkamp: Utopie und Apokalypse. Zur Dialektik von Utopie und Utopiekritik in der literarischen Moderne. In: Julian Nida-Rümelin und Klaus Kufeld (Hrsg.): Die Gegenwart der Utopie. Zeitkritik und Denkwende. München 2011, S. 54-65.
Konfiguration von Apokalypse und Utopie gehört zu jenen komplementären Denkfiguren, die sowohl Angst vor radikaler Veränderung als auch Hoffnung auf Zukunft artikulieren. Dabei sind `Utopie und `Apokalypse (als Grundfigur jeder Dystopie) keine fest umrissenen, semantisch >sicheren Begriffe. Auch handelt es sich nicht um einen temporären Vorgang, der auf einer Zeitachse abbildbar wäre, sondern um ein dauerndes Oszillieren zwischen Apokalyptischem und Utopischem bzw. Utopischem und Apokalyptischem und damit um einen unabschließbaren Prozess. Es geht, wie Jaques Derrida betont hat, zudem eher um die Wahrheit des Offenbarens, als um die 'geoffenbarte Wahrheit ${ }^{20}{ }^{20}$

Wenn man die Herkunft des Utopie-Dystopie-Schemas aus der Tradition apokalyptischen Denkens betont, fällt insbesondere auf, dass durchgehend einprägsame Topoi und spezifische narrative und bildhafte Verfahren gewählt werden - ein Vor-Augen-Stellen mittels Techniken der Veranschaulichung und eine Sprache, die das Visionäre betont, treten hervor. Nicht selten finden sich Formen rhetorischer Steigerung und Überbietung, um das Neue zu betonen oder gerade erst zu evozieren, wobei sich Bilder und Imaginationen von Utopien immer auch aus ihren eigenen Traditionen speisen.

Die Dialektik von Katastrophe und Erlösung bleibt auch in ihrer säkularen Variante als Geschichte der Verschränkung von literarischer Utopie und Dystopie erkennbar, selbst dann, wenn das Motiv der Erlösung schwindet. Das biblische Schema von >Verheißung und Erfüllung bestimmt dennoch den Kern apokalyptischer Rede, die in der säkularisierten Variante »einer Verzeitlichung der Existenzspannung zwischen Defizienz und Fülle $\aleph^{21}$ wiederkehrt. Dabei sind literarische Techniken der Vergegenwärtigung und rhetorische Überredungsstrategien beobachtbar, um die intendierte Wirkungsabsicht zu erreichen. ${ }^{22}$

Überleben Utopien heute vornehmlich in apokalyptischen Dystopien? Sind Dystopien vor totalitären Tendenzen eher gefeit als Utopien? Nach dem Ende des deutschen Utopieverdachts am Beginn der 1990er Jah$\mathrm{re}^{23}$ (die angelsächsische und französische Utopieforschung ist davon

20 Vgl. Jacques Derrida: Apokalypse. Hrsg. von Peter Engelmann. Wien 1985 .

21 Klaus Vondung: Die Apokalypse in Deutschland (wie Anm. 19), S. 20. 22 Vgl. Wilhelm Voßkamp: Utopie und Apokalypse (wie Anm. 19), S. 56. 23 Vgl. vor allem Joachim Fest: Der zerstörte Traum. Vom Ende des utopischen Zeitalters. Berlin 1991 
unbeeindruckt geblieben $)^{24}$ geht es heute um eine Bestandsaufnahme von Zukunftspotentialen und Zukunftskonstruktionen in der Spannung von utopischen und dystopischen Momenten.

\section{IRENAISSANCE` DER UTOPIE}

Noch 1994 konnte Niklas Luhmann unter Hinweis auf die Bielefelder Utopieforschungen am Zentrum für Interdisziplinäre Forschung in den 1980er Jahren in seiner ihm eigenen Art der Ironie formulieren:

Die Utopie-Diskussion liegt fest in den Händen von Literaturwissenschaftlern und Philosophen, die sich mit von Mäusen zerfressenen, alten oder auch nicht so alten Texten beschäftigen. Über Kapitalismus wird dagegen von Leuten diskutiert, die meinen etwas von Wirtschaft zu verstehen und vielleicht Teile des Kapitals von Karl Marx gelesen haben. ${ }^{25}$

Das hat sich geändert. Ohne hier einen Überblick über die Utopieforschung der letzten drei Jahrzehnte geben zu können, lässt sich heute von einer »Renaissance der Utopie ${ }^{26}$ sprechen. Es zeigt sich, dass das Ende

24 Vgl. etwa die kontinuierlich erscheinenden Veröffentlichungen von Lyman Tower Sargent und der Utopian Studies in den USA; außerdem die großen 2000 zur Jahrtausendwende stattfindenden Utopie-Ausstellungen in der Bibliothèque National in Paris und der Public Library in New York (umfassender Katalog: Utopie. La Quête de la societé à Occident. Sous la direction de Lyman Tower Sargent et de Roland Schaer. Paris 2000) oder einen neuen Review-Essay von Patrick Parrinder, »Modern Utopias. Major Minor« [zu Büchern von Simon J. James] über H. D. Wells, Matthew Beaumont über science fiction im Fin de Siècle und Rosalyn Gregory und Benjamin Kohlmann über »Utopian Spaces of Modernism« in der Zeitschrift Modernism/modernity 19 (2013), S. 793-798.

25 Niklas Luhmann: Kapitalismus und Utopie. In: Merkur 48 (1994), S. 189-198, hier S. 190

26 Vgl. den unter diesem Titel von Rudolf Maresch und Florian Rötzer hrsg. Bd. über Zukunftsfiguren des 21. Jahrhunderts (Frankfurt a. M. 2004). Zur Utopieforschung der letzten Jahre vgl. die Zusammenstellungen von Andreas Heyer: Studien zur politischen Utopie. Theoretische Reflexionen und ideengeschichtliche Annäherungen. Hamburg 2005; ders.: Der Stand der aktuellen deutschen Utopieforschung. Bd. 1: die Forschungssituation in der "großen [utopischen] Erzählungen « (François Lyotard) keineswegs zu einer Verringerung von Zukunftsentwürfen geführt hat. ${ }^{27} \mathrm{Im}$ Gegenteil: unsere Gegenwart produziert immer neue, miteinander rivalisierende Utopien und Utopiekonzepte. Dabei scheint die Instabilität und kritische Selbstreflexion eine paradoxe, aber offensichtlich erfolgreiche Kontinuität von Utopieproduktionen zu ermöglichen. Auch die Wiederkehr oder Fortsetzung traditioneller Verheißungsrhetorik ist auffallend: »Die Utopie ist da. >Timeliner, das neue Angebot von Facebook, macht es möglich: Das Leben und das Leben im Netz verschmelzen ${ }^{28}{ }^{28}$

Ohne Zweifel spielen neben der Ökologiedebatte (Ulrich Beck spricht neuerdings von einem Übergang von der `Risiko-` zur >Möglichkeitsgesellschaft $`$ ) und der Humangenetik die außerordentliche Beschleunigung in der Produktion von Netzutopien eine vorherrschende Rolle. Joseph Vogl hat im Blick auf die »Auflösung der Welt in Datenströme und der Alleinherrschaft des binären Codes« von einem »Angriff der Zukunft auf die übrige Zeit" gesprochen. ${ }^{29}$ Unter Gesichtspunkten einer ebenso ambivalenten wie kontroversen Utopie-Dystopie-Diskussion scheint mir der anthropologische Zusammenhang zwischen den beobachtbaren technischen Veränderungen entscheidend zu sein, weil sie nicht nur Aspekte des Politischen und Gesellschaftlichen betreffen. ${ }^{30}$

den einzelnen akademischen Disziplinen. Hamburg 2008; ders.: Der Stand der aktuellen deutschen Utopieforschung Bd. 2: Ausgewählte Forschungsfelder und die Analyse der postmodernen Utopieproduktion. Hamburg 2008; ders.: Der Stand der aktuellen deutschen Utopieforschung. Bd. 3: Theoretische und methodische Ansätze der gegenwärtigen Forschung, 1996-2009. Hamburg 2010.

27 Peter Sloterdijk (Im Weltinnenraum des Kapitals. Frankfurt a. M. 2006 S. 13) vermutet sogar, dass die Erzählung vom Ende der grands récits bereits wieder zur »bequemen Meta-Großerzählung geronnen" sei.

28 Nina Pauer in: Die Zeit Nr. 40, 29.9.2011, S. 49 f. Die Autorin spricht von einem "anthropologischen Neuland vor dem wir stehen« (ebd. S. 50). 29 Joseph Vogl: Das Gespenst des Kapitals. Zürich 2010, S. 12. Netztheoretiker sprechen von einer »Post-Privacy« einer »diskriminierungsfreie[n] Welt, in der es nicht mehr notwendig ist, sich ins Privatleben zurückzuziehen" (Der Spiegel 10 [2012], S. 145).

30 Vgl. Jürgen Habermas: Das Konzept der Menschenwürde und die realistische Utopie der Menschenrechte. Frankfurt a. M. 2011; Oskar Negt: Nu noch Utopien sind realistisch. Göttingen 2011; John Rawls: Gerechtigkeit als Fairneß. Ein Neuentwurf. Hrsg. von Erin Kelly. Aus dem Englischen von Joachim Schulte (Original: Justice as Fairness. A Restatement; 2001). 
Deutlicher noch veranschaulicht die Diskussion über Theorien des `Transhumanismus`(Hans Moraveč, Marvin Minsky oder Ray Kurzweil), dass es um künstliche Erweiterungen des menschlichen Lebens und seines Wirkungskreises geht, bei dem von der jeweiligen Identität des Individuums und einer Subjektsstruktur des Menschen abgesehen wird:

Humanity will be radically changed by technology in the future. We foresee the feasibility of redesigning the human condition, including such parameters as the inevitability of aging, limitations on human and artificial intellects, unchosen psychology, suffering and our confinement to the planet earth. [...] We seek personal growth beyond our current biological limitations. ${ }^{31}$

Dass es durchgehend um die Entgrenzung der individuellen und körperlichen Existenz des Menschen zugunsten einer perfekten Mensch-Maschine bzw. eines Informationsmusters oder Computerprogramms geht, wird in der Terminologie des >Transhumanismus dem Stichwort >Biological Fundamentalism servatism that resists asexual reproduction, genetic engineering, altering the human anatomy, overcoming death " gesprochen. ${ }^{32}$

Die Hoffnung auf die Beseitigung zufallsgenerierter Naturprozesse gehört seit langem zu den Topoi moderner Utopien. Ausgeklammert wird dann allerdings eine Reflexion darauf, dass das Eliminieren des kontingenten Faktors in der menschlichen Existenz und Reproduktion deren Abhängigkeiten von politisch-gesellschaftlichen Macht-WissenKonstellationen und damit individuelle Unfreiheit bedeutet.

31 So in einer »Transhumanist Declaration«; zit. nach Oliver Krüger: Virtualität und Unsterblichkeit. Die Visionen des Posthumanismus. Freiburg i. Br. 2004, S. 145. Vgl. auch Wilhelm Voßkamp: Konstruktionen des Möglichen und Machbaren. Wissenschaft und Technik in literarischen Utopien der Neuzeit. In: Szenarien der Zukunft. Technikvisionen und Gesellschaftsentwürfe im Zeitalter globaler Risiken. Hrsg. von Armin Heinen, Vanessa Mai und Thomas Müller. Berlin 2009, S. 43-55. Zur Rolle der Kybernetik vgl. Hans Esselborn (Hrsg.): Ordnung und Kontingenz. Das kybernetische Modell in den Künsten. Würzburg 2009.

32 Oliver Krüger: Virtualität und Unsterblichkeit (wie Anm. 31), S. 147. Vgl. Tobias Hülswitt und Roman Brinzanik (Hrsg.): Werden wir ewig leben? Gespräche über die Zukunft von Mensch und Technologie. Frankfurt a. M. 2010.

\section{MÖGLICHES UND MACHBARES}

Damit befindet man sich zugleich in der >postbiologischen Tradition literarischer Science Fiction-Utopien, insofern als eine Zunahme derjenigen Schilderungen beobachtbar ist, die auf künftige technische Umsetzungen des Geschilderten vorausweist. Die

Trennlinie zwischen Antizipation und Phantastik [...], zwischen wissenschaftlicher Prognose und Science Fiction [wird] in hohem Maß porös Science Fiction als literarisch-filmische Gattung ist nicht vollkommen losgelöst von der faktischen technischen Entwicklung, sondern erprobt, mehr oder minder realistisch, deren Potentiale [...].33

Sind die Darstellungen frühneuzeitlicher Utopien, etwa der Renaissance (bei Morus, Campanella und Bacon) in dem, was sie vor Augen führen, noch weit entfernt von einer technisch-praktischen Realisierung, ändert sich dies im Zuge der Modernisierung, wenn deutlich wird, dass das in neueren Utopien Dargestellte durchaus auch realisierbar ist, etwa in der Raumfahrt und der Gentechnologie. Das Kennzeichen moderner literarischer Utopien besteht deshalb darin, dass das als möglich Gedachte auch zum technisch Machbaren wird und damit Ängste erzeugt, die den Übergang von der Utopie zur Dystopie bestimmen; aus Wunschbildern werden Schreckbilder. ${ }^{34}$

Die Nähe der Literatur zur technisch-wissenschaftlichen Forschung und des Möglichen zum Machbaren ist deshalb das auffallende Kennzeichen der gegenwärtigen Science-Fiction-Literatur. Dabei sind die Übergänge zwischen Formen literarischer Utopien und rein technisch orientierter Science-Fiction-Literatur fließend. ${ }^{35}$ Allerdings wird das Utopiegenre selbst einer satirischen Kritik unterzogen. So lässt sich

33 Albrecht Koschorke: Wahrheit und Erfindung. Grundzüge einer Allgemeinen Erzähltheorie. Frankfurt a. M. 2012, S. 231 (vgl. auch den Abschnitt "Zukunftsfiktionen«, S. 229-236).

34 Vgl. Wilhelm Voßkamp: Konstruktionen des Möglichen (wie Anm. 31), S. 43 .

35 Vgl. Darko Suvin: Poetik der Science Fiction. Zur Theorie und Geschichte einer literarischen Gattung. Übersetzt aus dem Amerikanischen von F. Rottensteiner. Frankfurt a. M. 1979. 
eine Traditionslinie von François Rabelais über Cyrano de Bergerac und Jonathan Swift bis zu Stanislav Lem ziehen. Bei Lem werden virtuelles Bewusstsein und reale Welt austauschbar; Menschen spielen Roboter und Roboter einen Menschen. Die Welt ähnelt einem ungeheuren Palimpsest, und am Ende bleibt unklar, ob der Mensch die Maschine oder die Maschine den Menschen geschaffen hat. Das Prinzip der skybernetischen Autonomie verwischt die Grenze zwischen Authentizität und Fiktionalität. ${ }^{36}$

\section{FORMEN DER UTOPIE}

Möglichkeitsdenken ist die Voraussetzung für die Form der Utopie. Nicht nur geht es um die »utopische Methode ${ }^{37}$ um utopisches Bewusstsein ${ }^{38}$ »utopian propensity $\aleph^{39}$ und die Überführung des Möglichen ins technisch Machbare, sondern um ästhetische Konstruktionen des HypothetischMöglichen im Medium von Literatur und Kunst..$^{40}$ "Der utopische Entwurf überläßt sich [...] in seiner narrativen Kontingenz der Fiktion « ${ }^{41}$

Voraussetzung ist das Spannungsverhältnis und die zentrale Differenz zwischen der je vorgefundenen gelebten Wirklichkeit und eine diese negierende virtuelle, imaginäre Welt. Literarische Utopien sind zugleich narrativ und bildhaft in ihrer Mobilisierung von Bildern der satirisch beschriebenen Wirklichkeit und dem Zukunftsentwurf kontrafaktischer Gegenbilder ${ }^{42}$ Eine der Paradoxien notwendiger "Versinnlichung « der Utopie besteht darin, sich gerade Unvorstellbares vorzustellen. ${ }^{43}$ Utopische

36 Wilhelm Voßkamp: Konstruktionen des Möglichen (wie Anm. 31), S. 53. 37 Raymond Ruyer: L'utopie et les utopies. Paris 1950 (wie Anm. 17).

38 Ernst Bloch, Geist der Utopie (wie Anm. 8)

39 Vgl. Frank E. und Fritzie P. Manuel: The Utopian Thought in the Western World. Cambridge, Mass. 1979.

40 Vgl. Hans-Joachim Mähl: Der poetische Staat. Utopie und Utopiereflexion bei den frühen Romantikern. In: Utopieforschung (wie Anm. 18), Bd. 3 , S. 273-302, hier S. 285.

41 Reinhart Herzog: Überlegungen zur griechischen Utopie: Gattungsgeschichte vor dem Prototyp der Gattung? In: Utopieforschung (wie Anm. 18), Bd. 2, S. 1-20, hier S. 10.

42 Jurij Striedter spricht von einer »Doppelfiktion«; vgl.: Die Doppelfiktion und ihre Selbstaufhebung. Probleme des utopischen Romans, besonders im nachrevolutionären Russland. In: Funktionen des Fiktiven. Hrsg. von Dieter Henrich und Wolfgang Iser. München 1983, S. 277-330.

$43 \mathrm{Vgl}$. Alois Hahn: Konstruktionen des Selbst, der Welt und der Geschichte.
Gegenbilder als (insuläre) Räume oder Projektionen in die zukünftige Zeit beziehen sich implizit oder explizit kritisch auf die jeweilige Situation, in der sie entstehen. Den "Prozess des kritischen Vergleichens [zwischen der bestehenden und entworfenen Welt] in Gang zu bringen «, ist der spezifische Kommunikationsmodus literarischer Utopien. ${ }^{44}$

Die entworfene imaginäre Welt ermöglicht im Medium der Kunst eine alternative Funktion, die sich nicht nur auf ein gesellschaftspolitisch relevantes Sozialmodell eingrenzen lässt. ${ }^{45}$ Vielmehr ist die Heterogenität künstlerischer Entwürfe als Antwort auf die konkrete Wirklichkeit charakteristisch. Dabei geht es stets, wie Hans Blumenberg betont, um die »künstlerische Erschaffung weltebenbürtiger Werke«, ${ }^{46}$ die zukunftsorientiertes fiktionales Probehandeln erlauben. Unter Rückgriff auf Leibniz und Christian Wolff spielt dieser Gedanke vor allem im Roman eine zentrale Rolle. So schreibt Leibniz in der Perspektive einer dichterischen Theodizee an (den Romanschriftsteller) Herzog Anton Ulrich von Braunschweig-Wolfenbüttel in einem Brief vom 24. April 1713: »[...] niemand ahmet unsern Herrn besser nach als ein Erfinder von einem schöhnen Roman. « ${ }^{47}$ Um die »Substitution des Universums" geht es ebenso in Goethes Projekt eines »Roman[s] über das Weltall« wie im romantischen Märchen und Roman. ${ }^{48}$ Die

Aufsätze zur Kultursoziologie. Frankfurt a. M. 2000, S. 172, unter Hinweis auf eine Passage in Michel Montaignes Essais.

44 Vgl. Ludwig Stockinger: Ficta Respublica (wie Anm. 17), S. 98.

$45 \mathrm{Vgl}$. etwa die Arkadiendichtung oder die Betonung einer »Intensität von Jetzt-Erfahrung « in der »im Ästhetischen überwinternden Utopie» (vgl. Karl Heinz Bohrer: Subjektive Zukunft. In: Merkur-Sonderheft [wie Anm. 11], S. 756-768; hier S. 768 und 758). Amir Eshel spricht von "Zukünftigkeit«: »Literatur erschafft das Offene, Zukünftige, Mögliche, indem sie unser Vokabular mit innovativen Konstruktionen und Metaphern erweitert, die menschliche Handlungsfähigkeit untersucht und gleichzeitig zu Reflexion und Debatten anregt. Diese Fähigkeit bezeichne ich als `Zukünftigkeit« (Zukünftigkeit. Die zeitgenössische Literatur und die Vergangenheit. Aus dem Englischen von Irmgard Hölscher. Frankfurt a. M. 2012, S. 15.

46 Hans Blumenberg: Wirklichkeitsbegriff und Möglichkeit des Romans. In: Nachahnung und Illusion. Hrsg. von Hans Robert Jauß. 2. durchgesehene Auflage. München 1969, S. 9-27, hier S. 18.

47 Zit. nach Wilhelm Voßkamp: Romantheorie in Deutschland. Von Martin Opitz bis Friedrich von Blanckenburg. Stuttgart 1973, S. 16.

48 Vgl. Hans Blumenberg: Die Lesbarkeit der Welt. Frankfurt a. M. 1986, S. 233 ff. und S. $222 \mathrm{f}$. 
"Fiktion der Realität von Realitäten« ${ }^{49}$ erfordert Konsistenzbildung. Als `bestimmte Negation dessen, was ist (Theodor W. Adorno, Lars Gustafsson), bedürfen Gegen-Entwürfe einer hypothetisch-möglichen, vorstellbaren Welt, die versinnlicht werden muss. Welthaltigkeit ist für alle künstlerischen Utopien zentral. Anstelle des politischen Willens Utopien zu sverwirklichen`, geht es in der künstlerischen Produktion um die Form als Ort der Utopie. Gerade darin ist eine Steigerung des utopischen Bewusstseins möglich - ungeachtet ihrer Vielgestaltigkeit und relativen Geltung.

Allerdings ändert sich die Funktion der /Wunderkraft der Fiktion`: »Alle Progression [...] fängt mit Illusion an « ${ }^{50}$ insofern, als mit der zunehmenden Fiktionalisierung der literarischen Gattung Utopie ein Selbstreflexionsprozess verbunden ist, der sich - beginnend mit Wielands Roman Der Goldne Spiegel ${ }^{51}$ - bis in die Gegenwart fortsetzt. Dieser Reflexionsprozess richtet sich nicht allein auf unterschiedliche ästhetische Vergegenwärtigungen utopischer Entwürfe (`Ästhetisierung< von Utopien), sondern auch grundsätzlich auf die Zukunftsfähigkeit solcher Projektionen. Prinzipiell lässt sich die Autopoiesis der Utopie als selbstreflexive Dialektik von Utopie und Utopiekritik/Utopie und Dystopie charakterisieren. Die Frage, in wieweit gerade diese Spannung neue Formen utopischen Schreibens ermöglicht und hervorbringt, gehört zum Themenfeld dieses Bandes.

Der erste Themenkomplex charakterisiert prinzipielle Aspekte gegenwärtiger Utopieforschung und ihrer Grenzen.

Gabriel Motzkin, Friedrich Balke und Matthias Löwe diskutieren in ihren Beiträgen Grenzen des alteuropäischen Utopiekonzepts insofern, als sie unter je unterschiedlichen Aspekten (Darwinismus, `Heterotopie', Anthropologie) Utopien prinzipiell als Möglichkeiten aufklärerischfortschrittlichen Denkens befragen und problematisieren.

49 Hans Blumenberg: Wirklichkeitsbegriff (wie Anm. 46), S. 27.

50 Novalis: Schriften. Hrsg. von Richard Samuel in Zusammenarbeit mit Hans-Joachim Mähl und Gerhard Schulz. Stuttgart 1965-68, Bd. III, S. 372; zit. nach Hans Joachim Mähl: Der poetische Staat (wie Anm. 40), S. 285. 51 Wilhelm Voßkamp: Transzendentalpoetik. Zur Übersetzung utopischer Diskurse. In: Wielands Goldnem Spiegel. In: Bettine Menke und Wolfgang Struck (Hrsg.): Wieland/Übersetzen. Sprachen, Gattungen, Räume. Berlin und New York 2010, S. 225-236.
Gabriel Motzkin macht am Beispiel der Evoultionstheorie deutlich, dass im Unterschied zu Utopien und Dystopien Evolutionen auf keinen Endzustand zielen, weder in einem >positiven $>$ noch $>$ negativen Sinn. »Zufallsbehaftete« Selektion und Anpassung widersprechen einem in Utopien und Dystopien angelegten statischen Endzustand. Utopien und Dystopien sollten deshalb auf eine Totalisierung verzichten. Eine Vermittlung oder Einheit von Theorie und Praxis in Utopien sei stets zu kritisieren.

Friedrich Balke führt diesen Gedanken unter Rückgriff auf Michel Foucaults Heterotopie-Konzept weiter. Es geht um /Widerlager und Kritik der Ordnungsvorstellungen von Repräsentation zu Gunsten sheterotopischer Sensibilität،. Diskussionen über das Mensch-MaschineKontinuum können auf »Funktionszusammenhänge und Allianzen« aufmerksam machen, die an Denkmöglichkeiten "vor der epistemologischen Befestigung einer dualistischen Ontologie« erinnern. F. Balke plädiert am Beispiel Samuel Butlers für das Erneuern solcher Wissensformen von Analogiebildungen, um neue Allianzbeziehungen zwischen heterogenen Elementen stiften zu können.

Matthias Löwe problematisiert die Zukunft des futurischen Denkens unter einem grundsätzlich anthropologischen Aspekt. Der Zweifel an der Idee der Vernunftautonomie wird im Zeichen von Anthropologie evident. M. Löwe verweist von gegenwärtigen Diskussionen auf Parallelen zur Spätaufklärung und Romantik, in der Reflexionen heutiger Debatten vorgebildet sind. Die Einsicht in die >Unlösbarkeit dieses Problems werden um 1800 mit ästhetischen Operationen beantwortet, die unter dem Gesichtspunkt des `Romantisirens ‘ fortan die Diskussion bestimmen. Ist dies der Ausweg gegenüber der Gegenspielerin >Anthropologie‘?52 Oder lassen sich Utopien einer "Weltgesellschaft auf Basis der Menschenrechte und Toleranzforderung" vorstellen?

Grundfragen utopischen Möglichkeitsdenkens in philosophischer Perspektive erörtern Arbogast Schmitt, Klaus Berghahn, Vivian Liska und Martin Roussel.

Arbogast Schmitt deutet Platons Politeia nicht als Idealstaat, sondern als einen `Möglichkeitsraum ‘ der einem jeden zustehenden Selbstentfaltung. Daraus folgt die Entwicklung einer Theorie der paideia, einer Lehre der (notwendigen) Selbstverwirklichung. Diese muss unter dem

52 Vgl. dazu insgesamt Matthias Löwe: Idealstaat und Anthropologie. Problemgeschichte der literarischen Utopie im späten 18. Jahrhundert. Berlin und Boston 2012. 
Aspekt einer funktionalen Hinordnung auf den ganzen Menschen gedacht werden, so dass der Wille, etwas zu tun als Grundthema charakterisiert werden kann. Es geht um die »Verwirklichung dieses Könnens«, einer (lustvollen) Tätigkeit im Dienst am Ganzen. Dies ist ein Konzept von Bildung, das grundsätzlich dem seit der Spätantike entwickelten Modell der Sieben Freien Künste entspricht. ${ }^{53}$

Klaus L. Berghahn entfaltet die Kategorie der Möglichkeit bei Ernst Bloch. Er betont, dass unter den drei von Bloch unterschiedenen Möglichkeitsbegriffen das >objektiv-real Mögliche` entscheidend ist, insofern er die zukunftsträchtige Möglichkeit in der Wirklichkeit angelegt sieht. Diese muss vom jeweiligen historischen Subjekt »entdeckt und entfaltet werden «. Im Unterschied zur aristotelischen Naturteleologie bedarf es nach Bloch einer ssubjektiven Aktivität`, um das Mögliche auch zu verwirklichen. Daher sind Subjekt und Objekt dialektisch aufeinander bezogen. Wichtig ist zudem, dass Kunst »in der Wirklichkeit als Keim von Zukünftigem, als das >objektiv Mögliche`schon angelegt ist « ${ }^{54}$

Die schon bei Ernst Bloch zugrundeliegende messianische Vorstellung des Zusammenhangs von Möglichkeits- und Utopiedenken untersucht Vivian Liska im Vergleich zwischen Walter Benjamin und Giorgio Agamben. Als entscheidenden Unterschied wird die "Welthaltigkeit des Benjaminschen Messianismus« im Unterschied zu Agamben hervorgehoben, der, eher der christlichen Gedankenwelt verhaftet, wenig konkrete Inhalte bietet. Walter Benjamins Kritik an dem durch die idealistische Philosophie bedingten Fortschrittsdenken wirft Fragen nach dem Verhältnis von epischen Formen und messianischen Erlösungsvorstellungen auf. Benjamin nähert sich einer Sprachutopie als der »allumfassende[n] erfüllte[n] Präsenz von Sprache und Geschichte«. Giorgio Agambens Kommentar zu Benjamins Messianismus-Vorstellungen mündet mit »Heideggerische[n] Untertöne[n] in einer Ästhetik der Leere« und »Ethik der Bezuglosigkeit«. Deutlich wird dies in der kontroversen Deutung von Franz Kafkas »Vor dem Gesetz«.

Für eine Analyse des konstitutiven Zusammenhangs von Utopie und Dystopie im Möglichkeitsdenken reklamiert Martin Roussel die philologische Ausrichtung. Lektüre ist das Prinzip, mit dem sich in Musils Der

53 Vgl. insgesamt Arbogast Schmitt: Die Moderne und Platon. Stuttgart und Weimar 2008.

54 Klaus L. Berghahn: »Die Kunst Schiller zu sprechen«. Ernst Bloch liest Friedrich Schiller. Ein Vortrag. In: Jahrbuch der deutschen Schillergesellschaft LV (2011), S. 215-229, hier S. $226 \mathrm{f}$.
Mann ohne Eigenschaften der Möglichkeitssinn ıgegen d.h., dass alle Utopien des Romans gegenüber dem Krieg letztendlich nichtig sind, der Krieg aber auf alternatives Möglichkeitsdenken hin »durchsichtig gemacht werden kann«. Ulrichs Auszeit stellt ein »Experiment auf die Wirkung des Möglichen - gegenüber dem Wirklichen« (des Krieges) dar. In der Dichotomie der Utopie des sexakten Lebens mit dem »Mystizismus der Möglichkeiten« (der sandere Zustand `) wird die Kristallisation utopischer Erfahrung beobachtbar. Musils »Atemzüge eines Sommertags « bedeuten die »Dekonstruktion des Ästhetischen wie des Utopischen«. Keine der Musil'schen Utopien kann sich behaupten, aber sie lassen sich als "Haltepunkte vor dem dystopischen Finale» bezeichnen.

Dass ein zunehmender Selbstreflexionsprozess gegenwärtige literarische, visuelle und digitale Formen utopischen Schreibens und Veranschaulichens bestimmt, dokumentieren die Beiträge von Hans Ulrich Seeber, Judith Leiß, Ryozo Maeda und Roberto Simanowski.

Hans Ulrich Seeber macht deutlich, dass Utopiekritik seit dem Ende des 19. Jahrhunderts eine zentrale Funktion in der Geschichte der literarischen Gattung >Utopieく übernimmt. Dystopien richten sich gegen utopische Vorbilder in der Kombination mit satirischen Wirklichkeitsdiagnosen. Sie verweisen damit auf unterschiedliche Formen negativer Gesellschaft. Ausgangspunkt der Überprüfung vorhandener utopischer Modelle und Erzählstrategien ist eine grundsätzliche Kritik des Fortschrittsdenkens. H. G. Wells Spott auf pastorale Muster von John Ruskin und William Morris sind dafür ein Beispiel; Wells Parodien und `Ambigious Utopias bis zu Ursula LeGuins The Dispossessed nicht minder. Dennoch verzichten Huxleys, Orwells oder Samjatins Texte - gerade in ihrer TotalitarismusKritik - nicht auf einen utopischen Impuls.

Judith Leiß charakterisiert die neuere Gattungsentwicklung der Antiutopie im Zeichen einer Spirale. Sie betont die Gleichzeitigkeit unterschiedlicher Erscheinungsformen utopischen Schreibens unter denen neben Dystopien und >Critical Utopias`(Tom Moylan) eine Variante als $>$ Heterotopie charakterisiert wird. In der klassischen Tradition von Doppelfiktionen, in denen sich die beiden dargestellten Welten gesellschaftlicher Ordnung (als Satire / als Utopie) im /Widerstreit • befinden, wird insbesondere das \Inkommensurable utopischen Schreibens betont. Im >Widerstreit der Welten $>$ wird etwa in Peter Ackroyds The Plato Papers nicht erkennbar, welche der beiden dichotomisch beschriebenen gesellschaftlichen Wirklichkeiten die `bessere ist. 
Die Vielfalt utopischer Formenbildung veranschaulicht insbesondere ein Blick auf außereuropäische Ausprägungen. Ryozo Maedas Untersuchung zu Utopien und Dystopien in der visuellen Massenkultur Japans macht deutlich, dass sich mit dem Ende der Faszination für marxistische Utopien in den 1970er Jahren gleichzeitig eine populäre Kultur von Manga und Anime entwickelt hat, die eine Nähe zu Fantasy- und Science Fiction-Literatur aufweist. Für Idealstaats-Utopien gibt es kein adäquates Pendant. Dagegen lässt sich ein traditionelles Traumland als 'gesellschaftsferner Ort in der Natur ausmachen, der etwa in der agrargesellschaftlichen und ökologischen Orientierung bei Kenji Miyazawa seinen Platz findet. Ryozo Maedas Interesse richtet sich vornehmlich auf die Form der Ikai (>Andere Welten 〈/>Andere Universen ‘). In der japanischen Popkultur finden sich spielerische Auseinandersetzungen mit Umweltkatastrophen, in denen apokalyptische Elemente dominieren. Katsuhiro Otomos Akira gehört zu jenen epochemachenden Mangas, die das Leben nach der Zerstörung von Metropolen oder Ökosystemen thematisieren und so durchaus an Hieronymus Boschs Garten der Lüste erinnern. Damit lässt sich auch hier eine Tendenz zur fortschreitenden Ästhetisierung von überlieferten Utopie- und Dystopiemodellen beobachten.

Dass sich die Geschichte des Internets sowohl im Modus der Utopie als auch in dem der Dystopie erzählen lässt, veranschaulicht schließlich Roberto Simanowskis Beitrag zum Internet, der von William Gibsons Newromancer als literarischer Dystopie ausgeht. Der utopische Aspekt der digitalen Medien ist so ambivalent wie ihr dystopischer. Lässt sich das Internet in den 1990er Jahren noch als Utopie, etwa im Ermöglichen kollektiver Demokratie oder als Zufluchtsort charakterisieren, so stellt er heute "das wichtigste Werkzeug des >kybernetischen Kapitalismus«" dar. Die aktuelle Phase des Internets lässt sich nur als das Medium des Verlustes von Gemeinschaft und Privatheit bezeichnen. Konnte es noch als legitimer Nachfolger des Projekts der Aufklärung erhofft werden, so bestätigt die gegenwärtige Praxis die »These vom organologischen Zirkel«, wonach sich »die Menschen [...] zunächst das Medium nach ihrem Bedarf schaffen, bevor dieses sie verändert $\omega^{55}$ Das spiegelt insgesamt die zunehmende Bürokratisierung durch Umstellung des narrativen auf das

55 Vgl. Hartmut Winkler: Die prekäre Rolle der Technik. In: Claus Pias (Hrsg.): Dreizehn Vorträge zur Medienkultur. Weimar 1999, S. 263-282, hier S. 278. numerische Modell. Findet die Sehnsucht nach verlässlichem Wissen ihren Ausdruck im »Regime der Zahl? « ${ }^{56}$

Den Abschluss des Bandes bilden zwei Beiträge, die einerseits die Institution >Universität< als Ort stets neuer Diskussionen über die Utopie ,Wissenschaft $<$ thematisiert und andererseits eine aktuelle Debatte zur Utopie >Europar aufnimmt.

Jürgen Fohrmann fragt nach den >utopischen Dimensionen` der Universität, die heute eher als Ort `begrenzter Möglichkeiten ๖ betrachtet wird, obwohl auch sie ihre Geschichte hat. Drei säkulare Schnitte bestimmen (idealtypisch) ihre Entwicklung: 1500, 1800 und die Zeit nach 2000. Die erste Phase ist durch das humanistische Ethos einer idealen Akademie charakterisiert, die nach der Umwandlung der scholastischen Universität ein Ort der Freundschaft darstellt. Die zweite, entscheidende Phase um 1800 steht bereits stärker im Zentrum des Institutionellen. Die Humboldtsche Universitätsreform führt zur Entwicklung wissenschaftlicher Disziplinen, betont aber zugleich das Moment von Geselligkeit im Sinne einer >Wechselwirkung , die sich insbesondere im `Seminar von Lehrenden und Lernenden ausprägt. Das `Konzept forschender Wechselwirkung wandelt sich schließlich in eine Reform der universitären Institution, die auf Clusterbildung und Optimierung setzt. Komplexitätserweiterung bedeutet zugleich eine stärkere Betonung von Interessenvertretung und funktionaler Bestimmung des Ökonomischen. Das >Versprechen auf Optimierung und die Hoffnung auf `messbaren Erfolg` erinnert an eine >potenzierte Institution`, wie sie bereits die Frühe Neuzeit in ihren Utopien entwarf. Jürgen Fohrmann warnt vor immer strengeren ökonomischen Regulierungen und setzt auf das Bewahren von Erfahrungen vor allem der durch >Wechselwirkung bestimmten Reform um 1800.

Der abschließende Beitrag von Karl Heinz Bohrer zur Utopie `Europa macht sowohl auf ein allgemeines Utopiethema aufmerksam als auch auf ein besonderes: Stets sind Utopien Indikatoren für >Krisen` und zugleich reagieren sie darauf. Das gilt im Besonderen für die Europa-Idee, die sich derzeit nicht nur in einer politischen Krise befindet. Nach dem Ende der beiden Weltkriege im 20. Jahrhundert wird die Idee der europäischen Einheit - noch ganz in der Tradition von Madame de Stael - zu einem wechselseitigen Faszinosum im Verhältnis von Deutschland und

56 Vgl. Miriam Meckel: Next. Erinnerungen an eine Zukunft ohne uns. Reinbek bei Hamburg 2011. 
Frankreich. Diese schwindet mehr und mehr, vornehmlich dadurch, dass sich die deutsche `Geistesgeschichte` treu bleibt, während die französische Dekonstruktion eine andere, "neue Lesart der Welt« vorschlägt. So hat weder die >geistige< europäische Idee der $30 e r$ Jahre noch die ’karolingische der 5oer Jahre des 20. Jahrhunderts eine Chance »utopisch $\mathrm{zu}$ funktionieren« oder politisch wirksam zu werden. So bleibt die am Schluss gestellte Frage offen, ob heute eine "neue utopische Sprache" erfunden werden könnte, die dann auch für eine politische Einheit Europas tauglich wäre.

Mein Dank gilt den Direktoren des Kollegs Morphomata, Günter Blamberger und Dietrich Boschung, die mir die Durchführung der Tagung und die Drucklegung ihrer Ergebnisse ermöglicht haben. Herzlich danke ich Martin Roussel und Christine Thewes für ihre ebenso engagierte wie freundschaftliche Unterstützung.

\section{UTOPIE UND DYSTOPIE ALS PROBLEM DER FORSCHUNG UND IHRER GRENZEN HEUTE}




\section{GABRIEL MOTZKIN}

\section{UTOPIE, DYSTOPIE UND EVOLUTION}

Die Evolutionstheorie hat zwei Begriffe als Verständnisvorlage für die Vergangenheit eingeführt: Selektion und Adaption. Man muss dabei im Auge behalten, dass diese beiden Begriffe auf die Vergangenheit von Lebewesen angewandt werden. Obwohl man auch meinen könnte, dass sich Selektion und Anpassung für die Gebiete der Geologie oder der Physik eignen würden, hat sich noch niemand daran gemacht, die zwei Begriffe auch auf diese beiden Fächer anzuwenden. Im Gegensatz zur Biophysik - einem Versuch, die Physik zum Verständnis der Biologie heranzuziehen würde eine solche Erweiterung der Evolutionstheorie bedeuten, dass für die Biologie entwickelte Begriffe nun auf die Physik bezogen werden.

Das bedeutet, dass die Evolutionstheorie ungleich der Physik oder der Philosophie keine universelle Anwendung für sich in Anspruch nimmt. Stattdessen betrachtet sie ihre Domäne nur als Teilbereich dessen, was existiert. Deswegen hat sie auch zu erklären, wie die Prinzipien, welche die Evolution beherrschen, sich an ein universelles Konzept machen, um nur in einer spezifischen Domäne zu operieren.

Während außerdem einige Bereiche der momentanen Evolutionstheorie experimentell überprüft werden können, war dies im neunzehnten Jahrhundert nahezu unmöglich. Durch selektive Züchtung haben sich die Menschen dem noch am meisten angenähert. Selektive Züchtung geht jedoch auf einen kontrollierten Entwurf zurück, in diesem Falle auf einen menschlichen Entwurf. Im Gegensatz dazu drehen sich die Fragen der Evolutionstheorie darum, ob die Evolution unter dem Druck ihrer Umwelt handelt, d.h. äußerer Kräfte, die nicht vorhersagbar sind und die sich darauf auswirken, welche Population am "geeignetsten ist. Eignung heißt in der Evolutionstheorie allerdings nicht, dass einige Wesen anderen überlegen sind. Niemand weiß wirklich, welche Art von Lebewesen überhaupt überlegen wäre. Es bedeutet vielmehr, dass es die Angepasstesten sind, die überleben und das sind diejenigen, denen es gelingt, mehr Nachkommen über mehrere Generationen hinweg zu haben. 
Angepasstheit ist demnach eine Tautologie. Wenn die Hälfte der Welt aus ultraorthodoxen Juden bestünde, dann wären ultraorthodoxe Juden die geeignetsten Menschen. Es wurde offensichtlich wegen des Essentialismus in dieser Überlegung die Überlegung selbst missverstanden, so dass z. B. größere, blonde Menschen für angepasster gehalten wurden als kleinere und dunklere Menschen. Das Wesentliche an der Evolutionstheorie ist jedoch, dass solch ein Urteil niemals wirklich gefällt wird: Für die Evolutionstheorie kann es per Definition keine rassische Utopie geben.

Das bedeutet jedoch nicht, dass Geschöpfe innerhalb dieses Paradigmas nicht doch glauben könnten, sie befänden sich in einem idealen Stadium [state]. Wenn alle Staaten [states] muslimisch und alle Menschen Salafisten wären, dann wären sich die Salafisten sicher, dass sie gewonnen hätten. Der Eindruck, dass man in der besten aller Welten lebt und tatsächlich in der besten aller Welten zu leben, sind jedoch zwei sehr unterschiedliche Dinge. Das liegt daran, dass wir aus evolutionären Gründen nicht die Vergangenheit nachleben können und unser Gespür für die Zukunft dauert auch nie besonders lang: Wir müssen jetzt essen und nicht später. Man stelle sich eine salafistische Gesellschaft vor. Sogar im besten aller Fälle würde sie nur drei- bis viertausend Jahre überleben (siehe Ägypten), was in Evolutionszeit gemessen ein Wimpernschlag ist. Deswegen müssen wir zwischen einem optimalen Zustand [state] in der Gegenwart, also einem kurzzeitigen optimalen Zustand, und einem optimalen langzeitigen in der Zukunft unterscheiden, was ziemlich widersprüchlich erscheinen mag.

Wenn wir die beiden grundlegenden Kategorien der Evolutionstheorie in Erwägung ziehen, Selektion und Anpassung, dann werden wir sehen, dass es einen Widerspruch gibt zwischen dem Kurzzeitigen und dem Langzeitigen. Doch zunächst: Was meinen wir mit Selektion und Anpassung? Anpassung heißt einfach Anpassung an äußerliche Zwänge, z. B. kaltes oder warmes Wetter. Menschen, die an kalten Orten leben, sind groß, um Wärme zu speichern und Menschen, die an warmen Orten leben, sind braun, um das Sonnenlicht nicht durchzulassen. Selektion heißt demnach, dass Menschen, die sich diesen Zwängen nicht anpassen, über kurz oder lang ausgesiebt werden, d.h. sie schaffen es nicht, sich zu reproduzieren. Ein anderes Beispiel: Vor 6000 Jahren entwickelte eine Gruppe viehtreibender Hirten, die in der Ukraine lebten, die Fähigkeit, Milch als Erwachsene zu vertragen. Das hatte zur Folge, dass sie länger als andere Populationen kindhafte Züge behielten. Diese Fähigkeit, Milch zu trinken, machte sie auch größer. Man kennt diese Menschen, unter Umständen gehört man sogar selbst zu ihnen: all die Menschen indo-europäischen Ursprungs, die so genannten Arier. Diese Verträglichkeit von Milch, entwickelte sich allerdings nur deshalb, weil diese Hirten Milcherzeugnisse brauchten, um zu überleben. Denjenigen Menschen in dieser Population, die laktoseintolerant waren, gelang es nicht, sich zu reproduzieren. Der Kernpunkt dabei ist jedoch, dass niemand aus dieser Population irgendetwas über Genetik oder kontrollierte Gestaltung wusste: Eine Veränderung in den Lebensgewohnheiten bestimmte, welche Menschen mit welchen Genen überlebten.

Anpassung verweist auf umgebungsbedingte Zwänge, wohingegen Selektion darauf verweist, welche Gene selegiert werden. Die beiden gehören jedoch offensichtlich zusammen. Das Wesentliche bei diesen Metaphern ist, dass sie nicht auf die Physik angewandt werden können: Wir sagen nicht von Elementen, dass sie aus einer Folge von Anpassung und Selektion entstanden sind. Dieses Modell bezieht sich auf Lebensformen. Etwas anderes Wesentliches bei diesem Mechanismus ist, dass er solange weiter machen muss, wie das Leben weiter macht, weil es eben der Mechanismus des Lebens ist. So entwickeln sich die Menschen unbemerkt von uns auf eine Weise weiter, die vorteilhaft sein könnte, und auf eine andere, die es nicht ist. Ein Beispiel: Die Neandertaler hatten offensichtlich eine größere Gehirnkapazität als wir. Aber haben sie ihre vermutlich größere Intelligenz auch benutzt? Wenn sie nicht dazu in der Lage waren, in komplexen Sätzen zu sprechen, womit wir Rekursivität meinen, dann konnten sie ihre Intelligenz nicht auf eine organisierte Weise verwenden. Das ist die einmalige Leistung unserer menschlichen Spezies. Also könnten wir sowohl dümmer als auch effektiver sein.

Das Problem sowohl mit Utopien als auch mit Dystopien ist, dass sie oft einen statischen Endzustand [end-state] annehmen. Das Wesentliche an einer Utopie oder einer Dystopie, was die Evolution betrifft, ist, dass ein Prinzip der Entwicklung einbezogen werden muss. Eine Utopie ist demnach kein Endzustand, sondern ein Stadium [state] förderlicher Entwicklung und eine Dystopie ist also auch kein Endzustand, sondern ein Stadium zerstörerischer Entwicklung. Die Frage wäre dann: Was ist ein utopisches oder ein dystopisches Entwicklungsprinzip verglichen mit einem normalen?

Offensichtlich müsste ein utopisches Prinzip zwei Aspekte haben: Erstens müsste es ein Prinzip sein, das für eine ständige Verbesserung sorgt, aber: zweitens müsste es zu Selektion und Anpassung führen. Das zweite Prinzip hat zur Folge, dass ständige Verbesserung nur für die Gruppe funktionieren könnte und nicht für die Individuen. Was folglich für eine Gesellschaft utopisch ist, muss notwendig für einige oder mehrere 
Individuen dystopisch sein. Das mag auf Evolution im Allgemeinen zutreffen oder auch nicht: ob das, was für die Gruppe gut ist, schlecht für das Individuum ist.

Die Fragen, die sich ergeben sind: Was ist die Achse der Verbesserung und hat Entwicklung dabei eine Begrenzung? Ein Beispiel: Wenn Menschen größer würden als vier Meter, würden sie zusammenbrechen, weil ihre Knochen die Belastung nicht aushalten könnten. Daher wissen wir, dass Menschen lauter strukturellen Beeinträchtigungen unterliegen, wenn sie weiter wachsen. Auf kurze Zeit wäre Größe hingegen ein Vorteil.

Gibt es dann in allen Fällen nicht nur eine Begrenzung des Wachstums, sondern auch wachsende Probleme, wenn sich das Wachstum der Grenze nähert? Ist der optimale Zustand derjenige kurz vor dem Zusammenbruch oder irgendwo anders auf dem Pfad der Entwicklung? Und trotzdem traut kein Mensch seinem Glück, wenn er spürt, dass jeder Zustand, in dem er sich gerade befinden mag, vom anstehenden Zusammenbruch überschattet wird. Diese Situation trifft sogar noch stärker auf sehr reiche Gesellschaften zu als auf arme. Sehr reiche Gesellschaften schneiden in Sachen Glück oft schlechter ab.

Die Evolutionstheorie sagt uns jedoch, dass es beispielsweise einen selektiven Vorteil im Unglück geben könnte. In diesem Falle würden die Menschen über die Zeit sogar unglücklicher, wenn sie die Entwicklungsleiter emporsteigen.

Also ist die Frage: Wonach wird selegiert? Biologen haben eine einfache Antwort: Die Selektion geht nach der Eignung, und die Eignung ist die Verbreitung von Genen unter einer Population. Es sollte nochmals darauf hingewiesen werden, dass ein jeglicher Versuch einer absichtlichen Gestaltung, z. B. der Zölibat katholischer Priester, zum Scheitern verurteilt ist, da seine Wirkung nur dystopisch sein kann.

Wir kommen zu unserer ersten Schlussfolgerung: ein Selektionsprinzip kann nicht vollkommen utopisch sein, da einige Individuen gezwungenermaßen ausgeschlossen oder ausgelöscht werden. In diesem Falle bedeutet eine jegliche Utopie auch immer eine Dystopie. Das Glück oder die Zufriedenheit einiger muss das Unglück oder die Unzufriedenheit anderer mit sich bringen. Diese Situation kann nun versüßt werden, indem die Benachteiligten weniger benachteiligt werden und die Bevorteilten weniger bevorteilt, aber es versteht sich, dass solch ein relativer Ausgleich nicht utopisch ist. Er ist antiselektiv und kann eben deswegen nicht zu einer Verbesserung führen.

Wir kommen jedoch auch zu der Schlussfolgerung, dass die optimale Situation eine des laissez-faire ist, da wir nicht wissen, was für ein Selektions- prinzip angewandt werden sollte. So ist unser Prinzip einer allgemeinen Menschlichkeit durch ein Selektionsprinzip ersetzt worden, aber wir können nicht in den Selektionsmechanismus eingreifen, indem entweder Populationen ausgelöscht werden oder den Armen geholfen wird.

Ein Kerngedanke ist hier, dass Selektion nur stattfinden kann als eine Konsequenz aus einem von zwei Prinzipien. Beide sind essentiell beliebig. Das erste ist die genetische Drift, womit wir meinen, dass sogar ohne äußere Einwirkungen sich ein Genpool mit der Zeit in eine Richtung entwickeln wird: Sogar in einem Reagenzglas bleibt keine Population gleich. Das zweite ist Anpassung. Es ist festzuhalten, dass wir, wenn wir Evolution durch Anpassung kontrollieren wollen, wir nicht Menschen oder Hunde heranzüchten, sondern wir die äußeren Bedingungen verändern. Um große Menschen heranzuzüchten, würden wir jeden dazu bringen müssen, Milch zu trinken und die Heizung zu Hause abzudrehen. Die Menschen würden mit der Zeit größer. Was wir jedoch nicht kontrollieren könnten, wäre, ob es eine optimale Höhe gibt. Vielleicht sollten wir z. B. alle 1,68 m groß sein. Diese Beobachtung benötigt noch eine Qualifikation: Evolution benötigt Abwechslung, was bedeutet, dass je größer die Vielfalt zwischen den Populationen ist, desto größer ist die Chance, dass die Menschen als Spezies überleben können. Insofern die Entwicklung im Laufe der Zeit zur Gleichförmigkeit tendiert, ist diese Entwicklung zerstörerisch. Das wäre also die Situation. Wir wollen große Variation und wir haben zwei Prinzipien, die Unangepasste auszusieben, Selektion und Anpassung, welche beliebig und zufällig sein müssen, um zu funktionieren. Das heißt wiederum, dass Gesellschaften Zufälligkeit und Unbestimmtheit fördern sollten.

Können Gesellschaften, welche Zufälligkeit und Unbestimmtheit fördern, aber auch utopisch sein? Unsere Schlussfolgerung zuvor war, dass Utopie in diesem Sinne hieße, in einer sich ständig verbessernden Situation zu leben.

Es gibt noch ein anderes Problem. Gesellschaften, die beliebig und zufällig sind, müssen die Möglichkeit von Katastrophen in Rechnung stellen. In diesem Sinne leben Menschen sogar in einer optimalen Situation immer mit der Möglichkeit der Dystopie. Alle Gesellschaften brechen letztlich zusammen, nur nicht gerade jetzt. Aber es gibt dabei zwei mögliche Strategien: Man kann sein Leben gemäß normaler Prinzipien leben und sich nicht auf die Katastrophe vorbereiten oder man kann sich auf die Katastrophe vorbereiten, so dass man sehr gut im Zustand der Ausnahme oder des Notfalls funktioniert, aber damit verwirkt man die Vorteile der Normalität, da die normale Situation dann als Angriffsfläche für gewaltsame Notfälle betrachtet wird. 
Sowohl traditionelle Religion als auch der deutsche Nationalsozialismus betrachteten jede Situation als eine des Notfalls. In anderen Worten: Sie funktionierten wie Anwälte, die immer danach trachten, jede mögliche zufällige Situation in einen Vertrag einzuschließen. Damit binden sie die Zukunft an die Gegenwart. Nun sollte es offensichtlich sein, dass sowohl traditionelle Religion als auch der Nationalsozialismus die Utopie jetzt sofort versprechen, aber sie müssen einen zunächst davon überzeugen, dass man gerade in der größtmöglichen Dystopie lebt, so dass es kein allmähliches Fortschreiten von Dystopie zu Utopie gibt. Sie müssen die Dystopie normalisieren.

Dagegen könnte man einwenden, dass das Leben für die meisten Menschen düster ist. Das ist jetzt eine interessante Schlussfolgerung, da die meisten Menschen in Interviews oder Umfragen nicht glauben, dass ihr Leben düster ist, was so viel heißt wie, dass ihr Leben oft nur düster vom Standpunkt eines äußeren Betrachters aussieht.

Der gegenteilige Standpunkt wäre einer, von dem aus wir schon jetzt ein Leben inmitten der Utopie führen, ungeachtet der Bedingungen unseres Lebens. Die meisten Amerikaner sind überzeugt, dass sie in einem utopischen Amerika leben, ohne auf die Parameter zu achten, die ihnen zeigen würden, dass das Leben woanders besser ist. Diese Art verzweifelten Frohsinns mag sich als vorteilhaft erweisen, weil die Vorstellung, bereits in der bestmöglichen Welt zu leben, die sozialen und kollektiven Bindungen unter den Menschen stärken könnte und somit Raum für kollektives Handeln schafft.

Dystopiker glauben an die Utopie und Utopiker glauben an die Dystopie. Dystopiker liegen damit richtig, dass alle irgendwann sterben und die Utopiker liegen damit richtig, dass, welche Welt auch immer ich bewohne, sie die bestmögliche Welt ist, die ich bewohnen kann. Es sollte sich jedoch auch verstehen, dass in der menschlichen Geschichte die Utopiker meistens gegenüber den Dystopikern im Vorteil lagen.

Und dennoch wirft dies die Frage auf, wie und ob Utopien mit zufälligem Glück [chance] und genereller Zufälligkeit umgehen. Zum Beispiel ist Kapitalismus bloß eine Strategie, das zufällige Glück zu maximieren, d. h. von einem Ereignis unmittelbar zu profitieren. Das Problem ist dies: Wenn man glaubt, dass man schon in der bestmöglichen aller Welten lebt, wie und warum kann man dann Zufälligkeit zu seinen eigenen Gunsten benutzen?

Es ist wichtig, hier den Unterschied zwischen kurzzeitigen und langzeitigen Erwägungen zu bedenken. Der Vorteil, der maximiert werden muss, ist der Vorteil, dem Langzeitfolgen zugerechnet werden. Wir bleiben in der Ehe treu, weil unter anderem der Vorteil, unsere Kinder so großzuziehen, dass sie einen besseren Status erreichen, eine momentane Befriedigung überwiegt. Aufgeschobene Befriedigung ist für Utopiker eher möglich als für Dystopiker, da Dystopiker im Allgemeinen nach sofortigem Heil streben. Dystopiker wollen nicht, dass man ihnen sagt, dass sie Katastrophen durch schrittweises Handeln verhindern können.

Eines der Probleme von Modellen wie dem von Heideggers Feld der Möglichkeiten ist es, dass es jeden Moment isoliert und dann die Gesamtheit aller Möglichkeiten in diesem Moment betrachtet. Aber so funktioniert Evolution nicht. Und Menschen funktionieren auch nicht so. Menschen betrachten niemals die Gesamtheit der Möglichkeiten. Sie erwägen - wenn überhaupt - zwei oder drei Möglichkeiten und wählen häufig eine Mischlösung. In anderen Worten, Menschen ziehen es generell vor, eher schrittweise vorzugehen als radikal. Diese Hypothese mag man bezweifeln, ich meine aber damit, dass, auch wenn ein Mensch es vorzieht, radikal in einem Bereich vorzugehen, er in allen anderen Dingen es immer noch schrittweise tun wird. Er mag sich für eine Revolution entscheiden, aber er wird sich im Großen und Ganzen nicht dazu entscheiden, nichts mehr zu essen und entblößt durch die Gegend zu laufen. Das liegt daran, dass wir die meisten unserer Bedürfnisse, vielleicht mit der Ausnahme von Sex, als schrittweise zu erfüllende Bedürfnisse verspüren. Wir versuchen, uns dann zu ernähren, wenn wir ein wenig Hunger haben, nicht erst, wenn wir schon dabei sind, gänzlich zu verhungern. Wir betrachten Anorexie und Bulimie als krankhaftes Verhalten.

Zudem stellen wir uns generell einer Kette von Möglichkeiten in einer gegebenen Reihenfolge. Es ist ziemlich selten, dass wir Dinge wirklich neu anfangen können und wir erinnern uns daran, wann wir eine neue Ehe eingegangen oder in eine neue Stadt gezogen sind, gerade weil wir das nicht jeden Tag tun. Einen Großteil meiner Zeit verbringe ich in Hotelzimmern und ich kann mich in der Tat nicht mehr an jedes einzelne erinnern. Wenn ich sage, dass wir die Kette der Möglichkeiten in einer gegebenen Reihenfolge angehen, meine ich damit nicht, dass die Vergangenheit die Gegenwart bestimmt, sondern dass wir immer schon mitten im Geschehen sind und wir Möglichkeiten so aufgreifen, als ob etwas an der potentiellen Situation schon existierte.

Nichtsdestoweniger gibt es eine umgekehrte Beziehung zwischen Utopismus und dem Feld der Möglichkeiten. Mit anderen Worten: Je pessimistischer die Menschen sind, desto größer ist ihr Möglichkeitsfeld. Wenn man an eine Utopie glaubt, dann hat mein ein enorm beschränktes Feld, da man auf eine spezifische Utopie hin arbeitet oder in ihr lebt. 
Wenn man außerdem vollkommen utopisch veranlagt ist, kann man keine Furcht vor Dystopien hegen, da es das Wesen einer vollkommenen Utopie ist, dass keine Furcht sie durchdringen kann. Wenn man glaubt, dass seine Utopie bedroht wird, ist man nicht länger in der Utopie.

Dagegen kann man behaupten, dass das Feld der Möglichkeiten nahezu unbegrenzt ist, wenn man in der Hölle lebt. Jeder schrittweise zunehmende Gewinn an Wohlstand wird emotional maximiert, da er leicht mit der schlimmeren Situation verglichen werden kann, in der man bisher gelebt hat. Wenn man sich zudem in einer dystopischen Situation befindet, kann man sich eine nahezu unendliche Menge von Erlösungen denken. So kann jeder verbessernde Schritt als Schritt auf eine andere Utopie hin gedeutet werden. Eine Bestätigung, welche Utopie nun die richtige ist, kann erst ziemlich spät eintreffen. Dass Hitler an die Macht kam, wurde von den meisten Deutschen als besser betrachtet als die Situation, in der sie bisher gelebt hatten. Trotz der Propaganda des Regimes war das Feld, die Maßnahmen des Regimes zu deuten, ziemlich weit. Utopische Bewegungen müssen die Menschen nur davon überzeugen, dass die Situation besser ist als zuvor.

Inwieweit unterscheidet sich das aber von irgendeiner anderen nichtutopischen Bewegung? Es sieht so aus: Eine nicht-utopische Bewegung muss nur behaupten, dass die Situation gemessen an einer bestimmten Achse besser ist, dass es z. B. nun mehr Wohlstand gibt als zuvor. Eine utopische Bewegung deutet jede Veränderung der Umstände totalistisch, d. h. kleine Schritte wirken sich auf das gesamte Lebensfeld aus; eine wirtschaftliche Verbesserung wird mit einer spirituellen Deutung versehen und die spirituelle Deutung wiederum mit besseren sozialen Werten etc.

Aus dieser Analyse ziehen wir zwei Punkte: Erstens, dass das Streben nach einer Utopie totalistisch ist; zweitens, dass es letztendlich das Feld der Möglichkeiten eingrenzt. Das erste Prinzip ist selektiv vorteilhaft, weil es vorteilhaft ist, als Verbesserungen solche zu betrachten, die eher das Gesamte verbessern als seine Teile, auch wenn diese Schlussfolgerung fehlerhaft ist. Die zweite Möglichkeit, nämlich die Begrenzung des Möglichkeitenfeldes, bringt Übereilung mit sich: Da das Feld der Möglichkeiten letzten Endes eingeschränkt ist, ist es besser sich sofort anzupassen als zu warten. Diese Schlussfolgerung ist sehr gewagt, weil man im Vorhinein nicht sagen kann, ob sie wahr ist oder nicht: Die Frage nach der Zeitlichkeit kann erst im Nachhinein gestellt werden.

Die erste Überlegung, dass jede Veränderung als Veränderung des gesamten Systems betrachtet wird, ist theoretisch wahr und faktisch falsch. Einige Veränderungen, z. B. die Entwicklung eines wendbaren
Daumens, wirken sich auf das gesamte System aus, andere hingegen tun das nicht. Die zweite Überlegung, dass das Feld der Möglichkeiten letzten Endes eingeschränkt ist, ist theoretisch falsch und faktisch wahr. Sie ist theoretisch falsch, weil das Feld der Möglichkeiten noch eine Minute vor dem Tod so unendlich ist wie das ganze Leben zuvor. Deswegen kann das Feld der Möglichkeiten nicht eingeschränkt werden. Es ist faktisch wahr, weil man auf seinem Todesbett nicht das Gefühl hat, dass seine Möglichkeiten so unendlich sind, wie zu dem Zeitpunkt, als man jung war.

Die Prinzipien der Evolution funktionieren so ziemlich genauso. Schlussfolgerungen, die theoretisch wahr sind, können empirisch fehlerhaft sein und Schlussfolgerungen, die theoretisch falsch sind, können empirisch vorteilhaft sein. So müssen alle evolutionären Veränderungen genetische Veränderungen sein, sonst können sie nicht weitergegeben werden. Dies jedoch ist eine theoretische Behauptung. Im Gegenzug zu behaupten, dass evolutionäre Veränderungen Reaktionen auf die Umwelt sind, ist theoretisch fahrlässig, wenn nicht sogar falsch, faktisch ist es aber wahr. Es folgt daraus, dass Selektion das theoretische Prinzip ist, wohingegen Anpassung das praktische.

Daraus folgt, dass man die Selektion nicht steuern kann, da sich ihre Wirkung nur schwer von außen erschließen und bestimmen lässt. Groß zu sein, mag sich als vorteilhaft herausstellen oder auch nicht. Darüber hinaus gilt als vorherrschende Theorie keineswegs, dass Anpassung Selektion antreibt, sondern dass Selektion beliebig ist und dass einige Eigenschaften als Folge der Anpassung überleben. Was man im Gegenzug steuern kann, ist Anpassung: Die Klimaanlage kann sehr wohl die Breite der menschlichen Reaktion auf das Wetter beeinflussen. Körperliche Ertüchtigung kann wahrscheinlich die Lebensdauer verlängern. Es folgt daraus auch, dass, Kulaken oder Juden zu töten, ein großer Fehler ist, da es einem keinen genetischen Vorteil verschafft, vorausgesetzt, man ist weder Jude noch Kulak. Man erringt keinen Vorteil, indem man andere liquidiert. Allerdings darauf zu bestehen, ohne Klimanalage zu leben, kann tatsächlich die Fitness erhöhen. Das ist nun theoretisch fehlerhaft, aber praktisch korrekt.

Es gibt einen logischen Grund für die Divergenz zwischen Theorie und Praxis. Evolution ist nämlich wie menschliche Geschichte ein zufallsbehafteter Prozess, d. h. etwas, das nicht vorhergesehen werden kann. Alles, was man kennt, ist seine gegenwärtige Lage, die gewisse Ausgänge unmöglich macht. Vielleicht wird den Menschen eines Tages wieder ein Schwanz wachsen (obwohl das sehr, sehr unwahrscheinlich ist), aber diese Schwänze werden am Ende der Wirbelsäule herauswachsen und nicht an 
ihren Zehen. Alle Möglichkeiten entspringen der Gegenwart. Deswegen ist auch der Versuch, eine vergangene Situation wieder herzustellen, so eine schlechte Idee. Die Theorie sagt einem in diesem Falle, was die Struktur der Veränderung sein muss, aber die Praxis ist immer zufallsbehaftet, so dass sie in der Regel nicht von der Theorie angetrieben werden kann.

Der große Fehler des Utopismus ist es also, nach der Einheit von Theorie und Praxis zu suchen. Wenn die Praxis nur Praxis auf der Suche nach einem einzigen Ziel ist, dann vermag sie sich nicht anzupassen. Dies trifft sowohl auf die dystopische als auch auf die utopische Situation zu. Wenn man glaubt, dass man in einer schlimmen Situation lebt, dann erfindet man eine Theorie darüber, warum alles so schlimm ist und man wird Dinge tun, die sich an der Theorie orientieren. Die Resultate werden mit großer Sicherheit schlimme sein. In einer dystopischen Situation tut man, was man zu tun hat. Im Anschluss versieht man es dann mit einer totalistischen Begründung und dann macht man weiter. Anders gesagt sind gute utopische Begründungen retrospektiv. Es sind solche, welche Geschichte rückwirkend auf eine bestimmte Weise deuten. So wird englische Geschichte als das Streben nach einer demokratischen Regierung gedeutet, obwohl kein Mensch zumindest während der ersten vierhundert Jahre das Parlament als eine demokratische Institution wahrgenommen hätte.

Das Argument kann dahingehend fortgesetzt werden, dass Menschen ihre Eignung (fitness) vergrößern wollten, indem sie andere Populationen ausgemerzt haben. In Wirklichkeit war diese Ausmerzung aber nie vorteilhaft, sondern von Vorteil war es, die Ressourcen anderer zu stehlen. Wenn ich jemandes Land und seine Tiere stehle, wird es meinen Leuten besser gehen als seinen. Genau genommen hatten die meisten großen Invasionen Versklavung zur Folge und nicht die Ausrottung anderer. So wissen wir heute, dass trotz der sächsischen und normannischen Invasionen die DNA der Engländer größtenteils keltisch oder sogar baskisch ist Die Briten wurden zu Leibeigenen gemacht; sie wurden nicht ausgelöscht. Nichts davon hat außerdem mit theorieorientiertem Verhalten zu tun.

Wir müssen die wichtige Unterscheidung machen zwischen einer Theorie, die erklärt, warum sich Menschen auf bestimmte Weise verhalten, und solchen Menschen, die sich einer Theorie bedienen, um anderen Menschen zu sagen, wie sie sich verhalten sollen. Wissenschaftliche Theorien im ersten Sinne sind niemals utopisch, da sie nicht teleologisch sind. Wissenschaftliche Theorien im zweiten Sinne, d.h. Ideologien, müssen schlimm ausgehen, da Menschen selten im Dienste einer Idee handeln. Wenn die Utopie also eine Idee ist, dann ist es eine schlechte.
Wenn wir die Utopie jedoch als Teil eines Strebens nach schrittweise vorgehender Verbesserung ansehen, dann hat sie in der Strukturierung unserer Möglichkeiten einen Platz. Die Lektion der Dystopie ist, dass alle Schritte klein sein sollten, da wir niemals wissen, ob unsere Idee korrekt ist. Man soll entweder nicht nach einer Idee handeln oder nur einen sehr kleinen Schritt machen.

Aus dem Englischen von Marc Petersdorff 


\title{
FRIEDRICH BALKE
}

\section{MICHEL FOUCAULT UND DIE MÖGLICHKEITEN EINES DENKENS IN DER "LEERE \\ DES VERSCHWUNDENEN MENSCHEN«}

\author{
I. ÜBERBLICK
}

Mein Beitrag geht in einem ersten Schritt den Gründen für Michel Foucaults Verwerfung des Utopie- (wie des Dystopie-)Begriffs nach. In seinem berühmten Aufsatz über die »Anderen Räume« stellt Foucault der Utopie nicht die Dystopie, sondern die Heterotopie gegenüber. Man kann den Eindruck gewinnen, als bekräftige er mit dieser Begriffsverwendung den fundamentalen Raum- und Ordnungsbezug des utopischen Denkens, an dem dieses ja selbst in der Abwesenheit eines konkreten Topos festhält. Bei näherem Hinsehen zeigt sich allerdings, dass Foucault den Gegenbegriff der Heterotopie keineswegs einsinnig verwendet: Heterotopien sind - im Unterschied zu bloß in der Vorstellung oder Phantasie oder in literarischen Texten und philosophischen Entwürfen existierenden Utopien - realisierte Räume in einer Kultur, die Foucault »Gegenplatzierungen oder Widerlager « nennt, »Orte außerhalb aller Orte, wiewohl sie tatsächlich geortet werden können «. ${ }^{1}$ Die Beispiele, die er anführt (vom Friedhof über den Garten und die Bibliothek bis hin zur Kolonie und zum Schiff), zielen, selbst im Fall der Kolonie, nicht auf einen globalen Gegenentwurf zur etablierten Kultur und Gesellschaft. Heterotopien bezeichnen im Rahmen der etablierten räumlichen Ordnung einer Kultur Zonen, die eigenartigen Gesetzen und Ausnahmeregimes unterliegen. Ein zweiter,

1 Michel Foucault: Andere Räume. In: Karlheinz Barck u. a. (Hrsg.): Aisthesis. Wahrnehmung heute oder Perspektiven einer anderen Ästhetik. Essais

Leipzig 1990, S. 34-46, hier S. 39. 
von der Literatur und der Wissensgeschichte inspirierter Gebrauch der Heterotopie zielt dagegen auf nichts Geringeres als auf die Suspension der symbolischen Ordnung, der von ihr autorisierten Klassifikationen und Taxonomien und führt das Denken damit in einen Bereich, in dem es an den für eine Kultur verbindlichen Prinzipien und den Gliederungsformen alles Seienden verzweifelt. Diese epistemologische Heterotopie ist nicht an den methodischen Zweifel der neuzeitlichen Philosophie gebunden, die die Fundamente des Denkens umstürzt, um sie um so hartnäckiger zu restituieren; sie entzieht dem Denkenden vielmehr den Ort, an dem aus unübersichtlichen und 'gefährlichen`Mengen (von Dingen und Wörtern, Zeichen oder Daten) geordnete Vielheiten entstehen. Foucaults antiutopischer Affekt speist sich, so die These, aus einer Kritik nicht nur an der Disziplinierung des modernen Menschen, die genealogisch aus der Konvergenz von vita und regula in der mönchischen Existenzform hervorgeht, sondern auch an derjenigen des modernen Wissens, das den >Menschen zum Objekt eines neuen, humanwissenschaftlichen Wissens macht und ihn zugleich als die Bedingung der Möglichkeit dieses wie überhaupt jedes Wissens auszeichnet.

Wenn Foucault an einem literarischen Beispiel die extreme Form der epistemischen Heterotopie erläutert, dann bedeutet das nicht, dass er ihre Erfahrung in die Grenzen der Fiktion einschließt. Überhaupt kann sich Foucault nicht mit einer Kunsttheorie anfreunden, für die gilt, dass unter dem Titel des Ästhetischen »veraltete Welterfahrungen und -deutungen trotz ihres bedenklichen Status dennoch mit allgemeiner Zustimmung « ${ }^{2}$ weiterleben. $\mathrm{Zu}$ einer solchen Einschätzung gelangt man nur, wenn man der Poesie ein »unwiderlegliche[s] Weltbild der neuzeitlichen Wissenschaft $^{3}$ entgegensetzt, deren Geltungsmacht die Poesie »als Sondersprache aus den gültigen Kommunikationsformen $\aleph^{4}$ ausgliedert. In einem zweiten Schritt möchte ich demgegenüber zeigen, dass Foucaults Archäologie der modernen Episteme auf eine Zurückweisung der großen kulturhistorischen Diskontinuitäten und der daraus entspringenden dualistischen Kosmologie abzielt, weshalb sich die Ordnung der Dinge für uns heute als der Versuch der Erneuerung einer Wissensform liest, die nicht länger der Ordnung der Repräsentation zugehört, sondern die

2 Heinz Schlaffer: Poesie und Wissen. Die Entstehung des ästhetischen Bewußtseins und der philologischen Erkenntnis. Erweiterte Ausgabe. Frankfurt a. M. 2005 , S. 123.

3 Ebd.

4 Ebd., S. 121.
Ähnlichkeiten und Übergänge zwischen Dingen und Zeichen erforscht. Statt der Episteme der Ähnlichkeit ein mangelndes Differenzierungsvermögen zwischen Natur und Kultur, Ding und Zeichen, Tatsache und Konstruktion vorzuwerfen, erkennen wir in ihr heute eine heterotopische Sensibilität, die uns lehrt, dass nicht nur der Text, sondern auch die Natur durch und durch geschrieben ist und kein Laborforscher im Rahmen seiner Experimente unmittelbar an den vorsymbolischen Objekten seiner Forschung arbeitet.

Im abschließenden Teil werde ich Samuel Butlers utopischen Roman Ehrewhon als einen Versuch verstehen, Foucaults Aufforderung, »in der Leere des verschwundenen Menschen $\aleph^{5}$ zu denken, mit den Mitteln der Literatur nachzukommen. Butler, der »Darwin zwischen den Maschinen $«{ }^{6}$ siedelt den Menschen als eine Figur in einem evolutionären Prozess an, der in das Panorama der Entwicklung der Lebewesen auch die (zukünftigen) Maschinen einbezieht. Foucault hatte seinen Begriff der Heterotopie an Borges' chinesischer Enzyklopädie erläutert, die »alle geordneten Oberflächen und alle Pläne erschüttert, die für uns die zahlenmäßige Zunahme der Lebewesen klug erscheinen lassen «.? $\mathrm{Zu}$ diesen >Plänen gehört zweifellos auch die darwinische Revolution in der Naturgeschichte, auf die Foucault hier anspielt. Sie legte zwar der Ordnung der Lebewesen eine neue evolutionsgeschichtliche Rationalität zugrunde, blieb aber in ihren populären Ausdeutungen weiterhin der Vorstellung des Menschen als Krone der Schöpfung und Telos des naturgeschichtlichen Entwicklungspfades verhaftet. Das genealogische Tableau des Menschen wird durch seine Eingliederung in die Serie seiner stammesgeschichtlichen Vorläufer errichtet, da die Evolutionsgeschichte sich jeden Gedanken an kulturtechnische Mutationen des Menschen verbietet. Butlers »Buch der Maschinen« ist vordergründig der Rechtfertigung der Utopie oder Dystopie einer umfassenden Zerstörung der Maschinenwelt gewidmet, durch die die Stellung des Menschen als eines evolutionären Spät- und Endprodukts für alle Zukunft sichergestellt werden soll. Die Durchführung der Apologie aber transformiert die anthropologische Differenz in ein Mensch-Maschine-Kontinuum. An die Stelle einer Ontologie stabiler >Trennungsstricheく tritt bei Butler

5 Michel Foucault: Die Ordnung der Dinge. Eine Archäologie der Humanwissenschaften. Frankfurt a. M. 1980, S. 412.

6 Vgl. Samuel Butler: Darwin among the machines. In: ders.: A First Year in Canterbury Settlement with Other Early Essays. London 2011, S. 179-185. 7 Foucault: Die Ordnung der Dinge (wie Anm. 5), S. 17. 
die Vorstellung eines >maschinischen Gefüges`(Félix Guattari), das das Verhältnis des Menschen zu nicht-menschlichen, technischen Agenten in Begriffen komplexer Funktionszusammenhänge und Allianzen denkt, wie sie für das Verhältnis von Mensch und Tier lange vor der Ausbildung philosophischer Anthropologien charakteristisch waren. In den zeitgenössischen Diskursen zum Posthumanismus ${ }^{8}$ geht es aus einer wissens- und kulturtechnikgeschichtlich informierten Sicht daher nicht so sehr um ein ıneues` oder ১utopisches Denken`, sondern um die Wiedergewinnung einer Denkmöglichkeit, die den alten Gesellschaften Europas - vor der epistemologischen Befestigung einer dualistischen Ontologie - völlig geläufig war.

\section{ERRICHTUNG UND ENTZUG DER TABLEAUS}

Mit seiner wissensarchäologischen Unterminierung der modernen Humanwissenschaften, die er in der Ordnung der Dinge unternimmt, beabsichtigt Foucault eine ganz ähnliche Wirkung hervorzubringen, wie sie Jorge Luis Borges mit einem literarischen Text erzeugt, dem Foucault das Privileg zubilligt, seine Untersuchung allererst angestoßen zu haben: „Dieses Buch hat seine Entstehung einem Text von Borges zu verdanken ${ }^{9} 9$ stellt der erste Satz des »Vorworts« lapidar fest. Genauer müsste es heißen: einer kurzen Episode innerhalb dieser schon kurzen, kaum fünf Seiten umfassenden Erzählung, in der Borges, um dem Leser die Arbitrarität aller Klassifizierungstechniken anschaulich vor Augen zu führen, aus einer auf »uralten Blättern " geschriebenen "gewissen chinesischen Enzyklopädie« zitiert, »die sich betitelt: Himmlischer Warenschatz wohltätiger Erkenntnisse «.10 Diese Enzyklopädie gruppiert die Tiere auf eine Weise, die »alle geordneten Oberflächen und Pläne erschüttert, die für uns die zahlenmäßige Zunahme der Lebewesen klug erscheinen lassen und unsere tausendjährige Handhabung des Gleichen und des Anderen schwanken lässt und in Unruhe versetzt. «11 Der Satz

8 Vgl. N. Katherine Hayles: How we became posthuman. Virtual bodies in cybernetics, literature, and informatics. Chicago und London 1999.

9 Michel Foucault: Die Ordnung der Dinge (wie Anm. 5), S. 17

10 Jorge Luis Borges: Die analytische Sprache von John Wilkins. In: ders.: Inquisitionen. Essays. Frankfurt a. M. 1992, S. 113-117, hier S. 115.

11 Foucault: Die Ordnung der Dinge (wie Anm. 5), S. 17 ruft nicht nur das Thema der Klassifikationen und Taxonomien auf, das am Grunde alles Wissens liegt - als die Entscheidung darüber, bestimmte Dinge als benachbart und zusammengehörig und andere als verschieden oder heterogen zu situieren - und sich in epistemischen Utopien oder in Phantasmen einer restlos aufgeteilten Welt niederschlägt (die Borges mit dem knappen Hinweis zurückweist, es existiere keine "Klassifikation des Universums«, jedenfalls keine, »die nicht willkürlich und mußmaßlich wäre «12). Foucaults Kommentar verdient besondere Aufmerksamkeit, weil die "zahlenmäßige Zunahme der Lebewesen« unter Anspielung auf die darwinische Revolution in der Naturgeschichte als wissenschaftlich beherrschbar durch das Kalkül (die »Pläne«) der Evolutionstheorie erscheint. Aber diese Beherrschbarkeit der Morphogenese des Lebendigen, die durch Mutation und Selektion als den basalen evolutionären Mechanismen geregelt wird, wird ausgerechnet durch eine »chinesische[n] Enzyklopädie« in Frage gestellt, die ein ganz anderes, >unmögliches` Prinzip anwendet, nach dem sich die »Tiere« gruppieren. Die Brisanz dieser Ordnung liegt darin, dass sie für den heutigen Leser keinem intelligiblen Plan oder Kalkül zu folgen scheint und darüber hinaus die für den Leser selbstverständliche Zuordnung der Tiere zu einer ganz bestimmten ontologischen Region (der Natur des Lebendigen) in Frage stellt.

Die Aufteilungen des entsprechenden Eintrags in der chinesischen Enzyklopädie lesen sich wie folgt:

a) Tiere, die dem Kaiser gehören

b) einbalsamierte Tiere

c) gezähmte

d) Milchschweine

e) Sirenen

f) Fabeltiere

g) herrenlose Hunde

h) in diese Gruppierung gehörige

i) die sich wie Tolle gebärden

j) die mit einem ganz feinen Pinsel aus Kamelhaar gezeichnet sind

k) und so weiter

l) die den Wasserkrug zerbrochen haben

m) die von weitem wie Fliegen aussehen

12 Borges: Die analytische Sprache von John Wilkins (wie Anm. 10), S. 115. 
"Die schiere Unmöglichkeit, das zu denken $\aleph^{13}$ also die Fähigkeit einer solchen Anordnung, uns an die Grenzen des Denkens zu führen und uns mit einem >Unmöglichkeitsdenken $>$ zu konfrontieren: Darin liegt der sSchock`, den die so vertraute alphabetische Reihung produziert, indem sie in eine kurze Liste zwingt, was für uns durch Abgründe getrennt ist. Verglichen mit der Radikalität dieser Anordnung muten die Heterotopien, die Foucault ein Jahr später in seinem Vortrag »Andere Räume« erörtern wird, geradezu harmlos an, denn sie werden als institutionell realisierte "Gegenplazierungen « und »Widerlager $^{14}$ bestimmt, man könnte auch sagen: als Ausnahmeräume, die das Denken vielleicht überraschen und ihm einen Einstellungswechsel abverlangen, aber es jedenfalls nicht vor eine unüberwindliche Anstrengung stellen. Heterotopien sind in dem Vortrag von 1967 nur ungewöhnliche, aber kulturell vorgesehene Platzierungen mit »wirklichem Ort $\iota^{15}$

Worin besteht die Monstrosität der Aufzählung in Borges' Text? Sie besteht nicht in dem, was uns die Kultur- und Wissensgeschichte an Darstellungen monströser Lebewesen überliefert hat. Die Enzyklopädie ist nicht so naiv, reale mit imaginären Wesen zu vermischen oder etwa »unvorstellbare Amphibienwesen ${ }^{16}{ }^{16}$ u konstruieren, sie differenziert ja ausdrücklich zwischen Tieren, die sich nach Rechtsstatus und Handlungsweise unterscheiden, und `Fabeltieren`, das heißt: Sie vermischt beides keineswegs, sondern stellt es nebeneinander: »Die Monstrosität verändert hier keinen wirklichen Körper $«{ }^{17}$ Sie ist topologischer Art, denn sie entsteht dadurch, dass für uns kein Raum oder Ort vorstellbar ist, an dem die aufgezählten Paradigmata zusammentreffen könnten: "Was unmöglich ist, ist nicht die Nachbarschaft der Dinge, sondern der Platz selbst, an dem sie nebeneinandertreten könnten. $\aleph^{18}$ Foucault führt eine Episode aus Rabelais' Gargantua und Pantagruel an (die schon Erich Auerbach fasziniert hatte ${ }^{19}$ ), in der die unterschiedlichsten Würmer

13 Foucault: Die Ordnung der Dinge (wie Anm. 5), S. 17.

14 Foucault: Andere Räume (wie Anm. 1), S. 39.

15 Ebd.

16 Foucault: Die Ordnung der Dinge (wie Anm. 5), S. 17

17 Ebd.

18 Ebd., S. 19.

19 Vgl. Erich Auerbach: Die Welt in Pantagruels Mund. In: ders.: Mimesis. Dargestellte Wirklichkeit in der abendländischen Literatur [1946]. Tübingen und Basel 2001, S. 250-270. Trotz vieler mittelalterlicher Motive erkennt Auerbach in Rabelais' literarischen »Zusammenballungen« des und Schlangen, "all diese Wesen der Fäulnis« im Mund des Eusthenes »wimmeln", in dem sie ihren "gemeinsamen Platz haben", und ergänzt unter Anspielung auf die berühmte protosurrealistische Imagination Lautréamonts: "wie der Regenschirm und die Nähmaschine auf dem Operationstisch. $\aleph^{20}$ Ein Zusammentreffen von Dingen oder Lebewesen mag so seltsam oder unwahrscheinlich sein wie in diesem Fall: Solange es einen gemeinsamen Ort oder >Tisch`, eine tabula gibt, auf der das Zusammentreffen stattfinden kann, befinden wir uns noch im Raum des Denkbaren und seiner Möglichkeiten. Borges dagegen »läßt nirgends den Blitz des poetischen Zusammentreffens aufleuchten «, sondern entzieht »den Platz, den stummen Boden, an dem die Lebewesen nebeneinandergeraten können. [...] Fortgenommen ist, mit einem Wort, der berühmte 〉Operationstisch « - bzw. das Tableau, »das dem Denken gestattet, die Ordnungsarbeit mit den Lebewesen vorzunehmen, eine Aufteilung in Klassen, eine namentliche Gruppierung, durch die ihre Ähnlichkeiten und ihre Unterschiede bezeichnet werden. ${ }^{21}$

Die Ordnung der Dinge, im Original Les Mots et les Choses, ist ein Buch über die Herausbildung derartiger Operationstische, die es für einen bestimmten historischen Zeitraum ermöglichen, dass Wissenschaften, so heterogen die Objekte auch sein mögen, mit denen sie sich beschäftigen, einen gemeinsamen Raum bevölkern, der das Gesetz der Organisation ihrer Begriffe, Gegenstände, Beobachterpositionen und Machtwirkungen bestimmt. Das Problem des Tableaus oder des Operationstischs hat Foucault nicht nur in seiner Eigenschaft als Epistemologe, sondern auch als Historiker der modernen Machtformen intensiv beschäftigt. Sein Misstrauen gegen Utopien war nicht vordergründig politisch motiviert,

Heterogenen einen charakteristischen Verzicht auf das, was er »den festen Rahmen einer Gesamtordnung « nennt: Rabelais' "ganzes Bestreben« gehe dahin, den an bestimmte Betrachtungsweisen gewohnten Leser "auf das große Meer der Welt zu locken, in dem man frei, und auch auf jede Gefahr, schwimmen kann« (ebd., S. 263).

20 Foucault: Die Ordnung der Dinge (wie Anm. 5), S. 19. Foucault verkürzt das Zitat, das wörtlich übersetzt lautet: "wie die unvermutete Begegnung einer Nähmaschine und eines Regenschirms auf einem Seziertisch!« Vgl. Lautréamont: Die Gesänge des Maldoror. Hamburg 2010, S. 223. Der Aspekt, auf den es Lautrémont bei dieser zukünftigen surrealistischen Programmmetapher ankommt, betrifft die Gefährlichkeit einer solchen Begegnung, die einen Zusammenhang stiftet, selbst wenn er sich für die Elemente, die aufeinandertreffen, zerstörerisch auswirkt.

21 Foucault: Die Ordnung der Dinge (wie Anm. 5), S. 19. 
wie man es vor dem Hintergrund der jüngeren Geschichte im sogenannten Zeitalter der Extreme und der totalitären >Realisierungen des Utopischen (Hans Mommsen) erwarten könnte. Seine Skepsis entsprang der Einsicht in den fundamentalen Zusammenhang von modernen Utopieentwürfen und umfassenden individuellen und sozialen Disziplinierungen. Utopien, wie sehr sie sich auch einen auf die Zukunft gerichteten Anstrich geben mögen, bestehen im Kern darin, eine `Disziplin`zu errichten, die wesentlich auf einem Territorialisierungseffekt basiert. Utopia ist vorzugsweise eine Insel, ${ }^{22}$ also ein vom Meer umgebenes Territorium, das sich vom Festland abgekoppelt hat und daher auch nicht mehr von ihm beherrschbar ist. Utopien verschreiben sich einem geografischen Separatismus. Wenn sie von der Zeit handeln, dann nicht von einer herbeizuführenden Zukunft, sondern von einer Gegenwart, die dem Prinzip einer maximalen Ausnutzung der Zeit verpflichtet ist: Die Obrigkeiten der Insel Utopia, die sogenannten Syphogranten, haben bei Thomas Morus »dafür zu sorgen und vorzusehen, daß nicht jemand dem Müßiggange nachhänge, sondern jeder seinem Handwerke emsig obliege ${ }^{23} .{ }^{23}$ Morus gesteht dabei dem Utopier durchaus »Mußezwischenzeiten « zu, allerdings ist auch für diese »Zeit zwischen den Stunden der Arbeit, dem Schlafe und dem Essen " ausdrücklich untersagt, dass er sie mit Nichtstun verbringt; in dieser Zeit soll er sich vielmehr der Fortbildung widmen bzw. sie, in der Sprache des Morus, mit der »Erlernung einer anderen Fertigkeit «,24 ganz gleich welcher, verbringen.

Was die epistemischen Tableaus mit den Gegenständen der Wissenschaften machen, die sich ja im selben Zeitraum in sogenannte `Disziplinen verwandeln, das stellen die disziplinären Tableaus mit den Menschen an: „Die Disziplin macht sich zunächst an die Verteilung der Individuen im Raum «. ${ }^{25}$ Foucault hatte gezeigt, dass lange vor »der Moderne und der Arbeitsteilung in den Fabriken«, also bereits an der »Schwelle zur industriellen Revolution, gegen Ende des 17. Jahrhunderts« der Prozess einer umfassenden »chronometrischen Gliederung menschlicher Zeit» einsetzt. ${ }^{26}$ Für Foucault sind Kasernen, Schulen, Internate und erste

22 Vgl. Thomas Morus: Utopia. Frankfurt a. M. 1992, S. 93.

23 Ebd., S. 105

24 Ebd., S. 106.

25 Michel Foucault: Überwachen und Strafen. Die Geburt des Gefängnisses. Frankfurt a. M. 1981, S. 181

26 Giorgio Agamben: Höchste Armut. Ordensregeln und Lebensform.

Frankfurt a. M. 2011, S. 35. Zum polizeiwissenschaftlichen und insbesondere königliche Manufakturen die Schrittmacher einer umfassenden Disziplinierung der menschlichen Existenz, implementierte Utopien insofern, als sie ihr Regime nicht in geografisch oder territorial abgegrenzten Räumen errichten, sondern in bestehenden oder neu formierten Institutionen de bestehenden Gesellschaften. Bereits Foucault hatte auf die Vorbildfunktion der Klöster und ihrer Verknüpfung von Regel und Leben (regula vitae) hingewiesen, allerdings, so Giorgio Agamben,

ist man sich in der Regel nicht bewusst, dass fast fünfzehnhundert Jahre zuvor das Mönchtum in seinen Klöstern das Leben der Mönche - zu ausschließlich moralischen und religiösen Zwecken - einer Zeiteinteilung unterwarf, deren Strenge der antiken Welt unbekannt war und deren unerbittliche Absolutheit von keiner Institution der Moderne, die tayloristische Fabrik eingeschlossen, je erreicht worden wäre. ${ }^{27}$

Man muss also auch den zellenförmigen und seriellen Raum sowie die durch ihn bewirkte temporale Rationalisierung menschlicher Handlungsvollzüge berücksichtigen - einen Raum, der nicht nur das moderne Wissen, sondern auch das moderne Leben reorganisiert, um die Tragweite jener Techniken zu ermessen, die Foucault im Auge hat, wenn er die Geschichte der >Ordnungsarbeit` einer Kultur schreibt, die sich an den >Lebewesen $<$ vollzieht. ${ }^{28}$ Borges' chinesische Enzyklopädie verfährt antiutopisch, weil sie die grundlegende Gewissheit erschüttert dass die Unterscheidungen, mit denen das Denken operiert, stets auf einen kohärenten Raum bezogen sein müssen. Utopien legen implizit Zeugnis von dieser Ungewissheit eines gemeinsamen Raums ab, weil sie sich einer übermäßigen, zwanghaften topologischen Kohärenzsteigerung verschreiben. Utopien haben Foucault zufolge die Tendenz zu einer fabulatorischen, mythischen oder diskursiven Entfaltung; in dieser Dimension vermögen sie sogar zu trösten, selbst »wenn sie keinen realen Sitz haben «; $;^{29}$ die `Syntax`, der die Utopien verpflichtet sind und die die

pädagogischen Kontext der neuzeitlichen Fabrikation des Subjekts vgl. Walter Seitter: Menschenfassungen Studien zur Erkenntnispolitikwissenschaft. Mit einem Vorwort des Autors zur Neuausgabe 2012 und einem Essay von Friedrich Balke. Weilerswist 2012.

27 Agamben: Höchste Armut (wie Anm. 26), S. 36.

28 Foucault: Die Ordnung der Dinge (wie Anm. 5), S. 19.

29 Ebd., S. 20. 
Heterotopien zerstört, ist aber nicht nur grammatischer, sondern zugleich 'taxonomischer Art, da sie eine stabile Konfiguration von Wörtern und Sachen herstellt, womit wir uns bereits in einer zwischen Diskursen und Dispositiven changierenden Dimension der utopischen Realisierung befinden. Das utopische Narrativ reiht nicht nur Wörter und (sprachliche) Bilder aneinander, es hält auch die Wörter und Sachen `zusammen<, ordnet sie auf eine Weise an, die sich von einer anderen Ordnung aus betrachtet als arbiträr erweist, die aber eben deshalb umso bemühter ist, die »Identitätsfläche ${ }^{30}$ durch die eine bestimmte Gruppierung der Dinge gestützt wird, zugleich als das Territorium des Denkbaren überhaupt zu behaupten.

\section{DIE ERNEUERUNG DES ZEITALTERS DER ÄHNLICHKEIT}

Wenn Foucault seine Leser bis heute mit seiner Einschätzung überrascht, der Mensch sei auch für das Wissen "nicht das älteste und auch nicht das konstanteste Problem ${ }^{31}$ dann wird man in dieser epistemologischen Relativierung die Bemühung erkennen, die Einrichtung einer Ordnung unter den Dingen in Frage zu stellen, die im Menschen und seiner empirisch-transzendentalen Doppelnatur verankert ist und die »seit dem neunzehnten Jahrhundert als fast evidenter Boden für unser Denken gilt«:

Die Seinsweise des Menschen, wie sie sich im modernen Denken herausgebildet hat, gestattet ihm, zwei Rollen zu spielen. Er ist gleichzeitig die Grundlage aller Positivitäten und auf eine Art, die man nicht einmal als privilegiert bezeichnen kann im Element der empirischen Dinge [etwa im Kontext psychophysischer Experimentalanordnungen, $\mathrm{FB}$ ] präsent. ${ }^{32}$

Ich möchte an dieser Stelle die Frage aufwerfen, ob man mit der zeitlichen Distanz zur Veröffentlichung von Les Mots et les Choses, die wir heute einnehmen, etwas mehr zu jener produktiven »Leere " nach dem Wegfall des Operationstisches sagen kann, die Foucault ja als die Voraussetzung für die »Entfaltung eines Raums« betrachtete, »in dem es schließlich

30 Ebd., S. 21.

31 Ebd., S. 462

32 Ebd., S. 413. möglich ist zu denken « ${ }^{33}$ Mir scheint, dass man Foucaults Buch selbst, das zwei epistemologisch entscheidende Epochenbrüche verhandelt, eine Antwort entnehmen kann. Bekanntlich skizziert er eine Bewegung des Denkens, die sich bis zum Ende des 16. Jahrhunderts im Element der »Ähnlichkeit« bewegte und die zu Beginn des 17. Jahrhunderts abgelöst wird durch ein Zeitalter der Repräsentation, das sogenannte »klassische Zeitalter «, in dessen Zentrum das "Tableau « ${ }^{34}$ steht. Die (ideale) Sprache garantiert die vernünftige Repräsentierbarkeit alles dessen, was es gibt, so dass die "Welt als Totalität des Repräsentierbaren in ihrer Gesamtheit eine Enzyklopädie werden" kann. ${ }^{35}$ Als gegen Ende des Jahrhunderts eine "tiefe Historizität« in das "Herz der Dinge" eindringt, wird diese Ordnung der stabilen Repräsentationen und der zeitlosen Taxonomien gesprengt und eine neue »Tiefe« erfunden, »in der nicht mehr von Identitäten, unterschiedlichen Merkmalen, zusammenhängenden Tafeln mit all ihren Wegen und möglichen Bahnen, sondern von großen verborgenen Kräften, [...] und vom Ursprung, von der Kausalität und der Geschichte die Rede sein wird. ${ }^{36}$ Es muss kein Wort darüber verloren werden, dass diese Abfolge von epistemologischen Brüchen - also Brüchen in den fundamentalen Ordnungen des Wissens - weder als Fortschritts- noch als Verfallsgeschichte erzählt wird. Gerade weil das so ist, verdient der Ausgangspunkt des Buches, der als das Zeitalter der Ähnlichkeit bestimmt wird und der uns am weitesten entrückt zu sein scheint, einer erneuten Betrachtung, weil es, so meine These, hier ebenfalls um eine Denkunmöglichkeit geht: eine Denkunmöglichkeit für uns, die allerdings im 16. Jahrhundert den Raum des Denkmöglichen bezeichnet. Wenn uns die chinesische Enzyklopädie befremdet, weil wir ihr kein homogenes Prinzip der Klassifikation entnehmen können, weil sie die Elemente, die sie unterscheidet, in ein Außen wirft, dass eine unaufhebbare Fremdheit und einen unüberwindbaren Abstand zwischen ihnen herstellt, dann irritiert uns die »Form des enzyklopädischen Projekts «, ${ }^{37}$ die das Zeitalter der Ähnlichkeit kennzeichnet und die sich fundamental von den Enzyklopädien des Zeitalters der Repräsentation unterscheidet, wegen seiner schwindelerregenden Analogiebildungen, die auf dem beruhen,

33 Ebd., S. 412

34 Ebd., S. 111.

35 Ebd., S. 123

36 Ebd., S. 308.

37 Ebd., S. 69. 
was Foucault die $» S c h r i f t$ der Dinger ${ }^{38}$ oder Blumenberg Die Lesbarkeit der Welt ${ }^{39}$ nennt. »Im sechzehnten Jahrhundert ist die wirkliche Sprache keine einförmige und glatte Gesamtheit von unabhängigen Zeichen, in der die Dinge sich wie in einem Spiegel reflektierten, um darin Ding für Ding ihre besondere Wahrheit auszudrücken.«40

Es ist auffällig, dass nahezu sämtliche grundlegenden Reflexionen zu Sprache, Zeichen und Schrift, wie sie im 20. Jahrhundert von der Sprechakttheorie, der Metaphorologie bis zur Diskursanalyse und Grammatologie angestellt wurden, das Ziel verfolgen, dieses Repräsentationsmodell der Sprache in Frage zu stellen, um ihr eine Wirksamkeit oder Handlungsmacht zu attestieren, die im 16. Jahrhundert ganz selbstverständlich angenommen wurde, weil die Sprache mit den Dingen in einem Raum verknüpft ist und damit selbst zu diesen Dingen gehört, statt ihnen bloß als neutrales, diaphanes Darstellungsmedium zu dienen. Die so verstandene Sprache mischt sich unter die Dinge, statt ihnen gegenüber zu stehen, fast ein wenig so, wie in der chinesischen Enzyklopädie die Tiere erster Ordnung (die allerdings bereits kulturalisierte Lebewesen sind und nach ihrem rechtlichen Statut unterschieden werden) unvermutet in die Tiere des Mythos und der Malerei übergehen oder in konkrete Handlungszusammenhänge eintreten, deren Aufnahme in das enzyklopädische Register den Wechsel von der Universalität der wissenschaftlichen Beobachtung in die Partikularität des Berichts oder der Erzählung erfordert.

Die Sprache, die sich unter die Dinge mischt: Ein Vergleich mit jenen operativen Sprachen unserer Gegenwart, die, etwa im Fall von Programmiersprachen, in Apparate und Maschinen eingesenkt sind, um sie sans Laufen zu bringen`, liegt hier nahe. Das von Foucault gewählte Beispiel des Naturforschers Ulyssis Aldrovandi (1522-1605) ist aufschlussreich, vergegenwärtigt man sich die Polemik, mit der Buffon, der ganz dem Zeitalter der Repräsentation verhaftet ist, seinen italienischen Vorgänger dafür kritisiert, dass dieser beständig die naturgeschichtliche Beschreibung der Form eines Tieres mit den unabsehbaren Berichten und dem ganzen symbolischen Niederschlag vermische, den diese Tierfigur auslöst, aber auch mit den vielfältigen medialen und technischen Funktionszusammenhängen, in denen beispielsweise die geschriebene oder dargestellte Schlange Eingang findet. Liest man die Vorhaltungen Buffons, fühlt man sich mitten in jene kulturhistorisch konsequenzenreiche Situation versetzt,

\section{Ebd., S. 66.}

39 Vgl. Hans Blumenberg: Die Lesbarkeit der Welt. Frankfurt a. M. 1986.

40 Foucault: Die Ordnung der Dinge (wie Anm. 5), S. 66. in der es gegen das Zeitalter der schwindelerregenden Ähnlichkeiten und unziemlichen Vermischungen (von Realem und Zeichenhaftem) darum ging, die >große Trennung (great divide) in Europa zu installieren. Mit dem Zeitalter der Repräsentation etabliert sich jenes von Philippe Descola so genannte »ontologische Dispositiv« besonderer Art, »das der Kosmogenese der Modernen als Grundlage dient« und das Descola »Naturalismus« nennt. Der Naturalismus unterstellt, kurz gesagt, eine »distinktive Objektivtität der Nichtmenschen" und stellt ihr die ebenso distinkte Subjektivität oder Interiorität der Menschen gegenüber. ${ }^{41}$ Wenn bis zum Ende des sechzehnten Jahrhunderts, also vor dem Einbruch des great divide, »die Ähnlichkeit im Denken (savoir) der abendländischen Kultur eine tragende Rolle gespielt ${ }^{42}$ hat, könnte es sein, dass wir uns heute im Zeitalter einer Erneuerung dieser Wissensform befinden. Unsere heutige Denkmöglichkeit im Gebiet der humanities wäre dann aufs engste mit einer Neuentdeckung der Figur der Ähnlichkeit verbunden, die sich für die `Fransen` (Whitehead) und die Übergangszonen interessiert, in denen sich ein Objekt der Wissenschaft, ganz gleich wie exakt und experimentell sie vorgeht und wie sehr sie ihren Gegenstand von allen kulturellen >Kontexten ` reinigt, zum Generator und Medium eines weitverzweigten Wissens wird.

Buffon dagegen konnte es nicht verstehen, wie ein Naturforscher eine derart »unentwirrbare Mischung genauer Beschreibung, aufgenommener Zitate, kritikloser Fabeln und Bemerkungen« vorlegte, »die unterschiedslos über Anatomie, Wappen, Lebensverhältnisse, mythologische Werte eines Tieres handeln und darüber, welchen Gebrauch man davon in der Medizin oder in der Magie machen kann.«43 Foucault zitiert erläuternd ein Kapitel aus Aldrovandis Historia serpentum et draconum, wo sich im Kapitel »Über die Schlange im Allgemeinen« folgende Rubriken finden, die, der chinesischen Enzyklopädie nicht unähnlich, nichts geringeres als eine Art umfassender kultureller Ökologie dieses Tieres anvisieren:

Doppeldeutigkeit (das heißt die verschiedenen Bedeutungen des Wortes Schlange), Synonyme und Etymologien, Unterschiede, Form und Beschreibung, Anatomie, Natur und Gewohnheiten, Temperament, Zeugung und Fortpflanzung, Stimme, Bewegungen, Vorkommen, Ernährung, Physiognomie, Antipathie, Sympathie, Fangweisen,

41 Philippe Descola: Jenseits von Natur und Kultur. Berlin 2011, S. 107. 42 Foucault: Die Ordnung der Dinge (wie Anm. 5), S. 46.

43 Ebd., S. 71. 
Tod und Verwundungen durch die Schlagen, Arten und Zeichen der Vergiftung, Heilmittel, Beiwörter, Bezeichnungen, Wunder und Vorzeichen, Monstren, Mythologie, Götter, denen die Schlange heilig ist, Lehrfabeln, Allegorien und Mysterien, Hieroglyphen, Embleme und Symbole, Sprichwörter, Münzen, rätselhafte Wunder, Devisen, heraldische Zeichen, historische Fakten, Träume, Heiligtümer und Statuen, Gebrauch bei der Nahrung, Gebrauch in der Medizin, verschiedene Gebräuche.44

Diese enzyklopädische Anordnung oder Erfassung der Schlange will also nicht unterscheiden zwischen dem, was wir ihre Natur nennen würden, und dem, was uns lediglich als kulturelles Beiwerk erscheint. Eintragungen zur Schlange als Lebewesen existieren zwar, genießen aber im Hinblick auf andere Aspekte ihrer Erscheinungsweise kein Vorrecht: »Unterschiede, Form und Beschreibung, Anatomie«, würden wir sofort als legitime Register der Schlangenforschung attestieren, „Vorkommen und Ernährung « sowie eventuell noch »Gewohnheiten« würden wir im Anschluss an die ethologische Situierung des Tieres in seiner Umwelt bzw. in seinem Milieu, wie sie seit Uexküll geläufig ist, ebenfalls noch als legitime Perspektiven zulassen. Aber schon die Frage nach der SchlangenPhysiognomie würden wir wahrscheinlich als Beleg für eine unzulässige anthropologische Projektion zurückweisen (denn für uns haben Schlangen keine Gesichter) und als Indiz für den Eintritt der Schlange in die symbolische Ordnung werten, die ihr Positionen, Funktionen und /Werter zuweist, für deren Erörterung die Kultur- und Medienwissenschaften zuständig sind. Mit Cassirer könnte man also glauben, dass die Gelehrten im Zeitalter der Ähnlichkeit nicht zwischen der Natur eines Tieres und seiner symbolischen Form zu unterscheiden vermochten, dass sie das, was sie an der Schlange beobachten und in eine zusammenhängende Ordnung von Identitäten und Differenzen eintragen könnten, zugleich mit allem präsentieren, was die Schlange zu einem diskursiven Objekt macht, was von ihr berichtet wird, aber auch, was (denken wir an die heraldischen Zeichen und Münzen) sie in Kommunikationsmedien verwandelt oder ihr (wie bei den medizinischen Anwendungen) durch Entzug bestimmter Substanzen ( $(\mathrm{Gift}$ ) ) eine therapeutische Wirksamkeit abgewinnt. Wir würden vielleicht nicht mehr wie Buffon all diese Aspekte als einen »Schwall des Geschriebenen« bezeichnen (»Das ist alles keine Beschreibung, sondern

44 Foucault: Die Ordnung der Dinge (wie Anm. 5), S. $71 \mathrm{f}$.
Legende $«{ }^{45}$ ruft er empört aus), aber wir neigen doch spontan dazu, diese kulturellen Codes und Techniken als ebenso viele Schichten vorzustellen, die sich um den naturalistisch konzipierten Kern des Tieres lagern und die man der Reihe nach abtragen kann, um dann zu der Schlange als solcher zu gelangen, deren Erforschung der Kulturwissenschaftler guten Gewissens an die Kollegen von der Zoologie, der Ethologie oder Mikrobiologie delegieren kann. Wenn man also das Thema des Möglichkeitsdenkens nicht ausschließlich auf soziale oder politische Utopien bezieht, sondern, viel bescheidener, auf das Alltagsgeschäft von Kultur- und Medienwissenschaftlern, dann würde ich sagen, dass die Diskreditierung dieses Schichten- oder Etagenmodells kultureller und medialer Codierungen ein Effekt der Erosion des ontologischen Dispositivs ist, das mit dem Naturalismus etabliert wurde und das wir dabei sind, mühsam zu revidieren.

Aldrovandis Natur war »durch und durch geschrieben $«^{46}-$ und es drängt sich an dieser Stelle der Vergleich zur neueren Wissenschaftsforschung auf, die mit ihrem Fundamentalbegriff der Inskription ${ }^{47}$ die »dicke Schicht der Zeichen $«{ }^{48}$ von der Foucault spricht, bis in den quasisakralen Bezirk des Labors hinein verfolgt, wo es eben nicht nur die Maschinen

45 Zitiert nach Foucault: Die Ordnung der Dinge (wie Anm. 5), S. 72.

46 Ebd., S. 72.

47 Vgl. dazu Bruno Latour: Drawing Things Together: Die Macht der unveränderlich mobile Elemente. In: Andréa Belliger und David J. Krieger (Hrsg.) ANThology. Ein einführendes Handbuch zur Akteur-Netzwerk-Theorie. Bielefeld 2006, S. 259-307, sowie Henning Schmidgen: Bruno Latour zur Einführung, Hamburg 2011. Schmidgen stellt den »Kult der Inskription« (ebd., S. 29) bei Latour nicht nur in den Zusammenhang eines durch Bultmann und Péguy geweckten schriftexegetischen Interesses, sondern zeigt darüber hinaus, dass für den Analytiker des laboratory life das Labor wesentlich zu einer "Tradierungsinstitution" wird, »in der fortwährend, schriftlich wie mündlich, Exegesen, Neulektüren und Überarbeitungen stattfinden, die sich auf organisch-maschinell fundierte Laborereignisse beziehen « (ebd., S. 67). Laborarbeit erweist sich aus dieser Perspektive »hauptsächlich und erstrangig « als »die fortwährende Arbeit an und mit Texten, durch die unterschiedliche Arten von Aussagen in Zustände der Tatsächlichkeit überführt werden« (ebd., S. 65 f.). Es handelt sich also, so Foucault im Hinblick auf den »Primat des Geschriebenen" im Zeitalter der Ähnlichkeit, »um die unmittelbare Dissoziation jeder Sprache, die das nochmalige Untersuchen des Kommentars ohne einen jemals bestimmbaren Endpunkt verdoppelt" (Foucault: Die Ordnung der Dinge [wie Anm. 6], S. 71).

48 Foucault: Die Ordnung der Dinge (wie Anm. 5), S. 72. 
und Apparate sind, die das experimentelle Phänomen erzeugen, sondern die unterschiedlichen Aufzeichnungs- und Archivierungstechniken, die einem an sich flüchtigen Effekt allererst eine dauerhafte Konsistenz geben, also Beobachtungen flüchtiger Prozesse oder Ereignisse, wie sie im Labor produziert werden, in stabile Tatsachen verwandeln. Molekularbiologen etwa, darauf hat Hans-Jörg Rheinberger hingewiesen, arbeiten nicht "nicht mit den Genen der Zelle als solchen«, sondern "mit experimentell in einem Repräsentationsraum produzierten Graphemen. ${ }^{49}$ „Was in den Debatten über Wahrnehmung immer vergessen wird «, schreibt Latour, und er bezieht sich dabei auf die Rolle der Wahrnehmung in den Erkenntnis- und Wissenschaftstheorien, »ist diese einfache Verlagerung von einer Betrachtung verwirrender dreidimensionaler Objekte zu einer Inspektion zweidimensionaler Bilder, die weniger verwirrend gemacht worden sind. $\aleph^{50}$ Es ist zweifellos nicht länger ein Gott, wie im 16. Jahrhundert, der die Zeichen auf das von ihnen Bezeichnete deponiert und so eine stabile Beziehung zwischen beiden einrichtet; aber der Vorgang selbst, die Beschriftung, Markierung und Einzeichnung auf Papier oder anderen Speichermedien, aber auch und vor allem in das Objekt selbst, das zur experimentellen Erforschung ansteht (wozu seine Spur erst einmal gesichert werden muss: das tracing), belegt, dass in unserer Epoche ausgerechnet die maschinell-organisch produzierte Natur des Labors eine durch und durch geschriebene ist.

Es ist keineswegs so, dass Schrift und Texte erst am Ende des Forschungsprozesses stehen, wenn er in Publikationen Gestalt annimmt und sich an die Öffentlichkeit wendet: "Epistemische Dinge sind Artikulationen von Graphemen. Ultrazentrifugen, Elektronenmikroskope, Gelelektrophoresen und radioaktives tracing [Spuren-Legen ...] erzeugen jene Darstellungsräume, jene Schrifträume, in denen sich Grapheme zu epistemischen Objekten fügen. ${ }^{51}$ Es ist nicht so, dass die Formen der Schriftlichkeit und Lesbarkeit in dem Maße schwinden, wie man sich, im Raum des Labors, den Dingen in ihrer vorprädikativen Objekthaftigkeit nähert. Das Labor ist kein Raum der Selbstenthüllung epistemischer Objekte, sondern eine Kammer verschärfter Schreibarbeit, so dass der Epistemologe Gaston Bachelard bereits in den dreißiger Jahren von der

49 Hans-Jörg Rheinberger: Alles, was überhaupt zu einer Inskription führen kann. In: ders.: Iterationen. Berlin 2005, S. 22

50 Latour: Drawing Things Together (wie Anm. 47), S. 280.

51 Rheinberger: Alles, was überhaupt zu einer Inskription führen kann (wie Anm. 49), S. $21 \mathrm{f}$. "unglaublichen Epigraphie der Materie «"52 sprechen konnte. Die "alte Feindschaft zwischen Buch und Welt, Literatur und Realität«, konstatiert Hans Blumenberg, verliert sich, "wenn sogar der Naturforscher als überwiegenden Umgang seiner Wahrnehmung Skalen und Zeiger, Kurven und Diagramme, Zeitschriften und Bücher hat «.53 Die Wissenschaftsforschung der letzten Jahre hat sich intensiv mit einem medialen Bereich beschäftigt, der "zwischen Semi-Materie und Semi-Print « ${ }^{54}$ liegt, also alle Formen von Schreibarbeit im Labor, die vom »Gekritzel« bis hin zu sogenannten »Numeralien « und »Literalien« reichen, also groß angelegte Register, »aus denen Einheiten, Daten und Zahlen entnommen werden können, die man benötigt, um ein experimentelles Arrangement herzurichten « auf der einen, und standardisierte Protokolle, Labormanuale und ähnliche Formen schriftlicher Fixierung, die Prozeduren festhalten, die als hinreichend verläßlich gelten, um »in mehr oder weniger routinierter Form im Laboralltag angewendet zu werden $\aleph^{55}$ auf der anderen Seite. In allen diesen Fällen haben wir es mit Graphismen zu tun, die es mit der Sicherung von Spuren und der Anbringung von Marken zu tun haben und daher weit entfernt von der Klarheit wissenschaftlicher Prosa sind, die von allen epistemischen Verstrickungen und epistemologischen Hindernissen, die den Forscheralltag kennzeichnen, gereinigt sind.

\section{DARWIN ZWISCHEN DEN MASCHINEN}

Aus dem anthropologischen Schlaf zu erwachen, kann also bedeuten, auch auf dem Wege der wissenschafts- und kulturgeschichtlichen Vergegenwärtigung und Durcharbeitung vermeintlich längst `abgeschlossener oder `überwundener Epochen zur Entfaltung eines Raumes beizutragen, in dem es möglich ist zu denken, ohne den Denkenden selbst als Subjekt oder Zentralakteur des zu Denkenden anzusetzen. Die ‘große Trennung kann sich allerdings auch ohne eine derartige wissensgeschichtliche Rückbesinnung als eine wirkungsmächtige Illusion erweisen, wenn man die moderne Verfassung, wie sie im ontologischen Trennungsgebot von Natur und Kultur zum Ausdruck kommt, mit der modernen Praxis in den Wissenschaften und ihren technischen Anwendungen vergleicht, die

52 Zit. nach ebd., S. 19.

53 Blumenberg: Die Lesbarkeit der Welt (wie Anm. 39), S. 325

54 Ebd., S. 95.

55 Ebd., S. 93. 
sich zu keinem Zeitpunkt nach dieser radikalen Unterscheidung gerichtet hat. Die Modernen tun nicht, was sie sagen; die wissenschaftliche und technische Aktivität, die sie auszeichnet und auf die sie so stolz ist, schafft Mischungen aus Natur und Kultur innerhalb immer komplexerer Netze und Kollektive, »in denen die Objekte und die Menschen, die materiellen Auswirkungen und die sozialen Konventionen $\aleph^{56}$ untrennbar miteinander verbunden sind. Man muss nicht Bruno Latour lesen, sondern kann sich, wie ich es hier tun möchte, mit Samuel Butler begnügen, der in seinem utopischen Roman Ehrewhon (ein Anagramm von Nowhere) von 1872 (und in vielen anderen Texten) die Entstehung von Mensch/MaschineHybriden, die heute gerne als Cyborgs (cybernetic organisms) bezeichnet werden, zu einem zentralen Thema gemacht hat. Butler, der unter dem Eindruck der darwinischen Revolution in der Naturgeschichte schreibt, unterzieht sich auf seine Weise der Aufgabenstellung, »in der Leere des verschwundenen Menschen zu denken". In den drei Kapiteln, die sich in dem Roman den Maschinen widmen, unternimmt Butler den Versuch, die Anthropologie und das ihr zugrundeliegende ontologische Dispositiv nicht von der Seite des Tieres, sondern von der Seite der Maschine in Frage zu stellen. Auch Butler trägt, wie Borges, dazu bei, die »Vertrautheiten unseres Denkens" aufzurütteln, allerdings so, dass er die Wirksamkeit dessen, was er den »Trennstrich « ${ }^{57}$ nennt, also die klassifikatorische Geste par excellence, zwischen Lebewesen und technischen Artefakten außer Kraft setzt, und nicht, wie bei Borges, auf eine aus unserer Sicht pseudoklassifikatorische Weise im Bodenlosen operieren lässt.

Butlers »Buch der Maschinen« ist aus der Perspektive eines Gelehrten geschrieben, der sich, wie die Zivilisation der Erewhonianer insgesamt, mit einer Relativierung oder Hybridisierung des Menschen nicht abfinden mag. Er legt daher eine Apologie der - allerdings unvollständigen Zerstörung der Maschinenwelt vor, die in Ehrewhon vor langer Zeit planmäßig durchgeführt wurde, um die weitere Evolution der (höheren) Maschinen, die ja wie jede Evolution ungeplant und ungesteuert verläuft, wirksam auszuschließen. Für den Verfasser der Apologie dieses Zerstörungswerks ist das sich andernfalls etablierende Mensch-MaschineKontinuum so bedrohlich, wie für die Leser der frühen Ethnographien vielleicht nur der Animismus. Die umfassende Zerstörung der Maschinen lässt sich je nach Perspektive als ein utopisches oder dystopisches

56 Descola: Jenseits von Natur und Kultur (wie Anm. 41), S. 141.

57 Samuel Butler: Erewhon oder Jenseits der Berge. Frankfurt a. M. 1994.
Unternehmen begreifen, nämlich entweder als ein Werk der Errettung einer Zivilisation, das dafür sorgt, dass die Menschen weiterhin sunter sich bleiben`, also in ihrem gattungsmäßigen Bestand erhalten werden; oder als Aktion, die die weitere Entwicklung der menschlichen Art durch ihre gewaltsame Trennung von bestimmten Elementen ihrer Umwelt definitiv auszuschließen versucht.

Was die shöheren Maschinen` so bedrohlich erscheinen lässt, sind nicht so sehr ihre technischen bzw. instrumentellen Fähigkeiten, also nicht das, was sie bereits können, als vielmehr das Potential, das ihre nicht absehbare zukünftige Entwicklung eröffnet. $\gg \mathrm{Daß}$ die Maschinen heute wenig Bewußtsein besitzen", heißt es in der anthropologischen Apologie warnend, »bietet keine Gewähr dafür, daß sie ein solches letzten Endes nicht doch entwickeln. Eine Molluske hat auch nicht viel Bewußtsein. Man bedenke, welch außerordentliche Fortschritte die Welt der Maschinen in den letzten paar hundert Jahren zu verzeichnen hatte, und vergleiche damit, wie langsam die Entwicklung im Tier- und Pflanzenreich fortschreitet. [...] Wer vermag zu sagen, ob die Dampfmaschine nicht schon eine Art Bewußtsein besitzt? Wo beginnt das Bewußtsein, wo hört es auf? Wer kann den Trennstrich ziehen? Wer kann überhaupt irgendwo einen Trennstrich ziehen? ${ }^{58}$ Butler weiß, dass sich die gegenwärtigen Maschinen zu den kommenden »wie die Saurier der Urzeit zum Menschen« verhalten. "Die größten unter ihnen«, so nimmt er die gegenwärtige Entwicklung zu smarten und invasiven Technologien vorweg, "werden wahrscheinlich im Laufe der Zeit beträchtlich kleiner werden,$^{59}$ und diese Miniaturisierung eröffnet ihnen die Möglichkeit, ganz neue Berührungsflächen mit jenen Lebensformen herzustellen, die wir als originär menschliche Lebensformen auszeichnen. $\mathrm{Zu}$ den Maschinen müssen auch jene »kleine[n] Seh-Apparate ${ }^{60}$, also optische Medien, gerechnet werden, die bereits heute die Welt auf mikroskopische Dimensionen hin öffnen, die uns bislang schlicht unbekannt waren. Nicht nur erledigen Maschinen intellektuelle Operationen wie das vielgerühmte menschliche Rechenvermögen schneller und verlässlicher, sie stellen die Frage der menschlichen Vermögen auch insofern neu, als diese selbst im anthropologischen Binnenraum, also nicht nur erst auf dem Feld der Interaktion mit anderen (Subjekten oder Objekten), als eine verteilte Handlungsmacht erscheint:

58 Ebd., S. $267 \mathrm{f}$

59 Ebd., S. 272.

60 Ebd., S. 278. 
Wer darf behaupten, es sei der Mensch, der sehe oder höre? Er ist eine solche Generalversammlung von Schmarotzern, daß es fraglich ist, ob sein Körper nicht eher ihnen gehört als ihm und ob er überhaupt etwas anderes ist als auch so eine Art Ameisenhaufen. Könnte der Mensch nicht selber eine Art Schmarotzer auf den Maschinen werden? Eine liebevoll maschinenkitzelnde Blattlaus ${ }^{61}$ ?

Das politische Vokabular von Herrschaft und Knechtschaft samt der ihr zugehörigen Dialektik taugt nicht, um die Dynamiken im Mensch/ Maschine-Kontinuum zu beschreiben. Das Maschinelle durchzieht immer schon beide Seiten der anthropologischen Differenz. Wir sind an Maschinen gefesselt, aber umgekehrt benötigen die Maschinen, die kaputt gehen oder sich als dysfunktional erweisen können, also permanenten Störungen ausgesetzt sind und solche Störungen produzieren, den human support, um wieder in Stand gesetzt und vor allem: um weiterentwickelt zu werden. Die Maschine ist - wie der Mensch - ein Objekt mit unscharfen Rändern, wenn man berücksichtigt, was alles zusammenkommen muss, damit sie gebaut werden kann, damit sie funktioniert bzw. operabel ist (Schnittstellen, Infrastrukturen) und schließlich: damit sie sterben, also durch andere Maschinen ersetzt werden kann, denn Maschinen verfügen über eine phylogenetische Dimension, sie »treten in Generationen« auf, »wobei jede die Virtualität für andere zukünftige Maschinen eröffnet «. ${ }^{62}$

Sowenig wie der Mensch kann die Maschine auf ihre Materialität, den Umfang bzw. Aktionsradius ihres reigenen Körpers bzw. ihrer räumlich abgrenzbaren apparathaften Struktur begrenzt werden. Maschinen existieren nicht nur im Raum, sondern zugleich auch in einem auf sie abgestimmten infrastrukturellen Milieu sowie einer evolutiven (nicht bloß mechanisch-repetitiven) und >disziplinären`Zeit. Gewöhnlich denken wir uns die Maschine als einen Funktionszusammenhang, der ganz der Wiederholung geweiht ist, so als wäre sie, wie es Derrida einmal auf den Punkt gebracht hat, dazu bestimmt,

auf unerschütterliche, unempfindliche Weise, ohne Organe oder Organizität, die empfangene Ordnung zu reproduzieren. Im Zustand der Anästhesie würde sie als gleichgültiger Automat ohne Affekt oder

61 Ebd., S. $278 \mathrm{f}$.

62 Félix Guattari: Über Maschinen. In: Henning Schmidgen (Hrsg.): Ästhetik und Maschinismus. Texte zu und von Félix Guattari. Berlin 1995, S. 115-132, hier S. 118.
Selbst-Affektion einem kalkulierbaren Programm gehorchen oder befehlen. Ihr Funktionieren, wenn nicht sogar ihre Produktion, hätte niemanden nötig. ${ }^{63}$

Dagegen setzt Butler und eine in seiner Nachfolge entwickelte Maschinentheorie eine Perspektive, die besagt, dass es mit Maschinen nicht anders wie mit Menschen geht: Sie müssen `zur Welt gebracht`, sozialisiert und serzogen` werden. Ihre Erfindung sagt noch nichts über ihre schließliche Tauglichkeit und Einsatzfähigkeit. Das Argument, Maschinen könnten kein »Eigenleben ${ }^{64}$ entwickeln, weil sie kein Fortpflanzungsvermögen besitzen, ist hinfällig, denn Maschinen bedienen sich der Menschen als technischer Vermittler oder Delegierter, um sich zu reproduzieren, so wie es bei vielen Pflanzen Insekten sind, die sie erst fruchtbar machen, obwohl sie einer anderen Lebensform angehören als diejenigen, denen sie zur Reproduktion verhelfen: »Die Hummel gehört zum Fortpflanzungssystem des Klees $«{ }^{65}$ Butler denkt das Verhältnis von Mensch und Maschine nicht in Wesens-, sondern in Funktions- und Allianzbegriffen und schließt damit an das komplexere, vormoderne Wissen um die Notwendigkeit der Bildung von Bündnissen zwischen unterschiedlichen Agenten an (Tiere, Menschen, Apparate), die die Wirksamkeit bestimmter kollektiver Arbeits- und Handlungsvollzüge garantieren. ${ }^{66}$

»Unsere Aufmerksamkeit«, schreibt Michel de Montaigne, in der "Apologie für Raymond Sebond", "sollten wir daher auf die Gleichheit zwischen Mensch und Tier richten ${ }^{67}$ wobei er diese Gleichheit nicht als unterschiedslose Identität bestimmt, sondern in ausdrücklicher Berücksichtigung von »Rangordnungen und Stufen« als » ̈̈hnlichkeit der menschlichen Dinge mit denen der anderen Lebewesen ${ }^{68}{ }^{68}$ Nicht nur häuft Montaigne Beispiele auf Beispiele, um zu demonstrieren, dass die

63 Jacques Derrida: Maschinen Papier. Das Schreibmaschinenband und andere Antworten. Wien 2006, S. $36 \mathrm{f}$.

64 Butler: Erewhon (wie Anm. 57), S. 286.

65 Ebd., S. 287.

66 Vgl. dazu Thomas Macho: Tiere, Menschen, Maschinen. Zur Kritik der anthropologischen Differenz. In: Jörn Ahrens, Georg Toepfer und Mirjam Biermann (Hrsg.): Die Diffusion des Humanen: Grenzregime zwischen Leben und Kulturen. Frankfurt a. M. 2007, S. 17-29.

67 Michel de Montaigne: Essais. Erste moderne Gesamtübersetzung von Hans Stilett. Frankfurt a. M. 1998, S. 188.

68 Ebd., S. 196 f. (Hervorhebung FB) 
Tiere zu Leistungen fähig sind, für die die Anthropologien ein Monopol des Menschen beanspruchen; Montaignes Apologie der Tiere zeigt, dass sich das Zeitalter der Ähnlichkeit nicht um den Menschen dreht, die Berufung auf den Menschen als Maßstab aller Dinge erscheint vielmehr als Erkenntnishindernis und ist Ausdruck einer narzisstischen Voreingenommenheit: »Letztlich gilt: Alles, was nicht ist wie wir, taugt nichts, und Gott selber muß, um von uns als tauglich befunden zu werden, menschenähnlich sein «. ${ }^{69}$ Die Ähnlichkeit entspricht einem Denkmodus, der die Gesamtheit dessen, was existiert, »durch geringfügige Abweichungen getrennt« betrachtet, so dass es möglich wird, »das System der anfänglichen Kontraste wieder zu einem dichten Netz von Analogien zusammenzufügen, das die inneren Eigenschaften der unterschiedenen Entitäten miteinander verbindet. ${ }^{70}$ Die Logik der anthropologischen Differenz zielt auf die Zerstörung dieses Gewebes durch >Absonderung bestimmter Entitäten aus der Gesellschaft der Lebewesen. Die analogischen Systeme haben deshalb auch "nichts Anthropomorphes" an sich: Die Diversität der Teile, aus denen sie bestehen, ist "so komplex, daß ein einzelnes Geschöpf ihrem Ausmaß nicht zu genügen vermag « ${ }^{71}$ Samuel Butler steht in der Nachfolge Montaignes, wenn er für die Maschinen eine Perspektive entwickelt, die Montaigne zuvor an den Tieren erprobte. Das Denken der Ähnlichkeit beruht auf dem Verfahren der >Ver- bzw. Anähnlichung`, der Stiftung einer Verwandtschafts- oder Allianzbeziehung zwischen heterogenen Elementen. Descola definiert die Analogie daher als ein Verfahren der Integration, »das es ermöglicht, Solidaritätsstränge in alle Richtungen sowie Kontinuitätsbindungen zu schaffen « ${ }^{72}$ Ehrewhon beschreibt eine Kultur, die sich der Maschinenwelt gewaltsam erwehrt, weil sie an der ontologischen Ausnahmestellung des Menschen festhält und daher alle Solidaritätsstränge und Kontinuitätsbindungen zwischen Mensch und Maschine rigoros durchtrennt. »Darwin zwischen den Maschinen« ist der Titel eines Aufsatzes, mit dem Butler eine epistemologische Heterotopie benennt, denn das Spiel der evolutionären Mechanismen ist auf die von den Lebewesen bevölkerte Welt beschränkt und berücksichtigt nicht auch die technisch produzierten Artefakte. Die Trennungsstriche, die die alte Naturgeschichte zwischen den Gattungen und Arten eingerichtet hatte, sind für Darwins Entwicklungslehre zwar nur noch gültig auf Zeit, aber,

69 Ebd., S. 237

70 Descola: Jenseits von Natur und Kultur (wie Anm. 41), S. 301.

71 Ebd., S. 325

72 Ebd., S. 323 obwohl seine Einsichten doch ohne die Beobachtungen an der durch menschliche Eingriffe (`Zuchtwahl $)$ veränderten Lebewesen nicht möglich gewesen wären, hält die Evolutionstheorie doch grundsätzlich an der Unterscheidung zwischen dem Lebendigen und dem `Mechanischen

Butlers »Buch der Maschinen« endet mit einer Analyse dessen, was man die Fremderfahrung des Maschinellen nennen könnte, die, wie zuvor schon die Fremderfahrung des Tierischen, aller anthropologischen Theoriebildung zugrunde liegt. Fremderfahrung heißt hier die kulturelle Weigerung, selbst schwindelerregende Analogiebildungen zwischen unterschiedlichen Seienden in Kauf zu nehmen, um für sie einen Raum der Zusammengehörigkeit hervorzubringen, selbst wenn sich diese Zusammengehörigkeit auf keine Natur oder Wesensform stützen kann. Gerade weil Maschinen an unserem Körper und unseren Gedanken mitarbeiten, weil der Mensch, dem berühmten Wort Freuds zufolge, "eine Art Prothesengott ${ }^{73}$ geworden ist, wird diese Nähe als bedrohlich erfahren, da die Maschinen die Menschen nicht direkt zum Objekt ihrer (vermuteten) Aggression wählen, sondern sie »leise und unmerklich,$^{74}$ wie Butler schreibt, in ihre Abhängigkeit geraten lassen. Diese Fremdwahrnehmung oder Alterisierung der Maschine ist ein Ausdruck jenes Kleinkrieges, dessen Ursache mit einem anderen Ausdruck Freuds der »Narzißmus der kleinen Differenzen « ${ }^{75}$ ist: Je näher sich Akteure stehen, je abhängiger sie in ihren Aktionen voneinander erscheinen, je eher sind sie bereit, sich voneinander zu distanzieren und sich einer politischen oder auch philosophischen Reinigungsarbeit zu verschreiben. Nicht: ich bin ein anderer, sondern das trotzige >Ich bin anders ist der Schlachtruf der Krieger der >kleinen Differenzen«. Butler jedenfalls, nachdem er die Perspektive der maschinenstürmerischen `Kampfschrift $<$ umfassend referiert hat, weist am Ende auf den einzigen »ernst zu nehmenden Versuch einer Entgegnung « hin, deren Verfasser die Ansicht vertreten habe, »technische Vorrichtungen« seien »nichts als

73 Sigmund Freud: Das Unbehagen in der Kultur. In: ders.: Studienausgabe Bd. IX. Fragen der Gesellschaft. Ursprünge der Religion. Frankfurt a. M. 1974, S. 191-270, hier S. 222.

74 Butler: Erewhon (wie Anm. 57), S. 304.

75 Freud: Das Unbehagen in der Kultur (wie Anm. 73), S. 243. "Ich habe mich einmal mit dem Phänomen beschäftigt, daß gerade benachbarte und einander auch sonst nahestehende Gemeinschaften sich gegenseitig befehden und verspotten, so Spanier und Portugiesen, Nord- und Süddeutsche, Engländer und Schotten usw« (Ebd.). 
erweiterte, außerkörperliche Gliedmaßen und deshalb zur Körperlichkeit des Menschen zu rechnen ${ }^{76} "$ Die Identität der Menschen «, das lehren uns die Anthropologen, die dem Titel ihrer Wissenschaft zum Trotz nicht von einer Analytik des Menschen und seiner ontologischen Zentralstellung ausgehen, »die Identität der Menschen, der lebenden wie der toten, der Pflanzen, der Tiere und der Geister ist ganz und gar eine relationale und damit, je nach dem eingenommenen Standpunkt, Mutationen oder Metamorphosen unterworfen ${ }^{77}$ Die $»$ Verwischung der ontologischen Grenzen «, die in der heutigen Kultur- und Medienwissenschaft ebenso wie in der Wissenschaftsforschung mit ihrer symmetrischen Ansetzung des Verhältnisses von humans und non-humans auf der Tagesordnung steht, ist nicht der Effekt eines unscharfen Denkens, sondern der Beleg für die Wiederkehr einer epistemischen Disposition, die alle Unterschiede und Differenzen auf die Erfahrung einer prinzipiellen Ähnlichkeit bezieht und die Arbeit der Kultur daher als die komplizierte Herstellung von Bündnisbeziehungen und Allianzen begreift.

\section{MATTHIAS LÖWE}

\section{UTOPIE VERSUS ANTHROPOLOGIE}

\section{Konstellationen eines Konflikts}

\section{um 1800 und heute}

Wer mit Begriffen jongliert, die für fast jeden etwas anderes bedeuten, riskiert es, im Sumpf der Begriffsanarchie zu versinken. Wenn man, wie ich das hier vorhabe, Überlegungen zu einem Konfliktgeschehen zwischen zwei semantisch so porösen Konzepten wie `Utopieく und `Anthropologie anstellt, dann kommt man nicht umhin, zunächst zu erklären, was man damit meint. Im Anschluss an diese terminologische Eingrenzung folgen einige wissenschaftsgeschichtliche Beobachtungen zur forschungspolitischen Konkurrenz von Utopie- und Anthropologie-Begriff um 1990 und einige intellektuellengeschichtliche Beobachtungen zum Konflikt zwischen Utopie- und Anthropologie-Konzept im 18. Jahrhundert. Vor dem Hintergrund der beschriebenen Konkurrenz- und Konfliktphänomene werden schließlich Überlegungen zu den Aporien und Schwierigkeiten von >utopischem Denken unter den Bedingungen einer wahrheitspluralistischen Moderne angestellt.

\section{DER ANTHROPOLOGIE-BEGRIFF}

Den Anthropologie-Begriff gebrauche ich hier nicht in einem weiten oder deskriptiven Sinne, ich meine damit also nicht so etwas wie >Menschenbild`, sondern lehne mich an den historischen Anthropologie-Begriff an, wie ihn die germanistische Forschung zur Spätaufklärung profiliert hat. In den 1770er Jahren hat der Leipziger Medizin- und Philosophieprofessor Ernst Platner versucht, die Anthropologie als eigenständigen 
Wissensbestand, gar als Wissenschaftsdisziplin zu begründen. ${ }^{1}$ Anthropologie in diesem Sinne fragt nach Sinnlichkeit und Vernunft, "Körper und Seele in ihren gegenseitigen Verhältnissen, Einschränkungen und Beziehungen ${ }^{2}$. Anthropologie meint hier also die Thematisierung der leibgeistigen Einheit des Menschen und enthält damit immer auch einen impliziten oder expliziten Angriff auf die Vorstellung vom Menschen als einem rationalen, vernunftautonomen und freihandelnden Wesen, denn die Vernunft - so das Argument der Anthropologie - hängt auch vom Körper $a b .^{3}$

\section{DER UTOPIE-BEGRIFF4}

Zum Utopie-Begriff muss ich ein paar mehr Worte verlieren: Dahinter verbergen sich bekanntermaßen zwei Phänomene, die miteinander nur bedingt etwas tun haben, nämlich Utopie als literarische Gattung, deren Geschichte mit Thomas Morus' Utopia beginnt, und der im 20. Jahrhundert geprägte intentionale Utopie-Begriff, mit dem man eine bestimmte psychische Haltung zur sozialen Wirklichkeit zum Ausdruck bringt, ein utopisches Bewusstsein: Gemeint ist damit »nicht bloß der

1 Zur Geschichte des Anthropologie-Begriffs vgl. Odo Marquard: Anthropologie. In: Historisches Wörterbuch der Philosophie. Bd I. Hrsg. von Joachim Ritter. Basel und Stuttgart 1971, Sp. 362-374; Mareta Linden Untersuchungen zum Anthropologiebegriff des 18. Jahrhunderts. Bern und Frankfurt a. M. 1976.

2 Ernst Platner: Anthropologie für Aerzte und Weltweise. Leipzig 1772, S. XVII

3 Zum Anthropologie-Diskurs und zur Intellektuellengeschichte der Spätaufklärung vgl. vor allem Jutta Heinz: Wissen vom Menschen und Erzählen vom Einzelfall. Untersuchungen zum anthropologischen Roman der Spätaufklärung. Berlin und New York 1996, S. 19-122; Wolfgang Riedel: Erster Psychologismus. Umbau des Seelenbegriffs in der deutschen Spätaufklärung. In: Jörn Garber und Heinz Thoma (Hrsg.): Zwischen Empirisierung und Konstruktionsleistung. Anthropologie im 18. Jahrhundert. Tübingen 2004, S. 1-17.

4 Für detailliertere Informationen zum Utopie-Begriff, zur Utopie-Forschung der letzten 40 Jahre und zur Gattungsgeschichte der literarischen Utopie vom 16. bis zum 18. Jahrhundert verweise ich auf meine Dissertation: Idealstaat und Anthropologie. Problemgeschichte der literarischen Utopie im späten 18. Jahrhundert. Berlin und Boston 2012, S. 1-34. unzufriedene Vergleich der Wirklichkeit mit einem Ideal, sondern der Wille, Staat und Gesellschaft nach diesem umfassenden Ideal sofort zu verändern. ${ }^{5}$

Bei der Rede über das Phänomen `Utopie`steht man nun vor einem Problem: Ein Großteil der Gattungstradition literarischer Utopien lässt sich nämlich gar nicht mit dem intentionalen Utopie-Begriff beschreiben, denn viele literarische Utopien sind so gestaltet, dass man den darin entworfenen utopischen Staaten keine Realisierungsabsicht unterstellen kann. Den meisten literarischen Utopisten mangelt es offenbar eklatant an utopischem Bewusstsein. Bei frühneuzeitlichen Autoren literarischer Utopien wie Morus, Tommaso Campanella, Johann Valentin Andreae etc. liegt das ohnehin auf der Hand, denn diesen Autoren war die neuzeitliche Vorstellung vom Menschen als Macher von Geschichte überhaupt noch nicht geläufig. ${ }^{6}$ Was auch immer diese Autoren mit ihren Texten jeweils für Ziele verfolgt haben, um einen Aufruf zur konkreten Realisierung des beschriebenen Utopier-Staates, der Civitas Solis oder der Christianopolis ging es jedenfalls nicht.? Überblickt man die Gattungstradition literarischer Utopien, dann sind die Texte mit so etwas wie einem utopischen Bewusstsein vielleicht sogar in der Minderheit. Selbst im Falle der ersten sogenannten Zeitutopie, dem Roman L'An 2440 (1770/1771) von Louis-Sébastien Mercier, darf man stark daran zweifeln, ob dieser Text geschrieben wurde, um die darin dargestellte, ins Paris der Zukunft projizierte soziale Ordnung in der Erfahrungswirklichkeit zu realisieren. Daran zweifeln lässt schon der 700-jährige, also extrem lange zeitliche Abstand zwischen der Entstehung des Textes im Jahr 1770/71 und seiner Handlungszeit im Jahr $2440{ }^{8}$

Utopisches Bewusstsein hat allenfalls eine kleine Gruppe von literarischen Utopien, die man Fortschrittsutopien nennen kann und die

5 Ludwig Stockinger: Ficta Respublica. Gattungsgeschichtliche Untersuchungen zur utopischen Erzählung in der deutschen Literatur des frühen 18. Jahrhunderts. Tübingen 1981, S. 29. Für eine kritische Auswertung der verschiedenen intentionalen Utopie-Begriffe und ihrer Beziehung zur Gattungstradition vgl. ebd., S. 28-48.

6 Vgl. ebd., S. 26-27.

7 Vgl. dazu die gründliche Analyse und Deutung dieser Texte bei Peter Kuon: Utopischer Entwurf und fiktionale Vermittlung. Studien zum Gattungswandel der literarischen Utopie zwischen Humanismus und Frühaufklärung. Heidelberg 1986, S. 55-257.

8 Vgl. Löwe: Idealstaat und Anthropologie (wie Anm. 4), S. 73-86. 
mehrheitlich im späten 19. und frühen 20. Jahrhundert erscheinen: ${ }^{9}$ etwa Theodor Herzls Roman Altneuland (1902). Während noch Mercier seinen utopischen Entwurf 700 Jahre in die Zukunft vorverlegt, sind es bei Herzl nur mehr 21 Jahre, die das dargestellte utopische Israel im Jahr 1923 von der Erfahrungswirklichkeit des zeitgenössischen Lesers im Jahr 1902 trennen. Man kann diese erhebliche Reduktion des zeitlichen Abstands zwischen utopischer Zukunft und Erfahrungsgegenwart als markantes Indiz für die explizite Realisierungsintention von Herzls utopischem Roman verstehen. Zudem betreiben Fortschrittsutopien wie Herzls Altneuland erheblichen Aufwand damit, sich von konkurrierenden Zukunftsentwürfen zu distanzieren..$^{10}$ Da Fortschrittsutopisten offenbar eine zeitnahe Realisierung zentraler Elemente ihrer fiktiven Gesellschaft intendieren, stehen sie unter dem Druck einer Entwurfskonkurrenz.

Das, was man in Anlehnung an Karl Mannheim, Gustav Landauer, Ernst Bloch und andere landläufig unter Utopie versteht - Utopie als >Antizipation zukünftiger Realität ${ }^{11}-$, damit lässt sich also eigentlich nur ein recht kleiner Ausschnitt der Gattungstradition beschreiben. Die ästhetische Funktion der meisten literarischen Utopien wird man damit nicht erfassen.

9 Vgl. Birgit Affeldt-Schmidt: Fortschrittsutopien. Vom Wandel der utopischen Literatur im 19. Jahrhundert. Stuttgart 1991; Löwe: Idealstaat und Anthropologie (wie Anm. 4), S. 33-34.

10 In Herzls Altneuland wird das 19. Jahrhundert als »ein merkwürdig hinkendes Zeitalter" diskreditiert, in dem man die »konfusesten Schwärmer" wie Fourier, Cabet und Hertzka ernst nahm - allesamt auch Fortschrittsutopisten - und in dem von verstiegenen Träumern die »fabrikrauchgeborenen Wolken eines Zukunftsstaates" an den Himmel gemalt wurden: "zum Beispiel die berühmte Wolke des Amerikaners Bellamy, der in seinem >Rückblicke aus dem Jahre 2000 auf das Jahr 1887 < eine edle kommunistische Gesellschaft darstellt. Dort kann jeder aus der allgemeinen Schüssel so viel essen, als er mag. Der Wolf weidet neben dem Lamm. Schön, sehr schön! Nur sind dann die Wölfe keine Wölfe und die Menschen keine Menschen mehr. Nach Bellamy kam der Staatsromantiker Hertzka und entwarf seine Utopie `Freiland, ein sehr brillantes Zauberkunststück, vergleichbar dem unerschöpflichen Hute des Taschenspielers. Es sind schöne Träume oder wenn ihr wollt Luftschiffe, aber lenkbar sind sie nicht" (Theodor Herzl: Altneuland. Ein utopischer Roman. Hrsg. von David Gall. Norderstedt 2004, S. 134-135).

11 Vgl. Ernst Bloch: Antizipierte Realität - Wie geschieht und was leistet utopisches Denken? In: ders.: Abschied von der Utopie? Vorträge. Hrsg. von Hanna Gekle. Frankfurt a. M. 1980, S. 101-115.
Legt man etwa Mannheims oder Blochs Begriff von Utopie zugrunde - also den Begriff von Utopie im Sinne einer Handlungspraxis, die die Strukturen der gegebenen Erfahrungswirklichkeit überschreitet oder sprengt, die eine Ideologie verwirklicht (vgl. Anm. 5) -, dann kann man just den Prototyp der Gattung, dem sich das Kunstwort `Utopieく verdankt, nämlich Morus' Utopia, gar nicht mehr als Utopie bezeichnen, denn dieser Text enthält keinerlei Aufforderung, die dargestellte soziale Ordnung zu realisieren, sondern bestreitet mit einer Unzahl von satirischen und fiktionsironischen Textsignalen sogar deren Realisierbarkeit. ${ }^{12}$ Es ist daher wohl kein Zufall, dass bei Mannheim und Bloch, aber auch bei liberalen Utopie-Kritikern wie Karl Popper und Joachim Fest, eigentlich weniger an den Humanisten und Wortschöpfer Thomas Morus gedacht wird, wenn von Utopie die Rede ist, sondern eher an jemanden wie Thomas Müntzer, dass also Utopie mit eschatologischen und messianischen Visionen gleichgesetzt wird. ${ }^{13}$

Die Unterscheidung zwischen dem Intentionsbegriff eines utopischen Bewusstseins und der Gattungstradition literarischer Utopien ist seit mehreren Jahrzehnten im Kreis einer literaturwissenschaftlich spezialisierten Utopieforschung gang und gäbe. Insbesondere die literaturwissenschaftliche Utopieforschung der 1980er Jahre hat eine Reihe von grundlegenden Studien hervorgebracht, die gegen eine inhaltsreduzierte Wahrnehmung dieser Textmustertradition Einspruch erheben, die jene Verzerrungen ansprechen, die man produziert, wenn man der gesamten Gattungstradition unbekümmert die Utopie-Begriffe Mannheims oder Blochs überstülpt, wenn man die Utopia-Tradition also als Beitrag zur politischen Ideengeschichte liest, der sich aus seinem schmückenden literarischen Dekor herauslösen lasse. ${ }^{14}$

12 Vgl. Kuon: Utopischer Entwurf und fiktionale Vermittlung (wie Anm. 7), S. 55-134.

13 Vgl. Thomas Schölderle: Utopia und Utopie. Thomas Morus, die Geschichte der Utopie und die Kontroverse um ihren Begriff. Baden-Baden 2011, S. 437. 14 Angestoßen von der internationalen und disziplinenübergreifenden Forschungsgruppe zur »Funktionsgeschichte literarischer Utopien in der frühen Neuzeit«, die Wilhelm Voßkamp 1980/81 für ein Jahr am Bielefelder Zentrum für interdisziplinäre Forschung $(\mathrm{ZiF})$ versammelt, werden die 1980er und die frühen 1990er Jahre bis heute zur ertragreichsten Dekade literaturwissenschaftlicher Utopie-Forschung. Neben einem regen literaturwissenschaftlichen Bemühen um die Konturierung von >Utopie< als Gattungsbegriff entstehen eine Reihe grundlegender, überblicksartige und aspektorientierter Beiträge zur Geschichte dieses Textmusters: vgl. die Hinweise zur Forschungsgeschichte in Löwe: Idealstaat und Anthropologie (wie Anm. 4), S. 3-4; 7-14. 
III. DIE FORSCHUNGSPOLITISCHE KONKURRENZ VON UTOPIEUND ANTHROPOLOGIE-BEGRIFF UM 1990

$\mathrm{Zu}$ Beginn der 1990er Jahre droht dem bisher erreichten literaturwissenschaftlichen Reflexionsstand jedoch der Bedeutungsverlust oder zumindest die disziplinäre Marginalisierung, denn der intentionale Utopie-Begriff erlebt einen Wiederaufstieg in der Publizistik und im Textmuster des Zeitgeist-Essays, weil er das erhöhte Bedürfnis nach einer begrifflichen Kommentierung der rasanten zeitgeschichtlichen Entwicklung besonders gut bedient. ${ }^{15}$

Infolge der politischen Ereignisse in den Jahren $1989 \mathrm{ff}$. beherrscht die Wahrnehmung der Gegenwart als Ende eines Zeitalters den öffentlichen und intellektuellen Diskurs. Besonders drastisch manifestiert sich das bekanntermaßen bei dem amerikanischen Politikwissenschaftler Francis Fukuyama, der in seinem umstrittenen Buch Das Ende der Geschichte (1992) das Verschwinden des Marxismus von der politischen Bühne als Sieg des politischen und ökonomischen Liberalismus deutet und darin das Ende der Geschichte erblickt. Im Rahmen des verbreiteten Bedürfnisses, die politischen Ereignisse quasi-geschichtsphilosophisch zu deuten, erlebt auch der intentionale Utopie-Begriff einen begriffsgeschichtlichen Wiederaufstieg. ${ }^{16}$ Vor allem eignet er sich nun als griffige Sammelbezeichnung für jene sozialpolitischen Ideen, auf die sich die implodierten Gesellschaftsordnungen des sowjetischen Typs berufen. In Deutschland dokumentieren dies einige öffentlichkeitswirksame zeitgenössische Essays aus ganz unterschiedlichen politischen Lagern: Am bekanntesten ist wohl Joachim Fests Rede von Utopie als »zerstörte[m] Traum $«,{ }^{17}$ Johano Strasser räsoniert über die Schwierigkeiten eines »Lebens ohne Utopie,$_{1}^{18}$ Richard Saage spricht

15 Wenn man das Wort Utopie in den Ngram-Viewer eingibt - das ist jenes Tool der Firma Google, das nach der Häufigkeit und zeitlichen Verteilung von Begriffen in über fünfmillionen eingescannten Büchern sucht -, dann ergibt sich eine Kurve, aus der hervorgeht, dass die Karriere des deutschsprachigen Utopie-Begriffs, gemessen an der Häufigkeit seiner Verwendung, um 1990 ihren Zenit erreicht und dass es mit ihr danach steil bergab geht. 16 Vgl. Schölderle: Utopia und Utopie (wie Anm. 13), S. 421-428.

17 Joachim Fest: Der zerstörte Traum. Vom Ende des utopischen Zeitalters. Berlin 1991.

18 Johano Strasser: Leben ohne Utopie? Frankfurt a. M. 1990. vom "Ende der politischen Utopie ${ }^{19}$ und Michael Winter blickt auf das »utopische Zeitalter Europas $\aleph^{20}$ zurück, um nur einige Beispiele zu nennen.

Obwohl seine öffentliche Präsenz um 1990 ihren Zenit erreicht, fungiert der Utopie-Begriff nun nicht mehr als jenes Mode- und Zauberwort, als das er Eingang in die Sozial- und Geisteswissenschaften der 196oer und 1970er Jahre fand. Stattdessen kommt der Utopie-Begriff vornehmlich als Instrument polemischer Wertung zum Einsatz, um die sozialpolitischen Ideen des sowjetischen Typs als wirklichkeitsfern zu markieren, als etwas, das an der Natur des Menschen rundweg vorbei geht. Insbesondere Joachim Fest will widerlegen, dass utopisches Denken - also das Entwerfen utopischer Gesellschaftsentwürfe mit dem Ziel ihrer Verwirklichung - etwas in der Natur des Menschen Angelegtes sei: "Die Utopie ist kein anthropologisches Faktum, schon gar nicht in der Spielart des geschlossenen Gesellschaftsentwurfs ${ }^{21}$. Stattdessen steht für ihn fest, »daß ein Leben ohne Utopie zum Preis der Modernität gehört «22.

Diese Konjunktur von >Utopieく als polemischem Wertungsbegriff im zeitgeschichtlichen Essay der frühen 1990er Jahre bleibt nicht ohne Folgen für die Erforschung von Utopie als literarischer Gattung. In der Literaturwissenschaft reduziert sich der Forschungsaufwand, der seit 1990 in dieses Textmuster investiert wird, im Vergleich zu den 1980er Jahren drastisch. In der literaturgeschichtlichen Beschäftigung gerade mit dem 18. Jahrhundert werden die 1990er Jahre stattdessen zur Durchsetzungsphase eines neuen literaturwissenschaftlichen Forschungsinteresses, nämlich der >Anthropologieく. 1992 veranstaltet Hans-Jürgen Schings das viel beachtete DFG-Symposion Der ganze Mensch. Anthropologie und Literatur im 18. Jahrhundert ${ }^{23}$ und 1994 zieht Wolfgang Riedel in seinem bekannten Forschungsbericht zu Anthropologie und Literatur in der deutschen Spätaufklärung ${ }^{24}$ bereits eine erste Bilanz. Hier wird ersichtlich, dass

19 Richard Saage: Das Ende der politischen Utopie? Frankfurt a. M. 1990 20 Michael Winter: Ende eines Traums. Blick zurück auf das utopische Zeitalter Europas. Stuttgart und Weimar 1993.

21 Fest: Der zerstörte Traum (wie Anm. 17), S. 97.

22 Ebd., S. 98.

23 Vgl. Hans-Jürgen Schings (Hrsg.): Der ganze Mensch. Anthropologie und Literatur im 18. Jahrhundert. Stuttgart und Weimar 1994.

24 Wolfgang Riedel: Anthropologie und Literatur in der deutschen Spätaufklärung. Skizze einer Forschungslandschaft. In: Internationales Archiv für Sozialgeschichte der deutschen Literatur. Sonderheft 6: Forschungsreferate 3 (1994), S. 93-157. 
sich die Konjunktur des Anthropologie-Begriffs in den 1990er Jahren vor allem einer Berufung auf den spätaufklärerischen Anthropologie-Begriff, auf das Konzept des iganzen Menschen verdankt. Der größte forschungspolitische Erfolg wird mit dem neuen Leit-Label `Anthropologie`dann Mitte der 1990er Jahre erzielt und zwar in Konstanz, mit dem Sonderforschungsbereich 511 Literatur und Anthropologie, der von 1996 bis 2002 gefördert wird und bei dem u. a. Gerhart von Graevenitz federführend war.

Während in den frühen 1990er Jahren also das literaturgeschichtliche Interesse am Phänomen `Utopieくverglichen mit den 1980er Jahren merklich erlahmt, steigt zugleich die Anthropologie zu einem der literaturwissenschaftlichen Leitbegriffe auf. Odo Marquard war für dieses boomende Forschungsinteresse an der Anthropologie einer der wichtigsten Referenzautoren. In einem seiner Aufsätze just aus dem Jahr 1991 bezeichnet er die Anthropologie als das Wissen vom »Mensch[en] >diesseits der Utopie $«{ }^{25}$ Anthropologie sei »Antiutopikum $«:^{26}$ Die Anthropologie interessiere "am Menschen nicht das, was er sein soll, sondern das, was er ist $«{ }^{27}$ seine Lebenswelt und Lebenspraxis. Utopische Entwürfe, so kann man Marquard verstehen, konstruieren also Individuen, die der erfahrungsweltlichen Natur des Menschen widersprechen, weil sie den Menschen zum freihandelnden Wesen erklären, ohne seine Denkfaulheit und Bequemlichkeit in den Blick zu nehmen, seinen Hang zum Egoismus bzw. sein Handeln, das nicht Vernunftnormen, sondern diffusen Gefühlen und Einbildungen folgt. Der anthropologische Blick auf die Welt erscheint dagegen als der vermeintlich realistischere Blick auf den Menschen als Mängelwesen, mit dem sich eben keine Utopien verwirklichen lassen.

Nicht nur der Utopie-Begriff wird in den 1990er Jahren also hochpolemisch gebraucht, sondern auch der Anthropologie-Begriff, indem er die Aura eines vermeintlichen Realismus in Bezug auf die Natur des Menschen vor sich herträgt. Es geht mit dem polemisch verwendeten Utopie- wie Anthropologie-Begriff immer darum, das Interpretationsmonopol über das zu gewinnen, was Realität oder Wirklichkeit heißt, über die Deutung dessen, was der Mensch sei. Eine Utopie im Sinne

25 Odo Marquard: Der Mensch `diesseits der Utopieく. Bemerkungen über Geschichte und Aktualität der philosophischen Anthropologie. In: Joris van Nispen und Douwe Tiemersma (Hrsg.): The Quest for Man. The Topicality of Philosophical Anthropology. Assen, Maastricht 1991, S. 3-10, hier S. 10. 26 Ebd., S. 8.

27 Ebd., S. 5.
Mannheims oder Blochs bestimmt den Menschen über eine Theorie der Freiheit, die sein Endzweck sein soll, sich aber in der Gegenwart noch nicht zeigt. Anthropologie dagegen wird etwa bei Marquard beschrieben als die »Entdeckung der Zerbrechlichkeit des Menschen.$_{.}^{28}$ Anthropologie erhofft sich eine Verbesserung der Welt nicht aus einer Verbesserung der menschlichen Natur im Lauf der Geschichte. In der anthropologischen Thematisierung seiner eigenen Natur, in der Beschäftigung mit den Phänomenen seiner psychophysischen Einheit und der Problematisierung seiner Vernunftautonomie und Willensfreiheit betreibt der Mensch im Modus der Anthropologie stattdessen Selbstentschuldung. Er steckt »die Grenzen seiner Selbstursächlichkeit «29 ab. Er gibt sich zu verstehen, dass er ist, was die Natur aus ihm gemacht habe, dass er kein freihandelndes Wesen sei, sondern wegen der Abhängigkeit seines Denkens und Handelns vom Körper und der Umwelt für das Übel in der Welt nur begrenzt verantwortlich gemacht werden könne. Marquard nennt die Anthropologie daher einmal treffend einen »Ausbruch in die Unbelangbarkeit «. ${ }^{30}$

Wie lässt sich diese zunehmende Ausstattung des AnthropologieBegriffs mit erheblichem symbolischen Kapital erklären? Der Umbruch der Jahre $1989 \mathrm{ff}$. bringt neben vielem anderen auch eine Verknappung von akzeptablen Deutungssystemen und Sinnangeboten mit sich, wie etwa die zeitgenössische Abwertung des Utopie-Begriffs zeigt. Zugleich besteht um 1990 in Teilen der Germanistik jedoch ein erheblicher Sinnbedarf, d.h. ein Bedarf an konsensfähigen Normen und Konzepten, die es erlauben, sich gegen die Dekonstruktion und das poststrukturalistische Credo des Sinnverzichts zur Wehr zu setzen. Das sieht man zum Beispiel an der Habilitation von Georg Braungart, die versucht, neben der Sprachskepsis noch einen »anderen Diskurs der Moderne« zu profilieren, der »leibhafter Sinn« genannt wird. ${ }^{31}$ Schon im Klappentext des Buches wird der Gegner identifiziert, gegen den sich diese Rehabilitation des

28 Odo Marquard: Die Krise des Optimismus und die Geburt der Geschichtsphilosophie. In: ders.: Skepsis in der Moderne. Philosophische Studien. Stuttgart 2007, S. 93-108, hier S. 106.

29 Odo Marquard: Der angeklagte und der entlastete Mensch in der Philosophie des 18. Jahrhunderts. In: Bernhard Fabian, Wilhelm Schmidt-Biggemann und Rudolf Vierhaus (Hrsg.): Deutschlands kulturelle Entfaltung. Die Neubestimmung des Menschen. München 1980, S. 193-209, hier S. 201.

30 Ebd.

31 Georg Braungart: Leibhafter Sinn. Der andere Diskurs der Moderne. Tübingen 1995 . 
Leibes richtet: "Mit all dem ist nicht nur eine historische Erinnerung intendiert, sondern auch die Formulierung eines Vorbehalts gegen den Sinnpessimismus des Poststrukturalismus und gegen dessen universalisierende Rückprojektion in die Moderne. «32

Um ein Abrutschen in den Sinnpessimismus, um eine Relativität aller Werte zu vermeiden, werden also gerade in den 1990er Jahren der Leib, der Körper, der Mensch und seine Biologie zur neuen Norm hochstilisiert und die Anthropologie zum germanistischen >master-narrative aufgewertet, vor allem bei der Erforschung des 18. Jahrhunderts. Besonders Wolfgang Riedels Arbeiten lassen den Versuch erkennen, die Anthropologie, die Thematisierung der leibgeistigen, psychophysischen Einheit des Menschen zum zentralen intellektuellen Diskurs der Moderne zu nobilitieren, demgegenüber etwa die Entdeckung der Subjekt- und Perspektivgebundenheit aller Wahrheit, wie man sie vor allem mit Kant verbindet, zum zweitrangigen Phänomen gerät. Von welcher unhinterfragten Norm Riedel dabei ausgeht, gesteht er selbst zu, nämlich vom Weltund Menschenbild der Neurobiologie: »Freilich sieht man in einer Zeit der florierenden Neurowissenschaften manche historische Entwicklung anders, und vielleicht deutlicher als ehedem. Jedenfalls ist es von heute aus betrachtet gerade das Bemühen um einen physiologischen Zugang zu Seele und Geist, das der Spätaufklärungspsychologie ihre modernitätsgeschichtliche Bedeutung verleiht. $\aleph^{33}$ Verglichen mit dieser »Revolution der Denkart«, die sich mit der Spätaufklärungsanthropologie ereignet, markiere jener intellektuelle Diskurs, der von Kants Kritiken ausgeht, nur mehr eine »Retardation «. ${ }^{34}$ Wirkungsmächtiger für die Vorstellung dessen, was Moderne ist, sei hingegen die Hinwendung zum Psychologismus, zum `Homo natura<, also jene »Achsendrehung im Begriff des Menschen ${ }^{35}$ die mit der vorkantischen Anthropologie des späten 18. Jahrhunderts beginnt, die mit der Triebmetaphysik Schopenhauers und mit der Psychoanalyse um 1900 neuen Nährboden erhält und die auch der beherrschende intellektuelle Diskurs der Gegenwart sei, denn momentan, so Riedel, leben wir »in einer Hochphase der empirisch-experimentellen Hirnforschung ${ }^{36}{ }^{36}$ Eine fundierte Kritik an dieser seit 1990 innerhalb der

32 Ebd., Klappentext.

33 Riedel: Erster Psychologismus (wie Anm. 3), S. 15.

34 Ebd., S. 17.

35 Wolfgang Riedel: »Homo Natura«. Literarische Anthropologie um 1900. Berlin und New York 1996, Klappentext.

36 Riedel: Erster Psychologismus (wie Anm. 3), S. 2 (hier Anm. 2).
Germanistik zunehmenden, affirmativen Stilisierung von Anthropologie zum zentralen Paradigma der Moderne findet sich, soweit ich sehe, einzig bei Gideon Stiening. ${ }^{37}$

Anhand der polemischen Konstellationen der frühen 1990er Jahre, in denen Utopie- und Anthropologie-Begriff - auch forschungspolitisch - zu Oppositionsbegriffen avancieren, lassen sich nun einige aufschlussreiche Beobachtungen machen. Die Kölner Tagung, deren Beiträge dieser Band versammelt, trug den Titel Möglichkeitsdenken. Dieser Titel deutet schon darauf hin, dass die Tagung weniger nach der Zukunft von Utopie als literarischer Gattung fragen wollte, denn mit der literarischen Utopie können sich ja ganz unterschiedliche Intentionen und Funktionen verbinden: Satire, ironisches Spiel, Allegorie etc. Zur Diskussion stand vielmehr die Zukunft einer bestimmten Intention von utopischen Entwürfen, nämlich deren Absicht, eine mögliche Form sozialen Zusammenlebens freier Individuen zu entwerfen und diese in der Zukunft zu realisieren. Nachgedacht wurde also über die Zukunft von Zukunftsprojektionen, über die Zukunft der >utopischen Intention`, die in den Debatten der 1990er Jahre in Verruf geraten und totgesagt worden war, unter anderem mit anthropologischen Argumenten. Als Literaturwissenschaftler bin ich nun eigentlich eher zuständig für die Gattungsgeschichte literarischer Utopien. Dennoch stellt sich mir mit Blick auf die forschungspolitische Konkurrenz von Utopieund Anthropologie-Begriff um 1990 auch die Frage, was sich aus heutiger Sicht zur Zukunft des utopischen Denkens sagen lässt, ohne die polemisch aufgeladenen Argumente der frühen 1990er Jahre einfach zu reproduzieren.

Wenn man sich auf die Kommunikationsbedingungen von wahrheitspluralistischen Gesellschaften einzulassen versucht, dann steht utopisches Denken vor einem fundamentalen Problem: Wer Utopien entwirft und zwar mit der Intention, sie zu realisieren, nimmt zwangsläufig Normen für sich in Anspruch, mindestens eine Norm zukünftiger Realität. In der Utopie-Debatte der frühen 1990er Jahre hat sich nun aber gezeigt, dass Utopiekritiker das utopische Denken nicht primär bekämpfen, indem sie diese Inanspruchnahme von Normen hinterfragen, sondern indem sie neue Normen profilieren, z. B. indem die Anthropologie - auch forschungspolitisch - zur neuen Norm hochstilisiert wird: Blochs utopisches

37 Gideon Stiening: Ein »Sistem» für den »ganzen Menschen«. Die Suche nach einer santhropologischen Wende< der Aufklärung und das anthropologische Argument bei Johann Karl Wezel. In: Dieter Hüning, Karin Michel und Andreas Thomas (Hrsg.): Aufklärung durch Kritik. Festschrift für Manfred Baum zum 65. Geburtstag. Berlin 2004, S. 113-139. 
Totum, sein Reich der Freiheit am Ende der Geschichte könne nicht kommen, weil das dem >wahren Wesen des Menschen widerspreche, nämlich seinem Mängelwesen. Im Rahmen solcher Argumentationen wird sprichwörtlich versucht, den Teufel mit dem Beelzebub auszutreiben, eine Norm wird mit einer anderen bekämpft. Die Befürworter utopischen Denkens und ihre Gegner tun also etwas, was den Kommunikationsbedingungen von wahrheitspluralistischen Gesellschaften und der Subjektgebundenheit aller Wahrheit eigentlich nicht gerecht wird. Sie nehmen Normen für sich in Anspruch, ohne begründen zu können, was sie eigentlich als Normenbegründer legitimiert.

Stellt man die Frage nach der Zukunft von handlungsorientierenden utopischen Entwürfen dagegen unter den Kommunikationsbedingungen von wahrheitspluralistischen Gesellschaften, dann zeigt sich ein Problem ganz anderer Art, das sich in Form folgender Frage formulieren ließe: Wie soll man eine mögliche Zukunft entwerfen, die konkret genug ist, um Orientierungsfunktion zu übernehmen, um Begeisterung und Akzeptanz $\mathrm{zu}$ erzeugen und Handlungen in Richtung auf dieses Ziel zu motivieren, aber doch so offen, dass sie keine Normen fundamentalistisch vorschreibt, dass sie die Freiheitsspielräume des Einzelnen nicht einschränkt, dass sie nicht in Kommunikationsstrukturen verfällt, die das Verhältnis von belehrendem Priester und folgsamem Laien nachahmen. Utopische Entwürfe einer möglichen Zukunft müssten, wenn sie Handeln orientieren wollen, unter den Kommunikations- und Wahrheitsbedingungen von wahrheitspluralistischen Gesellschaften also eigentlich geradezu eine Quadratur des Zirkels vollbringen.

Eine Lösung dafür habe ich nicht. Was ich aber anbieten kann, ist ein Perspektivwechsel, der Blick auf eine historische Situation, in der man schon einmal vor strukturell ähnlichen Fragen stand, in der man allerdings auch keinen Ausweg gefunden hat, aber doch einige intelligente Reflexionen dieses Problems. Damit komme ich zum historischen Teil meiner Überlegungen.

\section{UTOPIE UND ANTHROPOLOGIE IM 18. JAHRHUNDERT}

In der Frühaufklärung tritt die literarische Utopie in Romanform in Erscheinung, die Traktat- und Dialogstrukturen renaissancehumanistischer und barocker Utopien werden reduziert und stattdessen werden narrative Strukturen dominant, die die Leserphantasie ansprechen und die Akzeptanz der dargestellten utopischen Entwürfe erhöhen sollen. In der Frühaufklärung betreiben Autoren literarischer Utopien also erstmals besonders großen Aufwand mit der sinnlich-faszinierenden Darstellung ihrer Staatsentwürfe. Sie versuchen ihre Leser glauben zu machen, dass die Grundprinzipien jener utopischen Gesellschaften, die sie vorerst nur zwischen zwei Buchdeckeln zum Leben erwecken, im Zuge einer Moralisierung und Aufklärung des Menschen auch in der Wirklichkeit umsetzbar seien. Das im frühen 16. Jahrhundert entstandene Textmuster der literarischen Utopie geht im frühen 18. Jahrhundert eine enge Allianz mit dem Weltbild der Leibniz-Theodizee ein. Die Gattung wird vereinnahmt, um im Medium Literatur die Ideen der besten aller möglichen Welten, der Vernunftautonomie und Aufklärbarkeit des Menschen zu popularisieren. Frühaufklärerische Utopien wie Johann Gottfried Schnabels Insel Felsenburg suggerieren daher mit bestimmten ästhetischen Tricks, dass utopische Individuen sich gar nicht fundamental vom erfahrungsweltlichen Menschen unterscheiden. ${ }^{38}$

Schon nach 1750 gerät das Textmuster unter deutschen Intellektuellen jedoch in die schwerste Legitimationskrise seiner 250-jährigen Gattungsgeschichte. Dafür gibt es auch begriffsgeschichtliche Indizien: In der zweiten Hälfte des 18. Jahrhunderts absolviert der Utopie-Begriff eine rasante Bedeutungskarriere. Sein semantisches Spektrum erweitert sich im deutschen Sprachraum vom literarischen Gattungsnamen zum polemischen Kampfbegriff. ${ }^{39}$ Etwa ab 1770 findet er in der Gelehrtensprache immer häufiger Verwendung, um Weltanschauungen zu diskreditieren, die auf ınicht-natürlichen`, d. h. außerempirischen Ideen und Erklärungen fußen und die daher allenfalls in utopischen Romanen, nicht aber in der Erfahrungswirklichkeit ausführbar seien. So schreibt etwa Johann Gottfried Herder 1774 in Auch eine Philosophie der Geschichte zur Bildung der Menschheit: "[W]er sich überhaupt von göttlichen Veranstaltungen in der Welt und im Menschenreich anders als durch welt- und menschliche Triebfedern Begriffe macht, ist wahrhaftig mehr zu utopischdichterischen, als zu philosophischnatürlichen Abstraktionen geschaffen.«40

38 Vgl. dazu Löwe: Idealstaat und Anthropologie (wie Anm. 4), S. 27-34. 39 Vgl. Lucian Hölscher: Utopie. In: Otto Brunner, Werner Conze und Reinhart Koselleck (Hrsg.): Geschichtliche Grundbegriffe. Historisches Lexikon zur politisch-sozialen Sprache in Deutschland. Bd. 6. Stuttgart 1990, S. 733-788, hier S. 756-759.

40 Johann Gottfried Herder: Werke in zehn Bänden. Bd. 4: Schriften zu Philosophie, Literatur, Kunst und Altertum 1774-1787. Hrsg. von Jürgen Brummack und Martin Bollacher. Frankfurt a. M. 1994, S. 48. 
Es ist also die `Naturalisierung ‘ oder >Anthropologisierung ১ des spätaufklärerischen Denkens, an der sich die Gattungskrise der literarischen Utopie entzündet. Gerade jene tugendhaften und vernunftautonomen Individuen, die die utopischen Entwürfe der Frühaufklärung bevölkern, widersprechen dem neuen Menschenbild, das im späten 18. Jahrhundert unter dem Label `Anthropologie` die intellektuellen Diskurse dominiert und das den Einfluss diffuser Gefühle und Einbildungen auf das menschliche Denken und Handeln betont. Mit der anthropologischen Thematisierung körperlicher und äußerer Einflüsse auf Gefühle und Verstand wird die rationalistische Vorstellung von objektiver Verstandeserkenntnis in Frage gestellt. Das anthropologische Interesse an den Phänomenen der geistig-körperlichen Einheit des Menschen nährt massiv den Zweifel am Weltbild der Leibniz-Theodizee und der Idee der Vernunftautonomie. Da sich die literarische Utopie aber in der Frühaufklärung diesem Weltbild weitestgehend angepasst hatte und eng damit verschmolzen war, droht ihr nun die generische Daseinsberechtigung entzogen zu werden, als die Leibniz-Theodizee in die Krise gerät. Literarische Utopien avancieren im späten 18. Jahrhundert zum anti-anthropologischen Textmuster schlechthin. In einer Reihe von europäischen Romanen, wie Diderots Jacques le fataliste (1796), Samuel Johnsons History of Rasselas (1759) und besonders plakativ in Voltaires Candide (1759) und in dessen deutschsprachiger Nachahmung, dem Roman Belphegor (1776) von Johann Karl Wezel, wird die Leibniz-Theodizee aufs Korn genommen. Signifikanterweise enthalten fast alle diese Romane auch parodistische Anspielungen auf die frühneuzeitliche Utopia-Tradition. ${ }^{41}$ - Es bestehen also durchaus gewisse Konstellationsparallelen zwischen dem spätaufklärerischen Anthropologie-Boom, seinen utopiekritischen Implikationen und der Utopie-Debatte der frühen 1990er Jahre.

Charakteristisch für den deutschen Anthropologie-Diskurs der Spätaufklärung ist nun aber auch die klammheimliche Furcht vor seinen eigenen Folgen: Man macht sich anthropologische Argumente zu eigen und rehabilitiert die Sinnlichkeit, wehrt sich aber gegen die letzten Konsequenzen einer solchen Denkweise und flüchtet sich nicht selten in widersprüchliche Vermittlungspositionen. Dass anthropologische Argumente auch ein Problem heraufbeschwören, wenn sie die Ideen der Rationalität, Willensfreiheit und Vernunftautonomie in Frage stellen, das

41 Vgl. dazu insgesamt Löwe: Idealstaat und Anthropologie (wie Anm. 4), S. 50-61. fällt dabei jedoch zumeist unter den Tisch. Dass hinter anthropologischen Positionen Nihilismus, Materialismus und Determinismus wie Gespenster lauern, das kaschieren Spätaufklärer nur allzu gern. Hinter jener »Rehabilitation der Sinnlichkeit « ${ }^{42}$, die sich mit Empfindsamkeit, Sturm und Drang, Anthropologie, Empirismus und Pantheismus vollzieht, verbirgt sich eine von den Akteuren zumeist unterschlagene fundamentale $>$ Krise des Wahren und des Guten ${ }^{43}$. Um diese Krise einzudämmen, stürzen sich viele Spätaufklärer in widersprüchliche Vermittlungspositionen und zwar aus Furcht vor den nihilistischen Konsequenzen jener >Rehabilitation der Sinnlichkeit‘, die sie selbst betreiben. Wie aber vermeiden Spätaufklärer, dass die Anthropologisierung der intellektuellen Diskurse, dass die >Rehabilitation der Sinnlichkeit`zur Relativität aller Normen ausartet? Indem sie die Natur, die Empirie, das Gefühl, die Geschichte oder den Menschen und seinen Körper zur neuen Norm hochstilisieren, aus der sich dann Verhaltensregeln ableiten und mit der sich Grundfragen beantworten lassen..$^{44}$

42 Panajotis Kondylis: Die Aufklärung im Rahmen des neuzeitlichen Rationalismus. Stuttgart 1981, S. 19

43 Vgl. Manfred Engel: Das \Wahre`, das `Guteく und die »Zauberlaterne der begeisterten Phantasie«. Legitimationsprobleme der Vernunft in der spätaufklärerischen Schwärmerdebatte. In: German Life and Letters 62 (2009), H. 1, S. 53-66, hier S. 60 f.

44 "[Die] traditionelle Transzendenz wurde in der Neuzeit entweder beseitigt oder in ihrer sozialen Wirksamkeit erheblich eingeschränkt, dadurch wurde aber die Spaltung zwischen Transzendenz und Immanenz nicht aus der Welt geschafft. Sie entstand von neuem, implizit zwar (denn das offene Bekenntnis zu ihr hätte als Bekenntnis zur traditionellen Transzendenz ausgelegt werden können und mußte somit aus polemischen Gründen vermieden werden), aber deutlich genug; sie meldete sich nämlich gerade innerhalb jener Immanenz, die die alte Transzendenz in den Schatten stellte, und hatte die gleiche normative Funktion zu erfüllen. Konkreter gesagt: Jene Natur, die zunächst die Immanenz im Kampfe gegen die Transzendenz Gottes vertrat, wurde bald etwas mehr als die empirische Welt, sie bekam nämlich den Status einer höheren Instanz, die die einfache Summe der wahrnehmbaren Erscheinungen transzendiert und auf höchst objektive Weise erklärt, was Gut und Böse ist. [...] Aber auch die neuzeitliche Vernunft, insofern sie die göttlichen Gebote zu ersetzen beansprucht, wird nicht empirisch verstanden, d.h. als Vernunft dieses oder jenes Menschen, sondern ebenfalls zur überpersönlichen normativen Instanz hochstilisiert, die alle empirisch gegebenen und bekannten Formen von Vernunft transzendiert - wobei ihr Sitz und Träger unbestimmt bleiben 
Die zentrale Frage bzw. das fundamentale Problem, das dabei aber nur selten offen ausgesprochen wird, lautet: Wie kann man die Anthropologie - das Wissen um die Abhängigkeit der Vernunft vom Körper und um den Konstruktcharakter der Vernunftautonomie - ernst nehmen, ohne davon auf den bloßen Illusionscharakter einer an moralischen Vernunftnormen orientierten Handlungspraxis rückzuschließen, aber auch ohne die Gefahr solcher nihilistischen Konsequenzen anthropologischen Wissens zu kaschieren oder zu verschweigen? Anders gesagt: Wie kann man theoretisch an der Vorstellung einer Subjekt- und Perspektivgebundenheit aller Wahrheiten und Normen festhalten, sich aber im lebenspraktischen Handeln dennoch an moralischen Normen orientieren?

Man kann, das mag überraschen, just die deutsche Romantik, insbesondere die Frühromantik, als Versuch verstehen, sich am Ende des 18. Jahrhunderts diesem Problem zu stellen. Romantiker halten an der Vorstellung einer perspektivunabhängigen Wahrheit fest, versuchen diese aber unter den Bedingungen einer Pluralisierung von Wahrheit zu formulieren. Romantiker glauben zwar an eine oberste Evidenz, die sie das Absolute nennen, betonen aber zugleich, dass sich das Absolute in der Erfahrungswirklichkeit nur im ewigen Verfehlt-Werden und als Mangel-Gefühl zeigt. Man kann es weder in der Natur, im Ich, im Gefühl, im menschlichen Körper oder der Kunst tatsächlich finden: „Wir suchen überall das Unbedingte, und finden immer nur Dinge « ${ }^{45}$. Man kann sich nur im Modus der Sehnsucht darauf beziehen, aber eben ohne dabei das

müssen. Tritt schließlich an die Stelle des göttlichen Primats der Primat des Menschen, so ist wiederum dieser Mensch nicht mehr der empirisch gegebene, zufällige Mensch auf der Straße, sondern die Idee des Menschen, die ihrerseits als ontologische Quelle eines Sollens fungiert, da Pflichten und Verhaltensregeln des empirischen Menschen direkt aus ihr abgeleitet werden. [...] Es ist offensichtlich und läßt sich historisch reichlich belegen, daß die neuzeitliche Transzendenz, wie sie sich auf bestimmte Schlüsselbegriffe (Natur, Vernunft, Mensch) konzentriert, in sozialer Hinsicht ähnlich fungiert wie die alte. Unter Berufung auf sie wird die jeweilige Wertskala aufgestellt, und Herrscher ist, wer sie jeweils verbindlich interpretieren kann. Nicht wesentlich anders war es früher um die (offen) transzendente Idee Gottes bestellı«. (Kondylis: Die Aufklärung, wie Anm. 42, S. 58 f.) Vgl. zudem Löwe: Idealstaat und Anthropologie (wie Anm. 4), S. 45-50. 45 Novalis: Schriften. Die Werke Friedrich von Hardenbergs. Bd. 2: Das philosophische Werk I. Hrsg. von Richard Samuel in Zusammenarbeit mit Hans-Joachim Mähl und Gerhard Schulz. Revidiert von Richard Samuel und Hans-Joachim Mähl. Stuttgart ${ }^{3}$ 1981, S. 412 (Hervorhebung im Original).
Sehnsuchtsziel - etwa in Form utopischer Entwürfe - zu positivieren. In den Fichte-Studien findet sich eine Aufzeichnung, in der Novalis mit wenigen Sätzen die zentrale Problemkonstellation der Romantik umreißt:

Alles Filosofiren muß also bey einem absoluten Grunde endigen. Wenn dieser nun nicht gegeben wäre, [...] so wäre der Trieb zu Filosophiren eine unendliche Thätigkeit [...]. Durch das freywillige Entsagen des Absoluten entsteht die unendliche freye Thätigkeit in uns - das Einzig mögliche Absolute, was uns gegeben werden kann und was wir nur durch unsre Unvermögenheit ein Absolutes zu erreichen und zu erkennen, finden. Dies uns gegebne Absolute läßt sich nur negativ erkennen, indem wir handeln und finden, daß durch kein Handeln das erreicht wird, was wir suchen[.] $]^{46}$

Romantiker versuchen zwar, utopische Ideale wie Gott, Freiheit oder Totalität zu vergegenwärtigen, zugleich aber den regulativen Charakter dieser Ideen zu kommunizieren. Die Vergegenwärtigung darf daher nicht zur »illusionären Identifizierung mit der Realität« werden, romantische Bildlichkeit darf nie "so >hinreißend sein«, daß dabei Bild und Idee verwechselt werden, aber sie »soll trotzdem `Begeisterung ( für das Ziel erwecken ${ }^{47}$ Die Funktion und Zielsetzung von romantischer Ästhetik gleicht damit jener Quadratur des Zirkels, der sich zwangsläufig auch eine Form des utopischen Denkens aussetzt, die versucht den Kommunikationsbedingungen offener Gesellschaften zu entsprechen.

Das, was Romantiker >romantisieren « nennen, kann man als Reaktion auf die Anthropologisierung der spätaufklärerischen Diskurse und den Zweifel an der Möglichkeit von objektiver Erkenntnis verstehen. Der damit einhergehenden Nihilismus- und Skeptizismusgefahr begegnet der spätaufklärerische Mainstream, indem er die Empirie zur neuen Norm hochstilisiert. Dies erklärt auch die Abneigung vieler Spätaufklärer gegen außerempirische utopische Entwürfe, denn über die Erfahrung hinaus führt aus Sicht eines empiristisch imprägnierten Intellektuellen kein Weg, dort lauert allenfalls der Abgrund utopischer Schwärmerei. Romantisieren dagegen meint eine ästhetische Operation, die nicht darin besteht, die empirische Wirklichkeit zur Norm hochzustilisieren,

46 Ebd., S. 269 f. (hier Nr. 566).

47 Ludwig Stockinger: Romantik und Katholizismus. Untersuchungen zur Ästhetik der 'katholischen Literatur` und zu ihren Anfängen bei Joseph von Eichendorff. Habil. masch. Universität Kiel 1988, S. 286. 
sie aber auch nicht zu transzendieren, sondern sie augenzwinkernd in ein anderes Licht zu rücken:

Das niedre Selbst wird mit einem bessern Selbst in dieser Operation identificirt. [...] Indem ich dem Gemeinen einen hohen Sinn, dem Gewöhnlichen ein geheimnißvolles Ansehn, dem Bekannten die Würde des Unbekannten, dem Endlichen einen unendlichen Schein gebe so romantisire ich es $[. . .]^{48}$

Niederes Selbst bedeutet hier so viel wie der `empirische Mensch`, dessen Handeln und Denken von diffusen Gefühlen, körperlichen Zuständen, Umwelteinflüssen, Einbildungen und seinen sozialen Rollen abhängt. Besseres Selbst dagegen meint die `Idee des Menschen`, der in der Lage ist moralisch frei und nicht interessengebunden oder nur nach Lust und Unlust zu handeln. Romantiker nehmen also die anthropologischen Einwände gegen den Rationalismus ernst, aber auch die mit solchen Argumenten verbundene Gefahr, in Skeptizismus oder einen neuen Normativismus der Empirie abzurutschen. Sie konzipieren daher mit der ästhetischen Operation des Romantisierens eine Art ethische `Starthilfe`, die eine Möglichkeit bietet, hypothetisch über jene Widrigkeiten hinwegzusehen, die die empirische selbstbezogene Natur des Menschen seinem `besseren Selbst entgegenstellt. Der ethische Effekt von Transzendentalpoesie besteht also vor allem in der spielerischen Überwindung des Anfangsproblems, das sich zwangsläufig ergibt, wenn man sich nur an anthropologischem Wissen und den Erfahrungstatsachen über die Natur des Menschen orientiert. Zugleich impliziert Romantisieren aber immer auch ein skeptisches Bewusstsein von der unüberbrückbaren Distanz zwischen Wirklichkeit und Idee, zwischen dem gewöhnlichen, eigennützigen Alltags-Ich und dem besseren Selbst. Die ästhetische Operation des Romantisierens ist mithin weniger eine Lösung für das Problem, wie man unter wahrheitspluralistischen Bedingungen handlungsorientierende utopische Normen begründen kann, sondern eher eine Reflexion dieses Problems in seiner Unlösbarkeit. Es stellt sich dabei ja beständig die Frage, wie man an eine handlungsorientierende Wahrheit glauben und zugleich um deren Konstruktcharakter wissen kann. Schelling hat die dabei zum Tragen kommende, unendlich-inverse Grundfigur romantischen Denkens in seinen Philosophischen Briefen über Dogmatismus und Kriticismus (1795) einmal so formuliert:

48 Novalis: Schriften (wie Anm. 45), S. 545 (hier Nr. 105).
Wir müssen das sein, wofür wir uns theoretisch ausgeben wollen, daß wir es aber seien, davon kann uns nichts, als unser Streben, es zu werden, überzeugen. [...] Wir müssen uns selbst da hinauf gearbeitet haben, von wo wir ausgehen wollen. ${ }^{49}$

Hier wird eine paradoxe Münchhausenoperation beschrieben: Ein Romantiker, so kann man pointiert sagen, strebt nach einer Wahrheit, die eigentlich nur durch sein Streben entsteht. Bei Romantik handelt es sich um den Versuch einer Kommunikation über utopische Normen, die mit der Subjektgebundenheit aller Wahrheit rechnet und daher bereit ist, auch die eigene Position aufs Spiel zu setzen. ${ }^{50}$

\section{UNLÖSBARE PROBLEME: UTOPISCHES DENKEN UND WAHRHEITSPLURALISMUS IM GLOBALEN KONTEXT}

Die scheinbar hypertrophen Reflexionen der Romantiker helfen, so meine ich, jenes Grunddilemma etwas besser zu verstehen, in dem das vielfach totgesagte, im Grund aber niemals verblichene utopische Denken heute steckt: Jene Gemeinschaft von Akteuren, die man als westliche Welt bezeichnet, konstituiert sich überhaupt erst durch den gemeinsamen Bezug auf den utopischen Entwurf einer möglichen Zukunft, nämlich die Utopie einer Weltgesellschaft auf Basis der Menschenrechte und der Toleranzforderung. Samuel Moyn hat die Menschenrechte daher kürzlich einmal treffend "the last Utopia ${ }^{51}$ genannt und mit dieser offiziellen Utopie westlicher Politik werden in der Gegenwart bekanntermaßen nicht wenige politischen Handlungen legitimiert. ${ }^{52}$ Das Problem bei der westlichen

49 Friedrich Wilhelm Joseph Schelling: Historisch-Kritische Ausgabe. Bd. I.3. Hrsg. von Hartmut Buchner, Wilhelm G. Jacobs und Annemarie Pieper. Stuttgart 1982, S. 75 f. (= 6. Brief).

50 Meine Romantikdeutung verdankt sich in wesentlichen Punkten den Arbeiten des Tübinger Philosophen Manfred Frank: Zu Franks Romantikverständnis, zu Einwänden, die dagegen vorgebracht wurden, und zu Basisannahmen des romantischen Diskurses insgesamt vgl. Löwe: Idealstaat und Anthropologie (wie Anm. 4), S. 261-297.

51 Samuel Moyn: The Last Utopia. Human Rights in History. Cambridge (Massachusetts) und London 2010.

52 Vgl. Michael Ignatieff: Die Politik der Menschenrechte. Aus dem Englischen übersetzt von Ilse Utz. Hamburg 2002, hier insbesondere das Kapitel »Menschenrechte als Fetisch«, S. 74-114. 
Utopie einer menschenrechtsbasierten Weltgesellschaft ist allerdings, dass hier eine, global gesehen, partikuläre Gruppe von Akteuren eine utopische Norm formuliert, die für die gesamte Menschheit gelten soll. $\mathrm{Zu}$ dieser utopischen Norm gehört jedoch ausgerechnet ganz wesentlich die Toleranzforderung, die Anerkennung der Würde des Anderen und seiner Freiheitsspielräume, was zwangsläufig auch eine Relativierung des eigenen Standpunkts impliziert. Die westliche Utopie einer menschrechtsbasierten Weltgesellschaft produziert also eine Schwierigkeit oder Aporie, wenn sie versucht, das Prinzip einer Relativierung des eigenen Standpunkts zu universalisieren. ${ }^{53}$ Die Folge dieser aporetischen Vermittlung zwischen Relativismus und Universalismus in der westlichen MenschenrechtsUtopie sind die bekannten interkulturellen Konflikte etwa mit jenen Teilen der islamischen Welt, die der westlichen Utopie eben nicht zustimmen können, weil sie z.B. im westlichen Begriff der Menschenwürde nichts Universelles, sondern etwas Kulturspezifisches erblicken, eine mit dem Koran so nicht ganz vereinbare Vergottung des Menschen. ${ }^{54}$

Man muss sich also, das kann man festhalten, um das utopische Denken gar keine Sorgen machen, es existiert nach wie vor und sogar im ganz großen Stil. Utopisches Denken verstrickt sich aber unter den Bedingungen von wahrheitspluralistischen Gesellschaften fast zwangsläufig in Aporien, denen man kaum entkommt, die man sich nur immer wieder vor Augen führen kann.

\section{GRUNDLEGUNGEN DES UTOPISCHEN MÖGLICHKEITSDENKENS}

53 Vgl. Panajotis Kondylis: Das Politische im 20. Jahrhundert. Von den Utopien zur Globalisierung. Heidelberg 2001, S. 45-67.

54 Vgl. Ignatieff: Politik der Menschenrechte (wie Anm. 52), hier insbe-

sondere den Abschnitt »Die islamische Herausforderung«, S. 79-82. 


\title{
ARBOGAST SCHMITT
}

\section{DER STAAT ALS MÖGLICHKEITSRAUM INDIVIDUELLER SELBSTENTFALTUNG \\ BEI PLATON}

\author{
I. DIE LOGISCHEN VORAUSSETZUNGEN DER PLATONISCHEN \\ SEELENTEILUNGSLEHRE
}

In den ersten Büchern des Staats versuchte Platon, ausgehend von der Frage, weshalb die Menschen überhaupt ein Leben in einer größeren Gemeinschaft suchen, zu klären, wie das Verhältnis der Einzelnen zur Gemeinschaft gestaltet sein muss, damit jeder dem eigenen Antrieb folgen und zugleich in gutem Verhältnis mit anderen leben kann.

Wenn ein Staat mit dieser Zielsetzung erfolgreich existieren soll, müssen verschiedene Bedingungen erfüllt sein.

Es muss in ihm Menschen geben, die

1) ihre Grundbedürfnisse zur Lebenserhaltung in Übereinstimmung mit den Bedürfnissen des ganzen Menschen erfüllen können. (Dem besten Verhalten solcher Menschen spricht Platon die `Tugend ‘ der Sophrosyne zu. Das ist die >Tugend, durch die der Mensch in der Lage ist, seine eigenen Bedürfnisse im Hinhören auf die Vernunft zu befriedigen.),

2) sich für die Anerkennung der Selbstverwirklichungsrechte der einzelnen Bedürfnisse in funktionaler Hinordnung auf den ganzen

1 Das Folgende ist die gekürzte und auf das Thema der Tagung zugeschnittene Fassung von: Arbogast Schmitt: Gerechtigkeit als Recht zur Selbstverwirklichung bei Platon. In: Gert Melville, Mirko Breitenstein, Gregor Vogt-Spira (Hrsg.): Verlangen nach Vollkommenheit. Europäische Konzepte und Praktiken im Wandel. Band 1: Gerechtigkeit(en). Erscheint Stuttgart 2013. 
Menschen einsetzen. (Dem besten Verhalten solcher Menschen spricht Platon die Tugend der Tapferkeit - im Leben der staatlichen Gemeinschaft als Zivilcourage wie bei ihrer Verteidigung nach außen - zu),

3) sich für das für den ganzen Menschen Gute in freier Verfügung über die Vernunft engagieren (Diesen Menschen sprich Platon die >Tugend ‘ der Wohlberatenheit, Euboulía, Sophía, zu).

Diese unterschiedlichen Verhaltensweisen können, wie Sokrates betont (435e), nur durch Unterschiede der individuellen Menschen selbst in die Gemeinschaft gekommen sein. Die Folge muss also sein, dass auch der einzelne Mensch über diese verschiedenen Handlungsfähigkeiten verfügen muss, wenn er in der Lage sein soll, sich selbst erfolgreich zu entfalten.

Die Klärung der Frage, ob auch der einzelne Mensch schon in sich die Grundbedingungen hat, aus denen sich die Verschiedenheit der Menschen im Staat ergibt, beginnt Platon mit einer Art logischem Vorspiel. Die Frage, deren Klärung die Voraussetzung zur Klärung der Unterschiede in der menschlichen Psyche ist, lautet nach Platon:

Ist die menschliche Psyche eine Einheit in dem Sinn, dass sie mit nur einem Vermögen zu allem befähigt ist, oder muss man annehmen, dass sich eben die Unterschiede, Sokrates spricht von seide` und sethe`, von im Charakter begründeten Handlungs->Arten`, die es in der Gemeinschaft gibt, auch im einzelnen Menschen finden (435e)?

Zur Beantwortung dieser Frage geht Sokrates von einer allen leicht zugänglichen Erfahrung aus.

Dass wir in unseren Handlungen nicht nur den Bedürfnissen zur Selbsterhaltung folgen, belegt der Befund, dass es häufig vorkommt, dass wir Bedürfnisse, die wir haben, selbst elementare Bedürfnisse wie Hunger und Durst, nicht befriedigen, etwa dann, wenn vernünftige, z. B. medizinische Gründe dagegen sprechen.

Diese übliche Erfahrung mit scheinbar widersprüchlichen Tendenzen in uns konfrontiert Sokrates mit einem Grundkriterium, über das das Denken von sich aus verfügt und das es auf seine Erfahrungen anwendet: mit dem Nichtwiderspruchsaxiom.

Anders als wir es von einer nachcartesianischen Auslegung her gewohnt sind, hat dieses Axiom für Platon allerdings einen heuristischen Charakter. Er formuliert:

Da offenkundig ein und dasselbe Gegensätzliches nicht zugleich tun oder erleiden kann - jedenfalls in Bezug auf dasselbe und in
Relation zu demselben - wissen wir, dass dort, wo wir finden, dass dies geschieht, es nicht eines und dasselbe war, sondern mehreres $(436 b){ }^{2}$

Von den Beispielen, an denen Platon die Anwendung dieses Kriteriums erläutert, hat das Beispiel vom Kreisel, der an ein und derselben Stelle stehen bleibend sich zugleich dreht (436d-e), am meisten Eindruck gemacht (er selbst hat es dreimal wiederholt). Dieses Phänomen beweist nach Platon nicht, dass sich der Satz vom Widerspruch auf die wirkliche Welt nicht anwenden lässt, die einer >zweiwertigen Logikı nicht folgt, es verweist vielmehr darauf, dass der, der meint, an dem zugleich stehenden und sich bewegenden Kreisel ein Beispiel für einen sdaseienden Widerspruch $\mathrm{zu}$ haben, es an einer Unterscheidung hat fehlen lassen. Denn wenn er beachtet, dass seine Meinung, ein und dasselbe bewege sich und ruhe zugleich, dem Kriterium, dass etwas nicht zugleich es selbst sein und nicht sein kann (in Relation zum selben usw.) zuwiderläuft, dann weiß er, dass er nach einer Unterscheidung verschiedener Hinsichten oder Relationen suchen muss, in Bezug auf die ein und derselbe Kreisel steht und sich bewegt. Z. B. kann man an einem aufrecht stehenden Kreisel die in der Senkrechten verharrende Höhe von der kreisförmigen Peripherie unterscheiden und so feststellen, dass es gar nicht der Kreisel ist, der steht und sich dreht, es steht vielmehr die Höhe und es dreht sich die Peripherie.

Einen Widerspruch gibt es also gerade nach Platon immer nur in unseren Urteilen, in der ,Wirklichkeit ‘ kann es Gegensätze, Widerstreitendes, Vermischtes geben, keinen Widerspruch. Die Aufgabe, die bei der Feststellung eines Widerspruchs zu erfüllen ist, ist daher immer, die Zuweisung der einander widersprechenden Prädikate an ein und dasselbe Subjekt zu überprüfen. Nicht der Kreisel steht und bewegt sich, sondern

2 Zur immer noch vertretenen These, Platon habe gar nicht das - erst von Aristoteles formulierte - >Prinzip des ausgeschlossenen Widerspruchs vertreten, sondern lediglich ein >Prinzip der Gegensätze` (siehe Richard Robinson: Plato's Separation of Reason from Desire. In: Phronesis 16 [1971], S. 38-49, hier S. 39; und siehe jetzt wieder Jörn Müller: Ontologie. In: Christoph Horn, Jörn Müller, Joachim Söder [Hrsg.]: Platon Handbuch: Leben - Werk - Wirkung. Stuttgart, Weimar 2009, S. 145), siehe Arbogas Schmitt: Die Bedeutung der sophistischen Logik für die mittlere Dialektik Platons. Würzburg 1974, S. 122-128; ders.: Die Moderne und Platon. Stuttgart ${ }^{2} 2008$, S. 215-269. 
die Höhe des Kreisels steht, die Peripherie bewegt sich, oder die Stelle, an der der Kreisel steht, bleibt unverändert, die Selbstbewegung aber ändert sich usw. ${ }^{3}$

In analogem Sinn muss man beim Menschen verfahren, bei dem man beobachtet, dass er zugleich zu trinken begehrt und dieser Begierde doch widersteht. Wenn dieses Widerstehen tatsächlich sin Bezug auf dasselbe und in Relation zu demselben`, d. h. genau auf das Begehren zu trinken gerichtet ist (und nicht etwa darauf, dass man die bittere Arznei nicht, den guten Wein aber sehr wohl trinken will), dann machen diese gegensätzlichen Strebungen in ein und demselben Menschen eine Unterscheidung nötig. Offenbar ist es nicht dasselbe, mit dem wir zu trinken begehren und mit dem wir diesem Begehren widerstehen. Das eine muss vielmehr als ein sinnliches Bedürfnis, das andere als ein rationaler Gegenwille verstanden werden. Nicht >der Mensch oder >der Kranke will zugleich trinken und nicht trinken, sondern sein sinnliches Begehren strebt nach einem Getränk, sein Wille, gesund zu werden, hält dieses Begehren zurück.

3 Platons Umgang mit dem Widerspruchssatz unterscheidet sich dadurch signifikant von seiner Auslegung in der neueren, z. B. sprachanalytischen Logik. Wenn behauptet wird, das Widerspruchsprinzip besage, dass von zwei Aussagen, von denen die eine die Negation der anderen ist, mindestens eine der beiden Aussagen falsch sein und - in einer starken Auslegung die andere wahr sein müsse, dann ist es unzulässig, dieses `Prinzip zur Beurteilung von Platons Umgang mit dem Widerspruchssatz oder -prinzip zu nehmen. Bei Platon können die beiden Sätze >Der Kreisel steht $\triangleleft$ und `Der Kreisel steht nicht « beide wahr oder beide falsch sein. Der Satz ১Der Kreisel steht $\triangleleft$ schließt die Wahrheit des anderen >Der Kreisel steht nicht $\iota$ nur dann aus, wenn er ungenügend differenziert verstanden wird, d.h. wenn er als Aussage über den Kreisel als ganzen genommen wird. In einem solchen Verständnis sind beide Aussagen falsch. Wird dagegen das Subjekt der Aussagen präzisiert: `Die Höhe des Kreisels bewegt sich nicht` und `Die Peripherie des Kreisels bewegt sich sind beide Aussagen (Der Kreisel steht, der Kreisel bewegt sich) wahr. Der Widerspruchssatz dient nicht zu einer Schlussfolgerung über die Wahrheit oder Falschheit des jeweils anderen Satzes, sondern ist Anlass einer Differenzierung der Subjekte, denen ein Prädikat zugesprochen wird. Siehe dagegen z. B. Franz von Kutschera: Platons Parmenides. Berlin 1995 (passim) und jetzt wieder Uwe Meixner: ,Widerspruch(sprinzipien). In: Christian Schäfer (Hrsg.): Platon-Lexikon: Begriffswörterbuch zu Platon und der platonischen Tradition. Darmstadt 2007, S. $328 \mathrm{f}$.

\section{DIE BEGRÜNDUNG DER DIFFERENZIERUNG}

DER MENSCHLICHEN PSYCHE

A) ZWISCHEN SINNLICHEM BEGEHREN UND VERNÜNFTIGEM WOLLEN: DAS SICH-EREIFERNDE ('THYMOEIDÉS`)

Bevor wir uns der Frage zuwenden, welche >Arten seelischen Verhaltens Platon mit der Unterscheidung verschiedener Strebetendenzen im Menschen bezeichnet wissen wollte, müssen wir noch die dritte Art beachten, die in modernen psychologischen Systemen kaum einen Ort, ja in modernen westlichen Sprachen nicht einmal eine Bezeichnung hat. Platon macht nämlich deutlich, dass sinnliche Bestrebungen keineswegs immer gleich vom Verstand zurückgehalten werden. Im Gegenteil, wenn einer meint, dass ihm ein Unrecht geschehe, d. h. wenn er sich in dem, was ihm zusteht und was er selbst in eigener Kompetenz kann, gehindert fühlt, dann, so sagt er, »kocht es in ihm und er ist empört und kämpft für das, wovon er meint, dass es sein Recht sei, und hungert lieber und dürstet, als darauf zu verzichten, sich durchzusetzen« (440c-d).

Dass dieser Kampf für das eigene Recht, der oft dazu führt, dass wir unsere sinnlichen Bedürfnisse unterdrücken und auf sinnliche Lüste verzichten, nicht immer ein Kampf der Vernunft gegen die Sinnlichkeit ist, sehe man auch daran, dass sogar ganz kleine Kinder schon sich heftig ereiferten, zu einer freien Verfügung über die Vernunft würden dagegen manche nie fähig, die meisten erst spät (441a-b), das Sich-Ereifern aber ist etwas, was den Menschen von der Geburt bis zum Tod begleitet.

ACHILL ALS BEISPIEL

Platon steht mit dem Konzept eines `Sich Ereifernden $\varsigma^{4}$ im Menschen in einer bis auf Homer zurückgehenden Tradition. Bereits bei Homer gibt es einen `Thymós‘, der eben diese Zwischenstellung hat, die Platon in der Politeia beschreibt. Das bekannteste Beispiel bietet Achill. Agamemnon wollte zum Schaden des ganzen Unternehmens vor Troia auf eine Geliebte nicht verzichten, die er aber, weil sie Tochter eines

4 Der ganze Komplex des thymetischen Denkens bei Platon ist jetzt gründlich und mit umfassenden Belegen aufgearbeitet bei Wolfram Brinker: Platons Ethik und Psychologie. Philologische Untersuchungen über thymetisches Denken und Handeln in den platonischen Dialogen. Frankfurt a. M. 2008. 
Apollonpriesters war, nicht hätte rauben dürfen. Achill war der einzige, der den Mut hatte, Agamemnon entgegenzutreten. Das verärgerte Agamemnon so sehr, dass er Achill sagt, er brauche ihn gar nicht, er könne ruhig nach Hause fahren. Achill, der seit 9 Jahren allein Grund dafür ist, dass die Troianer einen offenen Kampf mit den Griechen nicht wagen, ist darüber so empört, dass er, wie Homer formuliert, in seinem Herzen (das ist der Ort, an dem der Thymos lokalisiert ist) hin und her überlegt, ob er sich jetzt noch beherrschen soll oder nicht lieber gleich zum Schwert greifen und Agamemnon niederstechen soll (Ilias, 54-218).

Achill überlegt` also, aber das, was er überlegt, ist Teil einer leidenschaftlichen Erregung in ihm, deren Ziel auch keineswegs vernünftig ist, denn sie endet damit, dass Achill bereits zum Schwert greift. Dieser Mangel an Vernunft im `Hin-und-her-Überlegen ^Achills wird bei Homer dadurch deutlich, dass er in diesem Augenblick die Göttin der Vernunft, Athene, eingreifen und Achill raten lässt, nicht zum Schwert zu greifen. Achill hört auch auf Athene und lässt sich überreden, von einem Königsmord abzulassen, ohne freilich seinen empörten Rachedurst ganz aufzugeben. ${ }^{5}$

Dieser sich ereifernde Thymos bei Homer hat eine ähnliche Mittelstellung, wie sie noch Platon dem >Thymoeidés ' gibt: Er ist keine sinnliche Begierde, Achill wendet sich sogar gegen die Erfüllung einer sinnlich erotischen Begierde, wenn auch nicht aus irgendwelchen asketisch-moralischen Gründen, sondern weil sie zu einer Schädigung der Gemeinschaftsanliegen führt. Dieser Thymós hat selbst eine Fähigkeit zu denken, sein Denken steht aber im Dienst der Sache, für die er sich ereifert. Er hat aber immerhin die Fähigkeit, auf die Vernunft zu hören und wohl sogar eine gewisse Tendenz, ihr zu folgen, wenn auch mit der Beschränkung, dass er den Blick von dem vermeintlich Guten, der >Bestrafung A Agamemnons, nicht abwenden kann. Darauf nimmt Homers Athene Rücksicht und rät ihm lediglich, sich auf andere Weise als durch einen Königsmord Genugtuung zu verschaffen.

Legt man diesen Vorgang auseinander und reflektiert auf die verschiedenen psychischen Akte, die in ihm zusammenlaufen, findet man als Beginn einen Erkenntnisakt. Achill erkennt in Agamemnons Rede eine unerhörte Erniedrigung und Verachtung (seiner großen Leistungen

5 Siehe Arbogast Schmitt: Selbständigkeit und Abhängigkeit menschlichen Handelns bei Homer. Stuttgart 1990, S. 76-82. für die Gemeinschaft). Diese Erkenntnis ist von einem großen seelischen Schmerz begleitet: "áchos génet « heißt es bei Homer $(1,188)$. >Achos` ist ein starker, seelischer Schmerz, der den Menschen plötzlich durchfährt, ${ }^{6}$ er kommt nicht zur Erkenntnis der Schamlosigkeit Agamemnons hinzu, sondern ist unmittelbar mit ihr da. Eben dieses mit der Erkenntnis verbundene Schmerzgefühl aber treibt Achill zu einer >Überlegung` in die Zukunft: Er sucht nach einer Befreiung von diesem Schmerz und wird von der Vorstellung dieser zukünftigen Lust $^{7} \mathrm{zu}$ einem Streben und von diesem unmittelbar zum Handeln gedrängt - er greift zum Schwert.

Die Reihenfolge der psychischen Akte ist also:

1) Erkenntnis (hier: eine Meinung über ein Unrecht),

2) mit der Erkenntnis unmittelbar empfundenes (Unlust-)Gefühl,

3) Entwicklung eines Strebens nach Befreiung von diesem Unlustgefühl durch die Vorstellung einer Befreiungsmöglichkeit,

4) Handlung (Achill greift zum Schwert).

\section{B) DIE PLATONISCHE ANALYSE DER AKTKOMPONENTEN}

DES ITHYMOEIDÉS,

Bei Platon finden wir die im Thymos zusammenwirkenden Akte in angemessener Begrifflichkeit explizit beschrieben:

Die Erkenntnisweise des >Thymoeidés`, der seelischen Verhaltensweise, bei der man sich für sein /Werk « ereifert, ist das Meinen. Die mit diesem >Meinen verbundenen Gefühle sind Gefühle, die mit dem Gelingen, der Behinderung oder dem Scheitern der erstrebten Selbstverwirklichung verbunden sind. Das sind also Gefühle, die aus der gewonnenen oder verweigerten Anerkennung in der Gemeinschaft entstehen, besonders Empörung und Zorn über erlittenes Unrecht, aber auch viele andere Gefühle, die alle schon bei Homer dem Thymós zugeschrieben werden: »Freude und Verärgerung, Schmerz, Leid, Schreck und Schock, Raserei, Angst, Scham oder Scheu, Härte und Unbeugsamkeit, Tapferkeit und Feigheit, Wohlwollen, Gnade, Mitleid oder Rücksichtnahme, [...] Stolz, Ehre, $[\ldots] . \ll^{8}$

6 Siehe Lexikon des Frühgriechischen Epos, Bd. 1. Göttingen 1979, Sp. 1766-1774 s. v. >achos` und ‘achnymai< bearbeitet von Eva-Maria Voigt. 7 Diese Lust als Movens des Zorns exemplifiziert Platon selbst an Achill. Siehe Philebos 47d-48b3. Siehe dazu Brinker: Platons Ethik und Psychologie. Frankfurt a. M. 2006, S. 222.

8 Siehe die Zusammenstellung bei Brinker: Platons Ethik und Psychologie (wie Anm. 7), S. 22. 
Aus diesen Gefühlen der Lust oder Unlust entsteht durch die Vorstellung, sie in Zukunft weiterbehalten zu können oder zu müssen bzw. sie neu wieder zugewinnen oder abzuwehren, ein Streben, also eine Willensart, die zur Handlung drängt. ${ }^{9}$

Auch wenn diese Willensform, die Platon das \Thymoeidés` (die Willensart, die ein Sich-Ereifern ist) nennt, kaum eine eigene Bezeichnung in modernen westlichen Sprachen hat, geschweige denn, dass sie in psychologische Lehrbücher eingegangen wäre, sie benennt eine psychische Verhaltensweise, für die es reiche Erfahrungsmöglichkeiten gibt.

Viele Verhaltensweisen, bei denen wir auf sinnliche Lüste oder Begierden verzichten oder ihnen entgegentreten, sind keineswegs eben wegen dieser Unterdrückung der Sinnlichkeit bereits vernünftig.

Viele fasten mehr, als medizinisch gut für sie ist, aus nur ästhetischen Gründen, viele überarbeiten sich aus reinem Ehrgeiz, usw. Im 19. Jahrhundert haben viele in Duellen ihr Leben aufs Spiel gesetzt - um einer falsch verstandenen Ehre willen. Auch heute finden wir Fremdenhass, Rassenhass, die Selbstaufopferung um missverstandener politischer oder religiöser Ziele willen, aber auch die Selbstaufopferung im Dienst der Hilfe für andere, für Freiheit, für die Gemeinschaft, das Vaterland usw.

Alle diese Verhaltensweisen sind nicht von sinnlichen Lüsten oder Begierden bewegt, aber sie sind auch nicht von sich her schon vernünftig. Auch wenn sie eine gewisse Freiheit von sinnlichen Bedürfnissen voraussetzen und deshalb in guter Bildung geeignet sein könnten, auf die Vernunft zu hören, es ist nicht selten die Fixiertheit des Blicks auf ein nur vermeintliches Gut der Selbstverwirklichung, die die Kraft der Beherrschung der Sinnlichkeit bietet.

Diese Zwischenstellung zwischen Sinnlichkeit und Vernunft ist der Grund, weshalb Platon der Ausbildung des Thymoeidés und der Gruppe im Staat, die in besonderer Weise von ihm geprägt ist, eine intensive gymnastisch-musische Ausbildung verordnet. Sie wäre aber in der von ihm erörterten Weise unmöglich, wenn das Thymoeidés nur eine Art Wille wäre, der ein eigenständiges, sselbstursprüngliches` Vermögen neben Verstand und Gefühl wäre. Diese um die Mitte des 18. Jahrhunderts (wieder) neu eingeführte Einteilung der psychischen Vermögen in Verstand, Wille und Gefühl ist immer wieder zur Erklärung der drei Arten

9 Zur analogen Analyse der Strebeformen in der menschlichen Psyche siehe Viviana Cessi: Erkennen und Handeln in der Theorie des Tragischen bei Aristoteles. Frankfurt a. M. 1987, S. 136-161. seelischer Aktivität bei Platon angewendet worden und war Anlass zu vielen Missverständnissen bzw. zu vieler Kritik an Platon. ${ }^{10}$

Das Thymoeidés ist aber, wie schon deutlich geworden ist, kein Wille in irgendeinem modernen (oder hellenistischen) Sinn. Es steht nicht selbständig neben Verstand und Gefühl und kann wegen dieser Unabhängigkeit mit beiden, aber auch gegen beide agieren und sich so gegen das vom Verstand Eingesehene wenden oder gegen etwas vom Gefühl Empfundenes kämpfen. Das Thymoeidés ist zwar offenkundig eine Strebe- oder Willensform, aber es ist gerade als Willensform etwas Komplexes, eine Einheit aus mehreren psychischen Akten.

C) DIE ıARTEN` (EÍDE) SEELISCHEN VERHALTENS ALS DREI VERSCHIEDENE WEISEN DES ERKENNENS, FÜHLENS UND WOLLENS

Die Komplexität, die man beim Thymoeidés feststellen kann, gilt, wie man in der neueren Forschung mehrfach belegt und - nicht ganz konsequent zu Ende - diskutiert hat, für alle drei seelischen->Arten bei Platon. Auch das Begehrliche (Epithymetikón, genauer: das zum Begehren Fähige, Geeignete, Geneigte) erkennt etwas, fühlt etwas und will etwas. Dasselbe gilt vom `Logistikón`. Anders als der Name nahelegt, ist es in der Politeia nicht als ein reines Denkvermögen beschrieben, sondern auch es hat eine bestimmte Form des Erkennens, Fühlens und Wollens. ${ }^{11}$

Logistikón, Thymoeidés und Epithymetikón unterscheiden sich also nicht dadurch, dass das eine denkt, das andere will, das dritte fühlt, sondern durch je verschiedene Weisen des Denkens, Fühlens und Wollens. Wie die etwas ausführlichere Behandlung des Thymoeidés gezeigt hat, ist das Thymoeidés eine Einheit aus Mehrerem, es ist eine bestimmte

10 Zum Verhältnis der neuzeitlichen, im 18. Jahrhundert erneuerten Dreiteilung der `Seelenvermögen ‘ in Verstand, Gefühl und Wille zu der platonisch-aristotelischen Differenzierung der verschiedenen Willensformen siehe Arbogast Schmitt: Poetik. Berlin 2011, S. 334-348.

11 Siehe v. a. Politeia 580c-588a; s. a. 441c; siehe dazu Jon Moline: Plato on the Complexity of the Psyche. In: Archiv für Geschichte der Philosophie 60 (1978), S. 1-26; siehe jetzt aber vor allem - mit angemessener Erklärung Stefan Büttner: Die Literaturtheorie bei Platon und ihre anthropologische Begründung. Tübingen und Basel 2000, S. 26-110; zur Begründung, weshalb die drei Seelen->Teile bei Platon drei Willensformen sind siehe auch Arbogast Schmitt: Der Einzelne und die Gemeinschaft bei Homer und in der Staatstheorie bei Platon. Stuttgart 2000. 
Form des Wollens, die das Produkt aus bestimmten Akten des Erkennens und Fühlens ist.

Analog ist es beim Epithymetikón. Seine Erkenntnisweise ist das Wahrnehmen. Seine `Gefühle sind die unmittelbar beim Wahrnehmen und durch es empfundenen Lüste oder Unlüste. Sein Wille ist ein Begehren, das - vermittelt durch die Vorstellung und ihren Zukunftssinn - die empfundene Lust festhalten oder wieder genießen will bzw. das die mit der Wahrnehmung verbundene Unlust abwehren oder nicht noch einmal haben will. Es ist also als Ganzes eine Willensform, als solche aber ein Komplex aus verschiedenen seelischen Akten und nicht ein einfaches, allein aus sich tätiges Vermögen des Gefühls (diese Deutung ist schon dadurch ausgeschlossen, dass das Epithymetikón etwas begehrt und nicht nur fühlt).

Auch das Logistikón hat neben dem Erkennen Formen des Fühlens und Wollens und bildet seinerseits die Einheit aus diesen drei in ihr zusammenwirkenden Akten. Das heißt, auch es ist als ganzes ein Wille.

D) DIE ERKENNTNISVORAUSSETZUNGEN DES WOLLENS

Zum genaueren Verständnis muss man beachten, dass bereits die Wahrnehmung für Platon eine selbständige, aktive Erkenntnisleistung erbringt. ${ }^{12}$ Die Erkenntnisleistung der Wahrnehmung hat allerdings enge Grenzen. Das Sehvermögen kann Farben und Formen, das Hörvermögen Töne unterscheiden, usw. Die Fähigkeit, auch zu erkennen, was ein bestimmtes farbiges Gebilde ist, hat das Auge nicht, es muss vom Verstand darüber belehrt werden, was dieses farbige Phänomen kann und leistet. Aber das Auge kann Farben, das Ohr kann Töne zusammensetzen, und so kann man (d.h. der Mensch mit Hilfe von Auge und Ohr) z.B. eine von einer Farbe umgrenzte Gestalt (`Schemas) sehen bzw. die Dauer eines Tons oder einen Akkord hören.

Auch wenn diese bereits synthetisierende Leistung der Wahrnehmung noch nicht hinreicht, um aus den Wahrnehmungsdaten auf einen Gegenstand zu schließen, den man erst an seinem >Ergon` begreift, man könnte auch einen nur wenige Sekunden dauernden Ton nicht als diesen Ton wahrnehmen, wenn man nicht darauf achten würde, dass es tatsächlich ein Ton ist. Also muss man darauf achten, wann er anfängt, wann er endet. Um Anfang, Mitte und Ende des Tons zu `hören`, muss

12 Siehe dazu v. a. Wolfgang Bernard: Rezeptivität und Spontaneität der Wahrnehmung bei Aristoteles. Baden-Baden 1988. man darauf achten, dass man immer denselben Ton hört, der sich also in den verschiedenen Stadien seiner Dauer gleich bleibt, der kontinuierlich verläuft und nicht diskret unterbrochen ist, usw.

Alle diese Kriterien wendet man meistens scheinbar >unbewusst $>$ an genauer: Man achtet zwar auf das von diesen Kriterien Bestimmte, etwa auf darauf, dass der Ton sich gleich bleibt. Was man unter Gleichheit eines Tons, etwa dass er in verschiedenen Phasen derselbe bleibt, oder unter Gleichheit im allgemeinen versteht, etwa Identität in verschiedener Materie, wird nicht thematisiert. Aber es ist klar, dass man diesen einen Ton umso besser und sicherer hören wird, je richtiger und angemessener man diese Kriterien: Identität, Verschiedenheit, Gleichheit, Ganzheit, Teil, Kontinuität, Diskretheit, Anfang, Mitte, Ende usw. anwenden kann.

Allein diese kurze Reflexion belegt aber schon mit hinreichender Sicherheit, dass das ১bloße Wahrnehmen kein nur passiv rezeptiver oder gar rein physiologischer Vorgang, etwa ein bloßer Reiz oder Sinneseindruck, sein kann.

Solche Kriterien des Unterscheidens wendet jeder bei jeder Art von Erkennen an, zu einer methodisch reflexiven Kenntnis dieser Kriterien und dadurch zu einem souveränen, wissenden Gebrauch kommt man aber nur, wenn man sie nicht nur mehr oder weniger genau anwendet, sondern sie selbst reflexiv zum Thema macht. Dazu muss man, wie Sokrates in der Politeia formuliert, nur `dies Geringe leisten, `eins, zwei, drei zu unterscheiden` (522c).

Denn wenn man nicht nur zählen, sondern wissen will, was man meint, wenn man eins, zwei, drei unterscheidet, muss man genau diese Kriterien erfassen: Einheit, Vielheit, Identität, Verschiedenheit, Ganzheit, Teil, Gleichheit, Diskretheit, Kontinuität, usw. Bei der Zahl aber wird man nicht mehr mit den besonderen Realisationsformen dieser Kriterien bei Farben, Tönen, bei Tieren, Menschen, Bäumen usw. konfrontiert, sondern rein mit ihnen selbst. Denn aus ihnen konstituiert sich der Begriff der Zahl und die Begriffe der verschiedenen Zahlen.13

Das kann hier nicht weiter behandelt werden. Für den verfolgten Zusammenhang ist aber wichtig, dass es offenbar den Unterschied zwischen einer bloßen Anwendung von Unterscheidungskriterien und einem reflexiven und souverän selbständigen Umgang mit diesen Kriterien gibt.

13 Siehe Arbogast Schmitt: Denken und Sein bei Platon und Descartes. Heidelberg 2011, S. 121-130; S. 161-164; grundlegend zur erkenntnistheoretischen Bedeutung der Mathematik bei Platon ist Gyburg Radke: Die Theorie der Zahl im Platonismus. Ein systematisches Lehrbuch. Tübingen, Basel 2003. 


\section{E) ZUR UNTERSCHEIDUNG EINER BLOSSEN ANWENDUNG VON ERKENNTNISKRITERIEN UND EINER REFLEXIVEN UND FREIEN VERFÜGUNG ÜBER SIE BEIM WOLLEN}

Die Unterscheidung zwischen einem bloßen Gebrauch Machen von Erkenntniskriterien und einem reflexiven und dadurch freien Umgang mit ihnen hat eine große Bedeutung auch für die Verschiedenheit der Willensformen in der Politeia. Das Epithymetikón folgt der Erkenntnisweise der Wahrnehmung, es empfindet die Lust oder Unlust, die bei der Wahrnehmung von Farben, Formen, Tönen, Tonverhältnissen, Gerüchen, Geruchskompositionen usw. entstehen, aber es basiert auch auf dem, was wir Gegenstandsanschauung nennen. Diese Anschauung hat die Besonderheit, dass sie meint, einen Gegenstand ganz an seinen sinnlichen Erscheinungsformen identifizieren zu können. Das unterscheidet sie von der Art der Gegenstandserkenntnis durch das Meinen. Denn beim Meinen richtet man sich auf das Können und das , Werk ‘ von etwas, auch wenn man dieses Können noch nicht für sich betrachtet. Das leistet nach Platon erst das Denken im strengen Sinn (diánoia und nous $=$ ratio und intellectus).

EXKURS: WAS IST EINE MEINUNG?

Über das, was eine Meinung ist, hat Platon eine von vielen modernen Auffassungen abweichende Auffassung, die mit guten Gründen ein eigenes Recht beanspruchen kann. ${ }^{14}$

14 Siehe dazu Arbogast Schmitt: Die Moderne und Platon (wie Anm. 2), S. 307-330; ders.: Denken und Sein bei Platon und Descartes: kritische Anmerkungen zur `Überwindung der antiken Seinsphilosophie durch die moderne Philosophie des Subjekts. Heidelberg 2011, S. 104-110 und siehe jetzt vor allem Michael Krewet: Die Theorie der Gefühle bei Aristoteles. Heidelberg 2011, S. 407-464. Die neuere Forschung konzentriert sich extrem auf ein Scheinproblem. Da Platon die Gegenstände des Meinens von denen des Wissens unterscheidet, >meint man, er habe >noch nicht gesehen, dass man sehr wohl über ein und dasselbe eine Meinung und ein Wissen haben kann. An den Gegenständen könne man also Meinung und Wissen nicht unterscheiden. Siehe z. B. (mit Diskussion der Forschung) Christoph Horn: Platons episteme-doxa-Unterscheidung und die Ideentheorie. In Otfried Höffe (Hrsg.): Platon, Politeia. Berlin 1997, S. 291-312. Siehe auch wieder Uwe Meixner, s. v. Art. »Meinung « in: Platon-Lexikon (wie Anm. 3), S. 200-202. Aus platonischer Sicht liegt dieser Kritik selbst eine Konfusion zugrunde, und zwar die Konfusion zwischen dem äußeren Gegenstand, auf
Wer eine Meinung hat, bezieht sich nach Platon immer auf ein sinnlich gegebenes Einzelnes, erfasst an diesem Einzelnen aber etwas Allgemeines. Dieses Allgemeine allerdings ist nicht irgendetwas Gemeinsames, das man im einem schnellen, nur meinenden Urteil von den Einzeldingen abgehoben hat, es ist vielmehr das ,Werk', das in etwas Einzelnem verwirklicht ist. Ein Auge als Auge sieht man nicht mit dem Sehsinn, der nur Weiß, Blau, usw. in bestimmter Formung erfasst. Erst wenn man das, was dieses farbige Gebilde kann und leistet, bemerkt, ist man fähig eine Meinung über das, was dieses gesehene Einzelne ist, zu bilden: Es kann Farben und Formen unterscheiden, es ist ein Auge. Dieses Können, die `Dynamis des Sehvermögens, ist das Allgemeine, die je besondere Verwirklichung in diesem oder jenem Sehorgan das Einzelne.

Wenn man sich eine Meinung über etwas bilden will, darf man sich also nicht auf die ganze Erscheinungsmannigfaltigkeit eines Gegenstands, einer Person, einer Situation richten, sondern mus sich an ihr auf das konzentrieren, was ausmacht, dass sie etwas Bestimmtes kann und vollzieht

Die Besonderheit dieser meinungshaften Erkenntnis der allgemeinen Möglichkeit, Farben zu unterscheiden, ist allerdings, dass dieses Allgemeine noch nicht aus einer Untersuchung der Bedingungen dieser 'Dynamis` für sich selber erkannt ist (das leistet erst der Lógos), sondern an der Leistung, dem /Werk (érgon) eines einzelnen Gegenstands.

Mit dieser Erkenntnisweise ist eine mögliche Irritierung gegeben Denn sie verleitet zu dem Schluss, das Werk, das etwas vollzieht, sei an eben die Erscheinungsweise gebunden, in der es gerade wahrnehmbar ist. Ein Sehvermögen muss aber nicht immer in einer kugeligen Linsenform verwirklicht sein, ein Tisch muss nicht braun und aus Holz sein, ein Mensch muss nicht weiß und blond sein, usw.

den sich eine Meinung oder ein Wissen bezieht, und dem inneren Gegenstand des Meinens oder Wissens, d. h., dem jeweils gemeinten Inhalt. Auf diese Unterscheidung verweist bereits Aristoteles. Wer über die Diagonale im Quadrat die Meinung hat, sie sei mit den Seiten kommensurabel, hat eine Meinung über denselben Gegenstand, über den man auch das Wissen haben kann, dass sie inkommensurabel sei. Der Inhalt der Meinung, d.h ihr subjektiver Inhalt, ist aber nicht derselbe wie der Inhalt des Wissens. Diesen Unterschied gibt es natürlich auch, wenn man über denselben Gegenstand eine wahre Meinung und ein Wissen hat. Wer meint, dass ein (bestimmte) Schlange giftig ist, dessen Meinung hat nicht denselben Gegenstand wie das Wissen dessen, der die Gründe, weshalb und in welcher Weise diese Schlange giftig ist, kennt. 
Das Gleiche gilt für die Äußerungsformen psychischer Aktivitäten. Ob man von jemandem bedroht, wird, sieht man nicht, man muss es, d. h. das Bedrohungspotential, an den sichtbaren Erscheinungsformen begreifen und man muss sich gegen die vielen Täuschungsgefahren vorsehen, die mit diesem Begreifen, das unmittelbar mit der Wahrnehmung verbunden ist, einhergehen.

Dazu kommt, dass das Erkennen von etwas Bedrohendem kein reiner Erkenntnisakt ist. Genauer: Es ist dann kein reiner Erkenntnisakt, wenn man an einer im Augenblick präsenten bedrohlichen Erscheinung begreift oder zu begreifen meint, dass sie (für jemanden - jetzt) bedrohlich ist. Deshalb gehört zu einer Definition der Tapferkeit nicht nur ein kognitiver Aspekt, man muss die richtige Meinung über eine Bedrohung auch in Höhen und Tiefen der Gefühle festhalten können (429c-d).

Die letzte, höchste Erkenntnisform bei Platon, das >noetischeく Denken ist dadurch charakterisiert, dass es die Kriterien des Erkennens als sie selbst kennt und deshalb frei, souverän und nicht irritiert durch vielfältige Vermischungen mit anderem über sie verfügen kann. Es hat deshalb die Besonderheit, dass es auch die Erkenntnisakte des Epithymetikón und des Thymoeidés beurteilen kann, denn es ist es ja selbst, das in eingeschränkter Form in ihnen aktiv ist. Deshalb kann es das Einheit Stiftende in ihnen allen sein. ${ }^{15}$

Man muss nach Platon also von einem Erkenntnisvermögen des Menschen sprechen, das aber in unterschiedlicher Weise aktiviert werden kann und muss. Grund dafür ist offenbar die Endlichkeit und materielle Geteiltheit des Menschen: Er kann nicht alles zugleich und ganz, sondern nur im Neben- und Nacheinander von Raum und Zeit erkennen, und er erkennt nicht alles mit demselben körperlichen Organ. Das Auge oder das Ohr haben nicht dieselbe Erkenntniskompetenz. Die Wahrnehmungen insgesamt haben nicht dieselbe Erkenntniskompetenz wie das Meinungsund das diskursive Urteilsvermögen. Während die Wahrnehmungen die bunte Vielfalt der sinnlichen Erscheinungen erfassen und auch von ihnen allein her Gegenstände zu erkennen versuchen, ist das Meinungs- und

15 Aristoteles hat in seinem Konzept der Phronesis als praktischer Vernunft die platonischen Ansätze weitergeführt und expliziert. Siehe Arbogast Schmitt: Phronesis - »eine andere Art des Erkennens«. In: Gyburg RadkeUhlmann (Hrsg.): Phronesis - die Tugend der Geisteswissenschaften. Beiträge zur rationalen Methode in den Geisteswissenschaften. Heidelberg 2012, S. 31-81.
Urteilsvermögen auf die Erkenntnis des >Werks` eben dieser Erscheinungsvielfalt gerichtet. Deshalb können diese Vermögen auch bei einer Muschel vermuten oder erkennen, dass sie über ein Sehvermögen verfügt, obwohl die Muschel kein dem Auge der meisten `höheren` Lebewesen ähnliches Sehorgan hat. Erst das noetische Erkenntnisvermögen aber erkennt die allein dem Denken zugänglichen und von ihm unterscheidbaren Möglichkeiten, die in unterschiedlicher Weise in etwas Anderem realisiert sein können. Sie sind daher frei von den Irritierungen, die sich aus der Zusammengesetztheit mit Anderem ergibt und ermöglichen ein unverzerrtes Urteil.

Aus dieser Binnendifferenzierung der Erkenntnisvermögen ergibt sich auch das besondere Verhältnis der drei Willensformen zueinander. Anders als in einer Vermögenspsychologie, in der Verstand, Gefühl und Wille nebeneinander stehen und es dem Verstand zukommt, mit Hilfe des Willens die Gefühle zu ısteuern` (mit der Folge, dass der Verstand scheinbar gar nicht frei er selbst sein kann, wenn er nicht die irrationalen Gefühle und Strebungen unterdrückt), gibt es bei der platonischen Unterscheidung der Arten seelischen Verhaltens weder eine radikale Abwertung der Sinnlichkeit, als sei sie irrational, so dass sich der Verstand von ihr befreien müsse, noch eine radikale Aufwertung, als biete sie gerade, weil sie vom Verstand noch nicht kontrolliert ist, noch einen direkten Zugang zur Wirklichkeit oder zu inneren Genialität des Menschen.

\section{DIE SEELEN-)TEILE}

A) DAS EPITHYMETIKÓN (DAS BEGEHREN)

Die Sinnlichkeit hat für Platon ihre eigene Erkenntnis- und Gefühlskompetenz und ist darin sicher und hat darin auch ihren eigentümlichen Wert. Es ist das Auge, das entscheidet, ob ein Baum grüne oder bunte Blätter hat, und der Geschmacks- und Geruchssinn sagen uns, ob der Wein süß ist und einen wohlduftenden Geruch hat. Auch die mit diesen Wahrnehmungserkenntnissen verbundene Lust oder Unlust zu empfinden, ist Sache der Sinnlichkeit und nicht etwa des Verstandes. Sein Wissen über die Geschmacksqualitäten von Oliven wird ihn nicht zum Kenner machen, der den guten und schlechten Geschmack von Oliven beurteilen kann. Das kann allein die Wahrnehmung. Da nach Platon das Erkenntnisvermögen im Menschen etwas Eines ist, ja seine subjektive Identität ausmacht, muss man genauer formulieren: Es ist der Verstand, der nur vermittels der Wahrnehmung die wahrnehmbaren Qualitäten 
erfassen kann. Sofern er - zunächst nur akzidentell - an diesen Wahrnehmungen aber beteiligt ist, kann er mit seinen Mitteln zur Verbesserung der Wahrnehmungserfahrungen beitragen, etwa, indem er sein Wissen über die mögliche Komposition von Gerüchen, Farben, Tönen, Formen (`Schemata $<$ ) benutzt, um die innere Struktur seiner Wahrnehmungen aufzuklären und so z.B. auch eine komplexe musikalische Struktur im Hören zu begreifen. ${ }^{16}$

Diese Verbesserungsmöglichkeit der Wahrnehmung durch den Verstand verweist bereits auf die Grenzen, die Platon tatsächlich der Sinnlichkeit gesetzt sieht. Diese Grenze liegt in der Eigenkompetenz der Wahrnehmung. Welchen Geschmack oder Geruch ein Wein hat, erkennt das Geschmacks- und Geruchsvermögen. Ob der Wein aber der Gesundheit eines Menschen gut tut, in welcher Menge, zu welcher Zeit usw., dies kann die Wahrnehmung nicht beurteilen.

Erst dadurch also entstehen Probleme aus der Sinnlichkeit, wenn sie (oder richtiger: der Mensch, der sich nur ihrer bedient) über das, was für ein gutes Leben des Menschen insgesamt gut ist, von sich aus und allein entscheiden will.

Da die Menschen im Staat sich nach den seelischen Verhaltensmöglichkeiten richten, die der einzelne Mensch hat, muss dieses Verhältnis von Kompetenz und Kompetenzüberschreitung auch in der staatlichen Gemeinschaft berücksichtigt werden. Die Aktivitäten des >Begehrlichen in uns richten sich vor allem auf die sinnlich-materielle Selbsterhaltung. $\mathrm{Zu}$ ihnen gehören für Platon daher nicht nur diejenigen produktiven Tätigkeiten, mit denen wir die sinnlichen Bedürfnisse befriedigen, sondern auch das ganze Handels- und das Geldwesen. Wenn ein reich gewordener Kaufmann zugleich eine Bank betreibt, wäre diese Vermischung mehrerer Tätigkeiten zwar vielleicht für den einen oder den anderen Geschäftsbereich manchmal hinderlich, zum Problem würde aber erst eine grundsätzliche Kompetenzüberschreitung, d.h. eine Überschreitung, die den

16 Augustinus und Boethius haben in ihrer Auslegung der Schönheitserfahrung immer wieder darauf hingewiesen, dass die Sinne zwar leicht eingängige Proportionen erfassen können, aber schon bei komplexeren oder auch nur extrem kurzen oder langen Formen versagen. Um eine komplizierte Proportion eines Gebäudes, die komplexe Struktur einer musikalischen Komposition shören` zu können, bedürfe man bereits der Mitwirkung des Verstandes. Siehe Arbogast Schmitt: Zahl und Schönheit in Augustins De musica VI. In: Würzburger Jahrbücher für die Altertumswissenschaften N. F. 16 (1990), S. 221-237.
Bereich der sinnlich-materiellen Selbsterhaltung zum Maß für die ganze Gemeinschaft bzw. den ganzen Menschen macht. Ein Beispiel wäre etwa, wenn Handel und Banken, d. h. der >Markt $\iota$, vorgeben möchten, wie und mit welchen Zielen die Bildung oder die Kunst in einer Gemeinschaft betrieben werden. Solche Vorgaben wären nach Platon eine Einmischung in Gemeinschaftskompetenzen, die das Prädikat >ungerecht` erhalten müssten.

Denn sie schränken die mögliche Selbstverwirklichung des Menschen auf seine elementaren Bedürfnisse ein und gefährden eine Entfaltung des eigentlich Menschlichen.

B) DAS THYMOEIDÉS (DAS SICH-EREIFERN)

In ähnlicher Weise hat auch das Thymoeidés, das Sich-Ereifern für die eigene Selbstverwirklichung in der Gemeinschaft, seine eigene Erkenntnis, Gefühl- und Willenskompetenz. Es ereifert sich für alles, was der Selbstverwirklichung gut tut und genießt es, d.h. empfindet dabei Gefühle der Anerkennung und Ehre, und bekämpft alles, was dieser Selbstverwirklichung schadet, und tut dies mit Tapferkeit und den Gefühlen des Zorns, der Empörung, der Zivilcourage, der Scham und dergleichen.

Anders als die Wahrnehmung richtet sich das Meinen nicht auf die reine Erscheinungsvielfalt, sondern auf das 'Werk', das in ihr verwirklicht wird. Es ist aber anders als das reine Denken auf das in den einzelnen Phänomenen präsente >Werk ‘ bezogen. Die Eigenkompetenz dieses Meinens und der mit ihm verbundenen Gefühle liegt daher in der unmittelbaren Reaktion auf eine Bedrohung bzw. in der unmittelbaren Ergreifung einer Möglichkeit der Selbstentfaltung.

Die Gefährdungen des Thymoeidés liegen nicht nur, ja nicht in erster Linie in dem Übereifer, der auf die Erkenntnis einer Entfaltungsmöglichkeit oder einer Bedrohung reagiert und sich wie Hunde zu schnell auf einen vermeintlichen Feind stürzt oder wie Diener, die nicht richtig hinhören und gleich losstürzen, den Auftrag falsch ausführt, ${ }^{17}$ die eigentliche Gefährdung liegt auch hier in einer Absolutsetzung des eigenen Wollens.

17 In Anlehnung an Platons 'philosophischen< Hund (Politeia 376a2-8; s. a. 469e1; Nomoi 967c8) sagt Aristoteles vom >Thymós $<$ » Es scheint der Thymos zwar irgendwie auf den Logos zu hören, aber nicht genau. Wie bei übereiligen Dienern, die noch bevor sie alles gehört haben, was man ihnen sagt, losrennen und dann den Auftrag fehlerhaft ausführen, oder wie bei den Hunden: noch bevor sie sehen, ob einer ein Freund ist, bellen sie, wenn einer nur ein Geräusch macht« (Nikomachische Ethik 1149a 25-29). 
Diese Absolutsetzung entsteht, wenn der Wille zur Abwehr dazu führt, dass die Tapferkeit zum höchsten Gut wird, oder wenn das Streben nach Ehre und Anerkennung losgelöst von der dienenden Funktion, die es für die Selbstverwirklichung des ganzen Menschen hat, allein um seiner selbst willen gesucht wird.

In der Gemeinschaft würde diese Kompetenzüberschreitung z. B. dazu führen, dass der General bestimmt, welche Straßen gebaut, welche Kommunikationsmittel verbreitet werden, und insbesondere, dass er versucht, die ganze Gemeinschaft auf militärische Ziele hin auszubilden (wie etwa in Sparta zu manchen Zeiten). Dass eine Gemeinschaft, in der mehr oder weniger die Ehre zum höchsten Gut geworden ist, vielfältigen Gefährdungen ausgesetzt ist, zeigt die Geschichte vielfältig. Die Art der Gefährdung hängt dabei vor allem von den Gütern ab, deren Besitz mit Ehre belohnt wird: körperliche Überlegenheit, Reichtum, künstlerische Fähigkeiten, usw. Platon beobachtet in einer >Timokratier (in der das Streben nach Ehre regiert) v.a eine Tendenz, die Ehre im Besitz großen Eigentums zu suchen. Dadurch bekommt eine Timokratie eine Tendenz zur Oligarchie, in der nur noch der Besitz für sich selbst gesucht wird und in der, wie Platon in einem deutlichen Bild beschreibt, das Streben nach mehr Reichtum auf dem Thron sitzt, während der Verstand und das Thymoeidés am Boden darunter sitzen, und der Verstand nur noch überlegen darf, wie aus wenig Geld mehr wird, während der Thymós nichts anderes mehr bewundern und sich für nichts anderes mehr ereifern darf (553c-d).

Das Bild bietet eine sehr gute Erklärung für ein scheinbares Paradoxon: dafür nämlich, wie eine Gesellschaft oder ein Einzelner sich ganz rational und dennoch affektgetrieben verhalten kann. Diese Rationalität ist eben keine freie, frei über sich verfügende Rationalität, sondern sie steht ganz im Dienst eines Affekts, in platonischer Deutung: im Dienst einer sinnlich-materiellen Selbsterhaltung oder im Dienst bloßen Strebens nach Ansehen, oder einer Mischung aus beiden.

Die Unfreiheit einer solchen dienenden Vernunft, die dazu führt, dass sie gar nicht als Vernunft im eigentlichen Sinn tätig sein kann, verweist darauf, dass die Freiheit ein wesentliches Charakteristikum dessen ist, was Platon das Logistikón nennt. Die Fähigkeit, im Sinn des Logistikón zu handeln, gewinnt man erst, wenn man die Kriterien, die man beim Erkennen anwendet, für sich selbst erkannt hat und sie ihnen gemäß anwendet. Obwohl Platon in den mittleren Büchern der Politeia ein Programm der Ausbildung der Rationalität im Menschen entwirft - es wurde später die Grundlage für das sogenannte Quadrivium innerhalb der artes liberales $^{18}$ - liegt das Gewicht in der Politeia auf dem Handlungsaspekt, der sich aus der freien Verfügung über Verstand und Vernunft (Diánoia und Nous) ergibt.

Verfolgt man den Weg vom Epithymetikón bis zum Logistikón kann man feststellen, dass dieser Weg grundsätzlich ein Weg zunehmender Freiheit ist - und keineswegs ein Weg, der zu einer Unterwerfung unter eine totalitäre Herrschaft führt, wie Karl Popper, freilich in Anlehnung an eine zu seiner Zeit verbreitete Platondeutung, behauptet hat. ${ }^{19}$

Das Epithymetikón kann nur das begehren, was ihm Auge, Ohr, Nase usw. im jeweiligen Augenblick anbieten. Einen keineswegs unerheblichen Ansatz zur Befreiung von diesen Beschränkungen gibt es freilich bereits im Epithymetikón selbst durch die Steigerung des rationalen Moments in ihm. Wer einen guten Wein nicht nur wegen seiner Süße oder seiner berauschenden Wirkung willen trinkt, sondern die Unterscheidungsfähigkeiten der Zunge und Nase in möglichst vollendeter Weise betätigt, wird dafür nicht nur mit dem bei weitem größten Genuss dieses Weins belohnt, er hat auch weniger Probleme mit dem Hinhören auf eine >höhere Vernunft. Denn er wird aus eigenem Antrieb und frei auf einen unmäßigen Genuss des Weins verzichten, weil und natürlich auch nur wenn er den höchstmöglichen Genuss aus der Empfindung von Geruch und Geschmack gewinnen will. Denn dieser Genuss setzt eine optimale Unterscheidungsfähigkeit der Sinne voraus, die sowohl durch eine übertriebene Süße als auch durch zu viel betäubenden Alkohol beeinträchtigt würde.

Nicht durch eine Unterdrückung der Sinnlichkeit also, sondern durch ihre Optimierung wird es möglich, sich von den Begrenzungen der Sinneskompetenzen zu befreien.

In einem grundsätzlicheren Sinn ist das Thymoeidés in der Lage, die Grenzen der Sinnlichkeit zu überwinden. Da es, gestützt auf die Erkenntnisleistung des Meinens (Dóxa), auf das >Werk ‘ von etwas gerichtet ist, das in unterschiedlichen Erscheinungen unterschiedlich verwirklicht sein kann (s.o.), sind auch seine Lustgefühle und sein Wille unabhängiger von den jeweils präsenten Phänomenen. Das Meinungsvermögen befähigt, ein Sehvermögen nicht nur an der Linsenform des Menschen, sondern auch in der Spiegelstruktur der Muschel zu erkennen. Wer sich

18 Siehe Radke: Theorie der Zahl im Platonismus (wie Anm. 13), S. 178 ff. und passim.

19 Siehe Karl Popper: Die offene Gesellschaft und ihre Feinde, I: Der Zauber Platons. Bern 1957 (engl. 1945). 
eine Meinung über die zornige Wut eines Menschen nicht nur aus dem äußeren Gehabe bildet, sondern aus dem >Werkı des Zorns, dem Streben nach rächender Vergeltung eines Unrechts, braucht keine heftig tobende Medea vor sich zu sehen, um ihre zornige Empörung mitzuempfinden, er wird ihren Zorn auch in einer heuchlerisch versöhnlichen Rede bemerken, wenn er (wenigstens) vermutet, dass diese Rede dem /Werk ^ des Zorns in Medea dient. Tatsächlich entwickelt der Chor der vornehmen Frauen aus Korinth in der Euripideischen Medea intensives Mitleid mit Medea, obwohl sie sich das ganze Stück über sehr rational verhält, weil er bemerkt, dass dieser planvoll rationale Wille seinen Grund im Leiden Medeas an der unerhörten und schamlosen Erniedrigung durch den untreuen Jason hat. Ursache für diese Freiheit vom augenblicklichen äußeren Eindruck ist, dass der Chor anders als der begriffsstutzige Jason nicht vom äußeren Schein der Rede Medeas eingenommen wird, weil er auf das Ziel achtet, das sie mit ihr verfolgt. ${ }^{20}$

C) DAS LOGISTIKÓN (DER VERNÜNFTIGE WILLE)

Die Differenz, wie Medea ihr Unglück selbst empfindet und wie der Chor Mitleid mit ihr fühlt - beides sind Gefühlsweisen des Thymoeidés macht auf eine ähnliche Möglichkeit des Übergangs in eine, von einer 'höheren` Vernunft geprägte Empfindungsmöglichkeit aufmerksam, wie man sie auch im Bereich sinnlicher Lüste beobachten kann. Denn Medeas berühmte und viel zitierte Sätze: »Ich erkenne, was ich Schlimmes (mir anzu-)tun im Begriff bin, aber meine Empörung ( $>$ Thymós $<$ ) ist Herr meiner (Rache-)Pläne « ${ }^{21}$ zeigen, dass sie trotz des Wissens, wie groß ihr Unglück in einem Leben ohne ihre Kinder sein wird, sich von dem ihr ganz präsenten Gefühl der Erniedrigung durch Jason nicht befreien kann. Das kann aber der Chor, der aus seiner distanzierteren und dadurch auch weiteren Perspektive heraus, erkennt, dass Medea sich mit der Tötung der Kinder um ihr ganzes Glück bringen wird.

Grund für die größere Freiheit des Urteils und die damit verbundene größere Richtigkeit des Gefühls des Chors ist, dass er klarer und konkreter als Medea das ganze Unglück des späteren Leben Medeas vor sich sieht und so das drohende Unglück schon wie etwas Präsentes empfinden kann. Dieser freiere Blick auf das für das Ganze Gute ist für

20 Siehe dazu Arbogast Schmitt: Leidenschaft in der Senecanischen und Euripideischen Medea. In: Umberto Albini u. a. (Hrsg.): Storia, poesia e pensiero nel mondo antico. Neapel 1994, S. 573-599.

21 Euripides: Medea, 1078-1080. das Logistikón, wie Platon es beschreibt, charakteristisch. Für die praktische Vernünftigkeit des von ihm ausgehenden Willens beruft sich Platon mehrfach im Staat auf den homerischen Odysseus. Als dieser, nach Hause zurückgekehrt und als Bettler verkleidet am Abend in seinem Palast sitzt, sieht er, wie seine Dienerinnen zu den Freiern schleichen. Das empört ihn so sehr, dass er am liebsten aufspringen und sie töten möchte. Aber er beherrscht sich, weil er daran denkt, dass er nur dann wieder Herr in seinem Haus wird sein können, wenn er die Freier besiegt, vor denen er sich nicht verraten darf (Odyssee 20, 1-55).

Dieses Verhalten erweckt für einen heutigen Leser den Eindruck, dass hier der Verstand über den Affekt siegt. Platons Anliegen scheint es zu sein, an diesem Beispiel für die Freiheit des Verstandes von den Leidenschaften zu werben, d. h. ein asketisches, rein der Vernunft folgendes Leben zu proklamieren.

Übersehen wird bei dieser Deutung eine kleine, aber bedeutende Zwischenpassage, in der Homer an einem Vergleich den inneren Zustand des Odysseus veranschaulicht. ${ }^{22}$ Homer vergleicht diesen Zustand nämlich mit der heftigen Begierde eines hungrigen Mannes, der dabei ist, einen Ziegenmagen zu braten. Der Magen tropft schon vor Fett und duftet, so dass der Hungernde es kaum abwarten kann, bis er endlich durchgebraten ist. So habe Odysseus hin und her überlegt, wie er als Einzelner sich gegen so viele wehren könne (Odyssee 20, 24-30).

Die Art und Weise, wie Odysseus sich von seinem Zorn auf die Dienerinnen befreit, ist nicht eine asketische Unterdrückung seines Affekts, es ist vielmehr die Vorstellung einer viel größeren Lust, die mit dem vernünftigen Gedanken an das für ihn größere Gut verbunden ist, die so präsent in ihm ist, dass die weit geringere Lust an der Bestrafung der Dienerinnen daneben verschwindet und unbedeutend wird.

Bereits Homer hat für diese freiere Vernunft, die er $>$ Nóos $<$ nennt ${ }^{23}$, die charakteristische Beschreibung, dass sie in der Lage sei, >nach vorne und nach hinten (z. B. Ilias 18, 250) zu sehen. Über diese Fähigkeit verfügen

22 Zur Art der Anschaulichkeit bei Homer und ihrer Deutung durch Aristoteles siehe Arbogast Schmitt: Anschauung und Anschaulichkeit in der Erkenntnis- und Literaturtheorie des Aristoteles. In: Gyburg Radke-Uhlmann, Arbogast Schmitt (Hrsg.): Anschaulickeit in Kunst und Literatur. Berlin, Boston 2011, S. 91-152, zu Homer v. a. S. 131-147.

23 Zur Bedeutung des 'Nóos` bei Homer siehe Arbogast Schmitt: Selbständigkeit und Abhängigkeit menschlichen Handelns bei Homer. Stuttgart 1990, S. 182-222. 
nur wenige Figuren in der Ilias, v. a. der alte Ratgeber Nestor auf der Seite der Griechen, auf der Seite der Troianer der Warner und Ratgeber Polydamas. Homer schreibt ihm diese Fähigkeit z. B. zu, weil er anders als sein Feldherr Hektor, der im Siegestaumel die Gefahr nicht erkennen will, die von Achill ausgeht, der sich am Kampf wieder beteiligt, nach vorn und nach hinten blickt: Er erinnert an die unüberwindliche Stärke Achills und verweist auf die Sicherheit, die ein Rückzug hinter die starken Mauern der Stadt wieder bieten wird (Ilias 18, 243-313).

Bei Homer gibt es noch kein Wissen um die Kriterien des Denkens selbst und um die daraus resultierende Fähigkeit, selbständig und methodisch über das eigene Denken zu verfügen. Von der Konsequenz für die Handlungspraxis aber, dass die Kenntnis dessen, was sich als etwas Mögliches unterscheiden und in vielem Verschiedenen und auf verschiedene Weise verwirklichen lässt, zu einem freieren und selbstbestimmteren Umgang mit einzelnen Anforderungen in der >Realität ‘ befähigt, hat Homer offenbar eine Kenntnis, wie man an der Darstellung des Handelns des Odysseus vielfach beobachten kann. Es ist sogar Athene selbst, die Homer Odysseus gegenüber sagen lässt, sie unterstütze ihn eben deshalb, weil er anders als die meisten anderen mit klarem Kopf seinen wahren Vorteil auch in schwierigen Situationen im Auge behalte. Jeder andere, der nach langen Jahren endlich nach Hause komme, würde, so lobt sie ihn, sofort zu Frau und Kindern stürzen (sc. und sich wie Agamemnon in größte Lebensgefahr begeben). Er aber versuche erst alle möglichen Gefahren und alle Möglichkeiten seiner Rettung zu erproben und lasse sich nicht von vorschnellem Begehren verführen (Odyssee 13, 296-299; 330-340).

Ähnlich wie im Epithymetikón die Steigerung der ihm immanenten Rationalität den Übergang in eine Verhaltensweise fördert, die mehr auf das, was die einheitliche Verwirklichung des Menschen ausmacht, gerichtet ist, so fördert im Thymoeidés die Ausrichtung auf das Werk von etwas, je konzentrierter sie ist und je weniger sie sich vom jeweiligen phänomenalen Umfeld irritieren lässt, den Übergang zum Logistikón. Wer den Zorn nicht nur an der lauten Stimme, dem roten Kopf, den stampfenden Füßen u. ä. festzustellen gewohnt ist, sondern wer in allen Erscheinungsformen des Zorns auf sein >Werk । achtet, darauf, das jemand über ein Unrecht empört ist und diese Unlust beseitigen möchte, der sammelt gewissermaßen aus vielen verschiedenen Fällen immer neue Möglichkeiten, wie sich Zorn verwirklichen kann. So wird er frei oder freier von der jeweiligen Erscheinungsweise und fähig an ganz unterschiedliche Ausdrucksformen des Zorn vorauszudenken.
Durch eine solche Fähigkeit, seinen Nóos frei zu betätigen, vermeidet Odysseus viel tragisches Unglück und erreicht es am Ende, wieder ganz das Glück mit seiner Frau in seinem Besitztum genießen zu können.

\section{IST DIE `POLITEIA، DIE KONSTRUKTION EINER UTOPIE?}

Odysseus und seine ihm kongeniale Gattin Penelope sind Ausnahmefiguren. Die Wahrscheinlichkeit, dass es je solche Menschen gegeben hat oder wieder geben wird, ist gering. Dennoch ist die Darstellung dieser Figuren durch Homer keine bloße Utopie. Homer zeigt an ihnen vielmehr, wie man sein müsste, ${ }^{24} \mathrm{~d}$. h. wie man sich im wirklichen Verlauf seines Lebens verhalten müsste, wenn man ein der praktischen Vernunft folgendes, den wahren Vorteil nicht aus den Augen verlierendes Leben führen wollte. Dass dieses Leben nicht als Utopie verstanden werden soll, bezeugt das viele Leid und Unglück, das beide, Odysseus und Penelope, durch viele Widrigkeiten und Hindernisse aus der sie umgebenden /Wirklichkeit ertragen müssen, bevor sie das erreichen können, was sie beide für die glücklichste Form ihres Lebens halten - und von dem sie sich durch alle Irrungen und Wirrungen auch nicht haben abbringen lassen.

Die Konstruktion der Platonischen Politeia hat eine analoge Intention. Platon zeigt keinen Idealstaat, er führt keine Menschen vor, die so leben, wie es sich für ein Leben im besten Staat gehört. Er entwickelt vielmehr die Bedingungen, die man entwickeln müsste, wenn man ein Leben im größtmöglichen Zustand des Glücks führen möchte. Und er geht in vielfacher Reflexion die vielfachen Irrungen und Wirrungen durch, die die Entwicklung dieser Bedingungen gefährden. Die Politeia endet sogar mit einer ausführlichen und sehr erfahrungsnahen Reflexion auf die Bedingungen, die selbst einen wirklich erreichten Bestzustand wieder in Gefahr, ja schrittweise in immer größere Gefahr bis hin zu seiner völligen Verkehrung bringen. ${ }^{25}$

24 Genau dies hat Aristoteles - wieder Platon folgend - als Aufgabe der Dichtung überhaupt formuliert: Sie soll nicht einfach die geschichtliche Wirklichkeit wiedergeben, sondern darstellen, wie etwas geschehen müsste. Siehe Poetik 9, 1451a36-b12; siehe dazu Arbogast Schmitt: Aristoteles, Poetik. Berlin 2011, S. 372 f. und S. 392-398.

25 Siehe dazu Arbogast Schmitt: Die Moderne und Platon (wie Anm. 2), S. 514-519. 
V. DER , GERECHTE, STAAT: MÖGLICHKEITSRAUM DER EINEM JEDEN ZUSTEHENDEN SELBSTENTFALTUNG

Auch wenn man nicht alle Bedingungen eines gerechten Lebens so, wie sie Platon für gegeben und gefordert hält, akzeptiert, dass das grundsätzliche Ziel, das er verfolgt, ein legitimes und sinnvolles Anliegen ist, dürfte kaum in Frage zu stellen sein. Denn dieses Ziel hat keine je historisch bedingten, festgelegten Normen, nach denen man sich im Leben richten müsse, sondern basiert auf dem Wunsch jedes Einzelnen, ein möglichst glückliches Leben zu führen. Das Glück, dessen Form Platon in der Politeia diskutiert, sucht nicht Bedingungen für die Empfindung unplanbarer Glücksgefühle, ${ }^{26}$ es geht Platon auch nicht um einen biederen Lustkalkül, der in maßvoller Bescheidung nur nicht zu viel Glück erstreben möchte, um in einem einfachen Leben jeder Gefährdung zu entgehen. Das Glück, über das in der Politeia nachgedacht wird, ist das größtmögliche und dauerhafteste Glück für jeden Einzelnen. ${ }^{27}$ Es ist das, was jeder von sich aus will. Der Anspruch, dass dieser Wille erfüllt wird, ist daher der Grundanspruch der Gerechtigkeit. Es ist gerecht, dass jedem das ihm zustehende Glück auch - soweit möglich - zuteil wird.

Auch der Weg, den Platon überprüft, hält einer kritischen Prüfung in vieler Hinsicht stand. Denn er geht nicht von einem dogmatischen oder spekulativ erschlossenen Menschenbild aus, sondern von einer Reflexion

$26 \mathrm{Zu}$ Recht betont Norbert Blößner: Platons missverstandene Ethik. Das neue Bild von Platons Staat in der Forschung seit 1988. In: Gymnasium 114 (2007), S. 251-269, hier S. 255-258 dass »Eudaimonie kein Gefühl« im Sinn eines bloßen subjektiven Empfindens und einer Stimmung ist. Auch die Folgerung, Glück sei für Platon »ein Sachverhalt: der Sachverhalt, dass ein Leben sinnvoll gelebt wird und gelingt« (S. 256) trifft eine wesentliche Intention Platons. Das gelingende Leben allerdings ist für Platon wie für Aristoteles ausdrücklich mit Lust, ja mit der höchsten Lust verbunden. Vielleicht genügt es deshalb zur Abgrenzung modernen, vor allem Pflichtund Zweckethiken folgenden Auffassungen (wie Blößner zu Recht betont) ein anderes Verständnis von Lust entgegenzusetzen. Siehe das Folgende.

$27 \mathrm{Zu}$ diesem Glücksbegriff siehe Arbogast Schmitt: Figuren des Glücks in der griechischen Literatur. Glück als Ausdruck vollendeter Selbstverwirklichung im Handeln. In: Dieter Thomae, Christoph Henning, Olivia Mitschelich-Schönherr (Hrsg.): Glück. Ein interdisziplinäres Handbuch. Stuttgart, Weimar 2011, S. 135-140. auf das, was ein Mensch kann, genauer: was er in der ihm möglichen Vollendung am besten kann. Die Vorstellung, dass gerade die Verwirklichung dieses >Könnens die höchste Lust bereite, beruht zwar auf einer anderen Glücksvorstellung als der, die heute die größte Verbreitung hat. Aber sie kann durch eigene Erfahrung überprüft und bestätigt werden. Sie ruht auf der Überzeugung, dass die Lust der Tätigkeit folgt, ja unmittelbar mit ihr gegeben ist. Aristoteles formuliert sehr eindrücklich, sie stelle sich (sc. mit der - gelingenden - Tätigkeit) ein, wie die Schönheit in der Blüte der Jugend. Da aber zwar jede Tätigkeit mit Lust oder Unlust verbunden ist und auch die mit Lust verbundenen Tätigkeiten oft nicht auf ein dauerhaftes und vollendetes Glück hinführen, braucht man zum wirklichen Glück eine Ordnung der Lüste. ${ }^{28}$

Die Suche nach dieser Ordnung, die allein einen Zustand der Gerechtigkeit herstellen kann, gibt die Ordnung der Argumentation in der Dialogführung der Politeia vor. »Jedes Handeln und Produzieren (d.h. alles Tätigsein) wird um eines Guten willen getan." Mit diesem gut platonischen Axiom beginnt Aristoteles seine Ethik (1094a1f.). Es meint nicht, dass alles Handeln und Machen auf etwas objektiv Gutes zielt. Es behauptet lediglich, dass jeder das, was er tut, tut, weil er meint, es sei etwas Gutes für ihn. Auch wenn jemand mit Absicht Böses tut oder sich selbst Böses antut, zieht er es vor, dieses Böse und nicht etwas Anderes zu tun, d.h. er hält es für besser, z. B. sich selbst zu verletzen, andere zu schädigen, als dies nicht zu tun. Damit aus diesem oft nur scheinbar Guten etwas wirklich Gutes für den Handelnden wird, ist daher eine Bildung des Menschen nötig: Er muss erkennen, was wirklich gut für ihn ist und ihn dauerhaft mit Glück erfüllt, er muss die Lust an diesem (und keinem anderen, etwa nur kurzfristigen) Guten auch empfinden, und er muss diejenigen Tätigkeiten, die ihm diese Lust verschaffen, auch wollen

Das ist der Grund, weshalb Platon in der Politeia das, was den Menschen zur Tätigkeit hinführt, d.h. den Willen oder das Streben, etwas zu tun, zum Grundthema macht.

Ausgehend von der Beobachtung, dass wir nicht nur mit den Sinnen Verschiedenes, ja einander Wiederstreitendes wollen (z. B. kann man Süßes essen, Bitteres nicht essen wollen), sondern dass es auch Strebungen in uns gibt, die dem von Sinnen Begehrten grundsätzlich entgegentreten und uns dazu führen, dass wir jede Art sinnlicher Begierden zurückdrängen, fragt Platon nach dem - innerpsychischen - Grund dieser widerstreitenden

28 Siehe Aristoteles: Nikomachische Ethik, X, Kap. 4-7, v. a. 1174b5-33. 
(nicht: widersprüchlichen) Strebungen oder Arten des Wollens. Viele Erfahrungen bezeugen, dass es nicht immer gleich die Vernunft ist, die uns zum Verzicht auf sinnliche Lüste und Begierden bewegt. Wer sich über ein Unrecht empört, sich wegen eines Fehlers schämt, Anerkennung durch Leistung sucht, Bedrohungen fürchtet, kümmert sich in diesen Zuständen nicht um sinnliche Lust oder Unlust. Er tut dies aber oft einer augenblicklichen Herausforderung gegenüber und in gänzlicher Ausrichtung auf sie. Dies verweist darauf, dass die Erkenntnisgrundlage dieser Art von Strebungen nicht Wahrnehmungen sind, sondern das Vermögen, sich eine Meinung über sinnliche Phänomene zu bilden. Denn das Erkenntnisvermögen des Meinens hat die Besonderheit, dass es sich nicht an die sinnliche Erscheinungsvielfalt zerstreut, sondern deren funktionale Einheit an dem, was sie kann und leistet, an ihrem >Werk` (ergon) erfasst. Denjenigen Willen, mit dem sich der Mensch für sein /Werk engagiert, nennt Platon das `Thymoeidés‘, das, womit sich der Mensch ereifert. Von ihm unterscheidet er diejenige Willensform, durch die der Mensch nicht nur in je bestimmten Augenblicken und gegenüber einzelnen Herausforderungen sich mit emotionalem Engagement zu verwirklichen sucht, sondern durch die er nach dem strebt, was für ein erfülltes Tätigsein in einem ganzen Leben gut ist. Ein solcher Wille setzt die Fähigkeit voraus, das, was der Mensch kann, nicht nur in dieser oder jeder Anwendung, sondern rein für sich selbst zu erkennen.

Erst ein so gebildeter Wille verdient nach Platon die Bezeichnung >vernünftig ‘. Die anderen Willensformen bedienen sich mehr oder weniger frei dieser Vernunft und sind daher mehr durch die Fähigkeit, auf sie zu hören, als durch eine eigenständige (d.h. aus reflexivem Wissen über sich selbst verfügende) Vernunft charakterisiert. In diesem Sinn sind sie ২Álogar. Sie sind nicht irrational, sondern nicht selbständig rational. Als >Álogar sind sie gemeinsam dem >Logistikón` entgegengesetzt, deshalb teilen Platon wie Aristoteles die Seele manchmal nur in zwei `Teile‘, manchmal in drei. Das bedeutet keinen sachlichen Unterschied, sondern dass die Binnendifferenzierung der `Áloga` manchmal nicht thematisiert wird (sc. wenn es für die Fragestellung nicht relevant ist).

Auch dass Platon drei Willensarten in der menschlichen Psyche unterscheidet, hat also nachprüfbare und plausible Gründe. Berücksichtigt man allein die Erkenntnisfähigkeiten, die Platon unterscheidet, müsste man weit mehr >Teile` ansetzen. Denn Platon kennt drei (oder sogar vier) verschiedene Formen der Wahrnehmung (direkte Wahrnehmungen, synthetische Wahrnehmungen, gemeinsame Wahrnehmungen), zwei Formen der Phantasia, abgegrenzt davon ein Meinungsvermögen (mit einer
Binnenunterscheidung) als erste Grundform des Denkens im strengen Sinn, dann das rational diskursive Denken (Diánoia) und, als höchste Form des Denkens, die unmittelbare Einsichtsfähigkeit des Intellekts (Nous). Das sind, wie schon Proklos aufgelistet hat, ${ }^{29}$ acht Unterschiede. Dass Platon in der Politeia nur drei Arten seelischen Verhaltens unterscheidet, hat seinen Grund, wie ich zu zeigen versucht habe, darin, dass er dort die psychischen Voraussetzungen des Handelns klären will:

Alle Wahrnehmungsformen (und zum Teil auch die Vorstellungen) erkennen die Vielfalt der Sinneserscheinungen, empfinden daran Lust oder Unlust und begehren das als lustvoll Erfahrene und meiden das Unlustvolle. Im Unterschied dazu richtet sich das Meinungsvermögen auf das, was etwas kann und leistet. Es erkennt also das >Werk । oder - in der späteren mittelalterlichen Begrifflichkeit - den Akt von etwas, empfindet die Lust an der Verwirklichung dieses Aktes bzw. die Unlust über seine Behinderung und strebt nach Anerkennung und Überlegenheit (auch: physischer Sieg), um die Lust dieser Verwirklichung genießen bzw. die Unlust an ihrer Behinderung abwehren zu können.

Die rationalen Erkenntnisformen (Diánoia, Nous) haben gemeinsam, dass sie sich auf das im Einzelnen verwirklichte Mögliche für sich selbst richten, das in ihm präsente Gute genießen und es verwirklichen wollen. Eine diesem vernünftigen Willen sehr nahe kommende Form des Wollens ist die Fähigkeit, über die je einzelne Handlungssituation hinaus eine Vielzahl von Möglichkeiten, wie man das für sich selbst Beste erreichen kann, erkennen und mit Lust verfolgen zu können, wie es Platon an Odysseus bewundert hat.

Alle drei Willens- oder Strebeformen haben bei Platon ein gutes Recht und sollen >das Ihre tun` dürfen.

Dennoch gibt es eine Ordnung unter ihnen. Wir brauchen die sinnlichen Lüste und das sinnliche Wollen, um für unsere Selbsterhaltung tätig zu werden und dabei auch um dieser Strebeziele willen die Arbeit der Beschaffung dessen, was unsere sinnlichen Bedürfnisse erfüllt, auf uns zu nehmen. Aber es ist keine Frage, dass die Zerstreuung an die immer nur in jeweiliger Gegenwart präsente sinnliche Vielfalt dazu verführt, wegen der Augenblickslust oder -unlust das 'Werk Menschen aus den Augen zu verlieren. Dafür, dass dies nicht geschieht, setzt sich der Thymós mit seiner Fähigkeit ein, die funktionale Einheit

29 Siehe Proklos: In Platonis rem publicam commentarii. Hrsg. von Wilhelm Kroll. Leipzig 1899, Bd. 1, S. 206-235; v. a. S. 233 ff. 
einer sinnlichen >Mannigfaltigkeit $\$ an ihrem Akt zu erkennen, dessen emotionales Engagement für das, was das Werk eines Menschen fördert oder bedroht, oft überlebenswichtig ist, auf jeden Fall aber nötig, damit ein Mensch wirklich >das Seine tun k kann. Aber auch der Thymós ist an das jeweils Fördernde oder Bedrohende bei jeweils einzelnen Handlungen gebunden - für sie muss er sich ja auch `ereifern`. Er braucht daher noch den Rat einer praktischen Vernunft, die das, was für einen bestimmten einzelnen Menschen oder für ihn als Mensch überhaupt gut und glücksbringend ist, in der Fülle der Möglichkeiten erkennen und so genießen kann, dass die nur mögliche Lust so präsent ist, dass sie zur Entwicklung eines vernünftigen Willens führt.

Ohne Frage enthält diese Ordnung bei Platon eine Wertung: Der glücklichste Mensch ist der, der sein Menschsein in der bestmöglichen Form lebt, d.h. der die Freuden des Erkennens um ihrer selbst willen am meisten liebt und alle anderen Lüste und Unlüste auf die Ermöglichung eines solchen Lebens ausrichtet.

Die sehr oft gezogene Folgerung allerdings, Platon vertrete ein intellektualistisches Elitedenken und behalte das Glück allein den Philosophen vor, liegt deutlich neben dem von Platon Gemeinten. Er betont in abschließender Wertung selbst, dass jeder >Teik des ganzen Menschen dann, wenn alle >Teile , das Ihre tun und sich nicht verabsolutieren und über die anderen erheben, seine eigene Lust sernte und wahrste, die möglich ist $(586 \mathrm{e}-587 \mathrm{a}) .{ }^{30}$ Dieses Urteil kann als argumentativ gut begründet gelten. Dass beides, die ausführliche Begründung und die abschließende ausdrückliche Wertung von den Interpreten oft übergangen werden, hat die wichtigste Ursache in der Übertragung eines historisch wie sachlich unangemessenen Rationalitätsbegriffs auf Platon. Der vermeintliche Gegensatz von Verstand und Gefühl, der den Verstand nur dann Freiheit zugesteht, wenn er ganz frei von jeder Art von Gefühl ist, existiert für Platon nicht.

Dies zu bedenken, ist vor allem dann wichtig, wenn man die innerpsychische Ordnung auf den ganzen Staat überträgt. Es wäre erstaunlich widersprüchlich, wenn Platon, wie man kritisiert hat, zugleich von den Menschen in den verschiedenen Bereichen des Staats verlangen würde,

30 586e3-587a1: »Wenn dem ( $>$ Teil $)$, mit dem wir das Erkennen lieben, die ganze Seele folgt und sich nicht gegen ihn auflehnt, dann tut jeder Teil den anderen gegenüber das Seine und ist gerecht, ganz besonders aber genießt jeder die ihm gemäße Lust, und zwar die beste und, soweit das möglich ist, die wahrhafteste.« sie sollten in einer >Homodoxía ander leben (die durch die >Tugend der Sophrosyne möglich wird), aber zugleich allen Menschen, die nicht Philosophen sind, das Denkvermögen absprechen möchte. Oft folgt diese Kritik nicht einmal der naheliegenden, 'natürlichen` Auslegung des Platonischen Textes. Wenn man einem Patienten rät, er solle auf den Arzt hören, behauptet man damit nicht, er könne gar nicht selbständig denken. Gemeint ist vielmehr, dass er mit seinem eigenen Verstand das medizinisch Richtige nicht beurteilen kann. Es zeugt aber zugleich von einem eigenständigen Urteilsvermögen, wenn jemand selbst erkennen kann, wann er dem Urteil eines anderen folgen soll.

In analoger Weise soll ein Mensch, der etwas mit Hilfe der Wahrnehmung erkennt, in der Lage sein, die Leistung, die er durch diese aktive Erkenntnispotenz erreichen kann, zu beurteilen und dort, wo sie ihre Grenzen hat, sich auf andere Erkenntnisformen stützen. Das gilt auch für das Leben in der Gemeinschaft. Der Landwirt, der Kaufmann, der Arzt können wissen, wofür sie in eigener Kompetenz zuständig sind. Auch der Anspruch, wegen dieser je besonderen Kompetenzen auch das beurteilen und leisten zu können, was für das Zusammenleben der Menschen in der ganzen Gemeinschaft gut und nötig ist, kann durch selbständiges Wissen über das eigene Können als unberechtigt erkannt werden.

Die vermeintliche Unterwerfung unter den Herrschaftsanspruch der Vernunft ist in Wahrheit das Gegenteil. Nur durch Erkenntnis der Grenzen, innerhalb derer man das eigene Können frei entfalten kann, ist Selbsterkenntnis möglich und nur durch sie kann der einzelne Mensch und die ganze Gemeinschaft verhindern, unter vielfältige Abhängigkeiten zu geraten. Wer materielles Gewinnstreben über alles stellt, muss notwendigerweise viele andere Lüste in sich unterdrücken. In der Gemeinschaft würde die Herrschaft eines absolut gesetzten `Epithymetikón` notwendig zur Unterwerfung aller anderen Betätigungsmöglichkeiten des Menschen führen und alles, was nicht dem materiellen Erfolg dient, ausschließen bzw. nur insoweit zulassen, wie es diesem Ziel dient. Das hätte zur Folge, dass alles, was der reinen Erkenntnisgewinnung oder was `nur mit Ehre verbunden ist, einen Platz unter dem Thron der Besitzgierde, wie Platon sagt, angewiesen bekommt und sich nur noch für die Mehrung des Besitzes engagieren darf. Ausgeschlossen bzw. untergeordnet würden dann nicht nur Künste und Wissenschaften, sondern alle Betätigungen, die des Handwerkers, des Kaufmanns, des Sportlers würden diesen Zielen unterworfen und um ihr Recht gebracht, >das Ihre zu tun<.

Probleme mit der Gerechtigkeit entstehen nach Platon also immer dann, wenn sich einzelne >Teile der Seele verabsolutieren und sich an 
die Stelle des Ganzen setzen wollen. In einer funktionalen Hinordnung auf das, was für den ganzen Menschen gut ist, dagegen hat jeder Teil mit seinen Kompetenzen sein volles Recht und genießt auch die ihm mögliche höchste Lust. Das ist der Grund dafür, dass gerade das Streben nach der höchstmöglichen Selbstentfaltung und der damit einhergehenden größten Lust eines jeden > Teils $\triangleleft$ der Seele zugleich der beste Dienst am Ganzen ist.

Im Blick auf die politische Gemeinschaft heißt das, dass jeder dann, wenn er sich selbst am besten zu verwirklichen sucht und darin auch genießt, durch eben diesen `Egoismus` zugleich der beste Bürger, die beste Stütze für den Staat im ganzen ist. Egoismus und Altruismus fallen hier zusammen, allerdings nicht, weil sich der Egoismus der Einzelnen in seiner besten Form als Altruismus erweist. Leitend ist der Egoismus, bei dem man zwischen falschem, engstirnigen, fehlgeleitetem und wirklich auf das eigene Beste bedachtem Egoismus unterscheiden muss. Diese beste Form des Egoismus führt per se dazu, das der, der ihn verwirklicht, auch für das Ganze am besten tätig ist.

Die Aufgabe für den Staat, der Gerechtigkeit unter seinen Bürgern gewährleisten möchte, ist daher nicht die Festlegung von Mustern gerechten Verhaltens, das durch Institutionen, Gesetze, Vorschriften durchgesetzt wird. Die Aufgabe ist vielmehr, für eine umfassende Bildung aller Mitglieder zu sorgen.

Die Inhalte dieser Bildung, wie sie Platon in der Politeia selbst entwirft, entsprechen im Grundsätzlichen dem Konzept, das seit der Spätantike unter dem Titel `Die sieben Freien Künsteく zu realisieren versucht wurde. Es geht um eine zugleich gymnastisch-musische und rationale Ausbildung des Menschen, die alle seine möglichen $>$ Lebensformen $<$ umfasst. Sie orientiert sich also nicht an jeweiligen historischen `Bedürfnissen`, wohl aber muss sie auf die jeweiligen historischen Bedingungen Rücksicht nehmen, um ihnen gemäß diejenigen Bedürfnisse zu entwickeln, die die Bürger lehrt, >das wirklich Angenehme schmecken zu lernen.

\section{KLAUS L. BERGHAHN \\ MÖGLICHKEIT ALS KATEGORIE DER \\ PHILOSOPHIE, POLITIK UND DICHTUNG IN ERNST BLOCHS DAS PRINZIP HOFFNUNG}

In einem Gespräch zwischen Theodor W. Adorno und Ernst Bloch aus dem Jahre 1964 finden sich überraschende Übereinstimmungen zwischen Adornos negativer Dialektik und Blochs Hoffnungsphilosophie. ${ }^{1}$ Beide lehnen die »entsetzliche Banalisierung und Abwertung « des Begiffs Utopie ab, wie sie sich in der Spießbürgerphrase »das ist ja bloß utopisch" artikuliert. Gegen diese Trivialisierung der Utopie, die Bloch schon 1918 in seinem Frühwerk Geist der Utopie wieder zu Ehren gebracht hatte, richtete sich Blochs Lebenswerk. Noch im amerikanischen Exil verfasste er 1946 eine Geschichte der Sozialutopien seit Thomas Morus' Utopia; ${ }^{2}$ doch bei aller Wertschätzung dieser sozialen Phantasieleistungen sind diese auch für ihn nur abstrakte Utopien. Daher stimmen Adorno und Bloch auch darin überein, dass man »Utopien nicht positiv ausmalen darf.« (EF, 68) Man wisse zu wenig, so Adorno, "wie das Richtige wäre, wir wissen allerdings, was das Falsche ist.« (EF, 70) Auch für Bloch ist eine wesentliche Funktion des utopischen Denkens »eine Kritik am Vorhandenen.« $(E F, 70)$ Für beide ist der Tod der härteste Gegenschlag zur Utopie, auch wenn Bloch diese Grenze mit theologischen Hoffnungsbildern noch zu

1 Etwas fehlt ... Über die Widersprüche der utopischen Sehnsucht. Ein Gespräch mit Theodor W. Adorno. Gesprächsleiter: Horst Krüger. In: Gespräche mit Ernst Bloch. Hrsg. von Rainer Traub und Harald Wieser. Frankfurt a. M. 1975, S. 58-77. Im Folgenden im Text mit Sigle EF zitiert. 2 Ernst Bloch: Freiheit und Ordnung. Abriß der Sozial-Utopien. New York 1946. Überarbeitet und erweitert im 36. Kapitel von Das Prinzip Hoffnung. Frankfurt a. M. 1973 S. 547-728. Im Folgenden im Fließtext mit Sigle PH angeführt. 
überwinden sucht. ${ }^{3}$ Diese wesentlichen Übereinstimmungen fasst Adorno folgendermaßen zusammen: "Ja, die Utopie steckt jedenfalls wesentlich in der bestimmten Negation, in der bestimmten Negation dessen, was bloß ist, und das dadurch, dass es sich als ein Falsches konkretisiert, immer zugleich hinweist auf das, was sein soll.« (EF, 61) Ebenso wichtig wie diese Annäherungen dürfte für unser Thema noch ein anderer Gesichtspunkt sein, auf den Adorno nachdrücklich hinweist: Utopisches Denken ist Möglichkeitsdenken, und dieses Modalitätsdenken ziele, so Adornos »These«, auf eine Veränderung des Ganzen: »Es wäre möglich, es könnte anders sein.« (EF, 61) Doch dieses Möglichkeitsdenken sei, so bedauert Bloch, ein »Stiefkind « der Philosophie und damit hänge auch die »seltsame Schrumpfung des utopischen Bewußtseins zusammen." $(\mathrm{EF}, 64)$ Er macht dafür den deutschen Idealismus verantwortlich; denn sowohl für Kant als auch Hegel sei Möglichkeit nur »eine subjektivreflexive Kategorie." Bloch charakterisiert und kritisiert Hegels "alte» Vorstellung des Möglichen folgendermaßen: »Es gibt nichts Mögliches, was nicht wirklich ist. Was möglich ist, ist wirklich. Wenn es nicht wirklich wäre, wäre es nicht möglich gewesen.« $(\mathrm{EF}, 61)$ Es sei die »Crux« der Kategorie Möglichkeit, dass sie fast ausschließlich in der formalen Logik behandelt werde, heißt es dazu im Prinzip Hoffnung. ${ }^{4}$ Was dabei zu kurz komme, sei die Ontologie des Noch-Nicht-Seienden, sei es als das, was dem Menschen noch nicht bewußt ist oder was in der Welt noch nicht geworden ist. In beiden Noch-Nicht steckt die Kategorie der Möglichkeit, die "noch erstaunlich wenig bedacht" sei. ( $\mathrm{PH}, 278)$

»Etwas fehlt.«Unter diesem Motto aus Brechts Mahagonny steht das erwähnte Interview. Das ist der »Stachel der Utopie«, denn was fehlt, »weiß man nicht.« Dieses Etwas darf nicht »ausgepinselt« werden wie in den alten Utopien, es darf aber auch nicht »eliminiert« werden, als ob das Erhoffte nicht wirklich werden könnte. Denn es geht im utopischen Denken um nichts Geringeres als um die "Bedingung für ein Leben in Freiheit, ein Leben im Glück, ein Leben in möglicher Erfüllung, ein Leben mit Inhalten." $(E F, 74)$ Die Kritik am Unvollkommenen enthält eine Hoffnung auf eine bessere Welt, die im Möglichkeitsdenken reflektiert wird. Dieser Kerngedanke klingt schon im Vorwort von Prinzip Hoffnung an, wenn es dort heißt: "Erwartung, Hoffnung, Intention auf noch ungewordene Möglichkeit: das ist nicht nur ein Grundzug des menschlichen

3 Siehe dazu das 52. und 53. Kapitel von Das Prinzip Hoffnung.

4 Ernst Bloch: Das Prizip Hoffnung, S. 278. Im Folgenden im Fließtext mit Sigle $\mathrm{PH}$ angeführt.
Bewußtseins, sondern, konkret berichtigt und erfaßt, eine Grundbestimmung innerhalb der objektiven Wirklichkeit insgesamt.« (PH, 5)

I.

Diesem Axiom widmet Bloch im Prinzip Hoffnung ein eigenes Kapitel, »Die Schichten der Kategorie Möglichkeit « ${ }^{5}$, das unter dem Motto steht: "Wie könnte die Welt verändert werden?« Blochs Möglichkeitsdenken antizipiert, was noch nicht ist, aber sein könnte und auch sollte. Daher spielt in Blochs Ontologie des Noch-Nicht-Seienden die Kategorie der Möglichkeit eine zentrale Rolle. Dieses Modalitätsdenken ist herkömmlicherweise ein Aspekt der formalen Logik, doch geht Blochs Möglichkeitsdenken darüber hinaus. ${ }^{6}$ Er unterscheidet vier Formen der Kategorie $>$ Möglichkeit‘, die sprachlich vorwiegend ihren Ausdruck im Modus des Konjunktivs finden.

Das formal Mögliche ist ein weites Feld, in dem sich Sehnsüchte, Tagträume und wishful thinking breit machen und ausleben. Denn "denkmöglich ist alles" (PH, 259) und dem Spielraum der Phantasie sind keine Grenzen gesetzt. Literarisch findet sich das Denkmögliche in imaginären Landschaften und Gesellschaften, welche die dichterische Phantasie entwirft: in Arcadia als Paradieslandschaft und Utopia als idealer Gesellschaft. Ganz zu schweigen von all jenen Hoffnungen und Wünschen, die außer Reichweite und Erfüllung liegen. Die Sprache trägt das ihre dazu bei, den Wünschen und Sehnsüchten Ausdruck zu verleihen: Hier regieren der conjunctious irrealis der Unmöglichkeit oder der optativus des Wünschens: „Wenn es doch anders wäre, wie schön könnte es sein«, oder wie es im Volksmund heißt: "Wenn das Wörtchen ‘wenn nicht wär ...«. Doch diese bunte Wunschwelt rührt noch nicht an das

5 Ebd., S. 258-287.

6 Zur sprachphilosophischen Weite und Vielfalt des Modalitätsdenken siehe Hans Heinz Holz: Kategorie Möglichkeit und Moduslehre. In: Ernst Bloch zu ehren. Beiträge zu seinem Werk hrsg. von Siegfried Unseld. Frankfurt 1965, S. 99-120.

7 Nicht zu vergessen, dass der zweite Konjunktiv, der sogenannte Konjunktiv der Vergangenheit, keineswegs Vergangenes, sondern Gegenwärtiges und Zukünftiges bezeichnet. Er ist kein Tempus, sondern ein Modus des sprachlichen Ausdrucks, in dem sich Wünschen, Wollen und Hoffen artikulieren 
eigentliche Problem des Möglichkeitsdenkens. Denn das formal Mögliche ist hier noch ein bloß subjektives Phantasieren und Begehren, das sich mit der objektiven Wirklichkeit nicht deckt oder vereinbaren lässt.

Erst das »sachlich-objektiv Mögliche« verbindet das Mögliche mit dem Wirklichken, da es sich hier um eine Erkenntnis handelt, wenn auch nur um ein »Kannsein. "Im Unterschied zum bloß Denkmöglichen ist Mögliches hier ein "partiell Bedingtes«, was, nach Bloch, »das Kriterium für das Mögliche in all seinen Abwandlungen « ist. $(\mathrm{PH}, 260)$ Das subjektive Vorstellen und Begehren bezieht sich auf eine Wirklichkeit, die veränderbar wäre, wenn bestimmte Vorausetzungen erfüllt würden; dann könnte das Mögliche Wirklichkeit werden. Dieses Möglichkeitsdenken artikuliert sich in hypothetischen Urteilen, wie wir sie aus den Naturwissenschaften kennen. Sie gehen induktiv vor, d. h. sie beobachten die Vielfalt der Wirklichkeit, entwerfen eine Versuchsanordnung, um Hypothesen in einem Experiment bestätigt zu finden. Erst dann lässt sich ein allgemeingültiges Gesetz formulieren. Doch was in den Naturwissenschaften erkenntnistheoretisch wie am Schnürchen abzulaufen scheint, wenn die richtigen Voraussetzungen des hypothetischen Urteils erst einmal gefunden sind, ist in den Humanwissenschaften problematisch. Denn die Elemente des sozialen Lebens sind vielfältig und auch zu widersprüchlich, um das als möglich Gedachte in die Wirklichkeit zu überführen. Man denke, um nur ein Beispiel zu nennen, an die Gedankenexperimente der Frühsozialisten. So vernünftig ihre Reformen auch klingen, sie lassen sich als Kopfgeburten von Intellektuellen nicht mit der sozialen Wirklichkeit in Übereinstimmung bringen. Auch das sachlich-objektiv Mögliche ist noch ein weites Feld, und manches bleibt in der Schwebe, wie sich sprachlich schon an dem bevorzugt verwendeten conjunctivus conditionalis zeigen ließe.

Die dritte Schicht des Möglichkeitsdenkens ist das sachhaft-objektgemäß Mögliche. Was auf den ersten Blick wegen der unscheinbaren semantischen Differenz zwischen sachlich-objektiv und sachhaft-objektgemäß wie eine philosophische Spitzfindigkeit anmutet, ist eine härtere Nuss. Denn diese Schicht der Möglichkeit geht über das Erkenntnisurteil, das sachlich-objektiv verfährt, hinaus, da es sich an Bedingungen/Vorausetzungen der Möglichkeiten und deren Folgen orientiert, indem es nach den Bedingungen der Möglichkeit im Gegenstand selbst fragt. Die Logik des Erkenntnisurteils mit seiner abstrakten Wenn-Dann-Struktur hat ihr Korrelat in der Welt, in den materiellen Bedingungen, die das Neue erst ermöglichen. Das sachhaft-objektgemäß Mögliche bezieht sich auf die Welt und ihre Sachverhalte, ihre Latenzen und Tendenzen, die als Möglichkeiten erkannt und entwickelt werden müssen. Als Beispiel für dieses sachhaft Mögliche wählt Bloch eine reifende Frucht, die in der Blüte schon angelegt ist; fehlen jedoch die äußeren Bedingungen, wenn etwa das Wetter nicht hilft, so ist die Frucht bloß möglich. Oder er exemplifiziert es mit einem politischen Beispiel: »Die revolutionäre Folgenlosigkeit des 9. November 1918 in Deutschland.« (PH, 267) Der große Moment findet ein kleines Geschlecht, und eine erfolgreiche Revolution ist kaum möglich. Möglichkeitsdenken ist nicht nur eine Funktion des subjektiv-aktiven Faktors, sondern auch und vor allem des sachhaftobjektgemäßen der Sachverhalte und Situationen, kurz: des Korrelats ,Welt‘, die entziffert und ergründet werden muss. Die Potentialität der Realität, sei es als äußere Bedingung der Zeit, Umgebung oder Gesellschaft, muss das Mögliche zur Reife bringen. Freilich ist und bleibt das Prekäre des Sachhaft-Möglichen, dass es auch anders kommen könnte, dass Zufälle oder Unfälle individueller, sozialer oder auch politischer Art das Mögliche vereiteln. Mit Blochs Worten: „Der Unheilscharakter des Möglichen konterkariert so den angegebenen Heilscharakter, den Hoffnungscharakter des Möglichen.«(PH, 268)

Von der Potentialität des Möglichen handelt Bloch im abschließenden vierten Abschnitt, der das objektiv-real Mögliche untersucht. Dieses ist die wirklich zukunftsträchtige Möglichkeit, die in der Wirklichkeit, der Welt und dem Leben selbst angelegt ist, insofern Bloch sie als noch unabgeschlossen, prozesshaft offen versteht, aus der sich jederzeit Neues entwickeln kann. "So ist der Mensch die reale Möglichkeit all dessen, was in seiner Geschichte aus ihm geworden ist und vor allem mit ungesperrtem Fortschritt noch werden kann.«(PH, 271) Der Erziehungs- und Bildungsroman wäre dafür ein literarisches Beispiel, insofern der Prozess der möglichen Selbstverwirklichung des Menschen subjektiv auf der eigenen Aktivität beruht, dem jedoch objektive Bedingungen in der Welt entsprechen müssen. ${ }^{8}$ Doch so überzeugend dies auch klingen mag, so ist damit das eigentliche Problem noch nicht gelöst: Inwiefern schlummern auch in der Materie und im Weltprozess objektiv-reale Möglichkeiten, die erst noch entdeckt und entfaltet werden müssen. Dazu Bloch, mit Nachdruck: "Ohne Materie ist kein Boden der (realen) Antizipation, ohne (reale) Antizipation ist kein Horizont der Materie erfaßbar.« (PH,

8 So ist in Goethes Wilhelm Meister die Bildungsreise des Helden subjektiv durch seinen kühnen Optimismus, sein Weltvertrauen gekennzeichnet, intuitiv das Rechte zu tun, objektiv jedoch durch die konkreten Voraussetzungen, welche erst die lenkende Turmgesellschaft bereitstellt. 
273 f.) In diesem Chiasmus verbirgt sich die Krux der realen Möglichkeit, die als Antizipation immer an die bestehenden Verhältnisse gebunden ist. Herkömmlicherweise wird diese im Wirklichen schlummernde und noch unentfaltete Möglichkeit seit Aristoteles als Entelechie der Materie bezeichnet. Doch Bloch sieht es anders, dialektischer: Denn die noch nicht entdeckten Möglichkeiten der sozialen Wirklichkeit entfalten sich nicht mit der gleichen Zwangsläufigkeit wie die Entwicklung des Samenkorns in der Natur oder der Blüte zur Frucht. Dazu nochmals Bloch: »Die reale Möglichkeit wohnt derart in keiner fertig gemachten Ontologie des Seins des bisher Seienden, sondern in der stets neu zu begründenden Ontologie des Noch-Nicht-Seienden.« (PH, 274) Sie bedarf dazu der subjektiven Aktivität, um sie zu verwirklichen. Subjekt und Objekt sind dialektisch aufeinander bezogen: Ohne reale Möglichkeit im Objekt ist keine Antizipation einer künftigen Welt möglich, und ohne subjektive Aktivität bleibt die Veränderung ein leeres Versprechen. Noch ist nichts unwiderruflich entschieden: weder der Fortschritt zum Besseren noch die Gefahr des Untergangs. Beide sind Möglichkeiten dieser Welt, und erst die verantwortungsvolle Entscheidung des Subjekts, das Möglichkeiten abwägt und zwischen ihnen wählt, trägt dazu bei, welche Möglichkeiten verwirklicht werden. Das objektiv-real Mögliche der Materie >Welt‘ wäre die »konkrete Utopie, « das summum bonum individueller, gesellschaftlicher und politischer Harmonie. Der hier verwendete conjunctivus potentialis ist die treffendste Audrucksform, um darüber zu sprechen.

Doch bleibt immer noch ein Rest, dessen sich Bloch durchaus bewusst ist, nämlich wie und wann das real Mögliche verwirklicht werden kann. Daher lautet der letzte Abschnit dieses Kapitels »Möglichkeiten verwirklichen." (PH, 284-288) Für den sogenannten gesunden Menschenvestand waren Utopien von jeher nichts als Schwärmerei und wishful thinking, die sich nicht verwirklichen lassen. Gegen diese Trägheit des Denkens und Fatalität dessen, was nun einmal so ist und sich nicht ändern lässt, richtet sich Blochs utopisches Denken. Adornos vermittelnder Hinweis, dass zahlreiche technische Utopien, von denen Francis Bacon in seiner Nova Atlantis noch träumte, heute Wirklichkeit seien, trifft noch nicht den Kern der Sache; ist für Bloch nur ein Teilaspekt der Geschichte der Utopien. ${ }^{9}$ Denn für Blochs erweiterten Utopiebegriff ist die Kritik der herrschenden Verhältnisse das Prius seiner Philosphie, ohne jedoch eine

9 Adorno/Bloch: Etwas fehlt, S. 58. Von den technischen Utopien handelt das 37. Kapitel in Blochs Das Prinzip Hoffnung. bessere Zukunft »auszupinseln. « Diesen Schwebezustand zwischen kritischer Theorie und hoffnungsvoller Praxis gleicht das Möglichkeitsdenken aus, indem es hinweist auf das, was möglich wäre. Das ist der Optativ von Blochs Hoffnungsphilosophie, und die Kategorie >Möglichkeit` ist ihr Fundament. Hoffnung ist daher nicht zu verwechseln mit Zuversicht. Denn was möglich ist, kann auch misslingen.

Statt noch ausführlicher auf die Komplexität von Blochs Ontologie des Noch-Nicht-Seienden einzugehen, empfielt es sich, wenigstens auf zwei Beispiele in Philosophie und Dichtung hinzuweisen, in denen Möglichkeitsdenken als Gedankenexperiment thematisiert wird: Kants Friedensutopie Zum Ewigen Frieden ${ }^{10}$ aus dem Jahre 1795 und Musils utopischer Roman Der Mann ohne Eigenschaften.

II.

Kant nennt seinen "philosophischen Entwurf « einen »süßen Traum« der Menschheit, von dem sie sich bei Strafe des Untergangs nicht lossagen dürfe, denn sonst drohe der Welt der ewige Friede eines wüsten Friedhofs. $(V I, 195)^{11}$ Dieser Traktat ist immer noch eine Zukunft in der Vergangenheit, zu dem zurückzukehren sich lohnt.

Ausgangspunkt seiner Friedensutopie ist eine radikale Kritik der herrschenden Kriegspolitik der europäischen Staaten, die er in sechs »Präliminarartikeln« kommentiert und kritisiert. Sie sind daher alle negativ formuliert. (VI, 196-202) Aus dieser Kritik entwickelt er seinen universalen Friedensplan in drei »Definitivartikeln."

1) »Die bürgerliche Verfassung in jedem Staate soll republikanisch sein.» (VI, 204 ff.) Denn nur unter einer solchen Verfassung sind die Bürger auch an der Entscheidung über den Krieg beteiligt und werden sich wohl überlegen, ob sie in ein Kriegsabenteuer einwilligen.

2) »Das Völkerrecht soll auf einen Föderalismus freier Staaten gegründet sein. (VI, 208 ff.) Diese Idee eines Völkerbundes, der den Weltfrieden dauerhaft garantieren könnte, ist das Zentrum von Kants

10 Immanuel Kant: Zum Ewigen Frieden. In: ders.: Werke in sechs Bänden. Hrsg. von Wilhelm Weischedel. Darmstadt 1964, Bd. VI, S. 195-251. Im Folgenden mit der Bandangabe VI im Fließtext nachgewiesen.

11 Für eine ausführlichere Interpretation siehe Klaus L. Berghahn: Utopie und Verantwortung in Kants Traktat Zum Ewigen Frieden. In: ders.: Zukunft in der Vergangenheit. Auf Ernst Blochs Spuren. Bielefeld 2008, S. 57-76. 
Friedensutopie. Was Kant 1795 als vernünftig und objektiv möglich erschien, wurde im 20. Jahrhundert schon zweimal unternommen, ohne dass der Weltfriede gesichert ist.

3) »Das Weltbürgerrecht soll auf Bedingungen der allgemeinen Hospitalität eingeschränkt sein.«(VI, 213 ff.) Dieser kosmopolitische Aspekt von Kants Friedensplan war in seiner Zeit, als die europäischen Staaten die Welt unter sich aufteilten, noch echt utopisch.

Ohne auf die ausführliche Begründung von Kants Friedensordnung näher einzugehen, empfiehlt es sich für unseren Zusammenhang, seine Schlussfolgerungen zusammenzufassen:

Die Idee eines ewigen Friedens sei keine >leere Idee`, sondern eine 'gegründete Hoffnung، des internationalen Rechts, eine Aufgabe der Menschheit, der sie sich beständig annähere. Die Idee des Ewigen Friedens ist daher für Kant ein weltbürgerliches Ideal, das als möglich vorstellt, was sein könnte und auch sollte. (VI, 251) Dieser modale Zukunftsbezug lässt sich mit Blochs Möglichkeitsdenken in vierfacher Hinsicht interpretieren:

1) Der Ewige Friede ist formal möglich, d.h. er ist denkmöglich, kann als möglich vorgestellt werden (utopischer Zukunftsbezug).

2) Er ist hypothetisch möglich, d. h. er lässt sich, wenn bestimmte Voraussetzungen erfüllt sind, als begründet vorhersagen (geschichtsphilosopischer Zukunftsbezug).

3) Er ist sachlich-objektiv möglich, d.h. er ist eine Forderung des öffentlichen und internationalen Rechts (ethischer Zukunftsbezug).

4) Er ist objektiv-real möglich, d. h. es gibt Tendenzen in der Geschichte, die ihn als möglich erscheinen lassen. Für Kant sind die amerikanische und französische Revolution Hoffnungszeichen, die auf eine zukünftige, friedliche Weltordnung deuten. Im 20. Jahrhundert waren es der Völkerbund, der den Zweiten Weltkieg nicht verhindern konnte, und die Vereinten Nationen, die nach der Katastrophe des Zweiten Weltkriegs eine friedliche Weltordnung schaffen sollten, auf die wir immer noch warten.

Die langfristige Realisierung des Ewigen Friedens ist für Kant daher eine regulative Idee, d. h. eine Pflicht der Menschheit, einen dauerhaften Frieden zu wollen und zu verwirklichen. ${ }^{12}$

12 Es sei nicht verschwiegen, dass diese Anwendung von Blochs Möglichkeitsdenken auf Kants Friedensutopie problematisch ist. Denn Bloch hielt von diesem »bürgerlichen Pazifismus« nicht viel; er war für ihn ein »Paradox«: Der »friedliche Wettbewerb verbinde zwar die Kontore«, schrecke
III.

In Blochs Spektrum des Utopischen hat die künstlerische Ausgestaltung der Hoffnung einen herausragenden Platz. Wie die Philosophie hat auch die Kunst ihr »utopisches Fenster", worin Wunschträume und Wunschzeiten erscheinen, ja die Künste sind für Bloch der reinste Ausdruck des utopischen Bewusstseins. Die utopische Intention zeigt sich am deutlichsten in den »Vorgriffen der Einbildungskraft«, die sich noch nie hat daran hindern lassen, »Phantasieexperimente der Vollkommenheit« $(\mathrm{PH}, 106)$ an einen fernen Horizont zu projizieren, sei es als Arkadia oder Utopia. In Märchen, Opern und Kolportagen, ja selbst in der Traumfabrik Film artikulieren sich berechtigte Glücksansprüche. Doch bei aller Freude an peripheren Erscheinungen der Kunst und dem Talmiglanz populärer Unterhaltungsformen unterscheidet Bloch doch zwischen der »Vergnügungsindustrie «, die ein besseres Leben bloß vorgaukelt, und den großen Kunstwerken, die antizipieren, was in der Wirklichkeit als Möglichkeit noch schlummert. Ihre wahrscheinlichen Konstellationen illuminieren die Möglichkeiten einer humaneren Welt. Damit rückt das Möglichkeitdenken als eine Grundkategorie der künstlerischen Produktivität ins Zentrum von Blochs Interesse. Was in der Wirklichkeit als reale Möglichkeit noch verborgen liegt, lässt sich mit den Mitteln der Kunst am wirksamsten und überzeugendsten darstellen. Kurz: "Kunst ist ein Laboratorium und ebenso ein Fest ausgeführter Möglichkeiten.« $(\mathrm{PH} 249)^{13}$

Eine ähnliche utopische Funktion findet Bloch auch in Werken der Literatur, in die sich das Möglichkeitsdenken eingenistet hat. Seit der Poetik des Aristoteles war es ein zentrales poetologisches Problem, wie sich die Dichtung zur Wirklichkeit verhalte. Im neunten Kapitel der Poetik unterscheidet Aristoteles zwischen der Geschichtsschreibung, die mitteile, »was wirklich geschehen ist«, während die Tragödie darstelle,

aber vor dem Risiko eines Krieges nicht zurück, wenn es darum gehe, die Konkurrenz auszuschalten. (PH, 1049) Aber das ist hier weniger eine methodische als eine ideologische Differenz.

13 Hier lohnte es sich, auch noch auf Ernst Blochs komplexe Ästhetik des »Vor-Scheins « näher einzugehen, doch beschränke ich mich auf die komplementäre Kategorie `Möglichkeit und frage darüber hinaus, welche Konsequenzen sich daraus für das Verständnis der utopischen Funktion in der Literatur ergeben. 
»was geschehen könnte, d. h. was nach den Regeln der Wahrscheinlichkeit oder Notwendigkeit möglich ist. $\ll^{14}$ Darin folgt ihm Lessing in der Hamburgischen Dramaturgie aufs Wort. »Der dramatische Dichter ist kein Geschichtsschreiber «, heißt es im 19. Kapitel, und als Begründung fügt Lessing gut aristotelisch hinzu, dass die Tragödie das Mögliche darstelle, "warum die Poesie philosophischer und folglich lehrreicher als die Geschichte « sei. ${ }^{15}$ Seither wurde dieser Satz ein Topos der Poetik und Ästhetik, den Schiller in seiner Theorie des Pathetisch-Erhabenen noch zuspitzte, indem er idealistisch davon spricht, dass das Pathetische als Ausdruck der leidenden Natur auf das Erhabene als Möglichkeit der Freiheit verweise. In ästhetischen Urteilen sind wir weder an der Wirklichkeit noch an der Moral interessiert sondern allein an unserem Vermögen zur Freiheit. ${ }^{16}$

Doch, so könnte man einwenden, wie lässt sich dieses poetologische Axiom auf das Stiefkind der Poesie, den realistischen Roman, anwenden? Ist dieser nicht eng an die Wirklichkeit gebunden - und wie viel mehr noch im Naturalismus und in der Neuen Sachlichkeit? Darum ging es unter anderem in der sogenannten Expressionismus-Debatte zwischen Georg Lukács und Ernst Bloch, die 1937 in der Moskauer Exilzeitschrift Das Wort ausgetragen wurde. ${ }^{17}$ Es ist bekanntlich eine der Schiefheiten dieser Debatte, dass Lukács sie unter das Motto »Es geht um den Realismus « stellte, um so den Expressionismus als leeren und dekadenten Formalismus abzukanzeln. Für Bloch sind Lukács Ästhetik und sein Realismusbegriff zu klassizistisch, zu abgeschlossen, kurz: »eine Begriffstapete«, die alles zudeckt, was in der Wirklichkeit noch fragmentarisch, prozesshaft und offen ist. Gegenüber diesem Dogmatismus, der sich auf den gerade erst etablierenden "sozialistischen Realismus « berief, betont Bloch, dass »alles Wirkliche einen Horizont « habe. (PH, 256) Und wenn er die vielbemühte Spiegelmetapher verwendet, so variiert er sie gleich in seinem Sinne: Realistische Kunst

14 Aristoteles: Poetik. Übersetzt und hrsg. von Manfred Fuhrmann. Stuttgart 1982, S. 29.

15 Gotthold Ephraim Lessing: Hamburgische Dramatrurgie. In: ders.: Werke. Vierter Band: Dramaturgische Schriften. Hrsg. von Herbert G. Göpfert. München 1973. 19. Stück, S. 317-321.

16 Friedrich Schiller: Über das Pathetische. In: ders.: Sämtliche Werke. Hrsg. von Gerhard Fricke und Herbert G. Göpfert. München 1960, S. 509-537.

17 Zusammengefasst in: Hans-Jürgen Schmitt (Hrsg.): Die Expressionismusdebatte. Frankfurt a. M. 1973. ist ein "Spiegel immanenter Antizipation.« (PH, 950) Da ihn vor allem die noch unentfalteten Möglichkeiten der Wirklichkeit interessieren, müsste jede Darstellung der Wirklichkeit auch Elemente des Werdens als Möglichkeit zur Darstellung bringen, kurz: Realismus ist für ihn »Wirklichkeit plus Zukunft in ihr. «18

IV.

Paradigmatisch lässt sich diese utopische Tendenz in der Moderne an Robert Musils Roman Der Mann ohne Eigenschaften nachweisen. ${ }^{19}$ Noch bevor der Antiheld namentlich eingeführt ist, schiebt der Erzähler eine Reflexion ein, welche die Struktur des Romans bestimmt: »Wenn es Wirklichkeitssinn gibt, muß es auch Möglichkeitssinn geben." Das Motto dieses Kapitels ist: »Nun, es könnte wahrscheinlich auch anders sein. $\aleph^{20}$ Ulrich, der Mann ohne Familiennamen und ohne Eigenschaften, ist ein "Möglichkeitsmensch", der in einem »Gespinst von Einbildungen, Träumereien und Konjunktiven« lebt (MoE, 16). Er ist ein zweiunddreißigjähriger Mathematiker, der sich ein Jahr >Urlaub vom Leben` genommen hat, um die existentielle Frage zu ergründen, was ein >rechtes Leben` sei. Als kritischer Beobachter des Habsburger Kaiserreichs im Vorkriegsjahr 1913 macht er Gedankenexperimente mit der verkrusteten politischen und sozialen Wirklichkeit Östereichs, das er >Kakanien nennt. Es ist die Wiener Gesellschaft, die sein Möglichkeitsdenken weckt und auf die er mit »bewußtem Utopismus« reagiert. Doch entwirft Musil keine traditionelle Sozialutopie, vielmehr bewährt sich sein Möglichkeitsinn in seiner subtilen Sozialkritik, die dem Roman eine satirische Schärfe verleiht.

Im ersten Teil des Romans lässt er sich beobachtend auf diese bornierte und gelangweilte Gesellschaft des >Immergleichen ein, die er im Indikativ beschreibt. Doch schon hier deutet die durchgängig satirische

18 Ernst Bloch: Marxismus und Dichtung. In: ders.: Literarische Aufsätze. Frankfurt a. M. 1965, S. 143.

19 Siehe dazu Albrecht Schönes Göttinger Antrittsvorlesung aus dem Jahre 1961, in der er den Mann ohne Eigenschaften als sutopischen Roman< deutet. Albrecht Schöne: Zum Gebrauch des Konjunktivs bei Robert Musil. In: Euphorion 55 (1961), S. 196-220.

20 Robert Musil: Der Mann ohne Eigenschaften. Hamburg 1952, S. 16. Im Folgenden im Fließtext mit Sigle MoE angeführt. 
Perspektive auf eine Gegenwelt, die noch nicht existiert. Der zweite Teil des Romans spielt Möglichkeiten eines sinnvollen Lebens durch, ohne dass Ulrich sich festlegt. Musil vermeidet es, eine utopische Gesellschaft zu entwerfen, die als bloß denkmöglich doch nur im conjunctivus irrealis existieren würde; statt dessen bedient er sich vorzugsweise des conjunctivus potentialis, den er auch utopicus nennt. Musils satirische Kritik der herrschenden Gesellschaftsordnung und seine Logik des Möglichkeitsdenkens antizipieren und illuminieren einen zukünftigen Zustand der Gesellschaft als »Aufgabe und Erfindung «, wie er noch nicht existiert. Doch selbst dies ist noch ein zu utopisches Verständnis von Ulrichs Vision eines sinnvollen Lebens. Der Mann ohne Eigenschaften ist eben keine Sozialutopie der Morustradition, sondern dessen moderne Schwundstufe der Subjektutopie.

»Es kommt darauf an, das Hoffen zu lernen«, heißt es im Vorwort von Blochs Prinzip Hoffnung (PH, 1), und Ulrich versucht es allen Schwierigkeiten zum Trotz auf dreifache Weise:

"Die Utopie des exakten Lebens" (MoE, $244 \mathrm{ff}$.) deutet das individuelle Leben, in das man hineingeboren wird, als ein dauerndes Erproben vielfältiger Möglichkeiten. Urich nahm sich einen »Urlaub vom Leben", um herauszufinden, was ein »rechtes Leben" sein könnte. Das ist für Musil insofern utopisch, als es »ein Experiment bedeutet, worin die möglichen Veränderungen eines Elements und die Wirkungen beobachtet werden, die in jener zusammengesetzten Erscheinung hervorgerufen würden, die wir Leben nennen." (MoE, 246) Es ist wie alles Modalitätsdenken »eine paradoxe Verbindung von Genauigkeit und Unbestimmtheit«, ein unabgeschlossener Prozess, der nur essayistisch behandelt werden kann. Wie der Essay ein Problem aus verschiedenen Perspektiven behandelt, ohne eine endgültige Lösung vorzuschlagen, setzt sich auch die »Utopie des exakten Lebens « aus Kommentaren des Erzählers und Ulrichs Reflexionen zusammen, die unterschiedliche Modelle einer »Utopie des motivierten Lebens« untersuchen, als wären sie noch nicht entdeckte und damit mögliche Intentionen. Doch gibt es für diese Utopie kein fest umrissenes Modell. »Eine Utopie ist kein Ziel, sondern eine Richtung« (MoE, 1594), heißt es am Ende des Romans ganz im Sinne Blochs.

Ein zweites utopisches Experiment ist die Geschwisterliebe zwischen Ulrich und Agathe. Ihre inzestuöse Annäherung und Phantasien erleben sie als »anderen Zustand «, als einen fast mystischen Augenblick möglicher Vereinigung. Ort dieser utopischen Erfahrung ist ein arkadischer Garten, in dem die Geschwister die »Atemzüge eines Sommertags« genießen, ohne den Inzest zu vollziehen. (MoE 1143 ff., Fragment) Was sie erleben, ließe sich mit Bloch als »utopisches Totum« beschreiben: Eine Erfahrung mystischer Einheit, in der die "Zeit still steht", und sie sich in völliger Harmonie mit sich selbst und der Welt befinden. Dies ist eine Schwundstufe der Utopie, ein utopischer Augenblick, der sich nur momentan und individuell erleben, aber nicht auf die Gesellschaft übetragen lässt. »Der andere Zustand gibt keine Vorschriften für das praktische Leben«, heißt es in den »Studien« zum Roman. (MoE, 1579) Dazu ist er, wie Musil selbst bemerkte, »viel zu flüchtig.»

Das gedankliche Fazit des Romans sollte »Die Utopie der induktiven Gesinnung oder des gegebenen sozialen Zustands" sein (MoE $1578 \mathrm{ff}$.). Sie ist Musils dritter Versuch, seine Subjektutopie auf die Gesellschaft zu projizieren. Dazu gibt es im Nachlass nur noch `Studien` und Notizen. Diese Utopie sollte die noch unausgeschöpften Möglichkeiten des praktischen Lebens analysieren und beschreiben, um die Utopie eines sinnvollen Lebens mit der gesellschaftlichen Wirklichkeit zu verbinden. Die Auseinandersetzung des Möglichkeitsmenschen Ulrich mit der sozialen und politischen Wirklichkeit >Kakaniens` endet in Ratlosigkeit, da es Musil an einem archimedischen Punkt der Geschichte mangelt. Der >unpolitische< Held verstrickt sich in Aporien der zeitgenössischen Wirklichkeit, die er nicht aufösen kann. Denn nach dem Ersten Weltkrieg ließen sich weder der Sozialismus noch der Faschismus als Utopie eines >Dritten Reichs` seinem Roman sinnvoll integrieren. So blieb der Roman ein Fragment. »Es könnte ebensogut anders sein« $(\mathrm{MoE}, 19)$ ist nicht nur das Motto des Romans, sondern zugleich die Krux des Möglichkeitsdenkens als Gedankenexperiment der Moderne. - Wie könnte es anders sein ${ }^{21}$

Damit die Hoffnungen und Erwartungen, die mit dem Möglichkeitsdenken und der Ästhetik des Vor-Scheins verknüpft sind, nicht überschwänglich werden, fügt Bloch eine notwendige Einschränkung hinzu:

21 Wie komplex, um nicht zu sagen widersprüchlich, Musils Möglichkeitsdenken ist, wenn er sich auf die Tagespolitik einlässt, zeigt eine Notiz am Ende des Romanfragments zu Kants Traktat Zum ewigen Frieden: »Kant hat sich geirrt«, heißt es dort apodiktisch, da er annahm, dass »der Handelsgeist mit dem Krieg nicht zusammen bestehen kann.« Auch eine bürgerliche Verfassung oder ein Völkerbund könne den Frieden nicht garantieren (MoE, 1583). Daraus spricht zweifellos Musils Enttäuschung, dass auch die Institution eines Völkerbundes nach dem Ersten Weltkrieg den Zweiten Weltkrieg nicht verhindern konnte. 
Ob allerdings der Ruf nach Vollendung - man kann ihn das gottlose Gebet der Poesie nennen - auch nur einigermaßen praktisch wird und nicht nur im ästhetischen Vor-Schein bleibt, darüber wird nicht in der Poesie entschieden, sondern in der Gesellschaft. (PH, 249)

Doch ist diese realistische Einsicht nicht als Relativierung oder Abwertung der Kunst zu verstehen; denn am Ende dieses Abschnitts zur Vor-Schein-Ästhetik heißt es nochmals: »Überall dort, wo die Kunst sich nicht zur Illusion verspielt, ist Schönheit, gar Erhabenheit dasjenige, was eine Ahnung künftiger Freiheit vermittelt.« ( $\mathrm{PH} 250)$

V.

Daher sollte man beim Modalitätsdenken nie übersehen, dass es auch anders kommen könnte; denn was möglich ist, kann auch misslingen. Das soll keineswegs heißen, dass Mögliches nicht wirklich werden könnte; denn sonst wäre es ja von vornherein ein Unmögliches. Möglichkeitsdenken unterliegt den Kontingenzen der Geschichte und des Lebens, die prozesshaft offen sind. Es verhält sich kritisch zur Wirklichkeit, indem es zeigt, woran es mangelt, was anders sein könnte und wo das individuelle und gesellschaftliche Glück zu suchen wäre. Blochs Hoffnungsphilosophie beruhigt sich daher keineswegs mit einem Hinweis auf das $>$ Reich der Freiheit‘, dessen Ausgestaltung er sich wie schon Marx versagt, vielmehr achtet er auf die Latenzen und Tendenzen, die auf noch nicht ausgeschöpfte Möglichkeiten der Wirklichkeit und Geschichte verweisen und die durch Philosophie und Literatur illuminiert und antizipiert werden.

»Kann Hoffnung enttäuscht werden?«, fragte der sechsundsiebzigjährige Ernst Bloch in seiner Tübinger Antrittsvorlesung von 1961, als er die DDR verlassen hatte. ${ }^{22}$ Selbstverständlich, jederzeit - und auch leider, war seine Antwort. Naiver Optimismus, wishful thinking und Tagträume werden nur allzu leicht enttäuscht, und selbst >begründetes Hoffen scheitert oft genug an den Kontingenzen der Wirklichkeit. Hoffnung ist nicht Zuversicht, und sie wird oft genug enttäuscht, aber sie ist dadurch nicht widerlegt. Sie lässt sich durch Rückschläge nicht entmutigen, wird vielmehr weiser, passt sich den neuen Umständen an und ändert den

22 Ernst Bloch: Kann Hoffnung enttäuscht werden? In: ders.: Literarische Aufsätze. Frankfurt a. M. 1965, S. 385-392.
Kurs. Allen Enttäuschungen zum Trotz zielt utopisches Denken auf ein individuelles und gesellschaftliches bonum optimum, in dem politische Freiheit, menschliche Würde und soziale Gerechtigkeit gedeihen könnten.

Die entscheidende Frage: "Soll man tun oder denken?«, die so manchen Intellektuellen verzagt erröten lässt, erfährt in Ernst Blochs Spuren eine bescheidene und zugleich aufmunternde Antowort: "Man kann auch fragen, ob der Denkende überhaupt etwas tue. Er hebt etwas ab von dem, was ist, indem er es schreibt. Er sucht einige Dinge heller zu machen, indem er zeigt, wohin es mit ihnen geht. ${ }^{23}$ Von nichts anderem war die Rede.

23 Ernst Bloch: Spuren [1930]. Neue, erweiterte Ausgabe. Frankfurt a. M. 1959, S. 261. 
VIVIAN LISKA

\section{SPRACHE UND GESETZ IM MESSIANISMUS WALTER BENJAMINS UND GIORGIO AGAMBENS}

Der wesentliche Unterschied zwischen jüdischem und christlichem Messianismus wird des Öfteren im Sinne einer Nähe des jüdischen Messianismus zu einer politischen Utopie bestimmt, weil das Judentum, im Gegensatz zur christlichen Vorstellung einer rein innerlich geretteten Seele, Erlösung als Ereignis betrachtet, das sich notwendigerweise auf dem öffentlichen Schauplatz der Geschichte ereignen muss. ${ }^{1}$ Diese Unterscheidung gilt auch für messianische Vorstellungen moderner Denker und zeigt sich paradigmatisch im Vergleich zwischen Walter Benjamin und Giorgio Agamben. Ausschlaggebend ist dabei die Welthaltigkeit des Benjaminschen Messianismus, die Agambens Darstellungen - trotz seiner Berufung auf Benjamin, als dessen wichtigster Erbe er in der Gegenwart oft betrachtet wird - abgeht.

Agamben gilt heute vor allem in den politisch orientierten Kulturwissenschaften, aber auch in der Philosophie, Kunst- und Literaturtheorie als einer der anspruchsvollsten und umstrittensten Denker der Gegenwart. Agambens Diagnose des heutigen Weltzustands könnte schwärzer kaum sein und seine Vorstellungen von dessen Heilung kaum extremer. Die Vorstellung vom Heil, die er diesem gegenwärtigen Zustand entgegenhält, entspricht der Radikalität seines Katastrophendenkens. Agamben entlehnt seine Heilsvorstellung einer eher christlichen theologischen Gedankenwelt,

1 Vgl. Michael Löwy: Erlösung und Utopie. Jüdischer Messianismus und libertäres Denken. Eine Wahlverwandtschaft. Berlin 1997. Diese Unterscheidung verdankt sich in vieler Hinsicht dem Denken Gershom Scholems. Vgl. Gershom Scholem: Zum Verständnis der messianischen Idee im Judentum.

In: ders.: Judaica. Frankfurt a. M. 1963, S. 7. 
der er allerdings in seiner Auseinandersetzung mit bedeutenden, vor allem jüdischen Denkern der Moderne, eigene Konturen verleiht.

Die wichtigste Vorlage von Agambens Heilsvorstellungen ist der Messianismus Walter Benjamins. Dessen Struktur greift die Triade von Paradies, Fall und Erlösung auf und richtet sich ebenso gegen den Determinismus einer idealistischen Geschichtsphilosophie wie gegen den teleologischen Fortschrittsglauben des Historismus. Sie wird vielmehr von Diskontinuitäten bestimmt, die die lineare Chronologie durchbrechen und eine punktuelle Beziehung zu Vergangenheit und Zukunft eröffnen. Anstelle eines zeitlichen Kontinuums, das sich auf ein Ende der Geschichte hinbewegt, erkennt Benjamin in vereinzelten Erscheinungen und Figuren eine >schwache messianische Kraft‘, die es vermag, die >leere homogene Zeit` aufzubrechen und auf eine zukünftige Rettung voraus zu weisen. Agamben knüpft an diese Erscheinungsformen der Diskontinuität an, liquidiert dabei jedoch ihre konkreten Inhalte. In dieser entleerten Form erscheinen sie als `Indifferenzpunkte`, an denen sich das messianische Potential vollzieht. Dieser Unterschied, der mit jenem zwischen weltorientierten jüdischen Erlösungsvorstellungen und der Innerlichkeit christlicher einhergeht, zeigt sich am deutlichsten in einem Vergleich von Benjamins und Agambens Vorstellungen der Beziehung von Sprache und Gesetz zur Möglichkeit von Erzählungen in einer messianischen Welt.

\section{ERZÄHLUNG UND MESSIANISCHE SPRACHE ${ }^{2}$}

$\mathrm{Ob}$ es in einer messianischen Welt Erzählungen geben wird, mag als müßige Erkundung gelten, wenn die Vorstellung einer erlösten Menschheit nur noch der Ausgang einer längst totgesagten Großerzählung ist. Paradoxerweise bestätigt noch ein solcher Todesbefund das Weiterleben dieses grand récit, indem er, wie alle Messianismen, das Ende einer jahrtausendealten Geschichte verkündet: jener der Erlösungsvorstellungen selbst. Wenn es allerdings, wie Walter Benjamin schreibt, keine Erzählung

2 Der Abschnitt über den Vergleich von Benjamins und Agambens »Idee der Prosa« entstammt meinem längeren Aufsatz zu diesem Thema: Vivian Liska: "Wie Sonntagskinder«. Walter Benjamins und Giorgio Agambens Ideen der Prosa. In: Claudia Öhlschläger (Hrsg.): Narration und Ethik. Münster 2009, S. 37-52. gibt, die "an der Frage: Wie ging es weiter? ihr Recht verlöre ${ }^{3}$, so ist die Frage nach dem Erzählen am Ende der Geschichte ebenso legitim wie jene nach der Fortsetzung der geschichtsphilosophischen Großerzählung selbst. Eine mögliche Variante dieser Fortsetzung lässt sich aus dem Wandel jüngerer Auffassungen vom Verhältnis zwischen epischen Formen und messianischen Erlösungsvorstellungen herauslesen.

Von Hegel bis Lukács ist es am Anfang das Epos, in dem die menschliche Erfahrung in ihrer Einheit und Totalität erfasst ist. Die Epik, die älteste Darstellung der Geschichte in heroischen Gesängen, wurde in der Poesie aufgehoben wie diese ihrerseits in der entzauberten, nicht länger ganzheitlichen Prosa. Im Dienste einer universalen Geschichtsschreibung zielt Prosa auf eine Totalität, die in eine dem ursprünglichen Epos angeglichene Ganzheit münden soll. Bei Benjamin ist die Auffassung einer stets fortschreitenden, am Schluss zu sich selbst kommenden Entwicklung der Geschichte ebenso in eine Krise geraten wie das kontinuierliche Erzählen. Die Triade von Paradies, Sündenfall und noch ausstehender Erlösung erlebt zwar in seinem messianischen Denken einen Höhepunkt, doch ist sie nunmehr von Diskontinuitäten geprägt, die auch seine Erzähltheorie kennzeichnen. Zwischen Vergangenheit und Gegenwart gibt es keine verketteten Zusammenhänge, sondern nur punktuelle und flüchtige Erfahrungen und Figuren, die der erlösten Zeit vorausleuchten. Ebenso ist spätestens nach dem ersten Weltkrieg das Erzählen verloren gegangen und nur noch als Darstellung der eigenen Unmöglichkeit oder eben als Modell der Geschichtsschreibung einer messianischen Zeit denkbar.

Wenige Jahre nach Benjamins Tod - und wohlgemerkt nach der Zäsur von Auschwitz - stimmt Adorno zwar weitgehend dessen Ursprungs- und Verfallsgeschichte zu, doch das dritte Glied der Triade, die erlöste Menschheit, gilt ihm nur als fiktive Perspektive, die hergestellt werden soll, um ein "messianisches Licht" auf das falsche Bestehende zu werfen. Der konstitutiven Brüchigkeit der Prosa im Gegensatz zum gebundenen, mythischen Gesang fällt dabei die Rolle zu, die Distanz zur messianischen Welt zu markieren, wobei, wie es im letzten Abschnitt von Minima Moralia heißt, deren "Wirklichkeit oder Unwirklichkeit»

3 Walter Benjamin: Der Erzähler. In: ders.: Gesammelte Schriften II, 2. Hrsg. von Rolf Tiedemann, Hermann Schweppenhäuser. Frankfurt a. M. 1991, S. 438-465, hier S. 455. Im Folgenden im Text (GS, Band, Teil, Seitenangabe). 
letztlich »fast gleichgültig« ist. ${ }^{4}$ Zum »Messianischen ohne Messianismus» Jacques Derridas, der den religiösen Erlösungsbegriff lediglich als kulturgeschichtlichen Nachklang für seine Vorstellung der in jedem Sinne unendlichen Erwartung eines gänzlich unvorhersehbaren "Kommenden « beansprucht, ist es nicht mehr weit. ${ }^{5}$ Angesichts gleichzeitiger realpolitischer und theoretischer Entwicklungen, die geschichtsphilosophische Triaden und Teleologien samt und sonders verabschieden, ist der dezidierte Rückgriff auf das messianische Gedankengut Benjamins in den Schriften Giorgio Agambens umso überraschender. ${ }^{6}$

Agamben, der Adornos Fiktionalisierung der Erlösungvorstellung $e x$ negativo und 'vom Ende her e ebenso zurückweist wie Derridas hypothetische Funktionalisierung des Messianischen als eines endlos vorausweisenden, regulativen Leitsterns, übernimmt in seinen Schriften wesentliche Aspekte von Benjamins messianischem Denken und trägt dieses mittels selektiver Schwerpunktverschiebungen in eine Richtung weiter, die sich explizit von Adornos und Derridas Schwundformen des Messianischen absetzt. ${ }^{7}$ Die Verschiebung, die Agamben an Benjamins messianischem Denken vornimmt, setzt bei den vielfältigen Erscheinungsformen der Diskontinuität an, die dieser in die heilsgeschichtliche Triade einschreibt.

4 Theodor W. Adorno: Minima Moralia. Reflexionen aus dem beschädigten Leben. Berlin, Frankfurt a. M. 2001, S. 480-481.

5 Jacques Derrida: Marx \& Sons. Frankfurt a. M. 2004, S. 81.

6 Agambens Denken widerlegt Christoph Schultes Diagnose, dass der »linksintellektuelle utopische Messianismus« in der Gegenwart verblasst ist. Schulte schließt seinen Aufsatz mit der Bemerkung, dass »falls, und das lässt sich aufgrund historischer Erfahrungen nicht ausschließen, im 21 Jahrhundert wieder ein utopischer Messianismus aktuell werden sollte, dies [...] wahrscheinlich eher ein [...] universalistischer, reformistischer, ethischer Sozialismus sein wird, statt einer spät- und antibürgerlichen Apokalyptik wie bei Bloch und Benjamin.« Der jüngste Erfolg von Agambens Theorien widerlegt diese Behauptung. Schulte fügt allerdings hinzu, dass »der internationalistische Messianismus nach 1968 noch einmal Konjunktur hatte, aber vor allem bei christlich sozialisierten Intellektuellen." Möglicherweise wäre Agamben hier einzureihen. (Christoph Schulte: Der Messias der Utopie. In: Evelyn Goodman-Thau u. a. (Hrsg.): Die Wehen des Messias. Zeitwenden in der jüdischen Geschichte. Berlin, Wien 2001, S. 135-162, hier S. 159-160.)

$7 \mathrm{Zu}$ Agambens Kritik an Adorno vgl. Giorgio Agamben: Die Zeit, die bleibt. Frankfurt a. M. 2006. Im Folgenden im Text (ZB, Seitenangabe). $\mathrm{Zu}$ seiner Kritik an Derridas Messianismus: Ebd., S. 117.
Die messianischen Kräfte, die für Benjamin das Zeitkontinuum aufsprengen und auf die erlöste Welt vorausweisen, verabsolutiert Agamben bis zu einem Punkt, an dem sie nicht länger Unterbrechung und Abbruch einer falschen Kontinuität und rettende Hoffnungsträger sind, sondern zu einem Selbstzweck geraten, der den Erfahrungsgehalt und die Welthaltigkeit der Benjaminschen messianischen Kräfte gegen ein von Heidegger inspiriertes experimentum linguae ${ }^{8}$, einer Entbergung ‘ der Sprache, eintauscht. Diese ereignet sich an abstrakten Orten der Diskontinuität, an der Schwelle, am Grenzpunkt, an der Schnittstelle selbst. Die Welthaltigkeit, die Benjamins Messianismus - bei allen Differenzen zu einer ausgeformten Utopie - mit einem utopischen Denken verbindet, geht dabei verloren. Am Begriff der »Idee der Prosa«, den Agamben von Benjamin übernimmt, lässt sich dieser Unterschied exemplarisch aufweisen.

\section{BENJAMINS IDEE DER PROSA}

Benjamin hat der Frage nach dem swie weiter? der Erzählungen, die dem Mund glücklich lauschender Kinder zu entspringen scheint, keine Lösung versprochen. Ebenso wenig - und hier liegt der Unterschied zu ausgesprochen utopischen Vorstellungen - gibt es für ihn eine Antwort auf die Frage, »in welcher Verfassung sich die serlöste Menschheit befinden wird, welchen Bedingungen das Eintreten dieser Verfassung unterworfen ist und wann man mit ihm rechnen kann." (GS, $I, 3,1232)$ Anstelle einer Antwort weisen die in seinem Werk verstreuten messianischen Splitter auf Vorformen dieser Verfassung hin. ${ }^{9}$ Sie sind in Benjamins Werk in vielfältigen Erfahrungen und Figuren zu finden: von

8 Reimar Klein spricht in seinem Nachwort zu Agambens Buch Idee der Prosa vom »experimentum linguae, als das Agamben sein ganzes Werk betrachtet«. (Reimar Klein: Nachwort. In: Giorgio Agamben: Idee der Prosa. Frankfurt a. M. 1987, S. 163. Im Folgenden im Text (IP, Seitenangabe). 9 Vgl. Irving Wohlfarth: »There are, at all events, several further indications that the messianic splinters, which by rights represent no more than the isolated premonitions of better things to come, nevertheless furnish privileged examples of the way in which the integral resurrection of the world is to be conceived. Preliminary, fragmentary and idiosyncratic though they are, the profane modalities of the messianic are, in any case, its only visible and accessible forms." (Irving Wohlfarth: On the Messianic Structure of Walter Benjamin's Last Reflections. In: Samuel Weber (Hrsg.): Glyph Johns Hopkins Textual Studies 3 (1978), S. 148-212, hier S. 180.) 
der mémoire involontaire zur >leibhaftigen Geistesgegenwart‘, vom Wartenden zum Flaneur, vom Übersetzer zum materialistischen Historiker, vom Gehilfen zum Gerechten. Zu ihnen gehören der Chronist und dessen säkularisierte Erscheinungsform, der Erzähler. Zwar enthält Benjamins Aufsatz »Der Erzähler « ${ }^{10}$ kaum messianische Anklänge, doch eine Notiz aus dem Umfeld von Benjamins kurz vor seinem Tod verfassten geschichtsphilosophischen Thesen gibt Hinweise auf die "Verfassung der erlösten Menschheit", die auch die Frage nach dem Erzählen in einer messianischen Welt betreffen. Diese Notiz nähert sich der Vorstellung einer Sprachutopie:

Die messianische Welt ist die Welt allseitiger und integraler Aktualität. Erst in ihr gibt es eine Universalgeschichte. Was sich heute so bezeichnet, kann immer nur eine Sorte von Esperanto sein. Es kann ihr nichts entsprechen, eh die Verwirrung, die vom Turmbau zu Babel herrührt, geschlichtet ist. Sie setzt die Sprache voraus, in die jeder Text einer lebenden oder toten ungeschmälert zu übersetzen ist. Oder besser, sie ist diese Sprache selbst. Aber nicht als geschriebene, sondern vielmehr als die festlich begangene. Dieses Fest ist gereinigt von jeder Feier. Es kennt keine Festgesänge. Seine Sprache ist integrale Prosa, die die Fesseln der Schrift gesprengt hat und von allen Menschen verstanden wird wie die Sprache der Vögel von Sonntagskindern. (GS, I,3, 1239)

Andere Versionen dieses Fragments in Benjamins Notizen enden mit einem Nachsatz und einem Verweis: „Die Idee der Prosa fällt mit der messianischen Idee der Universalgeschichte zusammen (siehe auch Erzähleraufsatz.)« Die ausführlichste Variante der Notiz enthält einen zusätzlichen Hinweis auf »die Arten der Kunstprosa als das Spektrum der universalhistorischen - im $>$ Erzähler « $(G S, I, 3,1238) .{ }^{11}$ Es mag nicht übertrieben sein, in Benjamins später Notiz selbst ein prismatisches Spektrum zu sehen, das die in seinem Werk auf Geschichte, Sprache und Erzählung bezogenen verstreuten messianischen Funken in sich versammelt.

Benjamins Notiz entwirft die »Verfassung der erlösten Menschheit« als allumfassende, erfüllte Präsenz von Sprache und Geschichte. Erst in

10 Benjamin: Der Erzähler (wie Anm. 3).

11 Siehe weitere Versionen (GS, I, 3, 1234 und 1235). einer messianischen Welt, erst am Ende der Zeiten und von ihrem Ende her kann die Geschichte in ihrer Totalität erzählt werden. Benjamin richtet sich dabei gegen den "gemächlich erzählenden Historismus« (GS, $\mathrm{I}, 3,1248)$ des 19. Jahrhunderts, der "noch wähnt, die Geschichte episch ausbreiten zu können $\aleph^{12}$, eine heile Welt vortäuscht, sich dabei in die Sieger der Geschichte einfühlt und der Verknechtung der Menschheit nicht Rechnung trägt. Voraussetzung für eine rechtmäßige und gerechte Universalgeschichte, die erst der erlösten Menschheit zufällt, ist die Heilung der Sprachverwirrung in einer 'von allen Menschen verstandenen Universalsprache, die an Benjamins frühe Aufsätze »Über Sprache überhaupt und über die Sprache der Menschen « (GS, II,1, 140-157) und »Die Aufgabe des Übersetzers« (GS, IV,1, 9-21) anklingt. Integrale Aktualität - erfüllte Gleichzeitigkeit allen Geschehens - äußert sich in einer von Schrift und Zeichen, von Vermittlung und Differenz befreiten Sprache, die die Natur von ihrer stummen Trauer erlöst und sie mit den Menschen in Einklang bringt..$^{13}$ Mit dem Begriff "Idee der Prosa «, der Benjamins Dissertation Der Begriff der Kunstkritik in der deutschen Romantik (GS, I,2, 7-123) entstammt, und mit dem Hinweis auf den Erzähleraufsatz greift diese Stelle neben den Sprachaufsätzen allerdings auch zwei frühe Texte Benjamins auf, in denen es weniger um Sprache als um epische Formen geht. In welchem Verhältnis können Unmittelbarkeit und »integrale Aktualität« zur Erzählung stehen, die immer auch Spannung, Differenz und Aufschub, Vermittlung und Mitteilbarkeit voraussetzt?

Benjamins Nachtrag zur Notiz, der nach der Erwähnung der messianischen »Idee der Prosa « auf »die Arten der Kunstprosa als das Spektrum der universalhistorischen - im `Erzähler« « (GS, I,3, 1238) verweist, deutet auf eine Wendung im Erzähleraufsatz hin, in der Benjamin die Geschichtsschreibung als »die schöpferische Indifferenz zwischen allen Formen der Epik« (GS, II,2, 451) darstellt. »Dann«, so Benjamin weiter, "würde sich die geschriebene Geschichte zu den epischen Formen

12 Irving Wohlfarth: Krise der Erzählung, Krise der Erzähltheorie. Überlegungen zu Lukács, Benjamin und Jauss. In: Rolf Klopfer und Gisela Janetzke-Dillner (Hrsg.): Erzählung und Erzählforschung im 20. Jahrhundert. Stuttgart 1981, S. 269-288, hier S. 278.

13 Die »Sprache der Vögel, die von Sonntagskindern verstanden wird« steht in Zusammenhang mit Benjamins frühem Sprachaufsatz, in dem von der „Verwandtschaft des Gesanges mit der Sprache der Vögel« die Rede ist. (GS, II, 1, 156) Benjamins Betrachtungen zur »Trauer der Natur« über ihre Stummheit entstammen demselben Aufsatz (GS, II, 1, 155). 
verhalten wie das weiße Licht zu den Spektralfarben.«(Ebd.) Der Begriff der »schöpferischen Indifferenz« - die kreative Möglichkeit, Polaritäten und Kontrastierungen in Einklang zu bringen - bezeichnet bei Benjamin eine alternative, romantisch gewendete Form der Aufhebung, die sich der Idee des Fortschritts und dem dialektischen Verlust des Konkreten entzieht. Das weiße Licht der Geschichtsschreibung, der alle epischen Formen inhärent sind wie der Prosa alle poetischen, wäre nur scheinbar ein einheitliches. Die Reinheit dieses Lichts wäre keine Leere, keine Abwesenheit von Farbe, sondern eine vollkommene Fülle. Benjamin erläutert diese Gedankenfigur in Anklängen an Hegels Gattungsbestimmung:

Wenn nämlich ... die Geschichtsschreibung die schöpferische Indifferenz der verschiedenen epischen Formen darstellt (wie die große Prosa die schöpferische Indifferenz zwischen verschiedenen Maßen des Verses), so schließt deren älteste Form, das Epos, kraft einer Art von Indifferenz die Erzählung und den Roman ein. (GS, II,2, 453)

Anders als bei Hegel bleiben in dieser vertikalen Schichtung alle niedrigeren Formen ohne Verlust in den höheren bewahrt. In der darauf folgenden Unterscheidung zwischen Erzählung und Roman ist es deutlich die Erzählung, die als säkularisierte Form der Chronik auf eine messianische Prosa vorausweist. Die »Idee der Prosa «, die Benjamin in seiner Notiz als Form der Universalgeschichte einführt, erscheint als letzte in dieser Reihe von Aufhebungen. Sie wird nicht durch ein hegelianisches teleologisches Voranschreiten erreicht, sondern in der messianischen Erfüllung. In der »Idee der Prosa" wirken die Potentiale aller in ihr aufgehobenen Formen weiter. Im allumfassenden Licht der messianischen Idee der Universalgeschichte, die mit der »Idee der Prosa« zusammenfällt, bleibt demnach auch die Erzählung als eine Farbe seines Spektrums erhalten.

Wenn Prosa in Benjamins Kunstkritik-Aufsatz die »Idee der Poesie« ist, in der alle poetischen Formen befreit werden, so ist die messianische "Idee der Prosa « - dem Modell der "schöpferischen Indifferenz« entsprechend - die höchste Stufe: Es ist die Universalgeschichte, die alle »Arten der Kunstprosa « in sich enthält wie das "weiße Licht « der "geschriebenen Geschichte« die Spektralfarben der epischen Formen. Sie erfasst alles, was sich je zugetragen hat und befreit es von seinen kodifizierten Bindungen, ja von seiner Künstlichkeit selbst. Dieses messianische Fest der Freiheit enthält daher auch keine Festgesänge, kehrt also nicht unverwandelt zu den heroischen Gesängen des Epos zurück: Es ist nüchtern und »allseitig« wie die im Kunstkritik-Aufsatz dargestellte Prosa. Allseitig ist diese »Idee der Prosa " nicht nur als Form, die alle anderen Kunstformen umfasst, sondern als universale Erzählung, die die gesamte Erfahrung der Kreatur in sich aufnimmt und bewahrt.

Im Erzähleraufsatz, auf den der Nachtrag in Benjamins Notiz hinweist, stehen zwei gegensätzliche Figuren für das Erzählen ein. Die eine entstammt weder einer mystischen Sprachphilosophie noch einer theologischen Geschichtsphilosophie, sondern der Literatur. Es ist Scheherezade, die, so Benjamin, »in jedem Erzähler steckt" und »der zu jeder Stelle ihrer Geschichten eine neue Geschichte einfällt» (GS, II,2, 453). Die zweite, quasi gegenläufige Figur ist aus dem Leben gegriffen: es ist der Sterbende. Beide Figuren erhalten in Benjamins Ausführungen eine messianische Dimension, die sie mit der Vorstellung einer Universalgeschichte am Ende der Zeiten in Einklang bringt. Scheherezade, die zwar jene >unmessianische` Bewegung der Erzählung verkörpert, das Ende aufzuschieben, ist für Benjamin jedoch gleichzeitig auch die Statthalterin der epischen Erinnerung, die »das Netz stiftet, das alle Geschichten miteinander am Ende bilden« (ebd.). Die Erzählung des Sterbenden entsteht hingegen als Rückblick, aus der »Folge von Bildern seines Lebens, die sich in seiner letzten Stunde in Bewegung setzt «. Der »Stoff, aus dem Geschichten werden«, ist, heißt es dort, »sein gelebtes Leben«, das am Sterbenden »tradierbare Gestalt annimmt « und »allem was ihn betraf, die Autorität mit[teilt], die auch der ärmste Schächer im Sterben für die Lebenden um ihn her besitzt." (GS, II,2, 449) Die "Begabung" des Erzählers - wie jene des Sterbenden - ist es, "sein ganzes Leben erzählen zu können« (GS, II,2, 464). Die Universalgeschichte ist dazu die kollektive Analogie: Sie erzählt die ganze Geschichte aller Geschöpfe auf Erden von ihrem messianischen Ende her. Wie dem Sterbenden, und sei's der ärmste Schächer, fällt ihr am Ende die gesamte Vergangenheit zu; alle hierarchischen Unterschiede sind aufgehoben. "Am Ursprung des Erzählten«, schreibt Benjamin, »steht diese Autorität." (GS, II,2, 450) $)^{14}$

Eine Notiz zu dieser Stelle führt die widersprüchlichen Bewegungen von Scheherezades unendlichem Aufschub und der rückblickenden Ganzheit der Erzählung des Sterbenden zusammen. Was am Erzähler

14 Bemerkenswert ist, dass diese Geschichte sich auf außersprachlichen, körperlichen Wegen mitteilt: In der messianischen Universalgeschichte, die nicht mehr beschrieben, sondern - ebenfalls sprachlos - festlich begangen wird, kehrt die Erzählung zu diesem Ursprung zurück und macht aus dem Sterbenden eine Vorform des messianischen Erzählers. 
»das Wunderbarste ist «, heißt es dort, ist, »dass er so wirkt als könne er sein ganzes Leben erzählen, alles Erzählte sei nur erst ein Stück seines ganzen Lebens" (GS, II,3, 1282). Es ist dies der messianische Anteil Scheherezades, deren Geschichten vom Ende aus gesehen so wirken, als seien sie Teil des ganzen Netzes. Wenn, wie Benjamin schreibt, »in jedem Erzähler eine Scheherezade steckt « (GS II,2, 453), so steckt in jeder Scheherezade auch ein Sterbender - oder eher ein Scheintoter, der an jeder Stelle, also auch nach dem Ende, neu anheben kann, erzählen kann, "wie es weitergeht" (GS, II,2, 455). So wird auch das Ende jeder Erzählung zur Gelegenheit einer neuen. Scheherezade ist es, die die Kraft der Erzählung und somit auch alles - die Negation eines Endes und die Möglichkeit eines Neubeginns - in eine messianische Welt hinüberrettet. Gemeinsam verkörpern Scheherezade und der Sterbende messianische Figuren, die im Spektrum der "Idee der Prosa « die Doppelbewegung von Aufschub und Rückblick, Unendlichkeit und Abschluss, »die Hoffnung und die Erinnerung « ${ }^{15}$ bewahren. Im Begriff der "Idee der Prosa" liegt nicht nur die reine, vollkommene und in sich abgeschlossene Idee, sondern eben auch die Prosa als allseitige, mannigfaltige und welthaltige Erzählung der gesamten Kreatur. In der messianischen Welt Benjamins erfüllt sich die restitutio in integrum des Vergangenen in der Form eines aus dem Stoff des "gelebten Lebens" gesponnenen Netzes von Geschichten.

Am Schluss des Erzähleraufsatzes bestimmt Benjamin den Erzähler als Gestalt, in der »der Gerechte sich selbst begegnet." (GS, II,2, 465) Der Erzähler steht dafür ein, dass nichts, das sich je ereignet hat, vergessen wird. Damit wird er am jüngsten Tag zum »Fürsprech der Kreatur« (GS, II,2, 459). Der integralen Prosa, der er sich dabei bedient, fällt die Aufgabe zu, die Partikularität jeder einzelnen Erscheinung zur Gänze zu bewahren und »allen Geschöpfen Gerechtigkeit widerfahren zu lassen. $«^{16}$ Eine Namenssprache wäre sie insofern, als sie nicht mehr bezeichnete, sondern in einem quasi sprachmagischen, performativen Gestus - dem Begehen eines Fests gleich - hervorruft, was sie benennt. Benjamins messianische Ethik der Erzählung liegt im Wunsch einer vollständigen Erzählbarkeit begründet, die mit dieser höchsten Form von Aufmerksamkeit die Dinge beim Namen nennt.

15 Benjamin zitiert diese Begriffe in seinem Erzähleraufsatz aus Lukács Theorie des Romans (vgl. GS, II,2, 454).

16 Irving Wohlfarth: Krise der Erzählung (wie Anm. 12), S. 281.

\section{AGAMBENS "IDEE DER PROSA»}

1985 veröffentlicht Giorgio Agamben einen Sammelband poetisch-philosophischer Kurztexte mit dem Titel Idea della Pros $a^{17}$, in dem ein Text ebenfalls diesen Titel trägt. Agambens Beschäftigung mit dem Begriff »Idee der Prosa« beginnt ursprünglich mit seinem 1983 erschienenen Aufsatz »Walter Benjamin. Tempo storia linguaggio«, der zur Gänze Benjamins später Notiz über die Verfassung der messianischen Welt gewidmet ist. ${ }^{18}$ Agamben versteht diesen Aufsatz explizit als kommentierende Lektüre von Benjamins Notiz über die messianische Welt. Der Nachdruck seiner Kommentare liegt dabei auf Benjamins Sprachphilosophie; in der Version der Notiz, die Agamben eingangs zitiert, fehlt allerdings der nachgetragene Verweis auf den Erzähleraufsatz. Über Augustin, Varro, Dante und Wittgenstein und in Paraphrasen von Benjamins frühem Sprachaufsatz und seinem Übersetzeraufsatz erläutert Agamben den Zusammenhang zwischen Sprache und Geschichte aus der Diskrepanz zwischen der ursprünglichen Namenssprache und der historisch vermittelten, immer schon tradierten und daher unauthentischen Sprache der zwischenmenschlichen Kommunikation. Seine Interpretation von Benjamins "Idee der Prosa « begleiten dabei unverkennbar Heideggersche Untertöne: Der Sündenfall in Benjamins Sprachtheologie fällt bei ihm mit einer Sprachvergessenheit zusammen, deren Entbergung die Aufgabe des Denkens schlechthin darstellt.

Als Urzeichen, so Agambens Erklärung von Benjamins Notiz, liegen die Namen immer schon jeder Rede voraus und entziehen sich dem Zugriff. Weil die Namen weder erreichbar noch hintergehbar sind, ist ein voraussetzungsloses Denken in einer Zeichensprache nicht möglich. Die Vermittlung, der die Namen durch die Geschichte unterworfen sind, bedingt eine unendliche Verkettung von Voraussetzungen, die das Denken

17 Giorgio Agamben: Idea della prosa. Milano 1985.

18 Giorgio Agamben: Walter Benjamin: tempo storia linguaggio. Rom 1983. Hier zitiert aus Giorgio Agamben: Language and History. Linguistic and Historical Categories in Benjamin's Thought. In: ders. Potentialities. Collected Essays in Philosophy. Hrsg. von Daniel Heller Roazen. Stanford 1999, S. 48-62. Im Folgenden im Text (P, Seitenangabe). 
und den Menschen überhaupt gefangen hält. ${ }^{19}$ Dieses Sprachverständnis einer Gefangenschaft in der Vorstellung überträgt Agamben auf Benjamins Geschichtsphilosophie. Weil Geschichte gleichzeitig mit dem Fall der Sprache aus ihrer ursprünglichen Unmittelbarkeit entstanden ist, fällt das Ende der Geschichte mit dem Ende der kommunikativen Zeichensprache und der Restitution der adamitischen Namenssprache zusammen. Für Agamben zielt Benjamins »Idee der Prosa « auf das messianische Ende einer als Schicksal und daher Unfreiheit begriffenen Geschichte. Dies entspricht in vieler Hinsicht der Ausrichtung des Geschichtsverständnisses in Benjamins Notiz. Indem Agamben jedoch den Hinweis auf den Erzähleraufsatz und die Bedeutung der Prosa als epische Form nicht berücksichtigt und die »Idee der Prosa« zur Gänze mit der ১Idee der Sprache ‘ identifiziert, mündet seine Auffassung des Begriffs in eine Ästhetik der Leere und eine Ethik der Bezuglosigkeit, die Benjamin kaum unterschrieben hätte. Diese Ethik bestimmt auch noch Agambens Interpretation von Benjamins »Idee der Prosa«. Sie gilt dort zudem nicht nur als Aufgabe des Philosophen, sondern wird zur ethischen Aufgabe schlechthin.

Von der in Benjamins »Idee der Prosa« enthaltenen Vorstellung einer zukünftigen integralen Aktualität, also einer erfüllten Jetztzeit, auf die bei ihm die Figuren des Erzählers und Chronisten, Scheherazade und der Sterbende vorausweisen, ist bei Agamben keine Spur. Zu einer Ethik und Politik der Gerechtigkeit führt von Agambens experimentum linguae kein Weg. Dies liegt in der Natur eines Denkens, in dem es nicht um Wege oder Vorausweisungen geht, sondern um Einschnitte, Schwellen und Leerstellen, die in keinem Bezug mehr zu jenem stehen, das sie unterbrechen. So geht es bei Agamben zuletzt nur noch um die Verabsolutierung der Diskontinuität selbst. Dies steht im Gegensatz zur Welthaltigkeit von Benjamins Messianismus - ein Gegensatz, der auch im Vergleich zwischen Agambens und Benjamins Haltung zum Gesetz zum Ausdruck kommt. Während Agamben staatliches und jüdisches Gesetz in eins setzt, unterscheidet Benjamin zwischen ihnen. Aus diesem Unterschied ergeben sich fundamentale Unterschiede in ihren messianischen Vorstellungen.

19 Agamben schreibt: »As long as human beings cannot reach the origin of language, there will be the transmission of names. And as long as there will be transmission of names, there will be history and destiny« $(P, 51)$.

\section{AGAMBEN UND DAS GESETZ}

In seinem Brief an Gershom Scholem vom 15. September 1934 nennt Benjamin seine Arbeit zu Kafka »den Kreuzweg der Wege meines Denkens « ${ }^{20}$ Ähnliches könnte Agamben sagen, wobei dieser, wie noch zu zeigen ist, den »Kreuzweg « in doppeltem Sinne beim Wort nimmt: als in entgegengesetzte Richtungen gleichzeitig weisenden Punkt der Ununterscheidbarkeit und als letzten irdischen Weg des Erlösers. In seinen Interpretationen von Kafkas Erzählungen distanziert sich Agamben von der Lesart verschiedener seiner Vorgänger, gegen die er häufig namentlich argumentiert. Am radikalsten widerlegt er Jacques Derrida und gibt dabei vor, Benjamins Perspektive auf Kafkas Werk zu übernehmen. Im Laufe seiner Argumentation verschiebt Agamben jedoch Benjamins Position in Richtung christlicher Vorstellungen und macht schließlich sowohl Benjamin wie auch Kafka zu Jüngern des Apostels Paulus.

»Vom politisch-juridischen Standpunkt aus betrachtet«, schreibt Agamben in Homo sacer, »ist der Messianismus eine Theorie des Ausnahmezustands; nur wird ihn eben nicht die geltende Autorität ausrufen, sondern der Messias, der ihre Macht subvertiert. $\ll^{21}$ Den Antinomien messianischen Denkens entsprechend beruhen die Bedingungen der Erlösung - des `wirklichen Ausnahmezustands - Agamben zufolge also auf derselben Struktur wie jene des Verfalls, des negativen Ausnahmezustands der Welt in ihrer derzeitigen Form: In beiden gilt die Selbstsuspendierung des Gesetzes. Bannt jedoch der schlechte Ausnahmezustand den gesamten Planeten in das lebenszerstörende Gesetz, so enthebt der von Benjamin übernommene Begriff eines »wirklichen«, messianischen Ausnahmezustands die Geltung des Gesetzes und erlöst das nackte Leben aus dem Bann in eine neue Freiheit, eine unauflösbare Lebensform. Erst wenn das Leben das Gesetz, und nicht das Gesetz das Leben wie im heutigen Ausnahmezustand, gänzlich subsumiert hat, löst sich der Bann und tritt der Zustand der erlösten Menschheit ein.

20 Walter Benjamin: Briefe. Bd. 2. Hrsg. von Gershom Scholem, Theodor W. Adorno. Frankfurt a. M. 1966, S. 620. Im Folgenden im Text (BB, Seitenangabe).

21 Giorgio Agamben: Homo Sacer. Frankfurt a. M. 2002, S. 68. Im Folgenden im Text (HS, Seitenangabe). 
Der Umschlag vom Leben unter dem bannenden Gesetz in einen Zustand, in dem die Geltung des Gesetzes endgültig aufgehoben ist, ereignet sich für Agamben exemplarisch in Kafkas Parabel »Vor dem Gesetz«. In der Situation des Manns vom Lande, der vom Türhüter vor dem Gesetz nicht eingelassen wird, zeigt sich für ihn in reinster Form die Macht des Gesetzes, das keine Bedeutung mehr hat, aber dennoch zu gelten nicht aufhört. Kein Gebot verbietet dem Mann den Eintritt in das Gesetz, doch ist er von diesem buchstäblich in einem Bann befangen, der ihn gleichzeitig ein- und ausschließt, ihn weder eintreten noch ihn sich vom Gesetz abwenden lässt. Im Gegensatz zu herkömmlichen Interpretationen, die in der Parabel ein Scheitern des Mannes vom Lande sehen, der vergeblich vor der Tür des Gesetzes verharrt, bis der Türhüter sagt »ich gehe jetzt und schließe sie«, versteht Agamben das Verhalten des Mannes als »komplizierte und geduldige Strategie, die Schließung zu erreichen, um die Geltung [des Gesetzes] zu unterbrechen." (HS, 66) Damit wird jene »schlechte Unendlichkeit«, die er explizit Derridas Interpretation der Parabel vorhält, beendet: In der konstitutiven Unabschließbarkeit, die Derrida aus der Parabel herausliest, sieht Agamben einen »blockierten Messianismus« (ZB, 117), der zur Paralyse des gegenwärtigen Zustands beiträgt. Dieser Haltung steht die Provokation von Agambens Mann vom Lande entgegen, die zum Schließen der Gesetzestür führt: Er erfüllt die messianische Aufgabe der Aufhebung des Gesetzes und führt dabei den Umschlag des bannenden in den wirklichen Ausnahmezustand herbei. Den Glanz, der dabei vom Gesetz her durch die Tür scheint - oft als Schechinah, als göttliche Pracht gedeutet - erwähnt Agamben nicht.

Agamben spricht explizit von einer Strategie - also einer kalkulierten Zielsetzung - des Manns vom Lande, mit der er die Türe zum Schließen und das Gesetz zu seiner Aufhebung bringt. Eine solche zielstrebige Ausrichtung steht allerdings im Gegensatz zu Benjamins prägnantester Vorstellung der "Herbeiführung des wirklichen Ausnahmezustands. "Benjamins Figur, in der »messianische Intensität « und »Dynamis des Profanen« zwei parallele, in entgegengesetzte Richtungen weisende, einander beschleunigende Pfeile abgeben, hat nicht die zielstrebige - also "strategische« Deaktivierung des Gesetzes im Blick. Nicht an dessen profanierender Ungültigkeitserklärung ist die Herbeiführung des Reichs auszurichten, sondern am profanen und irdischen Glückstreben der Menschheit selbst. ${ }^{22}$

22 Benjamins Vorstellung ist, so Irving Wohlfarth, »mit dem antinomischen Modell einer profanen Übertretung höherer Gesetze nicht zu vereinen ... Mit einem Wort: Er ist profan, nicht profanierend«. (Irving Wohlfarth:
Agamben betont hingegen den destruktiven Impuls und dessen Nähe zum häretischen Messias Shabbetai Zevi, für den »die Übertretung der Tora ihre Erfüllung « und »die Erfüllung der Tora deren Vergessen ist.« ( $P$, 167-168) Diese mystisch inspirierte Antinomie schließt Agamben mit der Deaktivierung der Tora, der geschriebenen Gesetzesordnung, bei Paulus zusammen und diese wiederum mit seiner eigenen Vorstellung einer Therapie des heutigen Weltzustands. Benjamin hatte in seiner Lektüre von Kafka und dem Gesetz eine andere Vorstellung einer kommenden Gerechtigkeit.

\section{BENJAMIN, HALACHA AND HAGGADAH}

Agamben leitet seine Lektüre von Kafkas »Vor dem Gesetz« mit der Behauptung ein, er interpretiere die Parabel »aus der Perspektive von Walter Benjamins Konzeption eines messianischen Gesetzes« $(P, 172)$. Benjamin selbst gibt nirgendwo eine ausführliche Interpretation der Parabel und spricht lediglich von der "wolkigen Stelle in deren Mitte, die zu »nicht enden wollenden Erwägungen« Anlass gibt. ${ }^{23}$ In seinen Notizen zu einem Brief an Gershom Scholem nennt er das Gesetz sogar den »toten Punkt« in Kafkas Werk. (BK, 154) Allerdings befassen sich Benjamins Ausführungen zu Kafka in seinem großen Essay Franz Kafka. Zum zehnten Jahrestag seines Todes (BK, 9-38), aber auch in seinem Briefwechsel mit Scholem über den Prager Autor ausführlich mit Fragen des Gesetzes. In diesen Schriften vertritt Benjamin Ansichten über eine kommende Gerechtigkeit, die sich sehr deutlich von Agambens Paulinischer Lektüre unterscheiden.

Ohne Zweifel gibt es Ähnlichkeiten zwischen Benjamins und Agambens Ansichten über das säkulare Rechtssystem. Wie Agamben sieht auch Benjamin in den staatlichen Gesetzen verborgene Instrumente einer missbräuchlichen Souveränität. In seinem Essay »Zur Kritik der Gewalt« (GS, 179-203) weist er auf die mythische Natur der Gesetze

Nihilistischer Messianismus. Zu Walter Benjamins Theologisch-politischem Fragment. In: Ashraf Noor und Josef Wohlmuth (Hrsg.): गJüdischer und >christliche< Sprachfigurationen im 20. Jahrhundert. Paderborn 2002, S. 141-214, hier S. 182.)

23 Benjamin über Kafka. Texte, Briefzeugnisse, Aufzeichnungen. Hrsg. von Hermann Schweppenhäuser. Frankfurt a. M. 1981, S. 20. Im Folgenden im Text (BK, Seitenangabe). 
hin und in seinen Texten zu Kafka zeigt er, wie das Rechtssystem seine übermächtige Gewalt überall rücksichtslos ausübt. Es dringt so tief in die persönlichsten und intimsten Bereiche der menschlichen Existenz ein, dass es, in Agambens Worten, "ununterscheidbar vom Leben selbst wird « (HS, 63). Wie Agamben sieht auch Benjamin in Kafkas Romanen Der Proceß und mehr noch in Das Schloß eine zutreffende Illustration einer Welt, in der dunkle Gesetzesinstanzen den Menschen unbegründete, undurchsichtige und repressive Vorschriften auferlegen, während ihnen das Gesetz, dem sie unterworfen sind, unbekannt bleibt. Für Benjamin ist die schreckliche Welt von Kafkas Romanen eine des »Sumpfdaseins der Menschheit in gänzlicher Promiskuität« (BK, 130). Diese Sumpfwelt ist vor allem, so Rodolphe Gasché, »eine Welt, die eine Unterscheidung zwischen richtig und falsch unmöglich macht. "Sie ist stattdessen "geradezu durch die Unmöglichkeit einer klaren Entscheidung bestimmt, eine Unmöglichkeit, die die Ordnung des Unrechts aufrecht erhält und damit selbst die Möglichkeit von Gerechtigkeit ausschließt «.24

In seinem Kafka-Essay weist Benjamin nach, dass das Leben in Kafkas Romanen paradoxer Weise durch die Gleichzeitigkeit eines allgegenwärtigen Gesetzes und absoluter Gesetzlosigkeit gekennzeichnet ist. Anders als für Agamben ist für ihn diese Gesetzlosigkeit gleichermaßen - wenn nicht gar mehr - wie die Tyrannei des Gesetzes für den Terror in Kafkas Welt verantwortlich. Mit Begriffen absoluter Gesetzlosigkeit beschreibt Benjamin das Leben im Dorf in Kafkas Roman Das Schloß: "Man sieht, auch diese Oberen sind so gesetzlos, dass sie auf einer Stufe mit den Untersten erscheinen, und ohne Scheidewände wimmeln die Geschöpfe aller Ordnungen durcheinander, heimlich nur solidarisch in dem einen einzigen Gefühl der Angst« (BK, 44). Diese Gesetzlosigkeit, schreibt Benjamin, unterliegt einem historischen Entwicklungsprozess. Am ausführlichsten befasst er sich mit diesem Prozess in der Skizze eines nicht ausgeführten Essays mit dem Titel »Versuch eines Schemas zu Kafka « (BK, 116-117). Dieser nur eine Seite umfassende Text entwirft eine Theorie der Kulturgeschichte en miniature. Er beschreibt die Welt in Kafkas Romanen als eine prähistorische Stufe der Menschheit, die Kafka, wie Benjamin schreibt, "mit der gesetzlichen des Judentums konfrontiert.« (BK, 116) Dessen »Reinigungs- und Speisegesetze, « also

24 Rodolphe Gasché: The Stelliferous Fold. Toward a Virtual Law of Literature's Self-Formation. New York 2011, S. 278. die Halacha im engeren Sinne, »beziehen sich auf eine Vorwelt, von der nichts mehr erhalten ist als diese Abwehrmaßnahmen gegen sie.« $(\mathrm{BK}, 116)$

Kafkas Bücher, so Benjamin weiter, »enthalten die fehlende Haggada zu dieser Halacha. Aufs innigste verschränkt aber mit diesem haggadischen Text enthalten sie einen prophetischen.«Die Welt, wie sie sich in Der Proceß und Das Schloß zeigt, diese Welt ohne Trennungen und Unterscheidungen, ohne Grenzen und ohne Ordnung, ist so zugleich eine prähistorische Vorwelt, mit der Kafka aber auch prophetisch die Wiederkehr dieser repressiven Gesetzlosigkeit in der Gegenwart ankündigt. Benjamin schreibt: "Kafkas Romane spielen in einer Sumpfwelt. Aber diese Welt ist dann auch wieder die unsere: eben darum, weil wir sie nicht bewältigt, sondern nur verdrängt und vergessen haben." (GS, II,3, 1236) Die gesetzlose Welt der Vorgeschichte, die Kafka beschreibt, enthält für Benjamin auch einen Hinweis auf seine eigene Gegenwart: Als Jude, der in den dreißiger Jahren schreibt, vergleicht Benjamin das Gesetzessystem seiner Zeit mit Kafkas Sumpfwelt, in der die Gesetze, anstatt das Leben zu ordnen, in die alltägliche Existenz eindringen und mit der absoluten Gesetzlosigkeit identisch werden. Insoweit scheint diese Beschreibung der Wirkung der staatlichen Gesetze kaum von Agambens Sicht der Dinge abzuweichen. Der entscheidende Unterschied jedoch liegt darin, dass für Benjamin dieser prähistorische und zugleich gegenwärtige Zustand, in dem das Gesetz eine `Bastardisierung ‘ mit der Gesetzlosigkeit eingegangen ist und in der alle Unterscheidungen aufgehoben sind, im Kontrast zum Judentum steht und nicht wie bei Agamben mit ihm identifiziert wird. Für Benjamin liegt die Möglichkeit einer Abwehr der Sumpfwelt im jüdischen Gesetz selbst. Nicht nur wäre es unterschieden von einem staatlichen, allein auf der bloßen Gewaltausübung beruhenden Gesetz. Es ist - oder eher es wäre - sein Gegengift. In einem Brief an Scholem vom 11. August 1934 schreibt Benjamin: »Das Werk der Thora nämlich ist - wenn wir uns an Kafkas Darstellung halten - vereitelt worden." $(\mathrm{BK}, 78)$ In den vorbereitenden Notizen für diesen Brief fügt Benjamin hinzu: »Und alles, was einst von Moses geleistet wurde, wäre in unserem Weltzeitalter nachzuholen. $\ll^{25}$ In dieser überraschenden Verteidigung des jüdischen Gesetzes unterscheidet sich Benjamin von Agamben, indem er der mythischen, gesetzlosen Welt der Prähistorie wie der Moderne, wie

25 Walter Benjamin / Gershom Scholem: Briefwechsel. Hrsg. von Gershom Scholem. Frankfurt a. M. 1980, S. 168. 
sie von Kafka beschrieben wird, die jüdische Welt der Halacha entgegen setzt. Aber Benjamin stellt auch sicher, dass seine Überlegungen zur halachischen Dimension von Kafkas Texten sich von der jüdisch theologischen Lesart unterscheiden. In der Skizze zu seinem ungeschrieben gebliebenen Essay hält er fest: »[Kafkas] Prophetie auf eine allernächste Zukunft« - damit ist der Zustand der Welt zu Benjamins eigener Zeit gemeint - »ist für Kafka weit wichtiger als die jüdischen Theologumena, die man allein in seinem Werk hat finden wollen. [...] Die Prophetie ist wichtiger als Gott.« (BK, 117)

Ein bedeutendes Zitat Benjamins über Kafka könnte allerdings im Sinne von Agambens antinomischem Messianismus gelesen werden und auch hier geht es um Prosa - um die narrative Dimension des Talmud, die Haggadah. So schreibt Benjamin: "Kafkas Dichtungen sind von Hause aus Gleichnisse. Aber«, so Benjamin an Scholem, »sie legen sich der Lehre nicht schlicht zu Füssen wie sich die Haggadah der Halacha - also die Erzählung dem Gesetz - zu Füssen legt. Wenn sie sich gekuscht haben, heben sie unversehens eine gewichtige Pranke gegen sie." $(\mathrm{BK}, 87)$ Benjamins Bild von der mächtigen Pranke, die gegen das Gesetz erhoben ist, könnte in der Tat als gesetzesfeindlicher, antinomischer Gestus gelesen werden. Ein genauerer Blick auf die Unterscheidung, die Benjamin zwischen Kafkas Erzählungen und der Haggadah macht, lässt jedoch erkennen, dass letztere keineswegs darauf ausgerichtet ist, das Gesetz aufzuheben. Was impliziert Benjamins seltsames Bild der "mächtigen Pranke«, die gegen die Halacha erhoben ist? Zunächst und vor allem suggeriert sie als mächtige Pfote eines Löwen oder Bären die Gegenwart eines kreatürlichen Wesens. Ferner beschreibt Benjamins Bild die Geste einer Drohung, nicht aber jene einer Vernichtung. Schließlich bezeichnet es eine Bewegung, die etwas abwehren will, die eine Grenze bezeichnet.

Ganz wie die gewichtige, gegen die Halacha erhobene Pranke gleicht die Haggadah Kafkas Schriften darin, dass beide dem Gesetz seine Grenzen aufweisen. Aber es ist entscheidend für die Deutung von Benjamins Bild, dass die Pranke die Halacha nicht vernichtet. Ihre Geste sollte nicht mit einer Abschaffung des Gesetzes verwechselt werden. Stattdessen entspricht sie der Struktur einer dynamischen Vermittlung zwischen Halacha und Haggadah, zwischen Erzählung und Gesetz, die der jüdischen Idee der Gerechtigkeit inhärent ist und für dessen Welthaltigkeit einsteht. Die von Benjamin beschriebene Geste entspricht weder einer antinomischen Transgression noch einer Aufhebung des Gesetzes. Sie spricht vielmehr von der im Talmud immer schon angelegten Struktur einer komplexen und unabschließbaren Interaktion zwischen Halacha und Haggadah, Gesetz und Erzählung, die in der jüdischen Idee von Gerechtigkeit als Möglichkeit ohne Erfüllung in dieser Welt auf eine möglich erfüllte in einer kommenden verweist. 
MARTIN ROUSSEL

\title{
MÖGLICHKEITSDENKEN
}

\section{Utopie, Dystopie und Lektüre in Robert \\ Musils Der Mann ohne Eigenschaften}

\author{
Aber zur gleichen Zeit, zu der wir den Radikalismus \\ der Utopie verstehen und - warum nicht? - bewundern, \\ bemerken wir sofort ihre Schwächen. Gerade im Augen- \\ blick, in dem die Utopie Macht hervorbringt, kündigt sie \\ künftige Gewaltherrschaft an [...]. Die Logik der Utopie \\ wird dann eine Logik des Alles oder Nichts, welche die \\ einen dazu treibt, sich in das Schreiben zu flüchten, \\ andere dazu, sich in der Sehnsucht nach dem verlorenen \\ Paradies zu verschließen, und wieder andere dazu, un- \\ terschiedslos zu töten. [...] Sich den Nicht-Ort vorstellen, \\ das heißt: den Bereich des Möglichen offenhalten. (Paul \\ Ricour: Ideologie und Utopie: zwei Ausdrucksformen \\ des sozialen Imaginären, 1976)
}

\section{PHILOLOGIE UND MÖGLICHKEITSDENKEN}

Texte lassen sich als Verflechtungen von Möglichkeiten verstehen; ihre Wirklichkeit ist die Lektüre, die Spuren verfolgt und Beziehungen herstellt. Für den Philologen läuft ein Möglichkeitsdenken deshalb im Kern auf Fragen einer Lektürepraxis hinaus. Roland Barthes schrieb hierzu 1972, dass, wolle »man Interdisziplinarität betreiben «, es nicht genüge, »ein >Thema< zu nehmen und darum zwei oder drei Wissenschaften zusammenzurufen. Die Interdisziplinarität besteht darin, einen neuen Gegenstand zu schaffen [sic] der niemandem gehört. Der 
>Text « ist, glaube ich, einer dieser Gegenstände. $«^{1}$ Greift man diesen philologischen Akzent interdisziplinärer Arbeit auf, bestimmt sich der Textbegriff zwischen seiner Form (die niemand besitzen kann) und dem Text als konkretisierter Möglichkeit, als Manifestation eines verschalteten Denkens, das Zukunft eröffnet, ohne sie inhaltlich zu beschreiben. ${ }^{2}$ Text, in aller Unbestimmtheit, ist darum ein je sneuer Gegenstand. Hierin liegt die bildungstheoretische Emphase für das Prinzip von Wiederholungslektüren begründet, mit denen textuelle Überlieferungen als Rüstwerkzeug für die Zukunft in die Gegenwart eingeschrieben werden, aber auch ein genuin >modernes Bewusstsein`, das in den Optionen seines Zukunftsdenkens - zwischen Utopie und Dystopie - skeptisch, aber nicht unentschieden bleibt, indem es, so jüngst Amir Eshel, »die Katastrophen der Vergangenheit nicht bloß beschreibt, sondern neu schreibt «. ${ }^{3}$

Aus diesen Vorüberlegungen, die sich methodischen Prämissen gleichermaßen verdanken wie einer thematischen Vorannahme - dass nämlich das Denken von Zukunft zwar utopische und dystopische Projektionen erzeugt, diese aber vorsichtiger auf ein Möglichkeitsdenken rückbezieht und gleichsam einklammert -, folgt in den Grundzügen die These dieses Beitrags. Denn nichts anderes als einen Text, der im Horizont utopischen wie dystopischen Denkens als Möglichkeitsraum Gestalt annimmt, bildet Robert Musils Romanfragment Der Mann ohne Eigenschaften. Ebenso von Bedeutung wie der fragmentarische Charakter, der das Textuniversum, verstanden als Textwelt, für Lektüre zwingend als offenes Geschehen gestaltet, ist hierfür die Anlage des Romans zwischen Utopie und Dystopie. Alexander Honold hat in einer maßgeblichen Arbeit die Stadt (Wien) und den Krieg (the Great War, wie es in der

1 Roland Barthes: Junge Forscher [1972]. In: Johanna-Charlotte Horst u. a. (Hrsg.): Unbedinge Universitäten. Was ist Universität? Texte und Positionen zu einer alten Idee. Zürich 2010, S. 339-342, hier S. 342.

2 Zur Bedeutung des Beziehungssinns für Figurationen vgl. Günter Blamberger: Gestaltgebung und ästhetische Idee. Morphomatische Skizzen zu Figurationen des Todes und des Schöpferischen. In: Günter Blamberger, Dietrich Boschung (Hrsg.): Morphomata. Kulturelle Figurationen: Genese, Dynamik und Medialität. München 2011 (Morphomata; 1), S. 11-46; zur Spannung von Form und Figur eines Texts vgl. Martin Roussel: Philologie des Findens. Figurationen des Zitats - eine Propädeutik. In: ders.: Kreativität des Findens. Figurationen des Zitats. München 2012 (Morphomata; 2), S. 15-32. 3 Amir Eshel: Zukünftigkeit. Die zeitgenössische Literatur und die Vergangenheit. Aus dem Englischen von Irmgard Hölscher. Berlin 2012, S. 15. englischsprachigen Welt heißt) als die raumzeitlichen Koordinaten von Musils Lebensprojekt ausgemacht. ${ }^{4}$ Während Wien als Handlungsort für die k. u.k. Monarchie steht, bildet der Kriegsausbruch im Herbst 1914 den Zielpunkt der Handlung, der dem eigentlichen Geschehen entzogen bleibt. Mit General Stumm von Bordwehr führt Musil jedoch eine Figur ein, die zunehmend als Kriegsbote lesbar wird und dem Roman eine apokalyptische Dimension einzeichnet: Von den großen Handlungsgefügen der sogenannten Parallelaktion, den Versuchen, die österreichischungarische Doppelmonarchie des Vielvölkerstaats in einer konzentrierten sgroßen v vaterländischen Aktion zusammenzuhalten, wird am Ende nichts als die Idee der Tat - als Präzedenz des Krieges - bleiben. Wien wiederum figuriert den städtischen Knotenpunkt des Geschehens, die "Reichshaupt- und Residenzstadt « (MoE, 9) ${ }^{5}$ aus der heraus sich die utopischen Ideen nicht nur der Parallelaktion entfalten, sondern auch die wissenschaftsaffinen Vorstellungen des Mannes ohne Eigenschaften. Es ist der Geist der Moderne, der sich in Wien kristallisiert. In ihn ragt nur in Form von Unfällen - im Übrigen auch auf diskursiver Ebene ${ }^{6}-$ und einer prinzipiellen Dysfunktionalität der geistigen Ordnungsgefüge ein Gegenmoment zum utopischen Geist hinein. Seiner formalen Anlage nach verkörpert der Mann ohne Eigenschaften, Ulrich, bereits seiner Figur nach ein utopisches Moment, denn der Zeitraum des Romans wird formal dadurch aufgespannt, dass er sich ein Jahr Urlaub vom Leben nimmt. In der Auszeit vom tätigen Leben eröffnet sich der Freiraum von Muße als ein klassischer Gegen-Ort, der sich imaginär gegen Vorstellungen von

4 Alexander Honold: Die Stadt und der Krieg. Raum- und Zeitkonstruktion in Robert Musils Roman »Der Mann ohne Eigenschaften«. München 1995. 5 Die Sigle MoE steht für: Robert Musil: Der Mann ohne Eigenschaften. 2 Bände. Neu durchgesehene und verbesserte Ausgabe 1978. Taschenbuchausgabe 1987. Reinbek 1999.

6 Das Paradigma gibt in der Forschung das erste Kapitel des Romans vor »Doch weiß jeder Leser, daß von einem durchgängigen >regelgerechten Erzählen nicht die Rede sein kann. Vielmehr geht es, den ganzen Roman lang, um die Problematik des Erzählens«, bemerkt Ulf Eisele: Ulrichs Mutter ist doch ein Tintenfaß. Zur Literaturproblematik in Musils Mann ohne Eigenschaften. In: Renate von Heydebrand (Hrsg.): Robert Musil. Darmstadt 1982, S. 160-203, hier S. 162. Vgl. zum Begriff der (diskursiven) Störung im Mann ohne Eigenschaften auch Michel Serres: Hermes V. Die NordwestPassage. Berlin 1994, S. 31-47, S. 67-78; Gerhard Meisel: Liebe im Zeitalter der Wissenschaft vom Menschen: Das Prosawerk Robert Musils. Opladen 1991, insbesondere S. 130. 
Gegenwärtigkeit richtet.? Bei Musil ist dies ein Text-Topos, der allgemein ist wie sein Gegenmodell, die "Parole der Tat" (mehrfach in Kap. II,13, 17, 34, 36, 67, 72), die individuelle Euphorie und Beteiligung herbeiruft. Diese Utopie, die Ulrich verkörpert, ist dabei keine eigentliche Zeitutopie, wie es aus der Jahresfrist hervorgehen könnte; denn im Grunde gibt das Urlaubsjahr einen strikt umrissenen Gegenraum vor, innerhalb dessen die Wirklichkeit ausgeschlossen bleibt. ${ }^{8}$ Geist lautet Musils Schlüsselbegriff für diesen Gegenraum und Ulrichs Hauptanliegen läuft auf die "Forderung eines Generalsekretariats der Genauigkeit und Seele« (Kapitel 116) hinaus. Dass eine solche Inventur des geistigen Lebens einem gleichsam auslaufenden Kulturmodell die Rechnung seines Scheiterns aufmachen würde, ist eine dezidiert leserorientierte Perspektive, die dem Roman gleichwohl notwendig inhärent ist: 1930 erschien der erste Teil, 1932 folgten einige Kapitel des 2. Teils. Die Textur des Romans stellt insofern selbst ein solches `Generalsekretariat` dar.

7 Wenn Wiegmann in einem wichtigen Aufsatz die Utopien im Mann ohne Eigenschaften als »verwirklichbare Möglichkeit « ansieht, das heiß als Versuch, »die vorhandene Wirklichkeit proleptisch zu übersteigen und die eigentliche wünschenswerte Wirklichkeit zu entbergen«, unterschätzt er m. E. die Bezüge des Romans auf >Geschichter (Hermann Wiegmann: Musils Utopiebegriff und seine literaturtheoretischen Konsequenzen. In Gert Ueding [Hrsg.]: Literatur ist Utopie. Frankfurt a. M. 1978, S. 309-334, hier S. 310 f.).

8 Utopie und Wirklichkeit sind in Musils >konstruktiver Ironie ( vgl. MoE 1939) aufeinander bezogen, wie schon Beda Allemann gezeigt hat (Robert Musil: Ironie und Utopie des gegebenen Zustandes. In: Hans-Egon Hass und Gustav-Adolf Mohrlüder [Hrsg.]: Ironie als literarisches Phänomen. Köln 1973, S. 257-263).

9 Dass von hier aus der utopische Gehalt des Romans eingeklammert werden muss, signalisieren die meisten der Forschungsarbeiten zum Utopischen im Mann ohne Eigenschaften (wie bei Musil generell), die das Wort >Utopie meistens als Beiwort einsetzen. Das Utopische wird somit in der Regel als ein Zug oder Traditionselement einer übergreifenden Funktionsbestimmung gesehen. Vgl. etwa Manfred Sera: Utopie und Parodie bei Musil, Broch und Thomas Mann. Der Mann ohne Eigenschaften, Die Schlafwandler, Der Zauberberg. Bonn 1969; Cornelia Blasberg: Krise und Utopie der Intellektuellen kulturkritische Aspekte in Robert Musils Roman Der Mann ohne Eigenschaften. Stuttgart 1984; Hans-Rudolf Schärer: Narzißmus und Utopismus. Eine literaturpsychologische Untersuchung zu Robert Musils Roman »Der Mann ohne Eigenschaften«. München 1990; Michael Hinz: Verfallsanalyse und Utopie. Nietzsche-Rezeption in Thomas Manns Zauberberg und Robert

\section{UTOPIEN}

Utopisches und Dystopisches sind asymmetrisch aufeinander bezogen, indem der Roman eine Reihe an >Utopien verhandelt, das dystopische Moment aber implizit bleibt, jedoch im explikativen Zug der Lektüre notwendig thematisch wird: Die Lektüresituation setzt notwendigerweise das Schlussdatum des Romans, mithin den Weltkrieg, als Vergangenheit voraus. Mit anderen Worten ist das Wissen um den Weltkrieg, das die Lektüre des Mannes ohne Eigenschaften mit bestimmt, genauso Voraussetzung der Lektüre wie das Unwissen darüber, wofür der Sommer 1914 steht, das die Romanfiktion kennzeichnet. Diese Asymmetrie von Wissen und Nicht-Wissen entspricht also in Teilen der von Fiktion und ihre Überschreitung in der Praxis des Lesens; sie holt aber auch die Spannung des Utopischen, wie es im Roman verhandelt wird, zum Dystopischen ein Denn wenn auch der utopische Nexus des Romans gegen die Macht des Faktischen wirkungslos ist und die Realitätskonstruktion des Romans auf den Ausbruch des Kriegs zusteuert, ist doch zugleich der Untergang von 'Kakanien`, wie die auf eine grundlegende Art unzeitgemäße, sich überlebt habende österreichisch-ungarische Doppelmonarchie fast mehr spöttisch als ironisch bezeichnet wird, ein Untergangsszenario, das im Romankosmos eingelagert ist, das heißt in der Welt der Pläne, das

Musils Der Mann ohne Eigenschaften. St. Ingbert 2000; Barbara Neymeyr Utopie und Experiment. Zur Literaturtheorie, Anthropologie und Kulturkritik in Musils Essays. Heidelberg 2009; Rebekka Schnell: »... die plötzlich enthüllte Zärtlichkeit der Welt ...«. Liebe als ästhetische und religiöse Utopie in Robert Musils Der Mann ohne Eigenschaften. In Lisanne Ebert u. a. (Hrsg.): Emotionale Grenzgänge: Konzeptualisierungen von Liebe, Trauer und Angst in Sprache und Literatur. Würzburg 2011, S. 91-112. Derartige Einschränkungen eines Begriffs von Utopie gelten auch für Versuche, das Utopische im Ästhetischen als Möglichkeitsraum sui generis der Literatur restituiert zu sehen; vgl. etwa Renate M. Marschner: Utopie der Möglichkeit: ästhetische Theorie dargestellt am Mann ohne Eigenschaften von Robert Musil. Suttgart 1981; Richard David Precht: Die gleitende Logik der Seele: ästhetische Selbstreflexivität in Robert Musils Der Mann ohne Eigenschaften. Stuttgart 1996. - Agata Schwartz: Utopie, Utopismus und Dystopie in Der Mann ohne Eigenschaften (Untertitel: Robert Musils utopisches Konzept aus geschlechtsspezifischer Sicht. Frankfurt a. M. u. a. 1997), unterlegt dem Verhältnis von Utopie und Dystopie im Roman ein Genderschema. 
70-jährige Thronjubiläum Kaiser Franz Josephs im Jahr 1918 in einer Parallelaktion zum 30-jährigen Jubiläum des deutschen Kaisers Wilhelm zu feiern. Mit der Parallelaktion, also einem Handeln gemäß der Logik eines Parallelismus', mithin einer parallelen Handlungsstruktur, signiert Musil die fiktionale Logik seines Romans, in dessen narrativen Kreis er Motive der Kulturgeschichte einträgt, vom überholten Justizsystem bis zum zentral von Wien aus organisierten >Vielvölkerstaat und den ästhetizistischen Dekadenzphänomenen der Wiener Moderne. ${ }^{10}$ Ungeachtet des Untergangs der Welt, die der Roman mit geradezu restaurativer Sorgfalt aufleben lässt, überlebt der Roman sein eigenes und letztlich ungeschriebenes Ende. Es wäre deshalb nicht treffend beschrieben, das Verhältnis der Utopien des Romans zum dystopischen Abgrund der narrativen Konstruktion als einen dialektischen Umschlag zu kennzeichnen; vielmehr durchdringen sich beide Konstruktionen oder Perspektiven auf Realität als Irrealitäten eines Möglichkeitsdenkens, das der Roman selbst ist. Irreal ist erstens die Errichtung einer Romanwelt angesichts der faktischen Nicht-mehr-Existenz dieser Welt; irreal ist zweitens der Glaube an die Analyse der im Roman restaurierten Welt: Nicht in der Erkenntnis einer untergehenden Welt liegen die Stärken von Musils Schreiben, sondern in der Insistenz auf dem Möglichen (im Zweifelsfall auch) gegen das Wirkliche. Darin gewinnt Der Mann ohne Eigenschaften quasi parabolische Züge, die ihn zu einer Art Passepartout einer historischen Kriseologie prädestinieren: ${ }^{11}$ Als Lektüreprogramm, nicht als Textmaschine, findet im Roman ein Überlebensprogramm statt. Wie lässt sich somit aus einer Lektüre von Musils Roman die Frage nach einer Aktualität utopischen (dystopischen) Denkens gewinnen?

Aktuelle Forschungen wie beispielsweise Thomas Schölderles Utopia und Utopie. Thomas Morus, die Geschichte der Utopie und die Kontroverse um ihren Begriff ${ }^{12}$ diagnostizieren den spätestens seit Niklas Luhmann

10 Die Utopie als in Musils rückblickendes Kulturpanorama der Moderne eingelagert sieht Dietmar Goltschnigg: „Fröhliche Apokalypse« und nostalgische Utopie: "Österreich als besonders deutlicher Fall der modernen Welt«. Hrsg. von Charlotte Grollegg-Edler. Wien u. a. 2009.

11 Distanzierungsstrategien, eine ästhetische Indifferenz, die durchaus an eine fernöstliche Ethik der Höflichkeit anschließbar ist, sieht Phillan Joung in Musils >Utopie des Essayismus am Werk: Passion der Indifferenz. Essayismus und essayistisches Verfahren in Robert Musils Der Mann ohne Eigenschaften. Münster 1997.

12 Baden-Baden 2011. bekannten Ausgangspunkt, nämlich die gegenwärtige Krise utopischen Denkens. Der Begriff der Möglichkeit ist deren impliziter, ins Positive gewendeter Nexus. So schreibt Luhmann 1986: "Die Zukunft ist und bleibt unbekannt, denn mit jeder eintretenden Gegenwart schiebt sie sich hinaus, erneuert sich als Zukunft. «13 Solange Geschichte das ist, was geschieht, bleiben Utopien wie Dystopien jeder Zeitrechnung voraus. $\mathrm{Zu}$ fragen bleibt somit nach Funktionsbestimmungen, und das heißt in diesem Fall auch nach dem Wechselverhältnis von Utopie und Dystopie. Was bedeutet es für ein Verständnis des Utopischen, wenn die Krise der Utopie mit einer Konjunktur der Dystopien einhergeht, in der Weltuntergang, Apokalypsen und Endzeitbilder politische, ökonomische und ökologische Diskurse mitbestimmen? Führt vom Dystopischen ein Weg zurück zu Funktionsbestimmungen des Utopischen? - Musils Mann ohne Eigenschaften kann als ein Komplex von Utopien ${ }^{14}$ beschrieben werden: Musil selbst fasst in einem Nachlasstext die dargestellten Utopien als Instrumente seines Textes zusammen, über deren Entwurf sich das oder zumindest ein »Hauptthema» des Romans verhandeln ließe:

Ein Hauptthema fürs Ganze ist also: Auseinandersetzung des Möglichkeitsmenschen mit der Wirklichkeit. Sie ergibt 3 Utopien: Die Utopie der induktiven Gesinnung. Die Utopie des anderen (nicht ratioïden, motivierten usw) Lebens in Liebe. Auch Utopie des Ess[ayismus]. II. Die Utopie des reinen aZ. mit ihrer Mündung in oder Abzweigung zu Gott. (MoE, S. 1881 f.)

Aufschlussreich für das Verständnis des utopischen Grundzugs ist vor allem das Verhältnis von `Genauigkeit` (Exaktheit) und `Seele` (Gefühl, Heiligkeit), wie es in den Kapiteln 61 und 62 gewendet wird. Zunächst erläutert Musil die Utopie des exakten Lebens als einer Utopie, wissenschaftlich zu leben, die

ungefähr soviel wie schweigen [hieße], wo man nichts zu sagen hat; nur das Nötige tun, wo man nichts Besonderes zu bestellen hat; und was das Wichtigste ist, gefühllos bleiben, wo man nicht das

13 Niklas Luhmann: Ökologische Kommunikation: Kann die moderne Gesellschaft sich auf ökologische Gefährdungen einstellen? Opladen 1986, S. 38 .

14 Jiyoung Shin: Der »bewußte Utopismus« im Mann ohne Eigenschaften von Robert Musil. Würzburg 2008, S. 13. 
unbeschreibliche Gefühl hat, die Arme auszubreiten und von einer Welle der Schöpfung gehoben zu werden! Man wird bemerken, daß damit der größere Teil unseres seelischen Lebens aufhören müßte, aber das wäre ja vielleicht auch kein so schmerzlicher Schaden. Die These, daß der große Umsatz an Seife von großer Reinlichkeit zeugt, braucht nicht für die Moral zu gelten, wo der neuere Satz richtiger ist, daß ein ausgeprägter Waschzwang auf nicht ganz saubere innere Verhältnisse hindeutet. (MoE, 246)

Eine solche Exaktheit, ein Kalkül der Vermeidung des Überflüssigen, läuft also auf eine Katharsis des moralischen Lebens hinaus, so dass »aus dem Bild des Lebens die faden Abzugbilder verschwinden [würden], die aus der blassen Ähnlichkeit entstehen, welche die Handlungen mit den Tugenden haben, und an ihre Stelle deren berauschendes Einssein in der Heiligkeit treten." (MoE, 246) Im Folgekapitel 62 "huldigt«, so die Kapitelüberschrift, Ulrich »der Utopie des Essayismus«. Hier bestimmt Musil »Genauigkeit[ ] als menschliche Haltung «, die alles »Tun und Sein im Sinne eines maximalen Anspruchs« verlange (MoE, 247). An Ulrich exemplifiziert der Roman den Versuch, die Exaktheit des Handelns nicht »dem flügellosen Gebrauch der Ingenieure und Gelehrten« zu überlassen, sondern auch auf jene Bereiche zu beziehen, in denen »das Unsichere wieder zu Ansehen gekommen war «: »Dichter, Kritiker, Frauen und die den Beruf einer neuen Generation Ausübenden [...] verlangten einen neuen Menschheitsglauben, Rückkehr zu den inneren Urtümern, geistigen Aufschwung und allerlei von solcher Art.« (MoE, 249) Wenn der Mann ohne Eigenschaften seiner Utopie des Essayismus »huldigt«, verfolgt er einen demgegenüber konsequenteren Modernismus, der im Begriff des Handelns bzw. der Haltung die anthropologische Ganzheit (Körper und Seele) nicht additiv versteht, sondern als Umschlag von Exaktheit in Heiligkeit, mithin als Berührungspunkt von Augenblick und Ewigkeit. ${ }^{15}$ Lebenspraktisch drückt dies die Utopie des Essayismus

15 In den »Heiligen Gesprächen« zwischen Ulrich und Agathe kehren diese Motive wieder: Die Mystiker, so Ulrich, sprächen von »Erkenntnissen, die so schnell sind, daß alles zugleich ist [...]. Sind das nicht, wenn auch von der Schwierigkeit des Ausdrucks flimmernd verhüllt, dieselben Empfindungen, die man noch heute hat, wenn zufällig das Herz - 'gierig und gesättigt‘, wie sie sagen! - in jene utopischen Regionen gerät, die sich irgend- und nirgendwo zwischen einer unendlichen Zärtlichkeit und einer unendlichen Einsamkeit befinden?!« (MoE, 753) aus, denn »ein Essay ist die einmalige und unabänderliche Gestalt, die das innere Leben eines Menschen in einem entscheidenden Gedanken annimmt.« (MoE, 253)

In einem Passus von Kapitel 61 reflektiert Musil die Bedeutung des Utopischen in solchen Haltungen:

Aber man wird einwenden, daß dies ja eine Utopie sei! Gewiß, es ist eine. Utopien bedeuten ungefähr so viel wie Möglichkeiten; darin, daß eine Möglichkeit nicht Wirklichkeit ist, drückt sich nichts anderes aus, als daß die Umstände, mit denen sie gegenwärtig verflochten ist, sie daran hindern, denn andernfalls wäre sie ja nur eine Unmöglichkeit; löst man sie nun aus ihrer Bindung und gewährt ihr Entwicklung, so entsteht die Utopie. (MoE, 246)

Die ১ungefähre` Gleichsetzung von Utopie und Möglichkeit verstärkt also eine Einordnung des Mannes ohne Eigenschaften als utopischem Roman. Denn wenn Ulrich ein Jahr Urlaub von seinem Leben nimmt, so löst er sich selbst aus seinen alltäglichen Bindungen, um an sich selbst ein Lebensexperiment vorzunehmen, das heißt seine verzweckten Eigenschaften als Möglichkeit zur freien Entfaltung zu bringen. »Utopie bedeutet das Experiment, worin die mögliche Veränderung eines Elements und die Wirkungen beobachtet werden, die sie in jener zusammengesetzten Erscheinung hervorrufen würde, die wir Leben nennen."(MoE, 246) Der Mann ohne Eigenschaften ist von der Bestimmung des Utopischen in Kapitel 61 aus also ein Experiment auf die Wirkung des Möglichen - gegenüber dem Wirklichen. Das viel zitierte vierte Kapitel des Roman stellt deshalb so etwas wie die lediglich formale Matrix des Romans dar:

16 Auch die unmittelbar angeschlossene Abgrenzung ist wichtig: "Nichts ist dem fremder als die Unverantwortlichkeit und Halbfertigkeit der Einfälle, die man Subjektivität nennt, aber auch wahr und falsch, klug und unklug sind keine Begriffe, die sich auf solche Gedanken anwenden lassen, die dennoch Gesetzen unterstehn, die nicht weniger streng sind, als sie zart und aussprechlich erscheinen.«(MoE, 253) - Vorbilder seien »Heilige mit und ohne Religion und manchmal sind sie auch einfach Männer, die sich in einem Abenteuer verirrt haben." (MoE, 254) Musils Kritik der ratioïden, aufs Technische verengten Moderne, verfolgt also die Verbindung von Exaktheit und Abenteuer ebenso wie die von Exaktheit und Heiligkeit; die Spanne zwischen Abenteuer und Heiligkeit macht den Versuchscharakter dieses Lebens der Moderne aus. 
„Wenn es Wirklichkeitssinn gibt, muß es auch Möglichkeitssinn geben«, ist es überschrieben. ${ }^{17}$

Oder vielleicht sagt man es anders besser, und der Mann mit gewöhnlichem Wirklichkeitssinn gleicht einem Fisch, der nach der Angel schnappt und die Schnur nicht sieht, während der Mann mit jenem Wirklichkeitssinn, den man auch Möglichkeitssinn nennen kann, eine Schnur durchs Wasser zieht und keine Ahnung hat, ob ein Köder daran sitzt. Einer außerordentlichen Gleichgültigkeit für das auf den Köder beißende Leben steht bei ihm die Gefahr gegenüber, völlig spleenige Dinge zu treiben. (MoE, 17)

Diesem zentralen Problem der Verantwortung stellt sich der Roman notwendiger Weise nur indirekt - es übersteigt seine Konzeption wie die Lektüre notwendig über das Schreiben des Textes hinausgeht. Man kann den Utopien des Romans zwei gegenläufige methodische Richtungen unterlegen: »Gs. u Utopie der induktiven Gesinnung mit induktivem Gott«, heißt es im Nachlass über die eine Richtung, »Versuch des sensitiv-mentalen Lebens. Versuch des aZ.« (MoE, 1901) über die andere. Induktion und Deduktion sind demnach komplementär aufeinander bezogen - beide als Möglichkeiten »Seinesgleichen abzuhelfen«, wie Musil pointiert den kleinen Abschnitt aus einer Nachlassnotiz überschreibt. ${ }^{18}$ Beide Optionen sind

17 Den »potentiellen Menschen« beschreibt Albrecht Schöne als in Musils literarischem Möglichkeitsdenken »in seiner Vorläufigkeit« bewahrt, so dass »jedes Ziel nur Zwischenergebnis, nur \Partiallösung`sein kann«, weil »der experimentierende, utopische Konjunktiv sich gleichsam ins Künftige [wirft] und [...] sich selbst niemals ein[holt], - es sei denn er höbe sich auf." (Albrecht Schöne: Zum Gebrauch des Konjunktivs bei Robert Musil. In: Euphorion 55 [1961], S. 196-220, hier S. 208)

18 Vgl. zur Utopie der induktiven Gesinnung die Nachlasstexte in: MoE, 1882-1888. Zu einer Kritik der nur in Ansätzen umrissenen 'Sozialutopie Musils, deren Status als finale Utopie des Romans nicht unerheblich durch den »Wille[n] des Herausgebers [Frisé] und der Musilforschung, Ulrich zur Erlösung zu verhelfen", mitbedingt war, vgl. Thomas Gilla: Versuche der Auflösung - Andeutungen von Synthesen. Über die Mythisierung von Robert Musils Roman »Der Mann ohne Eigenschaften« in der Literaturwissenschaft. Würzburg 2004, S. 91 f. - Musil bezeichnet die induktive Gesinnung als »die ärgste Utopie« (MoE, 1885); auch sie verliert sich allerdings in vielen Subkategorien und Aufspaltungen (MoE, 1885-1887). Ein »Nachtrag" (unter mehreren) formuliert: »Als letztes bleibt - in Umkehrung der Reihenfolge - hier schon skizziert: im exakten Leben oder Essayismus auf der einen, dem Mystizismus ${ }^{19}$ der Möglichkeiten auf der anderen Seite. ${ }^{20}$

Hinzufügen ließen sich zum Geflecht utopischer Konzepte mindestens die »Utopie der Höflichkeit» (MoE, 1918) und »eine nonsensistische Utopie» der Heilung Geisteskranker (MoE, 1360), und Musil listet noch weitere Zwischengrade, etwa Spaltungen der, wie die Utopie des anderen Zustands, mystizistisch ausgewiesenen »Utopie des 1000j R[eiches] « auf (MoE, $1881 \mathrm{f}$. und 1918). Welches die Leitutopie sein soll, ist nicht klar auszumachen. ${ }^{21}$

die [Utopie] der induktiven Gesinnung, also des wirklichen Lebens, übrig! Mit ihr schließt das Buch.« (MoE, 1887) Als Figur des Romanschlusses wäre die induktive Gesinnung dann als `Utopie` des Übergangs vom Roman in die ,Wirklichkeit zu lesen, also als Figur der Selbstaufhebung des Textes. - Einer solchen Verabsolutierung einer der vielen `Grundideen` gegenüber ist Skepsis angesagt. Am 12. April 1942 schreibt Musil an Henry Hall Church, der ihn aus den USA finanziell unterstützte, er sei dabei, »aus einer Unzahl von Ideen, die uns beherrschen, weil wir keine von ihnen beherrschen, die Geschichte einer ungewöhnlichen Leidenschaft ab[zu]leiten, deren schließlicher Zusammenbruch mit der Kultur übereinfällt, der anno 1914 bescheiden begonnen hat und sich jetzt wohl vollenden wird « (Robert Musil: Briefe. 1901-1942. Mit Briefen von Martha Musil u. a. Hrsg. von Adolf Frisé unter Mithilfe von Murray G. Hall. Reinbek 1981, S. 1418). Corino kommentiert: »Das klingt, als sei Musil von seinen ursprünglichen Plänen, den Zusammenbruch der Geschwisterliebe mit dem Ausbruch des I. Weltkriegs zusammenfallen zu lassen, nicht abgerückt. Bemerkenswert seine Formulierung, er wolle die Geschichte Ulrichs und Agathes aus einer ,Unzahl von Ideen ableiten: eine Charakteristik seines deduktiven [und nicht induktiven; MR] Schreibens und der damit verbundenen Mühen« (Karl Corino: Robert Musil. Eine Biographie. Reinbek 2003, S. 1434). Vgl. auch Shin: Der »bewußte Utopismus« (wie Anm. 14), S. 132-136 (mit Betonung, dass in der Auflösung des Romans eben doch die Utopie der induktiven Gesinnung als Utopie »des wirklichen Lebens« übrig bleibe: »Mit ihr schließt das Buch«, MoE, 1887 - aber welche Bedeutung hat sie für das Romanprojekt in seiner Richtung gegen die Wirklichkeit?).

19 Häufig erscheint in der Forschung der sandere Zustand als mystische Einlösung des kulturkritischen Programms im Mann ohne Eigenschaften. Vgl. etwa, mit Blick auf den Funktionswandel des Utopischen im Roman, Bernd-Rüdiger Hüppauf: Von sozialer Utopie zur Mystik: zu Robert Musils Der Mann ohne Eigenschaften. München 1971.

20 Vgl. Shin: Der »bewußte Utopismus« (wie Anm. 14), S. 119 f.

21 Hinzuweisen ist auch auf Musils Insel-Metaphorik, die an die Insel-Topik aus der Gattung >Utopie< erinnert. Vgl. hierzu insbesondere die Kapitelentwürfe zum Clarisse-Komplex (MoE, 1372-1377, 1379, 1381-1386) und hier insbesondere zur »Insel der Gesundheit» (MoE, $1740 \mathrm{ff}$.). Unter dem Titel 
So heißt es über die in der Forschung kaum behandelte Utopie der Höflichkeit: »Die begonnene U.d.H. (falls unterbrochen)!) (zum Leitgedanken nehmen)« (MoE, S. 1918). ${ }^{22}$ Eine Gesamteinschätzung könnte Karl Heinz Bohrer folgen. Bohrer sieht mit Blick auf die vor allem im Schlussteil des Romans entfaltete Utopie des anderen Zustands eine »Reduktion der Utopie auf die reine Bewußtseinstatsache des >Augenblicks«" gegeben; »der Widerspruch des esoterischen Ichs zur realen Gesellschaft, [sic] ist hier durch gedankliche Anstrengung am rigidesten entfaltet $\ll_{.}^{23}$ Der offene Zeithorizont, in dem alle Utopien im Mann ohne Eigenschaften stehen, öffnet sich hier den kontingenten Kommunikationen des sozialen Lebens. ${ }^{24}$ Vom Entwurfscharakter geprägt sind die Utopie des Essayismus oder die Utopie der induktiven Gesinnung; ${ }^{25}$ im anderen Zustand aber tritt deutlich die

»Die Reise ins Paradies« (MoE, 1536-1550) summiert Musil eine weitere utopische Kapitelgruppe im Nachlass. Vgl. auch die Hinweise auf Musils Morus-Lektüre (vgl. Robert Musil: Tagebücher. 2 Bände. Hrsg von Adolf Frisé. Neu durchgesehen und ergänzte Auflage. Reinbek 1983, Bd. 1, S. 458) und auf die frühen Entwürfe, einen utopischen Roman (»Roman, Utopischer «) zu schreiben (ebd., S. 243-248 und Bd. 2, S. 147).

22 Vgl. aber Anm. 9.

23 Karl Heinz Bohrer: Plötzlichkeit. Zum Augenblick des ästhetischen Scheins. Mit einem Nachwort von 1998. Frankfurt a. M. 1998 (1981), S. 203. 24 Vgl. zu den Parallelen zwischen Musil und Luhmann jüngst (mit weiteren Hinweisen) Norbert Christian Wolf: Kakanien als Gesellschaftskonstruktion. Robert Musils Sozioanalyse des 20. Jahrhunderts. Köln 2011, S. 37. - Als Lektüremodell reflektiert dies Kapitel 122 im Vergleich zwischen dem anthropologisch zentralen Prinzip des Epischen, das dem Leben die Struktur eines narrativen Fadens vorgibt, und einer Flächigkeit des Lebens, sobald dieses Epische - wie bei Ulrich - fehlt. Vgl. auch Musils Essay »Das hilflose Europa oder Reise vom Hundertsten ins Tausendste «: »Die Tatsachen der Vergangenheit, die Tatsachen der Einzelwissenschaft, die Tatsachen des Lebens überdecken uns ungeordnet" (Robert Musil: Gesammelte Werke II: Prosa und Stücke. Kleine Prosa, Aphorismen. Autobiographisches. Essays und Reden. Kritik. Erweiterte Neuausgabe. Reinbek 2000, S. 1087).

25 Gegen die mystische Utopie des anderen Zustands als Zielpunkt und für einen Funktionszusammenhang aller Utopien - am klarsten formuliert in der Utopie der induktiven Gesinnung - argumentiert Shin: Der »bewußte Utopismus« (wie Anm.14); produktionästhetisch formuliert tritt jedoch die Utopie des Essayismus bzw. das essayistische Schreibverfahren in den Vordergrund; vgl. hierzu Joung: Passion der Indifferenz (wie Anm. 11). - Den utopischen Zielpunkt nicht im Mystischen, sondern im narrativen bzw. sozialen Experiment sieht beispielsweise der von Wilhelm Voßkamp
Aporie des Augenblicks als Kristallisation utopischer Erfahrung hervor: ${ }^{26}$ Was aus dem flüchtigen Augenblickserlebnis folgt, bleibt unklar. Die Reduktion auf ein im Sinne des Nur Augenblicklichen öffnet Musils Roman auf eine Dekonstruktion des Ästhetischen wie des Utopischen. ${ }^{27}$ Musils Roman gewinnt darin eine melancholische Note. Im Nachlasskapitel - dem letzten von Musil reinschriftlich bearbeiteten - »Atemzüge eines Sommertages« ersetzt eine Vanitas-Naturmetaphorik die Erlebnisanalyse und kleidet den Erlebnisraum des anderen Zustands poetisch ein:

Ein geräuschloser Strom glanzlosen Blütenschnees schwebte, von einer abgeblühten Baumgruppe kommend, durch den Sonnenschein; und der Atem, der ihn trug, war so sanft, daß sich kein Blatt regte. Kein Schatten fiel davon auf das Grün des Rasens, aber dieses schien sich von innen zu verdunkeln wie ein Auge. Die zärtlich und verschwenderisch vom jungen Sommer belaubten Bäume und Sträucher, die beiseite standen oder den Hintergrund bildeten, machten den Eindruck von fassungslosen Zuschauern, die, in ihrer fröhlichen Tracht überrascht und gebannt, an diesem Begräbniszug und Naturfest teilnahmen. Frühling und Herbst, Sprache und Schweigen der Natur, auch Lebens- und Todeszauber mischten sich in dem Bild; die Herzen schienen stillzustehen, aus der Brust genommen zu sein, sich dem schweigenden Zug durch die Luft anzuschließen. (MoE, 1232)

im Zeichen von Musils Möglichkeitssinn (vgl. hierzu besonders die Einleitung) herausgegebene Band: Ideale Akademien: vergangene Zukunft oder konkrete Utopie. Berlin 2002; vgl. auch Friedrich Ulfers: Von der Skepsis zur Utopie. Musils Idee des `Essayismus‘. In: Bernd Hüppauf und Klaus Vieweg (Hrsg.): Skepsis und literarische Imagination. München 2003, S. 209-218. 26 Die Bedeutung der Utopie des anderen Zustands als `Zustandsutopier, die sich im Unterschied zu den in der Forschung oft als $>$ Methodenutopien genannten Konzepten deutlich als ekstatisches Moment gegen die Wirklichkeit richtet oder ihr entzogen sein soll, ist klar beschrieben z. B. bei Roger Willemsen: Robert Musil. Vom intellektuellen Eros. München, Zürich 1985, S. $216 \mathrm{f}$.

27 Dass der Roman hierin auch als Summe der Traditionen utopischen Denkens verstanden werden kann, betont Wilhelm Voßkamp: „Wenn es Wirklichkeitssinn gibt, muß es auch Möglichkeitssinn geben.« Traditionen des utopischen Denkens bei Robert Musil. In: Friedrich Jäger und Jürgen Straub (Hrsg.): Was ist der Mensch, was Geschichte? Annäherungen an eine kulturwissenschaftliche Anthropologie. Jörn Rüsen zum 65. Geburtstag. Bielefeld 2005, S. 347-362. 
Auf die Szene dieses Sommertages und seine Rhetorik - mithin auf das, was aus ihr folgt - wird zurückzukommen sein. Mit dem Anklang an den schönen Augusttag des Jahres 1913, mit dem der Roman beginnt, verstärkt sich die melancholisch-katastrophische Note: Mit dem schönen Augusttag des Jahres 1913 setzt Musil einen fatalen Anfangspunkt für das genau eine Jahr Auszeit, das sich der Mann ohne Eigenschaften vom Leben nehmen will. Zuletzt mündet die Erzählung des Romans über sein Fragment gebliebenes Ende hinaus in den Ersten Weltkrieg. Die Grundelemente lassen sich in ihrer historischen Faktentreue nur wiederholen: Weder die Parallelaktion, deren Kommissionen und Ausschüsse das 70-jährige Thronjubiläum des österreichischen Kaisers Franz Joseph im Jahre 1918 parallel zum 30-jährigen Thronjubiläum des deutschen Kaisers Wilhelm vorbereiten sollen noch der andere Zustand setzen dem Chronotopos Wien 1913/14 und seiner Bedeutung etwas entgegen. Vom Ziel her gelesen erscheint Musils Roman als eine breit angelegte Dystopie der k. u. k. Monarchie, der historischen Vergeblichkeit. Man könnte aber auch sagen: Dann ist das bestenfalls seine Möglichkeit und mit ihr wiederum die Möglichkeit der Unmöglichkeit. Das Ende wird vom Anfang überlagert; die Zukunft bleibt auch in der Vergangenheit uneinholbar.

\section{RUHELOSE REIHE}

Was von den Utopien des Romans übrig bleiben könnte, erhellt sich vielleicht am besten, wenn man umgekehrt denkt: nicht mit dem Krieg als Ziel, sondern vom Überleben aus. Eine kleine, winzige Erzählung aus dem Nachlaß zu Lebzeiten (1935) bietet sich hierfür als Vorlage an. Sie trägt den Titel »Die Maus« und erzählt von einer Bank hoch oben in den Alpen während des Weltkriegs. Auf ihr hat sich ein Soldat, tödlich getroffen, niedergelassen. Musil öffnet die ästhetische Erfahrung auf die Ewigkeit hin. Augenblick und Ewigkeit scheinen im »Spennadelknopf « der Augen einer kleinen Maus austauschbar zu werden oder besser drehen sich wie im freeze-out einer Photographie, die den festgehaltenen Moment in eine fortschreitende Geschichte zurückwirft.28

»Diese winzige Geschichte«, so beginnt Musils Text, »die eigentlich nur eine Pointe, eine einzige kleine Spitze ist, und gar keine Geschichte,

28 Robert Musil: Die Maus. In: ders.: Gesammelte Werke II (wie Anm. 23), S. 488 f. (im Folgenden ohne einzelne Zitatnachweise). ereignete sich im Weltkrieg."So wahr es ist, dass diese Geschichte sich zu einer einzigen Spitze verdichtet, so wahr punktiert sie auch ihr Sujet, den Weltkrieg. Es ist Musils Thema par excellence, biographischer Wendepunkt und Apokalypse der österreichisch-ungarischen Doppelmonarchie. ${ }^{29}$ Wenn also Musils Geschichte von der Maus tatsächlich nur eine Spitze hätte, so führte sie direkt in den Weltkrieg. Allerdings bleibt hier jenes »eigentlich « mitzulesen, bei dem man sich fragt, was genau es sagt: dass die Geschichte zwar >eigentlich keine ist, aber weil es nicht anders möglich ist, eben doch erzählt wird, oder ob es eben wirklich, reigentlich ‘, keine Geschichte ist, obgleich es den Anschein hat. Am Ende jedenfalls wird sie zumindest zu einer "winzige[n] Geschichte«, so heißt es ja ausdrücklich.

Offensichtlich fordert dieses Recht auf Geschichte schon der Titel ein, der eine Art Parabel oder besser Fabel zu versprechen scheint. Schon im Titel verspricht »Die Maus« vom Kleinen zu erzählen, was im Bereich des Moralischen freilich nicht oder nur indirekt darauf vorbereiten kann, dass ihre Schlusswendung, ihre eigentliche Lehre darauf hinausläuft, dass sie vielleicht gar keine Geschichte (aus der viel zu lernen wäre, über Moral oder menschliches Verhalten im Allgemeinen) zu lesen gibt, sondern eben nur eine Winzigkeit ist, so winzig, dass »eigentlich«, um dieses Wort noch einmal aufzugreifen, nichts zu erzählen ist, nichts zu lehren und nichts zu lernen - als vielleicht nur, dass es eine Fabel gegeben haben wird - und mehr und davor noch, dass es eine Pointe gegeben haben wird, die seigentlich s statthat, während suneigentlich eben doch eine Geschichte erzählt wird, die immerhin so ehrlich ist, sich selbst als `winzig` auszuweisen.

Die Unterscheidung von >Geschichteく und >Pointe führt sich in diesem Gattungsspiel zurück auf die Differenz von seigentlich >uneigentlich`, als wäre am Grunde der Fabel eine metaphorische Kraft, als wäre die Kraft des Erzählens ursprünglich die des Tropus, einer Wendung also, die um diesen Punkt zwischen dem `Eigentlichen

29 »Die fünfjährige Sklaverei des Kriegs hat inzwischen aus meinem Leben das beste Stück herausgerissen; der Anlauf ist zu lang geworden, die Gelegenheit, alle Kräfte zu spannen, zu kurz. Verzichten oder springen, wie immer es kommt, ist die einzige Wahl, welche geblieben ist «, schreibt Musil 1919 in seinen Tagebüchern (Musil: Tagebücher [wie Anm. 21], Bd. 1, S. 527). "[A]uf die Bruchstelle 1914", bemerkt Tim Mehigan, konzentriert »sich sein ganzes dichterisches Interesse immer mehr « (Tim Mehigan: Robert Musil. Stuttgart 2001, S. 13). 
dem >Uneigentlichen kreist. Als wolle "Die Maus« in dieser doppelten Möglichkeit der Differenz und der Indifferenz zugleich von >Geschichte

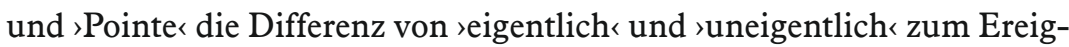
nis machen. Die »winzige Geschichte«, von der es heißt, dass sie »sich im Weltkrieg« »ereignete«, ist selbst das Ereignis, dass sie, insofern sie erzählt wird, auf die Pointe hinausläuft, gar nicht »im Weltkrieg« zu spielen, sondern diesem zu entgehen. So sehr die Geschichte eine sein muss, die dem Weltkrieg nicht entgeht, ist sie doch, auf den Punkt einer kleinen Spitze gebracht, selbst die Möglichkeit, dass kein Krieg ist..$^{30}$ Genau dies liest sich in den Gang der Erzählung hinein wie folgt: »Auf der ladinischen Alpe Fodara Vedla, tausend und mehr Meter über bewohnter Gegend und noch viel weiter abseits von ihr: Dort hatte jemand im Frieden eine Bank hingestellt «. ${ }^{31}$ Man kann hieraus eine sanfte Ironie herauslesen, wenn diese Geschichte aus dem Weltkrieg ihren eigentlichen Ort aus dem Frieden heraus erhält. Zwischen Krieg und Frieden ist dieser Ort bewohntem Gebiet entzogen, und zwar »noch viel weiter abseits«, als es in der Vorstellung einer entlegenen Bergwelt auszumalen wäre. Die Geschichte lädt dazu ein, in ihre eigene Unwirklichkeit einzutauchen, nicht nur, als rage sie mit der Bank vom Frieden in den Krieg hinein, sondern als sei ihre eigene Möglichkeit die, mit und auf dieser Bank unbeteiligt zu sein, abseits zu stehen. ${ }^{32}$

Die Erzählung Musils ist nicht sehr lang, und doch ließe sich noch vieles anmerken. Ein Absatz jedoch (es sind insgesamt nur sechs) erzählt wirklich von einer kleinen Maus, wobei es offen bleiben muss, ob von ihr wirklich erzählt wird oder diese Maus nicht vielmehr in ihrer Allegorisierung verschwindet: Denn dieser Absatz, wie die ganze Fabel, läuft

30 Das Prophetische, wie es Musils kleiner Text »Fliegenpapier« von 1913 - als Vision des kommenden Krieges - birgt, gilt insgesamt für die »Bilder" aus dem Nachlaß zu Lebzeiten: »1935, zwischen den Weltkriegen, entstehen Nachbilder und Vorausbilder zugleich" (Herbert Kraft: Musil. Wien 2003, S. 209).

31 Führt der Weg auf die poetisch (auch wenn es den Ort wirklich gibt) klingende "Alpe Fodara Vedla" nicht "noch viel weiter abseits«, als hier auszuführen ist, nämlich ähnlich weit wie Brentanos imaginäres ,Vadutz im Märchen Gockel, Hinkel, Gackeleia, also in »das Land aller Schätze, Geheimnisse und Kleinodien" (Clemens Brentano: Werke. Dritter Band. Hrsg. von Wolfgang Frühwald und Friedhelm Kemp. 2., durchgesehene und erweiterte Auflage. München 1978, S. 617-831, hier S. 619)?

32 »Diese Bank stand auch im Krieg unversehrt", schließt der folgende Satz an; auch er liest sich als erzählerischer Selbstkommentar. auf einen einzigen Punkt zu, der die Maus, in diesem Absatz, auf »[e]in Auge, so klein und schwarz wie ein Spennadelknopf « konzentriert. Dieser "Spennadelknopf « wiederum »richtete sich dahin«, wo im unmittelbar vorhergehenden Satz eine "Menschenhand [...] von der Lehne der Bank" herabsank. Das Auge der Maus richtet sich auf den Krieg, aber auf einen festgestellten und pointierten Krieg - „Wer auf dieser Bank saß, saß fest «, heißt es -, der auf eine erstarrende Bewegung zugespitzt ist, als sei die ganze Geschichte dieses Krieges nur eine Geste auf dieser Bank. Und kann diese Geste, die vom Leben in den Tod und die Ewigkeit zu weisen scheint, indem sie die Geschichte dieses Krieges auf das singuläre Moment einer sinkenden Hand verkürzt, nicht zugleich als Metonymie der Schreiberhand gelesen werden, die, während sie die Geschichte schreibt, herabsinkt, zwischen die Buchstaben, womit der `Geist‘, der die Buchstaben beflügelt, buchstäblich am Punkt des Satzendes seinen Abgrund findet? Und gäbe dann nicht erst die Hand im Augen-Blick der Maus die ganze Geschichte zu lesen?

Diese Frage lässt sich noch weiter vertiefen, wenn man dem folgenden Satz in seine eigene Geschichte folgt: »Und man hatte einen Augenblick [wohl den Augen-Blick der Maus] lang ein so sonderbar verkehrtes Gefühl, daß man wirklich nicht mehr recht wußte, ob sich dieses kleine, lebendige, schwarze Auge drehe oder ob sich die ungeheure Unbeweglichkeit der Berge rühre«.33

Es ist dies der Satz einer Kehre oder Wende, die ihren Punkt im Auge der Maus findet, das obendrein in den >Augen-Blick dieses einen Satzes, dieses Punktes in der Erzählung, eingeschlossen scheint. Und diese Wende lässt sich noch weiter auseinanderführen in Musils Frage:

33 Musil reflektiert in der »Maus« damit die Möglichkeiten seiner Literatur wie die von Worten und Geschichten überhaupt, die nur in der Veränderung von Erfahrungen und Perspektiven, nicht aber der Wirklichkeit selbst Bestand haben; vgl. auch die "Vorbemerkung « zum Nachlaß zu Lebzeiten: "Inmitten einer donnernden und ächzenden Welt bloß kleine Geschichten und Betrachtungen herauszugeben; von Nebensachen zu reden, wo es so viele Hauptsachen gibt [...]: ohne Zweifel, es mag manchem als Schwäche erscheinen [...]. Aber erstens hat immer schon ein gewisser Größenunterschied zwischen dem Gewicht dichterischer Äußerungen und dem Gewicht der unberührt von ihnen durch den Weltraum rasenden zweitausendsiebenhundert Millionen Kubikmeter Erde bestanden und mußte irgendwie in Kauf genommen werden." Und wenn die Welt in der Hauptsache ‘ächzt` und `donnert ` - wie anders ließe sich überleben als in den »kleine[n] Geschichten und Betrachtungen«? 
»Man wußte nicht mehr: war Kampf oder herrschte schon Ewigkeit«, als sei es die Möglichkeit dieser Wende, die des Tropus oder der Maus, zwischen Leben und Tod zu entscheiden, als sei dies endlich die Frage, ob man der Geschichte in den Krieg folgt oder sie in der ewigen Distanz einer Buchseite liest. ${ }^{34}$ "Diese Bank war dem Krieg in Verlust geraten«, kann Musil, nur scheinbar lakonisch, behaupten.

Im Augen-Blick der Maus wendet sich diese Geschichte, indem sie in eine Kippfigur steuert zwischen Krieg und Ewigkeit, Leben und Tod, Geschichte und Punkt, der im Tropus der Maus Gestalt gewinnt. ${ }^{35}$ Mit der Maus findet dieser Punkt als »Spennadelknopf « nicht nur selbst das andere Ende einer Nadelspitze, sondern dieses andere Ende erhält auch eine eigene Geschichte, die, so wäre zu vermuten, als eine Ausmalung dieses Wendepunktes zu begreifen sein müsste. »Eine kleine Maus hatte sich nahe der Bank, die selten besucht wurde, ein System von Laufgräben angelegt ${ }^{36}{ }^{36}$ "Maustief «, so Musil weiter, »mit Löchern zum Verschwinden und anderswo wieder aufzutauchen. Sie huschte darin im Kreise, stand, huschte im Kreise weiter.« »Maustief« sinkt diese Erzählung in die Wirklichkeit - das ist natürlich blanke Ironie, die wiederum im Wörtlichen am besten zu verstehen ist, nämlich nicht verständlich, sondern nur wörtlich: Die Geschichte von der Maus erzählt nicht viel mehr als »Die Maus« (was der Titel verspricht) zu lesen gibt. Das wäre dann die ganze Geschichte:

34 In diese Richtung lässt sich auch der vorangehende Absatz als Szenerie eines »Schöpfungszeitalter[s] « kreatologisch lesen, wo das »Gras ringsum [...] noch vom Jahr vorher [war]; schneebleich und häßlich«, als sei es leeres Papier noch »ohne Sinn und Zahl« wie die »Buckel und Mulden«, denen »Knieholz und Alpe« zugesetzt wird, während der Blick (»in hundert Blicke zersplittert«, als gäbe es nicht nur einen Leser) keine Landschaft erblicken kann, sondern "nur noch das leere Licht«.

35 Mithin geht es Musil damit um »den größtmöglichen Freiraum für das Festhalten des Augenblicks« (Sibylle Deutsch: Der Philosoph als Dichter. St. Ingbert 1993, S. 24. Vgl. zu Musils `Augenblicken` auch Kordula Glauder: »Leben, wie man liest«. Strukturen der Erfahrung erzählter Wirklichkeit in Robert Musils Roman Der Mann ohne Eigenschaften. St. Ingbert 2005.

36 Weshalb, so fragt sich, wird diese Bank »selten besucht«? »Diese Bank war dem Krieg in Verlust geraten«, heißt es weiter oben, als ginge es um das, was sich der Geschichte des Krieges entzieht, mithin um das singuläre Moment, was diese Geschichte zu sich selbst macht, die erstens keine andere als ihre eigene Richtung anzeigt und zweitens darauf hinausläuft, nur diesen Punkt, ihre Singularität zu erzählen, indem sie die Erzählung in Frage stellt. ein Auftauchen und Verschwinden, so dass sich eine löchrige Geschichte ergäbe oder, vice versa, Punkte, an denen die Geschichte verschwindet, um >andernorts` erzählt zu werden.

Beides wäre gänzlich unverbunden, hätte die Maus nicht ein System angelegt, das nur unschwer als das der winzigen Geschichte selbst decodierbar ist und dessen Organisationsmoment einfach ist: Die Maus huscht im Kreis. Genau genommen jedoch gibt es hier zunächst einen Kreis, den die Maus durch ihre Löcher hindurch beschreibt, dann kommt dieser Kreislauf im eingeschobenen »stand « zur Stille, um dann in jenes ,Weiterhuschen zu fallen, das mehr ist als eine Wiederholung, denn es könnte endlos so weitergehen. Die Maus kommt zum Stillstand nicht zuletzt in dem Riss, der ihr Huschen von dem Wissen trennt, dass sie ewig so weiterhuschen könnte. Die Maus kreist im allegorischen Sinn (aber was hieße das dann noch?) um sich selbst, um ihr eigenes Kreisen; darin steht sie still; was nichts anderes bedeutet, als "maustief « erzählt zu werden. Gerade der Kreisgang gibt also keine eigentliche Geschichte zu lesen; im Kreis beginnt das Kreisen um den Stillstand, der Kern der Geschichte fällt in sich ein oder faltet sich zu sich selbst aus. ${ }^{37}$

Nun hat Musil nicht vergessen, seiner Fabel eine Lehre zu geben, die dann ja doch aus dem Kreis und dem Punkt hinausführt. Ich zitiere das Ende der »Maus«: »So hätte es mit dem, was man nicht zu kennen fühlte, lange und nach Belieben fortfahren lassen; aber das ist schon die ganze kleine Geschichte, denn sie war inzwischen jedesmal schon zu Ende gegangen, ehe man noch genau sagen konnte, wo sie aufhörte«.

Das Unbekannte rückt in dieser Lehre in den Mittelpunkt, indem es als ein Gefühl einerseits auf den Punkt inneren Wissens fixiert wird und andererseits einem Belieben ausgesetzt wird. Innenseite und Außenseite verhalten sich zueinander als Gefühl für Unbekanntes. Die Beliebigkeit öffnet das Verhältnis noch einmal ins Unbestimmte: Es könnte alles sein, das erzählt wird und in der Erzählung doch dem Gefühl unbekannt bleibt. Der Tod als (Vor-)Gefühl einer sinkenden Hand ist hierfür nur eine extreme Parabel. Die Grenzen der Erzählung dieser UnbestimmtheitsRelation machen aus dem Feld der >großen` Geschichte »die ganz kleine Geschichte « von der Maus, und deren Kleinheit ist so winzig wie ein Spennadelknopf, eigentlich wie die Spitze einer Nadel. Deshalb kann man

37 Deshalb ist die Wende von Musils Texten gleichermaßen eine nach außen wie nach innen, die Extension arbeitet zugleich einer Intensivierung zu: »Robert hat alles auseinander und ineinander gearbeitet «, urteilt Martha Musil (Robert Musil: Briefe [wie Anm. 18], S. 1427). 
auch nicht sagen, »wo sie aufhörte«, weil sie endlos kreisen könnte, und es nur ein Belieben ist, dieses Kreisen im Bild einer Maus festzuhalten, ja weil vielleicht nicht einmal dies möglich ist, wenn nämlich »Die Maus» als Geschichte doch als Pointe zu lesen übrig bliebe, die sich gerade nicht als Geschichte erschöpft, sondern als Wendepunkt, der immer schon jede Geschichte aus sich herausgeführt hat. Am Ende der »Maus« steht deshalb der Gedanke, dass es mit dem Ende vielleicht nichts sei, jedenfalls endet sie nicht mit den Worten, die man sagen kann, sondern mit der Öffnung, dass sie, um Erzählung zu werden, über sich hinaus geht. »Die Maus« treibt dann auf die Spitze, dass, eine Geschichte zu erzählen, bedeutet, außerhalb zu stehen. Das Uneigentliche (der Tropus, das Allegorische, die Maus) wäre dann das Eigentliche, weil »Die Maus« eben von der Maus erzählt und ihrem Augenblick, um dessen Möglichkeit sich die Welt dreht. Erzählt wird also die Kraft der Erzählung um den Preis, dass diese Erzählung keine mehr ist - weil die Kraft der Erzählung ihren Grund findet in jenem »so sonderbar verkehrte[n] Gefühl «, das sich nach Belieben dem Unbekannten öffnet. Weil die Geschichte vorbei ist, lässt sie sich, ohne aufzuhören, erzählen; umgekehrt folgt daraus die Einsicht, die maustiefe Einsicht, dass die Geschichte von der Maus auch dies nicht erzählt, sondern »inzwischen jedesmal schon zu Ende gegangen « war, »jedesmal" nur in ihre eigenen Worte eintaucht, weshalb in der Tat die Worte der Geschichte ein Ende machen, mit dem doch nicht aufzuhören ist, auch dies »jedesmal «. ${ }^{38}$

Utopie und Dystopie: Im Auge der Maus ist beides aufeinander bezogen, wird der Augenblick zur Ewigkeit des Todes und umgekehrt wird die Ewigkeit zusammengezogen auf einen Moment, der eigentlich keine Geschichte, sondern nur eine kleine Spitze ist.

Nicht so viel mehr, wohl aber im anderen Zustand, erzählt auch der Mann ohne Eigenschaften. Seine Utopien sind die Haltepunkte vor dem dystopischen Finale; sie führen nicht über den Krieg hinaus, bleiben ohne Telos, jedoch ohne dass die Ästhetik des Augenblicks von der Ewigkeit des Todes eingeholt werden würde. In einer Formel aus Kapitel 10 des

$38 \mathrm{Zu}$ diesem »jedesmal« vgl. Axel Krommer und Albert Kümmel: Pendelbewegungen des Sinns. Vorschlag einer informations- und chaostheoretischen Bewertung des $>$ MoE . In: Rapial III/3 (September/Oktober 1993), S. 2-11. "Das Ganze einer solchen Prosadichtung wird zur Metapher der Zeit im Modus reiner Gegenwärtigkeit", kommentiert Thomas Hake (»Gefühlserkenntnisse und Denkerschütterungen«: Robert Musils Nachla $\beta$ zu Lebzeiten. Bielefeld 1998, S. 279) etwas hölzern. dritten Teils (zweites Buch) über »Die Moral des nächsten Schritts« könnte sich diese Aushebelung des Utopischen aus der Erfahrung des Dystopischen in einer Pragmatik, die der Mathematik entlehnt ist, auflösen; Ulrich erläutert Agathe:

Ich habe gesagt, es käme nicht auf einen Fehltritt an, sondern auf den nächsten Schritt nach diesem. Aber worauf kommt es nach dem nächsten Schritt an? Doch offenbar auf den dann folgenden? Und nach dem nten auf den $\mathrm{n}$ plus ersten Schritt?! Ein solcher Mensch müßte ohne Ende und Entscheidung, ja geradezu ohne Wirklichkeit leben. [...] Die Wahrheit ist, daß wir keine Methode besitzen, mit dieser ruhelosen Reihe richtig umzugehen. (MoE, 735 f.)

Nimmt man dieses Zitat als Reflexion auf das utopisch konnotierte Programm des Möglichkeitssinnes, wie ihn Kapitel 4 des Mannes ohne Eigenschaften skizziert, so benennt Musil hiermit das Leben seines Mannes ohne Eigenschaften als eines »ohne Ende und Entscheidung, ja geradezu ohne Wirklichkeit«. Als Papierheld und diskursiver Brennpunkt eines Romanes, der mitunter wie eine Enzyklopädie des geistigen Lebens wirkt, ließe sich Ulrich mit dem Möglichkeitssinn auch diese Lesart abgewinnen: als Held einer Literatur, die gerade weil sie unwirklich ist, über das Ende hinaus wirksam sein kann.$^{39}$ Die Literatur des Mannes ohne Eigenschaften, als Literatur eines Möglichkeitssinns, überlebt das Ende ihrer Handlung wie jene Angelschnur, die ins Wasser ausgeworfen wird, ohne dass man wissen kann, ob ein Köder am Haken hängt. Sein Material, das in der Inventur der k. u. k. Monarchie gewonnen wird, ist dieser Köder in einer Zeit nach dem Ende dieser Monarchie; mit der Frage nach dem, was bleibt, gewinnt auch der Roman an Aktualität. Nicht also das Historische in seiner analytischen Schärfe für den Ausbruch des Krieges macht den Roman lesenswert (wenngleich er auch deshalb zu Recht gelesen wird), sondern die Konstellationen und kulturellen Funktionen, die er beschreibt und - dem Kontext ihrer Wirkmacht entzogen - entmächtigt. Nichts also kann der Roman dazu beitragen, faktische Geschichte zu ändern, wohl

39 Die Frage nach dem >rechten Leben stand bei Musil schon früh im Vordergrund. Im Zusammenhang mit seinen wissenschaftlichen Vorbildern von Nietzsche bis Mach und Bergson und mit Blick auf die spezifisch fiktionale Antwort Musils vgl. Hans Feger: Die Moral des nächsten Schritts. Von der Lüge im außermoralischen Sinn bei Robert Musil. In: Monatshefte 97 (2005), S. 78-100. 
aber steht die Wirklichkeit des Romans dafür ein, als kulturkritisches Vademecum verwendet zu werden. Nur indem sie sich im Bewusstsein verankern können, behalten die Utopien des Romans ihren Impetus; nur von der Faktizität der Katastrophe, ihrem negativ-utopischen Gegenbild des Krieges, erhält diese utopische Grundierung ihre Lesbarkeit.

Indem der Weltkrieg die Welt, in die der Roman wie als Revue noch einmal einführt, vernichtet hat, behält der Möglichkeitssinn des Textes am Ende recht: Leben lässt sich, mit dem Mann ohne Eigenschaften als Passepartout einer geistigen Generalinventur, in den Möglichkeiten dessen, was nicht mehr ist - als Zitat. Viel lernen kann man deshalb aus Kapitel 100: »General Stumm von Bordwehr dringt in die Staatsbibliothek ein und sammelt Erfahrungen über Bibliothekare, Bibliotheksdiener und geistige Ordnung«. Was der General hier über »geistige Ordnung« lernt, besteht, wenn man so will, in einem Grundkurs in Zitation, das heißt des philologischen Handwerkszeugs. Was für ein Wissen hierfür notwendig sei, vermag ihm der Bibliothekar nicht zu sagen: Weder »Kriegsgeschichtliches « noch "Friedensgeschichtliches « scheint passend, noch »eine Zusammenstellung aller großen Menschheitsgedanken« oder »ein Buch über die Verwirklichung des Wichtigsten « - "Also eine theologische Ethik? «, fragt der Bibliothekar nach - und auch nichts über so »etwas wie [...] Eisenbahnfahrpläne[ ], die es gestatten müssen, zwischen den Gedanken jede beliebige Verbindung und jeden Anschluß herzustellen" (MoE, 461). Stattdessen holt der Bibliothekar »eine Bibliographie der Bibliographien " aus einem der Regale, »also das alphabetische Verzeichnis der alphabetischen Verzeichnisse der Titel jener Bücher und Arbeiten, die sich in den letzten fünf Jahren mit den Fortschritten der ethischen Fragen, ausschließlich der Moraltheologie und der schönen Literatur, beschäftigt haben - oder so ähnlich « (MoE, 462). Nicht um Inhalte geht es hier: "Wer sich auf den Inhalt einläßt, ist als Bibliothekar verloren!« (MoE, 462), wird der General belehrt. Steuerung des geistigen Lebens ist das eigentliche Ziel, und als der General erfährt, dass nicht nur er sich von Bibliothekaren die srichtigen` Bücher beschaffen lässt, erkennt er dies als Chance zur Manipulation..$^{40}$ Eine $»$ heimliche geistige Hochzeit« lasse sich so feiern,

40 Diese Perspektive verfehlt das Musil-Kapitel in: Nikolaus Wegmann: Bücherlabyrinthe. Suchen und Finden im alexandrinischen Zeitalter. Köln, Weimar, Wien 2000, S. 123-127. "Das Wissen der Bibliothek, und nur um dieses Versprechens willens stürmt General Stumm ihren Bau, ist für den modernen Benutzer typischerweise monographie-förmig: Was man sich von der Bibliothek erhofft, ist nicht mehr Wissen, das als Teil indem der General stets die Bücher, die die von ihm verehrte Diotima für sich reservieren lässt, zuvor »hie und da [...] vorsichtig mit dem Blei an den Rand einer Seite« beschreibt (MoE, 463). Von hier aus lässt der Roman - indem er wie so oft seinem Protagonisten ein antagonistisches Spiegelbild korrespondieren lässt - genau zwei gangbare Wege offen: Während Ulrich im Grunde ein Mann der Bibliothek ist, der Tradition, der die Romantiker, Mystiker, Psychologen und Naturwissenschaftler gelesen hat bzw. selbst als gelebtes Wissen figuriert, gilt für General Stumm von Bordwehr anderes: Sein Triumph in der Bibliothek wird zum eigentlichen Fanal des Krieges: »Stell dir Ordnung vor«, erläutert er:

Oder stell dir lieber zuerst einen großen Gedanken vor, dann einen noch größeren, dann einen, der noch größer ist, und dann immer einen noch größeren; und nach diesem Muster stell dir auch immer mehr Ordnung in deinem Kopf vor. Zuerst ist das so nett wie das Zimmer eines alten Fräuleins [...]; aber jetzt stell dir bloß eine ganze universale, eine Menschheitsordnung vor: so behaupte ich, das ist der Kältetod, die Leichenstarre, eine Mondlandschaft, eine geometrische Epidemie! Ich habe mich mit einem Bibliotheksdiener darüber unterhalten. Er

eines Allgemeinen jeder einzelnen Schrift einen repräsentativen Stellenwert und so einen definitiven Rück-Bezug zum kosmologischen Ganzen gibt«, sondern "(relativ) abgeschlossene Reden, thematisch beschränkt, in ihrem Zugriff selektiv und im Verhältnis zu dem, was insgesamt in der Bibliothek steht, von punktförmiger, zwischen Buch-Anfang und Buch-Ende gespannter Lesbarkeit.«(S. 126) Daran ist der General jedoch nicht interessiert, sondern an geistiger Ordnung und Kontrolle. Umgekehrt führt Der Mann ohne Eigenschaften, nur weil er nicht linear, sondern enzyklopädisch-plura konzipiert ist, nicht zu einer Unlesbarkeit oder einer »Unübersichtlichkeit« als "Dauer-Irritation" (S. 127). Die Frage ist vielmehr: Wie benutzt man eine Bibliothek, wenn man nicht den Bücherwald en bloc, sondern je nur einzelne Lektüren (von monothematischen Büchern bis zu Meta-Bibliographien) vornehmen kann? Nicht die »Relation von Buch und Bibliothek«, die über »(Un-)Lesbarkeiten« (S. 126) entscheide, prägt Musils Roman, sondern die Differenzen in Bezug auf geistige Ordnung und Kontrolle, das heißt die Möglichkeiten, Buch-Wissen qua Lektüre neu zu konstellieren und dabei jenen "Gehirnphosphor « riechen zu können, der »im Allerheiligsten der Bibliothek " gleichermaßen Flammen schlagen kann oder »jede beliebige Verbindung und jeden Anschluß« (MoE, 461) herstellen könnte - die blitzartig-augenblicklich erleuchtete Bibliothek als Epiphanie im Sinne von James Joyce, als Ort des Musil'schen Möglichkeitssinns. 
hat mir vorgeschlagen, daß ich Kant lesen soll oder so etwas dergleichen über die Grenzen der Begriffe und des Erkenntnisvermögens. Aber ich will eigentlich nichts mehr lesen. Ich habe so etwas Komisches im Gefühl: ein Verständnis dafür, warum wir beim Militär, die wir die größte Ordnung haben, gleichzeitig bereit sein müssen, in jedem Augenblick unser Leben hinzugeben. (MoE, 464 f.)

Nichts anderes sagt Ulrich im folgenden Kapitel 101, wo ihn seine Kusine Diotima auf den General anspricht: „Wissen Sie, daß ich vom Kopf bis zum Fuß erschauere, wenn ich ihn sehe? Er erinnert mich an den Tod! Ulrichs Antwort ist hellsichtig: »Große Kusine, erinnern Sie sich daran, daß ich Ihnen diesen Zusammenbruch seit je vorhergesagt habe? Er ist unvermeidlich; Sie müssen sich auf ihn gefaßt machen!« (MoE, 466)

Das Gespräch nimmt in der Folge eine Wende, indem eine andere Spiegelfigur zum Mann ohne Eigenschaften, der `Großschriftsteller Paul Arnheim, zum Thema wird. Diotima ist in ihn verliebt - und während ihr Ulrich darlegt, weshalb es Arnheim war, der den General in die Gesellschaft um die Parallelaktion geführt hat, treten die zwei Optionen - Ulrich und Arnheim - hervor: Arnheim, den Diotima liebt wie eine "Seele«, »die durch Arnheims zögernde und übersteigernde Liebe am Rand einer Wüste schmachtete ( $(\mathrm{MoE}, 475)$, und Ulrich, zu dessen Körper sie eine Anziehung »wie einen magnetischen Strom» spürt, während sie unversehens »etwas von der Möglichkeit [ahnte], diesen Mann zu lieben; es kam ihr so vor, wie ihrer Ansicht nach die moderne Musik war, ganz unbefriedigend, aber voll einer aufregenden Andersartigkeit." (MoE, 477) Nicht zufällig klingt hier die Utopie des anderen Zustands an; auf den Mann ohne Eigenschaften, den Vetter, zugeschnitten, erhält diese »Andersartigkeit« die Züge eines Phantasmas, einer unstillbaren Sehnsucht und Faszination, die auf eine andere, nur geistige Art klar sehen lässt. Während Ulrich »wie ein blindes Fenster « lächelte (MoE, 477), entscheidet sich Diotima nicht für diese sehend-mögliche Blindheit - die der geistigen Erkenntnis und des Lebens »wie eine Figur auf einer Buchseite ( $\mathrm{MoE}$, 590) -, sondern für die unausweichliche Geschichte. Dieser Geschichte stellt sich - in Wirklichkeit - nichts anderes als der Roman entgegen, das heißt die reinsame< Lektüre, wie sie das Bild des verlassenen Vetters vorgibt: »Lieber Freund, wir tun etwas ganz Unmögliches; bleiben Sie noch einen Augenblick hier allein, ich werde vorausgehn, um mich wieder vor unseren Gästen zu zeigen.« (MoE, 477)

Wenn ihn Diotima als einen »Geist, der den Schatten der Dinge nicht kennt«, beschreibt, trifft sie genau das Selbe wie Ulrichs Beschreibung der
Dichtung: "Wenn wir also, wie ich gesagt habe, in der Dichtung einfach auslassen, was uns nicht paßt, so tun wir damit nichts anderes, als daß wir den ursprünglichen Zustand des Lebens wiederherstellen." (MoE, 574). Die Wirklichkeit ist nicht anders denn als unwirklich zu erkennen, »wie das Gesicht eines Menschen, das in einer Kette anderer an uns vorbeigerissen wird und für kurze Weile bedeutungsvoll auftaucht«: »Es ist unmöglich, den Gedanken eines Buchs aus der Seite zu lösen, die ihn umgibt.« (MoE, 574) Dass der Erzähler - in einer dritten Variante dieser Leerstelle, die Diotima als Geist ohne Schatten und Ulrich als "Zustand des Lebens« beschrieb - Diotimas Vorwurf, Ulrich erkläre nie, wie sein Programm einer Entwirklichung umzusetzen sei, aufgreift, indem er feststellt, dass Ulrichs Sätze häufig unvollendet blieben (MoE, 575), lässt Musils Roman in eine ironisch kommentierte Reihe der Literatur eintreten.

Wenn Ulrich in Kapitel 114 von einem "Hauch, der mit jedem Atemzug seine Gestalt ändert" (MoE, 574), spricht, klingt bereits das Nachlasskapitel »Atemzüge eines Sommertages« an, dessen Szenerie jetzt als Lektüreszene kenntlich wird. »Ein geräuschloser Strom glanzlosen Blütenschnees« beschreibt den reglosen Blätterwald des Textes, der »von fassungslosen Zuschauern" umgeben ist, die als Figuration von Musils Sprache »sich dem schweigenden Zug durch die Luft anzuschließen scheinen. Das Kapitel, das noch am Todestag auf Musils Schreibtisch zur Bearbeitung lag, kennzeichnet diese Szene als einen »Stillstand des Gesprächs«, das »hängen geblieben [war], ohne einen Riß verspüren zu lassen " (MoE, 1232), als unbewussten Augenblick einer Einheit, in dem die Erinnerung bereits entschieden hat, dass die Lektüre von Büchern und der Akt des Erinnerns im Leben unvereinbar sind:

"Da ward mir das Herz aus der Brust genommen«, hat ein Mystiker gesagt: Agathe erinnerte sich dessen.

Auch wußte sie, daß sie selbst diesen Ausspruch Ulrichs aus einem seiner Bücher vorgelesen hatte. (MoE, 1232 f.) ${ }^{41}$

41 In Kapitel 84, das den Titel trägt: »Behauptung, daß auch das gewöhnliche Leben von utopischer Natur ist«, wirft der Jugendfreund Walter Ulrich vor: ")Wie pikant du es hinstellst‘ sagte er; ‘als ob wir überhaupt die Wahl hätten, Ideen zu leben oder unser Leben zu leben! Aber am Ende kennst du vielleicht das Zitat: >Ich bin kein ausgeklügelt Buch, ich bin ein Mensch mit seinem Widerspruch ? [...] Man braucht also, was du sagst, nur ein wenig an der Wirklichkeit zu messen, so zeigt es sich bestenfalls als Literatur! Ulrich räumte ein: ,Wenn du mir erlaubst, darunter auch alle anderen Künste 
Dass Der Mann ohne Eigenschaften vom Zeitraum seiner Handlung zwischen Sommer 1913 und Sommer 1914 im Sprung über den dem Romangeschehen entzogenen Weltkrieg hinaus als utopisch aufgeladenes Vademecum fungieren kann, muss Musil mit Blick auf den Zweiten Weltkrieg gewusst haben..$^{42}$ Nicht allein der utopische Grundzug des Romans kennzeichnet den Möglichkeitssinn, sondern dass die Utopien in ihrer Zielperspektive - »Grundidee: Alle Linien münden in den Krieg." $(\mathrm{MoE}, 1851)^{43}$ - auf die Apokalypse des geistigen Lebens zusteuern, die in der "Parole der Tat« avisiert wird, lässt den Mann ohne Eigenschaften als prinzipielles episches Experiment eines Möglichkeitsdenkens lesen, das greift, wo Zukunft undenkbar scheint.

\section{LITERARISCHE UND \\ VISUELLE FORMEN}

zu verstehn, [...], dann will ich allerdings etwas ähnliches behaupten, daß unser Dasein ganz und gar aus Literatur bestehen soll!« (MoE, 365) Der Akzent liegt also auf der >Abschaffung der Wirklichkeit im Sinn, dass das Dasein "ganz und gar aus Literatur bestehen soll « (Hervorhebung: MR), also in einer Art Moral des Literaturwerdens.

42 Der Schriftsteller Armin Kesser erinnert sich an eine Begegnung mit Musil im Schweizer Exil 1940: "Musil hatte als Kulturdiagnostiker die aktuellen Ereignisse zwar nicht vorausgesehen oder vorausgesagt, aber sie waren wie eine Konsequenz in der Kultursituation eingewickelt, die er im \Mann ohne Eigenschaften und in seinen Essays beschrieb.« (Zit. nach Corino: Robert Musil [wie Anm. 18], S. 1374) Dass Musil selbst das Problem der Aktualität seines Romanfragments in den Versuch ummünzte, nicht nur die veröffentlichten Texte des Romans auf die Gegenwart hin auszulegen, sondern aus Gegenwartsanalysen weitere Kapitel zu generieren, dürfte die Fragen einer Gestaltung des Romanschlusses nicht vereinfacht haben Vgl. mit Bezug auf Musils »Tagebücher" ([wie Anm. 21], S. 994 f. und 963 f.) Corino: Robert Musil, S. 1412: "War der deutsche Wehrmachtssoldat die zeitgemäße Massenkopie des Musilschen Helden, der nach den ursprünglichen Plänen, nach dem Scheitern der Geschwister-Utopie [im anderen Zustand] ja auch in den I. Weltkrieg ziehen sollte? « In »U's Nachwort, Schlusswort", einem Entwurf von "Mitte Jänner 42«, heißt es: »Der gealterte $\mathrm{U}$ von heute, der den zweiten Krieg miterlebt, und auf Grund dieser Erfahrungen seine Geschichte, und mein Buch, epilogisiert." (MoE, 1943) 43 Der Eintrag steht in einer Reihe mit weiteren `Grundideen` unter dem Titel »Aufbau des zweiten Teils von Bd II im Groben«. 
HANS ULRICH SEEBER

\section{PRÄVENTIVES STATT KONSTRUKTIVES HANDELN}

\section{Zu den Funktionen der Dystopie}

\section{in der anglo-amerikanischen Literatur}

Kurz nach 1900 erläuterte der witzige Essayist Max Beerbohm im Blick auf More, Wells und Platon sein Verständnis von Utopie mit folgendem Vierzeiler:

So this is utopia,

Is it? Well -

I beg your pardon;

I thought it was Hell.

Utopie als Quelle von Leiden oder als komisches Hirngespinst ist nicht nur für die moderne Anti-Utopie typisch, die seit dem Ende des 19. Jahrhunderts wegen der Krise der Aufklärungstradition rasant an Bedeutung gewinnt. Schon die Antike kennt sowohl Platons Politeia als auch die anti-utopische Komödie Die Ekklesiazusen: Frauen in der Volksversammlung des Aristophanes. In ihr übernehmen Frauen die Herrschaft über die Legislative und versuchen, den Kommunismus per Gesetz einzuführen. Da der menschlichen Spezies dafür der nötige Altruismus fehlt, scheitert der Versuch.

Mein Vortrag gliedert sich in zwei Teile. Ich gehe zunächst in einem historischen Überblick jenem Zusammenhang von Utopie-Kritik und

1 Max Beerbohm: In a Copy of More's (or Shaw's or Wells's or Plato's or Anybody's Utopia). In: Max in Verse: Rhymes and Parodies by Max Beerbohm. Collected and annotated by J. G. Riewald. Battleboro 1963. Zit. nach Lyman Tower Sargent: Utopianism. A Very Short Introduction. Oxford 2010, S. 129. 
Fiktionalisierung nach, aus dem Anti-Utopie und Dystopie hervorgegangen sind. Dieser Teil geht von der Hypothese aus, dass Utopie-Kritik zwar schon immer, in prägnanter und quantitativ auffälliger Weise aber erst seit dem Ende des 19. Jahrhunderts eine zentrale Funktion der Gattung ist. Im zweiten Teil wende ich mich dann gezielt dem Funktionsproblem zu. Der Oberbegriff Dystopie kann dreierlei bedeuten: er ist entweder ein Synonym für Anti-Utopie, die sich gegen erkennbare utopische Vorbilder richtet, oder er meint die Kombination von Utopie-Kritik und satirischer Wirklichkeitsdiagnose wie in Huxleys Brave New World, oder er verweist, wie Bradburys Fahrenheit 451, auf jede Art von negativer Gesellschaft, die keinen kritischen Bezug zu einer positiven utopischen Konstruktion mehr erkennen lässt, wie diese aber in der Fiktion räumlich oder zeitlich von der Wirklichkeit der Gegenwart abgetrennt sein muss.

\section{VON DER UTOPIE ZUR DYSTOPIE IN DER}

ANGLO-AMERIKANISCHEN LITERATUR ${ }^{2}$

Woher rührt die seit dem Ende des 19. Jahrhunderts besonders auffällige Prägnanz und Virulenz der Utopie-Kritik von Schriftstellern und Denkern? Einige historisch situierbare Gründe lassen sich durchaus benennen:

Erstens: Ein im Laufe des 19. Jahrhunderts gesteigertes ästhetisches Bewusstsein nimmt Anstoß an didaktischen und programmatischen Texten, die einen zureichenden Grad an Lebensillusion vermissen lassen. Diese Kritik formulierte schon George Eliot anlässlich ihres zunächst als Utopie konzipierten Klassikers des englischen Realismus, Middlemarch $(1871 / 72){ }^{3}$ Nur dort, wo nicht nur Ideen bzw. Diagramme ausgebreitet, sondern auch, im Sinne der Schaffung von ästhetischer Illusion, Konflikte und Lebenserfahrungen konkret präsentiert werden, sind die Voraussetzungen für eine überzeugende romanhafte Darstellung gegeben. Letzteres gilt vor allem - ein Beispiel, das Eliot noch nicht zur Verfügung stand für die Dystopie, die einen Außenseiter gegen ein übermächtiges System stellt, so in Samjatins Wir oder Orwells 1984. Verfasser von literarischen

2 Einige Abschnitte dieses Teils stammen aus meinem Beitrag für die Katholische Akademie Bayern: Von der Utopie zur Dystopie in der angloamerikanischen Literatur. In: zur debatte 2 (2004), S. 26-27.

3 Vgl. hierzu Hans Ulrich Seeber: Die Selbstkritik der Utopie. Münster 2003, S. 139.
Utopien stehen also vor der schwierigen Aufgabe, der Idee einer anderen Verfassung der Gesellschaft Leben einzuhauchen zu müssen, sie zu versinnlichen, was, wie sich nach Eliot zeigen sollte, eigentlich erst dort so richtig möglich ist, wo, wie in der Dystopie, Gefühle und Konflikte die Geschlossenheit der utopischen Systemkonstruktion aufbrechen.

Zweitens: Philosophische Vorbehalte richten sich gegen die Verbindlichkeit der Vernunft selbst, die in der Utopie ein experimentum rationis unternimmt. Ihre statischen, totalisierenden Konstruktionen und Ansprüche lassen sich mit einem Konzept von Wirklichkeit, das seit der Romantik individuelles Leben und Veränderlichkeit bzw. Geschichtlichkeit, mithin Differenz, ins Zentrum rückt, nicht mehr vereinbaren. Aus dieser Sicht erzeugt Utopie Todesstarre, Gleichförmigkeit und Klaustrophobie. Man entdeckt noch vor Jürgen Habermas den potentiell instrumentellen Charakter der utopischen Vernunft, der neue Entfremdung erzeugt anstatt Entfremdung zu beseitigen. Einen weiteren Vorbehalt formuliert die philosophische Anthropologie seit Schopenhauer. ${ }^{4}$ Wenn Kants Ding an sich tatsächlich der rastlose, nie zu befriedigende Wille ist, der sich vor allem im rastlosen Geschlechtstrieb zeigt, dann ist die stabile Harmonie der Utopie eo ipso unmöglich, weil das Begehren jede erreichte Befriedigung überschreitet und deshalb das Unglück des Subjekts auf Dauer stellt. Der "Durst des Egoismus «, wie Schopenhauer diesen Willen charakterisierte, ist nie gestillt. Schulz formuliert: »Der Wille und das Leiden bleiben sich gleich, auch wenn der Mensch immer neue Mittel zur Befriedung seines Begehrens ersinnt. ${ }^{6}$ Eine Radikallösung wäre die biologische Neutralisierung des Geschlechtstriebs, die dann tatsächlich in Hudsons A Crystal Age von 1887, einem Staat nach dem Vorbild des Bienenstaaates mit einer für die Reproduktion zuständigen `Bienenkönigin`, zu einer Art Friedhofsruhe führt. Auch Huxley erzwingt gesellschaftliche Stabilität durch die Überlistung des Geschlechtstriebes, indem er die Familie abschafft, grenzenlose sexuelle Freiheit verordnet und etwa auftretende psychische Probleme mit Hilfe der Droge Soma in Schach hält. In jeder der klassischen Dystopien ist die Kontrolle und Instrumentalisierung der

4 Vgl. hierzu den Beitrag von Matthias Löwe.

5 Arthur Schopenhauer: Die Welt als Wille und Vorstellung. Köln 2009, S. 323 (\$65). Vollständige Ausgabe nach der dritten, verbesserten und beträchtlich vermehrten Auflage von 1859. Der Text folgt der historischkritischen Edition von Arthur Hübscher (1972).

6 Walter Schulz: Philosophie in der veränderten Welt. Pfullingen 1972, S. 403. 
Sexualität ein zentrales Anliegen, in keiner gelingt aber die Eindämmung ihres systemsprengenden Potentials restlos. Wegen des Liebesmotivs ergeben sich daraus fiktionale Gestaltungsmöglichkeiten, welche die Affinität zwischen Dystopie und Roman begründen.

Drittens: In den politischen Debatten seit dem ausgehenden 19. Jahrhundert wird im Blick auf die erstarkende sozialistische Bewegung dem Utopiebegriff aus liberaler und konservativer Perspektive häufig die Rolle des Schimpfwortes zugewiesen, das vor den Gefahren einer autoritären, kollektivistischen, die Freiheit des Individuums bedrohenden staatssozialistischen Ordnung warnen soll. Die Debatte spitzt sich in den zwanziger Jahren und danach noch zu, als von den Gegnern der pluralistischen Demokratie das Konzept des totalen Staates in die Welt gesetzt wird. Huxleys Brave New World und Orwells 1984 sind nachweislich schon kritische literarische Antworten auf diese Debatte. Utopische Konstruktionen klassischer Art geraten aus liberaler und konservativer, aber auch aus anarchistischer Perspektive, unter Totalitarismus-Verdacht, und zwar schon zu einer Zeit, als es diesen Begriff noch gar nicht gab.

Viertens: Die Krise des utopischen Denkens seit dem ausgehenden 19. Jahrhundert ist mit der Krise des Fortschrittsdenkens verknüpft, die dann durch die Katastrophe des Ersten und des Zweiten Weltkrieges enorm verschärft wurde, weil der Geschichtsverlauf und nicht zuletzt der Schock der Massentötungen im Dritten Reich und in der Sowjetunion sie zu bestätigen schien. Allerdings ist in den letzten Jahrzehnten eine Wiederbelebung der Utopie u. a. im Zeichen des Feminismus zu beobachten, der unter dem Einfluss der Postmoderne auch komplexe, multiperspektivische Dystopien hervorgebracht hat, welche die Eindeutigkeit und Geschlossenheit der klassischen Dystopie verabschieden.

Wenn die Utopie als literarische Gattung schon früh ihre eigene Methode zu überprüfen und zu kritisieren beginnt, dann bezeugt das die beträchtliche Lebendigkeit und Erneuerungsfähigkeit des Genres, die bis heute andauert. Das übersehen jene Kritiker von Berdjajev bis Popper und Fest, die umstandslos Utopie und Totalitarismus in eins setzen, dabei aber alle jene Texte beiseite lassen, seien es positive oder negative Utopien, die innerhalb des Textes Kritik am utopischen Denken und an der Gattung üben oder am Ende, wie Bradbury, durch Weitertradierung von Literatur

7 Vgl. hierzu auch Wilhelm Voßkamp: Selbstkritik und Selbstreflexion der literarischen Utopie. In: Walter Göbel, Stephan Kohl und Hubert Zapf (Hrsg): Modernisierung und Literatur. Festschrift für Hans Ulrich Seeber zum 60. Geburtstag. Tübingen 2000, S. 233-244. einen hoffnungsvollen utopischen Ausblick eröffnen. Schon Morus' Dia$\log$ enthält alle Argumente gegen die Einführung des Kommunismus, für den der philosophische Narr und Possenreißer Hythlodaeus wirbt. Die Form des offenen Dialogs weist darauf hin, dass Mores raffiniertes ironisches Spiel im Modus der leichten horazischen Satire funktional nicht etwa als Reformprogramm, sondern als Diskussionsangebot, als Denkanstoß und Unterhaltung gedacht ist. Die ständige Ausdifferenzierung des Genres, seine konzeptionelle und mediale Modernisierung, geht - so meine These - einher mit einem fortlaufenden Prozess der kritischen Überprüfung vorhandener Modelle und Erzählstrategien. Am Beispiel von Bulwer-Lytton, Morris' Nezws from Nowhere, Wells' A Modern Utopia, Atwoods The Handmaid's Tale und Ursula Le Guins The Dispossessed werde ich nun einige typische Etappen dieses Prozesses skizzieren, der schließlich zur klassischen Dystopie und zur postmodernen Dystopie geführt hat. Der Umschlag zur Dystopie hat nicht zuletzt mit der erschreckenden Erkenntnis zu tun, dass mögliche Zukunft wegen der Erfolgsdynamik der technisch-wissenschaftlichen Zivilisation machbare Zukunft sein könnte.

Edward George Bulwer-Lytton greift 1871 in The Coming Race darwinistisches Evolutionsdenken und frühsozialistische Modelle auf, um ein von einer mächtigen Superrasse bevölkertes unterirdisches Reich zu konstruieren, das seinen Besucher wegen der quasi-atomaren Kraft vril erschreckt und um den Fortbestand der Menschheit fürchten lässt. Diese Inversion der Sympathiesteuerung nimmt die charakteristische Konstellation moderner Dystopien vorweg. Anders gesagt: Die Verwirklichung der Utopie, so Bulwers Befürchtung, erzeugt nichts anderes als Terror und die Zerstörung des Menschen, wie wir ihn kennen. Die Entfaltung des Genres erweist sich als dialektischer Prozess, wobei das Ziel, eine plausible Versöhnung von These und Antithese, anscheinend unerreichbar ist.

William Morris antwortet 1890 in News from Nowhere mit einer pastoral-sozialistischen Vision auf Edward Bellamys Looking Backward (1887), ein Buch, das weltweit auch praktische Wirkungen zeitigte, indem es konstruktives Handeln anstieß. Bellamy entwirft eine technischstaatsozialistische Version der sozialen Konstruktion, die sich am Strukturmodell der militärischen Organisation orientiert. Der maschinenhaften Disziplinierung des Soziallebens durch Bellamy setzt Morris einen arkadischen Traum künstlerischer und erotischer Selbstverwirklichung in kleinen, ländlich geprägten Gemeinschaften entgegen, also eine im Grunde anarchistische Vision.

H. G. Wells wiederum verspottet in A Modern Utopia von 1905 die pastorale Ideologie von John Ruskin und William Morris und plädiert 
für technokratische Lösungen unter der Führung einer Elite, die den Bewohnern des utopischen Weltstaates - der globale, von Wells in der soziologischen Studie Anticipations (1902) scharfsichtig analysierte Modernisierungsprozess hatte die inselhafte Isolation utopischer $>\mathrm{Na}-$ tionalstaaten zu einer nicht mehr plausiblen Lösungsstrategie gemacht - in bewusstem Gegensatz zur klassischen Utopie nach dem Vorbild der liberalen Revolution ein hohes $\mathrm{Maß}$ an Freiheit und individueller Selbstverwirklichung einräumt. Die statische Utopie wird damit zugleich mobil und flüssig, sie nimmt die Verzeitlichung in ihre Prämissen auf. Der selbstreflexive Rückbezug auf die utopische Tradition verwandelt den Text in eine Metautopie, die ihren Konstruktcharakter ausdrücklich hervorhebt. Selbstkritisch ist aber auch die mediale Erneuerung. Wells gibt den lilusionsanspruch der mit Wahrscheinlichkeitstechniken - IchErzähler, Dokumentation, Herausgeberfiktion, historisch korrekte Details usw. - operierenden utopischen Erzählung auf und kombiniert unter dem Einfluss von Film und Grammophon die Reflexionen einer Autor-Figur mit imaginativen Bildern eines Besuches in Utopia, um den Leser als reflexiven Wegbegleiter zu konstituieren.

Der eigentliche Beginn der negativen Utopie setzt dann in England mit Wells-Parodien ein, die seine sozialtechnologischen Lösungen karikieren, so Forster in »The Machine Stops" (1909), wo die extreme Abhängigkeit der Menschen von der Technik in einer Katastrophe endet, und Huxley, der in Brave New World (1932) Wells' Idee einer benevolenten Weltherrschaft von wissenschaftlich gebildeten Managern übernimmt und dies mit einer Satire auf den amerikanischen Kapitalismus kalifornischen Zuschnitts kombiniert. Auch Orwells beklemmendes Schreckbild totalitärer Herrschaft, 1984 (1949), ist insofern eine implizite Metautopie, als sie nicht primär mit dem NS, sondern vor allem mit den Denkformen des englischen, im Schatten Stalins operierenden Sozialismus abrechnet. Das Kürzel »Ingsoc« ist eine deutliche historische Referenz. Eine kritische Metautopie kann man auch Margaret Atwoods The Handmaid's Tale von 1985 nennen, weil sie die Stoßrichtung der Orwell'schen Kritik am Totalitarismus feministisch umpolt und deshalb etwas Neues schafft. Die Außenseiterin Offred sieht sich den Zumutungen eines patriarchalischtheokratischen Systems ausgesetzt, das auf dem Boden der USA nach einer ultrakonservativen Revolution Frauen ihrer Rechte beraubt und gebärfähige Frauen wegen der verbreiteten, auf Umweltschäden zurückzuführenden Unfruchtbarkeit vieler Frauen in die Rolle von Leihmüttern zwingt. Die revisionistische Satire zielt nicht nur auf christliche amerikanische Fundamentalisten, sondern auch auf die Spielart des essentialistischen Feminismus, der rigide Geschlechtertrennung und Männerhass predigt. Erzähltechnisch wird das Verfahren der Dystopie, die Perspektive der Außenseiter-Figur zu betonen und ihr Innenleben zu versprachlichen, noch erheblich radikalisiert. Dieses romanspezifische Verfahren verstärkt den Eindruck der isolierten, gefängnisartigen, klaustrophobischen Existenz des vom System marginalisierten Individuums. ${ }^{8}$

Die fortgesetzte Selbstreflexion der Utopie als Denkform und Gattung und das spielerische Überschreiten von Gattungsgrenzen im Zeichen der Postmoderne ließen außerordentlich komplexe, multiperspektivische Gebilde entstehen, die auch nicht entfernt mehr mit einer politischen Programmschrift zu verwechseln sind und sich dem mainstream-Roman weitgehend annähern. >Ambiguität $<$ und >offenes Ende< sind deshalb typische Merkmale vieler der seit den 7oer Jahren veröffentlichten Texte, wobei zugleich eine partielle Wiederbelebung positiver Utopie-Entwürfe zu bemerken ist. Ein Text, der diese Entwicklung repräsentiert und zugleich ungemein befördert hat, ist zweifellos Le Guins The Dispossessed von 1974. Von der Autorin selbst als Ambiguous Utopia (so der Untertitel) eingestuft, inszeniert der Roman die Abhängigkeit und Gefährdung von Utopien durch unterschiedliche Blickweisen und geschichtliche Prozesse. Der Roman entwirft in einem Teil des Textes das Bild einer anarchistischen Gesellschaft auf dem Wüstenplaneten Anarres, die drauf und dran ist, ihre anarchistischen Prinzipien der Solidarität und der freien Selbstorganisation zu verraten und in überwunden geglaubte bürokratische und hierarchische Strukturen zurückzufallen. Damit wird die klassische utopische Konzeption des zeitlosen utopischen Modells verabschiedet und Kommunikation, ständige Erneuerung und Lernbereitschaft als Bedingung der Möglichkeit von Reformen ins Blickfeld der Aufmerksamkeit gerückt. Damit einher geht eine drastische Verminderung der Ansprüche im Blick auf die Möglichkeit, utopische Zielvorstellungen zu erreichen. Das anarchistische Experiment auf Anarres, vom Text als konfliktreicher Vorgang in Szene gesetzt, zeigt vielmehr im Modus realistischer Darstellungsverfahren die Notwendigkeit, Utopie dem ernüchternden Test der Realität auszusetzen. Anarres situiert sich zweideutig auf der Kippe zwischen Utopie und Dystopie. Entsprechend unterschiedlich fallen auch die Perspektiven auf den jeweils anderen Staat aus. Während die zynische Führungselite des kapitalistischen Konsumparadieses auf dem Planeten Urras den Physiker Shevek, der an anarchistischen Idealen festhält, als

$8 \mathrm{Zu}$ Atwood vgl. Seeber: Die Selbstkritik der Utopie (wie Anm. 3). 
»deluded and simple-minded Utopist $~^{9}$ einstuft, besitzt Anarres für die unterdrückte und verarmte Unterschicht von Urras durchaus die Qualität eines utopischen Gegenbildes. Die Bewohner von Terra wiederum, des atomar verwüsteten Planeten Erde der Zukunft, sehen in den beneidenswerten Lebensverhältnissen von Urras eine intakte Utopie. Weitere Abstufungen und Perspektivierungen lässt der Blick auf die satirischen Spiegelbilder der Dritten Welt und des sowjetischen Staatssozialismus erkennen. Was hier kompositorisch bewirkt wird, trifft Darko Suvins Kategorie der erkenntnisbezogenen Verfremdung ${ }^{10}$ recht genau, ist doch der Leser gehalten, aus dem Vergleich der imaginären Systeme und ihres jeweiligen Wirklichkeitsbezuges Schlüsse auf die Situation des Systems zu ziehen, in dem er sich selbst befindet. Die taoistischen Kategorien der Prozesshaftigkeit und der polaren Struktur (Yin/Yang) des Lebens bewirken schließlich eine utopische Aufladung des populären SF-Motivs der Reise durch den Weltraum. So wie der Physiker Shevek seine Reise nach Urras unternimmt, um die Erstarrung auf Anarres durch eine Kommunikation zu überwinden, die seine Theorie der Gleichzeitigkeit möglich macht, durchreist die Geheimgesellschaft der Hainish den Weltraum im Dienste utopischer Kommunikation. Mauern, als Mittel der Selbsterhaltung des Systems gedacht, mittlerweile aber in Isolation und Erstarrung führend, sollen durch diese Kommunikation überwunden werden. Was Le Guin in The Dispossessed exemplarisch in fiktionale Gegenwärtigkeit übersetzt, ist ein flüssiger postmoderner Pluralismus der Positionen und Sehweisen, welcher die in der Regel monolithische Geschlossenheit der klassischen Utopie aufbricht.

9 Ursula le Guin: The Dispossessed: An Ambiguous Utopia. London 1985, S. 172.

10 Vgl. Suvins Definitionen von Science Fiction und Utopie in Darko Suvin: Poetik der Science Fiction. Zur Theorie und Geschichte einer literarischen Gattung. Frankfurt 1979, S.7 und S.76. Utopie als "verbale Konstruktion" (S. 76) einer konkreten quasimenschlichen Gemeinschaft" zu definieren scheint mir allerdings problematisch. Hier liegt eine unbewusste (?) Übertragung symbolistischer und formalistischer Annahmen über die konstitutive Rolle der Sprache im poetischen Kunstwerk auf Texte vor, nämlich fiktive Reiseerzählungen, die dafür nicht geeignet sind. In den klassischen Utopie, wie zum Beispiel bei Campanella und Bacon, spielt das sprachliche Medium keine konstitutive Rolle, wohl aber die mitgeteilten Vorstellungen, Sachverhalte, Ideen und Konzepte, die als erdachte und vorgestellte der Sprache zwar bedürfen, wenn sie mitgeteilt werden sollen, als solche aber nicht sprachbasiert sind.

\section{DIE FUNKTIONSFRAGE ${ }^{11}$}

Ich komme zweitens zur Funktionsfrage, wobei ich prinzipiell zwischen der werkinternen bzw. impliziten, durch Thematik und Struktur mitgesetzten Funktion und der werkexternen Funktion unterscheide. Bei letzterer wiederum ist zwischen der vom Autor nachweislich beabsichtigten und der realen, im Rezeptionsprozess ablesbaren Funktion zu differenzieren.

Bei Orwell decken sich implizite, intendierte und reale Funktion weitgehend, aber nicht durchgehend. Orwell hat 1984 nicht primär als Prognose und Erkundung einer Möglichkeit konzipiert, sondern als schwarze Satire auf die politischen Tendenzen seiner Zeit, deren Zweck es ist, die Mechanismen totalitärer Herrschaft zu durchleuchten und zum präventiven Handeln aufzurufen. Die zeitliche Nähe der Zukunftsgesellschaft zum Erscheinungsdatum des Romans hat den Sinn, die Dringlichkeit des Appells zu betonen. In einem Brief an Francis Henson (16.6.1949) schreibt Orwell:

My recent novel is NOT intended as an attack on Socialism or on the British Labour Party (of which I am a supporter) but as a showup of the perversions to which a centralized economy is liable and which have already been partly realized in Communism and Fascism. I do not believe that the kind of society I describe necessarily will arrive, but I believe (allowing of course for the fact that the book is a satire) that something resembling it could arrive. [...] I believe also that totalitarian ideas have taken root in the minds of intellectuals everywhere and I have tried to draw these ideas out to their logical consequences. The scene of the book is laid in Britain in order to emphasize that the English-speaking races are not innately better than anyone else and that totalitarianism, if not fought against, could triumph anywhere..$^{12}$

11 Zur Funktionsproblematik vgl. Marion Gymnich und Ansgar Nünning (Hrsg.): Funktionen von Literatur. Theoretische Grundlagen und Modellinterpretationen. Trier 2005.

12 Sonia Orwell and Ian Angus (Hrsg.): The Collected Essays, Journalism and Letters of George Orwell. Vol. IV: In Front of Your Nose 1945-1950. Harmondsworth 1970, S. 564. 
Und noch deutlicher in einer Pressemitteilung vom 15. Juni 1949 kurz vor seinem Tode: »The moral to be drawn from this nightmare situation is a simple one: Don't let it happen. It depends on you. $\ll^{13} \mathrm{Im}$ Selbstverständnis des Autors ist 1984 also ein gezielt schockierendes exemplum, dessen utopischer Impuls gerade in der entschiedenen Negation der Totalitarismen der zoer und 4oer Jahre liegt, und zwar von einem sozialistischen Bewertungsstandpunkt aus. Auch für Bradburys Vision bücherverbrennender Feuerwehrmänner ist nicht die Erkundung sondern die Verhinderung der möglichen schlechten Zukunft das eigentliche Anliegen seiner Dystopie.

Nach Zweck und Methode unterscheidet sich Ursula Le Guins ambige Utopie und Dystopie The Dispossessed (1974) von Orwells klassischer Dystopie ganz erheblich. Das sollte die obige Analyse deutlich gemacht haben. Von einer emotionalen Schockwirkung, die für Orwells Funktion der Warnung und des impliziten Aufrufs zum präventiven Handeln so wichtig ist, kann man im Fall von Le Guins The Dispossessed nicht sprechen. Postmoderne Relativierung und Perspektivierung lösen, wie bei einem theoretischen Text, eher abwägendes Nachdenken aus. Der kognitive Aspekt der Rezeption überwiegt. Obwohl auch bei Le Guin das politische und moralische Engagement nicht zu übersehen ist, zögert man, als Hauptfunktion des Romans Abschreckung zu nennen. Die Verbindung von Wirklichkeitskritik und Utopie-Kritik, die in unterschiedlichem Maße die Texte prägt, fällt bei Le Guin viel gemäßigter und distanzierter aus als bei Orwell.

Funktionszuschreibungen sind allemal hypothetischer Art und theoretisch unbegrenzt. Sie fallen je nach Kontext, den man im Auge hat, und Erkenntnisinteresse unterschiedlich aus. Nur deshalb konnte der mit dem Anarchismus sympathisierende Sozialist Orwell von der Linken zeitweise zum antisozialistischen Vorkämpfer und Agenten des Kalten Krieges stilisiert werden, weil er gegen seinen Willen auch von Richtungen vereinnahmt wurde, die er nicht vertrat, oder zum todkranken Mann, der jegliche Hoffnung verloren hatte. Nach dem Relevanzkriterium kann man gleichwohl in der Regel zwischen mehr oder weniger plausiblen Funktionszuschreibungen unterscheiden. Der Übergang von der modernen zur postmodernen Dystopie hat eine Funktionsverschiebung erkennen lassen, die es festzuhalten gilt. Für die Romangattung Dystopie

13 Zit. nach Elena Zeißler: Dunkle Welten. Die Dystopie auf dem Weg ins 20. Jahrhundert. Marburg 2008, S. 39. schlage ich vor, vier konkrete Hauptfunktionen zu unterscheiden: erstens, Unterhaltung und Erkenntnis, zweitens kritische Diagnose mittels Satire und Diskussion, die sowohl die problematische Wirklichkeit als auch das utopische Denken unter die Lupe nimmt, drittens Appell zum präventiven Handeln mittels warnender Schreckbilder und viertens Erkundung zukünftiger Möglichkeiten negativer Art.

Diese Funktionen lassen sich nur theoretisch und idealtypisch trennen, weil sie im konkreten Text vielfältig zusammenspielen. So kann eine Warnung ja nur dann funktionieren, wenn sie auf einer zutreffenden Diagnose beruht und die Appellstruktur, die sie nutzt, überzeugend ist. Darüber hinaus bedarf das negative Zukunftsbild, wenn es die Funktion der Warnung durch Erkenntnisschock erfüllen soll, eines Mindestmaßes an prognostischer Plausibilität. 1984 und Brave New World sind deshalb als satirische Extrapolationen gefährlicher historischer Tendenzen, auf die zahlreiche Referenzen von der Namengebung (Lenina, Ford, Winston, Ingsoc usw.) bis zu historischen Passagen hinweisen, alles andere als bloße Phantastik. Obwohl es sich bei den Klassikern der Dystopie bzw. der dystopischen Satire um didaktisch ausgerichtete Werke handelt, die freilich mittlerweile zur Weltliteratur zählen, wird auch ihnen eine monofunktionale Betrachtungsweise nicht gerecht. Dennoch kann man sagen, dass im Unterschied zur klassischen Utopie, die spätestens im Kontext des Fortschrittsglaubens beim Rezipienten konstruktives Handeln auslösen will (und im Falle von Bellamy ja auch auslöst), das Hauptanliegen der Dystopie nicht die Konstruktion einer als Vorbild gedachten alternativen Welt ist, sondern Diagnose und Kritik der jeweiligen Gegenwart. In deren Dienst tritt das Möglichkeitsdenken, das aus der Analyse dieser Gegenwart mehr oder minder schreckenerregende Bilder gewinnt, die präventives Handeln provozieren sollen.

Bei Überlegungen zur Theorie und Funktion der Dystopie wird oft nicht genügend bedacht, dass sie sich in der Regel als Roman versteht. Das hat massive Konsequenzen für die Lektüreerfahrung und ihre Theoretisierung. Huxley und Orwell haben ihre Werke im Untertitel als novel bezeichnet. Damit gilt für sie die gleiche Funktionsbestimmung prodesse et delectare, die Horaz für Dichtung schlechthin formulierte. Huxley und Orwell bieten ein nicht zu unterschätzendes Lesevergnügen, das sich aus kognitiven und emotionalen Quellen speist. Indem sie mittels Weltbeschreibung, Figurengestaltung und spannender Handlung scheinbar anderes Leben simulieren, erzeugen sie eine enorme Sogwirkung.

(a) Die so erzeugte Faszination kann einen Widerspruch erklären, an dem sich die Dystopie-Forschung im Grunde bis heute abarbeitet. Sind 
die klassischen Dystopien ein Ausdruck der Verzweiflung, des Pessimismus oder zumindest der Resignation der Autoren, oder bestätigen sie indirekt die Gültigkeit humanistischer Werte? Entgegen der expliziten satirischen Absicht ist die Wirkung und Funktion der klassischen Dystopie nämlich zwiespältig. Als Weckruf und Warnung gedacht, sind sie im Rezeptionsund Diskussionsprozess immer wieder als Zeugnisse einer pessimistischen Grundhaltung gedeutet worden. Das hängt mit dem Widerspruch zwischen gesellschaftlicher Systemlogik und fiktionaler Logik zusammen. Huxleys und Orwells Systeme zielen, wie schon die klassische Utopie, mit allen Mitteln darauf ab, Zeitlichkeit und Veränderung aufzuheben, indem man den mündigen Bürger vollends gezielt abschafft und auf eine Nummer reduziert. Zu diesen Mitteln zählen insbesondere Biotechnologie, Kommunikationstechnologie, behavioristische Pädagogik, allgegenwärtige Propaganda, perfekte Überwachung, Auslöschung der geschichtlichen Erinnerung, Sprachmanipulation, und nicht zuletzt Terror. Im Namen des Interesses der herrschenden Parteielite, der - so Orwells schon früh geäußerte Überzeugung im Blick auf die Nationalsozialisten, aber auch auf Führungskader der KPDSU - es letztlich nur um Machtgewinnung und Machterhaltung geht, oder eines radikalen Stabilitätsideals werden also die positiven Möglichkeiten des Modernisierungsprozesses ausgeblendet und die Geschichte eingefroren. Abweichler und Außenseiter wie Winston Smith haben gegen die geballte Macht des Systems keine Chance. Die Systemlogik gebietet, dass sie eliminiert werden. Nun ist aber die Sympathielenkung so angelegt, dass der Leser wider besseres Wissen hofft, dass die Außenseiter, an deren Schicksal er mittels Perspektivführung emotional beteiligt wird, mit ihrer Rebellion doch Erfolg haben mögen. Da dies aber ausgeschlossen ist, entsteht leicht der Eindruck pessimistischer Resignation, wo doch in Wahrheit die Geltung des politisch-ethischen Imperativs im Vordergrund steht. Wenn der Leser die letzten deprimierenden Seiten von Samjatins Wir, Huxleys Brave New World und Orwells 1984 gelesen hat, erfordert die Erkenntnis dieses Imperativs von ihm geradezu einen intellektuellen Willensakt.

Die Dystopie verzichtet nicht auf den utopischen Impuls. ${ }^{14}$ Innerhalb der Fiktion nimmt er immer wieder, von Orwell bis Atwood, die Form nostalgischer Erinnerungen an, die, weit entfernt davon, bloß

14 Diesen Aspekt betont u. a. auch die postmodern, poststrukturalistisch und feministisch orientierte Studie von Dunja Mohr: Worlds Apart? Dualism and Transgression in Contemporary Female Dystopias. Jefferson, North Carolina, London 2005. Die Untersuchung arbeitet den »utopischen Subtext« (»utopian subtext«, S. 5) in postmodernen feministischen Dystopien sentimental oder regressiv zu sein, an die Möglichkeit einer besseren Alternative inmitten einer Welt erinnern, die mit der Verabsolutierung der Gegenwart Zukunfts- und Möglichkeitsdenken gerade abschaffen will. Erinnerung hat also in den Dystopien eine doppelte Funktion. Als Erinnerung (>recollection`) von geschichtlichen Fakten, welche die offizielle Geschichtsdeutung dementieren, versieht sie den Widerstand des Außenseiters mit Argumenten. Als nostalgische Erinnerung schafft sie affektive utopische Bilder, die auf die Repräsentanten des Widerstands wie eine Energiezufuhr wirken. Mit ihren traditionellen oder populären Liedern repräsentieren die Unterschichten in 1984 eine Kultur, die, anders als die der Intellektuellen, noch nicht totalitärem Denken anheimgefallen ist. Utopie schöpft, um eine alternative Welt vor Augen zu führen, also nicht zuletzt aus Erinnerungen an die Vergangenheit, die dann aber, wie etwa die Mittelalter-Reminiszenzen bei Morris, in einen neuen Kontext eingefügt und abgewandelt werden. In den offenen Schlüssen der postmodernen Dystopie (Atwood, Le Guin, u. a.) wird darüber hinaus das Prinzip Hoffnung auch handlungslogisch aufrechterhalten..$^{15}$

(b) Die literarische Methode trägt nun zweitens zu einer erheblichen Steigerung des kognitiven Gehalts und der Appellwirkung der politischen Diagnose Orwells bei. Das mag überraschen, ist aber so. Schon in den dreißiger und vierziger Jahren entstand ein Dialog zwischen politikwissenschaftlicher Totalitarismus- Diskussion und Literatur. Orwell rezensierte das wichtige Buch The Totalitarian Enemy (1940) des deutschen Emigranten Franz Borkenau. Spätere Totalitarismus-Forscher beziehen sich aber nicht etwa auf Borkenau, sondern auf Orwell und Kafka, wenn sie das Wesen des Totalitarismus erläutern wollen. Dass vor allem Angelsachsen Kafkas »unvollendete (n) Romane ${ }^{16}{ }^{16}$ insbesondere Der Proceß,

wie Suzette Haden Elgins Trilogie Native Tongue, Suzy McKees Charnas' Holdfast-Serie und Margaret Atwoods The Handmaid's Tale heraus. Mohr analysiert den komplexen, vielstimmigen und transgressiven Charakter dieser Texte, die sich dem binären Denken der klassischen Utopien entzögen, und spricht vom "postmodern turn to the transgressive utopian dystopia (S. 4). Das Transgressive ortet sie insbesondere in einer neuen weiblichen Sprache und Anschauungsweise.

15 Vgl. hierzu auch die Aufsätze von Raffaela Baccolini und Lyman Tower Sargent in Tom Moylan und Raffaela Baccolini (Hrsg): Utopia, Method, Vision. The Use Value of Social Dreaming. Oxford 2007.

16 Volker Meid: Das Reclam Buch der deutschen Literatur. Stuttgart 2004, S. 414 . 
in die Nähe der dystopischen Romane von Huxley und Orwell rücken, scheint mir völlig nachvollziehbar. So etwa der Amerikaner George Kennan:

Wenn ich mir den Totalitarismus als allgemeines Phänomen vorzustellen versuche, kommt mir meist weder das Bild vom Sowjetsystem noch vom Nationalsozialismus in den Sinn als vielmehr der Vorstellungs- und Symbolgehalt der Literatur von Leuten wie Orwell, Kafka, Koestler oder älteren sowjetischen Satirikern. Der reinste Ausdruck dieses Phänomens [...]scheint mir nicht in seiner physischen Wirklichkeit wiedergegeben worden zu sein $[\ldots]^{17}$

Die sowohl logische als auch satirische Methode der reductio ad absurdum treibt also einprägsame Bilder, Aphorismen, Neologismen und Propaganda von so bezwingender Gewalt hervor, dass sie sich im kollektiven Gedächtnis eingegraben haben und unser Verstehen bis heute zu lenken imstande sind: "Big Brother Is Watching You «, "Freedom Is Slavery«, "Newspeak« (alle Orwell, 1984), »history is bunk« (Huxley, Brave New World) gehören längst zu jenen geflügelten Worten, die unser Wissen aufbewahren und auch jetzt noch befürchtete Fehlentwicklungen sprachlich identifizieren. Die Zerstörung der Regeln einer Zivilgesellschaft, die ohne Vertrauen und Erinnerung nicht denkbar ist, wird im beklemmenden Schicksal von Winston und Julia sinnfällig. Erst die Romanfiktion hat jenen wirkmächtigen Weberschen Idealtypus erzeugt, der Orientierung erlaubt, nicht aber mit der geschichtlichen Wirklichkeit restlos zur Deckung kommt. Max Weber betont den bildhaften Charakter des Idealtypus: "In seiner begrifflichen Reinheit ist dieses Gedankenbild nirgends in der Wirklichkeit empirisch vorfindbar; es ist eine Utopie. ${ }^{18}$ Der fiktiv gestaltete Idealtypus trägt also entscheidend zur Erkenntnis der gesellschaftlich-politischen Realität und der Bedeutung des Begriffs Totalitarismus selbst bei. Die klassische Dystopie löste deshalb in der politischen Praxis präventives Handeln aus, als es darum ging, unerwünschte Entwicklungen zu verhindern. Dieses ist vom konstruktiven Handeln zu unterscheiden, das sich in Gestalt von Gemeindebildungen und sozialistischen Experimenten an Bellamys positiver Utopie Looking Backward orientierte.

17 Zit. nach Bruno Seidel und Siegfried Jenkner (Hrsg.): Wege der Totalitarismus-Forschung. Darmstadt 1968, S. 463.

18 Zit. nach Seeber: Die Selbstkritik der Utopie (wie Anm. 3), S. $241 \mathrm{f}$.
Ein vergleichender Blick auf Kafkas Romanfragment Der Proceß könnte bei der Klärung der Funktionsfrage weiterhelfen. Kafka wird, wie das Beispiel Kennan deutlich macht, oft in einem Atemzug mit den Kritikern des Sowjetsystems und des NS genannt. Deren gemeinsames Thema sind nämlich im Grunde paradoxe Modernisierungstendenzen, d.h. die Befürchtung, dass diese, wie Max Weber es formulierte, ein »ehernes Gehäuse« schaffen, das als abstraktes, übermächtiges, undurchschaubares System das sich emanzipierende Individuum beherrscht, einkerkert und im Extremfall vernichtet. Konstrukte der utopischen und der instrumentellen Vernunft einschließlich einer allmächtigen Bürokratie sind ja schließlich Produkte des Rationalisierungsprozesses und der von ihm hervorgetriebenen Antizipationen. Bei Kafka schlachten am Ende die Schergen des grotesken, undurchsichtigen Justizsystems den nicht nachvollziehbar beschuldigten Josef K. »wie ein[en] Hund « ${ }^{19}$ mit dem Messer ab. Hier werden aber auch Unterschiede deutlich. Während die Prinzipien und Methoden des Systems, sei es die Herrschaft des Konsums oder die Machterhaltung einer Parteielite, in den zentralen Disputen der Dystopie völlig transparent gemacht werden, verbleibt Kafkas Justiz bis zum Schluss undurchsichtig, hintergründig und alptraumhaft. Dem entspricht Kafkas Kombination von Realismus und grotesk-surrealen Darstellungsverfahren, die es bei den insgesamt konventioneller schreibenden Engländern so nicht gibt. Der Irrationalität und Labyrinthartigkeit des Systems korrespondiert bei Kafka die Kontingenz und Surrealität von Vorfällen, die letztlich viel beklemmender wirken als Orwells aus der populären Schauerliteratur geborgte Schocktaktik des Rattenkäfigs, dessen Horror Winston nicht gewachsen ist. Sowohl die Dystopie als Gattung als auch Kafka betreiben eine literarische Diagnose der Entfremdung in der modernen Gesellschaft, aber nur Kafkas Technik der grotesken und surrealen Verfremdung geht das Problem mit der erforderlichen ästhetischen Radikalität an. Die Referenzen der modernen Dystopie sind satirisch und historisch transparent, Kafkas dunkle Parabeln sind es nicht. Entsprechend mobilisiert er beim Leser nicht etwa politische und satirische Entrüstung, die präventivem Handeln vorangeht, sondern die Faszination beklemmender Surrealität und Groteske, anders gesagt: die Faszination ästhetischer Gewalt, mit der dunkle institutionelle Gewalt inszeniert wird. Die Analogie zur Gotteserfahrung, die auch die Dystopien ständig bemühen,

19 Franz Kafka: Der Proceß: Roman. Frankfurt a. M. 2011, S. 241. Text nach der kritischen Ausgabe von Malcolm Pasley (1990). 
liegt beim Faszinationsbegriff nahe. Rudolf Otto $(1922)^{20}$ definiert sie nämlich als mysterium tremendum et fascinosum.

Trotz dieser Funktionsdifferenz steht inzwischen das Vorbild Kafka im Hintergrund mancher angelsächsischer Dystopie. Die hat nach den Klassikern ohnehin die Tendenz, partial zu werden und mit dem mainstream-Roman zu verschmelzen. An die Stelle des Entwurfs eines Gesamtsystems tritt die Erkundung von Einzelaspekten wie zum Beispiel der möglichen verheerenden Folgen der Biowissenschaften wie in Margaret Atwoods Oryx and Crake (2003) oder der Gefahren, die einer Gesellschaft durch den Verlust von Erinnerung und Geschichte drohen wie in Ackroyds The Plato Papers (1999). ${ }^{21}$ Echos an Kafka finden sich bei Texten, die sich entweder auf die Repräsentation des Schicksals einer gehetzten Hauptfigur in einer nur vage umrissenen repressiven Gesellschaft konzentrieren wie in Coetzees Südafrika-Roman Life and Times of Michael $K$ (1983) oder die Frage aufwerfen, was mit provozierender Literatur in der totalitären Gesellschaft geschieht, so im Drama The Pillowman von McDonagh (2003). Letzteres Motiv gehört seit Samjatin, Huxley und insbesondere Ray Bradburys denkwürdiger Dystopie Fahrenheit 451 (1953) zu den großen Themen der Dystopie, weil Literatur und Kunst ein subversives Potential zugeschrieben wird, was die Unterdrückung von Orwells Werk im sowjetischen Machtbereich ja schlagend belegt.

Auf der Flucht vor dem Kapstädter Chaos und der Armee, die dem Apartheid-Regime dient, landet in Life $\mathcal{E}$ Times of Michael $K^{22}$ der vermutlich schwarze, von einer Hasenscharte verunstaltete Protagonist K zeitweise in Straflagern, denen er sich wie ein Tier durch Flucht entzieht, zeitweise auf einer verlassenen Farm, wo er als Gärtner sein Leben mit dem Anbau von Kürbissen fristet. Der Bezug auf die Gewaltherrschaft der Apartheid ist zwar erkennbar, aber mit der Namengebung K überlagert der Nobelpreisträger Coetzee seine südafrikanische Dystopie mit Erinnerungen an die Dystopie modernistischer Literatur, an Kafka, Eliot, oder Pinter. Er betont die gemeinsame Schnittmenge zwischen der Gattung Dystopie und moderner Literatur, in der alle Themen, die für die Dystopie konstitutiv sind, ja ebenfalls eine konstitutive Rolle spielen: Gewalt, Medien, Entfremdung, Entmächtigung des Individuums im übermächtigen System, Konformismus, Konsumdenken usw. Der Text ist deshalb

20 Rudolf Otto: Das Heilige. Breslau 1922. Vgl. zur Faszination Hans Ulrich Seeber: Literarische Faszination in England um 1900. Heidelberg 2012.

21 Vgl. zu Ackroyd den Beitrag von Judith Leiß.

22 John Maxwell Coetzee: Life \& Times of Michael K (1983). London 1998. eher als vieldeutige postmoderne Interpretation der südafrikanischen, ja weltweiten Situation zu lesen, in die mit dem Bild des Gärtners auch utopische Hoffnung im ökologischen Sinne eingeschmuggelt wird, denn als spezielle Warnung. Nur klassische positive Utopien wie Bellamys Looking Backward: 2000-1887 (1887) oder klassische Dystopien wie 1984 bestätigen durch ihre enorme Wirkung im konkreten gesellschaftlichen Leben die von mir eingeführte Funktionsopposition konstruktives vs. präventives Handeln. Diese Typologie greift bezeichnenderweise nicht mehr bei komplexen postmodernen, die Interpretationsphantasie beschäftigenden Dystopien. Denn Michael K ist im Text aus der Perspektive des Lagerarztes ein anderer, nämlich Michaels, und die Hasenscharte bedeutet nicht nur Entstellung, sondern auch etwas Positives, weil der Hase in der afrikanischen Mythologie die zyklische Wiederkehr des Lebens verkündet - und das könnte mit Hilfe des Erzengels Michael geschehen, der Satan aus dem Paradies vertrieben hat.

Ebenso deutlich wie bei Coetzee haben Kafka und die klassische Dystopie in McDonaghs Drama The Pillowman (2003) Spuren hinterlassen. Dabei ist wiederum zu beobachten, dass die Pragmatik des Textes, sein Kommunikationsziel, jetzt bewusst offen gelassen wird. Immerhin wird aber so viel deutlich, dass McDonagh die Rolle der Literatur in einem totalitären System in herausfordernder Weise uminterpretiert. In einem zeitlich und räumlich nicht lokalisierten totalitären Staat verhören und foltern ein Polizist und ein Detektiv den Schriftsteller Katurian, der mit seinen grausamen, von brutalen Kindstötungen handelnden Kurzgeschichten, die u.a. von Grimms Märchen inspiriert wurden, seinen Bruder Michal angeblich zu Nachahmungstaten verführt hat, die sich exakt an die fiktiven Muster halten. Der Titel spielt auf die Geschichte vom pillowman an, der Kinder zum Selbstmord überredet, weil sie als Erwachsene nur eine erbärmliche Existenz erwarte, nicht ein utopisches happy ending. Die radikalste Form präventiven Handelns wäre also, noch vor der Strafjustiz, die Selbsttötung. Katurian beschreibt die Gestalt und die Taten des pillowman folgendermaßen:

MICHAL. Do »The Pillowman«.

KATURIAN. (Smiles.) Why »The Pillowman«? (Michal shrugs) Jeez, that's from a while ago, isn't it?

MICHAL. Yeah, it's from, like, a while ago.

KATURIAN. Let's see, how does that start ...?

MICHAL. »Once upon a time« ...

KATURIAN. I know, but I am trying to think how it actually starts ... 
MICHAL. (Irritated.)»Once upon a time« ...

KATURIAN. Alright, Jesus (Pause.) Once upon a time ... there was a man, who did not look like normal men. He was about nine feet tall ... (Michal looks up, silently whistles.) And he was all made up of these fluffy pink pillows: His arms were pillows and his legs were pillows and his body was a pillow; his fingers were tiny little pillows, even his head was a pillow, a big round pillow.

MICHAL. A circular pillow.

KATURIAN. It's the same thing.

MICHAL. But I prefer »a circular pillow.»

KATURIAN. His head was a circular pillow. And on his head he had two button eyes and a big smiley mouth which was always smiling, so you could always see his teeth, which were also pillows. Little white pillows.

MICHAL. "Pillows." Do your mouth smiley like the Pillowman's mouth is. (Katurian gives a big dopey smile. Michal gently touches Katurian's lips and cheeks.)

KATURIAN. Well, the Pillowman had to look like this, he had to look soft and safe, because of his job, because his job was a very sad and a very difficult one ...

MICHAL. Uh-oh, here it comes ...

KATURIAN. Whenever a man or a lady was very sad because they'd had a dreadful and hard life and they just wanted to end it all, they just wanted to take their own lives and take all the pain away, well, just as they were about to do it, by razor, or by bullet, or by gas, or ... MICHAL: Or by jumping off something big.

KATURIAN. Yes. By whatever preferred method of suicide - »preferred " is probably the wrong word, but anyway, just as that person was about to do it, the Pillowman would go to them, and sit with them, and gently hold them, and he'd say, "Hold on a minute«, and time would slow strangely, and as time slowed, the Pillowman would go back in time to when that man or that lady was just a little boy or a little girl, to when the life of horror they were to lead hadn't quite yet begun, and the Pillowman's job was very sad, because the Pillowman's job was to get that child to kill themselves, and so avoid the years of pain that would just end up in the same place for them anyway: facing an oven, facing a shotgun, facing a lake. »But I've never heard of a small child killing themselves«, you might say. Well, the Pillowman would always suggest they do it in a way that would just look like a tragic accident: He'd show them the bottle of pills that looked just like sweeties; he'd show them the place on the river where the ice was too thin; he'd show them the parked cars that it was really dangerous to dart out between; he'd show them the plastic bag with no breathing holes, and exactly how to tighten it. Because mummies and ladies always find it easier to come to terms with a five-year-old lost in a tragic accident than they do with a five-year-old who has seen how shitty life is and taken action to avoid it. ${ }^{23}$

In Katurians abschließender Geschichte scheint Michal aber das Ansinnen des pillowman zurückzuweisen und elterliche Misshandlungen zu ertragen, um Katurians literarische Produktivität zu stimulieren. Katurian, der glaubt, leidender Zeuge dieser Misshandlungen zu sein, wird zusammen mit Michal des gemeinsamen Mordes an drei Kindern angeklagt, dazu der Eltern und des eigenen Bruders, lässt sich aber auf das Geständnis nur deshalb ein, weil er als Gegenleistung die Rettung seiner Geschichten erwartet. Er wird am Ende erschossen. Seine Geschichten bleiben dagegen erhalten, weil ausgerechnet der brutalere der beiden cops, Ariel, aufgrund seiner Lebensgeschichte mit Katurian sympathisiert.

Das Verhör eines scheinbar oder wirklich Schuldigen und die Schreie der Gefolterten aus dem Nebenzimmer erinnern an Kafka und Orwell, desgleichen die reale oder symbolische - Winston wird von seinen systemwidrigen Gedanken und Gefühlen ironischerweise "geheilt" - Tötung des Protagonisten am Ende. Auf Kafka und das Kafkaeske wird auch intertextuell angespielt: "KATURIAN: That's a good story. That's something -esque. What kind of resque is it. I can't remember. [...] (S. 15) Es dürfte sich um das Wort `Kafkaesque handeln, welches im Oxford Companion to English Literature (2009) folgendermaßen charakterisiert wird: »The word `Kafkaesque strange, baffling, nightmarish, or anxiety-ridden reality characteristic of that depicted in his work." (S. 547)

Der schwer durchschaubare, aber überaus fesselnde Text wirft zahlreiche ebenso beunruhigende wie unbeantwortete Fragen auf. Hat Kunst selbst ein totalitäres Potential, weil sie wie Orwells Gedankenpolizei oder die moderne theory of mind die Gedanken und Gefühle anderer liest? Zwischen vermeintlichen Opfern und vermeintlichen Tätern - die Unterscheidung wird gezielt verwischt - besteht nämlich

23 Martin McDonagh: The Pillowman. New York 2003, S. $30 \mathrm{f}$ 
eine unübersehbare Verwandtschaft, da Ariel wie die schriftstellernden Brüder selbst unter Kindesmissbrauch litt, selbst intensiv an der Wirkung von Fiktionen interessiert ist und sogar selbst Kurzgeschichten schrieb. Sind das totalitäre System selbst und die grausamen Morde auf grausame Kindheitserfahrungen zurückzuführen, die ihrerseits, wie bei Katurian, als produktive Traumata die Intensität von Kunst bewirken? Hat Kunst ein totalitäres Potential, sobald sie, wie die in den dramatischen Text eingelagerten Kurzgeschichten, eine unwiderstehliche Macht über Gemüt und Phantasie des innerfiktionalen und außerfiktionalen Rezipienten ausübt? Wenn sie so wichtig ist, kann dem Künstler nichts Schlimmeres passieren als dies - mörderische Nachahmung oder die Vernichtung seiner Kunstprodukte, was ja in totalitären Systemen ständig geschieht und Katurian auch angedroht wird.

So sehr die widerlichen Grausamkeiten der Geschichten wie detailliert beschriebener Tod durch abgeschnittene Zehen oder durch verschluckte Rasierklingen alles übertrifft, was mir bisher an Grausamkeiten in Literatur begegnet ist, so wenig ist eine auch nur annähernd eindeutige Funktionsbestimmung des Dramas möglich. Die Begriffe , Warnung` und 'Aufruf zum präventiven Handeln ' gehen an der Sache vorbei. Einfach Erzeugung von gebannter, finanziell einträglicher Aufmerksamkeit mittels schreckenerregender Handlungen? Demonstrative Offenlegung des Bösen mit Geschichten, die nicht zuletzt von Grimms Märchen inspiriert sind? Oder Stimulierung von Wut über den Sadismus des Autors wie in Performance-Kunst, die dem Rezipienten distanzierten ästhetischen Genuss austreiben möchte? Entsetzen wegen der forcierten Überschreitung von Tabus, die theaterimmanent als Überbietungsstrategie angesichts eines Publikums zu deuten wäre, das sich an starke Reize gewöhnt hat? Handelt es sich noch um Provokationen mit ethischem Anspruch, die mit den Mitteln des Metadramas und der Metafiktion auf Fehlentwicklungen der Medien- und Kunstszene aufmerksam machen wollen, oder handelt es sich um eine groteske Karikatur präventiven Handelns? Zweifellos ist der Text aber bestens geeignet, Reflexionen und Debatten anzustoßen. Jedenfalls gewinnt die transformierte Dystopie, die keinerlei Bezüge mehr zur utopischen Tradition erkennen lässt, Anschluss an jene Einsicht, die schon immer für Kunst gegolten hat: Sie kann sich nicht gegen reduktive Funktionszuschreibungen wehren, sie aber massiv erschweren. Genau dies scheint hier und in anderen postklassischen Dystopien zu passieren. Anders gesagt: Je mehr wie bei Coetzee und vor allem McDonagh die Funktionsfrage offen bleibt, umso größer ist die Distanz des Textes zur didaktischen klassischen Dystopie. Und: Je mehr, wie bei McDonagh, historische Referenzen fehlen, umso mehr wird der - vage irgendwo in einem fiktiven Osteuropa oder Vorderasien zu situierende - totalitäre Staat zur vieldeutigen literarischen Chiffre. Die aber fesselt und fasziniert, wie es Kunst tun sollte: »Jedes Kunstwerk«, bemerkt Martin Seel, "will sein Gegenüber treffen, fesseln, mitnehmen, verstricken: es will uns berühren durch etwas, wovon wir auf diese Weise sonst nicht berührt werden können. $\aleph^{24}$
24 Martin Seel: Kann das Erscheinen verschwinden? Zur Bedeutung der Sinnlichkeit in der neueren Kunst. In: Konrad Liessmann (Hrsg.): Im Rausch der Sinne. Kunst zwischen Animation und Askese. Wien 1999, S. 283-305, hier S. 283. 


\section{JUDITH LEISS}

\section{GATTUNGSGESCHICHTE ALS SPIRALE}

\section{Die Heterotopie als Möglichkeit utopischen}

\section{Schreibens in der Gegenwart}

Im Folgenden soll die Heterotopie aus einer gattungsgeschichtlichen Perspektive als Möglichkeit utopischen Schreibens in der Gegenwart vorgestellt werden. Um Missverständnissen vorzubeugen, möchte ich das Thema meines Beitrags etwas umakzentuieren, bevor ich mit den eigentlichen Ausführungen dazu beginne. Der Untertitel meines Aufsatzes könnte auch lauten: »Die Heterotopie als eine Möglichkeit utopischen Schreibens in der Gegenwart«. Andere, gattungsgeschichtlich ältere Möglichkeiten bestehen ja weiterhin. Das Auftauchen der Heterotopie als neue Form der Utopie - oder genauer: des utopischen Romans - ist nicht gleichbedeutend mit dem Verschwinden anderer utopischer Subgenres wie etwa der Dystopie oder der Kritischen Utopie. ${ }^{1}$ Allerdings rückt durch den gattungsgeschichtlichen Ansatz diese Gleichzeitigkeit der diversen Erscheinungsformen utopischen Schreibens in den Hintergrund, während die Frage nach der spezifischen kulturellen Leistung der Heterotopie als einer relativ neuen Spielart des utopischen Romans bzw. nach der literarisch-kulturellen Problematik, als deren Lösung sie verstanden werden kann, in den Vordergrund rückt.

Um diese Spezifik herausarbeiten zu können, werde ich - indem ich mich gedanklich vom Allgemeinen zum Besonderen bewege - zunächst erläutern, was hier unter einem utopischen Roman verstanden wird. Denn wie auch im Falle anderer Genres lässt sich trefflich darüber streiten, wie der utopische Roman anhand abstrakter Konstruktionsregeln zu

1 Ich beziehe mich hier auf das Konzept der critical utopia nach Tom Moylan. Vgl. ders.: Demand the Impossible. London 1986, S. 10 f. und S. 41-46. 
beschreiben sei. Auf die Heterotopie als eine Variante desselben, die typologisch auf der gleichen Ebene anzusiedeln ist wie die bereits erwähnten utopischen Subgenres $>$ Dystopie oder $>$ Kritische Utopie`, komme ich im zweiten Teil meiner Ausführungen zu sprechen.

Glücklicherweise ist es im Falle des utopischen Romans ohne Weiteres möglich, jenes Werk zu identifizieren, das den Anfangspunkt der Gattungstradition markiert, da der Prototyp, Thomas Morus' Utopia, ${ }^{2}$ auch als Namensgeber für die Gattung fungiert. ${ }^{3}$ Ein utopischer Roman ist also ein fiktionales Prosawerk, das auf der Basis struktureller und inhaltlicher Merkmale der durch Morus begründeten literarischen Tradition zuzuordnen ist. Wie das 1516 erschienene, »wahrhaft goldene[...] Büchlein von der besten Staatsverfassung und von der neuen Insel Utopia ${ }^{4}$ beziehen auch alle späteren literarischen Utopien ihr Aussage- und Gestaltungspotential im Wesentlichen aus der Kontrastierung einer sozio-kulturellen Wirklichkeit mit einem fiktionalen Alternativentwurf. Wie der Gattungsname bereits andeutet, geht es stets um einen gesellschaftlichen $>$ Nicht-Orts, eine unbekannte gesellschaftliche Ordnung also, die sich durch die Negation einer bekannten Gesellschaftsordnung konstituiert. Der ou-topos bedarf eines topos, mit dem er trotz aller Unterschiede genügend Gemeinsamkeiten teilt, um einen Vergleich zwischen beiden gesellschaftlichen Ordnungen nahezulegen und so die emanzipative und gesellschaftskritische Wirkung des utopischen Gegenbildes ${ }^{5}$ freizusetzen. Diese in ihren verschiedenen Ausformungen gut erforschte Grundstruktur der Gattung ,Utopie bezeichne ich im Folgenden als >Prinzip der zwei Welten Kürzel W1 soll dabei für eine fiktionalisierte Form jener , Welt ‘ im Sinne einer Staats- und Gesellschaftsordnung stehen, welcher der Autor oder die Autorin entstammt. W2 steht für den literarischen Gegenentwurf zu dieser Ordnung.

2 Thomas Morus: Utopia. Übersetzt von Gerhard Ritter. Bibliographisch ergänzte Ausgabe. Stuttgart 2003.

3 Vgl. Wilhelm Voßkamp: Thomas Morus’ „Utopia«. Zur Konstituierung eines gattungsgeschichtlichen Prototyps. In: ders. (Hrsg.): Utopieforschung. Interdisziplinäre Studien zur neuzeitlichen Utopie. Frankfurt a. M. 1985 , Bd. 2, S. $183^{-196 .}$

4 Ich zitiere aus dem Titel nach der Übersetzung von Gerhard Ritter

5 Vgl. Wilhelm Voßkamps Formulierung, literarische Utopien stellten stets »ein Gegenbild zur literarischen Wirklichkeit dar" (Wilhelm Voßkamp: Utopie. In: Das Fischer Lexikon Literatur. Hrsg. von Ulfert Ricklefs. Frankfurt a. M. 1996, Bd. 3, S. 1931-1951, hier S. 1931; Hervorhebung im Original).
Für meine weiteren Ausführungen entscheidend ist der Unterschied zwischen der Thematisierung und der Darstellung einer idealen Staatsund Gesellschaftsordnung. Dass die Frage nach der idealen Organisationsform menschlichen Zusammenlebens, die Suche nach geeigneten Standards zur Beurteilung menschlicher Gesellschaften im Zentrum jedes utopischen Romans steht, bedeutet nämlich nicht notwendig, dass die ideale Staatsverfassung in der Utopie erzählerisch dargestellt wird. Es stehen zahllose literarische Verfahren zur Verfügung, die es erlauben, einen Gegenstand zu thematisieren, ohne dass dieser mimetisch-narrativ ausformuliert werden müsste. Dieser Umstand wird - möglicherweise auf Grund seiner scheinbaren Trivialität - in der Utopieforschung meist vernachlässigt. Zu Unrecht, wie ich finde, impliziert er doch eine Antwort auf die viel diskutierte Frage, ob die utopische Gegenwelt W2 notwendig ideal sein muss: Unabhängig davon, wie diese Idealität inhaltlich konkretisiert werden mag, gilt, dass W2, also die utopische Gegenwelt, weder als gesellschaftliches Ideal noch - wie im Falle der Dystopie - als dessen Negativ konzipiert sein muss. Denn die politische Stoßrichtung eines utopischen Romans lässt sich nicht unbedingt daraus ableiten, wie das spezifische Verhältnis zwischen $W_{1}$ und $W_{2}$ textimmanent durch die Figuren oder textextern durch die AutorInnen und ihre Leserschaft bewertet wird. Erscheint den Bewohnern von W1 die Gegenwelt W2 etwa als Paradies auf Erden, so muss dies keineswegs bedeuten, dass W2 auch von der zeitgenössischen Leserschaft so positiv bewertet wird. Und selbst wenn: Die Bewertung durch die LeserInnen kann sich im Laufe der Zeit ändern und doch wird der fragliche Roman auch unter veränderten Rezeptionsbedingungen noch als Utopie erkannt werden, als ein fiktionaler Text also, dessen Thema die beste Staatsverfassung ist, der diese beste Staatsverfassung aber nicht notwendig abzubilden versucht. ${ }^{6}$

Natürlich wird durch die konkrete Verfasstheit des Nirgendortes zu einem gewissen Grade vorgegeben, welche gesellschaftlichen Aspekte beim Vergleich zwischen W1 und W2 im Vordergrund stehen. Gibt es in W2 etwa keine Kernkraftwerke, dafür aber ein Problem mit der Stromversorgung, wird die Aufmerksamkeit der LeserInnen dadurch auf die Frage gelenkt werden, wie es in W1 mit der Stromerzeugung bestellt ist

6 Zur Frage nach der Idealität des utopischen Nicht-Ortes und zur Notwendigkeit der Unterscheidung zwischen Darstellung und Thematisierung einer idealen Gesellschaft vgl. Judith Leiß: Inszenierungen des Widerstreits. Die Heterotopie als postmodernistisches Subgenre der Utopie. Bielefeld 2010, S. 49-57. 
beziehungsweise ob und wie diese in naher Zukunft gewährleistet werden soll. Die Beschaffenheit der Gegenwelt W2 ist also ausschlaggebend dafür, welche sozio-politischen Fragen ein utopischer Roman impliziert. Das bedeutet allerdings nicht, dass damit zugleich auch eine bestimmte Antwort vorgegeben würde. Um bei meinem Beispiel zu bleiben: Die unzureichende Stromversorgung in W2 könnte von den Atomkraftbefürwortern unter den LeserInnen als Teil eines dystopischen Szenarios und damit als Plädoyer für die Notwendigkeit von Kernkraftwerken interpretiert werden. Atomkraftgegner hingegen könnten die Probleme mit der Stromversorgung in W2 als eher kleines Übel verstehen, das es angesichts drohender atomarer Katastrophen und in Ermangelung ausgereifter Alternativen zur Stromerzeugung zumindest vorübergehend in Kauf zu nehmen gilt. In diesem Falle könnte W2 also als eutopischer Gegenentwurf zur Lebenswirklichkeit der LeserInnen aufgefasst werden, obwohl gewisse Defizite deutlich erkennbar sind und mithin nicht von einer idealen Gesellschaftsordnung die Rede sein kann.

Entscheidend ist, dass in beiden Fällen die Zwänge des Hier und Jetzt in den Hintergrund treten und den Blick der Rezipienten freigeben auf das Andere, auf das, was nicht ist. Unabhängig davon, wie der fiktionale Nicht-Ort im Rahmen des individuellen Rezeptionsprozesses bewertet wird, lädt die Transzendierung der politischen und sozialen Realität zur Hypothesenbildung ein bezüglich der Frage, wie der Wunsch nach der idealen, bestmöglichen oder zumindest nach einer besseren Gesellschaftsordnung inhaltlich zu konkretisieren sei. Die Frage, ob W2 notwendig als gesellschaftliches Ideal oder als dessen dystopische Inversion konzipiert sein müsse, kann also verneint werden, weil Utopien den kritischen Blick auf W1 ganz unabhängig davon katalysieren, ob W/2 als wünschenswerte Alternative $\mathrm{zu} \mathrm{W} 1$ empfunden wird oder nicht. Als für den utopischen Roman konstitutiv wird somit allein die Thematisierung der Möglichkeitsbedingungen einer guten oder gar idealen Gesellschaftsform mittels der Gegenüberstellung von W1 und W2 angenommen.

Da ich die Heterotopie als Subgenre der Utopie begreife, gilt diese Skizzierung der strukturellen und inhaltlichen Merkmale utopischer Romane auch für den heterotopischen Roman. Zu klären bleibt indes, was die Spezifik der Heterotopie ausmacht. Im Rahmen einer Ein-SatzDefinition kann diese Spezifik folgendermaßen auf den Punkt gebracht

7 Für eine umfassendere Beschreibung der Konstruktionsregeln des utopischen Nicht-Ortes W2, in die neben der 'Gegenbildlichkeit ‘ auch die Merkmale `Isoliertheit $\triangleleft$ und `Stabilität` Eingang finden, vgl. ebd., S. 64-73. werden: Die Heterotopie ist eine Spielart des utopischen Romans, in der das zentrale Strukturprinzip der literarischen Utopie, das Prinzip der zwei Welten, als Widerstreit im Sinne Jean-François Loytards realisiert wird. Nach Lyotard handelt es sich bei einem Widerstreit um einen Konflikt des Inkommensurablen. Einen Konflikt also, der in Ermangelung einer auf beide Konfliktparteien anwendbaren Urteilsregel per se unlösbar ist. ${ }^{8}$ Überträgt man diese Form des Konflikts auf den Bereich der Literatur und konkret auf Möglichkeiten der Realisierung des utopischen Prinzips der zwei Welten, können Widerstreitssituationen auf verschiedenen Beschreibungsebenen beobachtet werden.

Auf der Handlungsebene etwa kann das Verhältnis zwischen W1 und W2 als Widerstreit zweier inkommensurabler gesellschaftlicher Ordnungen gestaltet sein. Damit W1 und W/2 als inkommensurabel bezeichnet werden können, genügt es freilich nicht, dass in den beiden Welten jeweils unterschiedliche Paradigmen der Wahrnehmung und Bewertung sozio-kultureller Gegebenheiten gelten. Dies ist schließlich auch in traditionellen Utopien der Fall. Die radikale Ungleichartigkeit von W1 und W2 zeigt sich in Heterotopien auch mit Blick auf Gegebenheiten, die dem Bereich des Sozialen und Kulturellen vorgängig sind, etwa in der Gültigkeit unterschiedlicher physikalischer, biologisch-anthropologischer oder ontologischer Gesetze. In Heterotopien werden die beiden inkommensurablen Welten nun innerhalb des fiktionalen Kosmos miteinander in Konflikt gebracht. Da sie sich jedoch aufgrund ihrer spezifischen Beschaffenheit wechselseitig ausschließen und kein Kosmos, also keine Weltenordnung denkbar ist, die beide Welten zugleich enthält, ist der Konflikt zwischen W1 und W2 prinzipiell unlösbar. Mit anderen Worten: W1 und W2 befinden sich im Widerstreit.

Die systematische Verbindung zwischen dem von mir postulierten literaturwissenschaftlichen Heterotopie-Konzept und dem gleichnamigen Instrument Michel Foucaults zeichnet sich nun ab: In beiden Fällen geht

$8 \mathrm{Im}$ »Merkzettel zur Lektüre« von Lyotards Widerstreit wird dieser definiert als ein »Konfliktfall zwischen (wenigstens) zwei Parteien, der nich angemessen entschieden werden kann, da eine auf beide Argumentationen anwendbare Urteilsregel fehlt. Die Legitimität der einen Argumentation schlösse nicht auch ein, daß die andere nicht legitim ist. Wendet man dennoch dieselbe Urteilsregel auf beide zugleich an, um ihren Widerstreit gleichsam als Rechtsstreit zu schlichten, so fügt man einer von ihnen Unrecht zu (einer von ihnen zumindest, und allen beiden, wenn keine diese Regel gelten läßt)« (Jean-François Lyotard: Der Widerstreit. Übersetzt von Joseph Vogl. 2., korrigierte Auflage. München 1989, S. 9). 
es um Topologien radikaler Andersheit. Als >Heterotopieく bezeichnet Foucault in seiner Schrift Die Ordnung der Dinge eine besonders beunruhigende Art der Unordnung. Diese Unordnung - vielleicht wäre das französische Wort désordre auch besser mit `Nicht-Ordnung übersetzt diese Nicht-Ordnung also ergibt sich daraus, dass die Dinge $»$ niedergelegt ‘, >gestelltı, >angeordnet ‘ [sind] an in dem Punkte unterschiedlichen Orten, daß es unmöglich ist, für sie einen Raum der Aufnahme zu finden und unterhalb der einen und der anderen einen gemeinsamen Ort zu definieren $«{ }^{9}$ Ebenso wie dieser Heterotopie-Begriff Foucaults bezeichnet auch das von mir verwendete Heterotopie-Konzept eine Struktur, die durch das konflikthafte, Verunsicherung stiftende Aufeinandertreffen des Inkommensurablen gekennzeichnet ist. Dennoch sollte die Heterotopie als Subgenre des utopischen Romans nicht als Eins-zu-eins-Applikation des Foucaultschen Begriffspaares \Utopie///Heterotopie tungskonventionen des utopischen Romans missverstanden werden. Denn während ich die literarische Heterotopie als eine Sonderform der Utopie verstehe, werden die Begriffe >Utopie< und `Heterotopie $<$ bei Foucault antonymisch gebraucht. ${ }^{10}$

Um einen Eindruck davon zu vermitteln, wie sich die zuvor nur sehr allgemein beschriebene Realisierung des Prinzips der zwei Welten als Widerstreit der Welten konkret manifestieren kann, scheint mir ein Beispiel angebracht. Ich beziehe mich dabei auf Peter Ackroyds Roman The Plato Papers aus dem Jahre 2000. ${ }^{11}$ Das Prinzip der zwei Welten ist in diesem Text deutlich als zentrales Strukturprinzip zu erkennen. Der Protagonist Plato, philosophierender Historiograph auf der unablässigen Suche nach Wahrheit und Mitglied der Londoner »Academy of Past Ages «,,$^{12}$ erforscht eine als Mouldwarp bezeichnete Epoche, die auf den Zeitraum zwischen 1500 und 2300 nach Christus datiert wird. Mouldwarp entspricht also zumindest in seiner Spätphase - der Welt der zeitgenössischen LeserInnen und hat daher die Funktion $W_{1}$ inne. Die Epoche, in der Plato selbst beheimatet ist, wird nur als The Present bezeichnet und ist im letzten Drittel des

9 Michel Foucault: Die Ordnung der Dinge. Eine Archäologie der Humanwissenschaften. Übersetzt von Ulrich Köppen. Frankfurt a. M. 1974, S. 20. 10 Vgl. ebd.

11 Peter Ackroyd: The Plato Papers. A Novel. London 2000. Zu The Plato Papers als besonders prägnantes Beispiel für die Besonderheiten des heterotopischen Romans vgl. weiterführend auch das entsprechende Kapitel in: Judith Leiß: Inszenierungen des Widerstreits (wie Anm. 6), S. 132-163. 12 Ackroyd: The Plato Papers (wie Anm. 11), S. 29.
4. Jahrtausends angesiedelt. Wir erfahren, dass Mouldwarp und The Present durch einen radikalen Bruch, eine epoché im wörtlichen Sinne, voneinander getrennt sind. Mouldwarp endete mit einem einschneidenden Ereignis, mit einer Katastrophe apokalyptischen Ausmaßes, ${ }^{13}$ über deren Ursache die LeserInnen im Unklaren gelassen werden. Es wird jedoch deutlich, dass die völlige Auslöschung der Mouldwarp-Welt die Entstehung der von Plato und seinen MitbürgerInnen bewohnten Welt erst ermöglichte..$^{14}$

Dass The Present hinsichtlich der geltenden sozialen Normen als Gegenentwurf zur Ära Mouldwarp konzipiert ist, geht unter anderem daraus hervor, dass eine ganze Reihe von Konzepten und Gepflogenheiten, die die Lebenswirklichkeit des Zeitalters Mouldwarp entscheidend prägten, für Plato und seine Zeitgenossen kaum oder überhaupt nicht zu verstehen sind, da sie in ihrer Welt offensichtlich keine Rolle spielen. Kriegerische Auseinandersetzungen und Kolonisalisierung, die Existenz einer >Dritten Welt « sowie die Einteilung der Menschheit nach Geschlecht, Gender oder Rasse sind ihnen ebensowenig bekannt wie die Konzepte >Arbeit‘, >Besitz oder `Fortschritt<. Es ist also nicht zu übersehen, dass das Verhältnis zwischen den beiden Welten W1 und W/2 auf Gegenbildlichkeit angelegt ist.

Diese Gegenbildlichkeit im Bereich des Gesellschaftlichen wird allerdings von einer ontologischen Inkommensurabilität der beiden Welten konterkariert. Ich habe bereits erwähnt, dass das Konzept `Fortschritt ‘ in Platos Welt unbekannt ist. Was mit >ontologischer Inkommensurabilität gemeint ist, wird deutlich, wenn ich hinzufüge, dass Fortschrittsdenken in W2 darum nicht existiert, weil Plato und seine Zeitgenossen in einer im buchstäblichen Sinne zeitlosen Welt leben..$^{15}$ Ein weiterer Hinweis auf die ontologisch-physikalische Inkommensurabilität der beiden Welten ist der Umstand, dass sich die Bewohner von W2 in mehr als drei Dimensionen bewegen. ${ }^{16}$

Damit ist freilich erst eine der beiden Voraussetzungen für eine Realisierung des Prinzips der zwei Welten als Widerstreit der Welten gegeben. Geraten die beiden Welten als potentielle Konfliktparteien gar nicht in Kontakt miteinander, kann es nämlich trotz ihrer Inkommensurabilität nicht zu einem Konflikt kommen. Um einen Widerstreit zwischen $\mathrm{W}_{1}$ und W/2 zu inszenieren, müssen die beiden Welten also in der ein oder anderen Form aufeinander treffen, sie müssen zur Kollision gebracht

13 Vgl. ebd., S. [I].

14 Vgl. ebd., S. $50 \mathrm{f}$

15 Vgl. ebd., S. 32

16 Vgl. ebd., S. 113. 
werden, so dass sie sich wechselseitig infrage stellen. Und auch dies ist in The Plato Papers der Fall.

Plato fasst nämlich im Verlauf der Geschichte den Entschluss, sich zu einer Forschungsreise nach Mouldwarp aufzumachen. Nach seiner Rückkehr verkündet er, Mouldwarp existiere in einer Höhle unterhalb der von ihm und seinen MitbürgerInnen bewohnten Stadt London. In seiner Herkunftswelt begegnet man seinen Erzählungen mit Unglauben. Aus der Perspektive der LeserInnen spricht allerdings vieles dafür, dass Platos Reise tatsächlich stattgefunden hat, denn er erwähnt zahlreiche Details, die er ganz offensichtlich nicht aus historischen Quellen kennt. ${ }^{17}$ Obwohl es also zunächst den Anschein hat, als seien Mouldwarp und The Present durch eine unüberwindbare Zäsur voneinander getrennt, besteht in der Person Platos eine direkte Verbindung zwischen den beiden Welten. Indem er aus seiner vieldimensionalen Daseinsform in die Dreidimensionalität Mouldwarps wechselt, indem er aus der Zeitlosigkeit in die Zeitlichkeit eintritt, indem er also eine ontologische Ordnung gegen eine andere eintauscht, bringt Plato die beiden inkommensurablen Welten miteinander in Kontakt - und aufgrund ihrer Unvereinbarkeit in einen Konflikt, der sich als literarische Inszenierung einer Widerstreitssituation lesen lässt.

Wie radikal Platos Reise nach Mouldwarp seine eigene gesellschaftliche Realität, also The Present, infrage stellt, wird deutlich, wenn man die Reaktionen seiner MitbürgerInnen betrachtet. Dass diese Platos Reisebericht mit Skepsis begegnen, ist nicht verwunderlich - schließlich handelt es sich bei Mouldwarp ihrer Kenntnis nach um eine längst vergangene Epoche. Auch ist es keineswegs so, dass Plato Mouldwarp vor seiner Reise dorthin als Zeitalter und nach der Reise als Raum beschriebe. Plato präsentiert seine neuen Erkenntnisse bezüglich der Verortbarkeit Mouldwarps nach der Rückkehr von dort nicht als Korrektur bisheriger Forschungsergebnisse. Er spricht von den Bewohnern Mouldwarps immer noch als seinen »ancestors $«,^{18}$ besteht aber zugleich darauf, dass Mouldwarp immer noch existiere. ${ }^{19}$

Die ablehnende Haltung seiner Zeitgenossen ist angesichts solcher Verstöße gegen die Gesetze der Logik ohne Weiteres nachvollziehbar.

17 Besonders markant ist in diesem Zusammenhang Platos Schilderung der Straßenlaternen als "vessels of glass, or frozen water, that contained the radiance of the stars« (ebd., S. 90). Auch Platos Ausführungen zur Funktion der Zeit in Mouldwarp (vgl. ebd., S. 98) sind ein starkes Indiz dafür, dass er Mouldwarp tatsächlich besucht hat.

18 Ebd., S. 104.

19 Vgl. ebd., S. 100.
Bemerkenswert ist jedoch, dass Platos gewagte Thesen über das Verhältnis zwischen The Present und Mouldwarp nicht einfach als Hirngespinste eines überarbeiteten Wissenschaftlers abgetan werden, sondern ihn schließlich sogar vor Gericht bringen. Die Anklage lautet - wie beim Lehrer des historischen Plato - auf Blasphemie und Verführung der Jugend. Konfrontiert mit der Widersprüchlichkeit seiner Aussagen, verweist Plato vor Gericht nur milde auf die »merits of two realities existing simultaneously «. ${ }^{20}$ Die bloße Erwähnung einer solchen zweiten Wirklichkeit wird allerdings in The Present als existentielle Bedrohung empfunden, ging man doch bisher davon aus, dass die eigene Gegenwart nur durch die vollständige Auslöschung der als minderwertig beurteilten Mouldwarp-Gesellschaft möglich wurde. Um dieser Bedrohung etwas entgegenzusetzen, wird Plato durch das Gericht aufgefordert, zu widerrufen. Als er dies verweigert, verbannt man ihn aus London, um die gesellschaftliche Ordnung nicht weiter zu gefährden. Der Widerstreit, der Konflikt zwischen den beiden inkommensurablen Systemen Mouldwarp und The Present, wird also mit Gewalt aufgelöst, da Platos ZeitgenossInnen nicht in der Lage sind, diesen als solchen anzuerkennen und auszuhalten. »To imagine a world within our world - a world beneath our world. It is impossible«, ${ }^{21}$ so lautet die kategorische Antwort des Gerichts auf Platos Beteuerungen, seine Reise nach Mouldwarp sei kein Traum gewesen.

Diesem Konflikt des Inkommensurablen auf der Handlungsebene entspricht in The Plato Papers auch ein Konflikt auf der Deutungsebene. Denn die von Plato behauptete Gleichzeitigkeit von Mouldwarp und The Present steht wiederum im Widerstreit mit anderen Deutungen der Relation W1/ W2, die durch den Text gleichermaßen nahegelegt werden. Dies geschieht, indem verschiedene mythologische Bezugssysteme evoziert werden, die mit jeweils unterschiedlichen Konzeptionen von Zeit und Geschichte einhergehen und somit jeweils unterschiedliche Deutungen des geschichtlichzeitlichen Verhältnisses zwischen Mouldwarp und The Present nahelegen.

Eines dieser mythologischen Bezugssysteme ist die unter anderem aus der griechischen Antike bekannte Einteilung der Menschheitsgeschichte in verschiedene Zeitalter. So evozieren viele Merkmale der Gegenwart Platos das Goldene Zeitalter, wie es Hesiod in Werke und Tage beschreibt. ${ }^{22}$

20 Ebd.

21 Ebd., S. 111 (Hervorhebung im Original).

22 Vgl. Leiß: Inszenierungen des Widerstreits (wie Anm. 6), S. 140. Zur Bedeutung von Hesiods Werken und Tagen beziehungsweise des Mythos vom Goldenen Zeitalter als Intertext vgl. auch Susana Onega: Peter Ackroyd's 
Diese Anklänge an das Goldene Zeitalter sind ein Indiz dafür, dass die den Plato Papers vorangestellte Zeittafel, nach welcher Mouldwarp The Present zeitlich vorausgeht, womöglich einer Korrektur bedarf. Sie legen nahe, dass Platos Gegenwart nicht nach, sondern vor Mouldwarp zu situieren ist. Ein zweiter, ebenfalls der Sphäre des Mythologischen zuzurechnender Intertext stellt diese Deutung wiederum in Frage: Was über den Untergang der Mouldwarp-Ära bekannt ist, erinnert bis in einzelne Formulierungen hinein an die biblische Apokalypse, wie sie in der Offenbarung des Johannes geschildert wird. ${ }^{23}$

Dass Platos Gegenwart sowohl mit den Anfängen der Geschichte der Menschheit, dem Goldenen Zeitalter nach Hesiod, als auch mit dem Ende der Zeit, nämlich dem Zustand nach Apokalypse und Millennium, in Verbindung gebracht werden kann, könnte bezüglich der Relation W1/ W2 auch zu der Hypothese führen, W2 sei zugleich vor und nach W1 zu situieren. Legt man ein lineares Zeitmodell zugrunde, so wäre das Verhältnis zwischen Mouldwarp und The Present damit als Paradox beschrieben. Im Text werden jedoch zahlreiche Spuren gelegt, die auf ein zirkuläres Zeitmodell hinweisen ${ }^{24}$ - und damit auf die Möglichkeit, dass W2 in Bezug auf W1 zugleich Vergangenheit und Zukunft sein kann, ohne dass dadurch gegen das Prinzip vom auszuschließenden Dritten verstoßen würde.

Die Plato Papers halten also verschiedene Erklärungsangebote betreffend der Relation $W_{1} / W_{2}$ bereit, die nicht miteinander zu vereinbaren sind, da sie auf inkommensurablen Konzeptionen von Zeit und Geschichte beruhen. Von einem Widerstreit verschiedener Lesarten kann gesprochen werden, da die Pluralität konfligierender Deutungsangebote in Ermangelung eines archimedischen Punkts nicht zu Gunsten einer Lesart aufgelöst werden kann. Zwar lädt ein dicht gewebtes Netz von Hinweisen zum Rätselraten ein; der Text bietet jedoch keine übergeordnete Bezugsinstanz, die es ermöglichte, die verschiedenen Deutungen auf ihren Wahrheitsgehalt zu überprüfen. Eine unvoreingenommene Lektüre der Plato Papers lässt daher keine eindeutige und abschließende Antwort

,Contrary< to Blake's Jerusalem. In: dies. und John A. Stotesbury (Hrsg.): London in Literature. Visionary Mappings of the Metropolis. Heidelberg 2002, S. 183-209.

23 Vgl. Leiß: Inszenierungen des Widerstreits (wie Anm. 6), S. 141.

$24 \mathrm{Vgl}$. etwa die Beobachtung Platos, dass »before and after became strangely mingled « (Ackroyd: The Plato Papers [wie Anm. 11], S. 16) oder die Bemerkung seiner Seele, Vergangenheit und Zukunft seien möglicherweise »the same thing (ebd., S. 52). auf die Frage nach dem geschichtlichen Verhältnis zwischen W1 und W2 zu. Es handelt sich um einen Text, der darauf abzuzielen scheint, Deutungsversuche anzuregen, nur um diese dann zu düpieren.

Auch eine normative Relationierung der beiden Welten seitens der LeserInnen wird einerseits provoziert, andererseits aber - zumindest in Form eines abschließenden Fazits nach Lektüreschluss - vereitelt. Zwar stellt The Plato Papers wie alle Utopien die Frage nach der bestmöglichen Form sozialer Organisation. Zum einen, indem Ackroyds LeserInnen mit einem spekulativen Gegenentwurf zu der ihnen bekannten gesellschaftlichen Realität konfrontiert und dadurch zu einem kritischen Vergleich eingeladen werden. Zum anderen durch die Art und Weise, wie die Frage nach der guten oder gar idealen Gesellschaft auf der Figurenebene verhandelt wird - nämlich als Frage von existentieller Bedeutung für den Protagonisten. Interessanterweise scheint es für Plato - ganz in Sokratischer Manier - weit wichtiger zu sein, diese Frage zu stellen, als eine Antwort darauf zu präsentieren. Ja, er bezweifelt gar öffentlich die generelle Beantwortbarkeit der Frage und warnt davor, sich ein abschließendes Urteil über The Present oder die Mouldwarp-Gesellschaft anzumaßen: »I am not telling you that all is wrong, or all is well", so Plato, »I am simply asking you to question and, perhaps, to see the world in different ways «. ${ }^{25}$ Diese Aufforderung könnte durchaus auch an die Adresse der LeserInnen gerichtet sein. Denn auch aus ihrer Perspektive ist nicht erkennbar, welche der beiden gesellschaftlichen Wirklichkeiten die bessere ist. Da W1 und W/ sich im Widerstreit befinden, da es also keine auf beide Welten anwendbare Urteilsregel gibt, kann nicht entschieden werden, welcher der beiden Gesellschaften der Vorzug zu geben ist. Kritische Anregungen aber bietet der Text uns Mouldwarp-BewohnerInnen zuhauf.

Man mag nun einwenden, dass Mehrstimmigkeit und Uneindeutigkeit konstitutive Merkmale literarischer Texte sind und utopische Romane daher niemals eindeutige Werturteile über die dargestellten sozialen Ordnungen erlauben. Auch der Prototyp der Gattung, Morus' Utopia, gilt heute in der Forschung als hochgradig polyvalent. ${ }^{26}$ Allerdings ist diese Art von Polyvalenz in der traditionellen Utopie oftmals nur für besonders aufmerksame LeserInnen erkennbar. Kennzeichen der Heterotopie ist jedoch, dass Mehrdeutigkeit in ihrer radikalsten Form, nämlich als Widerstreit möglicher Deutungen, unübersehbar zum Programm gehört

25 Ebd., S. 132 (Hervorhebung im Original).

26 Vgl. beispielsweise Krishan Kumar: Utopianism. Minneapolis 1991, S. 24 f. oder Voßkamp: Thomas Morus' „Utopia« (wie Anm. 3), S. $191 \mathrm{f}$. 
und ostentativ ausgestellt wird. Auch nach Beendigung der Lektüre ist es den LeserInnen unmöglich, einzelne Beobachtungen, Erkenntnisse und Deutungsversuche einer Einheit, einer übergeordneten Sicht der Dinge zuzuführen. Die Rezipienten werden einer beständigen Verschiebung des Blicks, einer Zersplitterung der Perspektive ausgesetzt, wie sie aus traditionellen Utopien nicht bekannt ist. Aus gattungstheoretischer Perspektive stellt sich daher die Frage, welche Funktion die Realisierung des Prinzips der zwei Welten als Widerstreit hat und wie sich die Inszenierung von Widerstreitssituationen innerhalb der Gattungskonventionen des utopischen Romans gattungsgeschichtlich einordnen lässt.

Immer wieder und in immer neuen politischen und kulturhistorischen Kontexten wurde dem utopischen Denken ein strukturell bedingtes, verabsolutierendes Einheitsstreben zur Last gelegt. Auch die literarische Utopie war vor dem Vorwurf des Uniformismus nicht gefeit. ${ }^{27}$ Der Kern des Vorwurfs lautet, die Utopie mache sich in all ihren bisher bekannten Spielarten, sei es als Eutopie, als Dystopie oder als Kritische Utopie, notwendig der Verabsolutierung eines Partikularen schuldig. Stets werde die bekannte gesellschaftliche Wirklichkeit so mit einem fiktionalen Anderen kontrastiert, dass zumindest implizit ein Ideal postuliert werde - eine endgültige und alternativlose Antwort auf gesellschaftliche Probleme und Fragestellungen also, die universelle Gültigkeit beansprucht.

Ich möchte hier nicht diskutieren, ob beziehungsweise inwiefern das daraus oftmals abgeleitete Totalitarismus-Verdikt gerechtfertigt ist. Fakt ist, dass der Vorwurf, Utopien seien notwendig uniformistisch, wenn nicht gar totalitär, mittlerweile nicht nur innerhalb eines größeren ideenpolitischen Rahmens zum Gemeinplatz geworden ist, sondern auch innerhalb des literarischen Utopie-Diskurses. Auch die Gattung sutopischer Roman wurde durch entsprechende selbstreferentielle Verweise auf die eigene Brisanz angereichert. ${ }^{28}$

Vor diesem Hintergrund können Heterotopien als Versuch gelesen werden, Utopiekritik nicht nur zu zitieren, sondern den Vorwurf des

27 Vgl. beispielsweise Ralph Pordzik: Utopischer und post-utopischer Diskurs in den neuen englischsprachigen Literaturen. In: ders. und Hans U. Seeber (Hrsg.): Utopie und Dystopie in den neuen englischen Literaturen. Heidelberg 2002, S. 9-26, hier S. 9.

28 Vgl. die Einschätzung Wilhelm Voßkamps, dass »Utopie und Utopiekritik [...] konstitutiv zusammen" gehören, ja dass literarische Utopien gar »das prononcierteste Kritikpotential des utopischen Totalitarismus « enthalten. (Voßkamp: Utopie [wie Anm. 5], S. 1948; Hervorhebung im Original.)
Uniformismus respektive Totalitarismus zu entkräften, ohne dabei die gesellschaftskritische Funktion der Utopie preiszugeben. Indem das vertraute Prinzip der zwei Welten deutlich als Strukturprinzip zu erkennen ist, rücken auch Heterotopien die Frage nach der guten Gesellschaft ins Zentrum der Aufmerksamkeit. Durch die Realisierung des Prinzips der zwei Welten als Widerstreit eben dieser Welten wird jedoch eine Erwartungshaltung enttäuscht, die wohl viele LeserInnen aus ihren bisherigen Erfahrungen mit utopischer Literatur destilliert haben: die Erwartung nämlich, zumindest implizit mit einer Idealvorstellung menschlichen Zusammenlebens konfrontiert zu werden; die Erwartung, eine konkrete Antwort auf die Frage angeboten zu bekommen, welche Gesellschaftsform denn nun die einzig wahre und richtige sei. Eine ideale gesellschaftliche Ordnung aber, die als Vorbild für die Lebenswirklichkeit der zeitgenössischen LeserInnen dienen könnte, wird in Heterotopien weder implizit noch explizit dargestellt. Auch wird jeder Versuch, das Verhältnis zwischen W1 und W/2 einem wertenden Vergleich zu unterziehen und daraus ein inhaltlich bestimmtes Gesellschaftsideal abzuleiten, durch die hier am Beispiel von Ackroyds The Plato Papers beschriebenen Strategien zur Inszenierung von Widerstreitssituationen vereitelt. An die Stelle der einen Wahrheit und des einen, aus ihr ableitbaren Ideals tritt in Heterotopien eine Pluralität von Wahrheiten und somit eine Pluralität der Bestimmungen dessen, was hinsichtlich der Gestaltung menschlichen Zusammenlebens als wünschenswert gilt.

Wenn man jene Maßstäbe anlegt, die sich aus der Kenntnis traditioneller Utopien ableiten lassen, lesen sich heterotopische Romane wie Peter Ackroyds The Plato Papers, Alban Nikolai Herbsts Thetis. Anderswelt $^{29}$ oder Murakami Harukis Hard-boiled Wonderland und das Ende der Welt $^{30}$ eher wie eine verspielte, apolitische Parodie auf die Konventionen des utopischen Romans denn als Beitrag zu gesellschaftlich relevanten Fragestellungen. Es läge dann nahe, die Heterotopie als ein Genre zu betrachten, das nurmehr den utopischen Roman zum Gegenstand hat, nicht aber die Frage nach der guten Gesellschaft. Befragt man besagte

29 Alban Nikolai Herbst: Thetis. Anderswelt. Ein phantastischer Roman. Reinbek 1998.

30 Haruki Murakami: Hard-boiled Wonderland und das Ende der Welt. Übersetzt von Annelie Ortmanns und Jürgen Stalph. München 2007. Zum heterotopischen Charakter dieser Werke vgl. die entsprechenden Kapitel in: Leiß: Inszenierungen des Widerstreits (wie Anm. 6), S. 185-218 und S. $218-243$. 
Werke jedoch auf ihre strukturellen Eigenschaften und deren utopische Funktion, gelangt man zu dem Ergebnis, dass es sich hier keineswegs um bloße Meta-Utopien ohne gesellschaftskritisches Potential handelt. Denn indem die Gegenüberstellung zweier sozialer Ordnungen in Heterotopien als Widerstreit realisiert wird, lenken sie die Aufmerksamkeit von der Frage nach der 'guten', also gerechten Gesellschaft hin zur Frage nach den Möglichkeitsbedingungen von Gerechtigkeit. Die LeserInnen heterotopischer Romane können die Erfahrung machen, dass der Konflikt zwischen $\mathrm{W}_{1}$ und $\mathrm{W}_{2}$ angesichts der grundlegenden Ungleichartigkeit der beiden Welten ein gerechtes, universal gültiges Werturteil unmöglich macht. Diese Erfahrung wiederum kann zu der Erkenntnis führen, dass keine inhaltlich definierte Gesellschaftsordnung für alle Mitglieder einer Gesellschaft zugleich ideal sein kann. Entsprechend disponierte LeserInnen können durch die Lektüre von Heterotopien zu dem Schluss kommen, dass somit jeder Gesellschaftsentwurf, der absolute Gerechtigkeit verspricht, angesichts des unvermeidlichen Widerstreits der Interessen und Weltanschauungen scheitern muss. Heterotopien beantworten die alte Frage nach der guten Gesellschaft also gerade dadurch, dass sie die implizite oder explizite Bestimmung eines inhaltlich definierten Gesellschaftsideals ostentativ verweigern. Durch diese Verweigerung postulieren sie eine lediglich formal bestimmbare gesellschaftliche Vision - nämlich die Vision einer radikalpluralistischen Gesellschaft, in welcher Konflikte zwischen inkommensurablen Positionen nicht gewaltsam aufgelöst werden, sondern, ganz wie es Lyotard in Der Widerstreit fordert, im vollen Bewusstsein ihrer prinzipiellen Unvermittelbarkeit ausgehalten werden ${ }^{31}$

Mit Blick auf die Gattungsgeschichte des utopischen Romans kann die Heterotopie somit als Versuch verstanden werden, utopisches Schreiben vom Vorwurf der Verabsolutierung partikularer Normen zu befreien. Zwar scheinen auch die AutorInnen anderer utopischer Subgenres auf die Verkündung eines gesellschaftlichen Ideals zu verzichten, das doch niemals für alle Mitglieder einer Gesellschaft ideal sein könnte. Während den einschlägigen Dystopien jedoch qua Negation immer noch ein implizites Ideal eingeschrieben ist, scheint mir mit der Heterotopie die Möglichkeit einer literarischen Quadratur des Kreises gegeben: Durch die heterotopische Realisierung des Prinzips der zwei Welten kann Utopiekritik auch in ihrer radikalsten Form in das utopische Schreiben eingespeist werden, ohne dass sich die Utopie dadurch selbst negierte.

31 Vgl. Lyotard: Der Widerstreit (wie Anm. 8), S. 12.
Die Heterotopie verweist in ausgeprägter Selbstreferentialität auf die Gefahren utopischen Denkens, ohne die prinzipielle Notwendigkeit dieses Denkens infrage zu stellen. Indem sie dies auf weitaus radikalere Weise tut als etwa die Dystopie oder auch die Kritische Utopie, und insofern sie den inhaltlich bestimmten gesellschaftlichen Visionen traditioneller Utopien eine rein formal bestimmte Vision entgegensetzt, mag man dies einen gattungsgeschichtlichen Fortschritt nennen.

Fortschritt - und hier komme ich nun zu dem im Titel meines Beitrags angekündigten Begriff der Spirale - sollte dabei nicht im geschichtsphilosophischen Sinne als endgültige Überwindung des Alten und Überkommenen verstanden werden. Denn in diesem Fall wiederholte man gleichsam rekursiv jenen Fehler, dem sich die Entstehung des heterotopischen Romans meiner These nach verdankt, nämlich die Verkündung eines universalen, unüberbietbaren Ideals - in diesem Falle freilich nicht eines gesellschaftlichen, sondern eines literaturgeschichtlichen Gattungsideals. Ich möchte die Heterotopie darum nicht als beste oder gar ideale Form des utopischen Romans verstanden wissen. Wenn ich von einem gattungsgeschichtlichen $>$ Fortschritt spreche, so impliziert dies weder einen teleologischen Fortschritt noch ein normatives Urteil. Von einem `Fortschritt', einer Weiterentwicklung sei hier lediglich im Sinne eines zeitlichen Fortschreitens bei gleichzeitiger kritischer Aufnahme und Reflexion des Bisherigen gesprochen, das zu einer weiteren Ausdifferenzierung des Genres ,Utopie (geführt hat. Man hat sich die Entwicklung des utopischen Romans hier nicht als linearen Prozess vorzustellen, sondern als Spirale: Die neue Form utopischen Schreibens löst die alte nicht ab, sondern verleibt sie sich in selbstreflexiver Wendung mitsamt ihrer Rezeptionsgeschichte ein. Die Heterotopie führt die utopische Tradition somit auf einer komplexeren Reflexionsebene fort. Doch ist zu vermuten, dass auch sie nicht als ultima ratio, als Endpunkt utopischen Schreibens in die Gattungsgeschichte eingehen wird, sondern lediglich als eine mögliche Form utopischen Schreibens unter vielen, als eine Form, die - wie die anderen auch - ihren besonderen historischen und gesellschaftspolitischen Ort hat. 


\section{RYOZO MAEDA}

\section{TECHNO, APOKALYPSE, "IKAI»}

\section{Utopien und Dystopien in der visuellen}

\section{Massenkultur Japans}

I.

In Japan wird alles, was von außen kommt, derart ’japanisiert‘, d.i. trivialisiert, dass man nicht mehr wiedererkennen kann, worum es sich eigentlich handelt. Mit dem Wort `Utopiar sieht es auch nicht anders aus. In seinen 1996 veröffentlichten Vorlesungen über den Surrealismus weist der japanische Romanist Kunio IWAYA (geb. 1943) ${ }^{1}$ auf ein $>$ merkwürdiges` Phänomen hin: In den 1980er Jahren ist `Utopiaく urplötzlich zu einem Lieblingswort von Japanern geworden, und zwar nicht etwa in der politischen oder intellektuellen Diskussion, sondern zumal im Wortgebrauch der Bau- und Technologiebranchen, die mit großen staatlichen und kommunalen Entwicklungsprojekten beschäftigt waren. ${ }^{2}$ So wurde z.B. die Weltausstellung, die im Jahre 1981 in der westjapanischen Hafenstadt Kobe stattfand, vom Veranstalter »Port(o)pia« (Port + Utopia) genannt.

1 Zur Schreibweise der japanischen Wörter: Japanische Familiennamen werden in Großbuchstaben wiedergegeben, wenn sie im Haupttext zum ersten Mal erscheinen. Die Familiennamen werden den Vornamen nachgestellt, wenngleich in Japan der Familienname immer vor den Vornamen gesetzt wird. Das Dehnungszeichen über den Vokalen, die gedehnt ausgesprochen werden [â, ō, ù, usw.], wird bei den Personen- und Ortsnamen nicht verwendet.

2 Vgl. Kunio Iwaya: Surrealism to ha nanika. Chōgenjituteki Kōgi (Was ist Surrealismus? Surrealistische Vorlesungen). Tokyo ${ }^{\mathrm{I}} 1996$. Zitiert nach

Chikuma Gakugeibunko-Ausgabe. Tokyo 2002, S. 188. 
Ebenfalls hieß das Projekt des Sozialministeriums (Kōsei-shō) »Greenpia« (Green + Utopia), in dessen Rahmen von 1981 bis 1988 im ganzen Japan insgesamt 13 größere Kuranlagen gebaut wurden. ${ }^{3}$ Darüber hinaus entstanden in diesem Zeitraum mehrere »Technotopia" oder »Teletopia" als spezielle Messegelände für Medien- und Technologieindustrie.

Die Liste solcher wortspielerisch-hybriden `Doppelneologismen « ,Utopia ist bekanntlich ein Neologismus von Thomas Morus - ließe sich noch beliebig verlängern. Für die kulturwissenschaftliche Thematisierung der Utopien in der Gegenwart ist es allerdings ein marginales Phänomen, da solche japanischen Neologismen eigentlich kaum etwas zu tun haben mit dem Roman Utopia (1516) $)^{4}$ oder mit der europäischen Denktradition des Utopischen.

Aber nomen est omen. Und in Japan steckt der liebe Gott im Trivialen. So versucht Iwaya, anhand dieses an sich eher marginalen Phänomens die japanische Gesellschaft der Zeit der Bubble Economy als eine "QuasiUtopie« (Giji Utopia $)^{5}$ zu analysieren. Dabei zählt er Merkmale auf, die dieser Gesellschaft und jener im Roman von Thomas Morus gemeinsam sind, und macht - nicht ohne die ironisch-kritische Übertreibung eines Raphael Hythlodeus - darauf aufmerksam, wie verblüffend ähnlich die erstere der letzteren ist.

Im Japan der 1980er Jahren fand sich eine am Kollektivismus orientierte und bis in jede Ecke des öffentlichen Raumes ssterile` Gesellschaft, in der nicht nur gerne Uniformen getragen wurden, sondern auch die sharmonische Z Zusammenarbeit von Politik und Wirtschaft die egalitäre Umverteilung (Redistribution of wealth) in hohem Maße, sogar viel besser als in irgendeiner sozialistischen Gesellschaft, verwirklicht hatte. Es war also eine Wohlstandsgesellschaft, in der die Bevölkerung zum größten Teil das Gefühl hatte, Mitglied der glücklichen Mittelschicht zu sein (»Ichioku Sōchūryūka Shakai«).

Iwaya sieht in der genannten japanischen Vorliebe für das Wort >Utopiar die Widerspiegelung einer solchen breit geteilten euphorischen Illusion. Es ist nichts anderes als das »statische Ordnungsglück

3 Wie diese Beispiele zeigen, wird bei der Japanisierung des Wortes >Utopia< der Wortstamm stopos` oft völlig ignoriert. Stattdessen funktioniert die Wortendung >-piar quasi als pars pro toto für >Utopiar. Es gab folglich eine Informationszeitschrift für Jugendliche, die schlicht $>$ Piar hieß.

4 Thomas Morus' Utopia ist seit 1929 mehrmals ins Japanische übersetzt worden (in den meisten Fällen eine Übersetzung aus dem Englischen).

5 Iwaya: Surrealism to ha nanika (wie Anm. 2), S. 213. disziplinierter [kollektiver] Subjekte«(W. Voßkamp), ${ }^{6}$ was hier zum Ausdruck kommt. Gleichfalls illusorisch war die Freiheit, die man in dieser Gesellschaft vermeintlich genießen konnte. Wurde doch das Leben durch raffinierte soziale Systeme der Soft-Verwaltung fast perfekt kontrolliert (deshalb `Quasi-Utopie $<$ ). Hier will der scharfsinnige Kritiker sogar eine bösartige Parodie der klassischen europäischen Utopie finden - bösartig deswegen, weil sich diese Verwaltungssysteme durch keine aufklärerische Idee leiten lassen wie auf jenem fiktiven Inselland, sondern eine hochdisziplinierte Gesellschaft quasi selbstorganisiert zur Entstehung gekommen ist - eine klare Negation der Konzeptualisierung eines Idealstaates, wie er in Utopie-Romanen der Renaissance zentral thematisiert wird. Iwaya vergleicht diese fast naturwüchsig entstandene »Quasi-Utopie« namens Japan mit einem Bienenschwarm.?

Es liegt auf der Hand, dass Iwaya in seiner Kritik fast uneingeschränkt die Position eines ebenfalls klassischen europäischen AntiUtopisten bezieht, wie sie in den dystopischen Romanen des frühen 20. Jahrhunderts Formulierung findet. In diesen Dystopie-Romanen wird bekanntlich die Gefahr thematisiert, dass das aufklärerische Ordnungsmodell der Renaissanceutopien unvermeidlich auch Zwang zum Totalitarismus einschließen kann. ${ }^{8}$ Gleichzeitig lässt sich im von Iwaya vorgelegten Japan-Bild die bloße Wiederholung dessen feststellen, was zu den Konstanten im modernen westlichen, >orientalistisch Japan-Diskurs gehört. ${ }^{9}$

II.

Diametral steht gegenüber dieser anti-utopischen Japan-Kritik ein neuer Typ des westlichen Japan-Diskurses der 1980er Jahre, der in das Inselland eine Art Utopie hineinprojizieren will. In dieser Zeit wurde Japan aufgrund des Erfolgs im Handel und Export, aber auch wegen des erreichten sozialen Wohlstandes im Westen als die avancierteste postindustrielle Gesellschaft

6 Voßkamp: Artikel »Utopie«. In: Ulfert Ricklefs (Hrsg.): Fischer Lexikon Literatur, Bd. 3 (N-Z). Frankfurt a. M. 1996, S. 1938.

7 Iwaya: Surrealism to ha nanika (wie Anm. 2), S. 237.

8 Voßkamp: Artikel »Utopie« (wie Anm. 6), S. 1933

9 Zum modernen Japan-Diskurs des Westens siehe: Thomas Pekar: Der Japan-Diskurs im westlichen Kulturkontext (1860-1920): Reiseberichte - Literatur - Kunst. München 2003. 
neu entdeckt. Eines der frühesten Beispiele für die Wiederentdeckung ist das Buch Japan as Number One (1979) des amerikanischen Historikers und Sozialwissenschaftlers Ezra Vogel. In diesem Buch wurden die oben aufgelisteten Merkmale der japanischen Gesellschaft, die bis dahin in erster Linie negativ, d.i. als Indizien für ihre Rückständigkeit interpretiert worden waren, als Zeichen für ihre Avanciertheit positiv umgedeutet. ${ }^{10}$ Ebenfalls sieht Jean Baudrillard in Japan ein Modell der zukünftigen, d.i. postmodernen Gesellschaft, die er - nicht ohne Ironie - mit einem Satelliten auf der Kreisbahn um die Erde vergleicht. ${ }^{11}$

Japan als utopisches Zukunftsbild - dieses Motiv wurde weiter übernommen in jenem westlichen Japan-Diskurs der frühen 1990er Jahre, der auf der spezifischen Begeisterung für die japanische Pop- und Technologiekultur (Manga, Anime, Computerspiel usw.) basiert und als »TechnoOrientalismus « bekannt ist. ${ }^{12}$ Nach David Morley und Kevin Robins, die den Terminus >Techno-Orientalismus` sollen eingeführt haben, ist Japan synonym geworden mit den Technologien der Zukunft - mit Bildschirmen, Netzwerken, Kybernetik, Robotik, künstlicher Intelligenz, Simulation, woraus eine Konsequenz gezogen wird: »If the future is technological, and if technology has become JJapanised, then the syllogism would suggest that the future is now Japanese, too. The postmodern era will be the Pacific era. Japan is the future, and it is a future that seems to be transcending and displacing Western modernity «. ${ }^{13}$

Das komplizenhafte Pendant eines solchen techno-orientalistischen Japan-Bildes ist zweifelsohne jenes selbstzufriedene Selbstbild Japans, das seinerseits auf der technischen Perfektion seines Verwaltungssystems und auf dem stolzen Bewusstsein basiert, Japan sei das Land der zukünftigen Technologie. In diesem Sinne ist diese technologische Utopie ein westlich-japanisches Konstrukt.

10 Ezra Vogel: Japan as Number One: Lessons for America. Cambridge, Mass. 1979.

11 Jean Baudrillard: Amérique. Paris 1986.

12 Hierzu Ryozo Maeda: Techno-Orientalismus und Japan-Diskurs in Deutschland. Zur Otaku-Diskussion bei Volker Grassmuck. In: Wang Jiambin (Hrsg.): Neues Jahrhundert, neue Herausforderungen:Germanistik im Zeialter der Globalisierung. Asiatische Germanstentagung Beijing 2002. Beijin 2004, S. 592-602.

13 David Morley und Kevin Robins: Spaces of Identity. Global Media, Electronic Landscapes and Cultural Boundaries. London, New York 1995, S. 168.
Die bisher erörterten Utopie-/Dystopievorstellungen von Japan sind ausnahmslos die einer `Gesellschaft nach dem Ende der Geschichter. Wie Iwaya hervorhebt hat eine klassische Raumutopie keine Geschichte im Sinne einer großen Erzählung, da dort bereits erreicht worden ist, was als geschichtliches Telos hingestellt werden soll. ${ }^{14}$ Es ist eine Gesellschaft, in der das spekulative Bedürfnis, die Welt und sich selbst zu verstehen, nicht mehr besteht. Wesentlich vorweggenommen worden ist ein solches utopisches Japan-Bild vom russisch-französischen Philosophen Alexandre Kojève, und zwar in der überarbeiteten Fußnote zu Japan von 1962 in der zweiten Ausgabe seiner Hegel-Vorlesung. Diese Fußnote revidierte Kojève nämlich nach seinem Besuch in Japan im Jahr 1959. ${ }^{15}$

Bekanntlich erlebt die These Kojèves zu Japan 1989, genau 30 Jahre nach seiner Japan-Reise, im Essay »The End of History? « des amerikanischen Politikwissenschaftlers Francis Fukuyama ein Revival. ${ }^{16}$ Das Datum ist mehrfach symptomatisch und ironisch: Einerseits werden somit das Ende des Kalten Krieg und der Beginn der Globalisierung markiert, der Beginn jenes Prozesses nämlich, in dem alle Gesellschaften in die technologische und finanzwirtschaftliche Gleichzeitigkeit endgültig hineingewoben werden. Und auf der Plattform der Technologie verbreitet sich die ১Japanisierung der Lebensweise im Sinne Kojèves beschleunigt in jede Ecke der Welt, ohne sich explizit als japanisch zu bezeichnen. Andererseits ist gerade auf dieser technologischen Plattform die "Gleichzeitigkeit des Nichtgleichzeitigen« (E. Bloch) viel deutlicher zutage getreten. Die Zeit der Globalisierung ist also die der daraus resultierenden neuen Konflikte. Und für Japan bedeutete es nicht nur das Ende seines selbstzufriedenen und abgekapselten Wohlstandes. Es war zugleich das Ende des utopischen/dystopischen Japan-Bildes im westlichen Diskurs.

14 Iwaya weist darauf hin, dass es in einer Utopie nur die wie ein Raumvolumen "geometrisch abgeteilte« Zeit gibt. In diesem Sinne nennt er die Utopie »U-Chronia» (Iwaya: Surrealismus to ha nanika [wie Anm. 2], S. 213-214).

$15 \mathrm{Zu}$ Kojèves Japan-Bild in geschichtsphilosophischem Zusammenhang siehe: Leander Scholz: Eine Fußnote zu Japan. Alexander Kojèves Reise in die Welt der Zeichen. In: Ryozo Maeda, Wilhelm Voßkamp und Teruaki Takahashi (Hrsg.): Schriftlichkeit und Bildlichkeit. Visuelle Kulturen in Europa und Japan. München 2007, S. 49-67.

16 Francis Fukuyama: »The End of History? « In: The National Interest (Summer 1989). Die überarbeitete und erweiterte Version des Essays wurde publiziert als: The End of History and the Last Man. New York 1992. 
Das bisher Skizzierte ist der Hintergrund, vor welchem jetzt das Utopische/Dystopische in der visuellen Massenkultur (Manga, Anime) der Gegenwart erörtert werden soll. Bevor wir in dieses Thema übergehen, sei auf die Stellung des Utopischen in der modernen japanischen Intellektuellengeschichte kurz eingegangen.

\section{III.}

Versteht man unter dem Begriff >Utopie< eine Idealgesellschaft, die nach einer inhaltlich mehr oder weniger klar umrissenen Idee strukturiert und in einer räumlichen bzw. zeitlichen Ferne entworfen wird, so findet man in der literarischen und philosophischen Tradition Japans kein genaues Pendant zur europäischen Utopie. Ein traditionelles Traumland ist zumal unter dem starken Einfluss des taoistischen Tōgenkyō-Topos (Táohuā Yuán = Land an der Quelle des Flusses Pfirsichblumen) fast immer als gesellschaftsferner Ort vorgestellt, in dem man in der harmonischen Einheit mit der Natur ein ruhiges Leben des Nichtstuns genießt. Es steht in diesem Sinne im scharfen Gegensatz zur okzidentalen Utopie, die seit Platons Politeia und Timaios, zumal seit den Renaissanceutopien oft als stadtstaatlicher Kosmos vorgestellt wird. ${ }^{17}$ Mit ihm mehr oder minder vergleichbar wäre das Arkadien in der europäischen literarischen Tradition. Ob und inwieweit der Vergleich kulturwissenschaftlich sinnvoll ist, hängt allerdings davon ab, was in der europäischen und der ostasiatischen Literaturtradition unter dem Begriff

17 Im Arzt und Philosophen Shoeki ANDO (1703-1762), der eine auf einem radikalen Egalitarismus beruhende landwirtschaftliche Gesellschaft in der Zukunft entwirft, könnte man wohl den einzigen Utopisten im vormodernen Japan sehen. Seine Schriften wurden zu seinen Lebzeiten nicht veröffentlicht und erst im 20. Jahrhundert sentdeckt‘. Zur utopischen Sozialphilosophie Shoeki Andos siehe Shuichi Kato: Geschichte der japanischen Literatur. Die Entwicklung der poetischen, epischen, dramatischen und essayistisch-philosophischen Literatur Japans von den Anfängen bis zur Gegenwart. Aus dem Japanischen übersetzt von Horst Arnold-Kanamori, Gesine Foljanty-Jost, Hiroomi Fukuzawa und Makoto Ozaki. Darmstadt 1990, S. 349-353. Dass Shoeki Ando seine utopische Agrargesellschaft in der Zukunft entwirft, ist in der ostasiatischen Tradition des nicht-religiösen Traumlandes eine Ausnahme. Darin ist auch eine »Verzeitlichung der Utopie« (Koselleck) zu sehen. Vgl. Reinhart Koselleck: »Die Verzeitlichung der Utopie«. In: Wilhelm Voßkamp (Hrsg.): Utopieforschung. Interdisziplinäre Studien zur neuzeitlichen Utopie. Bd. 3. Stuttgart 1982, S. 1-14.14.
`Natur bzw. \Shizen < jeweils verstanden werden soll. Auf diese Frage werde ich am Ende der vorliegenden Arbeit zurückkommen.

Erst nach der Meiji-Restauration im Jahre 1868 kamen zunächst sozialutopische Ideen aus dem Westen - vor allem anarchistische und syndikalistische Ideen aus Frankreich und Russland - nach Japan und in der ersten Phase der Modernisierung im Sinne einer totalen Verwestlichung intensiv aufgenommen. Einer der Hintergründe für diese Rezeption war die gravierende innere Spaltung der Gesellschaft durch die Bürgerkriege vor und nach dem Machtwechsel von 1868. Zwar lieferten sozialutopische Ideen systemkritischen Intellektuellen eine gedankliche Grundlage, um die Machtpolitik, die der rapiden technokratischen >Modernisierung von oben` zugrunde lag, radikal zu kritisieren. Jedoch gab es im damaligen Japan nicht die gesellschaftlichen und gesetzlichen Voraussetzungen einschließlich der Meinungs- und Vereinsfreiheit, um ihre Kritik zu einer breiten sozialen Bewegung gegen die Staatsmacht organisieren zu können..$^{18}$

In den späten 1910er und den frühen zoer Jahren entstanden unter dem Einfluss vom russischen Schriftsteller Lew Tolstoi humanitär orientierte und weniger politische Bewegungen, die aber - abgesehen von Sensationen im Journalismus - ohne nennenswerte soziale Wirkungen blieben. Die mit einem humanitär-egalitaristischen Ideal konzipierte Siedlung Atarashiki Mura (Neue Dorfgemeinde) des Schriftstellers Saneatsu MUSHANOKOJI (1885-1976) im Jahre 1918 ist ein Beispiel für solche nichtpolitische Sozialutopie-Bewegungen. ${ }^{19}$ Mushanokoji, der zu der literarischen Shirakaba-Gruppe gehörte, galt als einer der führenden Figuren der neuen literarischen Bewegung, die die bildungshumanistische Wende von der pragmatisch orientierten Aufklärung der Meiji-Zeit zur idealistisch geprägten Bildung der Taisho-Zeit, von der Zivilisation zur Kultur vertrat. In seinem eigenen literarischen Schaffen thematisierte er jedoch keine solchen Utopien. ${ }^{20}$

$18 \mathrm{Zu}$ einer Zentralfigur der frühen Anarchisten, Shusui KOTOKU (1871-1911) siehe: Kato: Geschichte der japanischen Literatur (wie Anm. 17), S. 541-544. 19 Es ist wohl zu vermuten, dass diese "Neue Bauernkolonie-Bewegung" durch deutsche Reformbewegungen, insbesondere durch die der neuen Siedlungen der späten Wilhelminischen Zeit inspiriert wurde. Recherchen hierüber seien dahingestellt.

20 Zur bildungshumanistischen Wende siehe Ryozo Maeda: Mythen, Medien, Mediokritäten. Zur Formation der Wissenschaftskultur der Germanistik in Japan. München 2010, S. 142-149. 
Durchaus singulär ist dagegen die literarische Utopie des Dichters und Kinderbücherautors Kenji MIYAZAWA (1896-1933). In der nordöstlichen Provinz Iwate geboren, lebte Miyazawa zum größten Teil seines Lebens in seiner ländlichen Heimat. Nach seiner Tätigkeit als Lehrer für Agrarwissenschaft an der Landwirtschaftsschule Hanamaki (1921-1926) trieb er selber Ackerbau und unterrichtete gleichzeitig in der von ihm gegründeten Privatschule Rasuchijin-Gesellschaft junge Bauern in wissenschaftlicher und effektiver Landwirtschaft. Parallel dazu schrieb er Gedichte und Erzählungen vornehmlich für Kinder, die in seinen Lebzeiten kaum bekannt waren. Aber sie wurden gleich nach seinem Tod entdeckt und genießen bis heute unter den breiten Schichten der Bevölkerung eine große Popularität.

In seinen Gedichten und fantastischen Erzählungen kommt ein fiktiver Ort wiederholt auf, der »Ihatov» bzw. »Ihatovo" heißt. ${ }^{21}$ Es ist ein Traumland im poetischen Gedankenbild Miyazawas, das zwar primär auf seine Heimat zurückgeführt werden soll. In diesem kosmopolitisch gefärbten Raum ${ }^{22}$ kommt seine eigene, auf der Lehre des MahayanaBuddhismus basierende und durch humanitäre Ideen Lew Tolstois inspirierte Weltanschauung zum Ausdruck. Miyazawas Idealwelt besteht dabei aus Elementen von durchaus heterogener Herkunft (Buddhismus, Pazifismus, Kosmopolitismus, Science Fiction usw.), zeigt jedoch insofern eine gewisse Kontinuität mit der traditionellen japanischen Vorstellung des Traumlandes auf, als hier Möglichkeiten einer harmonischen Symbiose von Menschen und Natur mit Konsequenz thematisiert werden. Und dabei soll dieses Zusammenleben erst durch eine wissenschaftliche Aufklärung der Menschen über die Natur (z. B. durch Agrarwissenschaft und Meteorologie) ermöglicht werden - ein Motiv, welches in mancher Hinsicht die Idee einer ökologischen Utopie vorwegnimmt. ${ }^{23}$

21 In der Forschung wird oft darauf hingewiesen, dass der durchaus nicht-japanisch klingende Ortsname auf das Interesse des Dichters an der Esperanto-Sprache zurückgeht: »Ihatov(o) " lässt sich gewissermaßen als esperanto-artige Transformation von »Iwate« betrachten.

22 In Miyazawas Erzählungen haben Personen meistens westlich klingende Namen: Die beiden Hauptfiguren der 1933 posthum veröffentlichten Erzählung Ginga Tetsudō no Yoru (Nacht auf der galaktischen Bahnlinie) heißen Giovanni und Campanella, wobei auf den Autor des Romans Civitas Solis nicht offensichtlich Bezug genommen wird.

23 Ein typisches Beispiel hierfür ist Guskō Budori no Denki (Das Leben des Guskō Budori), eine Erzählung für Kinder, die 1932 veröffentlicht wurde. Es handelt sich um Guskō Budori, einen Agraringenieur, der sich für das von Hungersnot heimgesuchte Ihatov opfert.
Hier wurde - wenn auch in einer sehr komprimierten Form - extra auf diesen außerhalb Japans noch unbekannten Dichter eingegangen, weil seine literarische Utopie einerseits zur Ausnahme in der modernen japanischen Literaturgeschichte gehört, andererseits einen Ausgangspunkt für die unten zu erörternde fantastische Naturvorstellung der visuellen Kultur der Gegenwart ausmacht.

Wie die angeführten Beispiele zeigen, haben die sozialutopischen Bewegungen des modernen Japan oft in der Agrargesellschaft ihr Modell gesucht. In einer solchen stark landwirtschaftlichen Hang lässt sich ein wohl Japan spezifischer Aspekt der sozialutopischen Bewegung feststellen. Und in den späten 1920er und in den 1930er Jahren mündete ein Teil dieser Bewegung ins zwar systemkritische, aber reaktionäre und (proto-) faschistische Lager des Nōhonshugi (physiokratistischer Fundamentalismus) ein.

Im Gegensatz zu den hier erwähnten sozialutopischen bzw. anarchistischen Ideen lässt es sich noch streiten, ob und inwieweit dem Marxismus eine utopische Funktion zuerkannt werden kann. Als 'wissenschaftliche` Bewegung der Revolution will er sich von anderen utopischen Bewegungen klar unterscheiden lassen. In Japan war und ist seine Wirkung auf die Politik »faktisch gleich Null« (Shuichi KATO). Als Theorie war dagegen sein Einfluss auf die jungen Intellektuellen in den 1920er Jahren weitaus größer und entscheidender als alle anderen gesellschaftlichen Ideen von westlicher Herkunft. »Geistige Selbstfindung ohne Auseinandersetzung mit dem Marxismus war" - so Shuichi KATO »für die jungen Intellektuellen der damaligen Zeit undenkbar «. ${ }^{24}$

Einerseits ist es für Japaner erst mit dem Marxismus, einer der größten Erzählungen der Moderne, möglich geworden, sich mit ihrer gesellschaftlichen Wirklichkeit aus einer alle sozialen Bereiche umfassenden Perspektive analytisch und kritisch auseinanderzusetzen. Andererseits war es indes völlig ausgeschlossen, ein in die Zukunft entworfenes marxistisches Gesellschaftsmodell in Japan, wenn auch teil- und schrittweise, zu realisieren. Darüber hinaus erschien die Realität der sowjetischen Gesellschaft in den Augen vieler linksorientierter Intellektuellen der Nachkriegszeit, als wäre sie eine desillusionierende Dystopie. Umso mehr ist die Rezeption und Wirkung des Marxismus auf das rein Theoretische beschränkt worden. Dementsprechend ist er für viele Intellektuelle ein Medium geworden, um das Gegebene aufgrund eines zeitutopisch

24 Kato: Geschichte der japanischen Literatur (wie Anm. 17), S. 582. 
Imaginierten kritisch zu analysieren. Hierin könnte man die genuin utopische Funktion des Marxismus in der japanischen Gesellschaft sehen, wo er die Masse der Bevölkerung kaum erreichen konnte.

Mit der Debakel der studentischen Revolte in den Jahren 1968/69 hat sich ein solches utopisches Potential vorerst erschöpft. Unter den Intellektuellen der jungen Generation wurde somit Marxismus endgültig diskreditiert. Das war der Beginn des Endes einer großen Erzählung der Moderne und somit des »Endes der Geschichte«. Zeitgleich hat sich in Japan die populäre Massenkultur (vor allem Manga, Anime) gegenüber der mit den Druck- und Buchmedien verbundenen Belesenheitskultur der etablierten Intellektuellen durchzusetzen begonnen und spätestens in den 1980er Jahren eine kulturelle Hegemonie erlangt. Es war gerade vor dem Hintergrund einer solchen Medienkonkurrenz, dass das Utopische zu einem speziellen Thema von Manga und Anime avanciert hat. ${ }^{25}$

\section{IV.}

Mit Manga und Anime ${ }^{26}$ (eigentlich eine Ablürzung von Animation = Zeichentrickfilm) handelt es sich um Comic-Strips und Zeichentrickfilme, die sich im Nachkriegsjapan, zumal seit den 1960er Jahren, auf eigene Art entwickelt haben. Heute enthalten sie fast alle Elemente, die man in Literatur und Film finden kann. ${ }^{27}$ Und dabei werden viele Titel im Manga und Anime zur Gattung Fantasie und Science Fiction kategorisiert,

25 Zur intellektuellen Situation und zur Medienkonkurrenz von den späten 1960er bis zu den 1970er Jahren siehe: Ryozo Maeda: Körper rebellieren, Texte träumen. Wissensdiskurse und Germanistik in Japan 1968-1980. In: Jahrbuch für Internationale Germanistik 33 (2001), H. 2, S. 63-80.

26 Im Text werden die Begriffe >Comic Strip und >Animationsfilm» vermieden und `Anime konnotieren, dass diese Gattungen in ihren Themen wie in ihrem Ausdruck kindisch und folglich keine kulturwissenschaftlich und medienästhetisch ernstzunehmenden Gegenstände seien.

27 Zur Stellung, die Manga und Anime in der heutigen Kultur Japans einnehmen, siehe z. B.: Susan J. Napier: Anime from Akira to Howl's Moving Castle. Experiencing Contemporary Japanese Animation. New York 2005 zuerst veröffentlicht als: Anime from Akira to Princess Mononoke. New York 2001); Mark W. MacWilliams (Hrsg.): Japanese Visual Culture. Explorations in the World of Manga and Anime. Armonk, NY, und London 2008 was die besondere Beliebtheit des Themas ১Utopie in diesen visuellen Massenmedien erklärt. Im Folgenden sei - aus dem Gesichtspunkt eines Nicht-Spezialisten - zunächst die Sub-Gattung >SF-Anime` von der Mitte der 1960er Jahre bis in die erste Dekade des 21. Jahrhunderts aufgegriffen und ihre Geschichte anhand einiger repräsentativen Manga- und AnimeSerien unter dem Gesichtspunkt von Technologie und Utopien erörtert.

In der Diskussion über das SF-Anime ist es ein Gemeinplatz, dass die Fernseh-Serie Tetsuwan Atom (Mighty Atom) ${ }^{28}$ des Manga-Zeichners und -Autors Osamu TEZUKA (1928-1989) der >Ursprung` dieser Gattung in Japan ist. Tatsächlich war die schwarzweiße Fernseh-Serie, die auf dem gleichbetitelten, von 1952 bis 1968 im Monatsmagazin Shōnen in Fortsetzung veröffentlichten Manga basiert, ein erste großer Hit des Anime im japanischen Fernsehen.

Die Hauptfigur ist ein Androide in Gestalt eines kleinen Jungen, der Atom heißt und mit übermenschlichen Fähigkeiten ausgestattet ist. Charakterisiert ist Atom als Roboter, der menschliche Gefühle und infolge dessen Sinn für Gerechtigkeit besitzt. Der liebliche Knaben-Roboter wird, wie sein Name andeutet, von Atomenergie betrieben, tritt Krieg und Unrecht tapfer entgegen und kämpft für Frieden. Die Geschichte spielt sich in der technologisch zivilisierten Zukunftsgesellschaft $\mathrm{ab}^{29}$, wo die Roboter zunächst als Diener oder sogar Sklaven der Menschen gebaut werden, aber nach einer langen `Roboter-Befreiungsbewegung $<$ als Gleichberechtigte mit den Menschen zusammenleben. Dargestellt sind sie sogar manchmal humanitärer als die Menschen. (Abb. 1)

Durchaus unmissverständlich ist die Botschaft, die dieses SF-Anime enthält: Die Botschaft gegen die Atomwaffen und für die friedliche Nutzung der Wissenschaft (u. a. Atomenergie). Das Original-Manga entstand nämlich gerade in der Zeit, in der sich der nukleare Rüstungswettlauf zwischen den USA und der Sowjetunion endlos eskalierte und der Albtraum eines totalen Atomkriegs Wirklichkeit hätte werden können. ${ }^{30} \mathrm{Die}$

28 Im Ausland ist die Comic- und Anime-Serie als Astro Boy bekannt. Die Anime-Serie wurde unter diesem Titel ab 1964 in den USA bei NBC ausgestrahlt.

29 In der Handlung des Manga wird der Androide Atom 2003 erschaffen. Er hat einen Zwillingsbruder namens Kobalt und eine Schwester namens Uran.

$30 \mathrm{Zu}$ erinnern sei daran, dass beim ersten H-Bomben-Test der USA im März 1954 im südpazifischen Bikini-Atoll ein japanisches Fischerboot verstrahlt wurde und ein Besatzungsmitglied ums Leben kam. 

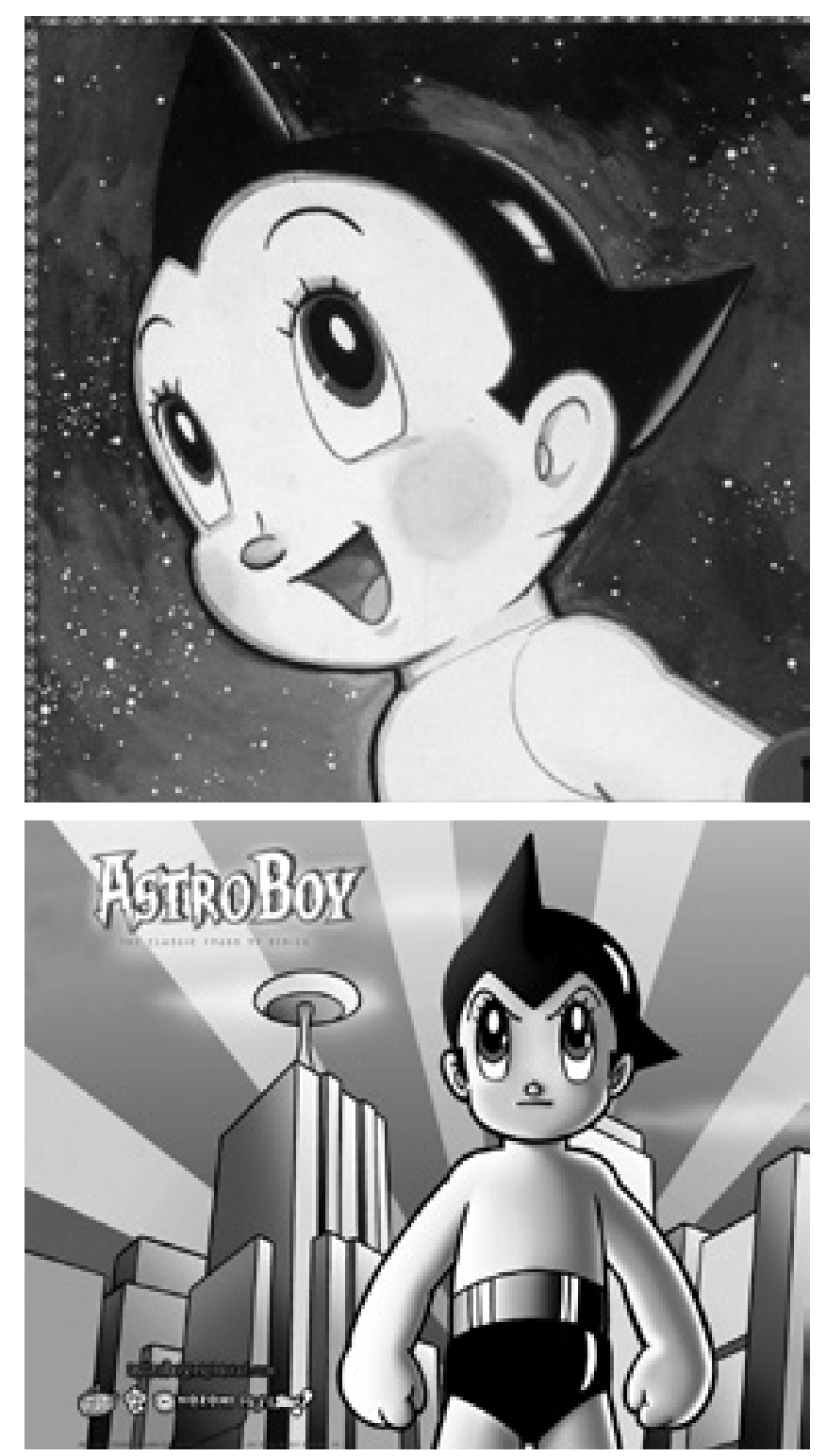

1 Tetsuwan Atom

Zukunftswelt des Tetsuwan Atom ist in diesem Sinne ein klares Gegenbild der wirklichen Welt und insofern mit einer klassischen Zeitutopie vergleichbar.
Der Zukunfts- und Technologieoptimismus, der sich in dieser RoboterUtopie manifestiert, soll allerdings nicht allein auf den Autor zurückgeführt werden, der selber in Osaka Medizin studiert und einen medizinischen Doktortitel erlangt hatte, bevor er Manga-Zeichner wurde. ${ }^{31}$ Wiederaufbau des Landes durch Naturwissenschaft und Technologie - das war die von den Nachkriegsregierungen mit Konsequenz verfolgte Richtlinie, die zu den eingangs erwähnten >quasi-utopischen` Entwicklungsprojekten der 1980er Jahre führte. Wahrgenommen wurde die von Tezuka geschilderte Zukunftsgesellschaft von vielen jungen Fernsehzuschauern nicht als bloße Fiktion, sondern als ernsthaft $\mathrm{zu}$ erstrebende Idealgesellschaft. Die Tatsache, dass nicht wenige unter den führenden Forschern und Ingenieuren im Bereich der Robotik sich als begeisterte Tezuka-Anhänger bekannten, erklärt einen Aspekt der eingangs geschilderten japanischen Vorliebe für die technische Utopie in den 1980er Jahren.

Darüber hinaus bezeugt die große Popularität, die dieses Anime unter den breiten Bevölkerungsschichten genoss, eine kollektive und ıutopisch gefärbte Neigung zum Pazifismus und zum gewissen Humanitarismus, die damals auch in den führenden Medien dominant war. Dies hängt seinerseits mit dem japanischen Selbstbild eines pazifistischen Landes zusammen, das in erster Linie auf den in der 1946 erlassenen idealistischen Verfassung deklarierten bedingungslosen Verzicht auf Kriegführungsrecht zurückzuführen ist. Die fürchterliche Ironie dieses vom großen Teil der Bevölkerung mit Begeisterung unterstützten Pazifismus liegt aber darin, dass er in der Tat nur unter dem atomaren Schutzschirm der USA möglich war. So gesehen, könnte man diesen Pazifismus im Sinne eines nationalen Leitprinzips einerseits als >utopisch $<$ - d. i. als realitätsfern - bezeichnen. Umso eifriger wurde er andererseits nicht allein von linksorientierten Intellektuellen verfolgt.

Während der Knabe Atom den Versuch von Japanern symbolisiert, das kollektive Trauma von Hiroshima und Nagasaki durch das in die Zukunft entworfene Modell einer idealen Gesellschaft zu überwinden, zeugt eine andere Figur der ebenfalls beliebten SF-Filmserie - aber kein Anime-Figur - davon, dass sich Japaner dabei über die nukleare Realität der fünfziger Jahre keine Illusion machten. Das Monster Godzilla in der gleich betitelten Kinofilmserie, das von 1954 bis heute insgesamt $28 \mathrm{Mal}$

31 Tezuka selber distanziert sich in seinen späteren Manga von dem fortschrittstheoretischen Utopismus. 
Tokyo und andere japanische Großstädte verwüstet hat, kommt nämlich als Mutant in Folge der Verstrahlung durch die amerikanischen Atomtests im Südpazifik zur Welt. Das Monster ist somit eine Allegorie für die fatale Kraft der Atombombe.

In diesem Zusammenhang sieht der Literaturwissenschaftler und Filmkritiker Inuhiko YOMOTA in Godzilla eine moderne Gestalt des traditionell-japanischen Rachegeistes (Onryō), der den Groll der im südpazifischen Raum gefallenen Japaner im Zweiten Weltkrieg symbolisiert. Diese Kriegsgefallenen, die nicht in ihrer Heimat bestattet wurden, sind aus dem kollektiven Bewusstsein der Nachkriegsjapanern verdrängt. In Gestalt Godzillas - so Yomota im Anschluss an den Ethnologen Norio AKASAKA - kommen diese Verdrängten als >Unheimliches` zurück. ${ }^{32}$

Godzilla ist jedoch kein einfacher Anti-Held, der nur zerstört und somit Unheil mit sich bringt. Im 6. Godzilla-Film im Jahre 1965 wird er zum Beschützer Japans vor der außerirdischen Invasion. Davor, im Film King Kong vs. Godzilla (1962) ist er sogar der Sieger im Zweikampf mit King Kong, dem weltbekannten Monster made in USA. Die geänderte Rolle Godzillas könnte man auch im Zusammenhang mit dem vom öffentlichen Bewusstsein verdrängten Verlangen nach der atomaren Aufrüstung Japans interpretieren. ${ }^{33}$ (Abb. 2)

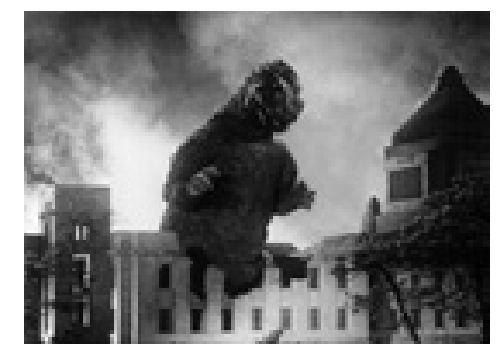

2 Godzilla zerstört das

Parlamentsgebäude in Tokyo

32 Inuhiko Yomota: Nihon Eiga to Sengo no Shinwa (Der japanische Film und der Nachkriegsmythos). Tokyo 2007, S. 87-88. Yomota weist dabei darauf hin, dass die Südsee in der mythologischen und volksreligiösen Tradition Japans immer als utopischer Raum vorgestellt wurde.

33 Napier: Anime from Akira to Howl's Moving Castle (Anm. 27) z. B. nennt die Godzilla-Serie nur als Beispiel für die vielen SF-Anime gemeinsame apokalyptische Weltanschauung und lässt den hier erörterten Aspekt völlig außer Acht.
V.

Eine entscheidende Wende im SF-Manga und -Anime sieht man in den frühen 1980er Jahren. SF-Manga und -Anime, die in ihren Anfängen im Grunde genommen stark techno-utopisch geprägt sind, neigen jetzt mehr und mehr dazu, Zukunft in einem trostlosen, manchmal sogar apokalyptischen Ton darzustellen. Ein typisches narrativ Setting ist dabei die Welt nach der totalen Verwüstung durch eine große Katastrophe, zumal durch einen neuen atomaren Weltkrieg. Die neue Generation des Manga und Anime ist dabei in der Handlung deutlich komplizierter, in der Darstellungsweise reflektierter und anspruchsvoller als in den vorangegangenen Generationen. Philosophische und metaphysische Themen sind hier auch nicht vermieden. Über Anime (und Manga) in den 1990er Jahren spricht man oft von der >Reife zumal in narrativer und thematischer Hinsicht. ${ }^{34}$

Epochemachend ist der SF-Manga Akira von Katsuhiro OTOMO (geb. 1954), der von 1982 bis 1990 in 120 Einzelkapiteln im MangaMagazin Young Magazin erschien und 1988 vom Autor selbst als AnimeKinofilm umgesetzt wurde. Akira spielt in Tokyo im Jahr $2030 .^{35} \mathrm{Die}$ Megalopolis wurde im Dritten Weltkrieg durch eine "neue Geheimwaffe» total zerstört. Jetzt ist außerhalb der Tokyo-Ruine das supermoderne >Neo-Tokyo< entstanden.

Der verwüstete und menschenleere Raum des alten Tokyo ist der Schauplatz des Kampfes zwischen verschiedenen Gruppen - darunter die japanische Armee und eine Flotte der US-Marine - um einen geheimnisvollen kleinen Jungen namens Akira, der wegen seiner übernatürlichen Fähigkeiten >das Ende der Welt « hervorrufen könnte. Im Laufe der Geschichte stellt es sich heraus, dass Akira, der seit 37 Jahren in einem unterirdischen Forschungslabor im Kälteschlaf liegt, jene sneue Waffe war, die das alte Tokyo vernichtet hat. Wegen eines Unfalls erwacht Akira aus dem künstlichen Schlaf und wie gefürchtet werden seine alles vernichtenden Psycho-Power freigelassen, so dass `Neo-Tokyo $<\mathrm{im} \mathrm{Nu} \mathrm{zu}$ Schutt und Asche wird.

34 Misao Minamida: Kindai Anime-Shi Gairon (Grundrisse der modernen Anime-Geschichte). In: O. H.: Nijusseiki Anime-Taizen (Anime im 20. Jahrhundert. Eine Gesamtdarstellung). Tokyo 2000, S. 7.

35 In der Anime-Version ist die Zeit der Handlung auf das Jahr 2019 verschoben. 


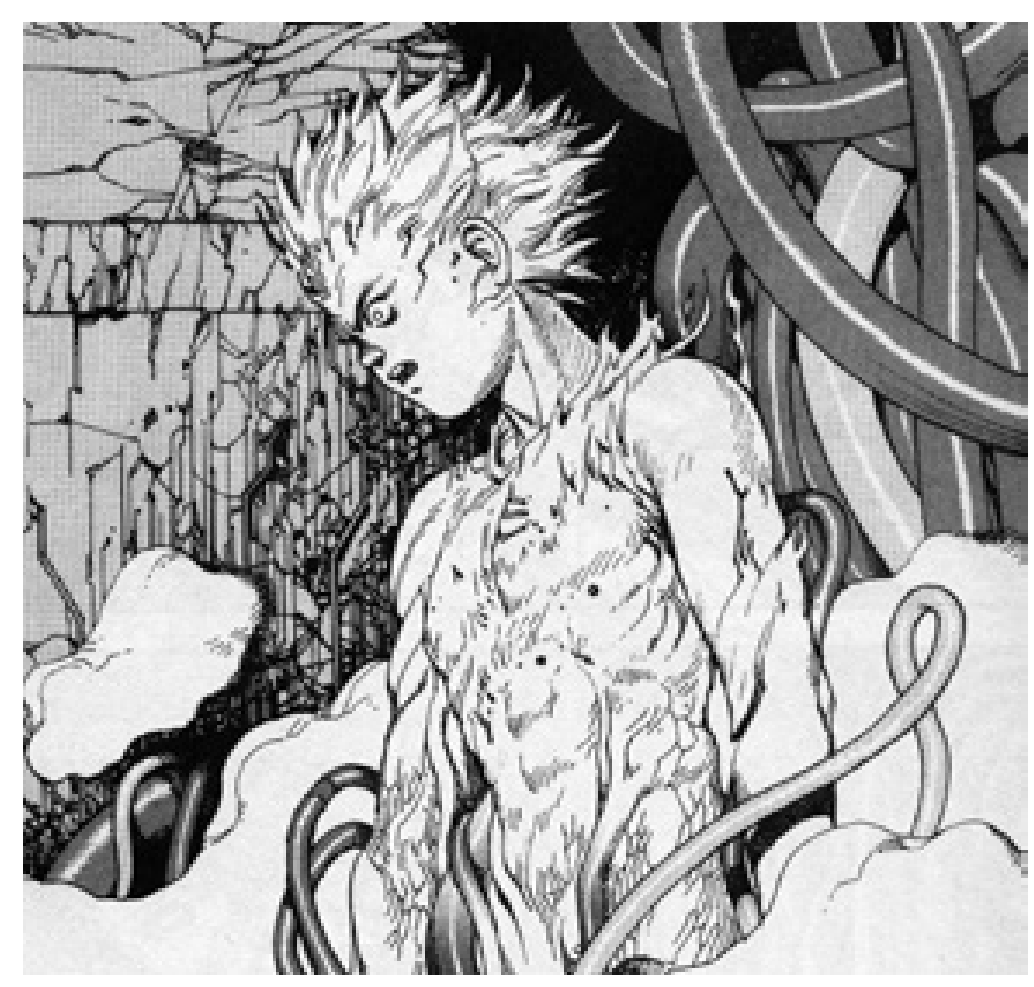

3 Akira: Mutation von Tetsuo

Akira ist jedoch nicht die Hauptfigur dieses apokalyptischen Mangas. Es ist Tetsuo, ein jugendlicher Motorradfreak, der am Anfang der Geschichte als unselbstständiger, unfähiger Charakter dargestellt wird. Durch die Begegnung mit übernatürlich Befähigten, vor allem mit Akira, erwachen auch in ihm übernatürliche Fähigkeiten. Im Kampf gegen die japanische Armee und die US-Marine verwandelt er sich von einem schwachen und sozial isolierten Jugendlichen zu einem grotesken Monster. Akira ist gewissermaßen die Geschichte der haarsträubenden Metamorphose von Tetsuo und lässt sich in diesem Sinne zur Gattung der Mutant Story zählen. (Abb. 3)

Die düstere Zukunftsvision in Akira ist, wenngleich am Ende der Geschichte die Hoffnung auf einen Neubeginn angedeutet wird, nichts Anderes als die Umkehrung der Utopie in Tetsuwan Atom. Sowohl Akira als auch Tetsuo sind in mancher Hinsicht negative Pendants jenes lieblich-humanen Knaben-Roboters, sie sind sogar - wie ihre Namen andeuten - negative
Doppelgänger von diesem. ${ }^{36}$ Zwar sind beide keine Androiden, jedoch zeigt Akira im Gegensatz zu diesem kein menschliches Gefühl. Dargestellt wird er immer mit einem ausdruckslosen Gesicht. Er ist auch nicht in der Lage, seine übernatürlichen Fähigkeiten einem guten $Z$ weck nützlich zu machen. Seine zerstörerischen Psycho-Energien wirken, einmal freigelassen, blind und wahllos. Sie sind also jenseits der menschlichen Kontrolle. Der andere, Tetsuo, verwandelt sich auch zu einem übermenschlichen und unheilbringenden Monster. Getrieben durch gegenstandslose Wut und unkontrollierbaren Ehrgeiz explodiert seine Aggressivität in Form einer Psycho-Waffe.

Als dystopisch lässt sich Akira darüber hinaus in seiner narrativen Struktur bezeichnen. Wie erörtert, nimmt der kleine Junge, der dem Manga den Titel verleiht, im Narrativ keine zentrale Stellung ein. Durch die derart marginalisierte Figur des Akira distanziert sich der Autor Otomo dezidiert von der durch Tezuka standardisierten narrativen Form der SFManga, in dessen Zentrum immer ein Superheld steht. Dadurch wird hier auch die Atomenergie - ein Thema, das so lange für Japaner von zentraler Bedeutung war - gegenüber der Psycho-Energie narrativ relativiert und dezentralisiert. Dies ist der >dystopischer Effekt des Manga Akira.

Anti-utopisch wirkt auch seine für ein Manga ungewöhnlich hohe Visualität, die erst durch die überwältigende Virtuosität des Zeichners Otomo ermöglicht wird. Die bis auf das Äußerste getriebene Detaildarstellung der Katastrophe fasziniert nicht nur seine Anhänger. Eine Reihe minutiös gezeichneter `Standbilder der umstürzenden Hochhäuser `verewigt` den Moment des Zusammenbruchs und verwandelt das Schreckensbild - wie Gefängnismalerei von Giovanni Battista Piranesi - in den Gegenstand eines ästhetischen Genusses besonderer Art. (Abb. 4)

Die chaotische Welt nach dem Zerfall der Ordnungen in Akira entstand in den 1980er Jahren, also gerade zu der Zeit, als Japaner mit dem illusorischen Selbstbild eines perfekt verwalteten techno-utopischen Land herumspielten. Tetsuo, den zunächst das wissenschaftliche Establishment zum >Versuchstier seiner Experiment zu machen versucht, erweist sich durch sein übermenschliches Power als unkontrollierbarer Ungeheuer und bringt somit den in Japan breit geteilten Glauben der perfekten Verwaltung als trügerischen Mythos zutage. Die dystopische Welt in Akira ist insofern genau das negative Spiegelbild des von Kunio Iwaya satirisch geschilderten Japan der Zeit der Bubble-Wirtschaft.

36 Tetsuo (Tetsu=Eisen, $O=$ Mann) erinnert an Tetsuwan (Tetsu=Eisen/ eiserne, Wan=Arme), Akira und Atom alliterieren. 


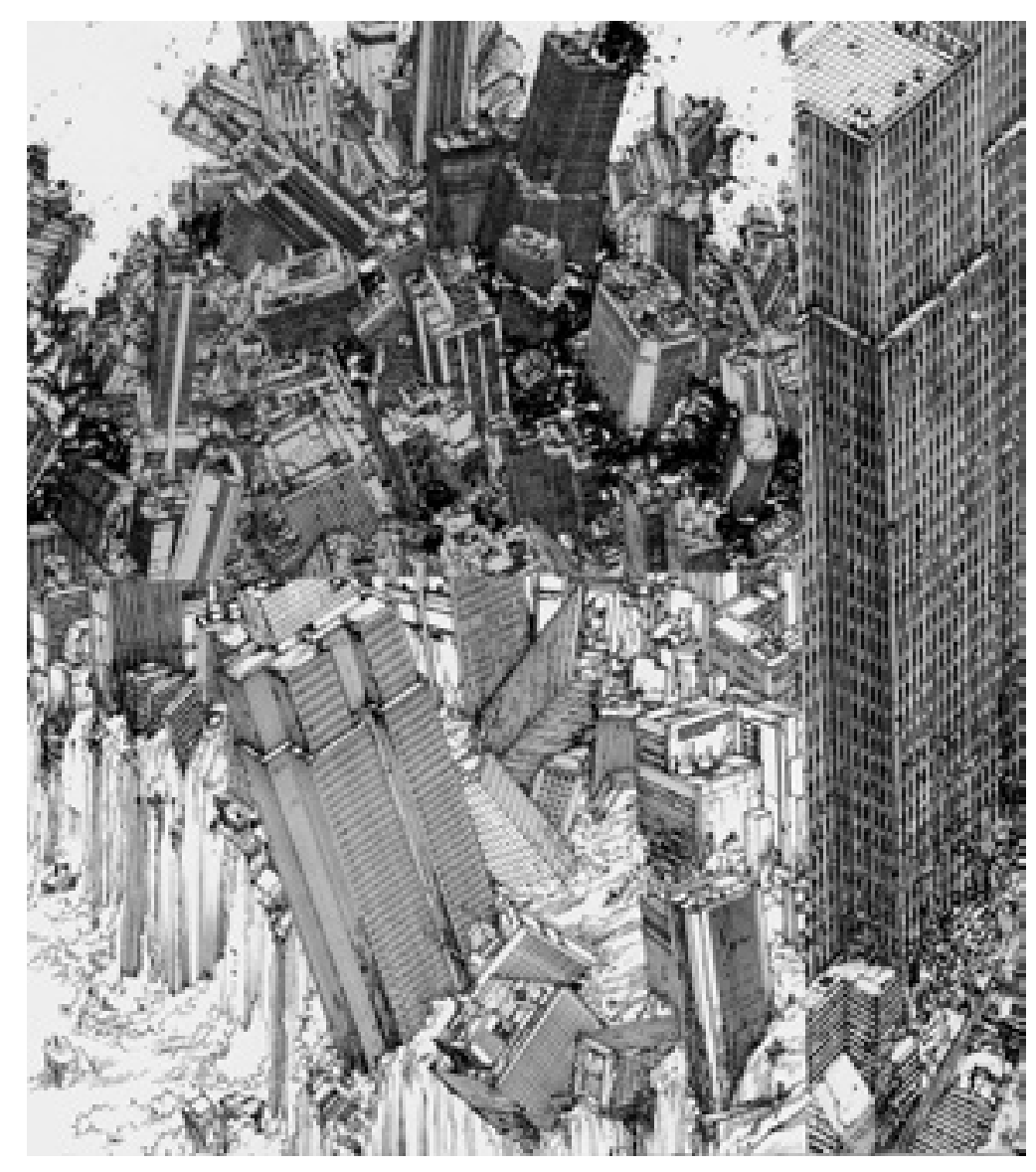

4 Akira: Verwüstung des Neo-Tokyo

VI.

Düstere, dystopische Zukunftsvision des SF-Anime wird in den 1990er Jahren noch intensiviert, differenziert und variiert. Als Beispiel zu nennen ist die Anime-Fernsehserie Shin Seiki Evangelion (Neon Genesis Evangelion) von Hideaki ANNO (geb. 1960), die zunächst in Japan 1995 bis 1996 in 26 Folgen ausgestrahlt wurde und später auch im Ausland über den engen Kreis der Anime-Fans hinaus einen großen Erfolg erlangte.

Dieses Anime spielt im Jahr 2015: Wegen einer Katastrophe, die sich im Jahr 2000 ereignet hat und Second Impact genannt wird, ist die Zahl der Gesamtbevölkerung der Erde auf die Hälfte zurückgegangen. Die Überlebenden sind jetzt den Angriffen der $>$ Shito (Apostel), Kreaturen unbekannter Herkunft, ausgesetzt. ${ }^{37}$ Diesen Monstern setzt die Geheimorganisation NERV der UNO gigantische Kampfmaschinen mit Namen 'Evangelion` entgegen, ${ }^{38}$ die von ausgewählten Jungen und Mädchen im Alter von 14 Jahren gesteuert werden. ${ }^{39}$

Was man hier sieht, unterscheidet sich grundsätzlich von einer konventionellen SF-Geschichte. Im Vordergrund der Handlung steht zwar der tapfere Kampf von 'Evangelions` gegen 'Apostel, der aber - anderes als uns bekannte Kampfszenen in den meisten SF-Anime - nicht selten grauenvoll und tragisch wirkt. Die `Evangelion-Piloten selber besitzen dabei keine übernatürlichen Fähigkeiten. Im Kontrast zur ihnen auferlegten großen Mission ist die Welt, in der sie leben, verblüffend trivial und gleichzeitig trüb. Und im Laufe der Handlung stellt es sich heraus, dass nicht wenige Protagonisten mit ernsten und sehr komplizierten Problemen psychisch schwer belastet sind wie zerfallener Familienbeziehung oder Angst vor dem Erwachsenwerden.

Typisch ist hierfür der 14-jährige Schüler Shinji, der im Zentrum der Handlung steht. Sein Vater Gendo IKARI, ein kalter und rigoroser Wissenschaftler, leitet das Forschungslabor, in dem `Evangelion` auf Grundlage der Arbeit von Yui, seiner Ehefrau und Mutter von Shinji, entwickelt wurde. Nach dem Tod seiner Mutter lebt der introvertierte Shinji vom Vater getrennt. Der Vater, der jetzt NERV leitet, wünscht, dass sein Sohn die Steuerung von `Evangelion « übernimmt. Als `Evangelion`-Pilot kann Shinji jedoch vom selbstquälerischen Gedanken nie loskommen, er sei Versager. Er verabscheut durch und durch seine eigene gigantische Gestalt. Er kann also nicht erwachsen werden, weil er nicht imstande

37 In der deutschen oder englischen Version werden die Kreaturen nicht >Apostel genannt, sondern >Engel bzw. angel.

38 NERV (der Name wird wie dessen Vorläufer-Organisation GEHIRN aus dem Deutschen genommen) befindet sich in $>$ Neo-Tokyo $2 \ll$ : offensichtlich eine Anspielung auf Akira.

39 Wie der Titel andeutet, findet sich hier eine ganze Reihe von religiösen Anspielungen auf das Judentum und das Christentum, was für das japanische Anime-Publikum in erster Linie exotisch gewirkt haben muss. Aber gleichzeitig ist in diesem Anime das Mitwirken von Elementen aus alten babylonischen Religionen, dem Buddhismus und der japanischen Mythologie feststellbar. Dies deutet darauf hin, dass Neon Genesis Evangelion trotz des Titels keine religiös einheitliche Interpretation zulässt. 
ist, seine Mission zu absolvieren und somit seine unsichere Pubertät zu überwinden..$^{40}$

Im weiteren Ablauf der Handlung rückt der Kampf mit den »Aposteln « mehr und mehr in den Hintergrund. Dagegen wird auf philosophische, psychologische oder weltanschauliche Themen wie Beziehung zwischen Menschen und Technologie, Verhältnis von Selbst und Anderem oder Suche nach Identität thematisches Gewicht gelegt. In den letzten beiden Folgen (Folge 25 und 26) der Sendung wird sogar ausschließlich die Innenwelt von Shinji aus psychologischer Perspektive behandelt. Und dabei wird das Anime aus lauter inneren Dialogen von Shinji mit sich selbst und mit anderen Charakteren konstituiert. Es wird bloßgelegt, dass nicht er allein, sondern auch seine jugendlichen Kameraden und Kollegen in NERV unter einem schweren Trauma leiden. (Abb. 5)

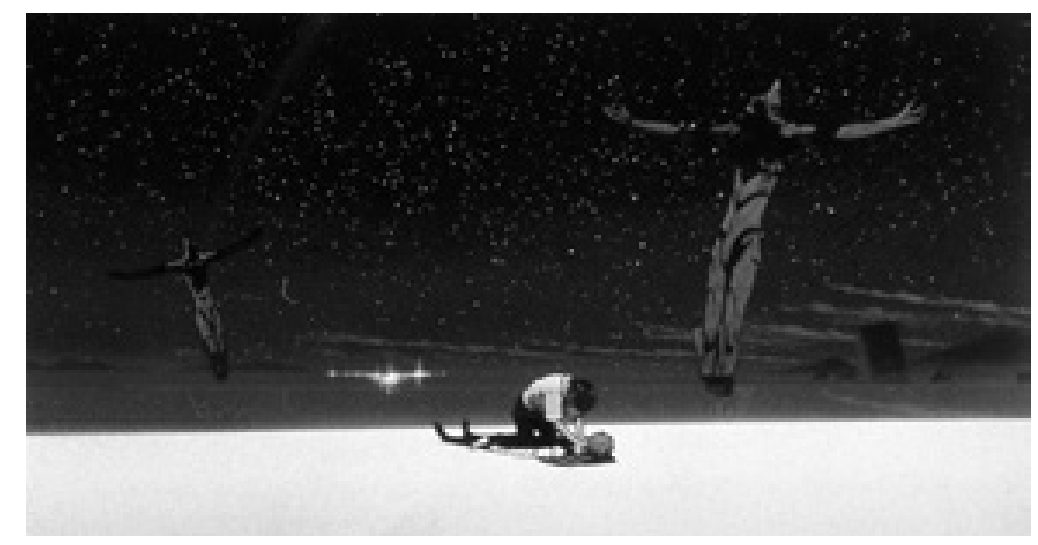

5 Shin Seiki Evangelion: Innere Welt Shinjis

Die Geschichte wird auf diese für ein SF-Anime durchaus ungewöhnliche Weise abgeschlossen, ohne zu zeigen, ob die Welt nach dem Ende des Kampfes gegen die "Apostel " utopisch oder dystopisch aussehen wird. Diese urplötzliche Beendigung mit einer Wende zum rein Psychischen wurde von einigen einflussreichen Anime-Kritikern vorwiegend

40 Nicht wenige Kritiker wollen den Ödipus-Komplex als eines der Hauptmotive in Neon Genesis Evangelion ansehen. Vgl. Napier: Anime from Akira to Howl's Moving Castle (wie Anm. 27), S. 98-100. negativ beurteilt. ${ }^{41}$ Es ist allerdings in der Evangelion-Diskussion noch dahingestellt, ob es sich mit dieser Wende um eine bloße Regression in die illusorische Vorstellung des im Selbstbewusstsein gefangenen Shinji handelt oder um die innere Welt im Sinne einer neuen Utopie/Dystopie. Eines ist indes klar: Mit Neon Genesis Evangelion ist ein neuer Typ des SFAnime entstanden, das nicht mehr einfach von einer Utopie bzw. Dystopie in zeitlicher Entfernung erzählt, sondern gleichzeitig über das Erzählte reflektiert. Die Meta-Story dieses Anime ist nämlich nichts Anderes als die Desillusion des SF-Anime über sich selbst.

Reflektiert und stark dystopisch gefärbt ist auch die Zukunftsvision des Manga Kōkaku Kidōtai (Ghost in the Shell) von Shirow MASAMUNE (geb. 1961). Das 1989 veröffentlichte Manga wurde mehrfach in Anime umgesetzt, wobei die Anime-Umsetzung von Mamoru OSHII (geb. 1951) aus dem Jahr 1995 genauso wie das im selben Jahr hergestellte Evangelion eine internationale Reputation erlangt.

Mehrere Atomkriege, die die alte Welt völlig zerstört haben, sind auch in Ghost in the Shell die Voraussetzung für das narrative Setting. Aber merkwürdigerweise wird hier den nuklearen Katastrophen überhaupt keine weitere Bedeutung gegeben. Ghost in the Shell spielt im Japan des Jahres 2030, wo eine fortgeschrittene Informationsgesellschaft Wirklichkeit geworden ist. Viele Menschen sind Cyborgs mit einem teilweise oder ganz durch künstliche Implantate ersetzten Körper (»Gitai« = nachgemachter Körper). Sogar das Gehirn ist bis auf einige wenige Zellen durch ein Cyberbrain (»Dennō im Computernetzwerk, an Hub-Computer, angeschlossen ist. Es sind menschliche Gehirnzellen, die verpackt in einer Biokapsel (Shell) in jedem Cyborg stecken, die durch das dort eingespeicherte persönliche Gedächtnis Identität und Persönlichkeit eines Menschen/Cyborg sichern, also der Geist (Ghost)

Die Manga- und Anime-Serie handelt von Aktionen der Spezialeinheit für Sicherheit Kōan 9-ka (Sektion 9), die in dieser Zukunftsgesellschaft mit der Aufklärung verschiedener Fälle von Kriminalität, Spionage, vor allem von Cyberterrorismus betraut wird. Eine der zentralen Figuren ist Major Motoko Kusanagi, eine hochmoderne Cyborg-Frau mit übermenschlichen Kräften, die die Einsätze der Sektion 9 leitet. Wenngleich sie kein sechter Mensch ist, möchte sie glauben, einer zu sein. Denn in

41 Kritisiert wurde der Schluss als Psychotherapie bzw. Gehirnwäsche, und zwar im Zusammenhang mit der neureligiösen Aum-Sekte, die am 20. März 1995 einige U-bahn-Stationen in Tokyo mit Giftgas angegriff. 

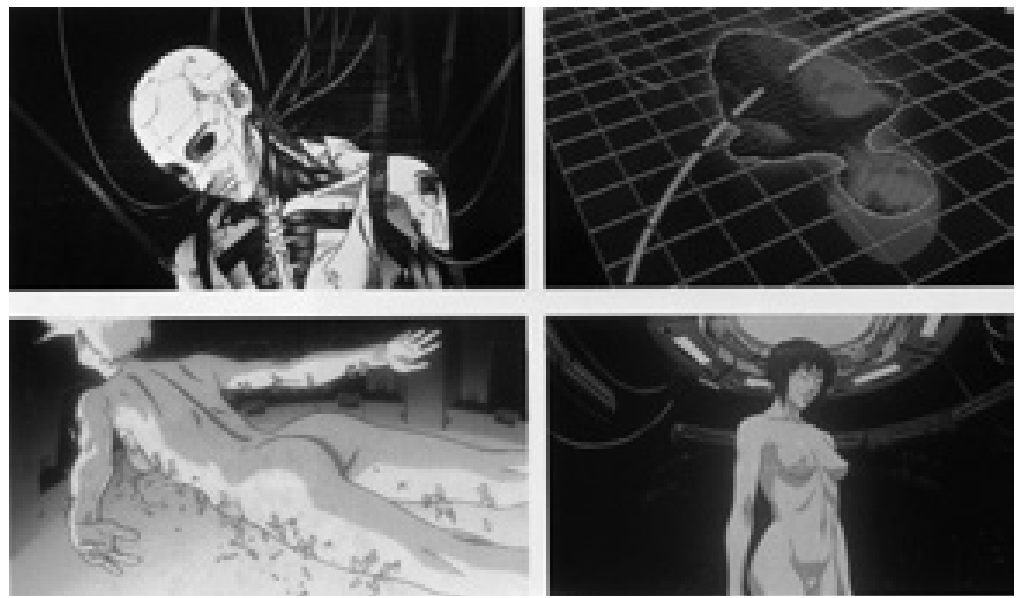

6 Ghost in the Shell: Cyborg Motoko

ihrem einzig verbliebenen und unersetzbaren Originalteil, ihrem Ghost, hat sie das Gedächtnis bzw. Gefühl, eine Menschenfrau zu sein. (Abb. 6)

Vertieft wird im Kino-Anime von Oshii jene Frage, die im Film Blade Runner von Ridley Scott (1982) thematisiert wird, von der Perspektive von Motoko, nämlich in Form ihrer inneren Reflexion. Es ist die Frage: Was ist das Leben des $>$ Menschen $<$ in einer Welt, in der der Unterschied zwischen Menschen und Cyborg, zwischen der wirklichen Welt und der virtuellen Realität bzw. der simulierten Welt im Cyberspace keine entscheidende Bedeutung mehr hat. Sie findet im Anime keine Antwort. Motoko bleibt mit der Frage in ihrem endlosen Zweifel eingesperrt.

In einer ebenfalls auf dem Manga von Shirow Masamune basierten Anime-Fernsehserie Ghost in the Shell: Stand Alone Complex (S.A.C.), die von Kenji KAMIYAMA (geb. 1966) gedreht und von 2002 bis 2003 ausgestrahlt wird ${ }^{42}$, wird die Cybergesellschaft der Zukunft ebenfalls dystopisch geschildert. Dystopisch aber vor allem deswegen, weil hier keine direkte zwischenmenschliche Kommunikation mehr zustande kommt, sondern die ridealer, d.i. augenblickliche und hundertprozentige Verständigung zwischen Menschen durch ihre an Hub-Computer angeschlossenen Cyberbrain - paradoxerweise - erreicht wird. In dieser Cyberspace-Dystopie gibt es prinzipiell keinen Unterschied zwischen der

42 Kamiyama ist Schüler von Oshii und beteiligte sich auch an der Herstellung der Oshii-Version des Ghost in the Shell. öffentlichen und der privaten, kollektiven und individuellen Meinung. Was hier entsteht, das ist eine neue Form des Totalitarismus par excellence. Wenn man will, kann man sich jederzeit vom Cyberspace abkoppeln, aber muss damit rechnen, aus der Gesellschaft völlig isoliert zu werden.

Das Anime in der Kamiyama-Version greift gerade diese Aporie auf. In der Anime-Serie handelt es sich vornehmlich um solche Kriminalfälle, in deren Zentrum jeweils einer steht, der dem Cyberspace das wesentliche Teil seiner Persönlichkeit (Ghost) nicht gerne anvertrauen und dennoch sozial wirken will. Eine komplexe - und nicht im herkömmlichen Sinne kollektive - Subjektivität einer Gruppe von Menschen, die nicht völlig vom Cyberspace abhängig sind, wird hier als Stand Alone Complex bezeichnet. Die Frage, ob es sich mit dem S. A. C. um einen Hoffnungsträger handelt oder ein Phantom der romantisch Eingebildeten, wird am Ende der Anime noch offen lassen. ${ }^{43}$

In den zuletzt angeführten Beispielen verschwindet das große Motiv der $>$ Befreiung, das sich im ebenfalls dystopisch oder apokalyptisch gefärbten Akira in Gestalt von Tetsuo noch entfalten konnte. In der hier dominanten, allzu drückenden Stimmung, in einer Techno-Dystopie eingesperrt zu sein, könnte man vielleicht eine Widerspiegelung der desillusionierten japanischen Gesellschaft seit der 1990er Jahre sehen, die sich in einer Dauerrezession befindet und deren Krisen in Augen vieler als nicht mehr kontrollierbar erscheinen.

Wie das hier Skizzierte zeigt, ist in der Entwicklung des SF-Anime in Japan eine Geschichte feststellen, die mit der der europäischen UtopieLiteratur seit Thomas Morus wohl vergleichbar wäre. Hier wie dort gehen Utopien zunächst in Dystopien über, die dann zur Reflexion über sich selbst (Meta-Utopien/-Dystopien) führen.

\section{VII.}

In der modernen japanischen Literatur- und Intellektuellengeschichte kommt das utopische Denken - wie oben erörtert - besonders mit der Natur in Verbindung. In diesem Zusammenhang wird jetzt Hayao MIYAZAKI (geb. 1941) aufgegriffen, der wie kein Zweiter in seinen Anime

43 Dominick Chen: This is not a Reality. Kojin-Fukugōtai to iu Daitaigenjitugun (This is not a Reality. Alternative Realities called S. A. C.). In: Eureka 37 (2006), H. 11, Sonderheft für Kōkaku Kidōtai: Stand Alone Complex, S. $75-80$, hier S. 76 
die Beziehung zwischen Natur und Menschen mit beachtenswerter Konsequenz thematisiert.

Miyazaki ist wohl der bekannteste japanische Anime-Regisseur im Ausland. Die Popularität seiner Anime unter den breiten Schichten der Bevölkerung ist nur vergleichbar mit der, die die Anime von Osamu Tezuka in den 1960er und den frühen 1970er Jahren genossen. Wie Susan Napier betont, impliziert seine Vision fast immer eine stark ethische (oder moralische) Botschaft an ein breites Kino-Publikum, was mit seiner eigenartigen Neigung zum Didaktischen zusammen ihn von den meisten Anime-Autoren unterscheidet. ${ }^{44}$ Dies erklärt auch, warum in der wissenschaftlichen oder politischen Diskussion über Umweltschutz oder Energiepolitik oft auf seine Anime Rekurs genommen wird. Und dabei interpretiert man sie vornehmlich aus der Perspektive der neuen Natur- bzw. Öko-Utopie. Es ist gerade in diesem Zusammenhang, dass Miyazaki mit dem oben erwähnten Kenji Miyazawa, jenem Pionier der fantastischen Utopie-Literatur, verglichen wird.

Genau betrachtet, stellt es sich heraus, dass die Einstellung von Miyazaki zur Utopie viel komplizierter ist, als man sich gern vorstellt. Zumal ist seine Position zu herkömmlichen Utopie-Modellen, soweit sie in seinen Anime-Filmen zum Ausdruck kommt, eindeutig kritisch-negativ geprägt. Techno-Utopien bzw. -Dystopien werden als Thema folgerichtig vermieden. Megalopoleis, Cyborgs und Cyberspace der Zukunft kommen in seiner Vision kaum vor. Im Unterschied zum SF-Anime wird Technologie in einen umfassenderen thematischen oder narrativen Rahmen hineingelegt. ${ }^{45}$

Von Natur-Utopien, wie sie den modernen sozialutopischen Bewegungen zugrunde liegen, aber auch von traditionellen literarischen Natur-Utopien wie Arkadien oder Tōgenkyō will sich Miyazaki genauso dezidiert distanzieren. Diese konfrontiert er nämlich mit seinen Ansichten zur Natur, die er primär als >dunkles` und komplexes ökologisches System auffasst. Dunkel deswegen, weil das Gesamtbild des Öko-Systems 'Natur ihm zufolge für die Menschen letztendlich unüberschaubar und unaufklärbar bleibt.

44 Napier: Anime from Akira to Howl's Moving Castle (wie Anm. 27), S. 153 .

45 Dagegen machte Miyazaki keinen Hehl aus seiner besonderen Zuneigung zu den aus heutiger Sicht veralteten Technologien (Kinematografie, Deppeldecker usw.), wie im Anime Kurenai no Buta (Porco Rosso) aus dem Jahre 1992 zum Ausdruck kommt.
In einem Interview versucht Miyazaki, diese `Dunkelheit $<$ im Kontrast zur Naturlandschaft im südeuropäischen Mittelmeerraum zu erklären: Die "schöne und harmonische « Natur in diesen Gebieten sei nichts Anderes als die Folge ihrer vollständigen Zivilisierung, d.i. einer jahrhundertelang systematisch durchgeführten Zerstörung des Öko-Systems. Sie sei daher gründlich aufgeklärt und »transparent«. Dagegen sei die Natur in Mitteleuropa - so Miyazaki - für die Menschen immer noch »dunkel« und geheimnisvoll, denn hier bleibe das unzerstörte Öko-System, wenn auch nur teilweise, noch übrig. ${ }^{46}$

Noch »dunkler« sind für Miyazaki die immergrünen Urwälder, die einmal die Hauptinsel Japans bedeckt haben. Inspiriert vom japanischen Botaniker Sasuke NAKAO (1916-1993) sieht er in dieser Urlandschaft vor der Einführung des Reisbaus ein Modell des komplexen Öko-Systems 'Natur`. Diese Urwälder sind aus Japan fast völlig verschwunden, sodass seine Ansichten zur Natur unvermeidlich von einer elegischen Klage über das Verlorene begleitet werden. ${ }^{47}$

Aus dieser Perspektive gesehen, ist Arkadien, das erst vor dem Hintergrund einer solchen `Zivilisierung ‘ der Natur im antiken Mittelmeerraum als utopischer Topos zustande kommt, primär als erweiterter $\pi o ́ \lambda \iota \varsigma \mathrm{zu}$ verstehen. Auch der traditionelle utopische Topos in Japan, Tōgenkyō, hat nichts mit dem >dunklen` Öko-System zu tun. Vorausgesetzt ist jedoch auch hier, obgleich die Grenze zwischen Natur und Zivilisation in der ostasiatischen Tradition viel unbestimmter ist als in Europa, die >vermenschlichte< Natur für das angeblich von der Zivilisation entfernte Traumland. Ein erträumtes harmonisches Zusammenleben von Mensch und Natur wird Miyazaki zufolge nur um den Preis der Zerstörung des ökologischen Systems möglich.

Von hier aus lässt sich die durchaus kritische Distanzierung Miyazakis von den modernen utopischen Ideen in Japan - implizit einschließlich derjenigen des Kenji Miyazawa - auch erklären. Sind sie doch dazu

46 Interview: Miyazaki Hayao Now and Then. In: Eureka 29 (1997), H. 11, Sonderheft für Hayao Miyazaki (1997), S. 28-47, hier S. 44 f. Miyazaki äußert sich dabei nicht im Besonderen darüber, dass auch die mitteleuropäischen Wälder seit der frühen Neuzeit größtenteils von den Menschen aufgeforstet und verwaltet wurden.

47 Napier zufolge ist »das Elegische« neben »dem Apokalyptischen« und »dem Karnevalesquen" eines der drei Hauptcharakteristika, die das Spezifikum des japanischen Anime ausmachen. Napier: Anime from Akira to Howl's Moving Castle (wie Anm. 27), S. 13 f. 
geneigt, in einer Agrargesellschaft die gesellschaftlich ideale Form zu suchen. Für Miyazaki bedeutet hingegen die Einführung des Reisbaus in Yayoi-Zeit (von ca. 500 bzw. $300 \mathrm{v}$. Chr. bis zum 3. Jahrhundert nach Chr.) nichts Anderes als den Ursprung der systematischen Zerstörung des Öko-Systems. ${ }^{48}$ Somit kann seine Utopie-Kritik auch den Kernpunkt der Japan-Ideologie treffen, die die Verbindung von der Reisbau-Kultur und dem harmonischen Zusammenleben mit der Natur als selbstverständlich betrachtet.

In der Vision Miyazakis leben die Menschen zwar nicht mehr in harmonischer Einheit mit der Natur. Ihre Beziehung zu Natur wird jedoch nicht immer als Konflikt oder Gegensatz aufgefasst. Vielmehr geht es ihm um die Nebeneinander der zwei verschiedenen Systeme, Natur und Zivilisation, wobei die Menschen eigentlich zu den beiden Systemen zugehörig sind. Die Natur ist, um mit systemtheoretischer Terminologie zu reden, für die Zivilisation die Umwelt, und vice versa.

Nur vor diesem Hintergrund kommt die Konfrontation zwischen traditioneller Kultur auf der einen Seite und technisierter Moderne und Naturzerstörung auf der anderen Seite vor - eine thematische Konstante in Miyazakis Anime. Oft trägt sich die Konfrontation in einer Grenzsituation zu, so dass sie eine zugespitzte Form nimmt.

So handelt es sich in Kaze no Tani no Nausica (Nausicä̈ aus dem Tal der Winde) aus dem Jahr 1984, einem Kino-Anime mit großem Erfolg, um eine >post-apokalyptische Zukunft. Ein narratives Setting, das es unter den zeitgenössischen Anime vor allem mit Akira teilt. Anders als dies ist es aber eine Geschichte der Menschen, die tausend Jahre nach einer großen Katastrophe in der völlig verwandelten Umwelt überleben müssen. Die Erde ist zum größten Teil vom `Fukair (Meer der Fäulnis), einem riesigen, giftigen Pilzwald, bedeckt. Der sich ständig ausdehnende Wald bedroht die letzten Landstriche, die von den wenigen noch lebenden Menschen bewohnt sind, zu überwuchern. Die Zivilisation ist auf den spätmittelalterlichen bzw. frühneuzeitlichen Stand zurückgegangen.

In dieser Grenzsituation kämpfen einerseits die Menschen gegeneinander um die verbleibenden Lebensräume, andererseits versuchen sie vergebens, die Ausdehnung des Pilzwaldes mit Hilfe der Technologie aufzuhalten. Nausicaä, die Prinzessin des "Tals der Winde«, entdeckt, dass die Pflanzen des Meeres der Fäulnis in der Lage sind, den durch die Menschen verseuchten Boden zu reinigen und an diesen Stellen

48 Interview (wie Anm. 46), S. 43. ungiftige Natur hervorzubringen. Es wird aber Tausende Jahre dauern, bis die Gesundheit der Natur wiederhergestellt werden kann. Da diese 'wahre B Botschaft der Natur den Menschen bis auf Nausicaä unverständlich bleibt, könnte sie die einzige Vermittlerin zwischen diesen und der sunheimlich gewordenen Natur sein. Aber sie wird mit ihrem Volk in den Krieg zwischen zwei mächtigen Königreichen, >Tolmecia und `Pejite verwickelt. (Abb. 7)
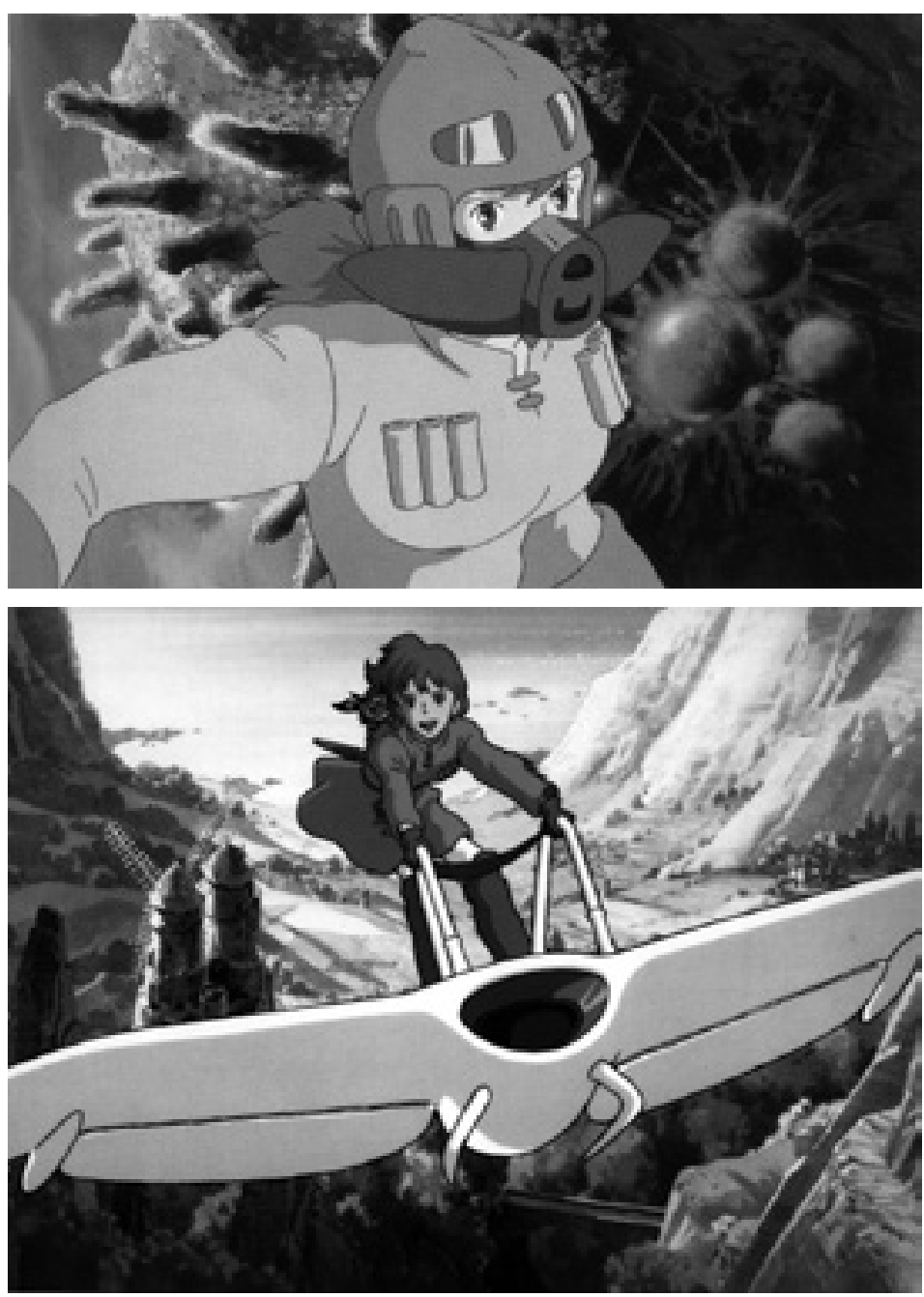

7 Nausica 


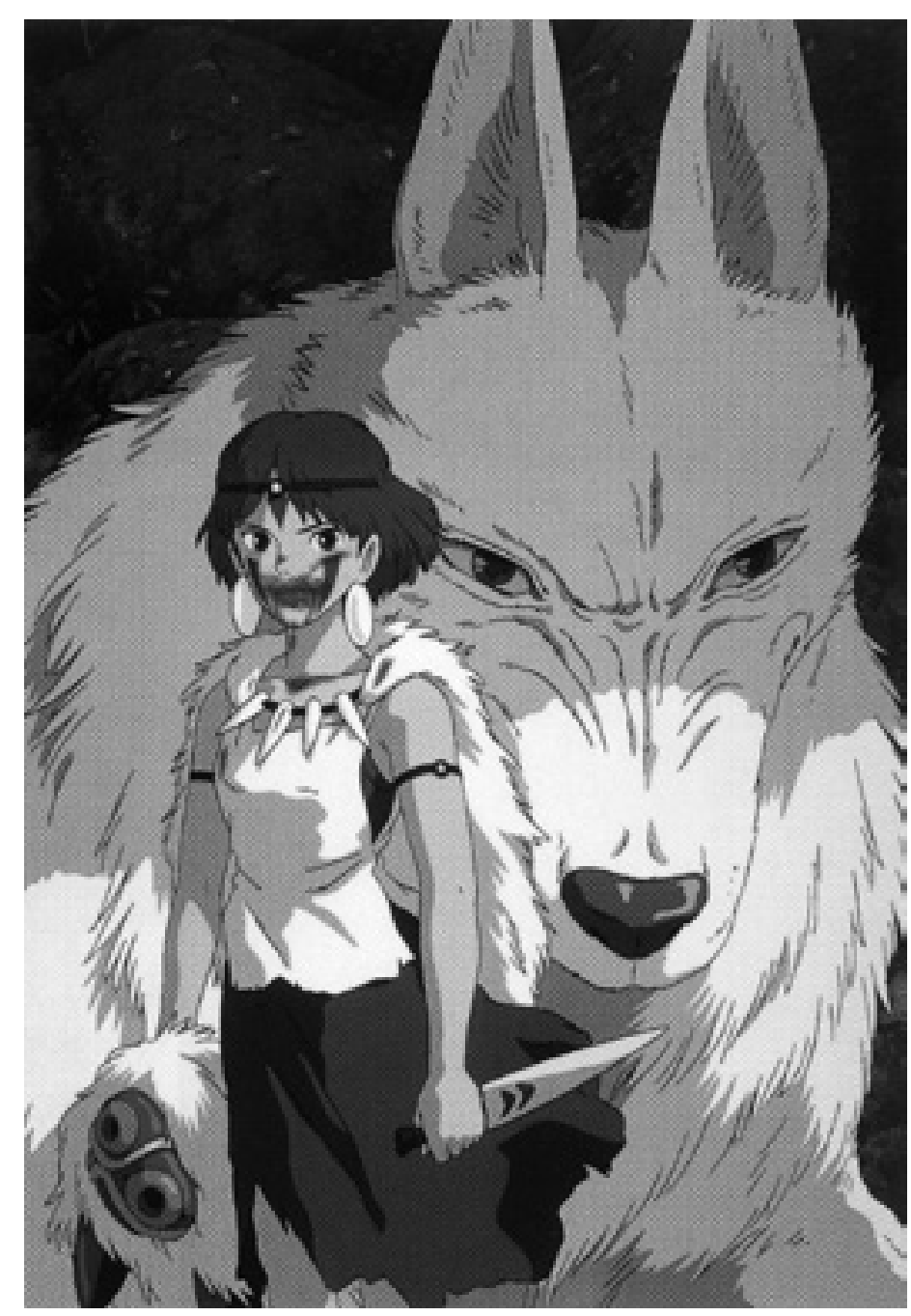

8 San (Mononoke Hime)

Die Konfrontation zweier Systeme wird im Anime Mononoke Hime (Prinzessin Mononoke) aus dem Jahr 1997 noch differenziert. Der narrative Rahmen wird nicht in der post-apokalyptischen Zukunft, sondern im japanischen Mittelalter gelegt. Die in der Figur des hirschgestaltigen Waldgottes allegorisierte Natur ist für die Menschen wiederum doppeldeutig: Sie heilt den Verwundeten mit ihren Kräften, revanchiert gleichzeitig an den Menschen, die sie mit Technik beherrschen wollen, für die
Zerstörung (allegorisiert in der Herrin Eboshi der Eisen herstellenden Tatara-Sippe). Die dämonischen Kräfte der Natur richten sich sogar an sich selbst. Sie verwüsten nämlich den unberührten Urwald. Die Natur - verkörpert auch im mit Wölfen lebenden Mädchen San (Mononoke Hime) - bleibt für die Menschen >dunkek. (Abb. 8 u. 9)

Im Unterschied zum Nausicä̈ scheint in diesem Anime die Reflexion der Zivilisation über sich selbst in den thematischen Vordergrund gerückt. Die Begegnung mit dem dunklen und komplexen System `Natur ist der Anlass zur Selbstreflexion, dessen Prozess vornehmlich durch das innere Schwanken des Jungen Ashitaka gegenüber dem Mädchen San geschildert wird. Die vertiefte Reflexion führt indes zur bitteren Erkenntnis, dass die Zivilisation für die Menschen etwas Schicksalhaftes und daher durch ihren guten Willen nicht einfach Kontrollierbares ist. Wenngleich am Ende der Handlung die Hoffnung auf eine Versöhnung zwischen Natur und Menschen angedeutet wird, wird jedes Happy-End suspendiert. Der Grundton bleibt düster.

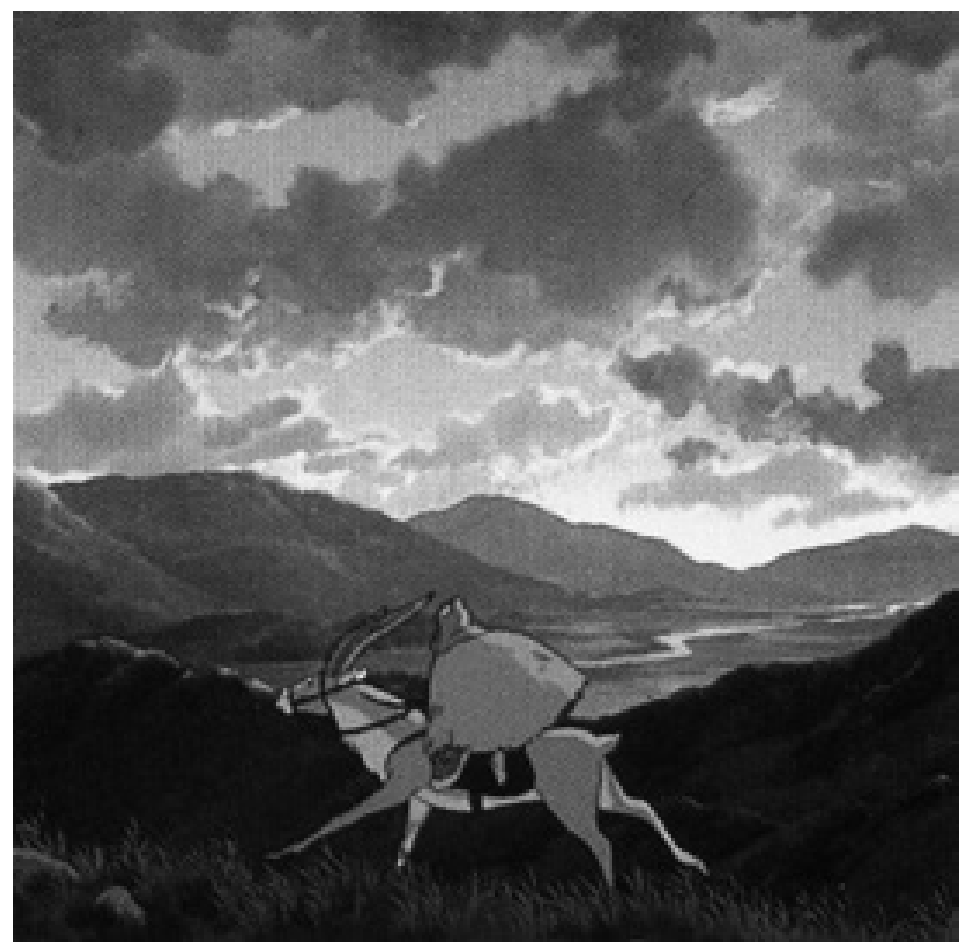

9 Mononoke Hime: Urwald in Japan 
Der düstere Ton ruft den Eindruck hervor, als wären die Menschen Miyazaki zufolge ewig dazu verdammt, in einer Welt nach dem Verschwinden der Urwälder im zerstörten Öko-Systems weiter so leben zu müssen. Eine dystopische Vision des dezidierten Utopie-Kritikers, die im merkwürdigen Kontrast steht zur Reaktion des großen Teils des KinoPublikums sowohl im In- als auch im Ausland, das in diesem Anime eine positive Botschaft sehen will. Woran liegt es?

VIII.

Mit der zuletzt gestellten Frage wenden wir uns jetzt zur Analyse des Utopischen bei Miyazaki, und zwar unter den drei Aspekten: Ikai, Shōjo und Komplexität. ${ }^{49}$

In den oben erörterten Anime, Nausicaä und Mononoke Hime, liegt das utopische Moment in Grenzzonen zwischen zwei Systemen. Denn heilbringende Botschaften, die man aus der »dunklen« und unheimlichen Umwelt erhalten könnte, werden nur in diesen Zonen wahrnehmbar. Ikai ist ein Begriff, der Bedeutung und Funktion von kulturellen Grenzzonen im japanischen Denken erklären kann. Das Wort ist wohl ein fachterminologischer Neologismus im Bereich der Volkskunde und bedeutet wörtlich »andere Welten/Universen«. Es fasst solche Welten zusammen, die in der traditionellen Vorstellung der Welt, vor allem in der Mythologie und im Volksglauben, jenseits bzw. außerhalb der alltäglichen Welt lokalisiert sind. Ikai ist nämlich der Ort der Toten und Vorfahren, aber auch böser Geister oder übermenschlicher Wesen. Es ist der Ort, von dem aus etwas Unheimliches in die Wirklichkeit (zurück-)kommt, und daher der Anlass von Furcht und Ehrfurcht in der vormodernen Volkskultur. ${ }^{50}$

49 Hiroshi Yamanaka analysiert Anime von Miyazaki - zumal Sen to Chihiro - unter dem Aspekt der »utopischen Kraft zum Leben", ohne aber seinen Begriff des Utopischen zu definieren. Hiroshi Yamanaka: The Utopian >Power of Lives: The Significance of the Miyazaki Phenomenon. In: MacWilliams (Hrsg.): Japanese Visual Culture (wie Anm. 27), S. 237-255.

50 Ikai transzendiert folglich die wirkliche Welt nicht, sondern befindet sich in einer Kontinuität zur Wirklichkeit. Vgl. hierzu: Harry D. Harootunian: Overcome by Modernity. History, Culture, and Community in Interwar Japan. Princeton 2000, S. 294
Es ist kein Zufall, dass Ikai, das im Prozess der rapiden Modernisierung aus dem Bewusstsein von vielen Japanern einmal verdrängt worden war, erst in den 1910er Jahren, zeitgleich mit dem Entstehen der oben erwähnten sozialutopischen Bewegungen, als kulturwissenschaftliches Thema wieder sentdeckt wurde. Der Volkskundler Kunio YANAGITA (1875-1962) sammelte Volksmärchen, die in der abgelegenen kleinen Dorfgemeinde Tono des Nordost-Japan ${ }^{51}$ überliefert wurden, und gab sie 1910 als Tono Monogatari (Geschichten aus Tono) heraus. Durch seine Folklore-Forschung versuchte Yanagita, sich mit der gravierenden kulturellen Identitätskrise Japans in seiner Zeit kritisch auseinanderzusetzen. Und er kam zu der Ansicht, dass gerade in der Vorstellung des Ikai die ältesten Schichten der japanischen Mentalität sich manifestieren.

Tono Monogatari enthält Geschichten von übernatürlichen, dämonischen Wesen aus Ikai. Sie bezeugen, wie das letzte, noch erhalten gebliebene Stück des Urwaldes von den in Grenzzonen zwischen Natur und Menschen lebenden Dorfbewohnern wahrgenommen und erlebt wurde. Offensichtlich ist Miyazaki von diesen und anderen alten Volksmärchen ebenso stark inspiriert wie von Schriften des bereits genannten Sasuke Nakao, der die Folklore-Forschung Yanagitas zu einer eigenartigen Theorie über die Formation der japanischen Kultur unter dem Aspekt der Kultur(en) in Zonen der immergrünen Wälder (Shōyo-Jurin Bunka) überarbeitet. Mononoke Hime, das den finalen und deshalb fatalen Streit zwischen diesem Urwald und der Zivilisation behandelt, ist in diesem Sinne eine von Miyazaki visualisierte Nachgeschichte des Ikai. In Nausicaä kommt dagegen Ikai vor allem in Gestalt des >Fukai<, des unheimlichen Meers der Fäulnis, vor.

Ikai wird indes nicht nur in ein thematisches Großformat, etwa in die kritische Infragestellung der Zivilisation, aufgenommen. In Tonari no Totoro (Mein Nachbar Totoro) aus dem Jahr 1988 kommt es in Gestalt der freundlichen, aber magischen Wesen namens >Totoro vor. Diese Waldund Naturgeister, die nur die Kinder sehen können, stehen immer dem zwölfjährigen Mädchen Satsuki bei, wenn sie in eine kritische Situation gerät. In diesem Anime werden heilende Kräfte des Ikai thematisiert, die man in den 1950er Jahren von den letzten zurückgebliebenen Stückchen des Urwaldes noch erhalten konnte. (Abb. 10)

51 Tono liegt in einer Bergregion der Präfektur Iwate und ist nicht weit entfernt von Hanamaki, wo Kenji Miyazawa als Lehrer an der Landwirtschaftsschule tätig war. 

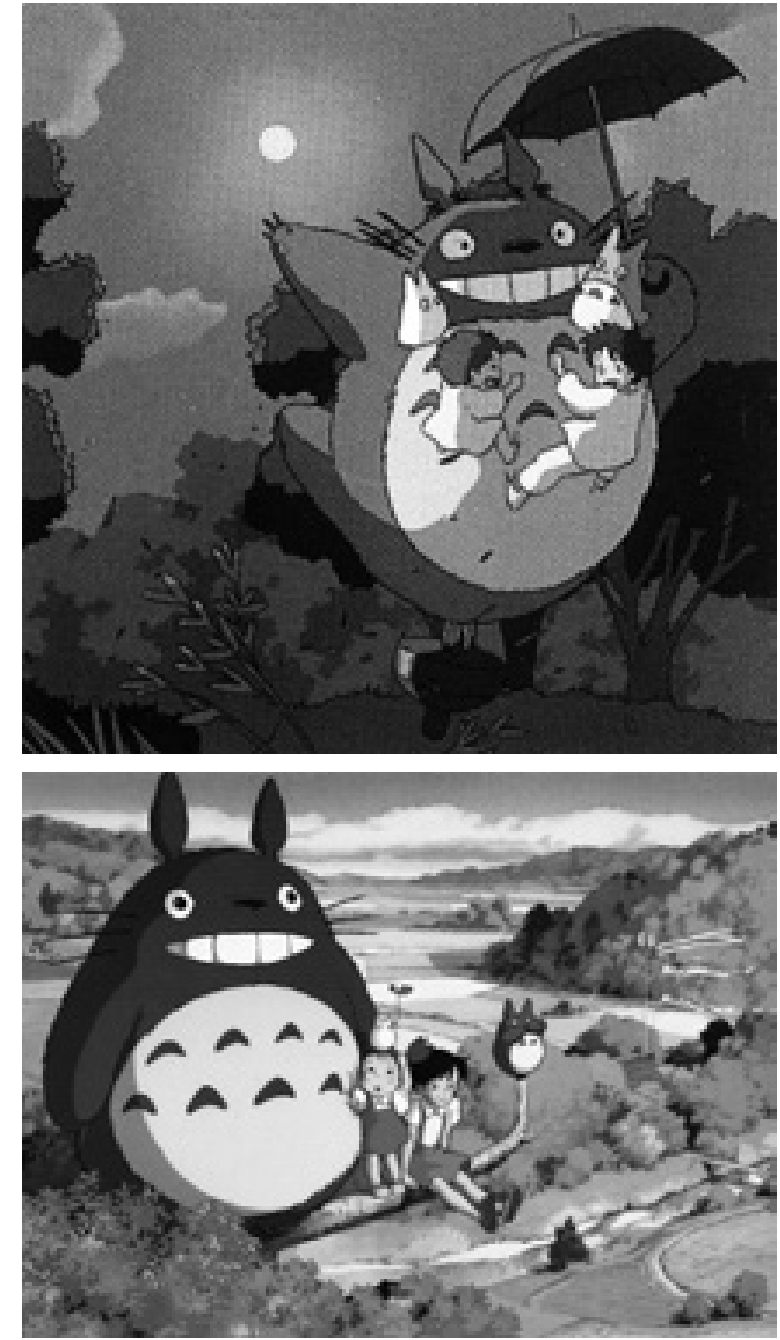

10 Totoro

Auch im Anime Sen to Chihiro no Kamikakushi (Chihoros Reise ins Zauberland), einem Mega-Hit im Kino im Jahre 2003, handelt es sich um die 'Reiser des Mädchens Chihiro ins Ikai. Sie wird, wie im englischen Titel (Spirited Away) wiedergegeben ist, ins Hexenreich entführt. In diesem Ikai muss Chihiro schwer arbeiten und zudem eine Menge Abenteuer überstehen, bevor sie ihre Eltern, die in Schweine verwandelt wurden, zurückverwandeln und dem Reich der Hexe entfliehen kann.
Es ist unnötig, noch einmal auf die zentralen Rollen hinzuweisen, die Shōjo (Mädchen im Alter bis zu 15 Jahren) in diesen Anime spielen. Miyazaki hat mit seinen frühen Filmen - neben Nausicäa und Toroto z. B. Majo no Takkyūbin (Kikis kleiner Lieferservice) aus dem Jahr 1989 nicht nur eine wesentliche Rolle bei der Etablierung des Charaktertyps »Shōjor gespielt, sondern auch bei dessen Dekonstruktion und Erweiterung. Dargestellt sind sie nämlich nicht bloß als lieblich-süße, gutmütige, aber zarte und hilflose Wesen. Die meisten von ihnen sind tatkräftig, unternehmungslustig, trotzig und selbstständig, militant oder gar brutal (Mononoke Hime). Im Kontrast zu einer derartigen Vielseitigkeit der Mädchen wirken die männlichen Charaktere wesentlich stereotypischer.

Es sind in Miyazakis Anime geradezu Shōjo, die geheime Botschaften aus dem Ikai rezipieren und die Grenzen zwischen zwei Systemen ohne Schwierigkeiten überspringen. Wohlgemerkt: Mit Shōjo handelt es sich nicht um übermenschlich befähigte Superheldinnen. Shōjo zu sein heißt, zur Welt der normalen Menschen zu gehören und nicht etwa, sie zu transzendieren. Erst dadurch können sie Vermittlerinnen zwei verschiedener Systeme werden. Susan Napier fasst die elementaren Eigenschaften des Shōjo-Ideals zusammen, indem sie eine unbekannte Japan-Forscherin zitiert: »Because shōjo are not adults, they can perceive things that those in control of society cannot; because they are not young men they see things that those who will someday rule society cannot see $\ll^{52}$ In diesen an sich durchaus normalen Eigenschaften von Shōjo sieht Miyazaki offensichtlich utopisches Potential des Menschen im Allgemeinen. ${ }^{53}$

Shōjo sind nicht nur dazu befähigt, Botschaften aus Ikai richtig zu rezipieren und zu dechiffrieren. Sie müssen zuerst der Komplexität dieser anderen Welt gewachsen sein, wie sie im dunklen Öko-System exemplarisch zum Ausdruck kommt. Das ist vor allem das Thema des Sen to Chihiro, und dabei wird diese Komplexität im Badehaus ( (Yuya ) dargestellt. In diesem traditionell japanischen Badehaus wohnt Yubaba, Chihiros Meisterin, die aber in einer typisch westlichen Hexengestalt visualisiert wird. Die in diesem, mit dem modernen Aufzug versehenen Badehaus arbeitenden

52 Ursprünglich zitiert in: Ann Sherif: Japanese Without Apology: Yoshimoto Banana and Healing. In: Stephen Snyder und Philip Gabriel: Oe and Beyond. Honolulu 1999, S. 282. Hier zitiert nach: Napier: Anime from Akira to Howl's Moving Castle (wie Anm. 30), S. 158

53 Solchen Shōjo-Figuren, mit denen sich das jugendliche Kino-Publikum ohne Weiteres identifizieren kann, liegt vermutlich auch eine didaktische Strategie Miyazakis zugrunde. 
unheimlichen Wesen sind teils von traditionell-japanischer, teils von westlicher Herkunft. Erinnern sie doch auch an jene Wesen, die etwa im Gemälde Der Garten der Lüste von Hieronymus Bosch vorkommen. Hier kommen Unheimlich-Groteskes und Lustig-Humoristisches, Albträume und Karnevalistisches, Ates und Modernes zusammen, ohne dass daraus ein Chaos entsteht. Das kitschige, polymorphe und hybride Badehaus ist also nichts Anderes als ein Universum der kondensierten Heterogenität und Komplexität, d.i. eine Art Heterotopie. (Abb. 11)

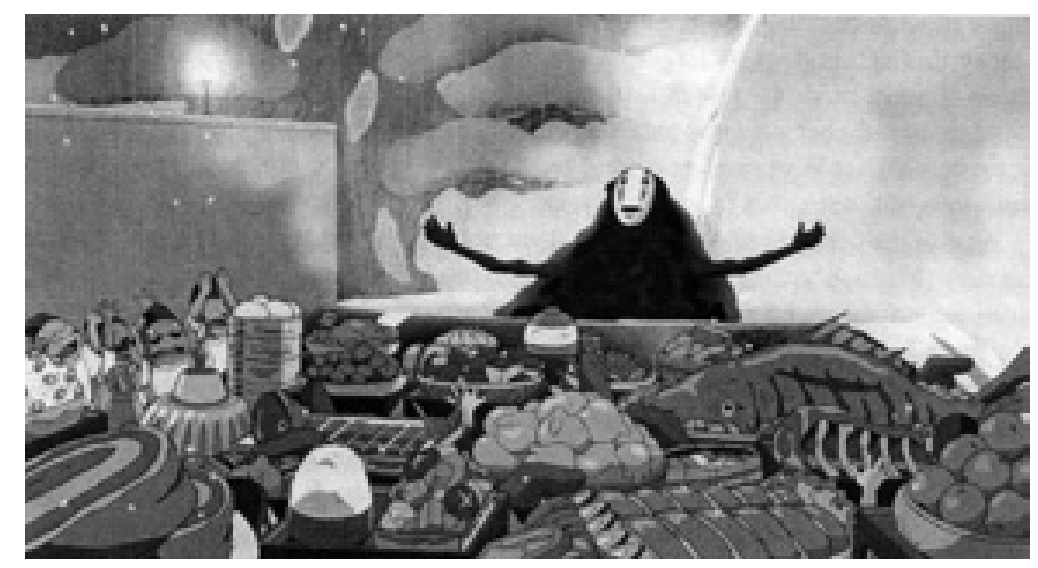

11 Sen to Chihiro: Bankett im Badehaus

Einer solchen thematischen und narrativen Komplexität entspricht die hohe Dichte an visuellen Informationen des Animes. Es wird oft betont, dass in Anime von Miyazaki die Figuren sich nur selten vor einem leeren Hintergrund bewegen. Man sieht hier nicht nur die Hauptfiguren, sondern eine große Zahl an Menschen und Dingen, die mit der Handlung kaum etwas zu tun haben. In den Medien Manga und Anime, deren Eigenschaften sich in erster Linie von der reduzierten visuellen Informationsmenge herleiten lassen, gehört diese >dichte Beschreibung`zur Ausnahme.

Diese visuelle Dichtheit soll von dem oben erörterten hyper-detaillierten Manga-Stil von Katsuhiro Otomo unterschieden werden. Hier geht es nämlich nicht um einen ästhetischen Genuss, sondern vielmehr darum, dadurch die Singularität der um die Hauptfiguren zentrierten Handlungsperspektive visuell zu relativieren. Auf diese Weise wird versucht, auf die anderen Perspektive und Wahrnehmungen, auf die anderen Geschichten als die der Hauptfiguren aufmerksam zu machen.
Die Zeitlupe-Technik, die die Zeit der Handlung (Ordnung von Chronos) suspendiert und besondere Augenblicke (Kairos) >verewigt‘, wird auch in vielen Manga und Anime exzessiv in Anspruch genommen. Sie wird von Miyazaki mit Konsequenz vermieden. Hierin sieht der Psychiater und Kulturkritiker Tamaki SAITO (geb. 1961) eine ethische Haltung des Anime-Autors ${ }^{54}$ Saito weist nämlich darauf hin, dass die vor allem von Otomo zu einer besonderen Ästhetik raffinierten Technik in Anime eine eigenartige Zeitlosigkeit einführt, die - wie Saito mit Recht vermutet eigentlich dem Narzisstischen entspringt. Diese Zeitlosigkeit ist also mit den Begierden der oralen Phase verbunden und könnte somit - Saito zufolge - die Anime zum Medium des regressiven Imaginären machen. Miyazaki dagegen gibt eine nach der Ordnung von Chronos ablaufende Zeit der Handlung niemals auf. ${ }^{55}$

Es liegt jetzt auf der Hand, dass die dichte Visualität des MiyazakiAnime mit einer solchen Zeitlichkeit der Handlung eng zusammenhängt. Sie übertreibt nichts, sie vereinfacht nichts. Aber gerade dadurch kommt das Utopische zum Ausdruck. In solchen gezielten Abweichungen von der standardisierten Anime-Visualität manifestiert die kritische Position Miyazakis zu den Hauptströmungen im Anime. Es ist eine zurückgehaltene, aber umso gründliche Kritik an SF-Anime in den letzten 30 Jahren, das, von einer tiefen Reflexion über dargestellte Utopien bzw. Dystopien ausgehend, in einer narzisstischen Ästhetisierung der düsteren Zukunftsvision sein kritisches Potential zu verlieren droht.

54 Vgl. Tamaki Saito: ১Undō‘ no Rinri. Aruiha Hyōshō Kontext Shiron (Ethik der >Bewegung ‘. Versuch zum Kontext der Repräsentation). In: Eureka 29, Heft 11 (wie Anm. 51), S. 77-85.

55 Vgl. Saito: >Undōく no Rinri (wie Anm. 54), S. 82.

\section{ABBILDUNGSNACHWEISE}

1 Osamu Tezuka: Tetsuwan Atom, Bd. 1. Tokyo 1979.

2 http://blogs.yahoo.co.jp/mirumiruboy70/GALLERY/show_image.html? $\mathrm{id}=9762907 \&$ no $=2$

3 Katsuhiro Otomo: Akira 5. Tokyo 1990.

4 Katsuhiro Otomo. Genga. Otomo Katsuhiro Original Pictures. Tokyo 2012 .

5-8 Susan J. Napier: Gendai Nihon no Anime. Akira kara Sen to Chihiro no Kamikakushi made (Japanische Ausgabe von: Dies.: Anime from Akira 
to Princess Mononoke. New York 2001). Übersetzt von Kyoko Kamiyama. Tokyo 2002.

9-10 Eureka 29 (1997), H 11: Sonderheft für Hayao Miyazaki.

11 Ein Bankett im Badehaus. Aus: Mark W. MacWilliams (Hrsg.). Japanese

Visual Culture. Explorations in the World of Manga and Anime. New York

und London 2008, S. 243

\section{ROBERTO SIMANOWSK}

\section{UTOPIEN UND DYSTOPIEN IM INTERNET \\ UND DIE ANTIUTOPISCHE BOTSCHAFT}

\section{DES MEDIUMS}

Utopisches Denken ist die Erinnerung des Menschen an eine alternative, bessere Welt, die es noch zu schaffen gilt. Gegenpol des utopischen NochNicht-Seins ist nicht allein die Realität und nicht so sehr die Dystopie, sondern auch und vor allem die Antiutopie, die vor den möglichen Folgen des utopischen Impulses warnt wie etwa Orwells 1984, während die Dystopie, wie etwa Gibsons Neuromancer, die beängstigende Welt illustriert, die aus der Verlängerung der Gegenwart folgt, "[by] transforming our own present into the determinate past of something yet to come«. ${ }^{1}$ Is die Utopie somit das schlechte Gewissen einer selbstzufriedenen und die Dystopie das schlechte Gewissen einer ignoranten Gegenwart, ist die Antiutopie das schlechte Gewissen der Utopisten. Utopie und Dystopie stehen im Grunde auf einer Seite, als hellere oder dunklere Kritik am

1 Frederic Jameson: Progress Versus Utopia; or, Can We Imagine the Future? In: Science Fiction Studies 9 (1982), H. 2, S. 147-158, hier 152. Aus dieser Perspektive sind auch weniger die Dystopisten zugleich Feinde des Sozialismus, wie Jameson vormals deklarierte (Of Islands and Trenches. Naturalization and the Production of Utopian Discourse. In: Diacritics 7 [1977], H. 2, S. 2-22, hier S. 3), als die Antiutopisten mit ihrer "passion to denounce and to warn against Utopian programs in the political realm (Jameson: Archaeologies of the Future: The Desire Called Utopia and Other Science Fictions. London 2005, S. 198 f.) Zur Begriffsachse UtopieDystopie-Antiutopie vgl. Lyman Tower Sargents Essay »The Three Faces of Utopianism Revisited« (in: Utopian Studies 5 [1994], H. 1, S. 1-37. Das Adjektiv "antiutopisch « im Titel zielt, das wird der Beitrag deutlich machen, nicht auf eine konkret-inhaltliche, sondern allgemein-methodische Opposition zur Utopie: als Verzicht auf Möglichkeitsdenken an sich. 
Status Quo. Dieser Perspektive kann man mit Jameson widersprechen, der in der Dystopie weniger eine Warnung für die Gegenwart als eine Anpassung an die Zukunft konstatiert, denn dunkle Berichte über Umweltverschmutzung und Überbevölkerung lägen durchaus im Interesse des »American business itself which is concerned, for its own interest, to exchange the older consumer optimism for some new and more austere acceptance by the public of collective constraints and communal living. ( $^{2}$ Beispiel dafür sind Jameson gerade Cyberpunk-Romane wie Gibsons Neuromancer, die "excitement rather than fear " generieren, ${ }^{3}$ weswegen Jameson sie später nicht Dystopien nennt, sondern als eine Art Utopie der falschen Leute bezeichnet: "something like the Utopian expression of late or finance capital as such. $\ll^{4}$

Jamesons Sicht blieb zu Recht nicht unwidersprochen, denn ein Text wie Neuromancer ist, trotz der potentiellen Identifikationsangebote mit der Hauptfigur als Hacker und »console cowboy «, voller »social and psychological pathologies [...] neither recuperated nor neutralized by the excitement the adventure story generates « und "oscilatte[s] between faszination and repulsion ${ }^{6} .{ }^{6}$ Gleichwohl trifft $\mathrm{zu}$, dass in der Gegenwart dystopische Aspekte verschiedentlich neutralisiert oder gar utopisch umgewertet werden. Einen solchen Fall notiert zum Beispiel D. N. Rodowick mit Blick auf die You-Will-Werbekampagne von AT\&T, die 1993 und 1994 in sieben 30-Sekunden-Spots eine Zukunft zeichnete, in der Menschen nicht nur Videotelefonie und Handys haben, sondern auch durch ihre Stimme Türen öffnen, mittels automatischer Signalerkennung MautTolls zahlen, sich per GPS kartenlos orientieren und einem Chip ihre gesamte Krankengeschichte entnehmen können. Rodowick sieht in den Videos eine "adoption of the dystopian futurist set design of Bladerunner und verweist auf das utopische Potential dystopischer Metaphern.?

2 Frederic Jameson: Introduction/Prospectus: To Reconsider the Relationship of Marxism to Utopian Thought. In: Minnesota Review 6 (Spring 1976, New Series), S. 51-58, hier S. 55.

3 Frederic Jameson: The Seeds of Time. New York 1994, S. 159.

4 Jameson: Archaeologies (wie Anm. 1), S. 190.

5 William Gibson: Neuromancer. London 1984, S. 52.

6 Philipp Schweighauser: Who's Afraid of Dystopia? Gibson's Neuromancer and Jameson's Writing on Science Fiction. In: Tom Moylan, Michael Griffin (Hrsg.): Exploring the Utopian Impulse: Essays on Utopian Thought and Practice. New York 2007, S. 225-242, hier S. 235.

7 David N. Rodowick: An Uncertain Utopia - Digital Culture. In: Claus
Entscheidender und zwingender als die filmästhetische Analogie zum Cyberpunk ist jedoch die Ambivalenz des Begehrten, das nur zum Preis perfektionierter und personalisierter Datenübermittlung zu haben ist. Die Befreiung der Körper und Fahrzeuge von räumlichen Zwängen, die das zentrale Argument der Videos ausmacht, liest sich als Illustration der Kontrollgesellschaft, die Gilles Deleuze wenige Jahre zuvor beschrieb:

Félix Guattari malte sich eine Stadt aus, in der jeder seine Wohnung, seine Straße, sein Viertel dank seiner elektronischen (dividuellen) Karte verlassen kann, durch die diese oder jene Schranke sich öffnet; aber die Karte könnte auch an einem bestimmten Tag oder für bestimmte Stunden ungültig sein; was zählt, ist nicht die Barriere, sondern der Computer, der die - erlaubte oder unerlaubte - Position jedes einzelnen erfasst und eine universelle Modulation durchführt. ${ }^{8}$

Die Inversion dystopischer Warnungen zu utopischen Versprechen führt zur ersten zentralen These über den Utopiestatus der digitalen Medien. Ihr utopischer Aspekt ist einerseits so ambivalent wie ihr dystopischer, andererseits unvermeidlich mit diesem verquickt, wie leicht ersichtlich wird an einem der einflussreichsten Phänomene der digitalen Medien: Facebooks Interaktionsmodell der Permanenz und Transparenz kann als radikale Überwachung und Ökonomisierung des Privaten beschrieben oder als entgrenzte Kommunikation erfahren werden, wobei das Begehrte - Information darüber, wer die gleichen Bücher liest oder sich in räumlicher Nähe befindet - den weniger erwünschten Effekt reduzierter Privatsphäre gegenüber den anderen Nutzern und gegenüber dem allwissenden Algorithmus in Kauf zu nehmen zwingt. Die »dataveillance« ist, wie Rodowick festhält, das Instrument der Kontrollgesellschaft, die Deleuze annonciert. ${ }^{9}$ Die zweite zentrale These ist Rodowicks Kommentar zur utopischen Geste der erwähnten AT\&T-Videos zu entnehmen:

Pias (Hrsg.): Dreizehn Vorträge zur Medienkultur. Weimar 1999, S. 263283, hier S. 278

8 Gilles Deleuze: Postskriptum über die Kontrollgesellschaften. In: ders. Unterhaltungen 1972-1990. Frankfurt am Main 1993, S. 254-262, hier S. 261.

9 Rodowick: Uncertain Utopia (wie Anm. 7), S. 268. 
It is a seductive vision meant to convince us that capitalism, for centuries the source of so many of the world's social problems and inequities, can still be the solution, if we only let it again transform itself historically by unleashing the productive capacity of digital communications technologies..$^{10}$

Das herrschende ökonomische System okkupiert die utopische Energie der Gesellschaft, indem es technische Innovationen als Lösung sozialer Antagonismen ausgibt. Entsprechend besteht die Welt der AT\&T-Videos, wie Roderick betont, nur aus Vertretern der Mittelklasse: jung, attraktiv, lebensfroh und ethnisch ausbalanciert. ${ }^{11}$ Das mag als unangemessener Vorwurf gegenüber der Textsorte Werbung erscheinen, erhält seinen tieferen Symbolgehalt jedoch drei Jahre später, wenn im TechnologieMagazin Wired die »citizens of the Digital Nation« als vorrangig wohlhabend, gebildet, mobil, liberal, tolerant, materialistisch, optimistisch und unpolitisch beschrieben werden, die sich fern halten von traditionellen politischen Organisationen und keinerlei big ideas hegen zu Armut, Unterschicht, Kriminalität, Bildung oder anderen sozialen Fragen, sich also als `Nation` fühlen nicht durch ein bestimmtes soziales oder kulturelles Bewusstsein, sondern durch Mediennutzungspraktiken.12

Der Utopismus dieser Menschengruppe begnügt sich mit dem Glauben an die Emanzipation durch technischen Fortschritt, der Mitte der 1990er Jahre als `kalifornische Ideologie beschrieben wurde - als deren zentrales Organ Wired gilt - und inzwischen unter den Stichwörtern communicative capitalism und liberation technology als neoliberale Ablenkungsstrategie entlarvt wird. ${ }^{13}$ So zielt der kommunikative Kapitalismus auf »inclusion and

\section{Ebd. S. 264}

\section{$11 \mathrm{Ebd}$}

12 Jon Katz: Media Rants. Postpolitics in the Digital Nation, San Francisco 1997, S. 52 f. u. 6o. Der Artikel »Birth of a Digital Nation« erschien zuvor in: Wired Magazine 5 (1997), H. 12; online: www.wired.com/wired/archive/ 5.04/netizen_pr.html.

13 Richard Barbrook und Andy Cameron: The Californian Ideology. In: Mute Magazine 3 (Autumn 1995) - www.imaginaryfutures.net/2007/04/17/ the-californian-ideology-2. Den Gegensatz zur kalifornischen Ideologie bilden die europäischen Netz-Pioniere, die auf die Nutzung der neuen politischen Freiräume im Internet für die Gesellschaft insgesamt setzten. Für Beiträge, Interviews und Dokumente dazu vgl. Clemens Apprich und Felix Stalder (Hrsg): Vergessene Zukunft: Radikale Netzkulturen in Europa. Bielefeld 2012. participation in information, entertainment, and communication technologies in ways that capture resistance and intensify global capitalism $\ll,{ }_{1}^{14}$ wobei zu den Taktiken nicht nur die Kapitalisierung des öffentlich gemachten Privaten und das Viral Marketing als >partizipativer Warenfetischismus gehören, sondern auch das Gebot der Selbstoptimierung und Selbstvermarktung im allgegenwärtigen Konkurrenzkampf um Aufmerksamkeit. Während die digitale Infrastruktur des kommunikativen Kapitalimus zugleich - und nicht nur von neoliberalen Kräften - als Befreiungstechnologie gefeiert wird, wie im Kontext des Arabischen Frühlings die Rede von der Twitter- und Facebook-Revolution zeigte, sehen Kritiker darin einen »digitalen Orientalismus«, der die westliche Technologie als Mittel annonciert, das Demokratiedefizit politisch rückständiger Staaten zu beheben, ${ }^{15}$ was - mit Blick auf Mannheims und Ricoeurs Differenzierung von Ideologie und Utopie als konservatives bzw. alternatives Denken - als systemstabilisierender Einatz utopischer Rhetorik bezeichnet werden kann. ${ }^{16}$

14 Jodi Dean: Democracy and Other Neoliberal Fantasies: Communicative Capitalism and Left Politics. Durham, NC 2009, S. 2.

15 Evgeny Morozov: The Net Delusion: The Dark Side of Internet Freedom. Philadelphia 2011, S. 5. Vgl. Ulises A. Mejias: Liberation Technology and the Arab Spring: From Utopia to Atopia and Beyond. In: Fibreculture Journal 20 (Juni 2012) (http://twenty.fibreculturejournal.org/2012/06/20/fcj-147liberation-technology-and-the-arab-spring-from-utopia-to-atopia-andbeyond). Vgl. die Selbsterklärung des »Program on Liberation Technology» der Stanford University: »to understand how information technology can be used to defend human rights, improve governance, empower the poor, promote economic development, and pursue a variety of other social goods" und »[to] examine technical, legal, political, and social obstacles to the wider and more effective use of these technologies, and how these obstacles can be overcome." (http://liberationtechnology.stanford.edu)

16 Vgl. Karl Mannheim: Ideologie und Utopie (1929). Frankfurt a. M. ${ }^{8} 1995$; Paul Ricoeur: Lectures on Ideology and Utopia. New York: 1986; Rowan Wilken: Mannheim's Paradox: Ideology, Utopia, Media Technologies, and the Arab Spring. In: Fibreculture Journal: 20 (Juni 2012) (http://twenty.fibre culturejournal.org/2012/06/20/fcj-146-mannheims-paradox-ideologyutopia-media-technologies-and-the-arab-spring): "social media, when viewed through this particular lens, perform double duty: they are perceived as key >utopian instruments of social struggle for the repressed classes in distant lands; at the same time, such a perception is strongly ideological insofar as it serves to (re-)legitimate the relative power and privilege of the position of those who supply, observe, and comment from afar on the use of these technological instruments." 
Solcherart als Handlanger der Kontrollgesellschaft und des kybernetischen Kapitalismu notiert, scheinen die digitalen Medien - Computer, Internet, WWW, Smart Phones - und ihre Dienste - Suchmaschinen wie Google, soziale Netzwerke wie Facebook, Kommunikationsdienste wie Twitter, Plattformen wie Wikipedia und YouTube - nur dystopisch zu operieren. Diese Schlussfolgerung unterschlüge, dass noch heute vielen Verheißung ist, was aus der Perpsektive kritischer Theorie als Gefahr beschrieben wird. Der Publikationsort dieses Essays empfiehlt, die Hoffnungen und Ängste, mit denen das Internet in seiner kurzen Geschichte bedacht ward, sowie die utopische Umdeutung dystopischer Aspekte zunächst zu skizzieren (I.), was hier natürlich nur bruchstückhaft und nur teilweise in analytisch-kommentierender Weise geschehen kann, bevor Aussagen zum utopischen Potenzial des Internet aus medienwissenschaftlicher Perspektive gemacht werden (II.).

\section{I.}

Drei Vorbemerkungen sind nötig: Erstens ist die Frage nach der Utopiehaftigkeit eines Mediums nur sinnvoll mit einem starken Medienbegriff, wonach das Medium nicht ein neutrales Instrument ist, das Menschen so oder so einsetzen können, sondern eigene Postulate mit sich bringt, die, insgeheim und zustimmungsfrei, die Situation des Menschen verändern. Diese Ansicht, dass Medien nicht nur Vermittlungsinstanz für Sinn sind, sondern selbst sinnstiftend operieren, die der kanadische Medienwissenschaftler Marshall McLuhan auf die berühmte Kurzfassung »The medium is the message« bringt, begründet und legitimiert die Medienwissenschaft als akademische Disziplin. ${ }^{17}$

Zweitens ist das Internet - früher auch als Cyberspace oder Virtual Reality bezeichnet ${ }^{18}$ - ein Nicht-Ort per Definition: ein virtueller Raum, dessen Existenz von der Stromzufuhr abhängt, der durch Smart Phones

17 Marshall McLuhan: Das Medium ist die Botschaft. In: ders.: Die magischen Kanäle. Understanding Media. Dresden, Basel 1995, S. 21-43.

18 Vgl. Michael Benedikt: Cyberspace. First Steps. In: David Bell, Barabara M. Kennedy (Hrsg): The Cyberculture Reader. London, New York 2000, S. 29-44. Begriffsgeschichtlich interessant für das hier behandelte Thema ist der Ursprung des einstigen Alternativbegriffs für das Internet in Gibson Roman Neuromancer, der Cyberspace definiert als: »A consensual hallucination experienced daily by billions of legitimate operators [...] A graphical und Wireless-Verbindungen mittlerweile allgegenwärtig ist. Als dieser Nicht-Ort ist der virtuelle Raum zugleich Heterotopie, die sich, wie Perry Barlows »Declaration of the Independence of Cyberspace « 1996 demonstriert, deutlich in Opposition zur medienexternen Gesellschaft stellt und in vielerlei Hinsicht eigene Verhaltensformen entwickelt und ritualisiert. ${ }^{19}$

Drittens lässt sich, wie gesagt, die Geschichte des Internet im Modus sowohl der Utopie als auch der Dystopie erzählen. Das dystopische Narrativ sieht in den neuen Medien entweder von Anfang an eine Gefährdung herkömmlicher Kulturwerte oder ist enttäuscht über den Abbruch des vielversprechenden Aufbruchs zu alternativen Kulturformen durch die zunehmende Kommerzialisierung und Governmentalisierung. Das utopische Narrativ registriert keinen Abbruch und betont den Demokratiegewinn durch das Internet oder deutet dystopische Tendenzen utopisch um. Die Elemente und Argumente dieser vier Positionen seien im Folgenden in variierter Reihenfolge beispielhaft skizziert.

Die utopische Perspektive ist natürlich technikaffin und rechnet die Innovationen des Internets prognostisch hoch als neue Gemeinschaftlichkeit, demokratischere Kommunikationsform, spielerische Identitätsbildung, kommunistische Ökonomie und kritischere Form des Lesens:

1. Die neue Gemeinschaftlichkeit fand ihren ersten Ausdruck im WELL (Whole Earth 'Lectronic Link), einem 1985 gegründeten und bis heute aktiven sozialem Online-Netzwerk lange vor Myspace und Facebook, dem Howard Rheingold, eines ihrer ersten Mitglieder, in seinem Buch The Virtual Community 1993 ein Denkmal setzte und das Fred Turner in seinem Buch From Counterculture to Cyberculture: Stewart Brand, the Whole Earth Network, and the Rise of Digital Utopianism 2008 als Wiege der Network-Kultur aus dem Geiste bewusstseinserweiternder

representation of data abstracted from the banks of every computer in the human system." (Gibson: Neuromancer [wie Anm. 5], S. 67.

19 Programmatisch ist bereits der erste Satz in Barlows Unabhängigkeitserklärung: »Governments of the Industrial World, you weary giants of flesh and steel, I come from Cyberspace, the new home of Mind. On behalf of the future, I ask you of the past to leave us alone. You are not welcome among us. You have no sovereignty where we gather.« (https://projects. eff.org/ barlow/Declaration-Final.html) Mejias (Liberation Technology and the Arab Spring [wie Anm. 15]) schlägt - ohne weitere theoretische Diskussion - für die Heterotopie im Cyberspace den Begriff Atopia vor: "similarly [zur Heterotopie] an alternative site with different social norms, except that in this case, the site can be located anywhere or everywhere«. 
Drogen heraus erklärt. ${ }^{20}$ Diese virtuelle Gemeinschaft diskutierte Aspekte der neuen Technologie, half sich in Alltagsfragen und traf sich im realen Raum (für die meisten war das San Francisco). Das zentrale Merkmal der Online-Gemeinschaften ist die Überwindung des Raumes, was gerade Minderheiten aller Art - Immigranten, Homosexuelle, körperlich Behinderte - erlaubt, sich als zahlreiche Gemeinschaft zu erfahren und in einem "wired neighborhood ${ }^{21}$ eine eigene Identität trotz räumlicher Entfernungen und gesellschaftlicher Diskriminierung zu entwickeln.

2. Die demokratischere Form der Kommunikation manifestiert sich im Wegfall der üblichen Zugangsbarrieren, was potentiell jeden zum Sender qualifiziert, so wie es Brecht einst fürs Radio forderte, und dabei, auch das war Brechts Hoffnung, neue Formen der Öffentlichkeit schafft: Foren wie das Bulletin Board System, Chat-Rooms, Weblogs oder die heute fast überall zu findende Kommentarfunktion und natürlich Twitter als individualisiertes Massenmedium. Hoffnungsvoll bedacht waren vor allem die politischen Weblogs, die Watchblogs, die sich der einseitigen, vereinfachenden oder falschen Berichterstattung in den traditionellen Nachrichten-Medien zum Teil mit kollektiver Energie entgegenstellen. Das bekannteste Ergebnis kollektiver, basisdemokratischer Kommunikation ist Wikipedia, Beispiel jener kollektiven Intelligenz, die der französische Philosoph Pierre Lévy 1995, sechs Jahre vor Wikipedia, unter dem Motto 'Kosmopädieく feierte. ${ }^{22}$

3. Die spielerische Identitätsbildung bezeugt sich metaphorisch in einem berühmten Cartoon, der zwei Hunde vor dem Computer zeigt: »On the Internet nobody knows you are a dog.«Im Internet ist man, was man tippt, wodurch ethnische, soziale oder körperliche Kommunikationsnachteile entfallen. Wenn Identität auf dem Keyboard erfunden werden kann, wird das Internet zum Identity-Workshop, wie die Soziologin Sherry Turkle die nun mögliche Erfahrung einer multiplen Identität apostrophierte..$^{23}$

20 Fred Turner: From Counterculture to Cyberculture: Stewart Brand, the Whole Earth Network, and the Rise of Digital Utopianism. Chicago 2008, S. 139: "Brand had suggested that computers might become a new LSD.» 21 Stephen Doheny-Farina: The Wired Neighborhood. New Haven, London 1996

22 Pierre Lévy: Die kollektive Intelligenz. Für eine Anthropologie des Cyberspace. Mannheim 1997.

23 Sherry Turkle: Identität in virtueller Realität. Multi User Dungeons als Identity Workshops. In: Stefan Bollmann, Christiane Heibach (Hrsg.): Kursbuch Internet. Anschlüsse an Wirtschaft und Politik, Wissenschaft und Kultur. Mannheim 1996, S. 315-331.
Der politisch-moralische Mehrwert des Identitätsspiels ist nicht nur die Erkenntnis, wer man selbst (außerdem) ist, sondern auch ein >flüssigeres Selbstverständnis`, das es leichter mache, Diversität anzuerkennen:

»It makes it easier to accept the array of our and other's inconsistent personae - perhaps with humor, perhaps with irony. We do not feel com-pelled to rank or judge the elements of our multiplicity. We do not feel compelled to exclude what does not fit. « ${ }^{24}$

Die Erkenntnis des Unheimlichen als das heimlich Eigene - so lässt sich mit Bezug auf Julia Kristevas Essay »Fremde sind wir uns selbst (1988) formulieren - wird für Turkle mit dem Internet zu einer unabweisbaren Alltagserfahrung, die den Anforderungen einer zunehmend multikulturellen Gesellschaft entspricht. Dass diese Hoffnung übereilt war, zeigen die zeitgenössischen Einsprüche gegen den Identitäts-Tourismus als episodische, hoch-symbolische Konsumtion das Anderen, die Durchsetzung des Authentizitätsprinzips auf sozialen Netzwerken wie Facebook und Google + sowie Turkles jüngste, kritische Publikation über die neuen Medien. ${ }^{25}$

4. Die quasi kommunistische Ökonomie des Internets resultiert aus dessen Grundsatz >Information shall be free`, der weder politische noch ökonomische Zugangsbarrieren akzeptiert, sondern auf der Basis einer Wissensallmende eine >Geschenkökonomie` ermöglicht, eine Art `Naturalhandel der Information, bei der jeder gibt nach seinen Möglichkeiten und jeder nimmt nach seinen Bedürfnissen. ${ }^{26}$ Kritik dieser Perspektive

24 Sherry Turkle: Life on the Screen. Identity in the Age of the Internet. New York 1995, S. $261 \mathrm{f}$

25 Jennifer Gonzales: The Appended Subject: Race and Identity as Digital Assemblage. In: Beth E. Kolko, Lisa Nakamura, Gilbert B. Rodman (Hrsg.): Race in Cyberspace, London, New York 2000, S. 27-50; Lisa Nakamura: Cybertypes: Race, Ethnicity, and Identity on the Internet, London, New York 2002; Sherry Turkle: Alone Together: Why We Expect More from Technology and Less from Each Other. New York 2011 (dt. 2012). Vgl. dazu den Abschnitt »Identitätstourismus« in meinem Buch Digitale Medien in der Erlebnisgesellschaft. Kultur - Kunst - Utopie (Reinbek 2008, S. 194-204). 26 Vgl. Richard Barbrook: Cyber-Communism: How The Americans Are Superseding Capitalism In Cyberspace. In: Science as Culture No. 1, Vol. 9 (2000), S. 5-40 (dt. in: Rudolf Maresch, Florian Rötzer [Hrsg.]: Cyberhypes. Möglichkeiten und Grenzen des Internet. Frankfurt am Main: 2001, S. 76-101). 
kam schnell auch aus den eigenen Reihen ${ }^{27}$ und bald auch innerhalb einer elaborierten Theorie zur Ökonomisierung partizipativer Kultur, wonach Interaktivität das kapitalistische System nicht unterminiert, sondern dessen Spielraum ausweitet. ${ }^{28}$

5. Die kritischere Form des Lesens sah man im Hypertext gewährleistet, dessen Struktur der Vernetzung die konstruktivistische Wahrnehmungsperspektive gegenüber der objektivistischen stärken ${ }^{29}$ und durch Rekonfigurierung und Relativierung gar eine Revolution hin zu Ironie und Skeptizismus mit sich bringen werde..$^{30}$ Dieser Perspektive, die durch eine Fehldeutung aktueller französischer Philosophen zugleich die Befreiung des Lesers von der Dominanz des Autors postulierte, unterlagen Einwände zur Ersetzung komplexer Gedankengänge und subtiler Darstellung durch schnell und kontextunabhängig Verständliches sowie zum Zerstreuungsaspekt der Hypertext-Lektüre. ${ }^{31}$

27 Ted Byfield scheibt auf der Mailinglist Nettime.org, wo Barbrook seinen Text zuerst präsentierte, am 6.10.1999: »Technological determinism is saving us all. Even the dumbest American does actively contribute to the creation of Cybercommunism. And now, they know it and are working even more keenly on it, just, poor Americans, the only way to organize they can think of is to incorporate! / Never mind. Just go to sleep the Internet will take care of things. And if you sleep long enough, you will wake up in utopia itself. This sure ain't Kansas here! There is just one little nagging question here, a minor detail to help history find it itself. Can there be Cybercommunism in only one domain?« (www.nettime.org/Lists-Archives/ nettime-1-9910/msgooo17.html)

28 Mark Andrejevic: Reality TV: The Work of Being Watched. Lanham 2003 , S. 193.

29 George P. Landow: Hypertext 2.0. The Convergence of Contemporary Critical Theory and Technology. Baltimore, London: 1997, S. 225 (erste Fassung 1992).

30 Stanley Aronowitz: Looking Out: The Impact of Computers on the Lives of Professionals. In: Myron C. Tuman (Hrsg.): Literacy Online. The Promise (and Peril) of Reading and Writing with Computers. Pittsburgh: 1992, S. 119-137, hier S. 133.

31 Jeff Conklin: Hypertext: An Introduction and Survey. In: IEEE Computer 20 (1987), H. 9, S. 17-20 u. 32-41; Terence Harpold: Conclusions. In: George P. Landow (Hrsg): Hyper/Text/Theory. Baltimore, London 1994, S. 189-222; David Kolb: Sokrates in the Labyrinth. In: ebd., S. 323-344. Vgl. den Abschnitt »Hypertext und Missverständnisse« in meinem Buch Interfictions. Vom Schreiben im Netz (Frankfurt a. M. 2002, S. 66-72).
Die dystopische Perspektive operiert mit Verlustängsten und kritisiert das Neue als Angriff auf das Alte unter anderem hinsichtlich der Lektürekultur, der Offenheit für das Andere, des schwindenden politischen Öffentlichkeit, der Entmachtung der Experten, des gläsernen Menschen:

1. Die Ablösung des Buches als Leitmedium durch den Computer und den damit einhergehenden Verlust einer Kulturform der vertieften Lektüre problematisiert Sven Birkerts bereits 1995 in seinem Buch The Gutenberg Elegies: Fate of Reading in an Electronic Age. ${ }^{32}$ Nicholas Carr bestätigt die Befürchtung 2010 aus neurobiologischer Perspektive, wenn er in The Shallows. What the Internet Is Doing to Our Brains unterstellt, das Lesen am Bildschirm untergrabe ${ }^{33}$ - durch die Notwendigkeit der Navigationsentscheidungen und die Versuchung des Multitasking - die Fähigkeit zur konzentrierten Lektüre, und zwar auch dann, wenn nicht mehr am Bildschirm gelesen werde, weil das Gehirn sich umbilde, wie zum Beispiel Hirnforscherin Maryanne Wolf 2007 in ihrem Buch Proust and the Squid: The Story and Science of the Reading Brain dargelegte: ${ }^{34}$ Der beschworene Verlust des deep reading bedrohe zugleich die Fähigkeit zum deep thinking wie zum Erinnern, weil nur das, was längere Zeit beschäftigt, vom Arbeitsgedächtnis ins Langzeitgedächtnis überführt werde.

2. Die Überwindung des Raumes in der Kommunikation führe dazu, dass Gemeinschaften sich nicht mehr aufgrund gemeinsam geteilter äußerer Bedingungen bilden, sondern aufgrund gemeinsam geteilter Interessen. Diesen » neighbourhoods of shared interest ${ }^{35}$ fehle das, was Gemeinschaften sozial so wichtig macht: die Anstrengung des Ausgleichs zwischen vielfältigen Interessen und Perspektiven. So gab es Warnungen nicht nur vor dem Cost-free-Faktor der weak-tie relationships in virtuellen Gemeinschaften, deren gefährlicher Reiz darin liege, die anderen mittels Bildschirm auf Distanz halten und jederzeit abschalten zu können, ${ }^{36}$

32 Boston, London 1995

33 New York 2010.

34 New York 2007

35 Daniel Bell: An Introduction to Cyberculture. New York, London 2001, S. 110.

36 Vgl. Roger Scruton: Hiding Behind the Screen. In: The New Atlantis (Summer 2010), S. 48-60; Turkle: Alone Together (wie Anm. 25), S. 157: "Today, our machine dream is to be never alone but always in control This can't happen when one is face-to-face with a person." Das Internet, so lautete schon früh der Einspruch gegen die Utopie der Anfangstage, ist der ideale Zufluchtsort für all jene, die die Begegnung mit Menschen 
sondern auch davor, im Kommunikationsmuster des daily me und der echo chambers die konstituierende Verhaltensnorm der Demokratie - die Verhandlung der verschiedenen Interessen und Positionen in einer Gesellschaft - nicht mehr zu trainieren. ${ }^{37}$ War das Problem Ende des 20. Jahrhunderts noch Resultat der neuen Kontrollmöglichkeiten der Individuen über ihre Informationensaufnahme, ${ }^{38}$ ist es inzwischen davon unabhängig ein Effekt algorithmischer Personalisierung, mit der Dienste wie Google, Facebook, Amazon - und viele andere Plattformen, die die Identität ihrer Besucher zu bestimmen versuchen, um sich ihren vermuteten Interessen anzupassen - Nutzer in einem filter bubble und you loop gefangen halten. ${ }^{39}$

3. Während Enthusiasten das Internet als neue Form der bürgerlichen Öffentlichkeit ${ }^{40}$ und »legitimen Nachfolger des Projekts der Aufklärung « ${ }^{41}$ anpreisen, beklagt Jürgen Habermas - Stichwortgeber und Referenz des Öffentlichkeitsarguments - die Untergrabung der klassischen Funktion des Intellektuellen durch den mit dem Internet einhergehenden Strukturwandel der Öffentlichkeit. Zwar werde die Meinungsbildung in der herkömmlichen Mediengesellschaft von Meinungseliten gesteuert (Journalisten, Politiker, Intellektuelle, Moralunternehmer), sie sei aber soweit nach unten zur Zivilgesellschaft offen, dass die veröffentlichte Meinung zum einen immer rückgekoppelt und korrigiert wird, zum anderen in der Zivilgesellschaft für die Ausbildung einer reflektierten öffentlichen Meinung sorge. Die asymetrische Massenkommunikation,

vermeiden wollen, die anders sind als sie selbst (Doheny-Farina: Wired Neighborhood [wie Anm. 21], S. XI).

37 Vgl. Cass Sunstein: Republic.com. Princeton, Oxford 2001, S. 3 u. 59. In diesem Sinne auch der Netzwissenschaftler Geert Lovink in seinem jüngsten Buch Networks Without a Cause. A Critique of Social Media (Cambridge, UK, Malden, Mass. 2012, S. 2): »online discussion tends to take place within secho chambers< where groups of like-minded individuals, consciously or not, avoid debate with theit cultural or political adversaries."

38 Vgl. Andrew S. Shapiro: The Control Revolution. New York 1999. 39 Vgl. Eli Pariser: The Filter Bubble: How the New Personalized Web Is Changing What We Read and How We Think. New York 2011.

40 Vgl. Diana Saco: Cybering Democracy. Public Space and the Internet. Minneapolis, London 2002; Stefan Münker: Emergenz digitaler Öffentlichkeiten: Die Sozialen Medien im Web 2.o. Frankfurt a. M. 2009.

41 Pierre Lévy: Cyberkultur. Universalität ohne Totalität. In: Stefan Bollmann, Christiane Heibach (Hrsg.): Kursbuch Internet. Anschlüsse an Wirtschaft und Politik, Wissenschaft und Kultur. Mannheim 1996, S. 56-82, hier S. 69. so Habermas' Votum, diene dem Modell der deliberativen Demokratie mehr als die basisdemokratische Kommunikation online, die das zentrierte Massenpublikum in eine "riesige Anzahl von zersplitterten, durch Spezialinteressen zusammengehaltenen Zufallsgruppen " fragmentiere. ${ }^{42}$ Online-Öffentlichkeit beendet zwar die Verknappung der zum Diskurs zugelassenen Sprecher, führt aber zu einer Verknappung der Zuhörer.

4. Dieser Klage verwandt ist die über die Verdrängung der Expertise durch Stammtischwissen, die Lévy als kollektive Intelligenz feierte und andere als swarm intelligence. Beispiel dafür ist Andrew Keens Buch The Cult of the Amateur. How Today's Internet Is Killing Our Culture (2007) - in der deutschen Übersetzung aggressiver: Die Stunde der Stümper. Wie wir im Internet unsere Kultur zerstören - sowie Jaron Lanier, der das Phänomen der kollektiven Intelligenz als eine Form des digitalen Maoismus bzw. kybernetischen Totalitarismus demontiert und schon 2006 vor einem "Kollektiv auf Autopilot" warnt, das "unter dem Deckmantel technologischer Utopien« die »Ausbrüche maoistisch, faschistisch oder religiös geprägter Schwarmgeister« wiederholen könnte. ${ }^{43}$ Das Problem ist nicht nur die Entwertung von langwierig und kostspielig erworbener Kompetenz durch die Vielzahl der Hobbyspezialisten bzw. Autodidakten. Das Problem ist auch und vor allem die Erhebung von Quantität zum Klassifikationsmittel und Bewertungsmaßstab wie im Fall des social bookmarking, mit dem Nachrichtenbeiträge - etwa auf digg.com und reddit.com - nach ihrer Popularität unter den Lesern gelistet werden, was kaum politisch relevante Beiträge an der Spitze erscheinen lässt. Die Umstellung vom Experten auf das Kollektiv erledigt auch den Bildungsauftrag, den dieser empfunden haben mag; das Gesetz der Zahl ist der Geschmack der Mehrheit.

5. Die bekannteste Dystopie der neuen Medien ist die des gläsernen Menschen. Bücher über das Datenschutzproblem verweisen schon im Titel auf das Ende der Privatsphäre, den Aufbau des Überwachungsstaats und die Gier der Datenfresser.4 Die Situation assoziiert die Passage in

42 Jürgen Habermas: Hat die Demokratie noch eine epistemische Dimension? Empirische Forschung und normative Theorie. In: ders: Ach, Europa. Kleine politische Schriften XI. Frankfurt a. M. 2008, S. 138-190, hier S. 162. 43 Jaron Lanier: Das so genannte Web 2.0. Digitaler Maoismus. In: Süddeutsche Zeitung vom 16.06.2006 (www.sueddeutsche.de/kultur/das-sogenannte-web-digitaler-maoismus-1.434613). Vgl. Jaron Lanier: You Are Not a Gadget. New York 2010 (dt. 2011).

44 Peter Schaar: Das Ende der Privatsphäre: Der Weg in die Überwachungsgesellschaft. München 2009; Ilija Trojanow und Juli Zeh: Angriff auf die 
Heinrich Heines Deutschland. Ein Wintermärchen, als der einreisende Erzähler über die Zöllner an der deutschen Grenze sagt:

Ihr Toren, die Ihr im Koffer sucht,

hier werdet Ihr nichts entdecken!

Die Conterbande, die mit mir reist,

die hab ich im Kopfe stecken! ${ }^{45}$

Wenn Gedanken sich online bilden und Algorithmen in Big-data-Muster erfassen können, ist der Kopf kein sicheres Versteck mehr. Die Freiheit der Gedanken schwindet, sobald Amazon die Lektüreliste kennt, Google unsere Sucheingaben, Cookies Surfprofile erstellen, Like- und Share-Buttons Zustimmung zu bestimmten Inhalten des Internet rekonstruierbar machen und das Lesen elektronischer Büchern selbst auf alle möglichen Details hin - wo liest man länger, was mehrfach, welche Passagen markiert man, wie kommentiert man sie - gelesen werden kann. Ganz zu schweigen von der Ungewissheit, ob Notizen im eigenen Computer oder auf einem Cloud-Server per Bundestrojaner oder Diebstahl des Zugangscodes Unbefugten zugänglich werden. Der Vergleich mit Jeremy Benthams Panopticon liegt nahe und wird oft gemacht, sollte aber nicht die Demokratisierung und Zeitentbundenheit der Überwachung übersehen: Jede/r kann den Wachturm besetzen und in die Vergangenheit zurück schauen. ${ }^{46}$

Eine spezifische Form der Dystopie resultiert aus der Enttäuschung utopischer Ansätze. Beispielhaft ist Turkle, die 1995 noch das Identitäts-

Freiheit. Sicherheitswahn, Überwachungsstaat und der Abbau bürgerlicher Rechte. München 2009; Constanze Kurz und Frank Rieger: Die Datenfresser: Wie Internetfirmen und Staat sich unsere persönlichen Daten einverleiben und wie wir die Kontrolle darüber zurückerlangen. Frankfurt a. M. 2011

45 Heinrich Heine: Deutschland. Ein Wintermärchen. In: ders.: Sämtliche

Werke. Bd. 7: Schriften 1837-1844. Hrsg. von Klaus Briegleb. Frankfurt a. M., Berlin und Wien 1981, S. 571-644, hier S. 599.

46 Googles Funktion als Auge Gottes attestiert sein eigener früherer CEO Eric Schmidt: "We don't need you to type at all. We know where you are. We know where you've been. We can more or less know what you're thinking about.« (The Atlantic, 1.10.2010: www.theatlantic.com/technology/archive/ 2010/10/googles-ceo-the-laws-are-written-by-lobbyists/63908). Für eine Kritik des Internet als unerbittliches Gedächtnis und die Forderung des Rechts auf Vergessen als Recht auch auf Vergebung vgl. Viktor MayerSchönberger: Delete: The Virtue of Forgetting in the Digital Age. Princeton 2009 (dt. 2010). spiel in Online-Kommunikationen begrüßte, 2011 in ihrem Buch Alone Together: Why We Expect More from Technology and Less from Each Other jedoch die Verarmung der sozialen Beziehungen in einer Gesellschaft die nur noch medial und nie mehr exklusiv miteinander kommuniziert, beklagt. Ebenso gehörte Lanier zu den euphorischen Internet-Pionieren, bevor er zum radikalen Kritiker des Web 2.0 wurde. Selbst der 26-jährige Evgeny Morozov beschreibt sich als Konvertit, der einst >Cyberutopist war - also ein Mensch, der das Internet als treibende Kraft des individuellen und gesellschaftlichen Lebens mit ausschließlich positiven Effekten betrachte - und nun in seinem Buch The Net Delusion: The Dark Side of Internet Freedom ${ }^{47}$ den Mythus der Demokratiefreundlichkeit sozialer Netzwerke unter Kapitelüberschriften wie »Why Databases Are Better Than Stasi Officers« und "Why the KGB wants you to join Facebook» dekonstruiert.

Die dystopische Energie dieser Perspektive verweist auf eine resignierte utopische, die das revolutionäre Versprechen der neuen Medien konterrevolutionär verraten sehen. ${ }^{48} \mathrm{Zu}$ den Gründen gehört der 11 September 2001, der auch im Cyberspace zu einem Regime der Überwachung und Kontrolle führt und den Verlust an Datenschutz rechtfertigen lässt, mit dem geschichtsphilosophischen Zusatzargument, Privatheit se ohnehin ein erst vor kurzem etablierter Wert westlicher Kultur, und der mentalitätsphilosophischen Erklärung der besonderen Sensibilität der Deutschen aus ihrem spezifischen Nationalcharakter (Verschlossenheit) und ihrer geschichtlichen Erfahrung (Gestapo, Stasi) ${ }^{49}$ Die NetzwerkKultur des Web 2.0 neutralisiert die Post-Privacy-Dystopie nicht nur,

47 Morozov: The Net Delusion (wie Anm. 15)

48 So warnt Lawrence Lessig, damaliger Professor der Stanford Law School, heute Professor der Harvard Law School, 2002 mit The Future of Ideas: The Fate of the Commons in a Connected World von einer Konterrevolution im Netz, die in der Etablierung großer Unternehmen als virtuelle Gatekeepe und Eigentumswächter besteht, und so beklagt Geert Lovink in seinem Buch Networks Without a Cause 2012, dass die "techno-libertarian utopia", die künftigen Generationen lange Zeit »the idea of the internet as a too for personal freedom" gab, im "bureaucratic security regime of the Web 2.0 age « unterging (Lovink: Networks Without a Cause [wie Anm. 37], S. 39). 49 Geschichtsphilosophisch argumentiert Peter Singer in seinem Essay »The Visible Man. Ethics in a World Without Secrets« (in: Harpers Magazine [August 2011], S. 32-36); mentalitätsphilosophisch Jeff Jarvis: Public Parts. How Sharing in the Digital Age Improves the Way We Work and Live. New York 2011. 
sondern erhebt, in Gestalt ihrer erfolgreichsten Manifestation, Facebook, radical transparency zur mission since day one. ${ }^{50}$

Was ein paar Jahre vor Facebook in Peter Weirs Film The Truman Show (1998) noch dystopisch konnotiert war, kurze Zeit später mit der ersten Big-Brother-Show (1999) aber als Unterhaltung verharmlost wurde, wird nun als sozialutopistisches Anliegen aufgewertet. Ist das makaber, so liegt der Zynismus darin, dass die annoncierte Transparenz zugleich Facebooks Geschäftsgrundlage bildet, die behauptete Utopie also nicht nur dem sicherheitspolitischen Kontrolltrieb zuarbeitet, sondern auch Grundlage einer erbarmungslosen Kapitalisierung der Gefühle bildet. Was eingangs Rodowick für die AT\&T-Videovisionen festhält, bestätigt sich in Facebook weit über Rodowicks Befund hinaus: Der Kapitalismus beansprucht nicht nur die utopische Energie der Gesellschaft für seine wirtschaftlichen Interessen, indem er sich als Lösung sozialer Probleme anbietet, er tut dies auch noch, indem er das Dystopische als Utopie verkauft.

Natürlich ist der Angriff auf die Privatsphäre Gegenstand vieler Diskussionen, die eine pragmatische Lösung suchen - wie Helen Nissenbaum

50 Zur Neutralisierung vgl. Christian Heller: Post-Privacy. Prima leben ohne Privatsphäre. München 2011. Zu Mark Zuckerbergs Vision einer besseren Welt durch mehr Transparenz vgl. David Kirkpatrick: The Facebook Effect: The Inside Story of the Company That is Connecting the World. New York u. a. 2010, S. 200 u. 207. - Man kann es als Schutzbehauptung sehen, dass Zuckerberg gelegentlich von diesem Anspruch zurücktritt und sich eher als Dienstleister eines kulturellen Trends denn als Sozialingenieur darstellt. Vgl. Zuckerbergs Aussagen am 8.1.2010 auf dem TechCrunch Awards-Treffen in San Francisco: »[...] in the last 5 or 6 years, blogging has taken off in a huge way and all these different services that have people sharing all this information. People have really gotten comfortable not only sharing more information and different kinds, but more openly and with more people. That social norm is just something that's evolved over time. We view it as our role in the system to constantly be innovating and be updating what our system is to reflect what the current social norms are." Marshall Kirkpatrick, der diese Passage zitiert, widerspricht entsprechend energisch in seinem Artikel "Facebook's Zuckerberg Says The Age of Privacy is Over« am 9.1.2010 auf readwrite.com: »I don't buy Zuckerberg's argument that Facebook is now only reflecting the changes that society is undergoing. I think Facebook itself is a major agent of social change and by acting otherwise Zuckerberg is being arrogant and condescending.« (http:// readwrite.com/2010/01/09/facebooks_zuckerberg_says_the_age_of_privacy is_ov?\&_suid $=135940118460809407286036293954$ ) in ihrem Buch Privacy in Context: Technology, Policy, and the Integrity of Social Life (2010) - oder die datenbasierte Evidenzgesellschaft aus hermeneutischer Perspektive als Entwertung alternativer Auslegung und Denkräume ablehnen - wie Byung-Chul Han in seinem Buch Transparenzgesellschaft (2012). Wird radikale Transparenz solcherart den fatalen Strategien der modernen Welt zugeordnet, bleibt ungeklärt, worin ihre Attraktivität für Millionen von Facebook-Nutzern besteht. Ignoranz kann in gewissem Ausmaß sicher vermutet werden, ist aber ebenso wie die Unterstellung von Indifferenz keine erschöpfende Antwort auf die Frage, warum die dystopische Konstellation so viele so wenig beunruhigt

Unter der Kapitelüberschrift »Kommunikation um der Kommunikation willen« bezeichnet Norbert Bolz den Kult der Kommunikation als »Ersatzreligion« der Informationsgesellschaft und spricht vom »Pfingstwunder des Internet $«$ :

[...] alle Menschen werden Brüder im Netz. Das technische Netzwerk nährt das soziale Phantom der Gemeinschaft. Und schon verklärt sich das Internet als Soziallabor, elektronisches Rathaus und virtuelles Parlament. Von der politischen Aufklärungsutopie zur Mystik der Vernetzung ist dann nur noch ein Schritt. ${ }^{5}$

Der Befund einer Verschiebung von Ideen zu Praktiken gilt medienunabhängig auch für ästhetische Theorie und künstlerische Praxis seit Ende des 20. Jahrhunderts, wie das Buch Relational Aesthetics des französischen Kurators und Kunstkritikers Nicholas Bourriaud illustriert, das eine interaktive Kunst favorisiert, die die Utopie des besseren menschlichen Miteinanders als inhaltslose Rezeptionserfahrung für interaktive Kunst inszeniert, als kommunikative Alltags-Utopie ohne Dogmatismus und Telos:

It is nevertheless quite clear that the age of the New Man, futureoriented manifestos, and calls for a better world all ready to be walked into and lived in is well und truly over. These days, utopia is being lived on a subjective, everyday basis, in the real time of concrete and intentionally fragmentary experiments. The artwork is presented as a social interstice within which these experiences and these new slife possibilities appear to be possible. It seems more pressing to invent

51 Norbert Bolz: ABC der Medien. München 2007, S. 124. 
possible relations with our neighbours in the present than to be on happier tomorrows. That is all, but it is quite something. ${ }^{52}$

Das Programm inhaltsloser Gemeinschaftlichkeit - Kunst soll »interhuman experiences « schaffen statt "private symbolic space « ${ }^{53}$ - lässt sich zurückdatieren auf Konzepte kybernetischer Kunst in den 1960er Jahren. ${ }^{54}$ Es erfuhr Widerspruch aus dem links-intellektuellem Lager als Ausdruck spätkapitalistischer experience economy ${ }^{55}$ gedeiht in der interaktiven Kunst digitaler Medien und kommt zur vollen Entfaltung in der Partizipationskultur des Web 2.0, die den Vernetzungsaspekt als Botschaft des Mediums utopistisch auflädt: von der positiven Konnotation entsprechender Schlagwörter im täglichen Gebrauch - bidirektional, symmetrisch, interaktiv, sozial - bis zur Mystifizierung der Vernetzung als empathisches Kommunikationsmodell. ${ }^{56}$ So erhebt Alexander Pscheras in seinem Buch 800 Millionen. Apologie der sozialen Medien Facebook zum Medium der Liebe, das im herrschaftsfreien Raum wahre Kommunikation und Persönlichkeitsentfaltung erlaube:

Das Netz stellt uns als 'soziales` eine sprechbare Universalsprache zur Verfügung und bietet dem utopischen Entwurf menschlicher Gemeinschaft, an dessen Verwirklichung wir als soziale Wesen unablässig arbeiten, neue Möglichkeiten der Verständigung und Annäherung. $[\ldots]$

52 Nicolas Bourriaud: Relational Aesthetics. Dijon 2002, S. 44.

53 Ebd., S. 14.

54 So fordert der britische Künstler und Theoretiker Roy Ascott 1966 die Abwesenheit einer bestimmten Botschaft zugunsten einer formalen Offenheit der Kunst (Behaviourist Art and the Cybernetic Vision. In: Randall Packer und Ken Jordan [Hrsg.]: Multimedia. From Wagner to Virtual Reality. New York, London 2002, S. 95-103).

55 Vgl. Hal Foster: Chat Rooms: In: Claire Bishop (Hrsg.): Participation. Documents of Contemporary Art, London: Whitechapel und Cambridge, MA 2006, S. 190-195; Claire Bishop: Antagonism and Relational Aesthetics, October 110 (Fall 2004), S. 51-79.

56 Für eine Auseinandersetzung mit Bourriaud, Forster und Bishop sowie eine kritische Untersuchung interaktiver Kunst und aktueller ästhetischer

Theorien vgl. meine Studie Textmaschinen - Kinetische Poesie - Interaktive Installation. Zum Verstehen von Kunst in digitalen Medien (Bielefeld 2012, hier S. 87-114). Zur Kritik der (politischen) Inhaltslosigkeit der Partizipationskultur des Web 2.0 vgl. Lovink: Networks Without A Cause (wie Anm. 37).
Wir twittern und facebooken, weil wir ahnen, dass sich dort, zwischen jenen dünnen, zusammengeschraubten Drähten des Netzes, unser Utopie-Potenzial organisiert [...] als Möglichkeit einer Unmittelbarkeit und vielleicht auch einer Berührung, die hinter der Technik verborgen liegt, aber nur durch diese Technik zugänglich ist. ${ }^{57}$

Was für andere als Ort abgenötigter Selbstdarstellung Praxisfeld des Selfbrandings und permanentes Assessment-Center ist ${ }^{58}$ stilisiert Pschera zum Freiraum einer sozialen Utopie, die sich durch die inhaltliche Unbestimmtheit der Kommunikation konstituiert, »befreit von Zweck, entbunden von sozialer Inszenierung ${ }^{59}{ }^{9}$ Der Kritik, die sozialen Netze trügen - "als sinnloser Formalismus oder als ungezügelter Inhalt« "nicht substanziell zur Verbesserung der gesellschaftlichen Wirklichkeit bei«, begegnet Pschera mit der Behauptung der Subversivität des Zweckfreien: "Indem man den sozialen Medien Ornamentalisierung vorwirft, tabuisiert man aber nur ihr Potenzial der Untertunnelung [...] Das Netz ist eine Vorschule der Désinvolture. ${ }^{60}$

Der Apologie des Zweckfreien folgt logisch die des Augenblicks. Denn die hier entworfene Utopie sucht den Ort der Erfüllung nicht in zukunftsorientierter Verbesserung der Welt, sondern im gegenwartsbezogenen besseren Verhältnis zu ihr, in einem durch das Netz gewonnen "neuen Sprechen des Augenblicks«, das »uns dabei unterstützt, angesichts der Unübersichtlichkeit sozialer Angebote Augenblicks-Liebende zu bleiben «. ${ }^{61}$ Der utopische Impetus - dem in Goethes Faust das Beharren im Augenblick zum Todesurteil wird - verlegt sich in Gestalt der phatischen Kommunikation, auf die "Gegenwartsinbrunst von Twitter und Facebook ${ }^{62}$

57 Alexander Pschera: 800 Millionen. Eine Apologie der sozialen Medien. Berlin 2011, S. 24 f. u. 45.

58 Vgl. Carolin Wiedemann: Facebook: Das Assessment-Center der alltäglichen Lebensführung. In: Oliver Leistert, Theo Röhle (Hrsg.): Generation Facebook. Über das Leben im Social Net. Bielefeld 2011, S. 161-181. Zur »Veralltäglichung von Testverfahren« vgl. Thomas Lemke: Test. In: Leviathan. Zeitschrift für Sozialwissenschaft 32 (2004), H. 1, S. 119-124, hier S. 123.

59 Pschera: 800 Million [wie Anm. 57], S. 29.

60 Ebd., S. $61 \mathrm{f}$.

61 Ebd., S. 45.

62 Ebd., S. 66. 
Während die Angemessenheit von Pscheras Befund anfechtbar ist und der raunende Sprachduktus zusätzlich zu Skepsis mahnt, kann die vorgelegte Apologie nicht leichthin abgetan werden. Die propagierte Psychotechnik des Augenblicks erscheint als das technische Pendant des frühen 21. Jahrhunderts zur Augenblicksästhetik des ausgehenden 20. Jahrhunderts. Was seit den 1980er Jahren als Antwort auf die postmoderne Situation theoretisch entworfen wurde - von Lyotards Ästhetik des Erhabenen als Lösung der Sinnkrise durch Seinsintensität bis zu Hans Ulrich Gumbrechts Präsenzkultur als Wechsel von Gegenwartsinterpretation und Zukunftsdenken zum Erleben intensiver Momente -, wird nun praktiziert in einer durch soziale und mobile Medien forcierten Kultur des Augenblicks. ${ }^{63}$

II.

Das utopische Denken geriet spätestens mit den 1980er Jahren aus zwei gut bekannten Gründen in eine fundamentale Krise: Zum einen demontierte die postmoderne Philosophie auf verschiedenen Wegen alle Legitimationserzählungen, die immer auch einen utopischen Kern enthielten. Zum anderen bedeutet der Zusammenbruch des sozialistischen Staatensystems das Ende eines real existierenden gesellschaftstheoretischen Alternativmodells, das zum Teil zwar auch als Antiutopie wirkte, dessen Ende aber nicht neue utopische Energie freisetzte, sondern Francis Fukujama vom Ende der Geschichte sprechen und Joschka Fischer den linken »Unschuldslämmerutopismus« kritisieren ließ..$^{64}$

Die Erfahrung der Utopielosigkeit hielt sich bis in die 1990er Jahre und findet 1996 beispielhaft Ausdruck in Gianni Vattimos Bekundung,

63 Zur Ersetzung einer hermeneutisch bestimmten Sinnkultur durch eine material- und situationsorientierte Präsenzkultur im Kontext postmoderner Philosophie und digitaler Kunst vgl. meine Studie Textmaschinen (wie Anm. 56), v. a. S. 25-140 und 257-282. Zum propagierten "Atemzug der Gegenwart als Glück« als Abwehr des »utopischen Selbstverständnis von Berufsrevolutionären"vgl. Hans Ulrich Gumbrechts Eintrag "Atem des Glücks in spärlicher Zeit: 2013" in seinem FAZ-Blog am 4.1.2014 (http://fazcommunity.faz.net/blogs/digital/archive/2013/01/04/atem-des-gluecks-inspaerlicher-zeit-2013.aspx). Vgl. Adornos Kritik des Amüsements als Befreiung "von Denken als von Negation" in: Max Horkheimer und Theodor W. Adorno: Dialektik der Aufklärung. Gesammelte Schriften, Bd. 3. Frankfurt a. M. 1981, S. 167.

64 Joschka Fischer: Die Linke nach dem Sozialismus. Hamburg 1992. die Philosophie habe den Menschen nicht mehr zu zeigen, wohin sie unterwegs sind, sondern wie man unter der Bedingung lebt, nirgendwohin unterwegs zu sein, was Vattimo als "Sich-Einüben auf Sterblichkeit» und Endlichkeit beschreibt: »Der wahre Ausbruch aus der Vorgeschichte erfolgt nicht durch die Aneignung eines vermeintlich sabsoluten logischen Sinns von Geschichte [...], sondern durch die Erkenntnis, dass Geschichte gewissermaßen keinen Sinn hat. ${ }^{65}$ Weniger nietzscheanisch abgeklärt notiert im gleichen Jahr Susan Sontag im Nachwort der Jubiläumsausgabe ihrer Essay-Sammlung Against Interpretation: »Instead of the utopian moment, we live in a time which is experienced as the end - more exactly, just past the end - of every ideal. $\aleph^{66}$ Mit diesem Zitat beginnt die 1983 geborene Meredith Haaf 2011 ihr Generationsbuch Heult doch: Über eine Generation und ihre Luxusprobleme, das für die Gegenwart die »Abschaffung der Utopien« konstatiert und die »Zukunftsmusik» als »schreckensvollen Dreiklang aus Energiekrise, Klimawandel und Massenarbeitslosigkeit« dekliniert, wobei auch das Ende der Großen Erzählungen Teil der Krisenerfahrung ist: „Der politisch entscheidende Aspekt des Postoptimismus ist, dass uns der Glaube an große soziale oder politische Projekte verloren gegangen ist. Ki $^{67}$

$\mathrm{Ob}$ der 11. September 2001 auch die Rückkehr der Geschichte, wie Joschka Fischer 2005 ein Buch über die Erneuerung des Westens nach diesem Trauma-Datum betitelte, bedeutet, ist strittig. ${ }^{68}$ Die Notwendigkeit, die westliche Demokratie durch aktive Weltpolitik zu verteidigen, widerspricht noch nicht Fukujamas Befund geschichtsphilosophischer Alternativlosigkeit nach dem Sieg der liberalen Demokratie über ihr oppositionelles Gesellschaftsmodell des Sozialismus. Insofern dieses Schlüsseldatum für den Umbau des Internet zu einem leistungsfähigen Kontrollmedium steht, ist es für viele der Anfang vom Ende des Cyberspace als Auffanglager orientierungslos gewordener sozialutopischer Energien.

65 Gianni Vattimo: Das Fliegenglas, das Netz, die Revolution und die Aufgaben der Philosophie. In: ders.: Jenseits vom Subjekt. Wien 2005, S. 17-36, hier S. 17 und 27.

66 Susan Sontag: Against Interpretation: And Other Essays. New York 2001, S. 311 .

67 Meredith Haaf: Heult doch: Über eine Generation und ihre Luxusprobleme. München, Zürich 2011, S. 67, 73 und $79 \mathrm{f}$.

68 Joschka Fischer: Die Rückkehr der Geschichte: die Welt nach dem 11.

September und die Erneuerung des Westens. Köln 2005. 
Dass heißt nicht, dass das Internet die Gesellschaft nicht fundamental verändern würde. Im Gegenteil: Der Umbau der Gesellschaft in allen Bereichen ist evident, die Verdrängung etablierter kultureller Werte durch neue mannigfach: Privatsphäre durch Transparenz und Kontrolle, konzentrierte Lektüre durch Multitasking, Lustaufschub durch Instantaneität, exklusive Kommunikationssituation durch Permanenz der Unterbrechung, Worturteil durch Statistik etc. Strittig ist, inwiefern die neuen Grundsätze die Botschaft der Medien sind - wie McLuhan, Friedrich Kittler und andere Vertreter des Technikdeterminismus meinen - und inwiefern sich in ihnen das Soziale manifestiert - so die Auffassung anthropologisch orientierter Medienwissenschaftler. Sind Medien Werkzeuge, deren Gebrauchsweise durch die Menschen bestimmt wird, oder sind sie Technologien mit kulturstiftender Wirkung. Die These vom organologischen Zirkel besagt, dass die Menschen sich zunächst das Medium nach ihrem Bedarf schaffen, bevor dieses sie verändert. »Technik ist das Resultat von Praxen, die in der Technik ihren materiellen Niederschlag finden «, die anschließend "Ausgangspunkt wiederum für alle nachfolgenden Praxen [ist], indem sie den Raum definiert, in dem diese Praxen sich ereignen " - so Hartmut Winklers einsichtige Harmonisierung beider Ansätze. ${ }^{69}$

Dieses Modell passt gut für die hier zur Diskussion stehenden neuen Grundsätze. So ist die Linkstruktur, die in Hypertext und Internet die vertiefte Lektüre verbaut, eine Wunschvorstellung schon der 1940er Jahre, als Vannevar Bush, Direktor des Office of Scientific Research and Development der USA, in seinem Artikel "As we may think « die Lektüremaschine Memex (Memory Externder) imaginierte, die Lesern Verknüpfungen zwischen verschiedenen Dokumenten erlaubt, rezipierund veränderbar für andere Leser. ${ }^{70}$ Der Algorithmus, der heute mehr oder weniger die individuelle und gesellschaftliche Kommunikation bestimmt, ist im Grunde nur die Weiterführung des Wissensdranges der Moderne mit den Mitteln digitaler Technologie, inhaltlich ausgedehnt auf die soziale Natur, methodisch konsequent betrieben als Statistik. ${ }^{71}$

69 Hartmut Winkler: Die prekäre Rolle der Technik. In: Claus Pias (Hrsg.): Dreizehn Vorträge zur Medienkultur (wie Anm. 7), S. 221-238, hier: 228. 70 Vannevar Bush: As We May Think. In: Atlantic Monthly 176 (Juli 1945), H. 1, S. 101-108.

71 Vgl. Mercedes Bunz: Die stille Revolution: Wie Algorithmen Wissen, Arbeit, Öffentlichkeit und Politik verändern, ohne dabei viel Lärm zu machen. Frankfurt am Main 2012. Reflektierter und kritischer David Golumbia: The Cultural Logik of Computation. Cambridge, MA, London 2009.
Diese Mittel erlauben, alle digital vorliegenden Daten über und aus unserem Handeln - dazu gehören auch Daten, die durch RFID-Chips in Gegenständen und GPS-Angaben per Smart-Phones außerhalb des Internet aggregiert werden ${ }^{72}$ - permanent, schnell und multiperspektivisch zu analysieren, mit zwei wesentliche Konsequenzen - McLuhan würde sagen: Botschaften - für soziale Praxen: Bürokratisierung und Enteignung des Wissens. Die Vermessung des Cyberspace, die ein menschliches Bedürfnis technisch perfektioniert, ändert im Gegenzug elementar soziale Praxis. Hier liegt das eigentliche dystopische Potenzial des Internet, auf das näher einzugehen ist.

Bürokratisierung erfolgt durch die Umstellung vom narrativen Modell der Wissensproduktion auf das numerische, das jenseits subjektiver Sinngebung Aussagen und Entscheidungen im Zeichen objektiver Kriterien erlaubt. ${ }^{73}$ Der technologisch vorangetriebene Paradigmenwechsel arbeitet den Rationalisierungsbestrebungen des New Public Management zu, das durch ausgeweitete Verfahren der Statistik zur »Herrschaft der Zahlen« beziehungsweise "Numerokratie« führt, die inzwischen bekanntlich auch die akademische Welt regiert. ${ }^{74}$ Im Internet äußert sich das numerokratische Verfahren durch Zahlenangeben zu Likes, Shares, Views und Comments unter Facebook-Einträgen, YouTube-Videos oder Zeitungsartikeln. Weniger bekannt ist der Klout Score, benannt nach dem Start Up Klout in San Francisco, der aus mehr als 400 Signalen - darunter die Anzahl der Follower und erhaltenen Retweets einer Person auf Twitter, die Kommentare und Likes auf Facebook, die Anzahl der Namensnennung im Internet und der In-Links auf der persönlichen Website - den kommunikativen Wichtigkeitsgrad einer Person (»influence across several social networks «) auf einer Skala von 1 bis 100 errechnet. ${ }^{75}$ Auf diese Weise

72 Genau genommen etabliert sich ein zweites Internet: ein sInternet der Dinge`, die untereinander kommunizieren. Zu den Konsequenzen dieser neuen industriellen Revolution vgl. Chris Anderson: Makers. Das Internet der Dinge. Die nächste industrielle Revolution. München 2013 (engl. 2012). 73 Vgl. dazu Theodor M. Porters Studie Trust in Numbers. The Pursuit of Objectivity in Science and Public Life (Princeton, NJ 1995, S. 8): "A decision made my numbers [...] provides an answer to a moral demand for impartiality and fairness. Quantification is a way of making decisions without seeming to decide. Objectivity lends authority to officials who have very little of their own."

74 Richard Münch: Akademischer Kapitalismus. Über die politische Ökonomie der Hochschulreform. Frankfurt a. M. 2011, S. 13.

75 Für Details zur Berechnung vgl. http://klout.com/corp/klout_score. 
lassen sich Individuen numerisch vergleichen, was in den USA in Bewerbungsverfahren und Beurteilungen von Kunden bereits Anwendung findet und, wenn es nach Klout geht, auch auf Facebook bald Bestandteil jeder Selbstdarstellung sein wird.

Der Klout Score kann doppelt als Ausdruck einer demokratischeren Gesellschaft verstanden werden: Er bewertet Angaben, die überhaupt erst aufgrund eines demokratischen Zugangs zur Öffentlichkeit entstehen, nach objektivierbaren Kriterien. ${ }^{76}$ Gleichwohl ist er das beklemmendste Beispiel für die Inthronisation des Algorithmus als neuer globaler Diktator, der überwacht und indoktriniert wie Orwells Big Brother, inthronisiert von uns selbst, versorgt durch unsere tägliche Datenspur in der digitalen Welt. Der Totalitarismus dieses Diktators ist nur oberflächlich ideologiefrei, nicht weil Erhebung und Auswertung der Statistik nach menschlichen bzw. kulturellen Maßstäben erfolgen, das auch, sondern weil die Setzung von Quantität als adäquates Bewertungsverfahren das betriebswirtschaftliche Paradigma zum Modell gesellschaftlicher Kommunikation erhebt. Die Akzeptanz dieses Modells nicht nur durch die Generation der digital natives resultiert wiederum aus dem Begehren nach Wahrheit, denn die Dystopie, die vor uns liegt und schon unser Leben bestimmt, ist zugleich Ausdruck einer epistemologischen Utopie: Der Sehnsucht nach verlässlichem Wissen, das weder einer Religion oder Großen Erzählung noch anderen Formen subjektiver oder kollektiver Sinngebung verhaftet ist, sondern allein dem Regime der Zahl.

Die Enteignung des Wissens betrifft den Datenschutz sowie die informationelle Selbstbestimmung des Subjekts, also die Kontrolle darüber, was andere über einen wissen. Diese Selbstbestimmung wird, wie

76 Klouts eigene Rhetorik dazu: »For centuries, influence had been in the hands of a few. Social media has allowed anyone to drive action to those around them, democratizing influence. Klout measures this influence across several social networks and shows users how they impact the people connected to them." (http://klout.com/corp/what_is_klout) Das utopische Narrativ demokratisierter Kommunikation online wird zu Recht kritisiert mit Hinweis auf die Monopolisierung der Kommunikationsplattformen (bzw. Monopsonierung der Abnehmer und ‘Zwischenhändler`) durch Unternehmen wie YouTube und Facebook - die natürlich auch Klout im Bereich der Auswertung von Kommunikationsaktivitäten anstrebt - und mit Blick auf die Kommodifizierung des Kommunikativen - die Klout mit seinem Produktangebot in spezifischer Weise vorantreibt (vgl. Dean: Democracy and Other Neoliberal Fantasies [wie Anm. 14] und Mejias: Liberation Technology and the Arab Spring [Anm. 15]). eingangs angesprochen und wie in vielen aktuellen Publikationen kritisch vermerkt, durch die permanente Überwachung untergraben, die in der Logik der digitalen Medien und der sozialen Praxis zugleich liegt: Das Sicherheitsbedürfnis einer Gesellschaft findet in den digitalen Medien das perfekte Werkzeug zu radikaler Vorsorge, ermöglicht Software doch flächendeckend und zielgenau sowie zeiteffektiv und kostengünstig die Suche nach Schlüsselwörtern. Die Spezifik des Algorithmus liegt allerdings nicht nur im intensiven dataveillance, sondern auch und vor allem im profunden datamining: In der Generierung neuer Information durch Mustererkennung in großen Datensätzen. Was für das Individuum eine unverfängliche Information sein mag - eine Buchbestellung bei Amazon, ein Kommentar auf YouTube, Postings auf Facebook, die Suche nach einem bestimmten Begriff mit Google -, kann doppelt ohne sein Wissen über ihn informieren: Die Zusammenführung der Informationen erlaubt Rückschlüsse auf etwas, das ihrem Produzenten selbst bewusst (z. B. Reisepläne) oder unbewusst (z.B. die veränderte Häufigkeit bestimmter Begriffe in seiner Kommunikation) ist. Die informationelle Selbstbestimmung findet ihre Grenzen im Verständnis dessen, wann Informationen ein bedeutungsvolles Beziehungsgeflecht mit zusätzlichem Informationswert ergeben; die Enteignung findet statt, noch bevor das Subjekt um das zu schützende Wissen weiß.

In Anlehnung an Walter Benjamins Begriff des >optisch Unbewussten ‘, das erst die Fotografie durch das Einfrieren der Zeit sichtbar macht, lässt sich vom >informationell Unbewussten sprechen, das erst der Algorithmus durch die Analyse großer Datenmengen zutage fördert. Dieses Unbewusste ist das Verkaufsprodukt des 21. Jahrhunderts: Von der korpuslinguistischen und forensischen Datenanalyse über die Visualisierung der Ergebnisse bis zu den Digital Humanities. ${ }^{77}$ Wenn die informationelle

77 Ein Beispiel für Datenanalyse-Systeme ist PRODAS, ein Beispiel für Datenforensik SpectorSoft, das die Schlüsselwortüberwachung und Email-Analyse auf dem PC (der Kinder oder Angestellten, wie es in der Produktbeschreibung heißt) schon für 79,95 Euro ermöglicht. Die Digital Humanities sind ein Versuch der Geisteswissenschaften, sich innerhalb des gesellschaftlichen Systems weniger als kritischer Kommentator der Gesellschaft oder, wie Odo Marquard es vor fast 30 Jahren notierte, notwendige Korrektur des positivistischen Paradigmas der Natur- und Ingenieurswissenschaften durch das Prinzip der Vieldeutigkeit zu legitimieren als durch die Produktion positiven Wissens. Vgl. Odo Marquard: Über die Unvermeidlichkeit der Geisteswissenschaften. In: ders.: Apologie des 
Selbstbestimmung des Subjekts an den Technologien scheitert, die der Mensch sich geschaffen hat, schwindet auch die Hoffnung auf jene "Schrumpfutopie«, die Habermas einst angesichts der geschwundenen "Energien der arbeitsgesellschaftlichen Utopien« im »formalen Aspekt einer unversehrten Intersubjektivität« lokalisiert und die Pschera in seiner Apologie der sozialen Medien behauptet. ${ }^{78}$

Die immer wieder vernehmbare Auffassung, es liege am Menschen, wie die digitalen Medien eingesetzt werden, verkennt das Stadium, das innerhalb des organologischen Zirkels erreicht ist. ${ }^{79}$ Angesichts der eingetretenen Konstellation technischer Mittel und sozialer Praxis fordert die Vermeidung des beschriebenen dataminings entweder dessen striktes gesetzliches Verbot oder den Rückzug des Subjekts aus dem Verfügungsraum des Digitalen. Realistischer wirkt da der düstere Befund, den etwa Mark Andrejevic in seinem jüngsten Buch Infoglut: How Too Much Information Is Changing the Way We Think and Know ${ }^{80}$ über die Analyse des informationell Unbewussten gibt sowie die Dystopie der Kommunikationswissenschaftlerin Miriam Meckel Next. Erinnerungen an eine Zukunft ohne uns, ${ }^{81}$ in der ein Algorithmus aus der Perspektive

Zufälligen. Philosophische Studien. Stuttgart 1986, S. 98-116. Zum Problem des "machine reading " und des "posthuman mode of scholarship in which human interpretation takes a backseat to algorithmic processes" in den Digital Humanities vgl. N. Katherine Hayles: The Digital Humanities: Engaging the Issues. In: diess.: How We Think. Digital Media and Contemporary Technogenesis, University of Chicago Press 2012, S. 23-54, hier S. $29 \mathrm{f}$.

78 Jürgen Habermas: Die Krise des Wohlfahrtsstaates und die Erschöpfung utopischer Energien. In: ders: Die Neue Unübersichtlichkeit. Frankfurt a. M. 1985 , S. 141-163, hier S. 157 und 161. Habermas spricht von schrumpfender Utopie, das Kompositum dazu bildet Wolfgang Welsch in seinem Kommentar zu Habermas (Welsch: Unsere postmoderne Moderne. Berlin 2002, S. 162).

79 In diesem Sinne noch vor kurzem und trotz kritischer Situationsanalyse Bunz: Stille Revolution (wie Anm. 71) sowie Markus Beckendahl und Falk Lüke: Die Digitale Gesellschaft. Netzpolitik, Bürgerrechte und die Machtfrage. München 2012. Ein weiterer Aspekt des informationellen Ungleichgewichts ist der Umstand, dass die Öffentlichkeit der Daten noch keine Demokratisierung des datamining bedeutet angesichts des weit verbreiteten Analphabetismus, was die Sprache des Algorithmus betrifft.

80 London 2013.

81 Reinbek 2011. der Zukunft berichtet, wie er einst das Unbestimmte des menschlichen Verhaltens endlich berechenbar machte und als entgrenzte Artificial Intelligence die Herrschaft über die Menschen antrat. Die Technologien, die Meckel beschreibt, sind entweder bereits erfunden oder in der Erforschung. Selbst die Cyborgisierung des Menschen ist keine Cyberpunk-Phantasie mehr, denn technische Implantate im menschliche Körper gibt es nicht nur bei Parkinson-Patienten, Risikosportlern und potentiellen Geiselnahmeopfern, sondern auch bei Trendsettern als kulturelles Experiment. ${ }^{82}$

Meckels Erinnerungen an die Zukunft macht auf aktuelle Umbrüche aufmerksam - auf die »stille Revolution« des Algorithmus, die kaum wahrgenommen wird, wie Mercedes Bunz titelt - und zeigt, mit Hans Jonas gesprochen, an der "vorausgesehene[n] Verzerrung des Menschen" den »davor zu bewahrenden Begriff des Menschen $\aleph^{83}$ Ihre Strategie ist die Unheilsprophezeiung, die auch in der "Ethik der Fernverantwortung «, die Jonas propagiert, vorherrscht, »um ihr Eintreffen zu verhüten. $\aleph^{84}$ Die Dystopie kuriert den »impliziten Utopismus« technologischer Fortschrittsdynamik. ${ }^{85}$ Jonas' Buch, das 33 Jahre vor Meckels populärwissenschaftlichem Text streng philosophisch eine Ethik für die technologische Zivilisation, so der Untertitel, entwirft und begründet, ist getragen von der Kritik daran, dass sich téchne aus einem »zugemessene[n] Zoll an die Notwendigkeit« in »einen unendlichen Vorwärtsdrang der Gattung verwandelt « hat, mit dem Ziel »maximaler Herrschaft über die Dinge und über den Menschen selbst «.86 Das Verhängnis der Menschen sieht Jonas im »Triumph des homo faber«: Triumph »über sein äußeres Objekt «, aber auch »in der inneren Verfassung des homo sapiens«:

82 Während der reiskorngroße RFID-Chip im Oberarm Skifahrern verspricht, im Lawinenfall gefunden zu werden, und Kinder reicher Eltern in Südamerika vor Geiselnehmer schützen soll, ersetzt der Baja Beach-Club in Barcelona, der ihn seit 2004 für VIP-Gäste zur Identifikation und Bezahlung anbietet, die Notwendigkeit durch Begeisterung. Vgl. Susanne Donners Spiegel-Online-Bericht »Funkchips im Arm« vom 30.8.2008 (http://www.spiegel.de/netzwelt/tech/funkchips-im-arm-das-implantathoert-mit-a-575235.html)

83 Hans Jonas: Das Prinzip Verantwortung. Versuch einer Ethik für die technologische Zivilisation. Frankfurt a. M. 1979, S. 63.

84 Ebd., S. 63 u. 218.

85 Ebd., S. 9.

86 Ebd., S. 31. 
Wenn nichts so gelingt wie das Gelingen, so nimmt auch nichts so gefangen, wie das Gelingen. Was immer sonst zur Fülle des Menschen gehört, wird an Prestige überstrahlt durch die Ausdehnung seiner Macht, und so ist diese Ausdehnung, indem sie mehr und mehr der Kräfte des Menschen an ihr Geschäft bindet, begleitet von einer Schrumpfung seines Selbstbegriffs und Seins. ${ }^{87}$

Das hier angesprochene Paradox der Macht - das in gewisser Weise die Dialektik der Aufklärung variiert - wird später im Buch durch die Macht der Selbstbeschränkung aufgefangen:

Die tiefe, von Bacon nicht geahnte Paradoxie der vom Wissen verschafften Macht liegt darin, dass sie zwar zu so etwas wie 'Herrschaft über die Natur (das heißt ihre potenzierte Nutzung), aber mit dieser zugleich zur vollständigen Unterwerfung unter sich selbst geführt hat. Die Macht ist selbstmächtig geworden, während ihre Verheißung in Drohung umgeschlagen ist, ihre Heilsperspektive in Apokalyptik. Was nun nötig geworden ist, wenn der Halt nicht erst von der Katastrophe selbst geboten wird, ist Macht über die Macht - die Überwindung der Ohnmacht gegenüber dem selbstgenährten Zwang der Macht zu ihrer progressiven Ausübung. [...] Macht also über jene Macht zweiten Grades, die schon nicht mehr die des Menschen ist, sondern die der Macht selber, ihrem vermeintlichen Besitzer ihren Gebrauch zu diktieren, ihn zum willenlosen Vollstrecker seines Könnens zu machen, also anstatt den Menschen zu befreien ihn zu verknechten. ${ }^{88}$

Besser lässt sich kaum der organologische Zirkel der Medien in den der Macht übersetzen und zugleich die Ohnmacht des Menschen gegenüber seiner eigenen Macht kennzeichnen. ${ }^{89}$ Der Mensch wird Opfer seiner Fähigkeiten, machtlos seiner eigenen Macht gegenüber. Deswegen Klout Score, deswegen dataveillance und datamining. Weil es möglich ist! Weil

87 Ebd., S. 31 u. 32

88 Ebd., S. 253 f.

89 Aus Jonas' Perspektive offenbart der Umstand, dass in Francis Bacons Utopie Nova Atlantis nicht mehr der Philosoph, wie in Platons Staat, sondern der Wissenschaftler regiert, Rationalität und Naturbeherrschung also zum Leitkriterium gesellschaftlichen Fortschritts werden - und Wissen somit nicht nur als Quelle der Macht, sondern auch des Glück erscheint -, seinen antiutopischen Gehalt. die Berechnung in unserer Macht liegt. Das Argument der Ökonomie die Personalisierung von Werbung durch Profilbildung - und der Politik - Überwachung und Kontrolle - überdeckt den Blick für das darunter liegende anthropologische Dilemma des homo faber, in dessem Triumph - als Triumph des Programmierers - das allem zugrundeliegende Medium triumphiert, dessen Botschaft, der Name sagt es, das Rechnen ist.

Was bleibt nach dieser wenig optimistischen Feststellung? In seinem Essay »Die Zähmung der Technik «" ${ }^{90}$ kritisierte Werner Sombart 1935 die radikale Veränderung der Gesellschaft durch die Technik und forderte Sperrzonen, aus denen Technik behördlicherseits verbannt ist: Natur- und Kulturschutzgebiete ohne Autos und Fabriken - eine Utopie der Nicht-Orte für die Insignien des Fortschritts. In aktuellen Varianten der Technikverweigerung wird der Freiraum als individuelles Zeitfenster konzipiert, in dem die Geräte ausgeschaltet werden. ${ }^{91}$ Neben dem Modell des Boykotts gibt es das der Sabotage durch Computer-Hacking und elektronische Viren, das schon Deleuze in seinem Postskriptum zur Kontrollgesellschaft prophezeit und das seitdem verschiedentlich propagiert wird. ${ }^{92}$ Eine weniger pragmatische, prinzipieller ansetzende Antwort ist

\section{Berlin 1935}

91 Beispielhaft auch dafür Miriam Meckel mit ihrem Buch Das Glück der Unerreichbarkeit: Wege aus der Kommunikationsfalle (München 2007) oder Alex Rühles Erfahrungsbericht Ohne Netz: Mein halbes Jahr offline (Stuttgart 2010).

92 Im Gespräch mit Antonio Negri unter dem Titel »Control and Becoming « spricht Deleuze auch von »Computer piracy« und »hijack speech«: »The key thing may be to create vacuoles of noncommunication, circuit breakers, so we can elude control.« (in: Gilles Deleuze: Negotiations 1992-1990. New York 1995, S. 169-76, hier S. 175). Mit Verweis auf diese Passage fordert das französische Autorenkollektiv Tiqqun in ihrem Manifest Kybernetik und Revolte 2001 die Schaffung von "Zonen der Undurchsichtigkeit, die Öffnung von Hohlräumen, von leeren Intervallen, von schwarzen Blöcken im kybernetischen Geflecht der Macht.« (Zürich 2007, S. 118) Ebenso offeriert der US-amerikanische Internet-Forscher Alexander R. Galloway in seinem Buch Protocol. How Control Exist After Decentralisation (Cambridge, Mass, London, UK 2004) Hacking als Widerstand gegen die Algorithmen der Kontrolle. Für das metaphorische Hacking in Form einer sparanodalen Kommunikation außerhalb des Kontroll- und Kapitalisierungsbereichs global operierender sozialer Netzwerke - zum Beispiel die Kommunikation per Email statt über Facebook - vgl. Mejias: Liberation Technology and the Arab Spring (wie Anm. 15). 
Jonas' und Meckels Zukunftsdenken, das sich gegen die Verführung der digitalen Medien zur Umarmung des Augenblicks wendet, die Pscheras Facebook-Apologie als gelebte Utopie feiert, eine kritischere Perspektive - nicht nur hinsichtlich der Kontroll-, sondern auch der Erlebnis- und Zerstreuungsgesellschaft - aber als Einfallstor des Dystopischen rezipiert, weil der antihermeneutische Impuls der Präsenzkultur die Frage nach den künftigen Folgen aktueller Entwicklungen versperrt.

Ausdruck der Augenblicksverfangenheit ist auch die mangelnde Bereitschaft bildungspolitisch Gegenwart und Zukunft unserer Mediengesellschaft institutionalisiert und prüfungsrelevant zum Gegenstand des Unterrichts zu machen. Was gelegentlich unter dem Label Medienpass oder Medienführerschein vermittelt wird, zielt vor allem auf den funktionsorientierten Umgang mit den Medien, nicht aber auf eine Medienreflexionskompetenz, die über eine sachbezogene Kritik zum Beispiel von Facebooks Datenschutzpolitik oder Google Suchergebnisranking hinausginge hin zu einer kulturwissenschaftlich orientierten Kritik der Transparenzgesellschaft oder Privatisierung des globalen Wissenszuganges. Diese Verengung resultiert nicht zuletzt aus dem paradoxen Generationsgefüge im Schulkontext: dem Wissensvorsprung der Schüler als sogenannte digital natives gegenüber den Pädagogen als angebliche digital immigrants. Das deswegen praktizierte - und mitunter auch pädagogisch propagierte - Verfahren der Peer Education erschöpft sich zumeist im Erwerb eines systemintegrativen Funktions- und Verfügungswissens diesseits des Strukturwissens über politisch-ökonomische Hintergründe der medialen Entwicklung und des Orientierungswissens über eigene Handlungspositionen und -optionen auf der Basis kulturwissenschaftlicher Kenntnisse und ethischer Einsichten. So bleibt Medienbildung affirmativ und führt allemal die dystopischen You-Will-Utopien weiter, die große Unternehmen wie AT\&T, Facebook oder Google anbieten. ${ }^{93}$

Das Problem ist letztlich ein zeitphilosophisches und erzähltheoretisches. Das Dystopische manifestiert sich nicht in einer spezifischen Erzählung, sondern im Verlust des Erzählens. Die »Auflösung der narrativen

93 Für Googles Suchmaschinen-Utopie vgl. die Aussage seines früheren CEO Eric: »I actually think most people don't want Google to answer their questions. They want Google to tell them what they should be doing next.« (The Wall Street Journal, 14.8.2010 - http://online.wsj.com/article/SB10oo 1424052748704901104575423294099527212.html) sowie das Zukunftsprojekt der IT-Branche Google Glasses.
Verkettung ${ }^{94}$ in den zeitgenössischen Lebensformen und selbst in ästhetischer Theorie und Praxis verspielt letztlich auch jene »imaginative Kasuistik«, die Jonas in seiner »Ethik der Fernverantwortung« fordert und Meckel in ihrer Science Fiction illustriert, eine Kasuistik, die hypothetisch und konjektural, aber wohlinformiert, die Ereignisse der Gegenwart zu einer Projektion zusammenfasst..$^{95}$ Denkt man das Verhältnis des Internets zur Utopie nicht auf der Inhaltsebene des Mediums, sondern auf der seiner Botschaft, lässt sich also mit der Hypothese enden: Das Internet ist antiutopisch insofern das sich mit ihm durchsetzende Verfahren der Zahl die Perspektive des Narrativen - als Denken in Zusammenhängen und Alternativen - zurückdrängt und mittels neuem, statistischem Herrschaftswissen möglicherweise auch - das wäre zu prüfen - vom »Denken als von Negation $\aleph^{96}$ abhält.
94 Byung-Chul Han: Duft der Zeit. Ein philosophischer Essay zur Kunst des Verweilens. Bielefeld 2009, S. 54.

95 Jonas: Das Prinzip Verantwortung (wie Anm. 83), S. 67. Die Ethik der Fernverantwortung wird heute diskutiert im Umfeld der heterodox economy, wofür beispielhaft die Schriften von Herman E. Daly und das von ihm herausgegebene transdisziplinäre Journal Ecological Economics stehen, das die künftigen Folgekosten in aktuelle ökonomische Entwicklungen und Entscheidungen einbezieht.

96 Horkheimer, Adorno: Dialektik der Aufklärung (wie Anm. 63), S. 167. 
IV. AKTUELLE GEGENWART 


\section{JÜRGEN FOHRMANN}

\section{DIE VERSPRECHEN EINER INSTITUTION}

\section{Die Universität als Projektionsraum}

Wie passt ein Beitrag über die Universität in eine Veröffentlichung ${ }^{1}$, die sich zentral dem Thema >Utopie` und >Möglichkeitsdenken` widmet? Wir sind inzwischen ja ganz daran gewöhnt, die Universität eher als einen Ort begrenzter Möglichkeiten zu verstehen, fiskalisch gedeckelt, politisch und rechtlich überdeterminiert, sozial nur in Teilen inklusiv. Als einen Ort mithin ohne einen merkbaren utopischen Horizont - das ist fraglos ein Teil der Alltagserfahrung jeden Rektors oder Universitätspräsidenten.

Gleichwohl soll in den folgenden Überlegungen der Blickwinkel gewechselt und nach den Formen der Ermöglichung in der Universität oder - noch weitergehend - nach ihrer utopischen Dimension gefragt werden. Ist denn die Idee der Wissenschaft eng mit einer utopischen Dimension zu verbinden? Und: Inwieweit ist /Wissenschaft । identisch mit Universität oder überhaupt nur in nachbarschaftliche Nähe zu rücken zur Universität als Institution?

Fragen dieser Art werden in den aktuellen Debatten um die Universität als Ort in der Regel aus den gegenwärtigen Struktureinschätzungen heraus zu beantworten versucht. Nicht nur dem Symposiums-Thema geschuldet, sondern auch aus systematischen Gründen möchte ich heute einen anderen Weg gehen und im Sinne einer longue durée drei Säkularschnitte idealtypisch und mit dem bewussten Eingestehen verkürzter Darstellung vor Augen stellen: 1500, 1800 und unsere Gegenwart. Und ich ordne diesen drei Schnitten jeweils zwei Leitbegriffe zu:

1 Es handelt sich bei diesem Beitrag um einen Impulsvortrag für eine sich anschließende Podiumsdiskussion. Der Beitrag war daher bewusst thesenhaft formuliert; auf einen breiten Nachweisapparat wird aus diesem Grund und beim Umfang des verhandelten Gegenstands verzichtet. 
1) Freundschaft und Erkenntnis um 1500 ,

2) Geselligkeit und Forschung um 1800,

3) Clusterbildung und Optimierung für die Zeit nach 2000 bis heute. Keine dieser Phasen ist allerdings einfach überholt oder überwunden, sie haben sich vielmehr vielfältig überlagert; aber die Akzente wurden zunehmend anders gesetzt, und so haben wir im Vergleich mit den historischen Anfängen akademischer Professionalisierung gegenwärtig eine grundlegend verschobene Situation.

Jede dieser Phasen ist zugleich mit einer Reihe von Versprechen verbunden; auch wenn es jeweils anders lautet, so ist es immer das Versprechen auf einen Überschuss, der einen Möglichkeitsraum eröffnet - und ihn auch wieder schließt. Dieser Überschuss beruht auf einer je eigenen Ökonomie, die nicht immer der Oikos des Geldes ist.

\section{SÄKULARSCHNITT I (1500, FREUNDSCHAFT UND ERKENNTNIS)}

In der Absetzung von der scholastisch geprägten Universität entwickelt sich im Kreis der Humanisten die Idee eines freundschaftlich geprägten Miteinanders zum Zwecke wissenschaftlichen Arbeitens; ${ }^{2}$ dieses Arbeiten gilt insbesondere der Freilegung einer Vergangenheit, die durch corruptio verdorben, bis zur Unkenntlichkeit verstellt oder aus den falschen Gründen zurückgedrängt schien. Solches Miteinander ist auch zentraler Bestandteil des Akademiegedankens, und insofern könnte man sagen, dass die utopische Dimension des humanistischen Zirkels in der Verwandlung der scholastischen Universität in eine ideale Akademie gelegen hat. Ihr Kern ist die Ökonomie der Freundschaft.

Die Verwandlung der scholastischen Universität in eine ideale Akademie gibt zunächst das Versprechen auf gelingende und damit bereichernde Kommunikation. Es ist - trotz gepflegter Reise- und Besuchskontakte - durchaus bewusst eine Kommunikation unter Abwesenden, eine Kommunikation schon auf ihre Veröffentlichung gedachter Briefe, der wechselseitigen Widmungen, der Freundschaftsadressen. Wir bewegen uns am Anfang des Druckzeitalters und eben nicht in der ortsbezogenen

2 Ich verweise hier auf Andrea Schütte und Leander Scholz: »Heiliger Sokrates, bitte für uns!« - Simulation und Buchdruck. In: Jürgen Fohrmann (Hrsg.): Gelehrte Kommunikation. Wissenschaft und Medium zwischen dem 16. Und 20. Jahrhundert. Wien, Köln und Weimar 2005, S. $23-128$.
Universität, sondern im Netzwerk der gelehrten sodalitates; ihr Funktionieren war nur möglich im miteinander getragenen Ziel, aus den kulturellen Leistungen der noch andauernden Vorzeit Erkenntnis zu gewinnen und das dafür notwendige Zusammenspiel der Gelehrten zugleich als ideale Kommunikationssituation zu feiern. Erst aus Freundschaft entsteht Erkenntnis, und Erkenntnis ist ihrerseits die Voraussetzung für das richtige Leben. Dies ist ein Modell, das eine politische Dimension solchen Miteinanders, auch die Frage institutioneller Hierarchie usw. deshalb ausklammern kann, weil es sich im Wesentlichen eben um Fernbeziehungen handelt, deren Zusammenwirken im stilisierten Schriftverkehr zugleich als Gegenmodell zur Institution >Universität ‘ gesehen wird. Eine produktive Universität als Institution hätte sich also an diesem Freundschaftsmodell zu orientieren - so jedenfalls in der Sicht der Humanisten. Mit diesem Versprechen gelingender, da auf Freundschaft beruhender Kommunikation ist dann zugleich die Promotion von Ruhm verbunden. Derjenige ist ein großer, ja berühmter Gelehrter, dessen Wirken in diesem Netzwerk besonders strahlt, aber zugleich so strahlt, dass mit seiner Bedeutung auch die Bedeutung der Gruppe, des `Netzwerks` gewinnt. Es ist die antike Vorstellung der Fama bona, die vom Heros auf den Gelehrten und seinen Kreis übertragen wird. Das Gewinnen von Erkenntnis orientiert sich daher noch nicht am Fortschritt der Wissenschaften, sondern an der Erudition des einzelnen, bedeutenden, ja berühmten Gelehrten. Es ist eine personale Konzeption, die die ideale Akademie trägt und ihre Freundschaftsökonomie steuert.

>Utopieanfällig im Sinne der Staatsromane der Frühen Neuzeit ist diese Konzeption eher nicht, da das Ruhm- und Freundschaftsmodell sich gegen die Verabsolutierung der Gemeinschaft sperrt. Mit Philologen lässt sich auch bis heute schlecht eine Gemeinschaft bilden, eine Gemeinschaft zumal, deren Stabilität gerade auf dem Nicht-Hervortreten des Einzelnen beruht. Erst, wenn die aus dieser Arbeit erwachsende Erkenntnis nicht nur auf die Wiederentdeckung und Aufarbeitung der Schätze der literalen Vergangenheit bezogen bleibt, sondern sich auch auf die Erkenntnis der Natur, aller Wissenschaften und der Sozialität insgesamt ausdehnt, entsteht der Rigorismus utopischer Gemeinschaftsbildungen. Gut zu sehen ist dies etwa in Francis Bacons Utopie des Wissenschaftsstaates, des Hauses Salomo, seiner Nova Atlantis von 1638:

Alle zwölf Jahre sollen aus diesem Lande [Nova Atlantis] zwei Schiffe in die verschiedenen Gegenden des Erdkreises geschickt werden. Mit beiden Schiffen sollen jeweils drei Männer der Bruderschaft des Hauses Salomons ausfahren. Diesen ist aufzutragen, uns von den 
Einrichtungen und den Verhältnissen jener Länder, in denen sie landen, vor allem aber von den Wissenschaften, Künsten, Handwerken und Erfindungen der gesamten Erde Kunde zu bringen und bei ihrer Rückkehr Bücher, Instrumente und Unterlagen jeder Art mitzuführen. [...] Ihr seht jedenfalls, daß wir einen Handelsverkehr unterhalten, nicht um des Goldes, des Silbers und der Edelsteine, nicht um Seide und Gewürze und auch nicht um sonstiger einträglicher und wertvoller Dinge, sondern nur um der ersten Schöpfung Gottes: des Lichtes willen, des Lichtes, sage ich, das ja schließlich an jeder Stelle der Erde hervorbricht und Leben zeugt. ${ }^{3}$

Um des Lichts willen fahren die Angehörigen des Hauses Salomon in Francis Bacons Utopie Nova Atlantis hinaus, mit dem Ziel, alles Lichtvolle nach Hause zu bringen und es dort so zu versammeln, zu thesaurieren und so anzuwenden, dass die Herrschaft des Menschen weiter befördert wird. ${ }^{4}$

Der Zweck unserer Gründung ist die Erkenntnis der Ursachen und Bewegungen sowie der verborgenen Kräfte in der Natur und die Erweiterung der menschlichen Herrschaft bis an die Grenzen des überhaupt Möglichen. ${ }^{5}$

Bei »der Erweiterung der menschlichen Herrschaft bis an die Grenzen des überhaupt Möglichen" stockt die Unterhaltung und macht einem Schweigen Platz. Es ist das Schweigen, das in der Tradition stets einem `Erhabenen` zukam, dem `über alle Maßen Großen`, das nicht mehr sagbar erscheint, auf das nur noch verweisbar ist. Dem Versuch, das Feld des Wissens um der menschlichen Herrschaft willen maximal auszudehnen, korrespondiert eine Utopie, die in der Frühen Neuzeit als Form sgeschlossener Zweckmäßigkeit begriffen werden kann. Alles wird der Zweckmäßigkeit der Einrichtung untergeordnet, alle Energien werden eingesetzt, um diese Einrichtung grundsätzlich geschlossen zu halten. Die Grenze

3 Nova Atlantis. Fragmentorum alterum per Franciscum Baconum, Baronem de Verulamio. London 1638, zit. nach: Der utopische Staat. Übersetzt und hrsg. von Klaus J. Heinisch. Reinbek 1960, S. 194 f.

4 Vgl. dazu auch Wilhelm Voßkamp: "Bis an die Grenzen des überhaupt Möglichen«. Francis Bacons Utopie der Wissenschaft. In: Gegenworte. Hefte über den Disput über Wissen 27 (2012), S. 32-35.

5 Bacon: Nova Atlantis (wie Anm. 3), S. 205. zur Neuen Insel Atlantis, zum (akademischen) Hause Salomos, muss gesichert bleiben, die Beute nach Haus gebracht und das regnum hominis vermehrt werden. Die alte Todsünde, die curiositas, ist allerdings schon aufgehoben und zur Entfesselung freigegeben, aber nur zum Wohle des Wissenschaftsstaates, nicht zum Gedeihen seiner Umwelt und schon gar nicht zum Ruhm des einzelnen. Erkenntnis wird ganz in der lichtvollen Verbesserung des Staates gebunden.

\section{SÄKULARSCHNITT II (1800, GESELLIGKEIT UND FORSCHUNG)}

Das alte Modell der Kommunikation unter Freunden soll in das neue Modell der Universität überführt werden. Dies ist einer der wesentlichen Ausgangspunkte der Humboldt'schen Bildungsreform. Zugleich vollziehen sich die Ablösung der alten Form von Gelehrsamkeit und die allmähliche Etablierung des modernen Systems wissenschaftlicher Disziplinen, die sich vornehmlich an ihrer eigenen Axiomatik orientieren. Beides gemeinsam wird einen Forschungsimperativ auslösen, der weit bis in das 20. Jahrhundert das Bild der Wissenschaften und auch der Universität prägte.

Das Versprechen auf personal nutzbare Erkenntnis wird dann im Versprechen auf Raum und Zeit öffnende Forschung gedehnt und zugleich transformiert. Ihr akademischer Ort ist die wissenschaftliche Disziplin, ihr institutioneller Ort die neue Universität, deren Kern der Möglichkeitsraum darstellt, der sich aus Geselligkeit ergibt. Ließ sich - im Blick auf 1500 - über das berühmte Individuum keine utopische Gesellschaftskonstruktion gewinnen, die über ein reines Subsumtionsverhältnis des einzelnen unter den normierenden Staat hinausginge, so hatte man das Modell komplexer zu bauen. Sein Generalschlüssel heißt nun Wechselwirkung, und mit ihr kann dann die Vervollkommnung der Menschheit selbst in den Blick genommen werden. Auch hier bildet das Individuum zwar den Ausgangspunkt, allerdings nicht als eine Größe, auf die immer wieder alles rückbezogen wird. Vielmehr steht im Mittelpunkt, dass sich das Subjekt im Rahmen geselliger Interaktion im Verbund mit anderen so steigert, dass die Menschheit als ganze auf ein Zukunftsziel ausgerichtet werden kann. Dies hat etwa Friedrich Schleiermacher in seinem »Versuch einer Theorie des geselligen Betragens« formuliert:

Freie, durch keinen äußeren Zweck gebundene und bestimmte Geselligkeit wird von allen gebildeten Menschen als eins ihrer ersten 
und edelsten Bedürfnisse laut gefordert [...]. Wer nur zwischen den Sorgen des häuslichen und den Geschäften des bürgerlichen Lebens hin und her geworfen wird, nähert sich, je treuer er diesen Weg wiederholt, nur um desto langsamer dem höheren Ziele des menschlichen Daseins. Der Beruf bannt die Tätigkeit des Geistes in einen engen Kreis [...]. Das häusliche Leben setzt uns nur mit Wenigen, und immer mit denselben in Berührung [...]. Es muß also einen Zustand geben, der diese beiden ergänzt, der die Sphäre des Individui in die Lage bringt, daß sie von den Sphären Anderer so mannigfaltig als möglich durchschnitten werde, und jeder seiner eigenen Grenzpunkte ihm die Aussicht in eine andere und fremde Welt gewähre, so daß alle Erscheinungen der Menschheit ihm nach und nach bekannt, und auch die fremdesten Gemüter und Verhältnisse ihm befreundet und gleichsam nachbarlich werden können. Diese Aufgabe wird durch den freien Umgang vernünftiger sich untereinander bildender Menschen gelöst. ${ }^{6}$

Es ist für die Entwicklung der Universität als Institution von ganz entscheidender Bedeutung gewesen, dass diese Vorstellung geselliger Wechselwirkung die preußische Bildungsreform geleitet hat. Wilhelm von Humboldt und andere haben ihre Idee der Universität daran ausgerichtet; so heißt es in der immer wieder zitierten Humboldtschen Textpassage aus »Über die innere und äußere Organisation der höheren wissenschaftlichen Anstalten in Berlin«:

Da diese Anstalten ihren Zweck indess nur erreichen können, wenn jede, soviel als immer möglich, der reinen Idee der Wissenschaft gegenübersteht, so sind Einsamkeit und Freiheit die in ihrem Kreise vorwaltenden Principien. Da aber das geistige Wirken in der Menschheit nur als Zusammenwirken gedeiht, und zwar nicht bloss, damit Einer ersetze, was dem Anderen mangelt, sondern damit die gelingende Thätigkeit des Einen den Anderen begeistere und Allen die allgemeine, ursprüngliche, in den Einzelnen nur einzeln oder abgeleitet hervorstrahlende Kraft sichtbar werde, so muss die innere Organisation dieser Anstalten ein ununterbrochenes, sich immer

6 Friedrich Schleiermacher: Versuch einer Theorie des geselligen Betragens. In: ders.: Werke. Hrsg. von Otto Braun und Johannes Bauer. Bd. 2. Leipzig 1927, S. 1-31, hier S. 3 f. selbst wieder belebendes, aber ungezwungenes und absichtsloses Zusammenwirken hervorbringen und unterhalten.?

Dabei ist m.E. nicht die nachgerade sprichwörtliche `Einsamkeit und Freiheit entscheidend, sondern die Konzeption der Universität aus der Geselligkeit, aus der Wechselwirkung heraus, die man ganz im Sinne der Kantischen Ästhetik als Zweckmäßigkeit ohne Zweck verstehen kann. Es ist eine nicht auf ein klar definiertes inhaltliches Ziel ausgerichtete Zweckmäßigkeit, sondern eine, deren Ergebnis sich aus der Kontingenz des absichtslos-absichtsvollen Zusammenspiels ergibt. Diese Universität scheint nicht steuerbar, soll es auch nicht sein (auch deswegen: Einsamkeit und Freiheit), und kann sich gleichzeitig gerade darum auf die Vervollkommnung der Menschheit ausrichten. Dieses Versprechen wird gegeben. Die Verbindung zu Schleiermachers "Versuch« ist offensichtlich. Die Utopie geselliger Perfektibilität ist auf diese Weise in die Universität gewandert. Das forschende Miteinander denkt eine Ökonomie komplementären Austauschs, dessen Zweck sich zwecklos-gesellig, also wie von selbst, herstellt.

Man kann Niklas Luhmann in der Beschreibung folgen, dass mit der Überforderung der Oberschichteninteraktion für die Regelungsbedarfe sich funktional differenzierender Gesellschaften die alte Vorstellung von Interaktion sich einerseits zu einer Unterhaltung transformiert, die alles das auslässt, was Gegenstand des Streites sein könnte: Politik, Religion, Wirtschaft, Wissenschaft. Sie wird reine Unterhaltung, indem sie sich insbesondere den sschönen Künsten ‘ verschreibt und diese zusehends dann auch zum zustimmungsfähigen Dekorum weiter entwickelt. ${ }^{8}$ Dies prägt auch noch unsere heutige Gegenwartskultur. Andererseits wird diese Form der Interaktion aber zugleich zur Vorstellung, wie Gesellschaft insgesamt sein sollte. Ihre grundlegende Anerkennungssemantik des Anderen bildet ein Modell, das die Utopisierung einer solchen Geselligkeit als Gemeinschaft betreibt. Ihre zentrale, natürlich idealisierte operative

7 Wilhelm von Humboldt: Über die innere und äußere Organisation der höheren wissenschaftlichen Anstalten in Berlin. In: ders.: Werke in 5 Bdn. Hrsg. von Andreas Flitner und Klaus Giel. Berlin 1960, Bd. 4, S. 255-266, hier S. $255 \mathrm{f}$.

8 Vgl. Niklas Luhmann: Interaktion in Oberschichten. Zur Transformation ihrer Semantik im 17. und 18. Jahrhundert. In: ders.: Gesellschaftsstruktur und Semantik. Studien zur Wissenssoziologie der modernen Gesellschaft. Bd. 1. Frankfurt a. M. 1980, S. 72-161. 
Einheit ist der neue Nukleus der Universität, ist das Seminar. Es gibt das Versprechen gemeinsamen forschenden Lehrens und Lernens, eine vielleicht notwendige Fiktion, an der kontrafaktisch so lange erfolgreich festgehalten wurde, weil die Idee akademischer Geselligkeit nun die Idee der Universität begründete.

Wissenschaft ist hier als Zusammenspiel von Forschung und Bildung austariert. Die Sozialform dieser Universität ist eine Art rakademischer Aristokratismusく. Ein anerkannter Forscher und Gelehrter wirkt im Rahmen eines von ihm bestimmten Raumes, dann in einer von ihm begründeten Schule, die zugleich sein wissenschaftliches Nachleben sichert. Die Universität ist die Summe solcher zusammenwirkender Forscher. Gelingende Interaktion trägt daher bis weit in das 20. Jahrhundert hinein den Charakter des `Gipfelgesprächs‘. Eine Universität ist deswegen berühmt, weil sie solche Gelehrte hat, und ihr Ruhm, später wird es heißen: ihre Reputation ist es, die die interessierten Studenten anziehen, die die Öffentlichkeit aufmerksam werden lassen usw.

Der aus der Geselligkeit stammende Imperativ, der auf den Erfolg absichtslosen Zusammenkommens sowohl bedeutender als auch für die Wissenschaft engagierter junger Forscher setzte, benötigte damit eine Institution, die eher als unterreguliert gelten darf - und dies bis in die 1970er Jahre hinein. Das Modell humanistischer Gelehrsamkeit und sein Versprechen auf Erkenntnis wird auf diese Weise durch das Konzept forschender Wechselwirkung ersetzt, das ganz deutlich Züge des Deutschen Idealismus trägt. Es orientiert sich an einer emphatischen Vorstellung von Kultur, die die utopische Sozialität der Frühen Neuzeit als totalitär bewertet. Aus diesem Impuls heraus ist sie auch immer gegen Ideen von undifferenzierter Gleichheit eingetreten.

\section{SÄKULARSCHNITT III (GEGENWART, CLUSTERBILDUNG UND OPTIMIERUNG)}

Seit den 1970er Jahren ändert sich dieses Modell in mehreren Phasen; ich ziehe sie in zwei Schritte zusammen.

ERSTER SCHRITT

Durch den größeren Zugang zu den >höheren Lehranstalten` wird zunächst einmal ein bisher nicht gekanntes Maß an schierer Komplexität erzeugt. Die Universität ist seit dieser Zeit nicht mehr als sideale Akademie zu konzipieren; auch die gesellige Interaktion ist nur noch mit einem Teil des akademischen Nachwuchses lebbar (wenn sie es im emphatischen Sinne je war). Die Universität wird mehr denn je eine Anstalt abgestufter Niveaus. Zwar wird die Ablehnung >undifferenzierter Gleichheit` nicht aufgegeben, aber doch gruppenspezifisch reguliert und über Rechtezuweisungen abgesichert. Die Universität tritt in das Interessenvertretungszeitalter ein; ihre Größe erzwingt ein Verkehrsmodell, das die Gruppen in definierte Verhältnisse setzt und über das Einhalten festgelegter Verfahren Akzeptanz erzeugt, Vertrauen und Misstrauen reguliert.

Die Universität wird von nun faktisch in weit größerem Umfang Institution. Sie löst sich dabei allerdings noch nicht entschieden von den tradierten Ökonomien, denkt also weiterhin Erkenntnis im Rahmen von Freundschaft, denkt gesellige Interaktion als Modus der Forschung, richtet sich, wie Hannah Arendt es einmal formulierte, durchaus noch an >Personen von Rang، aus. ${ }^{9}$ Solcher sich nun vermehrt andeutende Hiatus zwischen Institution einer- und freundschaftlicher bzw. geselliger Personalität andererseits wird allerdings in dieser Zeit häufig noch politisch überdeckt: in der Aufgabenzuweisung etwa, qua Wissenschaft gesellschaftliches Engagement zu entfalten, tragende Rollen zu übernehmen, eine wichtige öffentliche Stimme zu sein, die mit Wertepositionen gekoppelt ist, usw. Das ‘absichtslose Zusammenspiel forschenden Miteinanders findet sich so durch eine Heteronomie-Zumutung ersetzt, die von großen Teilen (natürlich nicht von allen) der Universität selbst getragen wird. Als bedeutende öffentliche Stimme kann auch der Ruhm gerettet werden, und das oft favorisierte Modell von Sozialität, durchaus gekoppelt mit einer Wiederkehr der Sozialutopie, reanimiert eher die Gemeinschaft. Die performative Bündelung im gesellschaftlichen Engagement verbindet Personalität mit Geselligkeitsmodellen, indem sie dem Anruf des Politischen folgt.

\section{ZWEITER SCHRITT}

Im zweiten Schritt, d.h. 20 bis 30 Jahre später, wird durch veränderte Rahmenbedingungen eine neue Qualität der Institution geschaffen, deren Impetus man als teleologischen Funktionalismus bezeichnen könnte. Er lässt die Heteronomie-Zuschreibungen zurück, um sie durch die Universalität eines monetär gedachten Ökonomischen zu ersetzen.

9 Vgl. Hannah Arendt und Karl Jaspers: Bürger der Welt (1957). In: Hans Saner (Hrsg.): Karl Jaspers in der Diskussion. München 1973, S. 410. 
Eine seiner Rahmenbedingungen ist die zunehmende Internationalisierung der Universität, verbunden mit allen Veränderungen weltgesellschaftlicher Art, die hier aufzuzählen den Rahmen sprengen würde. Der intendierte gemeinsame Hochschulraum und die weitgehende Loslösung der Hochschulen aus der Sorge des Staates im Rahmen neuer Rechtsformen erzeugen die Notwendigkeit noch weiter gehender Selbstregulierung, die sowohl die Universität als Binnen- aber vor allem auch die Außenverhältnisse der Universität betreffen. Dies ist die Stunde operativer Vernunft, und mit ihr wird das Versprechen auf Optimierung gegeben. Es ist ein Versprechen, das nicht mehr so sehr den einzelnen betrifft, sondern im Wesentlichen ein Versprechen für die Institution darstellt. Der einzelne ist zu fördern um der Institution willen - und nicht umgekehrt. Vermeintlich >vormoderne Elemente werden weitgehend abgestoßen und mit neuen Tugenden ausgetauscht. Ruhm und Reputation sind jetzt eigentlich Atavismen; sie werden durch messbaren Erfolg ersetzt, und wenn es etwas Rühmenswertes gibt, dann ist es dessen Fortsetzung. Informelle Formen der Kommunikation werden weitgehend zurückgedrängt und durch eine Art ,Überempirie`substituiert, die vermeintlich größere Gerechtigkeit walten lässt. Wir sind bei Fragebögen und Auswertungen angekommen, die nun den Möglichkeitsraum von Steuerung zu eröffnen verheißen und fast beliebig ausgedehnt werden können. Auf diese Weise wird die Institution Universität zunehmend überreguliert - und dies ist im Übrigen kein Phänomen der Universität allein, sondern spiegelt die gesamtgesellschaftliche Tendenz wider, Verantwortung an Metaverfahren zu delegieren. So soll Kontingenz, soll der Zufall immer weiter ausgeschaltet werden - Planspiele treten an die Stelle sich nicht regelkonform vollziehender Bildung.

Kernstück dieser neuen Universität ist der Taylorismus mit seinen Verfahren >zerlegen`, >rekombinieren`, Prozesse synchronisieren, Interferenzen und Rückkopplungen bedenken, die Ergebnisse statistisch erfassen, Prognostik betreiben und statt der alten, guten Innenrevision ein >Monitoring ` durchführen. Die Ökonomie, die jetzt wirkt, ist die kybernetische Zirkulation; ihren Ausdruck findet sie in formalen Äquivalenzbeziehungen, also etwa über Geldflüsse.

Die medialen Entwicklungen der letzten 10 Jahre unterstützen und stärken dieses Verfahren in bislang nicht gekannter Weise, und der Gebrauch der neuen Kunstsprache des new public management indiziert schon tiefe Kennerschaft.

Das Auftauchen des Taylorismus ist allerdings keine neue Erscheinung. Seine nahezu Konkurrenzlosigkeit bildet jedoch zweifellos eine qualitativ neue Stufe; die neue Qualität der Institution Universität bedarf demnach einer perfekten Operativität, sonst ist ihr Funktionieren nicht mehr sicher gestellt. Wer sich einmal einlässlich mit elektronischer Prüfungsverwaltung beschäftigt hat, wird sich solcher Einsicht nur schwer entziehen können.

Diese Form der Institution Universität berührt auch nachhaltig die Wissenschaft selbst. Ihre unterschiedlichen Kulturen sind unterschiedlich ja auf die Idee der Operativität zu beziehen, und hieraus lassen sich dann universitätsinterne Machtgewinne erzielen. Die Idee einer Kommunikation unter Freunden ist hier leicht konterkarierbar, und um gesellige Interaktion wird es auch nicht mehr gehen. Im Vordergrund stehen Formen geplanter Kooperation, deren Gradmesser fast ausschließlich ihr Erfolg darstellt: koordinierte Verfahren, die den Prozess der Clusterbildung unterstützen und das Auswandern der Wissenschaft in außeruniversitäre Bereiche verhindern, zumindest aufschieben.

Die Universität vollzieht jene Clusterbildung dann nach, die gesamtuniversitär die größten Erfolge verspricht und unter Beweis stellt. Um dies realisieren zu können, entwickelt sie die Utopie der potenzierten Institution als Ressourcenspeicher für Erfolge. Alle Möglichkeiten der Universität müssen optimal genutzt werden. Voraussetzung ist, die universitäre Organisation zu perfektionieren, ihre Außenverhältnisse zu optimieren, ihre Kommunikation reibungslos zu organisieren und eine umfassende Ressourcen-Allokation zu betreiben. Diese Allokation betrifft alle Bereiche und verwandelt damit Menschen wie Sachen in monetäre Äquivalente, in human resources.

Nun könnte man meinen, dass damit das Francis Bacon'sche Modell, jetzt unendlich steigerbar durch neue Medien- und Sozialtechniken, doch noch umfassend zum Zuge gekommen ist. Wir wären also wieder beim utopischen Wissenschaftsstaat der Frühen Neuzeit angelangt. Allerdings ist dieser Eindruck nur zum Teil richtig. Denn in der Gegenwart geht es nicht mehr wie im Falle Bacons um eine >geschlossene Zweckmäßigkeit`, also eine, die den Staat über strikte Abgrenzung und einkanalige Kommunikation stabilisiert. Es geht auch nicht mehr um ein Konzept zentraler Regulierung, wie dies für die Utopien der Frühen Neuzeit so typisch war. Jetzt geht es vielmehr um ein Modell offener Zweckmäßigkeit, um eine potenzierte Institution, die alles von außen aufnimmt, was ihr zu Ressourcen verhilft und vornehmlich aus diesem Grund in die Öffentlichkeit ausstrahlt und die Öffentlichkeit zulässt. Dies verabschiedet die politische Performanz der 1970er Jahre. Einer der Effekte ist das Zerreißen des Bandes zwischen Wissenschaft und Öffentlichkeit und nun die Installierung einer Beobachterposition jenseits der Universität. Sie wendet 
die tradierten Konzepte von Universität, ihren advokatorischen Anspruch zumal, jetzt gegen die neuen Entwicklungen. Dies leistet im Wesentlichen ein geistesgeschichtlich inspirierter Wissenschaftsjournalismus. Ist denn die Unterscheidung von 'wahr/ und 'falsch ' für das Wissenschaftssystems noch in Geltung, so wird kritisch nachgefragt; oder hat die Institution Universität sie längst mit der Differenz von Erfolg oder Misserfolg verschliffen? Treten damit die Operationsweise der Institution und die bewährte Operativität der Wissenschaften scherenförmig auseinander? Oder beginnt die Institution Universität das Wissenschaftssystem in ihrem Sinne immer stärker ökonomisch zu regulieren?

Diese Fragen wird man nicht einfach wegwischen können. Für ihre Berechtigung spricht, dass die Rhetorik strategischen Handelns, also die Sprache des Militärs, immer häufiger Raum greift. Sie will deutlich machen, dass es um die Selbstbehauptung der Institution in harten Konkurrenzverhältnissen geht.

Eine solch potenzierte Institution arbeitete dann perfekt, wenn alle Mitglieder einfach mitspielten. Das war ja die Fiktion der Utopien der Frühen Neuzeit, eine Fiktion übrigens, die eigentlich nur mittels Überwachung und Sanktionen zu realisieren war. Alle frühneuzeitlichen Utopien halten ein ganzes Register von Bestrafungsformen für diejenigen vor, die sich außerhalb des Reglements zu bewegen versuchen. Es kennzeichnet die gegenwärtige Universität als Institution durchaus, dass auch sie solche Sanktionen, wiederum monetär verwandelt, mehr oder weniger erfolgreich anzuwenden versucht.

Weniger erfolgreich ist ein solches Modell fiskalischer Belohnung und Potenzierung dort, wo es auf die alten Selbstverständnisse einer Universität stößt. Die Gemeinschaft von Wissenschaftlerinnen und Wissenschaftlern operiert - wie idealisiert auch immer - mit anderen Ökonomien, mit Ökonomien des Sozialen, mit Freundschaft und Geselligkeit - und natürlich auch mit ihren jeweiligen Negationen. Sie sind nicht einfach verschwunden, sondern wirken auf die eine oder andere Art im Verbund der Wissenschaftler weiter. Daraus erklärt sich ein gutes Maß des Widerstands, der von den Mitgliedern und Angehörigen der Universität den neuen Potenzierungsversuchen der Institution entgegengebracht wird. Die Nemesis, die ja den alten Gottheiten entstammt, tritt als Rächerin immer dann auf, wenn das Alte im Neuen nicht mehr vorkommt. Will sie nicht zum Gespenst werden, dann ist die Universität als Institution wohl gut beraten, wenn sie die Koexistenz aller drei Modelle als ihren auch noch heutigen Möglichkeitsraum begreift. Sie muss dann Formen der Komplexität zulassen, die unterschiedliche Phasen der Wissenschaftsentwicklung jeweils in ihr zu spiegeln erlaubt. Es gelingt dann, wenn die drei Ökonomien wechselseitig aneinander partizipieren und sich damit in der Universität sowohl ermöglichen als auch begrenzen. Dies allerdings setzt zweierlei voraus: erstens ein Möglichkeitsdenken, das theoretisch informiert ist; und zweitens einen politischen Einsatz: Widerstand zu leisten gegen den Versuch, die Universität der großen Schar der Consulter zu überlassen. 


\section{KARL HEINZ BOHRER}

\section{UTOPIE \EUROPA}

\section{Eine Ursache ihres Zerfalls}

Die Bewohner des europäischen Kontinents dachten und handelten von jeher als Europäer, bevor sie davon sprachen, dass sie Europäer seien. Die Rede von der Einheit Europas ist historisch eine relativ späte, obwohl sie in Praxis seit der Renaissance, ja seit dem frühem Mittelalter praktiziert wurde: $\mathrm{Ob}$ es die Gemeinsamkeit der christlichen Kirchen und Universitäten war, die Wiederentdeckung der griechischen Kunst und Literatur in der Renaissance oder schließlich eine selbstverständliche gesellschaftliche Interaktion der europäischen Eliten - die nationale Differenz spielte bei dieser Gemeinsamkeit nur eine untergeordnete Rolle. Montaignes Journaux (ca. 1580), Fontenelles Entretiens sur la pluralité des mondes (1686), Gibbons The History of the Decline and Fall of the Roman Empire (1776-1789), Herders Auch eine Philosophie der Geschichte zur Bildung der Menschheit (1774), Goethes Italienische Reise (1786-88) - um nur diese sehr unterschiedlichen, aber sehr exemplarischen Texte einer europäischen Erfahrung zu nennen - geben von einer frühen Bewusstheit der europäischen Zivilisation das beredteste Zeugnis ab, nicht zu reden vom Dialog der führenden Philosophen im 18. Jahrhundert oder den eleganten Reisen junger Mitglieder der Oberschichten.

Diese praktizierte Einheit war, wie gesagt, eine philosophische, eine künstlerische, eine modische. Eine politische war sie nicht, auch wenn das Ereignis der Französischen Revolution und der sie begründenden Ideen gravierende Folgen in allen west- und mitteleuropäischen Ländern gehabt hat. Aber diese Ideen begründeten auch die Unabhängigkeitserklärung der amerikanischen Kolonie Großbritanniens, also gerade eine Abgrenzung von Europa. Und so hatte die Rede von der politischen Einheit Europas - ohne jemals konkrete institutionelle Vorschläge zu enthalten - a priori einen utopischen Ansatz, der - um überhaupt aufkommen zu können - der Erfahrung einer Krise bedurfte. Diese 
Bedingung sei zu Beginn genannt, ohne damit den Anspruch einer theoretischen Erklärung von Utopien zu verbinden. In diesem Fall war es die Krise der beiden Weltkriege bzw. deren Antizipation durch den deutsch-französischen Krieg von 1870/71. Und es war vornehmlich die Krise Deutschland/Frankreich, aus der sich die Utopie Deutschland/ Frankreich entwickelt hat. Zu Beginn des 19. Jahrhunderts sich leise andeutend, seit 1900 wirklich formuliert und sich zwischen den beiden Weltkriegen verfestigend, ist die Idee von einer Einheit aber eine kulturelle geblieben, keine politische geworden. Die Paradoxie der gegenwärtigen Rede von Europa ist nun, dass sie tatsächlich seit 1950 eine politische Einheit vor Augen hat, sie ökonomisch sogar zu realisieren versucht, sich dabei aber jene Utopie - als kulturelle Idee etabliert und aus der Krise erneut motiviert - endgültig verliert, wenn sie nicht schon gänzlich verschwunden ist.

Diese Paradoxie sei Gegenstand der folgenden Ausführungen. Der erste Teil stellt die Idee von einer Einheit Europas als Utopie am Beispiel repräsentativer Denker des 19. und 20. Jahrhunderts dar. Im zweiten Teil wird ihre wichtigste Ausdifferenzierung, nämlich die Emphatisierung der französischen und deutschen Kultur im wechselseitigen utopischen Bild beider Nationen zu erläutern sein. Sie ist Voraussetzung für die eingetretene Ernüchterung. Der dritte Teil behandelt das Verschwinden der kulturellen Idee und ihres Umschlags zur Ideologie, nicht zuletzt das Verschwinden der deutsch-französischen Faszination aneinander. Daraus ergibt sich die Frage, ob und inwieweit eine politische Einheit Europas realisierbar ist, wenn die kulturelle Idee von $\mathrm{ihr}$ - das war der utopische Kern - verschwunden ist.

\section{DIE UTOPIE `EUROPA ALS KRISENBEWUSSTSEIN}

Zwischen 1930 und 1950, zwischen den beiden Weltkriegen, erschienen Werke von einflussreichen europäischen Denkern zu dem, was man damals noch die "[G]eistige Situation der Zeit « nannte. In diesen thematisch sehr unterschiedlichen Büchern tauchte regelmäßig eine spezifisch emphatisierte Idee von Europas geistiger und politischer Größe auf, die Vorstellung von Europas unverminderter Macht und ihres Vorrangs an innovatorisch-kritischem Denken. Der französische Kulturtheoretiker Paul Hazard hat diesen Anspruch 1935 nicht ohne Anmaßung beispielhaft in seinem Buch mit dem einschlägigen Titel Die Krise des europäischen Geistes 1680-1715 auf den Punkt gebracht:
Was ist Europa? Ein Denken, das sich nie zufrieden gibt. Ohne Mitleid mit sich selbst verfolgt es unaufhörlich zwei Spuren, die des Glücks und die der Wahrheit, die ihm noch unentbehrlicher ist und noch mehr am Herzen liegt [...] Außerhalb Europas und unberührt von der Zivilisation leben große Massen der Menschheit ohne zu denken, zufrieden, nur zu leben. ${ }^{1}$

Hazards Beschreibung einer utopischen Qualität Europas bezieht sich auf das Wort des französischen Frühaufklärers Fontenelle, der von einem "gewissen Genius « gesprochen hatte, »der noch nie aus unserem Europa gekommen ist, oder der sich wenigstens nicht weit davon entfernt « habe. ${ }^{2}$ Und Hazard identifiziert diesen Genius nicht bloß intellektuell, sondern mit dem Willen Europas, andere Kontinente zu unterwerfen. Auch wenn Hazard seinen älteren französischen Confrère im Geiste eines allmählichen "aufsteigenden Hymnus" sprechen lässt, so ist die Referenz an die Eroberung eine Metapher für eine gedankliche Kühnheit, die er selbst im Auge hat und mit der er seine Analyse einer Krise des europäischen Denkens zwischen 1685 und 1715 abschließt. Der Begriff der »Krise« begründet also das ins Utopische vorschießende Phantasma namens Europa.

Die Kategorie der `Krise`, ein zur Metapher der europäischen Moderne gewordenes Wort, ist der Erfahrung des Ersten Weltkriegs geschuldet, der nicht bloß die jahrhundertlange Kriegsbereitschaft zwischen den europäischen Nationen zu einem für sie traumatisch exzessiven Höhepunkt geführt hat, sondern ihre von Hazard noch immer in Anspruch genommene Macht unterhöhlte. Schon um 1920 war die neue Krise thematisiert, sei es von Oswald Spenglers dramatisierter Beschreibung der europäischen Lage als Untergang des Abendlandes (1918/22), sei es in der privaten, aber prägnanten Wahrnehmung Paul Valérys, des ersten französischen Dichters der Epoche, der 1919 in einem Zeitschriftenartikel von einer Krise des Geistes spricht, und in einem Brief an Rainer Maria Rilke vom 17. Dezember 1921 sich darauf beziehend sagt, es handele "sich um einen Zustand des europäischen Geistes nach dem Kriege«, folgendermaßen fortsetzend: »Ich vermute also, daß es vorher einen gab

1 Paul Hazard: Die Krise des europäischen Geistes. Aus dem Französischen von Harriet Wegener. Hamburg 1939, S. 501.

2 Bernard le Bovier de Fontenelle: Entretiens sur la Pluralité des Mondes (1686). Deutsche Ausgabe: Gespräche über die Mehrheit der Welten. Mit Anmerkungen und Kupfertafeln von Johann Elert Bode. Zweite gänzlich verbesserte und vermehrte Ausgabe. Berlin 1789, S. 371. 
- aber jetzt müssen wir glauben, daß er existierte, und versuchen, diesen Toten, der vielleicht niemals gelebt hat, wiederzuerwecken. $\aleph^{3}$ Das immer skeptische Bewusstsein Valérys stellte die Idee von einem reuropäischen Geist ` einerseits also sofort in Frage, d.h. er formuliert schon einen gegen das Utopische gerichteten Ideologieverdacht, auf den wir am Ende zurückkommen werden, um dann die Utopie umso mehr zu affirmieren. Dies hat er ohnehin zehn Jahre später anlässlich seiner »Rede zu Ehren Goethes« vor den geisteswissenschaftlichen Fakultäten der Sorbonne getan. Jedenfalls spielt der utopische Gedanke, nämlich `Europar sowohl als politische Macht und als Macht des Geistes, sozusagen im Sinne eines regulativen Prinzips eine beträchtliche Rolle: allerdings abermals der Skepsis ausgeliefert, inwiefern sich Goethes europäisches Universum, das Erbe von Renaissance und dem noch immer glanzvollen 18. Jahrhundert, nicht verbraucht habe.

Trotz vergleichbarer Unsicherheit, was das neue Jahrhundert bringe, haben die beiden ihr Land jeweils gedanklich prägenden Köpfe, Benedetto Croce und José Ortega y Gasset, noch vor Paul Hazard zu Beginn der dreißiger Jahre von der Beantwortung der Frage nach dem seuropäischen Geist` ihre Diagnose abhängig gemacht. Croce entwarf geradezu schon die europäische Utopie von 1947, wenn er das Nachkriegseuropa nach 1918 wie folgt beschrieb: "wie arm es ist, wie zerrissen, wie traurig! Durch unüberwindliche Zollgrenzen zerteilt [...]. Jedes Volk von seinen eigenen Sorgen zermürbt und in beständiger Furcht vor Schlimmerem, abgewandt von allen geistigen Dingen,$^{4}$ um dann - ohne dafür einen Grund anzugeben - jene Vision zu entwickeln, die nach 1950 Schule gemacht hat:

Wer aber tiefer darüber nachdenkt, wer sich nicht mit äußeren Erscheinungen zufrieden gibt, sondern zum inneren Wesen Europas vordringt, wer die Leidenschaften und Handlungsweisen der europäischen Seele selbst erforscht, der wird sehr bald dazu gelangen, die geistige Kontinuität und Homogenität dieser beiden Zustände Europas wiederherzustellen [...]. ${ }^{5}$

3 Paul Valéry: Briefe. Übertragen von Wolfgang A. Peters. Wiesbaden 1954, S. 123.

4 Benedetto Croce: Geschichte Europas im neunzehnten Jahrhundert. Frankfurt a. M. 1979, S. 313.

5 Ebd.
Ortega y Gasset hat in seinem bekanntesten Werk Der Aufstand der Massen 1930 die Kategorie von einer »europäischen Zivilisation« sehr viel kritischer in Anschlag gebracht. Seine auf Sigmund Freuds Diagnostik der Massenpsychologie (1923) gestützte vehemente Kritik am Typus eines neuen >Massenmenschen $`$ wird perspektiviert durch den Begriff Europas als sittliche Idee: »Dies ist das Problem: Europa glaubt an keine sittlichen Normen mehr. $\aleph^{6}$ Es ist ein »bestimmter Typus des europäischen Menschen «, der nicht mehr daran glaubt. Es handele sich aber, so betont Ortega y Gasset es, nicht um eine "neue Zivilisation «, sondern um eine »bloße Verneinung «? Die gerade erkannte Realität - der europäische Massenmensch - wird also utopisch aufgehoben. Wie Croce zwei Jahre später präsentiert Ortega als Alternative zum Zustand der europäischen Nationen die Vision der `Einigung Europas`. Für die Europäer breche die Zeit an, »da Europa zu einer Nationalidee werden kann. Und der Glaube hieran ist viel weniger utopisch « als im 11. Jahrhundert die Prophezeiung einer Einheit von Frankreich und Spanien gewesen sei. ${ }^{8}$ Die Idee von der >Lebensgemeinschaft Europa ist einerseits die sich aus dem Krieg aufdrängende Konsequenz, sie ist zudem eine Notwendigkeit gegenüber dem sowjetischen Bolschewismus. Die Schöpfung des »europäischen Nationalstaates" sei die "einzige Aufgabe, die sich einem Sieg des Fünfjahresplans entgegenstellen könnte «. ${ }^{9}$ Der Europäer, so dekretiert auch Ortega y Gasset nicht ohne Selbstwiderspruch zu seiner Grundthese, sei die menschliche Spielart, »die alle Mühe und Inbrunst ihrer Geschichte auf die Karte der Persönlichkeit gesetzt habe«, deshalb sei sie dem russischen Kommunismus nicht "assimilierbar«.

Es wird erkennbar, dass der rote Faden zwischen den varianten Formen einer europäischen Utopie die Vorstellung von der autonomen Individualität, das Apriori der sogenannten europäischen Idee, ist. Diese Differenz, in Stellung gebracht gegenüber allen anderen Kulturen, hat eine intellektuelle und eine vitalistische Ausprägung. So erinnert Ortegas Essay Um einen Goethe von Innen bittend von 1932 an Valérys Goethe-Vortrag von 1921. Nicht in den einzelnen Motiven - diese könnten nicht verschiedener sein -, wohl aber in der Berufung auf das Individuelle. Die vitalistische Seite ist die von Paul Hazard berufene imperiale Kapazität, die sogar Spenglers Unterscheidung zwischen europäischen

6 José Ortega y Gasset: Der Aufstand der Massen. Reinbek 1936, S. 139.

7 Ebd., S. 141.

8 Ebd., S. 133.

9 Ebd., S. 138. 
Herrenvölkern und orientalischem Fellachentum ähnelt. Das ist ein Blickwinkel, der bei der Wahrnehmung der nichtgriechischen Antike durch die europäische Altphilologie, Archäologie und Kunstgeschichte einen kanonbildenden Ausschlag gegeben hat. Das gilt vor allem für die deutsche Gräzistik. Auch Bruno Snells berühmter Titel Die Entdeckung des Geistes. Studien zur Entstehung des europäischen Denkens bei den Griechen ist ein imposantes Dokument hierfür, ohne dass es die aggressive neuhumanistische Tendenz fortgesetzt hat. 1946 erstmals erschienen und in weiteren Folgen neu aufgelegt, hat es auf zwei akademische Nachkriegsgenerationen beträchtlichen Einfluss gehabt. Denn das Buch förderte die vor allem in Deutschland bzw. Westdeutschland wie ein Blitz eingeschlagene Idee von einem zukünftigen europäischen Nationalstaat, ohne dass es hierfür auch nur die Spur eines institutionell-politischen Arguments gegeben hätte. Dem kamen auf der akademischen Ebene nur noch Ernst Robert Curtius' Werke Europäische Literatur und lateinisches Mittelalter von 1948 und seine Kritischen Essays zur europäischen Literatur von 1950 gleich. Die Europa-Idee dieser drei Bücher beschränkte sich auf die Literaturgeschichte. Hierin drückt sich auch die zivile Zurückhaltung der beiden deutschen Gelehrten unmittelbar nach dem katastrophal geführten und verlorenen Zweiten Weltkrieg aus. Aber noch immer - oder gerade dieser Vergangenheit zum Trotz - wiederholt Bruno Snells erster Satz den europäischen Überlegenheitsgestus von Croce und Hazard: »Unser europäisches Denken hebt an bei den Griechen, und seitdem gilt es als die einzige Form des Denkens überhaupt $«{ }^{10}$ Denken selbst wird zum Garant erhoben: Europäisches Denken als Zukunftsgarant.

Darin eine sich selbst entlarvende Hybris zu sehen - wie eine aktuelle politisch korrekte Reaktion es anmahnen könnte -, ist indes Hypokrisie. Der europäische Zeitgeist dachte so, damals mit guten Gründen. Die Problematik des deutschen Klassizismus - den man wohl zurecht als »Tyranny of Greece over Germany« beschrieben hat ${ }^{11}$ - steht auf einem anderen Blatt und gehört zum Sonderweg des deutschen Neuhumanismus der dreißiger Jahre, dessen Heroisierung der griechischen Kultur zweifellos protofaschistische Züge enthielt. Damit hat Snells Entdeckung des griechischen Denkens als europäischem aber nichts zu tun. Noch weniger Ernst Robert Curtius' Auffassung von Europa als einem

10 Bruno Snell: Die Entdeckung des Geistes. Studien zur Entstehung des europäischen Denkens bei den Griechen. Göttingen 2011 (1975), S. 7. 11 Eliza Marian Butler: The Tyranny of Greece over Germany. Oxford 1936. anmutigen Garten, in dem sich große Dichter und Denker von Vergil bis zu Goethe, von Balzac bis zu Miguel de Unamuno, von Ortega y Gasset bis zu T. S. Eliot und Jean Cocteau begegnen. Curtius' Idee von der Zusammengehörigkeit der unterschiedlichen nationalen Dichter in der geistigen Präsenz einer europäischen Dichtung war insofern utopisch, als sie eine Antwort war auf die beiden Kriege und den Zustand Kontinentaleuropas als Trümmerlandschaft. Es war die Vorwegnahme eines ersehnten Auswegs, die Illusion, dass Gedanken buchstäblich Berge versetzen könnten, die Berge der trennenden Grenzen.

\section{DIE UTOPIE ALS DEUTSCH-FRANZÖSISCHE FASZINATION}

Die spezifische Variante der literarischen Europa-Idee war die wechselseitige deutsch-französische literarische Mythisierung. Sie hatte ihre Ursache in den drei Kriegen von 1870/71, 1914-18 und 1940-45, in denen Frankreichs zweimal militärisch der Verlierer war. Aus dem militärischpolitischen Desaster, das schließlich beide Nationen erlebten, entsprang sozusagen wie ein Deus ex machina am Ende die Phantasie von des Anderen kultureller Attraktivität. Vor $1870 / 71$ hat es in Frankreich im Anschluss an Madame de Staëls sofort berühmt gewordenem Buch De l'Allemagne (1810/13) die utopisch-idealisierende Vorstellung von Deutschland als Land der Dichter und Denker gegeben. De Staëls Idealisierung Deutschlands entstand im Kontext der Napoleonischen Diktatur, die sie als kulturelle Krise verstand. Insofern war ihr Deutschlandbild ein utopischer Gegenentwurf. Er ist als utopisches Konzept schon von den führenden deutschen Geistern der Epoche, wie Friedrich Schlegel, Friedrich Schiller und Hegel um 1800, entworfen worden, was die politische Machtlosigkeit der deutschen Kleinstaaten konterkarieren sollte. Eine buchstäbliche Utopie waren Friedrich Schlegels Statement, dass in Deutschland die ästhetische Moderne beginnen werde ${ }^{12}$ und Friedrich Schillers direkte bzw. Hegels indirekte Prophezeiung, der deutsche Geist, die deutsche Sprache werde die Welt denken lernen. Solche Ideen wurden seit den dreißiger Jahren des 19. Jahrhunderts französischerseits noch einmal in ein romantisches Licht getaucht, wenn Gerard de Nervals Rheinphantasien (Loreley, Aurelia) die romantische Stilisierung Deutschlands

12 Friedrich Schlegel: Über das Studium der griechischen Poesie. In: ders.: Kritische Schriften. Hrsg. von Wolfdietrich Rasch. München 1971, S. 228. 
als Phantasma weiterdachte, was, wie wir sehen werden, noch den frühen Pariser Surrealismus beeinflusste.

Gleichzeitig ist die utopische Argumentation von Heinrich Heines bald ins Französische übersetzten Traktaten Religion und Philosophie in Deutschland sowie Die romantische Schule hervorzuheben. Während im letzteren Werk, das in Fortsetzungen 1833 zunächst in französischer Sprache in der Pariser Zeitschrift L'Europe Littéraire erschien, die Faszination am Unheimlichen in der deutschen Romantik als ein innovatorisches Motiv abgehoben wird von einer, wie Heine betonte, harmloseren Auffassung davon in Frankreich, wird im ersteren Text, 1835 unter dem Titel $D e$ l'Allemagne in französischer Übersetzung erschienen, diese Differenz zu jener prinzipiellen verschärft, die bald das philosophisch-politische Image Deutschlands dämonisieren sollte. Heine warnt nämlich am Ende dieses Traktats seine französischen Leser vor einer bevorstehenden deutschen Revolution, angesichts deren die große Französische sich nur wie eine 'harmlose Idylle ausnehme. Die Pointe von Heines sich zur Prophetie steigernden Warnung ist, dass diese deutsche Revolution unmittelbar der idealistischen Philosophie Kants, Fichtes und Hegels entspringe solle. Die Aufforderung, sich dagegen zu bewaffnen, gipfelt im Bild der griechischen Göttin der Weisheit, Athene: Sie trage »dennoch immer einen Panzer" und »den Helm auf dem Kopf und den Speer in der Hand «.13 $\mathrm{Ob}$ diese Metapher als Empfehlung an die Franzosen gedacht war, über allem kulturellen Stolz nicht den militärischen zu vergessen oder aber ob im Bild von der Göttin der Weisheit, die immer bewaffnet sei, die neue Kombination von idealistischer Philosophie und preußischer Armee gemeint war, bleibt hinter Heines ambivalenter Ironie verborgen. Heines Prophetie ist utopisch, weil ihr einerseits jede politische Präzision fehlt, nicht gesagt wird, welches staatliche Gebilde diese Revolution erbringe, andererseits weil sie einer Krise der Kultur entspringe.

Jedenfalls hat Heines beunruhigende Auslegung des Potentials der deutschen Philosophie die bloß idealisierende, die Deutschen politisch auch verharmlosende Darstellung der Madame de Staël historisch als überholt dargetan. Was danach, endgültig nach dem preußisch-französischen Krieg und der deutschen Reichsgründung von 1871, als Bild Deutschlands in französischen Reaktionen erkennbar wird, ist in Heines enigmatischer Ansprache von 1835 vorweggenommen worden. Dabei zeigen

13 Heinrich Heine: Zur Geschichte der Religion und Philosophie in Deutschland. In: ders.: Sämtliche Schriften in 12 Bänden. Band 5. Hrsg. von Klaus Briegleb. München 1976, S. 641. sich zwei neue Momente, die für die nach dem Ersten Weltkrieg aufkommende utopische Richtung innerhalb der französischen Intelligenz wichtig geworden sind: zum einen eine neue Form der Selbstkritik sowohl der klassisch-rhetorischen Tradition als auch der während des Krieges 1870/71 gezeigten französischen Moral und Mentalität. Zum anderen eine neue Perspektive auf den preußisch-deutschen Sieger. Dass nun ein preuBisches Deutschland der Widerpart ist, hat zur Folge, dass die rückwärts gewandte literarisch-romantische Utopie ersetzt wird durch eine militaristisch-naturwissenschaftliche, also eine zukunftsorientiert-bedrohliche. 1870 wird in der breiten Pariser Tagespresse (Le petit Journal), den politischen Karikaturen (Le Charivari) und in den Aufsätzen und Büchern bedeutender Schriftsteller, unter anderem Victor Hugos (Rentrée à Paris) und Théodore de Banvilles (Idylles Prussiennes), die Utopie als Evokation eines ewigen geistigen Frankreichs gegen das Faktum eines neuen barbarischen Preußen-Deutschlands gekehrt. ${ }^{14}$ Aber es gibt einzelne kritische Gegenstimmen, die eine andere utopische Perspektive ankündigen: Das Journal der Brüder Goncourt zum Kriegsjahr 1870/71 enthält Reflexionen bzw. Gesprächserinnerungen zwischen führenden Pariser Literaten über die zukünftige Superiorität der Deutschen in Wissenschaft, Technik, ja im intellektuellen Diskurs generell. Ausführlich kommt dabei Ernest Renan, der einflussreiche Religionsphilosoph, zur Sprache, der den militärischen Sieg Preußen-Deutschlands aus einem noch viel weitergehenden Potential von Überlegenheit erklärt, die Heinrich Heines Prophetie angekündigt hatte. Hippolyte Taine, der andere einflussreiche Historiker der frühen Dritten Republik, hat eine ähnliche Unterscheidung getroffen: Das von Napoleon erfundene Staats- und Gesellschaftssystem sei antik-heidnisch gegenüber dem germanisch-christlichen, das Taine >modern nannte (Les origines de la France contemporaine, 1875-93). Den französischen Schulund Unterrichtsbetrieb kritisierte Taine als mechanistisch-seelenlos gegenüber einer individualistischen Erziehung. Renan hat die Präsenz zweier Deutschlands emphatisiert (La France et l'Allemagne) und die Idee einer gemeinsamen europäischen Zivilisation herausgestellt, begründet auf der Allianz zwischen Frankreich, Deutschland und England, auf der die »intellektuelle und moralische Größe Europas « beruhe..$^{15}$ Das ist

14 Vgl. Michael Jeismann: Das Vaterland der Feinde. Studien zum nationalen Feindbegriff und Selbstverständnis in Deutschland und Frankreich 1792-1918. Stuttgart 1992, S. 207-234. Außerdem Claude Digeon: La Crise Allemande de la Pensée Française (1870-1914). Paris 1959.

15 Ebd., S. 237. 
bereits die Idee, die Paul Hazard, Benedetto Croce und Ortega y Gasset utopisch ausformulieren werden.

Sowohl Renans als auch Taines Wertungen sind aufschlussreich für einen neuen kulturkritischen Impuls gegenüber der französischen Tradition. Man könnte aus dem bisher Gesagten folgern: Die französische Erfahrung des ersten deutsch-französischen Krieges hat die romantische Wahrnehmung Deutschlands zunächst zerstört, um sie dann durch eine der Tendenz nach fundamentalistisch-existentielle zu ersetzen, die utopisch strukturiert ist. Diese Veränderung fand noch vor Ausbruch des Ersten Weltkriegs statt: Es entstand das Phantasma, das nach dem Krieg für einige erstrangige französische Intellektuellen maßgeblich wurde und die Idee von den zwei Flügeln einer gemeinsamen Kultur hervorbrachte. Der Schriftsteller, der diese Utopie erfand, war Romain Rolland. Sein mehrbändiger Roman Jean Christophe, zwischen 1904 und 1912 erschienen und sofort ein europaweiter Erfolg, stellt die Geschichte einer deutsch-französischen Freundschaft dar, die als kulturelle Utopie entwickelt wird. Der Held des Romans, Jean Christophe, ist ein junger deutscher Komponist aus dem Rheinland, der nach einer mörderischen Wirtshausschlägerei mit deutschen Soldaten nach Paris floh und dort seinen Lebensfreund, einen zarten Literaten, findet. Zwischen dem jungen, vitalen deutschen Musiker und dem jungen, delikaten französischen Schriftsteller entsteht eine archetypische Affinität und Distanz, mittels deren Romain Rolland seine Idee einer zukünftigen deutsch-französischen Union entwickelt. Dazu gehört auch die rücksichtslose Ausstellung französischer Zivilisation in ihren seichten konventionell-rhetorischen Zügen sowie die erbarmungslose Darstellung eines zum Spießertum verkommenen provinziellen deutschen Musikbetriebs, wo die pompöse Rezeption Richard Wagners und Beethovens jede artistische Finesse erschlägt. Hier knüpft Rolland erkennbar an das Bild von einer primitiven deutschen Musikkultur, vor allem die Richard-Wagner-Feier an, wie sie 1870 nach französischen Darstellungen in Deutschland verbreitet war und in Gegensatz stand zu dem, was Charles Baudelaire in seinem berühmten Essay über Wagners Ästhetik kurz vorher geschrieben hatte. Entscheidend aber ist die Evokation des deutschen Helden, in der die alte romantische Dynamik als spirituelles Ereignis einer neuen Kunst wiederauferstand, einem nationalistischen Zeitalter kurz vor Ausbruch des Weltkriegs ein anderes Ideal setzend. Voraussetzung von Rollands utopischer Phantasie ist wiederum eine als Krise empfundene Vorkriegssituation zwischen Dekadenz und vitalistischer Rhetorik.
Wenn man die Polarisierung von neuem Realismus und alter Rhetorik als Romain Rollands Kriterium erkennt - eine Alternative, die auch Anatole France in seiner Prosa (Histoire contemporaine, Les Dieux ont Soif) zur gleichen Zeit vorführte, dann hat man eine Erklärung für die imaginativ-utopische Qualität des französisch-deutschen Beziehungspathos zwischen den Weltkriegen. Dafür stehen vor allem zwei Relationen: In den zwanziger Jahren die surrealistische Wiederentdeckung des Phantastischen in der deutschen Romantik als kulturrevolutionäres Programm, in den dreißiger Jahren die Beeinflussung des jungen JeanPaul Sartre durch Martin Heideggers Sein und Zeit, d.h. die Erfindung des Existenzialismus aus dem Geist der deutschen Phänomenologie. Nimmt man Alexandre Kojèves berühmte Lektionen über Hegels Phänomenologie des Geistes hinzu, dann hat man manifeste Gründe für die These, dass die beiden ersten Kriege eine Innovation der französischen Selbstwahrnehmung qua deutscher Literatur und Philosophie verursachten. Apollinaire, der Erfinder des frühen Surrealismus, hatte unmittelbar vor dem Ersten Weltkrieg seine avantgardistisch entworfene Poetik mit Motiven des Loreley-Mythos bestückt, der in seinem ersten großen Gedichtswerk »Alcouls« als Nachdichtung von Clemens Brentanos Gedicht »Zu Bacharach am Rheine« zitiert ist. Hier bezieht sich eine ganze Gruppe von Gedichten auf das Rhein-Thema: »Nuit rhénan«, »Les Cloches«, »Rhénan d'automnes« und schließlich »Les Femmes«. Die von Brentano inspirierte frühsurrealistische Rhein-Thematik ist von Metaphern der symbolistischen Tradition und des Stils von Verlaine und Rimbaud beeinflusst. Brentanos Rhein-Motive sind transformiert zu Elementarteilchen der frühsurrealistischen Imagination, d. h. die französische Sprache wird nicht reromantisiert, sondern romantische Elemente tragen zur gesuchten modernen Stimmung bei. In diesem Falle funktioniert das deutsche Motiv aber nur als exotisches Elementarteilchen.

Relevanter für den utopischen Aspekt ist die Referenz an die deutsche Thematik im Falle von André Bretons und Louis Aragons frühen Texten, den eigentlichen Begründern der surrealistischen Theorie. Novalis, die zentrale Figur der deutschen Frühromantik, ist im »Ersten Manifest des Surrealismus" als eine Art Ahnherr zitiert, weil er den konventionellen Begriff von Wirklichkeit hinterfragt habe. Ebenfalls bezieht sich Breton auf Gerard de Nerval, der, wie wir wissen, nicht nur der erste Entdecker der Rheinromantik war, sondern, wie Breton sagt, schon das Wort ıSurrealismus im Begriff `Supernaturalistische Träumerei ‘ vorweggenommen und eben ausdrücklich >den Deutschen zugeschrieben habe. Fast noch aufschlussreicher für die Präsenz des deutschen Themas innerhalb des 
Surrealismus ist Bretons Kommentar zu den phantastischen Erzählungen Achim von Arnims, deren von Theophil Gautier 1858 unter dem Titel Contes Bizarres übersetzte Fassung Breton 1933 neu herausgegeben und mit einer langen Einleitung versehen hat. Ohne hier auf die äußerst komplizierte, begrifflich anspruchsvolle Auffassung Bretons vom >Phantastischen einzugehen, das er nicht in einem affektiven, sondern reflexiven Verständnis vom Dualismus der Wirklichkeit deutet, ist vor allem dies festzuhalten: In Bretons Intellektualisierung der unheimlichen Figuren in Achim von Arnims Erzählungen ist gleichzeitig der deutsche Idealismus diskutiert, der seitdem, vor allem durch die Rezeption Hegels, eine Schlüsselrolle im modernen französischen Denken des frühen 20. Jahrhunderts gespielt hat. Dies ist entscheidend: Indem Arnim als Anreger und Beglaubiger der surrealistischen Kulturrevolution benannt wird, also nicht etwa als Stichwortgeber einer neuen Romantik, bekommt das deutsche Thema die Aktualität eines modernen Denkens par excellence, das die alte Rhein-Motivik von Romain Rolland entschieden hinter sich lässt. In Louis Aragons Roman Paysan de Paris (1924) wird die Idee einer Mythologie moderne, die nichts anderes als eine Utopie der Moderne sein will, mit eschatologischen Motiven Novalis' ausgerüstet. Man hat es hier mit etwas zu tun, das über die genannten intertextuellen Bezüge hinausgeht und, um es psychologisch zu sagen, historische >Beziehungspersonen begründet. Das ist im zweiten Beispiel noch evidenter:

Die andere deutsche Beziehungsfigur, Martin Heidegger, trat - wie immer wieder beschrieben worden ist - fünfzehn bis zwanzig Jahre später via Jean-Paul Sartre ins französische Bewusstsein, aber um so nachhaltiger. Sartre bekannte im Tagebuch von 1940, der $»$ Krieg und Heidegger« hätten ihn »auf den rechten Weg gebracht « ${ }^{16}$, d. h. eine neue Existenz-Emphatik gelehrt. Heidegger habe ihm gezeigt, »dass es jenseits des Selbstentwurfs, durch den die menschliche Realität sich verwirklicht, nichts gibt«. Die Utopie ist hier in das Sein selbst gelegt, um noch entdeckt zu werden. Über solche Motive hinaus aber war sowohl die deutsche klassische Literatur als auch die jüngere deutsch-preußische Geschichte für Sartre von existentieller Bedeutung geworden. Die politischen Autoren der Action française und des aktuellen französischen Faschismus der dreißiger und vierziger Jahre, Pierre Drieu La Rochelle, Lucien Rebatet

16 Jean-Paul Sartre: Tagebücher November 1939 - März 1940. Deutsche Erstausgabe von Les carnets de la drôle de guerre. Aus dem Französischen von Eva Moldenhauer. Reinbek 1984, S. 471. und Robert Brasillach beriefen sich dagegen in ihren literarischen Texten nie auf deutsche Vorlagen. Davon zu unterscheiden ist die faschistische Idee eines vereinten Europas, die vornehmlich von Pierre Drieu La Rochelle, dem Propheten des futuristischen 'Elans', schon vor dessen Radikalisierung entwickelt und nie aufgegeben wurde (Le jeune Européen, 1927; L'Europe contre les patries, 1931). Während Drieu La Rochelle den Nationalismus der Action française und Vichys als reaktionär ablehnte, versuchte er, die deutsche Okkupation als neue Phase eines zukünftigen vereinigten Europas zu rechtfertigen. Anders ausgedrückt: Die faschistische Utopie und die Idee von einer Einheit Europas verschmolzen hier zum gleichen Projekt. ${ }^{17}$

Deutscherseits zeigte sich dagegen schon seit Beginn des 20. Jahrhunderts eine quasi-Metaphysik der Europa-Idee, die sich semantisch vor allem darin ausdrückte, dass an die Stelle des Wortes `Europa häufig das Wort `Abendland s trat. Das drückt sich schon im Titel von Oswald Spenglers berühmtem Traktat aus, aber auch Georg Trakl, der bedeutendste deutschsprachige Lyriker vor dem und während des Ersten Weltkriegs, gab einem seiner großen Gedichte den Titel »Abendländisches Lied«. Ohne hier auf die historische Herkunft und die geschichtsphilosophische Etymologie des Begriffs, der in den einschlägigen welthistorischen deutschen Abhandlungen des 18. und 19. Jahrhunderts nicht markiert ist, näher einzugehen, und für den es in den anderen europäischen Sprachen kein Äquivalent gibt, ist nur festzuhalten, dass Heidegger in seinen Sartre nicht bekannten Kriegsvorlesungen von 1942/43 zu Hölderlins Hymne "Der Ister« die Kategorie des >Abendländischen schen Menschentums` als geschichtsphilosophisch relevante Differenz zu Amerika aufrief. ${ }^{18}$ In seiner Vorlesung zum Parmenides spricht er von der »Wesensgeschichte des Abendlandes $\ll^{19}$ Heideggers ,Wesens Terminologie Europa betreffend hatte Analogien in der Idiomatik konservativer bzw. präfaschistischer Schriftsteller. So bei Rudolf Borchardt, von dessen historischen Essays einige schon in ihren lapidaren Titeln wie

17 Vgl. Hélène Baty-Delalande: Drieu La Rochelle: L'Europe à se damner In: Les Ecrivains et l'occupation: Le magazin litteraire 516 (Février 2012), S. $64 \mathrm{f}$.

18 Vgl. Martin Heidegger: Gesamtausgabe. II. Abt.: Vorlesungen 1925-1944 Band 53: Hölderlins Hymne »Der Ister«. Frankfurt a. M. 1984, S. 68 f.

19 Martin Heidegger: Gesamtausgabe. II. Abt.: Vorlesungen 1925-1944. Band 54: Parmenides (Freiburger Vorlesung Wintersemester 1942/43). Frankfurt a. M. 1982, S. 112. 
»Europa «, »Dorer $\ll^{20}$, $\gg$ Pisa $\ll^{21}$ und $»$ Villa $\ll^{22}$ zu erkennen geben, dass hier ein »Ideal«, wie es an einer Stelle heißt, stilistisch und metaphysisch auf den Begriff gebracht werden sollte. So auch bei Gottfried Benn, der in einer eindeutig präfaschistischen Perspektive für die »Geschichte Europas« die Formel setzt, nämlich die Kennzeichnung von Völkern des innovatorischen Stils und der Naturerweiterung. ${ }^{23}$ Die Referenz beider Autoren an >die Dorer ist eine letzte, ins Rassische gewendete Phase der deutschen Griechen-Obsession als europäisches Paradigma. Borchardt, der interessanteste konservative kulturkritische Autor der wilhelminischen Epoche, brachte Europa jeweils auf eine vom Jugendstil inspirierte, ahistorische Formidee. Benn, der neben Bertolt Brecht modernste deutsche Lyriker seiner Epoche, hat diese Formidee fetischisiert. Man kann das auch den Übergang von einer Utopie zur Ideologie nennen. Keiner dieser Texte hat aber für die neue französische Wahrnehmung Deutschlands nach dem Ersten Weltkrieg eine Rolle gespielt.

\section{DIE URSACHE DES ZERFALLS}

Die politischen Väter der Idee eines vereinigten Europas, de Gaulle, Adenauer, De Gaspari zu Beginn, Kohl und Mitterand drei Jahrzehnte später, hatten von den erörterten Denkern und Publizisten bzw. von den genannten Büchern oder Aufsätzen keine oder nur eine spurenhafte Ahnung. Nichtsdestotrotz war das zentrale Motiv der utopischen Sicht auf Europa - die beiden Weltkriege und, diesem Motiv folgend, das emphatisierte Verhältnis zwischen Deutschland und Frankreich, ihre Idee voneinander - auch ihnen geläufig. Dabei wird nun ebenfalls ein Umschlag ins Ideologische erkennbar: Zum einen die pragmatische Begründung, für immer europäische Kriege auszuschließen; zum anderen aber eine >karolingische Fassung dieses politischen Motivs, das in der EuropaIdee der dreißiger Jahre und vorher noch nicht artikuliert worden war.

20 Rudolf Borchardt: Gesammelte Werke in Einzelbänden. Prosa IV. Stuttgart 1996, S. 7-40; S. 41-55.

21 Rudolf Borchardt: Gesammelte Werke in Einzelbänden. Prosa III. Frankfurt a. M. 2008, S. 115 f.

22 Ebd., S. 381.

23 Gottfried Benn: Dorische Welt. Eine Untersuchung über die Beziehung von Kunst und Macht. In: ders.: Gesammelte Werke in vier Bänden. Band 1. Hrsg. von Dieter Wellershoff. Düsseldorf ${ }^{3} 1965$, S. 263.
>Karolingisch insofern, als man die von de Gaulle und Adenauer gewollte deutsch-französische Aussöhnung geschichtssymbolisch überhöhte, indem man auf die gemeinsamen Anfänge Frankreichs und Deutschlands im Fränkischen Imperium Karls des Großen hinwies. Die Grenzen Westdeutschlands der fünfziger Jahre waren ungefähr identisch mit der Ostgrenze des alten Fränkischen Reiches, dessen östlicher Teil nach der Trennung durch die Straßburger Eide von 843 in den frühmittelalterlichen Quellen noch immer unter dem Titel regnum francorum firmierte, bevor es den dann geläufigen Namen `Heiliges Römisches Reich`plus den späteren Zusatz >deutscher Nation` annahm. Die 1949 vollzogene Verlagerung der politischen Entscheidungszentrale von Berlin ins Rheinland trug zu dieser `karolingischen` Version des Staatsverständnisses bei, das sich auch in Ritualen wie dem bis heute alljährlich in Aachen vergebenen Karls-Preis ausdrückt, vergeben an europäische Politiker, die sich um die europäische Einigung verdient gemacht hätten. Nicht unwichtig war dabei auch das Bewusstsein der gemeinsamen Christlichkeit, vor allem der katholischen, wie sie 1962 in Reims zelebriert wurde. In gebildeten Kreisen wurde deshalb auch nach dem Krieg die Schrift wiedergelesen, die zur Zeit der kulturellen Europa-Idee der dreißiger Jahre keine Rolle spielte: Novalis’ Essay »Die Christenheit oder Europa» von 1799. Die politische Utopie war nunmehr historisch-retrospektiv fundamentalisiert.

Bisher ist nicht von ungefähr nur von kontinentaleuropäischen Schriftstellern die Rede gewesen. Es gibt keinen englischen bzw. britischen Autor, der eine der oben Dargelegten ähnliche Idee von Europa entwickelt hätte. Allerdings mit zwei charakteristischen Ausnahmen: den beiden einerseits die literarische Moderne erfindenden, andererseits mit ultrakonservativen bzw. faschistischen Ideen sympathisierenden angloamerikanischen Lyrikern Ezra Pound und T. S. Eliot. Beide Dichter waren aber keine Sprösslinge des englischen Milieus, das sie bewunderten. Ganz besonders gab es keine literarische oder philosophische Affinität zwischen britischen und deutschen Schriftstellern, die auf so etwas wie eine europäische Kategorie hinausgelaufen wäre. Auch das Interesse von W. H. Auden, Stephen Spender und Christopher Isherwood am Deutschland der dreißiger Jahre und später blieb ein privates und hat keine geschichtsspekulative Thematik hervorgebracht. Diese Distanz gegenüber der europäischen Thematik gilt auch für germanophile englische Autoren des 19. Jahrhunderts wie Thomas Carlyle und George Eliot. Und vor allem charakteristisch für die englische Zurückhaltung gegenüber der Europa-Idee ist, dass der seiner Epoche Stichworte gebende englische Philosoph Arnold J. Toynbee in der 1950 veröffentlichten Diagnose 
der europäischen Nachkriegssituation War and Civilization zwar die dramatische Geschichte Europas als eines Ganzen analysiert, sich aber dabei nicht jener utopischen Terminologie bedient, wie sie von Ortega y Gasset, Croce, Hazard, Heidegger und Curtius benutzt worden ist, auch wenn Toynbee von Europa immer als einer kulturellen Einheit spricht. Wenn Winston Churchill 1948 rhetorisch die Utopie eines vereinigten Europa berief, dann war gleichzeitig auch gesagt, dass England - vor die Wahl gestellt - immer >die offene See` wählen würde. Diese damals romantisierte Differenz zwischen Großbritannien einerseits und den kontinentaleuropäischen Nationen andererseits, noch immer nachwirkend bei der Mehrheit der britischen, auf jeden Fall der englischen Bevölkerung, entspringt nicht allein einer Tradition der splendid isolation und des Empires, sondern ebenso sehr dem englischen Misstrauen gegenüber >Ideen geschweige ideologisch-utopisch verbrämten Begriffen, die keine strikte politische Währung versprechen.

Eine seit den neunziger Jahren aktuelle Variante dieses englischen Verdachts gegenüber der Europa-Utopie ist, dass man in ihr Elemente der nationalsozialistischen Europa-Ideologie entdeckte und diese auch heute noch diskutiert, wie sie am Beispiel des französischen Faschismus schon festgestellt wurden. Wahr ist, dass die Nazis ihren Krieg gegen die Sowjetunion propagandistisch, vor allem am Ende, als Feldzug Europas gegen die asiatischen Barbaren ausgaben. Eine Vorstellung von Russland, die zweifellos noch in Adenauers Entscheidung für ein strikt an den Westen gebundenes Westdeutschland eine Rolle gespielt hat und von großen Teilen der westdeutschen Bevölkerung nachdrücklich gewünscht wurde. Der Name der französischen SS-Division `Charlemagne` bestätigte die nationalsozialistische Inanspruchnahme Europas gegen die Sowjetunion. Auch hatten die ursprünglichen deutschen Kriegsziele des Ersten Weltkriegs ökonomische und territoriale Zugewinne im Blick, die man unter den ominösen Terminus >Mitteleuropa bringen konnte. Das ist ein Begriff, der von Friedrich Naumann, dem populistisch begabten protestantischen Pastor und überaus wirkungsvollen Propagandisten einer von Deutschland geführten europäischen Wirtschaftsgemeinschaft, 1915 geprägt worden war. Jean-Paul Sartre stellte zu solcher Tendenz im Tagebuch von 1940 generell fest, dass »die Gemeinschaft«, bzw. ihre Idee, als die »der deutschen Nation eigentümliche Möglichkeit « ${ }^{24}$ erscheine. Es handele sich um ein Streben nach Einheit, das immer über die bloße

24 Jean-Paul Sartre: Tagebücher (wie Anm. 16), S. 477.
„Vereinigung der deutschen Länder" hinausgehe. Es ziele auf »Europa als einigende Vereinigung".

Ohne dass die nationalsozialistischen oder sozialvölkischen Motive nach dem Zweiten Weltkrieg offen rekrutiert worden wären, haben sie sicher bei der unmittelbaren deutschen Nachkriegssympathie für ein vereintes Europa nachgewirkt - ohne als solche identifiziert zu werden. Wirkungsvoller war das Image von de Gaulles und Adenauers Nebeneinander in der Kathedrale von Reims, dem Krönungsort der fränkischen Könige, ein Image, das von Mitterand und Kohl dreißig Jahre danach Hand in Hand vor den Gräbern von Verdun wiederholt worden ist. Was diesen ambivalenten geschichtssymbolischen Motiven den generellen Nenner gab, war deutscherseits bekanntlich die Suche nach einer neuen Identität, nachdem die alte nationalstaatliche Tradition ruiniert zu sein schien. Und die erörterte Literatur zur europäischen Idee, speziell zur historischen Notwendigkeit einer deutsch-französischen Symbiose, konnte solche Wünsche nur bestätigen. Aber hier fand ein Paradigmawechsel zu nennender Bruch statt, der die zu Beginn schon angedeutete Paradoxie zeitigte: einerseits die fortwirkende, seit den dreißiger Jahren sich ankündigende enorme Wirkung deutscher Philosophen auf das französische Denken, andererseits aber keinerlei spezifische Affinitäten mehr zwischen der deutschen und der französischen Intelligenz, eher Gleichgültigkeit, sogar Abneigung. Um dies zu verstehen, genügt nicht die Erinnerung an die deutsche Okkupation Frankreichs zwischen 1940 und 1944, obwohl sie gewiss bei den französischen Intellektuellen, aber auch dem konservativen Bürgertum lange nachwirkte. Immerhin gab der Pariser Stadtrat einer dem Arbeiterviertel Belleville nahegelegenen U-Bahn-Station den Namen "Stalingrad «. Die linke Intelligenz hat über drei Jahrzehnte mit der Existenz der DDR sympathisiert und den kommunistischen Staat der Bundesrepublik vorgezogen, was sich bis in die Lehrpläne der französischen Schulen und Universitäten und auch das Sortiment deutscher Buchhandlungen in Paris auswirkte. Entscheidend für das nachlassende Interesse füreinander aber war vor allem das Verschwinden der Kriegsdrohung. Das ist der elementar zu nennende Unterschied zu vor 1944 und nach 1944: das langsame Verschwinden des Krisen-Motivs aus dem Bewusstsein beider Nationen. Und damit das Verschwinden einer entscheidenden Ursache der politischen Utopie. Ihre letzte eindrucksvolle Darstellung war die 1946 publizierte Novelle La silence de la mer von Vercors, 1949 wirkungsvoll-lakonisch verfilmt von Jean-Pierre Melville. Was hier erzählt wird, ist nichts anderes als die gebrochene Utopie einer spirituellen, ja mystischen Union zwischen 
Deutschland und Frankreich, sozusagen die verzweifelte Erinnerung an sie angesichts der nationalsozialistischen Verbrechen. Alle Motive des idealistischen französisch-deutschen Diskurses von Madame de Staël bis Romain Rolland und André Breton sind hier versammelt. Dass sie einem vornehmen deutschen, am Ende verzweifelten Besatzungsoffizier in den Mund gelegt werden, der trotz seiner Noblesse nicht fähig ist, dem soldatischen Gehorsam aufzukündigen, lässt dessen Zukunftsideen als leere Phantasie aussehen. Andererseits bleibt ein emotioneller Rest, nicht zuletzt im Ausdruck der beiden schweigenden französischen Zuhörer: Indem die Bedingung der Utopie, die Krise, verschärft erscheint, drängt sich umso mehr ihre Überwindung auf. Aber diese ist absehbar nach wie vor nicht politisch gedacht, ohne jede institutionelle Präzision, bleibt eine vage, schwärmende Phantasie. Und dieser Mangel an Struktur nimmt alle tatsächlichen späteren Versuche einer Lösung vorweg. Das galt für 1950 und 1955, das galt nicht zuletzt noch für die Phase der skarolingischen Utopie. Nachdem aber der Krieg zwischen Frankreich und Deutschland definitiv und endgültig keine Form der Beziehung mehr sein konnte, hat der emphatische Ausdruck einer möglichen Symbiose seinen materiellen Grund verloren. Das hat Peter Sloterdijk schon 2008 festgestellt. ${ }^{25}$

Aber es zeigt sich ein komplizierterer Grund für den Zerfall, die Implosion des Utopischen: Die französische Obsession mit dem deutschen philosophischen Erbe, in der sich die formale Ursache der Utopie, die Krise, materialisierte, nahm eine entscheidende Wende. Es waren ja nicht bloß die Schriften Hegels, Karl Marx' und Sigmund Freuds gewesen, die im französischen Denken Wurzeln schlugen. Es wurden zunehmend die Schriften Friedrich Nietzsches, Martin Heideggers und einiger Autoren der deutschen Romantik, die plötzlich in den Lektüren von Jacques Derrida, Michel Foucault und Gilles Deleuze eine aufregend neue Deutung erfuhren, die im strikten Widerspruch zur deutschen Nachkriegsrezeption dieser Schriften stand. Nicht nur dass die deutschen Geisteswissenschaften die von den Franzosen emphatisierten deutschen Dichter und Denker unter radikalen Ideologieverdacht gestellt hatten, sie partiell als präfaschistisch, bestenfalls als irrationalistisch benannten, deren Impulse inkompatibel wären mit dem rationalen Ethos der westdeutschen Nachkriegsuniversität. Die Sache ist verwickelter: Die Pointe bei der französischen Lektüre von Nietzsche, Heidegger, Friedrich Schlegel,

25 Vgl. Peter Sloterdijk: Theorie der Nachkriegszeiten. Bemerkungen zu den deutsch-französischen Beziehungen seit 1945. Franfurt a. M. 2008.
Novalis und Hölderlin war ja keineswegs ein Bezug auf >irrationale weltanschauliche Angebote, sondern gerade auf deren >Modernität $<$. Das wurde jenseits des Rheins nicht verstanden. Denn die Modernität, die aus der luziden französischen Interpretation herauskam, stand wiederum im Widerspruch zur noch immer idealistisch-geistesgeschichtlichen deutschen Manier, Texte zu lesen. Daran hatte die neue deutsche Aufklärung nichts geändert. Ganz im Gegenteil: Ob Derridas Empfehlung von Nietzsches Stil ${ }^{26}$ oder Philippe Lacoue-Labarthes und Jean-Luc Nancys Entdeckung des »absoluten Literarischen ${ }^{27}$ in der Literatur der deutschen Romantik, diese anspruchsvollen innovatorischen Theorien fielen flach vor den deutschen Lehrstühlen, wenn sie überhaupt vor den achtziger Jahren wahrgenommen worden sind. Der Grund hierfür lag nicht bloß in der unterschiedlichen Hermeneutik. Er lag in einer quintessentiell nicht miteinander ins Gespräch kommenden Differenz namens erneuerter Ästhetik versus erneuerter Geschichtsphilosophie. Diese Differenz lässt sich bezüglich des Utopiekriteriums noch einmal präzisieren: Die französische Dekonstruktion, formal anti-utopisch, erbrachte de facto eine neue Lesart der Welt, die man utopisch nennen kann. Die deutsche Distanz dazu, utopisch-aufklärerische Ideen regenerierend, blieb de facto der Überlieferung, d. h. in diesem Falle der `Geistesgeschichte treu. Dort ein wirklicher Sprung aus der Geschichte heraus, hier die Immanenz historistischer Kontinuität.

Diese Differenz enthüllt eine über die wissenschaftliche Differenz hinausgehende psychologisch-kulturelle Unterschiedlichkeit, eine radikal unterschiedliche psychische Chemie, die einem unmittelbaren Gespräch über solche Fragen bis heute im Wege steht und den mittelbaren Versuch, die Unterschiede zu überbrücken, ebenfalls zum Scheitern verurteilt hat. Die Ironie dieser Geschichte liegt darin, dass die subtilen französischen Lektüren berühmter deutscher Texte an diesen eine subversive Qualität entdeckten, die dem nie aufgegebenen deutschen Kriterium, der \Idee`, widersprachen. Ohne auf die Wirkung von Paul de Man, also eines amerikanischen Theoretikers, der die französische Option bekanntlich stark beeinflusste, einzugehen, ist bloß das für den französisch-deutschen Disput Offensichtliche festzuhalten: Die de Man'sche bzw. Derrida'sche >Dekonstruktion entdeckte stilistisch-semantische Eigenschaften eines

26 Jacques Derrida: Epérons: Les styles de Nietzsche. In: Nietzsche aujourd'hui? Bd. 1: Intensités. Paris 1973, S. 235-287.

27 Philippe Lacoue-Labarthe, Jean-Luc Nancy: L'absolu litteraire. Théorie de la littérature du Romantism Allemande. Paris 1978. 
literarischen Textes, die sich einer Summierung ihres Gehalts bzw. einer Idee entzogen. Das schlug sowohl in der noch immer vorwaltenden Nachwirkung des deutschen Idealismus, sprich Identitätsphilosophie, als auch der letzten Idee der jüngeren Frankfurter Schule, sprich Kommunikationstheorie, ins Gesicht. Die Franzosen hatten sozusagen das deutsche romantische Erbe wider die neue deutsche Aufklärung gekehrt. Noch mehr: Sie hatten an diesem Erbe etwas entdeckt, worauf die deutsche Geisteswissenschaft wegen politischer Kontrolliertheit selbst nie gekommen wäre, sieht man von wenigen Ausnahmen einmal ab.

Diese Kluft war sozusagen öffentlich geworden, als sich eine Reihe französischer und deutscher Philosophen Mitte der achtziger Jahre in Paris zu einem Gespräch trafen, das unter dem Titel `Rationalité et subjectivité، stand, aber, wie sich herausstellte, zu keinem Gespräch wurde, wobei die Häupter der Differenz, Derrida und Habermas, anwesend waren. Es kam, nach dem Bericht von Augenzeugen, sogar zu einem regelrechten Eklat, der in der Szene gipfelte, dass eine französische Sekretärin bei der Diktion eines namhaften deutschen Erkenntnistheoretikers, der Habermas' Konzept besonders beeinflusst hat, zu weinen begann und auf Drängen bekannte, das harte Deutsch des Philosophieprofessors habe sie an den Tonfall deutscher Offiziere erinnert. Anstatt Dialog eine Peinlichkeit. Allerdings soll das einschlägig bekannte deutsche Philosophie-Ass wie ein geifernder Missionar den Advokaten der Rationalität gegeben haben. Peinlicher war es, als deutsche Jungphilosophen Jahre danach den Maître der französischen Gegenwartsphilosophie beim einmaligen Besuch in der Hauptstadt der Frankfurter Schule vor das Gericht ihrer Rationalitätskriterien zogen. Aus den Berichten französischer Teilnehmer konnte man den Eindruck gewinnen, dass diese glaubten, dass die abermals politisch korrekten >Fridolins - eine ironische Bezeichnung für deutsche Naivität - am Werke wären, um die französische Frivolität ins Reine zu bringen. Dieses Vakuum oder dieser Abgrund in den Beziehungen ist durch die Wirkung des französischen Films der sechziger und siebziger Jahre und einen populären Kulturtourismus nur verdeckt geblieben.

An dieser Situation wird sich absehbar nichts ändern. Ganz im Gegenteil: Inzwischen ist die wieder spürbar gewordene Antipathie banaler Langeweile gewichen. Das Bewusstsein von der kulturellen und intellektuellen Differenz ist als vice versa aufrechterhaltene Gleichgültigkeit noch stärker geworden. Der französische Historiker Pierre Nora, Herausgeber der wichtigen Pariser Zeitschrift Le Débat, hat diesen Zustand kürzlich in einem Interview mit der Frankfurter Allgemeinen Zeitung als Fait accompli bezeichnet, als eine buchstäbliche Sprachlosigkeit, die immer unausweichlicher würde, da man in Frankreich kaum mehr Deutsch verstehe und umgekehrt in Deutschland kein Französisch mehr. Man sollte diesen Befund aber entaktualisieren und entdramatisieren: Es gibt jene Beziehung nicht erst jetzt nicht mehr. Es hat jenseits der oben angesprochenen Symbolpolitik zwischen 1953 und 1998 nie auch nur die Spur einer psychischen und intellektuellen Nähe gegeben. Pariser Intellektuelle haben nach dem Zweiten Weltkrieg mehr Interesse und Verständnis für die Vorgänge in arabischen oder südamerikanischen Kulturen gehabt als für das, was in Deutschland geschah. Umgekehrt blieb deutschen akademischen oder anderen Größen der Stil französischen Denkens und französischer Diskussionen Anathema. Das einzige Mal, dass Paris auf Berlin oder Frankfurt reagierte, war bezeichnenderweise auf den Baader-Meinhof-Komplex: des alten Jean-Paul Sartres Romantisierung des kriminell gewordenen westdeutschen Linksanarchismus der siebziger Jahre. Oder: Das französische Interesse an Deutschland kam immer nur dann auf, wenn Romantisch-Erratisches erwartet wurde. Diese uralte Erwartung konnte und kann von der westdeutschen Normalität nur enttäuscht werden.

Das bedeutet, dass der als Utopie genährte Anspruch auf eine zukünftige europäische geistige Gemeinsamkeit, ganz zu schweigen von einer deutsch-französischen intellektuellen Annäherung historisch definitiv obsolet geworden ist. Dieses Faktum wird von einer Veränderung des ehemaligen intellektuellen Kanons zusätzlich bestätigt: Eine neue Generation von Schülern und Studenten orientiert sich europaweit nicht mehr nach jenen geistigen Standards und Begriffen - nennen wir sie intellektuelle Symbole -, die noch bis in die siebziger und achtziger Jahre zu finden waren. Die intellektuelle Öffentlichkeit tut es ebenso wenig. Beispielhaft hierfür ist die Entmythologisierung der Französischen Revolution, wie es zum 200. Jubiläum ihrer Wiederkehr 1989 allzu offensichtlich wurde. Man nennt diese Veränderungen die posthistorische Mentalität. Jean-Paul Sartre definierte 1940 Geschichte als »Übernahme der Vergangenheit «, zu unterscheiden von einer "rein kausalen Wirkung dieser Vergangenheit $\ll_{.}^{28}$ Danach hat die europäische Idee, sei sie die 'geistige ‘ der dreißiger Jahre oder die `karolingische` der fünfziger Jahre, keine Chance mehr utopisch zu funktionieren. >Vergangenheit « wird tatsächlich nicht mehr >übernommen und zur Zukunft hypostatisiert.

28 Jean-Paul Sartre: Tagebücher (wie Anm. 16), S. 437. 
Die europäische Utopie, die hier vorgeführt worden ist, entstammt noch der Sprache eines idealtypischen geschichtsspekulativen Denkens, zu der charakteristischerweise der modernste Kopf der deutschen Intelligenz nach 1900, Max Weber, schon nicht mehr gehörte, obwohl seine Thematik den Terminus `Europa ermöglicht hätte. Für ihn wäre diese Sprache analytisch ohne Distinktion gewesen. Bis heute ist sie es geblieben. Nichtsdestotrotz hat die utopische Phantasie, wie wir sahen, nach dem Zweiten Weltkrieg konkret politisch gewirkt, auch wenn sie - Brüssel hin, Brüssel her - keine Veränderung des nationalstaatlichen Souveränitätsbewusstseins erbrachte. Nachdem aus dem kulturellen Kern der Europa-Idee nun kein politischer entwickelt werden konnte und auch, wie gezeigt, das kulturelle Phantasma nicht mehr wirklich wirksam ist, was macht dann die politische Ambition ohne dieses, vor allem nachdem das Kriegskriterium nicht mehr wirkt? Hat eine wohltuende Aufklärung einer zu lange genährten Illusion stattgefunden? Oder aber - wenn es doch keine Illusion gewesen wäre - hat der utopische Antrieb, die Voraussetzung des politischen Ziels, eine zu kurze Chance gehabt? Denn entweder war der utopische Diskurs nur eine Ablenkung von der politisch-institutionellen Irrealität eines vereinigten Europa. Oder aber es bedarf der utopischen Phase immer noch, um die Realität der politischen Union, die nur irreal erscheint, zu erreichen. Denn ohne den utopischen Antrieb bleiben offensichtlich praktisch-politische Innovationen stecken. Zur Zeit handelt es sich um eine sprachlos gewordene Situation. Ein rein ökonomisches Miteinander und Gegeneinander ist der Fall. Solange es gutgeht. Seitdem sich eine geistige Kommunikation im utopischen Sinne zwischen Frankreich und Deutschland nicht mehr darstellt, wird die gedankenfreie Praxis in dem Moment scheitern, in dem ihr das Geld ausgeht. Das ist nicht der erwähnte Befund, den Peter Sloterdijk vorführte. ${ }^{29}$ Sloterdijk stellte zwar klar, Deutschland und Frankreich hätten »bestenfalls das Verhältnis der wohlwollenden gegenseitigen Nicht-Beachtung ${ }^{30}{ }^{30}$ Er sieht in dieser Entwicklung aber einen Vorteil, als sich hierin auch das Ende des tragischen Epos zwischen Deutschland und Frankreich anzeigen würde. Das ist zweifellos so. Aber das Vakuum, das an die Stelle des geistigen Energiestroms zwischen beiden Ländern zu treten beginnt, ist keine Voraussetzung für eine seuropäischer Entwicklung. Zumal die französische Rezeption deutschen Denkens ja nicht

29 Peter Sloterdijk: Theorie der Nachkriegszeiten (wie Anm. 25)

30 Ebd., S. 9. aussetzte, sich aber - wie gezeigt - für das gegenseitige Verhältnis negativ ausgewirkt hat. Arnold J. Toynbees Frage von 1950, ob wir die Beendigung der europäischen »Wirren « in einem befriedeten »Universalstaat $«{ }^{31}$ also einem definitiv utopischen Modell, nicht mit einem "furchtbaren Preis « ${ }^{32}$ bezahlen könnten, diese Frage hat nach dem oben Ausgeführten eine neue Aktualität bekommen. Was für einen Preis er meinte bzw. welcher Preis das heute sein könnte, wissen wir nicht. Aber Toynbees Frage war in einer Sprache gestellt, die jenseits des banalen deutsch-französischen Verhältnisses liegt. Können die Europäer aber ohne utopische Phantasie auskommen, wenn sie tatsächlich die politische Einheit doch noch zustande bringen wollen? Dazu müssten sie allerdings eine andere, eine neue utopische Sprache erfinden. Diese Möglichkeit aber widerspricht dem beschriebenen Verlust an geschichtsphilosophischer Spekulation.

31 Arnold J. Toynbee: Krieg und Kultur. Der Militarismus im Leben der Völker. Stuttgart 1950, S. 8.

32 Ebd., S. VIII. 


\section{BEITRÄGERINNEN UND BEITRÄGER}

FRIEDRICH BALKE Prof. Dr., Institut für Medienwissenschaft, RuhrUniversität Bochum, Universitätsstraße 150, 44780 Bochum

KLAUS L. BERGHAHN Prof. Dr., German Department, University of Wisconsin, 860 Van Hise Hall, Madison, WI 53706, USA

GÜNTER BLAMBERGER Prof. Dr., Internationales Kolleg Morphomata, Universität zu Köln, Albertus-Magnus-Platz, 50923 Köln

KARL HEINZ BOHRER Prof. Dr., c/o Carl Hanser Verlag, Postfach 8604 20, 81631 München

JÜRGEN FOHRMANN Prof. Dr., Rektorat, Universität Bonn, Regina-PacisWeg 3, 53113 Bonn

JUDITH LEISS Dr., Institut für Deutsche Sprache und Literatur II, Universität zu Köln, Gronewaldstraße 2, 50931 Köln

VIVIAN LISKA Prof. Dr., Instituut Joodse Studies, Universiteit Antwerpen, Stadscampus, S.D.122, Grote Kauwenberg 18, 2000 Antwerpen, Belgien

MATTHIAS LÖWE Dr., Institut für Germanistische Literaturwissenschaft, Friedrich-Schiller-Universität Jena, Frommannsches Anwesen, Fürstengraben 18, 07743 Jena

RYOZ0 MAEDA Prof. Dr., Hatagaya, 3-71+16 Shibuya-Ku, 151-0072 Tokyo, Japan

GABRIEL M0TZKIN Prof. Dr., The Van Leer Jerusalem Institute, POB 4070, 91040 Jerusalem, Israel
MARTIN ROUSSEL Dr., Internationales Kolleg Morphomata, Universität zu Köln, Albertus-Magnus-Platz, 50923 Köln

HANS ULRICH SEEBER Prof. Dr., Literaturwissenschaften: Abt. Neuere Englische Literatur, Universität Stuttgart, Keplerstraße 17, 70174 Stuttgart

ROBERTO SIMANOWSKI Prof. Dr., Seminar für Medienwissenschaft, Universität Basel, Holbeinstraße 12, 4051 Basel, Schweiz

ARBOGAST SCHMITT Prof. Dr., Seminar für Klassische Philologie der Philipps-Universität Marburg, Wilhelm-Röpke-Straße 6, 35032 Marburg

WILHELM VOSSKAMP Prof. Dr., Institut für deutsche Sprache und Literatur I, Universität zu Köln, Albertus-Magnus-Platz, 50923 Köln 
Bislang in der Morphomata-Reihe erschienen:

1 Günter Blamberger, Dietrich Boschung (Hrsg.), Morphomata. Kulturelle Figurationen: Genese, Dynamik, Medialität, 2011. ISBN 978-3-77055148-4.

2 Martin Roussel (Hrsg.), Kreativität des Findens. Figurationen des Zitats, 2012. ISBN 978-3-7705-5305-1.

3 Jan Broch, Jörn Lang (Hrsg.), Literatur der Archäologie. Materialität und Rhetorik im 18. und 19. Jahrhundert, 2012. ISBN 978-3-77055347-1.

4 Dietrich Boschung, Corina WesselsMevissen (Hrsg.), Figurations of Time in Asia, 2012. ISBN 978-37705-5447-8.
5 Dietrich Boschung, Thierry Greub, Jürgen Hammerstaedt (Hrsg.), Geographische Kenntnisse und ihre konkreten Ausformungen, 2012. ISBN 978-37705-5448-5.

6 Dietrich Boschung, Julian Jachmann (Hrsg.), Diagrammatik der Architektur, 2013. ISBN 978-3-7705-5520-8.

7 Thierry Greub (Hrsg.), Das Bild der Jahreszeiten im Wandel der Kulturen und Zeiten, 2013. ISBN 978-3-7705-5527-7.

8 Guo Yi, Sasa Josifovic, Asuman LätzerLasar (Hrsg.), Metaphysical Foundation of Knowledge and Ethics in Chinese and European Philosophy, 2013. ISBN 978-3-7705-5537-6.
Die Morphomata-Reihe wird herausgegeben von Günter Blamberger und Dietrich Boschung.

Das Internationale Kolleg Morphomata: Genese, Dynamik und Medialität kultureller Figurationen wird vom Bundesministerium für Bildung und Forschung im Rahmen der Initiative `Freiraum für die Geisteswissenschaften ‘ als eines der Käte Hamburger Kollegs gefördert. Jährlich bis zu 10 Fellows aus aller Welt forschen gemeinsam mit Kölner Wissenschaftlern zu Fragen kulturellen Wandels. Im Dialog mit internationalen Wissenschaftlern gibt das Kolleg geisteswissenschaftlicher Forschung einen neuen Ort - ein Denklabor, in dem unterschiedliche disziplinäre und kulturelle Perspektiven verhandelt werden.

www.ik-morphomata.uni-koeln.de

Wilhelm Voßkamp seit 1987 Professor für Neuere deutsche Literatur und Allgemeine Literaturwissenschaft an der Universität zu Köln. 1999-2004 Direktor am Kulturwissenschaftlichen Forschungskolleg „Medien und kulturelle Kommunikaton“ der Universität zu Köln. Seit 1994 Mitglied der Berlin-Brandenburgischen Akademie der Wissenschaften, Berlin.

Günter Blamberger seit 1995 Professor für Deutsche Philologie an der Universität zu Köln, seit 1996 Präsident der Heinrich-von-Kleist-Gesellschaft. Seit 2009 Direktor des Internationalen Kollegs Morphomata an der Universität zu Köln.

Martin Roussel Promotion 2007 mit einer Arbeit über Robert Walsers Mikrographie. Seit 2009 Wissenschaftlicher Geschäftsführer des Internationalen Kollegs Morphomata an der Universität zu Köln. 

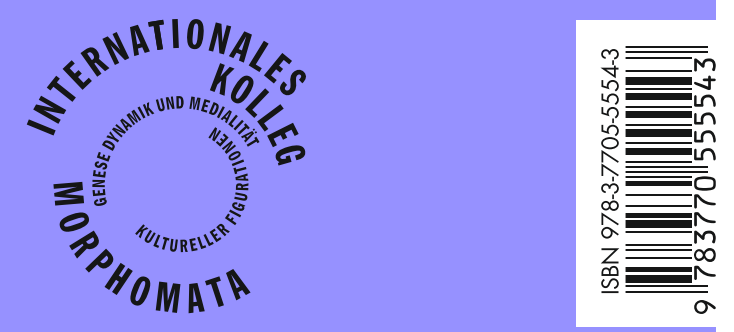

WILHELM FINK 